\title{
DIE \\ ZINNGIESSER DER SCHWEIZ \\ UND IHR WERK II
}



$y=$
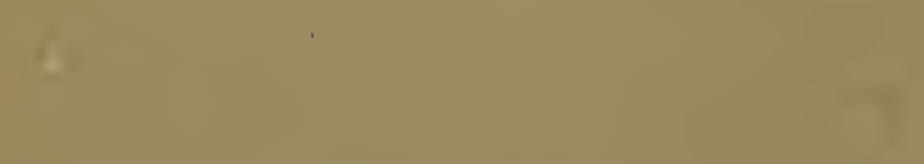







\title{
DIE ZINNGIESSER DER SCHWEIZ UND IHR WERK
}

\author{
BAND II
}


Copyright by Dr. Gustav Bossard, Zug

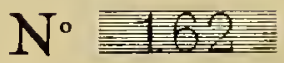




\section{DIE ZINNGIESSER}

\section{DER SCHWEIZ}

\section{UND IHR WERK/ BAND II}
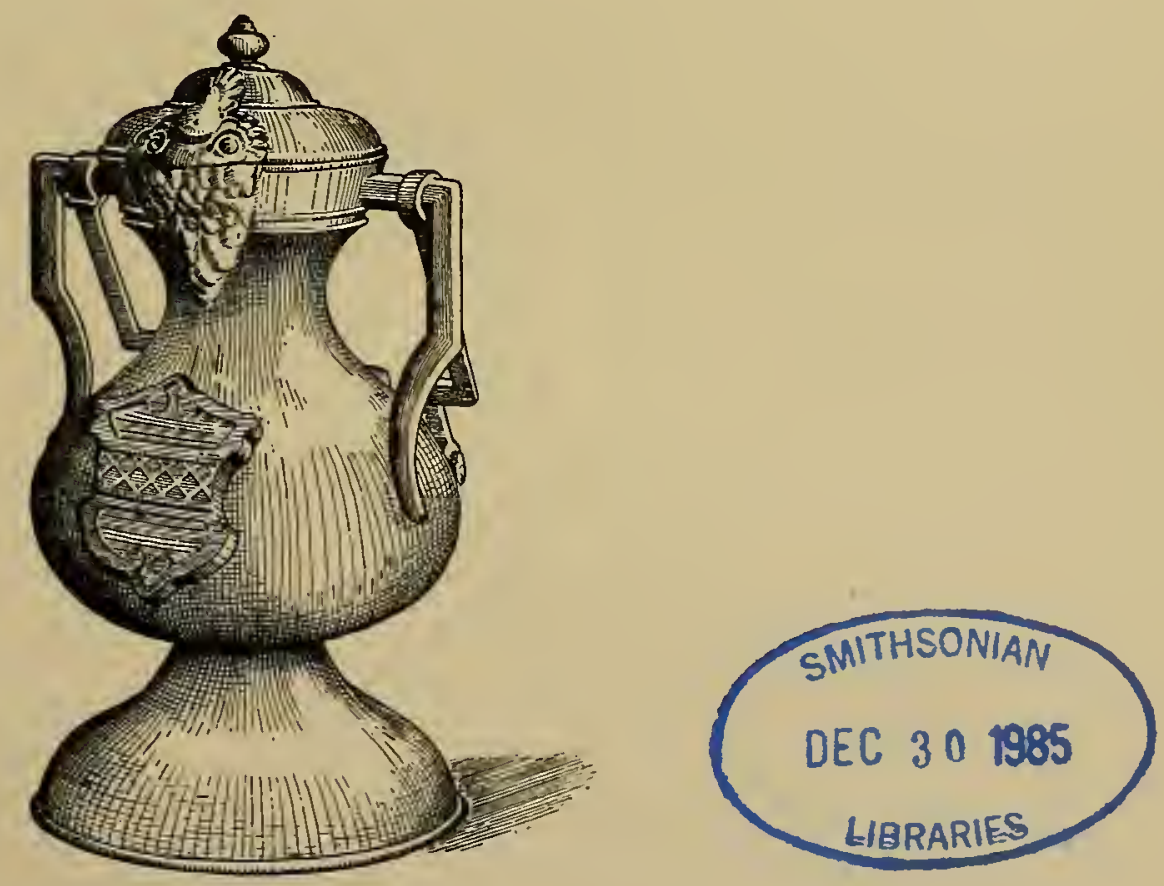

HERAUSGEGEBEN VON Dr. GUSTAV BOSSARD, ZUG

IM SELBSTVERLAG DES VERFASSERS DRUCK ROTO-SADAG A.-G., GENF 1934 


\section{Vorwort und Einleitung}

Dreihundert Jahre lang lieferte das Zinngiessergewverbe dem Bürger das gesammte Essund Trinkgeschirr, ausserdem eine Unmenge von Haushaltungsgegenständen wie Kerzenstöcke, Tintenfässer, ferner kirchliche Kultgegenstände, u.s.wv. Die Schweiz ist das Land, in welchem drei Kulturen zusammenstossen und dieser Moment bedingt einen Formenreichtum, welchen kein anderes Land Europas aufweisen kann.

Vorliegendes Buch ist in erster Linie für den Sammler bestimmt. Die Grundlage bilden die noch vorhandenen Zinngegenstände in der Schweiz und zwar von den frühesten Zeiten bis ungefähr zum Jahre 181 o. Zu diesem Zwecke wurden nicht nur die öffentlichen Sammlungen benutzt, sondern ganz besonders auch die oft schwer zugänglichen Privatsammlungen. Nicht selten wurde mir die Angabe des Besitzers eines Gegenstandes untersagt. Falls keine Angabe vorhanden ist, befindet sich der Gegenstand in meiner Privatsammlung. In den öffentlichen Sammlungen befinden sich die meisten Stadt- und Kirchenkannen, weniger qualitätsreiches Gebrauchszinn. Letzteres ist fast stets in den kleinen Privatsammlungen zu finden. Auch ist es dringend notwendig, in den öffentlichen Museen die Falsifikate und Compilationen zu entfernen; dieses ist in St. Gallen, Basel, Genf und Neuenburg schon geschehen, und zwar infolge der in den letzten Jahren erschienenen Werke und Monographien von Ernest Naef, Genf, L. Reutter, Neuenburg, Th. Gränicher, Zofngen, W. Bourquin, Biel und meines I. Bandes : Die Zinngiesser der Scbweiz und ibr WWerk. In zuvorkommender Weise haben mir diese Autoren einen grossen Teil ihres Materiales zur Verfügung gestellt und zwar auch Zeichnungen und photographische Aufnahmen. Ich spreche ihnen hiemit meinen Dank aus.

Seit dem Erscheinen des I. Bandes, Die Zinngiesser der Schweiz und ibr W 14 Jahre verflossen. Die archivalischen Forschungen haben viele Fragen geklärt: viele neue Meister wurden gefunden; andere mussten ihren Platz wechseln. Ganze Tafeln mussten infolgedessen neugezeichnet werden. Sie befinden sich im vorliegenden Band stets beim zugehörigen Giesserort; die einzelnen, neugefundenen Meisterzeichen immer beim betreffenden Meister.

Infolge des 1920 erschienen Prachtwerkes von ERnest NAEF, L'Etain et le livre Ju potier J'étain genevois, habe ich den Ort Genf nur kurz behandelt und nur diejenigen Zinngiesser erwähnt, von welchen Arbeiten erhalten sind. Naef behandelt in sehr gründlicher und ausführlicher Weise das gesammte Zinngiesserhandwerk der Stadt Genf. Die Abbildungen der Giessermarken sind von einer bewundernswerten Genauigkeit und Vollkommenheit; ebenso die photographischen Reproduktionen der Zinngegenstände. Bei letztern sind allerdings bei der Zuteilung einzelne Irrtümer vorgekommen, so z. B. ist die Seite 14 abgebildete Freiburger Kanne ein Werk des Ulmer Meisters Georg Wilhelm Werlin (zit. 1652). Ferner ist Tafel IV, Nr. 9 eine St. Galler Glockenkanne; auf Tafel XV befinden sich oben zwei Schaffhauser Glockenkannen, unten zwei Churer Kannen.

Herr Th. G. GränICHer behandelte das Zinngiesserhandwerk von Zofingen im Anzeiger für schweiz. Altertumskunde, Bd. XIX, S. 26 u. 99, Zürich 1917. Durch archivalische Studien fand er alle wesentlichen Lebensdaten der einzelnen Meister. Ihren Werken widmete er ebenfalls ausführliche Beschreibungen und ein gutes Bildmaterial ergänzt dieselben (unter Benutzung der öffentlichen und privaten Sammlungen). 
Im Musée Neuchâtelois, 1919 und 1920, veröffentlichte Herr Architekt Louis REuTtER eine Monographie, "Les potiers d'étain neuchâtelois ", welche diese Meister ziemlich ausführlich behandelt. Ihm verdankte ich seiner Zeit viele Originalzeichnungen zu Meisterzeichen und Gegenständen.

In den Bläller für bernische Geschichte, Kunst und Allerlumskunde, 1921, Heft 3-4, befindet sich eine ausgezeichnete Arbeit von Herrn Werner Bourquin, Direktor des Museums Schwab in Biel, betitelt: "Bieler Zinngiesser ". Auch in dieser Abhandlung sind alle biographischen Daten der einzelnen Meister in ausführlicher Weise enthalten. Die Abbildungen stammen teilweise aus meiner Privatsammlung.

Im Jahre 1930 erschien das mustergültig abgefasste Buch von John A. Brown, Das Zinngiesserbandwerk der Schweiz. Auf rein archivalischer Basis schuf er eine Entwicklungsgeschichte des Zinngiesserhandwerkes. Ueber die Entstehung, Entwicklung und den Untergang dieses Gewerbes finden sich alle wünschbaren Aufschlüsse. Auch die Verordnungen, die Proben, die Organisation (Lehrling, Geselle und Meister), der Handel und die Märkte sind eingehend behandelt. Ferner finden sich wertvolle Angaben über das Zunftwesen und die behördlichen Maassnahmen zum Schutze des Gewerbes. Literatur- und Quellenverzeichnis vervollständigen das Werk. Der illustrative Teil ist allerdings sehr mager. Die Kleinheit der Figuren erinnert an Puppenzinn und verunmöglicht die Darstellung von Einzelheiten. Auch sind auf Tafel IV, Nr. 1 und 3, zwei Falsifikate abgebildet, Walliserkannen mit eingesetztem, polyedrischem Korpus, aus Museumsbesitz (!).

Von Prof. Erwin Hintze, Breslau, erschien im Jahre 1931 als VII. und letzter Band, Die Deulschen Zinngiesser und ibre Marken, der Band Südeutuche Zinngiesser, Teil III, mit Anhang Elsass, Oesterreich, Schweiz, Ungarn. Bei Hintzes ausserordentlicher Gründlichkeit der Behandlung der deutschen Zinngiesser wäre der Anhang "Schweiz " besser unterblieben. Trotz ausgiebiger Benutzung meines Bandes I lässt sich " die Schweiz " nach vierwöchentlicher Reise nicht als Anhang abtun. Die Urkantone sind gar nicht berücksichtigt und von der übrigen Schweiz fehlen mehr als die Hälfte der Meisterzeichen, obwohl Hintze alle noch lebenden, in Band I erwähnten Sammler und Historiker aufsuchte. Die Zinngiesser hatten in der Schweiz oft Nebenberufe, z. B. sogar Weibel, Totengräber, u.s.w. Die bei Hintze, S. 351, angeführten Berufe schliessen denjenigen des Zinngiessers absolut nicht aus. Im Gegenteil befassten sich Spengler, Glaser und besonders Goldschmiede oft mit demselben; bei Zaccharias Täschler kommt die Herstellung des schönen St. Galler Relieftellers sicherlich in Betracht.

Bei der Abfassung des Bandes II wurde ich von den Herren Museumsdirektoren der Schweiz in zuvorkommenster Weise unterstützt. $Z u$ besonderem Danke bin ich verpflichtet dem Vicedirektor des schweiz. Landesmuseums, Herrn Dr. K. Frei, dem Herrn Direktor Dr. Wegelin, Bern, dem Direktor des historischen Museums St. Gallen, Herrn Dr. Ehrenzeller ; den Direktoren der Museen von Basel, Aarau, Schaff hausen. Mit Wehmut gedenke ich der vielen verstorbenen Pionire, Sammler und Mithelfer des Bandes I. Zum II. Band erwähne ich ferner die ausserordentlich tatkräftige Unterstützung durch Herrn Staatsarchivar P. X. Weber, Luzern durch die Archivarin Frl. Dr. J. Niquille, Freiburg, durch Herrn Kanzleidirektor Styger, Schwyz, und den dortigen Staatsarchivar P. Fridolin Segmüller. Wertvolle Auskünfte erhielt ich von den noch tätigen Zinngiessermeistern Charles Moriggi in Vevey und Lorenzo della Bianca in Visp; ferner von Herrn F. Herrmann, Holzbildhauer in Yverdon. Unter den verstorbenen Mitarbeitern gedenke ich in erster Linie meines Freundes Caspar Hirsbrunner, Luzern, ferner der Herren Dr. A. Zesiger, Bern; Max de Techtermann, Freiburg; Prof. Dr. Friedrich Hegi, Zürich; Dr. J. Egli, St. Gallen; Dr. F. v. Jecklin, Chur; J. Kubly-Müller, Glarus ; Dr. Durrer, Stans; J. von Flue, Sachseln; Dr. Etli, Sarnen.

Beim Durchgehen des photographischen Nachlasses meines verstorbenen Freundes Caspar Hirsbrunner bewunderte ich mit berechtigtem Erstaunen die ausserordentliche Menge von Zinn-Rapsen, welche Herr Manfred Dürr von Burgdorf in langjähriger Pionirarbeit zusammengetragen hatte und welche ich im Band I verwertet habe. Er verdient es reichlich, hier als einer der ersten Zinnforscher der Schweiz festgehalten zu werden. 
Auch von den ältern Sammlern erhielt ich stets reichliches, mehr lokales Material. Ich verdanke es besonders den Herren Dr. Friedrich Horner, Weesen; F. Pappe, Bern; Jules Simmen, Solothurn; L. Gally-von Mechel, Basel; J. Vogt-Ammann, Basel; Prof. Dr. Weber, Genf; Viktorin Luthiger, Zug, und vielen kleinen Sammlern. Die Erlaubnis zur Reproduktion der Bilder der Tafel XIII und XIV, 1 und 2, verdanke ich dem grossen Entgegenkommen von Herrn Ernest Naef in Genf.

Während meiner vierzigjährigen Sammlertätigkeit war ich Zeuge, mit welcher fatalen Regelmässigkeit die schönen und guten $Z$ inngegenstände sich verminderten und zum grossen Teil im Ausland verschwanden. Im Fremdenverkehr erwiesen sich besonders die Engländer und Amerikaner als die grössten Liebhaber. Darum habe ich im II. Bande möglichst viele Gegenstände Bilde festgehalten und im Texte denselben oft lange Beschreibungen gewidmet; denn leider sind es oft Nekrologe. Der Nachwelt mag das Buch das Erinnerungsbild eines ausgestorbenen, bodenständigen Handwerkes sein.

Inter artem medendi exercendam opus hoc labore nocturno annis XL, confectum est.

Zug, Juni 1934 .

Dr. Gustav BOSSARD. 



\section{Inhalts -Verzeichnis}

Vorwort und Einleitung . . . . . . 7

Literatur-Verzeichnis :

a) Schweiz . . . . . . . . . 13

b) Ausland . . . . . . . . 14

c) Auktions-Kataloge . . . . 17

Ergänzungen und Korrekturen $\mathrm{zu}$ Band I . . . . . . . . . . 18

\section{Erster Teil}

Das Zinn und seine Eigenschaften . . 21

Die Zinnpest . . . . . . . . . . 22

Die Werkstatt . . . . . . . . ${ }_{23}$

Die Verarbeitung des Zinnes:

Der Zinnguss . . . . . . . 24

Das geschlagene Zinn $\ldots \ldots . \quad . \quad 25$

Das getriebene Zinn . . . . . . 25

Die Dekoration der Zinngegenstände :

Der Reliefguss . . . . . . . . ${ }_{2} 6$

Die getriebenen Ornamente . . . $\quad 26$

Messingbronze-Ornamente . . . $\quad{ }_{26} 6$

Die Gravirung . . . . . . 27

Die Aetzung . . . . . . . . . 27

Die Vergoldung . . . . . . . 27

Die Bemalung. . . . . . . . . 27

Die Zinngiesser-Zeichen . . . . . . 27

Lehrzeit und Wanderschaft. . . . . ${ }_{2} 8$

Die Meisterschaft. . . . . . . . . ${ }_{2} 8$

Die Zinnkannen im Bilde und in der

Poesie des XV. und XVI. Jahr-

hunderts . . . . . . . 29

Historische Einleitung . . . . . . 33

Die Stadt- und Gemeindekannen :

Die älteste Gruppe . . . . . . 35

Die Ausläufer dieser Gruppe . . 36

Die nordostschweizerische Gruppe

Die Kannen mit linsenförmigem Korpus
Die Bulgen . . . . . . . 40

Die Abendmahlkannen . . . . . $4^{1}$

Die Formen der gebräuchlichen Zinn-

kannen (im privaten Haushalt) . 44

Die Glockenkanne . . . . . . 44

Die Stitze . . . . . . . . . . 45

Die prismatischen Kannen . . . 46

Die Rundle . . . . . . . . 47

Die Freiburger Kanne . . . . 48

Die Berner Kannen . . . . . . 48

Die Genf-Waadt-Walliserform . 50

Die seltenen Kannenformen . . . $\quad 5_{1}$

Die andern Zinngegenstände:

Die Maasse . . . . . . . . . 52

Die zinnernen Flaschen . . . . 54

Die Messkännchen. . . . . . . 54

Die Humpen . . . . . . . . . 54

Die Brunnenkesselchen . . . . 54

Die Giessfässer . . . . . . . . 55

Die Platten und Teller . . . . 56

Die Wandplatten . . . . . 57

Die Ohrenschüsselchen . . . 57

Verzeichnis weiterer Gegenstände $\quad 57$

Die geographische Verteilung der Kannenformen in der Schweiz und ihre Beeinflussung durch die Stilarten . . 58

Die Rats- und Gemeindekannen . 58

Die Gebrauchskannen des Volkes 60

Die französischen Stilarten des XVIII. Jahrhunderts . . . . 61

Die Zinnfälschungen und die Kopien . $\quad 61$

Der Zinnsammler, Repariren und Reinigen . . . . . . . . . . . 63

Alphabetisches Meisterverzeichnis . . 65

Alphabetisches Ortsverzeichnis . . . 76

$39 \quad$ Verzeichnis der Tafeln . . . . . 77 1 44 4 5 6 47 8 


\section{Zweiter Teil}

A. Nordostschweiz

Zürich :

Zürich . . . . . 80

Winterthur . . . $9_{95}^{5}$

Stein am Rhein . . . 97

Eglisau . . . . . 99

Rheinau . . . . 99

Elgg . . . . . . 99

Zug $\quad$. . . . . . . 101

Luzern : Luzern . . . . 108

Beromünster . . . . 112

Schwyz ........ . 113

Uri ........ 115

Unterwalden: Nidwalden . . . . 117

Obwalden . . . . 118

Glarus . . . . . . . 120

Graubünden . . . . . . . 122

Schaffhausen und Hallau. . . . . ${ }_{128}$

Thurgau Frauenfeld . . . ${ }_{1} 3_{7}$

Bischofszell . . . . $\quad{ }_{\mathbf{1}} \mathbf{3 8}$

Ermatingen . . . 140

Steckborn . . . . 140

Weinfelden . . . 142

Diessenhofen . . . . 143

St. Gallen : St. Gallen . . . . 145

Rheineck . . . . ${ }_{154} 54$

Rorschach . . . . 155

Wyl ...... ${ }_{155}$

Rapperswil . . . . . ${ }_{1} 58$

Lichtensteig. . . . 160

Sargans, Gossau . . ${ }_{1} 6_{1}$

Appenzell . . . . . . . . ${ }_{161}$

B. Nordwestschweiz

Basel: Basel ...... 163

Liestal . . . . 172

Solothurn . . . . . . . 173

Freiburg: Freiburg . . . . 183

Bulle . . . . . . 188

Estavayer . . . . 188

Murten . . . . . 189
C. Bern und der Aargau

Bern :

Bern. . . . . 190

Thun ..... . 202

Burgdorf . . . . 204

Biel . . . . . . 205

Neuenstadt . . . . 211

Münster . . . . . . 212

Pruntrut . . . . 212

Delsberg. . . . . 212

Aargau: Aarau . . . . 213

Brugg . . . . . 217

Bremgarten . . . 218

Wettingen.... 218

Lenzburg . . . 218

Zofingen . . . . 218

Baden . . . . . . 228

D. Südwestschweiz

Genf

Waadt :

. . . . . . . . 229

Lausanne . . . 234

Vevey . . . . . 237

Yverdon . . . . 243

Orbe . . . . . 244

Payerne . . . . 245

Moudon . . . . 245

Morges . . . . . 245

Gland bei Morges . . 246

Grandson. . . . . 246

Neuenburg: Neuenburg . . . 247

Môtiers-Travers . . $\quad 252$

Wallis : Sitten . . . . ${ }_{2} 52$

Martigny . . . . ${ }_{2} 5_{7}$

Monthey . . . . . . $\quad{ }_{2} 57$

Visp . . . . . ${ }_{2} 58$

Brig . . . . . . . . ${ }_{2} 58$

Leuk . . . . $\quad{ }_{259}$

Tessin : Tessin . . . . ${ }_{260}$ 


\section{Literatur - Verzeichnis}

\section{SCHWEIZ}

Babel, Antony. Histoire corporative de l'horlogerie, de l'orfèvrerie et des industries annexes. Genève 1916.

Blavignac. Revue Florimontane, 1874 , Genève.

Bossard, Gustav. Schweizer Zinnkannen. Beilage zum Jahrbuch des S. A. C. 1908.

Bossard, Gustav. Die Zinngiesser der Schweiz und ihr Werk. Band I, 1920. Kommissions-Verlag Karl Strübin, $Z$ ug.

Bossard, Gustav. Die Zinngiesser der Schweiz und ihr Werk, Band II, 1934. Selbstverlag. Druck von Roto-Sadag S. A., Genéve.

Bourquin, Werner. Bieler Zinngiesser. Blätter für bernische Geschichte, Kunst- und Altertumskunde, 1921 . Heft 3 und 4. Bern.

Bourquin, Werner. Biel. Ein Führer für Geschichtsund Altertumsfreunde. Biel 1922. Andres \& Cie.

Brown, John A. Das Zinngiesserhandwerk der Schweiz, 193o. Solothurn. Petri u. Cie., Verlag.

Burkhardt, R. F. Der Basler Münsterschat z, Base 1933 . S. 175 .

Buss, Ernst. Die Kunst im Glarnerland, 1920, Glarus. Die Zinngiesser, S. 12.

Chappuis, Robert. Catalogue de l'Exposition d'objets de culte à la Cathédrale de Lausanne. 1930.

Choisy, Albert. Les potiers d'étain generois. Bulletin de la Société d'histoire et d'archéologie. Genève $19^{\circ} 7$.

Demmin, Auguste. Revue panoptique de la Suisse, Paris 1892.

Demmin, Auguste. Souvenirs de voy age et causerie d'un collectionneur. Paris 1864 .

Encyclopédie de Felice. Yverdon 1775.

Von Flüe, Josef. Einheimische Zinngiesser in Unterwalden. Bruder-Klausen-Kalender. 1922. S. $58 \mathrm{ff}$.

Fluri, Ad. Kulturgeschichtliche Mitteilungen aus den bernischen Staatsrechnungen des 15 . Jahrhunderts. Bern 19 if.

Frei, K. Zwei gotische Zinnkannen aus dem Wallis. Jahrsb. des schweiz. Landesmuseums, 1930, S. $48 \mathrm{ff}$.

Fümm, S. Das Rathaus von Davos. Davos-Platz 1915.

Füssli, J. R. Allg. Künstlerlexikon oder kurze Nachricht von dem Leben und den Werken der Mahler, Bildhauer..., Kunstgiesser etc. Zürich, Heydegger \& Comp. ${ }^{7763 / 67}$, 2 Bde.
Geering, Traugott. Handel und Industrie der Stadt Basel im Mittelalter. Basel 1886 .

Gessner-Siegfried, A. Katalog des kant. Antiquariums in Aarau, Aarau 1912, S. 121.

Godet, Alfred. Nos industries neuchâteloises. L'Etain. Musée Neuchâtelois 1872 , S. 142 und $1889, S, 78$.

Gränicher, Th. G. Das Zinngiesserhandwerk in Zofingen. Anzeiger für schweiz. Altertumskunde, $\mathrm{Bd}$. XIX. S. 26 und 99. Zürich. 1917.

Gross, Victor. Protohelvètes, Tafel XXII fig. 15. Landesmuseum Zürich.

Hauser, K. Geschichte der Stadt, Herrschaft und Gemeinde Elgg. Elgg 1895 .

Hegi, Friedrich. Die Zunft zur Schmieden in Zürich. Zürich 1912 .

Heyne Moritz. Kunst im Hause, II. Reihe. Abbildungen von Gegenständen aus der Mittelalterlichen Sammlung zu Basel. C. Detloffs Buchhdlg. 1882.

Von Jecklin, Fritz. Der Kampf der Churer um die Gewerbefreiheit. Chur 1917.

Lehmann, Hans. Die gute, alte Zeit. Neuenburg. F. Zahn.

Meyer-Zschokke, L. Die Schweizer ZinnfigurenIndustrie. Wegleitungen des Kunstgewerbe-Museums Zürich. 1916, Nr. 12, S. 7 .

Morgenthaler, Hans. Beiträge zur Bau- und Kunstgeschichte Solothurns in 15. Jahrhundert. Anzeiger für schweiz. Altertumskunde 1924.

Müller-Dolder, E. Die Zinngiesser A. und L. Petermann in Beromünster. Festnummer der Münsterer Zeitung vom 16. September 1913.

Næf, Ernest. Les potiers de'tain genevois. Genève 1904 : Nos anciens, S. 87-115.

Næf, Ernest. L'étain et le livre des potiers d'étain genevois. Genève Sonor. 1920.

Oesterreichische, patriotische Kriegsmetallsammlung. Katalog. Wien $1915 / 16$ und Nachtrag $1915 / 16$.

Peissard, N. Fribourg artistique à travers les âges. Société des Amis des Beaux-Arts. 1913.

Rabut, M. Laurent. Revue Florimontane, 1875 . (Artikel über Genfer Zinnmarken). 
Reutter Louis. Les potiers d'étain neuchâtelois. Musée neuchâtelois $1919 \mathrm{Nr} .4$ und 5. (Juillet-Octobre) und 1920 (Juillet-Août).

Schilling, Diebold. Luzerner Bilderchronik. 1513. Verlag Sadag S. A. Genf 1932.

Schwab, Fernand. Beitrag zur Geschichte der bernischen Geschirrindustrie. Schweiz. Industrie- und Handelsstudien. 1921 Heft 7 .

Schwab, Fernand. Die industrielle Entwicklung des Kantons Solothurn. 1926. Band I.

Schweizerischer Künstlerlexikon, rom schweiz. Kunstverein. 4 Bände. 1905/17. Frauenfeld.

Stauber, Emil. Sitten und Bräuche im Kanton Zürich. 122. Neujahrsblatt der Hülfsgesellschaft in Zürich. 1922, S. 51 . ff.

Stebler, F. G. Ob den Heidenecken, 1901. Das Goms und die Gomser, 1903. Am Lötschberg 1907. Sonnige Halden am Lötschberg 1913.

Valèr, M. Geschichte des Churer Stadtrates. 1922.

Vuilliemin. Der Kanton Waadt. Historisch-geographisch-statistisches Gemälde der Schweiz. 1847 .

Zesiger, Alfred. Das hernische Zunftwesen.

Die Angaben über die handschriftlichen Que]len finden sich bei den einzelnen Giesserorten (II. Teil) in den Fussnoten.

\section{AUSLAND}

Baader. Beiträge zur Kunstgeschichte Nürnbergs. Nördlingen. Beck. 1860, 1862.

Baader. Beiträge zur Kunstgeschichte Nürnbergs. Jahrbücher für Kunstwissenschaft. A. von Zahn, Leipzig. I. Jahrgang 1868. S. 221 . ff.

Balet. Das alte Zinngiesserhandwerk in Ulm. Cicerone 1912. S. $887 \mathrm{ff}$.

Bapst, Germain. L'étain. Paris. G. Masson 1884. J. Michelet 1888.

Bell, Malcolm. Old Pewter, London and New-York 1913.

Berger, Dr. Franz. Rieder Zinngiesser. Rieder Heimatkunde, Ried 1909. I. S. 15.

Berling, K. Sächsische Zinnmarken. Kunstgewcrbeblatt III, 1887 . S. $133 \mathrm{fr}$.

Berling, K. Prof. Dr. Stadtmarken der Zinngicsser von Dresden, l,cipzig und Chemnitz. Neucs Archiv 'für sächsische Geschichtc XV1, 1895 . S. 123 fr.

Berling, K. Stadtmarken sächsischer Zinngiesser. Dresden. C. Heinrich. 1913.

Berling, K. Altes Zinn. Bcrlin. R. Carl Schmid. 1919.

Berling, K. Einiges über $Z$ innfälschungen. Jahrbucls für Kunstsammler; IV. und V. Band. Frankfurt 19:5.
Bösch, Hans. Hans Sachs' Spruchgedichte von den Nürnberger Kandelgiessern. Mitteilungen aus dem germanischen Nationalmuseum II. S. $73 \mathrm{ff}$.

Braun. Ein Werk des Joachimstaler Zinngiessers Hans Wild. Kunst und Kunsthandwerk 1914. S. $533 \mathrm{ff}$.

Brauns. Warum sind Zinngeräte aus der Bronzezeit selten? "Aus der Natur 1906 . S. $7_{7}^{3}$ ff.

Brinkmann. Das hamburgische Museum für Kunst und Gewerbe. Hamburg, 1894 . Leipzig. Seemann.

Bucher. « Mit Gunst ». Aus Vergangenheit und Gegenwart des Handwerks. Leipzig. Grunow. 1886.

Burns, Thomas. Old Scottish Communion Plate. 1892.

Castan. Les origines montbéliardaises du ciseleur François Briot et du monnayeur Nicolas Briot, Besançon. Dodivers \& Cie. 1880.

Castan. Le graveur François Briot, bourgeois de Montbéliard, analyse d'une étude de $M$. Alexandre Tuetey, extrait des Mémoires de la Société d'Emulation du Doubs. séance du 18 juin 1887 . Besançon.

De Champeaux. Dictionnaire des fondeurs, ciseleurs, modeleurs en bronze et doreurs. London Gilbert Wood \& Co, tome I. A.-C. 1886.

Cicognara. Storia della scultura. Venezia, Picotti. II. Band. 1816 .

Cotterell, Howard, Herschel. Old Pewter. Its Makers and Marks in England, Scotland and Ireland, London. B. T. Batsford. 1929. Daselbst ausführliches englisches Literaturverzeichnis.

Cotterell, Howard Herschel and Vetter, Robert M. ; Pilgrims and other Flasks in pewter. Internat. Studio. New-York. November $19^{2} 8$.

Demiani, Hans. François Briot, Caspar Enderlein. und das Edelzinn. Leipzig, K. W. Hirsemann. 1897.

Demiani, Hans. Zinn. Mitteilungen des nordböhmischen Gewerbemuseums. XVIII. Reichenberg 1900 . Heft 2.

Demiani, Hans. Sächsisches Edelzinn. Neucs Archiv für sächsische Geschichte 1904, S. 1 und 305 ff.

Demiani, Hans. Neues uiber altes Edelzinn. Dresdner Jahrbuch 1905 S. 55 ff.

Demiani, Hans. Kunsthandwerk X. Wien 1907 , S. $82-89$.

Demmin, Auguste. Studien über die stofflich-bildenden Künste und Kunsthandwerke. Vierte Folge. Die Edel-oder Gold- und Silber-Schmiedekunst : das Treiben, besonders der Dinandrie, das Zinngiessen usw., in ihren geschichtlichen Entwicklungen, Leipzig, Thomas 1888.

Dietz, Dr. Alexander. Das Frankfurter Zinngiessergewerbe und seine Blütezeit im 18. Jahrhundert. 1903. Festschrift des städtischen historischen Museums in Frankfurt a. M. Frankfurt 1903. S. 176 .

Doppelmayr. Kunst-, Gewerbe- und HandwerksGeschichtc der Stadt Augsburg. 1779. 
Dufréné. Etude sur l'histoire de la production et du commerce de l'étain. Paris, Lacroix, $188_{1}$.

Encyclopaedia Britannica. Pewter.

Encyclopédie Diderot et d'Alembert. Paris ${ }_{17} 5_{1}$,

Von Falke. Geschichte des deutschen Kunstgewerbes. Berlin, Grote 1888.

Von Falke. Ueber altes und neues $Z$ inngerät. Kunstgewerbeblatt 1895/96. S. $165 \mathrm{ff}$.

Figdor, Dr. Albert. Wiener Kunst und Kunsthandwerk. Vll. Abteilung. Wien 1904.

Figdor, Dr. Albert. Die Sammlung Dr. Albert Figdor. Wien. Erster Teil, erster Band, verzeichnet von Otio von Falke. 1930. Waldheim-Eberle, Wien.

Focke. Vom bremischen Zinngiesseramt, Mitteilungen des Gewerbe-Museums zu Bremen. 1887. S. 33 ff.

Focke. Bremische Werkmeister. $189^{\circ}$.

Forrer, Dr. Robert. Les étains de la collection Alfred Ritling à Strassbourg, Strassbourg. 1905.

Forrer, Dr. Robert. Zinn-Cimelien der Sammlung Hofrat Kahlbau. Strassburg i. E. 1908.

Gahlnbäck, Johannes. Russisches Zinn. Band I. Moskau. Band II. Leningrad. K. W. Hiersemann, Leipzig $193_{2}$.

Gale, Edwards J. " Pewter and the Amateur Collector» 1910.

Gebert, Carl Friedrich. Die Zinngiesser Hilpert in Nürnberg. Mitteilungen aus dem germanischen Nationalmuseum. Nürnberg 1914/15.

Graul. Kunstgewerbliche Streifzüge. III. Von der Zinnausstellung des mitteldeutschen Kunstgewerbevereines in Frankfurt a. M. Kunstgewerbeblatt $1885 / 86$. S. 198 ff.

Gurlitt. Die Dresdner Ausstellung alter Zinnarbeiten. Kunstgewerbeblatt 1890 . S. 22 ff.

Halm. Das Zinn im Kunsthandwerk. Zeitschrift des bayrischen Kunstgewerbevereines, Heft 1, S. $8 \mathrm{ff}$, München 1895 .

Havard. Dictionnaire de l'ameublement et de la décoration. Paris. Quantier II. Band. Artikel Estaimier et Etain.

Heyne Moritz. "Das altdeutsche Handwerk " Strassburg 19:8. S. 181.

Hintze, Erwin Prof. Dr. Die deutschen Zinngiesser und ihre Marken. Leipzig. K. W. Hiersemann. Band I.VII. $19^{21} / 3_{2}$.

Hintze, Erwin. Nürnberger Zinn. Der Cicerone XII. Heft 15 und 16 .

Hintze, Erwin. Die schlesischen Zinngiesserwerkstätfen. Jahrbuch des schlesischen Musenms für Kunstgewerbe 1909 , S. $169 \mathrm{ff}$.

Hintze, Erwin. Eine schlesische Zinnkanne von 1506. Cicerone 1910. S. $303 \mathrm{ff}$.

Hintze, Erwin. Schlesische Zinngeräte in geäztem und gegossenem Dekor. Cicerone 1910. S. $485 \mathrm{ff}$.

Hunt. The Perih Hammermen Book. Quart. 1889.
Jacquemart, Albert. Histoire du Mobilier..., eic. Paris, 1876 .

Jal. Dictionnaire critique de biographie et d'histoire. Paris, Plon. I. Auflage, $186_{7}$.

Jouve. Biographie générale des Vosges: Woeiriot Les Briot - Fratzel. Paris, chez l'auteur, 1890.

Kahlbau. Studien ïber Nürnberger $Z$ inn. Handschrift im Kunstgewerbe-Museum in Leipzig.

Karafiat. Zinn und Zinngiesser in Teplitz. Tätigkeitsbericht der Museums-Gesellschaft in Teplitz 1915/16.

Kugler. Beschreibung der in der königl. Kunstkammer zu Berlin vorhandenen Kunstsammlung. Berlin. Heymann, 1838 .

Kunstgewerbeblatt, Leipzig, Seemann.

Kyrle, Eduard. "Schärdinger-Zinn ». Innviertler Heimatkunde auf das Jahr 1917, Branan am Inn, S. 4o ff.

Lacher. Hostienbehältcr im Museum zu Graz. Kunst und Kunsthandwerk. 1906, S. 596.

Von Lanna, A. Sammlung A. von Lanna. Auktion bei Rudolf Lepke in Berlin 1909.

Leitschuh, F. Kunststätten, Strassburg 1903. Elsässisches Zinn. Das Kunstgewerbe in Elsass-Lothringen II. 1901/02. Strassburger Zinn.

Lessing, Julius. « François Briot und Caspar Enderlein». Tahrbuch der königl. preuss. Kunstsammlungen. Berlin, Grote, Band X (1899) Heft IV.

Lessing, Julius. Künstlerisches Zinngerät im 16. Jahrhundert "Das Museum » II. S. 65 ff.

Lill, Georg. Nürnberger Zinnfiguren der Familie Hilpert. Kunst und Kunsthandwerk, Zeitschrift des bayririschen Kunstgewerbevereins München. $19^{20}$. Heft 3.

Lüer, Dr. Herrmann. Geschichte der Metallkunst, Stuttgart 1904. Band I.

Lungwitz, Herrmann. Edelzinn in Privatbesitz. Chemnitz ${ }^{1} 9^{17}$.

Macht. «Zinnarbeiten », in den Mitteilungen desk.k. österreichischen Museums für Kunst und Industrie. Wien. Gerold. VIII. Jahrgang. 1893. Heft VII und VIII.

Markham. C. A. The Church plate of the County of Northampton. Illustratet. 1894 .

Mantz. » Recherches sur l'histoire de l'orfèvrerie française », Gazette des Beaux-Arts. Paris. IX vol. 1861.

Maze-Sencier. Le livre des collectionneurs. Paris. Renouard, 1885.

Massé, H. J. L. Pewter Plate. A historical and descriptive handbook. 1904.

Massé, H. J. L. Old pewter plate, $2^{\text {nd }}$ édition, London 1910. George Bell and sons.

Massé, H. J. L, Chats on old pewter. London 1911. Fisher Unwin.

Moore, N. Hudson. Old pewter, copper and Sheffield plate (N. D.). 
Von Murr. Beschreibung der vornehmsten Merkwürdigkeiten in der H. R. Reichs freyen Stadt Nürnberg etc. Nürnberg. Zeh. 1778.

Von Murr. Versuch einer Nürnbergischen Handwerksgeschichte etc. Aus Murrs Journal zur Kunstgeschichte und zur allgemeinen Literatur. Nürnberg. Zeh. V. Theil. $(1777)$.

Neudörfer, Des Johann Neudörfer, Schreib- und Rechenmeisters zu Nürnberg, Nachrichten von Künstlern und Werkleuten daselbst aus dem Jahre ${ }_{1} 547$ nebst der Fortsetzung des Andreas Gulden, herausgegeben von Lochner. Wien. Braumüller, 1875 .

Nightingale, James $\mathbf{E}$. The Church plate of the County of Dorset, ${ }^{1889}$.

Nightingale and Goddard, E. H. The Church plate of the County of Wilts. $18 \mathrm{gi}$.

Oberwalder, Dr. Oscar. Altes Zinn, Heimätgäue. Linz. $1919 / 20$, S. $247 \mathrm{ff}$.

Reiber, Emile. L'art pour tous (XVIme_XVIl ${ }^{\text {me }}$ siècle).

Von Rettberg. Nürnbergs Kunstleben. Stuttgart. Ebner \& Seubert. 1854 .

Reyer, E. Zinn, eine Monographie. Berlin 188ı. Bei G. Reiner.

Riff, Adolphe. Archives Alsaciennes d'histoire de l'art. IlI. 1924. Deux artisans alsaciens du XVIIme siècle, les fondeurs Isaac Faust et Auguste Guentzer.

Riff, Adolphe. Les Etains Strasshourgeois du XVIme au XlXme siècle. Strassbourg 1925 .

Riff, Adolphe. L'Orfèvrerie d'étain en France. Les écuelles à bouillon. Strassbourg $19_{2} 5$.

Riff, Adolphe. L'Orfèvrerie d'étain en France. Les Aiguières en casque, Strassbourg 1926 .

Robert-Dumesnil. Le peintre-graveur français. Paris, Bouchard-Huzard, Rapilly. Leipzig, Weigel Band IX, 1865 .

Von Rziha, Franz R. «Böhmische Zinngefässe», in den Mittheilungen der K. K. Centralkommission zur Erforschung und Erhaltung der Kunst- und historischen Denkmale. Wien, Braumüller. Neue Folge. XVIII. Jahrgang, $89^{2}$, S. $27 \mathrm{ff}$.

Von S. R. "Zinngeschirr », in der von Bruck berausgegebenen Zeitschrift für Kunst- und Antiquitätensammler. Leipzig, Hucke. 1884 .

Salmon, M. Marchand Potier d'Etain, à Chartres. Art du potier d'étain. Paris, chez Moutard 1788.

Deutsch von Rosenthal im XX. Band von "Schauplatz der Künste und Handwerke o etc., Berlin, Pauli 1795.

Schirek. Das Zinngiesserhandwerk in Mähren. Mitteilungen des mährischen Gewerbemuseums in Brïn. Brünn 1893 S. 37 ff. ; 1894 S. 129 ff. ; 1899 S. 49 ff. ; 1900 S. 165 ff. ; 1904 S. 145 ff.
Von Schorn. Kunst und Gewerbe zu Nürnberg. 1879 . Sprengel. Handwerk und Künste in Tabellen. IV. Sammlung, Berlin,-Verlag der Realschul-Buchhandlung, ${ }_{1769}$

Stieda. Das Amt der Zinngiesser in Rostock. Jahrbuch des Vereins für meklenburgische Geschichte. 1888 , S. 13 iff.

Stockbauer. Nürnbergisches Handwerksrecht des XVI. Jahrbunderts. Nürnberg, Korn 1879.

Tischer, Friedrich. Böhmisches Zinn und seine Marken. Leipzig, K. W. Hiersemann 1928.

Tischer, Friedrich. Das Zinngiesserhandwerk in Böhmen. Kunst und Kunsthandwerk, 1917, S. 231 ff.

Töpfer. Das Gebrauchszinn. Mitteilungen des Gewerbemuseums zu Bremen. 1902, S. 81 ff.

Trollope Andrew. An Inventory of the Church Plate of Leicestershire. $18 \mathrm{go}$.

Tuetey. Mémoires de la Société d'émulation de Montbéliard en 1887 .

Tuetey. Le graveur lorrain François Briot, d'après les documents inédits. Als Buch erschienen 1889 bei Charavay frères in Paris.

Walcher von Moltheim, Alfred. Deutsches und französisches Edelzinn aus zwei Wiener Sammlungen. Kunst und Kunsthandwerk VII. Wien 1904.

Walcher von Moltheim, Alfred. Deutsches Edelzinn im Museum Carolino-Augusteum in Salzburg. Kunst und Kunsthandwerk. Wien 2910. XIII.

Walcher von Moltheim, Alfred. Das Zinngiesserbandwerk der Stadt Salzburg. 19ı. Salzburg.

Warneke, Johannes. Die Zinngiesser zu Lïbeck, Lübeck 1922. Gebr. Borchers.

Welch, Charles. History of the Worshipful Company of Pewterers on the City of London. Two vols. 1902.

Wieditz, B. Altes Zinn. Velhagen u. Klasings Monatshefte, Oktober 1908. (Gute Bilder, Text wertlos.)

Withington, Lothrop. Elizabethan England « Camelot Classics \$ 1886.

Wood, Ingleby, L. "Scottish Pewterware and Pewterers .1905 .

Das „Zinn im Kunstgewerbe“, in der Wochenschrift "Kunst und Gewerbe », Nürnberg, Korn, XIII. Jahrgang, 1879 (von Steckbauer).

Zœllner, Julius. Das Zinn in alter und neuer Zeit.

Zœllner, Julius. Zinnstempel und Zinnmarken. Leipzig. Zeitschrift für bildende Kunst. N. F. ${ }_{1} 898$ S. $159 \mathrm{ff}$. (IX Heft $7: \mathrm{X} \mathrm{Heft}_{4}$ und 5).

Zukal. Troppauer Zinngiesser his zum Beginn des 19. Jahrhunderts. Zeitschrift für Geschichte und Kulturgeschichte österreichisch Schlesiens V1ll. I und 2. 


\section{Auktions Kataloge mit wesentlichen schweizerischen $Z_{\text {innbeständen. }}$}

\section{SAMMLUNG}

Angst, H., Konsul, Zürich. Auktion in Zürich 1919. II. 16./18. bei J. H. Heberle, Köln.

Arndt, Fritz, Oberwartha. Auktion in München 1930. XI. 13./14. bei Hugo Helbing, München.

Arnold, M , Luzern. Auktion in München 1913. XII. 2. bei Hugo Helbing, München.

Audéoud, Edouard, Genf. Etains anciens. Auktion in Zürich 1925. IV. 28./29. durch A. Mincieux und J. Kündig, Genf.

Bossard, J., Luzern. Auktion in Luzern 1910. VII. 4 . durch Hugo Helbing, München.

Engelmann, Dr., Basel. 1. Auktion in BaseI 1918. V. 24./27. durch H. Messikommer, Zürich.

2. Auktion in Basel 1932. III. 14/16. durcb Dr. Jules Coulin, Kunsthaus pro Arte, Basel.

Von Gasser, Rudolf, München. Auktion in München 1912. II. 28. ff. durch Hugo Helbing, München.

Gubler, F., Zürich. Auktion in Zürich 1911. XI. 27. durch H. Messikommer in Zürich.

Gubler J. J., Zürich. Auktion in Zürich 1893 . IX. 4./12. durch J. M. Heberle in Köln.

Hengeler, Adolf, Prof., München. Auktion in München 1931. VII. 3. bei Hugo Helbing, Nünchen.

Helbing Hugo, München. Altes Schweizer Zinn. Katalog mit Verkaufspreisen 1908.

Hirsbrunner, C., Luzern. Auktion in Zürich 1929. III. 8./9. durch Dr. Störi, Zürich.

Kende, Albert, Wien. Auktion in Wien 1918. II. 4. Schweizer und Nürnberger Zinn. Verkauf durch Albert Kende, WVien.
Von Kleist, Ewald, Freiherr, Zürich. Auktion in Zürich 1933. V. 17/19. durch Theodor Fischer, Luzern.

Kodella, Dr., Graz. Auktion in Luzern 1934. VIlI. 19./ 3o./31. durch Theodor Fischer, Luzern.

Lepke, Rudolph, Berlin. Auktion 1914. III. 24/27. und 1914 . IV. $28 . / 30$.

Mincieux und Kündig. Genf. Auktion einer schweiz. Zinnsammlung in Zürich 1925. IX. 29.

Nestel, Carl, Stuttgart, Auktion in München 1916. X. 26. durch Hugo Helbing in München.

Oesterreichische, patriotische Kriegsmetallsammlung, $\mathrm{Ka}$ talog und Nacbirag 1915/16 vom K. K. Kriegsministerium Abt. 7. Wien.

Oppler, Edwin, Hannover. Auktion in Berlin 1913. II. 25./III. I durch Rudolph Lepke, Berlin.

Von Pourtalès. Inventar des Schlosses Mauensee bei Luzern. Auktion in Zürich 1932. V. 26./28. durch Theodor Fischer, Luzern.

De Ridder, Frankfurt a. Main. Auktion in München 1919 durch Hugo Helbing in München.

Sch..., Dr., Basel. Auktion in Zürich 1929. IX. ${ }_{2} 6 / 27$. durch Dr. Störi in Zürich.

Thierstein, H., Bern. Auktion in Bern 1920. XI. 15./29. durch Kunsthaus Thierstein, Bern.

Wessner, Otto, St. Gallen. Auktionen in Zürich.

I. Teil 1924. X. 14./15. durch Hugo Helbing, München.

II. Teil 1925. XI. 3./5. durch Hugo Helbling, München,

H. Messikommer, Zürich und Mincieux und Kündig, Genf.

Woog, L. Bern. Auktion in Bern 19:9. V. 3./14. durch die Erben. 


\section{Ergänzungen und Korrekturen zu Band I.}

Die neu gefundenen Meisterzeichen sind im Band II bei den betreffenden Meistern abgebildet.

Seit dem Erscheinen des Bandes 1 sind nun vierzehn Jahre verflossen. Die vielen Meisterzeichen baben die lokale Forschung bedeutend angeregt und dadurch sind viele verborgene Schätze gehoben worden. Auch wurden neue Marken gefunden, teils Varianten schon bekannter Meister, teils Zeichen bisher unbekannter Zinngiesser. Die Beschau- und Giesserzeichen der Urkantone haben sich bedeutend vermehrt. Ebenso mussten die Tafeln Biel und Solothurn aus dem gleichen Grunde neu gezeichnet werden .

Mehrere Meister mussten anderweitig zugeteilt werden, so z. B. sind die Beschauzeichen von Solothurn und Ulm infolge Gleichheit des Wappens zum Verwechseln ähnlich. Obwobl sämtliche Abänderungen bei den einzelnen Meistern zu finden sind, folgt hiemit ein kurzer Ueberblick über die Abänderungen auf den einzelnen Tafeln des Bandes I.

TafeL 1. Die Beschauzeichen von Uri und die Meisterzeichen von Schwyz sind zahlreicher geworden. $\mathrm{Zu}$ Uri kommt nocb Nr. 4 a und $q$ b; zu Schwyz Nr. 5 a und $6 \mathrm{a}, \mathrm{b}, \mathrm{c}$ und $\mathrm{d}$ (Kloster Einsiedeln).

Nidwalden und Obwalden bilden eine neue Tafel $1 \mathrm{~b}$; die Nr. 543 und 605 des Bandes 1. gehören zu Obwalden.

Zu Luzern kommen fünf Meisterzeichen ron Beromünster in Band II als Nr. 24 a, b, c d, e ; Franz Antoni und Joseph Leodegar Petermann, beide 1748 erwähnt.

TAFEL II. $Z u$ $Z$ u g kommt das Meisterzeichen Nr. 34 a und 27 a, das auf $Z$ inn geschlagene Goldschmiedzeichen des Wolfgang Vogt. Bei Nr. 28 S. K. (nicht S. R.).

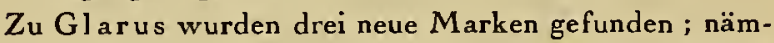
lich zwei ( $\mathrm{Nr} .53 \mathrm{a}$ und b). Meisterzeichen des Hans Weiss und dasjenige von Hans Jakob Spälti I und II Nr. 49 a.

TafBL IlI bleibt unverändert (Boden-Rosetten).

$T_{A F E L}$ IV. Züricb. Neu ist das Meisterzeichen des Heinricb Sommerauer Nr. 73 a (Band II), (zünftig 1680, gestorben 1726). Die Meisterzeichen Nr. 75,76 und 77 konnten genau bestimmt werden. Nr. 80 gehört an Jörg Zubler und Witwe (zit. 1618-1641); Nr. 81 an Johann Heinricb Baltischwiler I und II $\left(16_{47^{-1}} 730\right.$; $\left.1676-?\right)$.

TAFEL V bleibt unverändert (Zürich).

TAFrL VI. Zü rich. Nr. 121,123,125 gehören der Lisabeth Manz, Witwe des Caspar (1743-1804). Nr. 122, 124 gebören der Lisabeth Manz, Witwe des Friedrich $(1812-1880)$. Nr. 136 gehört zu Julius Lachmund $(1801-1874)$.

TApEL VII. Zürich. Zu Nr. 139, Johannes Caspar Ziegler $\left(177^{6-18}, 4\right)$ wurden zwei neue Stempelvarianten gefunden : Nr. ${ }^{3} 9$ a und $b$ (Band II).

$\mathrm{Zu}$ Winterthur Nr. 143 a, Meisterzeichen von Antonius I Graf geb. 16:7, gestorben 1686 (Siehe Band II Nr. 143 a).

Nr. 148 a, Band II ; Meisterzeichen von Johann Heinrich Furer, geboren 1812 , verheiratet 1843 , gestorben?.

$T_{\text {AfrL }}$ VIII. Zu Elgg gehören auch die Nr. 184 und 185 der Tafel IX, Band I. Beide gebören dem J. Heinrich
Tracbsler, zit. 1780,1788 bis 1804 . Nr. 177 , Jakob Friedrich Lauffer, geboren 1804 .

TAFEL 1X. Sch affhausen. Nr. 184 und 185 gehören zu Elgg (J. Heinrich Trachsler). Nr. 190 ist das Meisterzeichen von Hans Conrad Hurter, geboren 1671 , gestorben ${ }_{1744 .} \mathrm{Zu} \mathrm{Nr} \cdot 196$ wurde eine weitere Stempelvariante gefunden. Ausserdem wurden folgende Meisterzeichen gefunden : Nr. 178 a, Hans Bäschli, zit. 1554 ; Nr. ${ }_{7} 8$ b Alexander I Abegg, geboren 1607 , zit. 1643 : Nr. 178 c Alexander II Ab-Egg, geboren $163_{7}$, gestorben 1685 ; Nr. 189 a Johannes I Pfänder, geboren 1656. gestorben 1694 .

Tafel X. Schaffhausen. Zwei neu gefundene Giessermarken Nr. 206 a und 206 b gehören dem Meister Johannes Hoscheller; geboren 1792, gestorben 1840 .

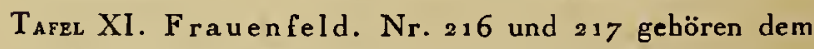
Hans Melchior Teucher, 1703 zuinftig, gestorben 1742 . Nr. 217 a Hans Ulrich Kappeler, erwähnt ab 1664 , gestorben 1712 .

Diessenbofen. Nr. 218 , Benker Erhart, zit. 1660, gestorben 1711 . Nr. 218 b (neu) Benker Hans Rudolf, geboren 165o, gestorben ${ }_{1723}$. Nr. 219 Benker Jonas, geboren $166_{2}$, gestorben 1735 . Nr. 218 a Stadtzeichen von Diessenhofen.

Steckborn. Nr. 2 ig b und c (neu) Hans Jakob Basler, I, II und III. Eine Zuteilung an einen der drei ist nicht möglich. Nr. 220, 221, 222, 223 und noch weitere Varianten gehören den sechs Andreas Wüger. Eine genaue Zuteilung ist eine Aufgabe der Lokalforscbung, ebenso wie die folgenden drei Johannes Wüger, Nr. 224. 225 und noch weitere Varianten.

Weinfelden. Nr. 230 (neu) und 230 a und b, Jobann Jakob Thurnbeer, geboren ${ }_{17} 36$, lebte ${ }_{17} 69$ noch. Nr. 231, Hans loachim Keller, geboren 1708, lebte 1765 noch.

Nr. 227 gehört zu Beromünster.

TafzL XII. B isch of z ell. Neu gefunden wurde Nr. 242 a, Meister I. M. Ferner Nr. 241 c, Hans Jakob Daller, $169^{2}$ Lehrling bei Andreas I Wüger, gestorben um 1750 . Ermatingen. Nr. 296. Tafel XIV und 296 a (neu) gehören dem Bernhard Ammann, erwäbnt 1744 . 
TAFel XIII. St. Gallen. Nr. 262 , der Stempel ist stark deformiert und (neu) wird auch wie Nr. ${ }_{2} 6_{2}$ a entziffert. Neu ist Nr. ${ }_{2} 62$ b das Eigentumszeichen des KJosters St. Gallen. Nr. 260, 261 gehören nicbt zu St. Gallen, sondern zur deutschen Stadt Glogau. Zu Nr. 278 und 291 gibt es viele Stempelvarianten; eine einwandfreie Zuteilung an Abraham und Adrian I und 11 Hiller ist nicht möglich. Nr. 271 Hans Jakob Zingg, 1702-1756 (nicht Zollikofer). In Band 11 findet sich der Versuch einer Zuteilung der sechs verschiedenen Marken Nr. 279-284 und der Varianten 282 a, 280 a und $b$, $283 \mathrm{a}, \mathrm{b}, \mathrm{c}, \mathrm{d}$.

$\mathrm{Nr}, 279,28_{2}$ und 282 a, Jakob Glinz, 1694 geboren, 1747 gestorben.

Nr. 280, 281 und (neu) 280 a und b, Joachim I, II, 111 Girtanner und Johannes Girtanner.

Nr. 283 und (neu) 283 a, b, c, d, Jakob I. Il, III Gmünder.

Nr. 262 b (neu in Band Il) Eigentumszeichen des Klosters St. Gallen.

Tafel XIV. St. Gallen. Nr. 289 gebört zu Rorschach (Tafel XV). Nr. 293 Heinrich Haussknecht, geboren 1726, gestorben 1792. - Nr. 296 gehört zu Ermatingen (Thurgau).

Rapperswyl. Nr. 299 a (neu) Jakob (?) Rothenfluh ; auf der Kanne die Jahrzahl 1696.

Rheineck. Alle Marken konnten zugeteilt werden und zwar Nr. 300, Johannes Pfeifer, geboren 17.1, gestorben 1779 .

Nr. 301, Johannes Höchner, geboren ${ }^{7} 75_{1}$, gestorben 1801 .

Nr. 3o2- $(=230$ a $)$ gehört zu Weinfelden.

Nr. 3o3 Johannes Bösch, geboren ${ }^{2} 755$, gestorben?

Nr. 304 Hans Jakob Berlocher, heiratete ${ }_{2} 670$, starb ${ }_{1690 .}$

Lichtensteig. Nr 305 Lichten-Steig oder Lichtensteig Steiger 1, II Jakob (?) - Nr. 3o6, Joh. Conrad Steiger, gebaren 1724 , gestorben 1792 .

Nr. 307, 3o8, vielleicht Jakob III Steiger, heiratete 1718 . Bodenrosette N. 338 b (neu).

Neu : Nr. $3 \circ g$ a J. Girtanner.

Wyl. Nr. 312, Hans Melchior Muiller, geboren 166o, gestorben 1733. Nr. 313 ist wahrscheinlich das Zeichen des Formschneiders des Gussmodelles (Wyler- und St. Galler Teller mit dem Apfelschuss Tells im Fundus). Gossau. Nr. 3,3 a (neu) A. W. M. Gossau.

TAfrL XV. St. Gallen, Appenzell. Nr. $3_{2} 3$ G. Cane; Nr. 324 F. Cane : Nr. 325 Fratelli Cane. Neu Nr. 325 a. Fratelli M. F.P. Cane.

Rorschach. Nr. $3{ }_{2} 6$ a (neu), unbekannter Meister.

TAfEL XVI. Es gibt noch viele andere St. Galler Bodenrosetten. In Band II kommen neu Nr. 338 a des Meisters I. B. von Appenzell und $\mathrm{Nr} .338$ b des Meisters Jakob III Steiger von Lichtensteig.

TAFBr XVII. Chur (Graubiinden). Als neu im Band II figuriert Nr. 340 a, Christopb II Hempel, zünftig 1645 , erwähnt noch $1684 . \mathrm{Zu} \mathrm{Nr} .35_{2}$ wurden zwei neuc Varianten gefunden $\mathrm{Nr} .352 \mathrm{~b}$ und c. Joh. Jakob Ulrich Bauer, erwähnt 1783-1826.



Tafel XIX. Basel. Nr. 374 a (neu) Zeichen auf den Kannen des Basler Muinsterschatzes. Nr. ${ }_{74}$ b. Gegossene Meistermarke (ncu) des Onophrion Werlin, erwähnt von 1547-1571, Nr. 379 gebört zu Hans Jakob Basler in Steckborn; siehe Tafel XI. Nr. 219 b und c.

$T_{A F E L} X X$. Basel. Keine Abänderungen.

Tafel XXl. Basel. Nr. 426 ist wahrscheinlich kein Basler Meisterzeichen. Nr. 435 Bodenrosette des Steckborner Meisters Hans Jakob Basler.

Tafec XX11. Aarau. Nr. 439. 440 Joh. Arnold Beck, geboren 1698 , gestorben 1766 (anstatt 1626-1665). Neu vom gleichen Meister Nr. 440 a, mit Engelmarke. Nr. $44^{3}$ und 444 sind deutsche Meisterzeichen.

Tafbl XXIII. Aarau bleibt unverändert.

Tafec XXIV. Zofingen. Neu gefunden wurde das Meisterzeicben des 1. Rudolf von Zofingen; als Nr. 462 a, Hans Ulrich Rudolf, 1598 Bürger, gestorben 1646 oder 1647 . Ferner als Nr. 468 b, Jakob Rudolf, getauft 1687, gestorben 1761. Beide Meisterzeichen fehlen in der Monographie von Th. Gränicher, über Zofinger Zinngiesser.

Tafel XXV. Zofingen. Keine Abänderungen. Baden. Neu Meisterzeicben eines Zinngiessers... Falk (Casper) als $\mathrm{Nr}_{\mathrm{r}} 500$ a und b.

Tafrc XXVI. Bern. Neu als Nr.501 a : Peter II Baumgarter, geboren 1550, erwähnt bis 1581 . Nr. 531 . wahrscheinlich ein Thuner Meister; dazu neu die Stempelvariante $\mathrm{Nr} .531$ a. $\mathrm{Nr} .525$ gehört dem Bieler Meister F. Niclaus Hemmet und Nr. 526 vielleicht dem Bieler Meister Heinrich Borlier (Siebe bei Biel).

Tafec XXVII. Bern. Nr. 533, 534, 538 und vielleicht auch 539 : Johann Rudolf Grütter, erwähnt von 1705 175o. - Nr. 535, 536, 537 : Jakob Ganting, erwähnt von 1710 ab. Nr. 543 gehört dem Obwaldner Meister Josef Etli (Siehe unter Obwalden).

Tafrl XXVIII. Bern. Neues Meisterzeichen Nr. 568 a und $b: \ldots$ Sesiani.

Thun. Hieher gehört auch Nr. 53ः (Tafel XXVI) und die Variante Nr. 53 r a (neu).

Tafel XXIX. Biel. Nr. 575 : Alexander Bäschlin, zitirt von $1615-36 . \mathrm{Nr} .576$. Statt $H \mathrm{P} E$ soll es heissen H F E, Hans Friedrich Eberhart, erwähnt 1646-166o. Nr. 577, Hans Caspar Witz, nachweisbar $1667-1677$. Nr. 578, David III Witz, geboren 169o, gestorben 1771. - Nr. 579, Friedrich Niklaus Hemmet, erwähnt 1775. - Da noch 15 neue Meisterzeichen gefunden wurden, wurde ein eigenes Blatt gezeichnet für den I1. Band. Zu Nr. 584 gibt es ebenfalls die Variante Nr. 584 a.

Neuenstadt. Nr. 591, David I Witz, in Neuenstadt 
erwäbnt von 1663-1677: zog dann nach Biel. Nr. 591 a, b, c, Meister I. B., Meister- und Stadtzeichen, Bodenrosette und Schützengaben-Zeichen.

Tafel XXX. Solothurn. Nr. 593, 594 sind Ulmer Meisterzeichen. Nr. 598 gehört dem Urs Victor Graff, geboren 1713, gestorben 1791. - Nr. 605 gehört dem H. Josef Etli, Obwalden. Weil 14 neue Meisterzeichen gefunden wurden, erhält Solothurn im Band Il eine neugezeichnete Tafel mit 27 Meister- und 8 Beschauzeichen von Solothurn. Ausserdem im Text Nr. $59^{2}$ c, A. Wiell (?), erwäbnt $1615: \mathrm{Nr} .598$, Christoff Graff, erwähnt ${ }^{6} 679$. Nr. 598 d, Stempel-Variante des Josef Graff, $1685-1750$.

TAFrL XXXI.Solothurn. Bodenrosette Nr.611 gehört dem Ulmer Meister G. W. W., Nr. 593, Tafel XXX.

Bodenrosette Nr. 616 gehört dem Obwaldner Meister H. Josef Etli.


Bernard, erwähnt von 168a-1735. - Nr. 622, Germain Peroulla, erwähnt von $1718-1730$. Neu in Band Il seine Stempel-Variante Nr. 622 b. - Nr. 623, Joseph Perret, erwähnt von $1680-1693$. Neu in Band II seine Stempel-Variante Nr. 623 b. - Nr. 63o, Christoffel Müller, erwähnt 1759-176o. - Nr. 634, ein Londoner Meister (Cotterell Nr. 4651).

Nr. 645, Frantz Fracheboud, erwähnt 1695-1725.

Nr. 638, 639 David (?) Frénéysy, Orbe, erwähnt 1711.

Tafel XXXlll. Neuenburg. Keine Abänderungen. In der Abhandlung von Louis Reutter, Neuenburg, Les pôtiers d'étain neuchâtelois, Musée neuchâtelois 1919 (Nr. 4 und 5) und 1920 (Juillet-Août) befinden sich noch mehr Stempel-Varianten.

Tafel XXXIV. Neuenburg. Nr. $684^{-87}$ und Nr. 710 , 711 gehören alle zu Domenico Morigi. geboren 1805 , seit 1835 in Neuenburg, gestorben 1873 . - Nr. 682, 683, Achille Morigi, geboren 1833, Bürger von Neuenburg 1858, arbeitet als Zinngiesser daselbst ab 1867 ; gestorben 1873 . Charles I Morigi, Meisterzeichen Nr. 688, $7 \cdot 3-716$, geboren 1839, in Neuenburg bis 1869 (Meistermarke $\mathrm{Nr} .688$ ), in Vevey von 1869 ab (Stempel Nr. $713-16)$.

TAfel XXXV. Lausanne. Nr. 689, Jean-Jacques Reuchlin, 1759 . Bürger von Prilly, ebenso Frédéric Reuchlin, Nr. 690, 691. - Nr. 692, Alexandre Goldner, getauft $1_{776}$, ab 1803 in Lausanne, gestorben 1826 . Nr. 693-95 Louis 1 Lacombe, geboren ${ }_{1} 811$, in Lausanne tätig von $1834-1857$, nachher in Genf.

Vevey. Nr. 697 Jehan Utin, erwäbnt 1699 , gestorben ${ }_{17} 3_{1}, \mathrm{Nr} .699,701$, André Utin, erwähnt 1736 . Nr. 698 Jean-Jacques-Samuel Utin, oft in Verbindung mit Nr. 701 . Als neu im Band [I, als zu den Utins gehörend; Nr. 836 (Tafel XLII) und Nr. 721 a und $b$ (Einfluss von Bern) Nr. 824, 825 (Tafel XLII) Pierre Magnin, gestorben in Vevey 1712. - Nr. 826, Etienne Magnin, vielleicht der Sohn, erwähnt auf dem Meisterzeichen 1710. - Nr. 702, Philippe Benjamin
Doret, geboren 1771, tätig ab 1795. - Nr. 704-706, David Angelin, geboren 1780 , gestorben 1844 . Nr. 707 . Louis Goldner, Mitte des 19. Jahrhunderts.

Orbe. Nr. 712, Charles-Christophe Goldner, geboren 1736 , gestorben 1809 .

Payerne. Nr. 842 (Tafel XLII) J.-Daniel Rapin, auf Platte datirt $17^{21}$.

Vevey. Nr.710, 7 1 1, Dominico Morigi, geboren 1805 , nach 1835 in Neuenburg.

Tafel XXXVI. Vevey. Keine Abänderungen.

Tessin. Keine Abänderungen.

Tafel XXXVlI. Genf. Nr. 728. Estienne Charton, erwähnt ab 1572 , gestorben 1606 oder 1607. - Nr. 729 Anthoine I und II Charton 1618-97, resp. 1644-99. Nr. 733 Jean-Antoine Charton, geboren 1658 , gestorben 1739. - Nr. 736, Jean II Charton, geboren 1728, gestorben 1799. - Nr. 738,739 , Gabriel Il Charton, geboren 1726 , gestorben 1802 .

Nr. 740-42. Léonard I Bourrelier, geboren 1639 , gestorben 1730 .

TAfel XXXVIII. Genf. Nr. $750-52$, Nicolas Paul, geboren 1729, gestorben 1766 . - Nr. 753 Jaques Morel, geboren 1678 , gestorben 1752 . - Nr. 754,755 , Jakob Morel (und Jaques) geboren 1714 , gestorben 1776 . Nr. 761, Pierre Goncet, gehört unter Waadtland. Nr. $7^{6}{ }_{2}$ Isaak Classen, geboren 1804 , gestorben 1884. - Nr. 763, Louis Lacombe, geboren 1811 , in Genf tätig ab 1857 ; schliesst sein Geschäft 1897 .

TAfel XXXIX. Genf. Nr. 768 , Stempelvariante de Jean Bourrelier. geboren 1676 , gestorben 1755 . - Nr. 769 , Jakob Valin, geboren ca. 2600 , Bürger 1635, gestorben nach 1671 . Nr. 770, Stempelvariante des Pierre Morel, geboren 1710 , gestorben 1781 .

TAfel XL. Wallis. Nr. 788 , Johannes Surd, Jahrzahl 1651 auf seinem Walliser Blumenteller. - Nr. 797 , Petrus Giuseppe Maciaco, geboren 1820 , gestorben 1892. Nr. 798 Paulo G. Maciago, vor 1842 in Brig. ${ }_{1842}$ nimmt er Giuseppe Maciaco in sein Geschäft auf. Nr. 799. Giuseppe Maciaco, arbeitet ab 1842 mit seinem Onkel, gestorben 1850 .

Tafer. XLI. Wallis. Nr. 813, Lorenzo della Bianca, geboren 1867 , lebt in Visp.

TAFEL XLII. Unbekannte Giessermarken der Westschweiz.

Nr. 824, 825, Pierre Magnin, Vevey, gestorben 1712 (S. 284 ).

Nr. 826, Etienne Magnin, Vevey, erwähnt 1710 (S. 284). Nr. 836, Utin, Vevey (S. 283).

Nr. 837, David Michod, vielleicht Yverdon (S. 286).

TAFR XLIII. Schitzengabenstempel. In Band II, neu, Nr. 856 a, Schützengabenzeichen von Siders (Sirrum) 1681 auf Genferkanne und Breitrandplatte von Jean Antoine Charton. Neu als Nr. 591 c, Gabenzeichen von Neuenstadt (Band II). 


\section{ERSTER TEIL}

\section{Das Zinn und seine Eigenschaften}

Das Zinn stammte, soweit es für das schweizerische Zinngiesserhandwerk in Betracht fällt, aus England und dem sächsisch-böhmischen Erzgebirge. Das reine Zinn ist ein weiches, weisses, silberglänzendes und sehr luftbeständiges Metall. Das einmal gründlich gereinigte Zinngeschirr hält sich jahrelang blank in der Zinnsammlung. Je geringer der Bleigehalt, umso länger bleibt es silberweiss. Nur ganz allmälig wird es etwas dunkler und matter; es bildet sich eine Patina, welche bei nicht stark bleihaltigem Zinn silbergrau und leicht irisierend ist. Diese fein wirkende Patina sollte nicht mehr durch Reinigung beseitigt werden; es genügt, solches Geschirr mit Zeitungspapier und einem Wolltuch zu reiben.

Das Zinn schmilzt bei $230^{\circ} \mathrm{C}$; deshalb darf das Zinngeschirr nicht auf eine eiserne Kochplatte oder auf einen eisernen Ofen zum Trocknen gestellt werden. Gegen die meisten Säuren in nicht zu starker Concentration, ist das Zinn sehr widerstandsfähig. Auf dieser Eigenschaft beruht eine spezielle Reinigungsart stark verunreinigten oder pestkranken Zinngeschirrs.

Chemisch reines Zinn fand nur selten Verwendung in der Zinngiesserei. Das Handwerkszinn enthält $10-50 \%$ Bleizusatz. Die diesbezügliche, zulässige Höhe bildet einen Hauptpunkt in den amtlichen Verordnungen über das Gewerbe. Dieselben finden sich bei allen wichtigen Produktionsorten im laufenden Texte erwähnt. Dank dieser gesetzlichen Bestimmungen (ordonnances) findet man in der Westschweiz und in Bern das qualitativ beste Geschirr.

Der Bleizusatz erfolgt nicht etwa nur der Verbilligung wegen. Das Blei macht das Zinn flüssiger, und die Form besser ausfüllend; auch bekämpft es am sichersten den schlimmsten Feind des Zinngeschirrs, die $Z$ innpest. Je nach der Grösse des Bleizusatzes wird die Legierung dunkler und schwärzlicher; auch verliert die Oberfläche die seidenartige Glätte. Reinigt man stark bleihaltige Zinngegenstände mehrmals mit verdünnter Salzsäure ( $1: 30-50$ ), so wird allmälig die Oberfläche weisser, glänzender und hält sich viel länger blank. Es scheint, als ob die Oberfläche durch die Säure "entbleit » werde und dass deswegen quasi eine reinere zinnerne "Haut" entsteht. Ob dieses wirklich möglich ist, sei einer metallographischen Untersuchung überlassen. Tatsache ist nach meinen langjährigen Erfahrungen der Umstand, dass stark bleihaltiges Zinngeschirr nach der Säurebehandlung viel länger weiss und blank bleibt.

Das Zinn ist weich und dehnbar. Diese Eigenschaft hat den Nachteil, dass der Zinngegenstand sich schnell abnützt und bei Druck leicht deformirt wird. Allerdings kann eine kundige Hand die Beule einige Male beheben; doch schliesslich wird die Wandung zu schwach und der Gegenstand unbrauchbar. Doch ist das Metall nicht verloren; es dient nun zum "Umschmelzen". Diese Procedur bildete einen grossen Teil der Arbeit des Zinngiessers. Das Umgiessen und der Handel mit dem Altmetall war Jahrhundertelang ein Streitpunkt zwischen der Obrigkeit, den ansässigen und den fahrenden Zinngiessern.

Die gesundheitschädlichen Eigenschaften des Bleies waren schon in frühesten Zeiten bekannt; allein man findet nirgends in den Protokollen Bemerkungen über aufgetretene Bleivergiftungen, obwohl z. B. in Luzern, $Z$ ug und in der Innerschweiz Zinngeschirr vorkam, ivelches bis $50 \%$ Bleizusatz aufweist. 


\section{Die $Z_{\text {innpest }}$}

In den alten Zinnsammlungen der kleinen ungeheizten Museen, in den Mauernischen der alten Kapellen, in welche die Messkännchen hineingestellt wurden, findet man oft Zinngeschirr, welches eigentümliche Veränderungen aufweist. Glatte Tellerböden zeigen schwarze, warzenartige Erhöhungen, welche sich nur schwer abkratzen lassen. Nach Entfernung der Warzen sieht man, dass die Krankheit auch noch in die Tiefe geht und in dem schlimmsten Fällen den ganzen Tellerboden durchgefressen hat; so sind oft grosse Löcher entstanden. In den Mauernischen fand ich ehemalige Messkännchen, von welchen nur noch Stücke erhalten waren; sie wurden seit Jahren nie mehr gebraucht und waren an Ort und Stelle zu Pulver zerfallen. Erhitzt man solches Pulver in einer Eisenkelle, so erhält man wieder weissglänzendes Zinn.

Schon im Jahre ${ }_{1} 851^{\prime}$ beobachtete Erdmann einen ähnlichen Zerfall an Orgelpfeiffen der Schlosskirche zu Zeitz (preussisch Sachsen). In Winter 1868 berichtete man aus dem Zollamt von Petersburg über den Zerfall von Blöcken reinen Bankazinnes in ein graues Pulver. Fritsche in Petersburg gab als Ursache die Kälte an und machte selbst sogar diesbezügliche Experimente. Beim Uebergang des Zinnes in die Form des grauen Pulvers nimmt das Volumen stark zu. Prof. Cohen in Utrecht setzte die Untersuchungen fort und fand, dass die "TransformationsTemperatur " (welche bei Wasser-Eis bei oo liegt) bei reinem Zinn schon bei $+18^{\circ} \mathrm{C}$ liegt. Wie es aber auch unterkühltes Wasser von einigen Graden unter Null gibt, so gibt es auch weisses, metallisch-kristallinisches Zinn unterhalb $+18^{\circ} \mathrm{C}$. Die Volumen-Zunahme des amorphen Zinnes beträgt ca. 3o \%; daher kommt dieWarzenbildung auf den Zinntellern. Der Zusammenhang des Metalls wird gebrochen. Bei der hohen Transformations-Temperatur des Zinnes sollte man meinen, dass die Zinnpest häufiger sein sollte; allein der Zerfall findet nur bei tiefen Temperaturen rasch statt. Wie im unterkühlten Wasser ein hineingeworfener Eiskrystall sofortiges Gefrieren hervorruft, so beschleunigt die Anwesenheit amorphen Zinnes den Zerfall der kristallinisch-metallischen Form. So erklärt sich die Uebertragbarkeit der Zinnpest, die Contagiosität. Der amorphe Zinnpartikel bildet den Ausgangs- und Mittelpunkt der Transformation.

Der Zusatz von Blei setzt der Zinnpest heftigen Widerstand entgegen. So erklärt sich die Tatsache, dass ich auf 200 Jahre alten, zinnernen Kirchturmspitzen im Berner Oberland nur wenige Spuren von Zinnpest fand, obwohl daselbst im Winter Temperaturen von - $20-30^{\circ} \mathrm{C}$ häufig vorkommen. Das Gleiche gilt für Zinngegenstände, welche auf den Dachböden Jahrzehntelang unter dem alten Gerümpel ruhten. Dass das pestkranke, gewöhnliche Zinngeschirr nicht sogleich zu Pulver zerfällt, sondern harte Warzen bildet, kommt ebenfalls vom Bleigehalt her. Das Blei der Legierung bildet in den Warzen ein ziemlich festes Stroma, eine Art Wabe, in deren Zellen das pulverförmige Zinn liegt. Das Blei zerfällt erst viel später in der Kälte und zuletzt sogar das oft darin vorkommende Antimon. Nach allen diesen Aufklärungen mutet es seltsam an, in einem Buche vom Jahre 193o (John A. Brown, Das Zinngiesserhandwerk der Schweiz, Seite 1-2) die Stelle zu finden: "die Zinnpest sei eine pilzartige Krankheit ».

Die Behandlung der Zinnpest ist eine etwas umständliche, aber nach meinen Erfahrungen meist erfolgreiche. Selbstverständlich kommen nur wertvolle Gegenstände in Betracht. Das pestkuanke Geschirr wird zuerst vernittelst einer Wurzelbürste mit heissem Seifenwasser gründlich gereinigt und mit heissem Wasser exakt abgespült. Dann kommt dasselbe für 6-8 Stunden in einen Holzbottich voll $10 \%$ er Salzsäurelösung. Die kranken Stellen werden mit Stahlwolle peinlich genau ausgerieben. Dann kommt der Gegenstand nochmals für drei Stunden ins Säurebad. Nachher folgt ein stundenlanges Heisswasserbad. Nach grïndlicher Tröcknung wird mit Papier (Zeitungspapier) und Wollappen nachgerieben. Nun wird das Geschirr für Tage und Wochen möglichst warm, auf Kachelofen und dergl.,

'Mitteilungen von Ingenicur R. M. Vetter. Zusammenstellung von Notizen nach einer Vorlesung von Prof. Cohen, Utrecht, gehalten vor der Faraday-Gesellsehaft in London, 1913. 


\section{Der Randelgiéfer.}



Kupferstich von ca. 1700

\section{Der Kandelgiefler.}

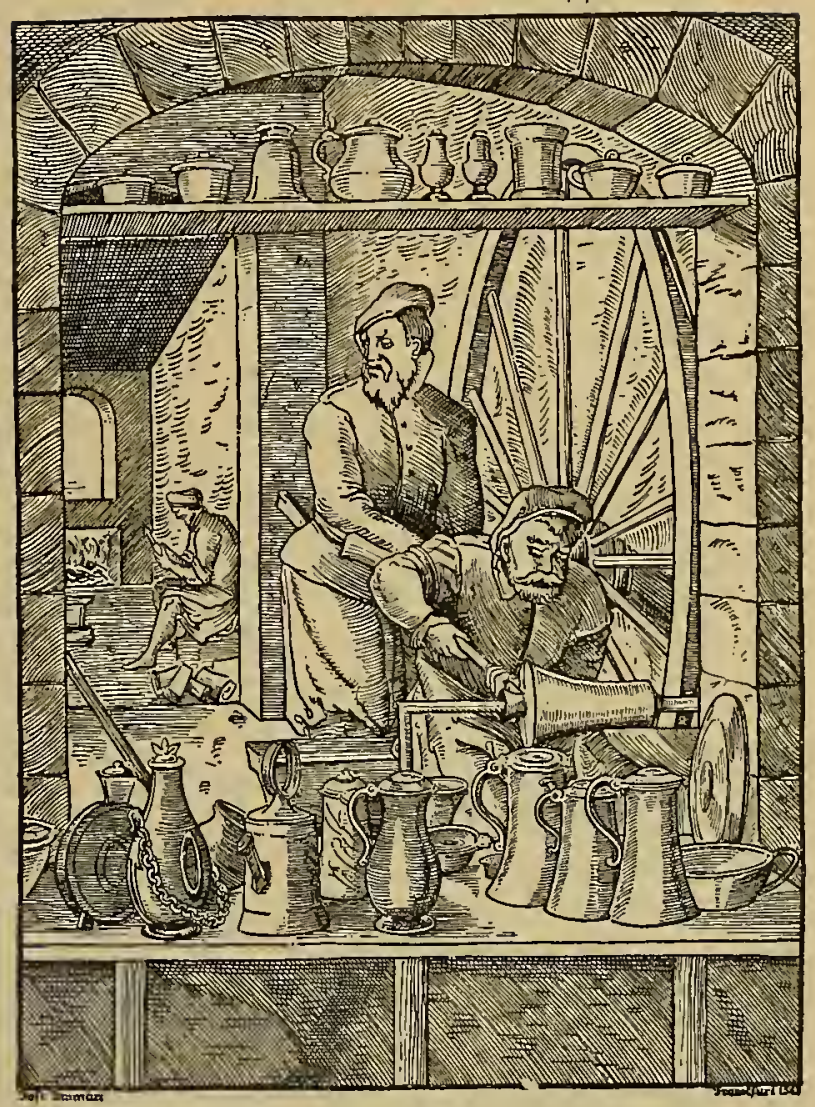

Holzschnitt von Jost-Ammann, datirt 1568

aufgestellt, am besten in einem eigenen Zimmer, abseits der gereinigten und guten Zinnsachen. Das Aufschichten von Tellern und Platten ist stets zu vermeiden. Auch das gereinigte, ehemals pestkranke Zinngeschirr isoliere man für lange Zeit.

\section{Die Werkstatt}

Einen Hauptbestandteil bildete der gemauerte Ofen mit dem eisernen Schmelzkessel für einen grossen Guss; dazu die zugehörigen Blasbälge. Für kleine Mengen hatte der Meister eiserne Schmelzpfannen und Kellen mit Holzgriffen. Beim Giessen wurde das flüssige Zinn mit dem Giesslöffel geschöpft. Im Feuer befanden sich stets die spitzigen eisernen Brennkolben zum Abbrennen der Gusszapfen und die kupfernen Lötkolben. Das flüssige Zinn musste auf der richtigen Temperatur gehalten werden; war dieselbe zu niedrig, so wurde der Guss matt und kaltbrüchig; war sie zu hoch, so wurde die Ware irisierend und rotbrüchig. Das geschmolzene Zinn musste stets gerührt werden, damit sich das schwere Blei der Legierung nicht am Boden anhäufte.

Ein weiteres wichtiges Instrument war die Drehbank, welche durch ein grosses Schwungrad betrieben wurde. Zum Antrieb desselben verwendete man oft die Mägde, arbeitslose Leute, sogar Blinde. Die Drehbank diente zur Herstellung der Modelle und zum Abdrehen der gegossenen Gegenstände. Hiezu benötigte man eine grosse Menge von Dreheisen oder Stahlmeisseln mit verschiedenen Profilen.

Zur Bearbeitung der halbfertigen Ware hatte man einige massive, aus Holzbalken konstruirte Werkbänke und Tische, mit vielen Oeffnungen zum Einsetzen von Keilen, Vierkantstangen, u. s. w. Eine Unmenge verschiedener Hämmer diente zum Schmieden, 
Planiren und Treiben der Zinngegenstände; ferner gehörte zum Werkzeuge eine grosse Anzahl verschieden geformter Zangen und Klammern, Ziehklingen aller Arten, Bohrer, Schaumkellen, Stechbeutel, u. s. w.

Den finanziell wertvollsten Teil der Ausrüstung bildeten aber die Gussmodelle. Für einfache Teller, Schüsseln und Näpfe waren dieselben oft nur aus Sandstein. In der Altstadt in Zug findet man heute noch solche Formen, eingehauen in die Sandsteinplatten des Kellerbodens eines Hauses, in welchem vor 200 Jahren ein Zinngiesser arbeitete. Auch Lehmformen wurden häufig verwendet. Bei diesem rohen Formenmaterial war eine nachträgliche Bearbeitung der Gussflächen unumgänglich (Abdrehen, Schleifen, Planiren, etc.). Auch in Sandformen wurde gegossen und es ist unglaublich, welch eine feine Arbeit möglich war. Moderne Zinngiesser bringen sogar Abgüsse von Meistermarken zustande. Für Gegenstände, welche in grosser Anzahl hergestellt werden mussten, hatte man Messingformen und zwar schon seit dem XVI. Jahrhundert. Diese Formen waren relativ teuer und ein nur einigermassen completes Formenlager stellt einen bedeutenden Geldwert dar. Einen guten Einblick bieten die Inventare des Nachlasses verstorbener Meister. Die Messingformen wurden sehr oft von verschiedenen Meistern benutzt. Es gab ebenfalls eiserne Formen und ihre Herstellung war noch schwieriger. Damit das Zinn beim Guss nicht festklebte, wurden die Steinformen mit rotem Bolus eingepinselt, die Messingformen mit Fett oder Graphit. Auch musste die Form vorgewärmt werden. (Tafel XXV.)

Ferner bedurfte der Zinngiesser grösserer Räume für das alte Schmelzzinn, für die Modelle, für das Brennmaterial. Wegen der Feuersgefahr und des stinkenden Fettrauches waren die Zinngiesser als Nachbaren nicht beliebt. So brannte in Genf im Jahre ${ }_{1} 670$ das ganze Zinngiesser-Viertel auf der Insel der Rhone nieder.

\section{Die $V$ erarbeitung des Zinnes}

Das Zinn wurde häufig in ziemlich reinem Zustande, als Feinzinn, verarbeitet; immerhin ist zu bemerken, dass es sich auch hiebei nicht um chemisch reines Zinn handelte; es enthielt stets einige Prozente Blei, oft etwas Kupfer oder Antimon, je nach den Bergwerken, welchen es entstammte. Man bezeichnete also als Feinzunn auch noch eine Legierung, welche nicht mehr als $10 \%$ Blei enthielt.

Die Zusammensetzung der Zinn-Blei-Legierung ist eine sehr verschiedenartige; der Bleigehalt schwankt von 10-33\%. Bei jedem Zinngiesserort finden sich die nötigen Angaben (II. Teil des Buches). Als gemeines Zinn bezeichnete man Legierungen von $5: 1$; $4: 1$ und in Luzern sogar $2: 1$. Letztere Zusammensetzung wurde an andern Orten als " FaulZinn" bezeichnet. Merkwürdigerweise findet man in den Ratsprotokollen niemals Bemerkungen über stattgehabte Bleivergiftungsfälle.

Der Zinnguss. - Die allgemeinen Grundsätze des Zinngusses dürfen als bekannt vorausgesetzt werden, insbesonders die Eigenschaften des zu heissen oder zu wenig heissen flüssigen Zinnes. Teller, Platten und einfache Gegenstände konnten in einer einzigen Form gegossen werden. Die Kannen, Giessfässer u. dgl. wurden aus verschiedenen Stücken zusammengesetzt. Die Henkel, Deckel, die Drücker, Knöpfe und kleinen Ornamentgegenstände, oft sogar die Bodenrosetten, die Scharnire, der Ausgusschnabel u. s. w. mussten in einzelnen Formen gegossen werden. Die Zusammensetzung der Stücke erfolgte nach zwei verschiedenen Methoden. Unter "Anblasen" verstund man das $Z$ usammenlöten mit dem Lötkolben vermittelst Schnellot (1 Teil Blei und 1 Teil Zinn). In dieser Manipulation hatten die alten Meister eine ganz ungewöhnliche Fertigkeit. Infolge der guten Verarbeitung der Lötfugen, ist es oft sehr schwierig, dieselben noch nachzuweisen. (Tafel XXV.)

Als "Feuerarbeit" oder "Aufbreiten" verstund man die Methode, kleinere Bestandteile an das sonst fertige Gefäss anzugiessen. So z. B. wurde die Henkelform mit Lehm an der Kanne angebracht und dann ausgegossen. Der in Kannen-Innern sich 
befindliche, rauhe, mit Lehmwasser befeuchtete Lumpen verursachte am Henkelansatz einen Abdruck im Gusse (Lumpendruck). Ebenso häufig wurden auch die Ausgussschnäbel bei den Stitzen direkt angegossen und nicht angelötet.

Alle Gusszapfen und Gussnähte rurden mit der Feile, oft auch auf der Drehbank, sorgfältigst entfernt. Oft wurde sogar noch das Zieheisen angervendet. Die Spuren des Abdrehens sind meistens leicht nachweisbar ("Drehzüge ").

Das geschlagene Zinn (Etain forgé). - Auch in der Schweiz sind Gegenstände, welche nach dieser Art hergestellt wurden, vor dem Jahre 1700 nicht selten. In Deutschland findet sich der Ausdruck schon bei Hans Sachs, Kandelgiesserspruch von 1543, Zeile 19, "Schussel geschlagenn und ungschlagenn ". In Frankreich galt bis 1750 nur gegossenes und abgedrehtes Zinn als nicht vollwertige Arbeit. M. Salmon ${ }^{1}$ widmet dem geschlagenen Zinn, Etain forgé, in seinem instruktiven Buch "Art Ju Potier J’Etain» (Paris, 1788) das ganze XIII. Kapitel. Es handelt sich bei diesen Arbeiten wirklich um ein Schmieden und nicht um ein "Treiben» (bosseler). Der Hauptzweck des Schlagens resp. Schmiedens besteht darin, dem Zinn mehr Festigkeit zu geben und die oberflächlichen Gussporen zu schliessen. Darum werden auch vollkommen ebene Flächen gehämmert. Ein klassisches Beispiel bildet die Breitrandplatte oder "Hutplatte ». Der glatte Boden und der ebene Rand sind gehämmert und mit kreisförmig angeordneten Hammerschlagspuren überzogen. Allerdings wird beim Schmieden insofern auch "getrieben ", als infolge des Hämmerns das Zinn dünner wird und so der Fundus zuerst halbkuglig herausgetrieben wird. Die so entstandene Calotte wird dann zurückgehämmert und so erst entsteht die ebene Fläche des Bodens. Bei der Breitrandplatte ist auch die aufgebogene Seitenwand des Fundus gehämmert. Dementsprechend waren auch die Formen des fein polierten, stählernen Ambos. Es gab ganz ebene, ferner apfel- oder birnförmige Exemplare (pomme, poire). Aus einer vollkommen glatten Zinnscheibe wurde die Breitrandplatte herausgeschmiedet und zwar einzig und allein mit dem Hammer und Ambos.

In meiner Sammlung fand ich geschlagene Platten (Hutplatten) aus Genf, dem Waadtland, Freiburg, Solothurn, Bern, Chur und Zug. Es ist also hauptsächlich die Westschweiz, rvelche diese Arbeitsmethode anwandte, und zwvar auch bei den Kannen (über dem kugelförmigen Ambos).

Auf vielen $\mathrm{schwe}$ izerischen $M$ eistermarken figurirt ebenfalls der Zinngiesserhammer als Emblem dieses Handwerkes, so im Waadtland, im Wallis, in Freiburg und Neuenburg in vorwiegender Weise; seltener in Solothurn, Bern, Basel, Zug und Schwyz. Also auch in diesem Punkte überwiegt die Westschweiz bei weitem.

Die in meiner Sammlung sich befindlichen Breitrandplatten aus Paris, Lyon, sind ohne Ausnahme gehämmert und zwar mit einer bewundernswerten Feinheit und Meisterschaft. Frankreich ist also die wahre Heimat des geschlagenen Zinnes.

Das getriebene Zinn (étain bosselé). - Es gibt auch in der Schweiz Zinngegenstände, welche der Dekoration wregen mit getriebenen Buckeln überzogen wurden. Die Anordnung der Buckel entspricht einer Zeichnung; oft handelt es sich nur um oval- oder kreisförmig angeordnete Reiben. Das Herausklopfen erfolgte vermittelst eines Holzhammers, welcher auf dem Zinn keine Schlagflächen hinterliess. Der Vorgang ist also ein reines "Treiben ", ohne die Oberfläche des Zinnes wesentlich zu verändern, wie beim Schmieden. Die Umrisse der herausragenden Buckel wurden mit der Punze (ein kleiner, halbstumpfer Meissel) linienförmig eingehämmert.

Oft fand ich Schalen, deren Buckel nur infolge des Punzens der Conturen entstanden waren, so, dass das Herausklopfen der Buckel fast überflüssig geworden war. Nur die tief eingeschlagenen Rillen mussten also das Relief vorspiegeln. So kann sich auch das "Treiben " und das Einschlagen der tiefen Rillen summieren, um den Effekt zu erhöhen (Schalen von Basel). Das “Treiben " des $Z$ innes hatte mithin einen ausgesprochen dekorativen $Z$ weck.

1 M. Salmon. Art du Potier d'Etain. Paris 1788. S. 96-103. Moritz Hejne. Das altdeutsche Handwerk. Strassburg 1908 . S. $181 \mathrm{ff}$. 
Das Hämmern oder Schmieden des Zinnes erhöhte die Festigkeit der Zinngegenstände, es verminderte die Deformation und verringerte die Verbeulung, Momente, welche besonders bei den Breitrandplatten von grosser Bedeutung waren. Da die Methode des Hämmerns nur am Feinzinn und niemals an den Bleilegierungen angewendet werden konnte, so sind gehämmerte Zinngegenstände demgemäss einzuschätzen.

\section{Die Dekoration der Zinngegenstände}

Die wirkungsvollste und zum Zinngeschirr am Besten passende Form der Verzierung ist das im gleichen Guss ausgeführte Relief. Die höchste Stufe der Entwicklung erreichte es zur Renaissancezeit in Frankreich und Deutschland (François Briot und Caspar Enderlein), sowohl bei den Platten als bei den Krügen.

In der Schweiz findet man nur wenige Vertreter dieser Gattung. Ein gelappter Teller, mit den Wappen der 13 alten Orte am Rande, hat im Fundus das Reichswappen und zwei Mal das Wappen der Stadt St. Gallen (Bär mit Halsband); ein zweiter hat im Fundus die drei ersten Eidgenossen. Dann gibt es noch zwei kreisrunde Teller, mit den Wappen der 13 alten Orte am Rande, mit Tells Apfelschuss im Fundus, entweder mit dem Beschauzeichen von Wyl oder St. Gallen. Endlich gibt es im Wallis noch einen reliefirten Teller mit Blumenranken am Rande und einer Renaissance-Vase im Fundus von Joannes Surd. Die Beschreibung dieser fünf verschiedenen Teller befindet sich bei den zugehörigen Orten (St. Gallen, Wyl und Wallis). Kannen mit Reliefdekor sind in der Schweiz sehr selten; eigentlich handelt es sich nur um die Maskaronstitzen von Zofingen und Burgdorf des Meisters Johann Friedrich Lang. Relifierte Gegenstände in der sogenannten Holzstock-Manier kommen in der Schweiz nicht vor. (Tafel XXVIII, 1-3.)

Die kleinen, vollrund gegossenen Reliefstücke. Als Deckeldrücker findet man häufig Widder- oder selten Hundsköpfe (Waadt, Wallis und Genf), Eicheln, aufgesprungene Granatäpfel, Akanthusblätter in verschiedener Ausführung, geflügelte Engelköpfe, vasenartige Ornamente. Als $\mathrm{Kn}$ op $\mathrm{f}$ in der Mitte des Deckels sind ebenfalls Tierköpfe, sitzende Löwen, Delphine, Trauben, Eicheln, Negerköpfe, etc., beliebt. Sehr originell ist der Ausgusschnabel in der Form eines bärtigen Mannskopfes (Solothurn, Zofingen und Burgdorf). Die mächtigen Stadtkannen haben am Ende der Ausgussröhre meistens einen Tierkopf und auch die Stadtwappen sind in massigem Reliefguss. - Die seitlichen Oesen der Kannen und Brunnenkesselchen sind oft auf reliefirte Maskarons montiert. Die Traghenkel der Zofinger, Bieler- und Neuenstadterkannen sind häufig mit Blatt- und Blumenranken in Reliefguss vollständig überzogen. Auf dem Deckel der Giessfässer sitzen zwveischwänzige Meerweibchen, Löwen, Delphine, Blattornamente, u.s.w.

Alle diese Dekorationen haben nur handwerklichen, niemals künstlerischen Charakter. Das Gleiche gilt auch von den Weihwasserkesselchen, deren Rückwand oft eine reliefirte Madonna ziert, z. B. beim Modell von Zug.

Bei den grossen Ratskannen sind oft einzelne Teile in Messing-Bronzeguss ausgeführt, so z. B. die Einfassung des Fusses, der Ausgusschnabel, die Traghenkel samt den Oesen. Bei den Luzerner Kannen besteht auch noch das Stadtwappen aus Messing, so dass für den Zinngiesser nur noch der kahle Korpus übrig geblieben ist. Man kann also kaum mehr von einer Zinnkanne sprechen.

$\mathrm{Ab}$ und zu findet man auch bei den gewöhnlichen Gebrauchskannen Messingfassung des Fusses (z. B. Basler Stitzen) oder des Deckels. Dass Messingornamente in Zinn eingelegt wurden, wie z. B. in Bremen, konnte ich in der Schweiz niemals konstatiren. Hingegen wurde ab und zu Zinn als Einlage in Tischblätter oder Lehnstühle verwendet, z. B. für die Initialen der Besitzer und die Jahrzahl (Lehnstuhl in Menzingen : 17 M. Z. 67).

Die zweite Form der Dekoration bestand im Heraustreiben von verschieden angeordneten Buckeln (étain repoussé oder bosselé) aus der ebenen oder kugelförmigen 
Oberfläche. Meister Josef Etli in Obwalden lieferte Messplättchen, deren Rand eine Reihe ovaler Buckel aufweist. Die grosse Glockenkanne der Stadt Werdenberg hat an der Aussenwandung eine breite, circuläre Zone grosser, ovaler Buckel. Ferner gibt es schön gebuckelte Wöchnerinnenschüsselchen (von Zug), Blumenvasen (von St. Gallen), Früchtenschalen (von Basel und Luzern) aller Grössen. Sehr selten sind die gehämmerten (étain forgé) Schalen von Solothurn. (Tafel X.)

Die beliebteste und häufigste Verzierungsart des Zinngeschirrs war die Gravirung. Wie der Kupferstecher beim Kupferstich, so wurden auf Kannen und Platten Zeichnungen aller Art angebracht; meistens waren es Blatt- und Blumenranken, Fruchtzweige, Wappen, Initialen und Jahrzahlen. Oft findet man auch figürliche Darstellungen, wie Hirtenszenen, Soldaten, Tänzerinnen u. dgl. Die Qualität der Bilder ist ebenso wechselnd wie diejenige der Hersteller. Im Allgemeinen ist die Zeichnung primitiv, oft linkisch und komisch; wirkliche künstlerische Leistungen sind selten. Die Zeichnung wird mit dem Grabstichel ausgeführt; oft wird die Vorzeichnung mit einer Reihe von Punzenschlägen nachgeschlagen. Sehr häufig findet man in der Schweiz die Anwendung des "Fleckelns". Mit einem wackelnd geführten feinen Meisselchen wird der Zeichnung nachgefahren; die so entstehende Zickzacklinie heisst bei den Schweizer Sammlern "Tremolirstich"; bei den Böhmen "girigari". Am häufigsten wurde er an den kleinen Giesserorten angewandt.

Durch Aetzung erzeugte Ornamente konnte ich in der Schweiz niemals finden. In Deutschland und Oesterreich sollen sie ebenfalls recht selten sein.

Auch die technisch schwierige Zier - Vergoldung mit Blattgold ist nicht häufig. Salmon widmet dieser Methode das Kapitel XVII, S. 144. Ab und zu fundet man bei Basler- und Solothurner Stitzen, an kleinen Humpen gravirte Zeichnungen, welche teilweise Ausfüllung derselben mit Blattgold aufweisen. Da diese Vergoldungsart für eine wirklich dauerhafte Vergoldung ziemlich schwierig ist, constatirt man meistens nur noch Spuren derselben. Der grösste Teil ist wohl infolge der Reinigung wieder abgefallen. Uebrigens passt die stolze Vergoldung nicht gut zum volkstümlichen Zinn.

Das Gleiche gilt auch für die Bemalung, das teilweise Ueberziehen des Zinnes mit Lackfarben. Ab und zu gibt es Kerzenstöcke aus der Empire- und Biedermeierzeit mit partiellen Bemalungen. Die Dekorationswirkung ist meistens nicht gut. Im 19. Jahrhundert blühte in Aarau die Fabrikation von $Z$ innsoldaten. Die Bemalung erfolgte durch Hausindustrie (vergleiche die Monographie von L. MEYer-Zschoкke: Die Scbweizer Zinnfiguren-Industrie. Wegleitungen des Kunstgewerbemuseums Zürich, 1916, Nr. 12, S. 7).

\section{Die $Z_{\text {inngiesserzeichen }}$}

Die Behandlung dieses Kapitels bildet den völlig selbstständigen Inhalt des Bandes I. Diese Entlastung ist für den Band II unbedingt notwendig. Zur Orientirung gebe ich hier nur die Einteilung der Giessermarken nach Band I.

I. Die offiziellen Zinngiessermarken :

1. Ortszeichen.

2. Zinngiesserwappen (Meisterzeichen).

3. Qualitätszeichen.

II. Akzidentelle Zeichen :

1. Aichzeichen und Jahrzahlen.

2. Besitzerzeichen.

3. Schützengabenzeichen.

4. Zeichen für andere Zwecke (kirchliche oder für Vereine).

Bezüglich der Engelmarken ist Folgendes zu bemerken. Der früheste schweizerische Engelstempel, auf welchem aber jegliche Initialen fehlen, trägt die Jahrzahl 1704. Auf der Engelmarke des Zinngiessers Joh. Arnold Beck in A a ra befindet sich die Jahrzahl 1724. 
(Meistermarke Nr. $440 a$ und $b$, Bd. II). In Bern findet man bei den Meistern Johannes Küpfer, Johann Rudolf Grütter, Jakob Ganting und Abraham Ganting nach 173o an Stelle des Stadtzeichens, des Berner Wappens, die Engelmarke. Der Berner Rat gab diese merkwürdige Erlaubnis im Jahre 1729 (siehe bei J. A. Brown, S. 84), nachdem schon Thuner Zinngiesser den Engelstempel führten. Später fand die Engelmarke an allen andern Orten Eingang.

\section{Lehrzeit und W anderschaft}

Ein Meister durfte zur gleichen Zeit nur einen Lehrling ausbilden, allerdings auch neben seinem Sohne. Der Lehrvertrag, auch wenn er nur mündlich zustande kam, wurde vor mindestens zwei Zeugen geschlossen. Hiebei wurde sowohl die Lehrzeit als auch das Lehrgeld festgesetzt. Die Lehrzeit betrug wenigstens drei, oft aber sogar vier bis sechs Jahre. Mit dem Abschluss des Lehrvertrages wurde der Lehrling ein Glied der Meistersfamilie. Kost, Wohnung und oft auch die Kleider erhielt der Lehrling vom Meister. Er musste auch im Haushalt nachhelfen, Schuhe putzen, Reinigungsarbeiten verrichten, Kommissionen machen u. dgl. Dass die Meisterin hiebei keine unwichtige Rolle spielte, ist selbstverständlich. Der Besuch der Kirche und eine christliche Erziehung wurde genau innegehalten. Die Behandlung war aber meist eine gute und es kam selten vor, dass ein Lehrling davon lief oder die Lehrzeit bei einem andern Lehrmeister vollendete.

Der Geselle benötigte zu seiner Fachausbildung meist mehrere Jahre Wanderschaft; denn nicht nur die Technik des Zinngiessers war eine schwierige, sondern besonders die Herstellung der Modelle und die verschiedenen Arten der Dekoration. Darum dauerte die Wanderschaft drei bis sieben Jahre. Ferner verlangte die Eröffnung eines eigenen Geschäftes bedeutende finanzielle Mittel. Immerhin wurde in der Schweiz wohl jeder Geselle einmal Meister, wenn auch oft in primitivster Art und neben einem andern Berufe, welcher ihn oft nur einige Stunden in Anspruch nahm, z. B. Totengräber, Weibel, Küfer, u.s.w.

Bei der Einstellung eines Gesellen wurden zuerst der Ausweis über die Lehrzeit und die "Schriften " abverlangt. Wechselte einer seine Stelle in der gleichen Stadt, so musste der frühere Meister seine Einwilligung geben. In den grossen Städten war zum Empfang der Gesellen der "Uertengesell " bestimmt. Dieser war auch der Obmann aller in der Stadt arbeitenden Gesellen. Waren in einer Stadt keine Gesellen, so musste der jüngste Meister das Amt des Uertengesellen übernehmen. Sobald ein Geselle in die Stadt kam, ging er in die Herberge, erkundigte sich über die Arbeitsverhältnisse und rief den Uertengesell. An kleinen Orten ging er direkt zum Meister. Oft spielten Empfehlungsschreiben eine nicht unbedeutende Rolle. Der Geselle hatte zuerst eine Probezeit von zwei Wochen zu bestehen, bevor er endgültige Anstellung erhielt. Auch die Gesellen hatten an kleinen Orten Kost und Logis beim Meister und mussten Abends nach 9-1o Uhr zu Hause sein.

\section{Die Meisterschaft}

Nach genügender Ausbildung, oft einer Wanderschaft von drei bis sieben Jahren, konnte der Geselle Meister werden. Die Söhne von Meistern wurden aber so stark begünstigt, dass sich eigentliche Zinngiesser-Dynastien herausbildeten. Meistersöhne mussten oft nicht einmal auf die Wanderschaft. Im Meisterzeichnis finden sich in allen grossen und kleinen Städten lange Reihen Meister g:leichen Familiennamens. Wenn an einem Ort ein Zinngiesser fehlte, so wurden auch Fremde gerne aufgenommen (siehe unter Biel, Orbe, Solothurn, u.s.w.).

Wurde ein Geselle Jungmeister, so musste er die übrigen Meister zu einem Gelage einladen, oft sogar mehrere Male : bei der Abnahme des Meisterstückes, bei der Geschäftseröffnung. Dadurch entstanden Missbräuche, sodass z. B. das puritanische Genf die Gelage schon seit 1537 verbot. 
In allen grössern Städten war ein Meisterstück vorgeschrieben; die Söhne konnten dasselbe in der Werkstatt des Vaters ausführen. Es war den Gesellen und dem Meister verboten, dem angehenden Meister zu helfen. Das fertige Meisterstück wurde dann von mehrern Meistern geprüft, nachdem der angehende Meister geschworen hatte, dass er die Arbeit selbst und allein gemacht habe. Als Meisterstücke kamen in Betracht: Schenkkannen und Platten mit den dazugehörenden Formen; oft dazu noch ein Giessfass, Humpen, Suppenschüsseln u. dgl. Stets musste auch das Modell und die Form selbst gemacht werden. Ab und zu wurde ein Stück verlangt in nicht landesüblicher Form, z. B. ein Kugelkrug, eine Kanne mit Steg in Ulmerform. Deswegen beklagten sich oft die Meister, welche mit diesen abnormalen Formen keine verkäufliche Ware herstellen konnten. Eine ausführliche Behandlung des ganzen Themas findet man im Buche John Brown's, Das Zinngiesserhandwerk der Schweiz, Solothurn, Petri \& Co., 1930 .

\section{Die Zinnkannen im Bilde und in der Poesie des XV. und XVI. Jahrhunderts}

Im 15. und im Anfang des 16. Jahrhunderts waren Zinnwaren noch Luxusgegenstände. Im täglichen Gebrauche fanden sich Ton- und Holzgegenstände als Ess- und Trinkgeschirr. In der Schweiz waren in dieser Zeit hölzerne Kannen recht häufig.

In der Berner Chronik von Tschachtlan aus dem Jahre 1470 findet sich eine hölzerne Kanne auf Tafel 83 (Neudruck 1933 der Handschrift A 120 der Zentralbibliothek $Z$ ürich). Die in Weidenreifen gefasste Holzkanne ist vielleicht der Vorläufer der Glockenkanne, deren circuläre Wülste den ehemaligen Weidenreifen entsprechen. Auch Jost Ammann hat 1568 beim "Bierbreuwer " noch hölzerne Humpen mit Reifen (S. HIRTH, Kulturgeschichtliches Bilderbuch aus Jrei Jahrbunderten, 3. Band, S. 810, Nr. 1199). Zinnkannen konnte ich bei Tschachtlan nirgends finden.

Die im Jahre 1513 dem Luzerner Rate überreichte Luzerner Chronik von Diebold Schilling bildet in jeder Beziehung einen gewaltigen Unterschied zu der nur 43 Jahre ältern Berner Chronik. Eine neue Zeit ist angebrochen. Tracht, Waffen und der ganze Haushalt stellt sich um. Auf Tafel 11 (Neu-Ausgabe von 1932, Verlag Sadag A.-G., Genf), Schlacht bei Sempach, steht im Harst der Luzerner, hinter der ersten Kampfreihe, eine Marketenderin mit der linsenförmigen, zinnernen Feldflasche. A uf Tafel 38, Gastmahl König Sigismunds, befindet sich in der rechten, untern Ecke eine grosse Glockenkanne in einem Kühleimer. Sie trägt den Zugerschild. Neben dieser Kanne steht eine Prunkkanne, welche genau die Form der noch erhaltenen Ratskannen von Baar aufweist. Auf der untern Randleiste der Tafel 159 , Tagung der acht Orte zu Stans, steht eine zinnerne Glockenkanne. Auf T a fel 163, Peter von Stalden unter der Linde von Schlüpfheim, sind zwei grosse Glockenkannen auf den Sitzbänken, während Zinnbecher und Esswaren auf dem Tische stehen. Die Henkelkanne auf Tafel 201 ist vielleicht auch eine Zinnkanne. Im Zuge der französischen Söldner über die Berge, Ta fel 389 , schreitet eine Marketenderin mit einer prismatischen Kanne in der linken Hand.

Bei Urs Graf findet man auf einer Handzeichnung, datiert ${ }_{1515}$, eine ähnliche Zinnkanne mit linsenförmigem Korpus wie auf Tafel 11 des Luzerner Schilling.

Auf dem Blatte Albrecht Dürrers (1471-1528), die Geburt der Maria, Holzschnitt (Bartsch 8o) finden sich zwei grosse Kannen in der Form der Berner-Kanne ohne Steg (Hirth, Bilderbuch, Band I,S. 8).

Hans Burckmair der A eltere (1471-1532) bringt auf einem Holzschnitt zur Tragödie der Coelestine ein zinnernes Giessfass mit Untersatz (HirTh, I. Band, S. 10-11, Nr. 19).

Auf dem Familienbild der Familie Fäsch von Basel, gemalt 1559 von Hans Kluber, befunden sich zinnerne Feldflaschen in richtiger Flaschenform und Henkelkannen vom Typ der Berner Kannen ohne Steg, welche in Kühleimern stehen. 
Jost Ammann (geboren ${ }_{1539}$ in Zürich, gestorben 1591 in Nürnberg) illustrirte im Jahre 1568 mit vielen Holzschnitten die Eygentliche Bescbreibung aller Stände auff Erden, etc., Frankfurt am Main, 1568. Auf dem Holzschnitt "der Kandelgiesser " finden sich Feldflaschen mit linsenförmigem Korpus, Glockenkannen, Rundelen, Stitzen, Breitrandplatten, Becken, Pfefferbüchsen, Dosen, u.s.f. Jedes Bild wurde "durch den weitberümpten Hans Sachsen Gantz fleissig beschrieben und in Teutsche Reimen gefasset ". Beim "Balbierer " (Hirth, III. Band, S. 812, Nr. 1207) hängen Barbierschüsseln aus Zinn an der Wand.

In der Sammlung Gladbach im Landesmuseum von Zürich befindet sich ein Bild, Wohnzimmer in Wolfenschiessen, datiert ${ }_{1586}$. Darin befindet sich in einem Buffet ein Zinngiessfass mit Untersatz und auf dem Tisch eine Glockenkanne mit Bajonetverschluss (siehe H. Lehmann, Die gute, alte Zeit, S. 5o8).

Auch auf Glasgemälden und Scheibenrissen findet man ab und zu Zinnkrüge. Auf dem Oberbild eines Glasgemäldes im Landesmuseum in Zürich finden sich drei Glockenkannen (H. Lehmann, Die gute alte Zeit, S. 23).

Auf einer Rundscheibe des 16 . Jahrhunderts steht in der Mitte, neben einem Klosterwappen, eine Berner-Kanne ohne Steg; auf dem Deckel als Knopf eine gotische Kreuzblume (Katalog der Sammlung A. Huber, Sihlbrugg; Auktion in Zürich 1909; Katalog-Nummer 654 mit Bild).

Auf einem Glasgemälde-Entwurf im schweizerischen Landesmuseum, aus dem 16 . Jahrhundert, findet sich ein hübsches, einteiliges Buffet mit zinnernem Giessfass und Zinn-Untersatz (H. Lehmann, Die gute alte Zeit, S. 609).

Die Poesie. - Aus dem Jahre 1543 stammt ein Spruchgedicht von Hans Sachs. Man findet es in den Mitteilungen aus dem germanischen Museum II, Nürnberg 1889, S. 74 u. folg., veröffentlicht von Hans Bösch. Es lautet:

\section{Der Kandelgiesser spruech, von 1543}

Alls ich eins tags gen Nurmberg Kam gienng Ich vngefer fur einnen kram darinen sach $\mathrm{jch}$ alle waher vonn Silberweiß so glancz vnd Clar vonn allerhandtt drinckgschir visierlich So kunstlich arttlich vnd so zirlich das ich gleich gruest jm kramb den altten vnnd batt jn arg mir Nitt zue halttenn Sonnder woltt mir erzellenn her welchs Hanttwercks er ein maister wer Er anttwortt mir wiß das jch bin ein kandtengiesser, mach aus $\mathrm{Zin}$ kandell, pauchett, schwebisch vnnd glatt außgestochenn Nach kunstlichem Ratth mitt pildwerckh gewechsenn vnd plumen die kantten mitt Rören auch von vns kumen schenckh kantten darmitt man Fursten thutt schencken

vnd leuchtter die man auff thutt hencken Schussel geschlagenn vnd vngschlagenn darin man thutt zue essenn tragen Senffttschusell, vnd schusell mitt Oren So fur kindtpetterin gehörenn dischteller, plecz, vnd groß plattenn, darauff man tregtt fisch vnd das pratten vnd auch die Engelschenn patten auch kantten so auff drey fuessen sten Großstendner vnd auch Zinen stuczen die man Nur zue dem Bier ist Nuczen geschraufftt allerlei kunstlich flaschenn, klein vnd groß, Sackpfeiffen vnd Taschen Buecher, Narenkapenn puchssen vnd partten daraus einer mag Eins trunckhs gewarttenn Salczuaß verguldett vnd auch Schlechtt Salczuaß So man Indt kuchen hechtt der kandell hett ich Schier Vergessenn, darmitt man thutt den Wein außmessenn, pecher Schusselein zue pranttem wein zum meth kunstlich Schallen fein auch puchsenn jnn die apodeckenn aus den manch Specerei ist schmecken puchsenn zue Milraum vnd Oll darin alding Rein bleiben söll die prennheutt scherbenn vnd schusselring pecher groß vnd clein kupfferling auch bschlagen wir manchen gießkaltter O kunstlicher vil, dan vor altter mitt aichelnn vnd mancherlei gisfaß 
zirlich geschmuckhtt Neben das mach wir kunstlich vnd woll Besünen vill lustiger Springender prunen, die man schenckhtt jn die Landt von ferenn auch machen wir Bad fur Fursten vnd herren Auch beschlagen wir die kirchenthurn Sambtt knopffenn So darauff geburn also hab ich erzellett jn eyll vnsers hanttwrecks den maisten theil welches Zirett vberall manches Fursten tisch vnd Saal gannze hewsser, Clöster vnd Stett das an diß hanttwerckh mangel hett vnsers hanttwercks jnn gesellen schiessen thutt mancher gutter schucz genyessen So er ein Fannen thutt erraichen auf jedes Zin schlagen wir ein Zaichen der Statt wapenn, Ein halben Adler finden die gschwornen einen dadler der wirtt gestrafftt mitt harttenn Wandel auf das bei der statt bleib der handell mitt guttem lob, wie vor vil jaren Ein Ratth thutt auch kein mueh nitt sparen all jar, all maister nimbtt in pflichtt kein felscherey zue brauchen nichtt auch das jeder maister nitt mer dan $j n$ vier jaren ein junger ler dergleichen vil ander geseczs auff das keiner den andern leczs auch Ernehren wir vil armer plinden die Sich Rad ziehens vntterwinden Sambt dem vllein vnd seins Gleichen die vnserm hanttwerckh steczs nach-

Ich fragett weitter disenn altten schleichen wie thuns dan Eucher gesellen haltten er anttwortt mir mein Freundt So wist das es ein gschenckhtes Hanttwerckh ist Ein vatter haben $\mathrm{Si}$ gewunnen am Vischpach doben bei der Sunen alda habens schenckh all vier wochenn da leidens kein palgen noch pochen Jeder mues von jm thon Sein tegenn vrtten maister machens alwegen die frembden gsellen Sindtt darbey an der Schenckh ganczer Örtten frey vnd da jr hanttwerckhs gwonheitt haltten wie es auff Si kam von den alttenn vnd welcher gsell nichtt kem and schenckh aus hochmuett kargheitt der gleich Renckh derselbig mues doch gleich woll eben wie ein ander gancze Vrtten geben vnd Solche jre hanttwercks gewonheitt halttens in landen weitt vnd Breitt Inn pehem, poln, pomern Vnd preusen Inn pairn, schwaben, Sachsen vnd Rewsen bald ein frembder gsell her ist komen So wirtt er Freundtlich angenommen Vnd zeucht zu einem maister Ein Essenn vnd drincken gibtt man in vnnd nachden örtten meistern sendtt denselbenn er Sein grueß bekentth vonn welcher statt er Herkumb denn schickhtt er Nach arbeitt Vmb kan man kein arbeitt jm auff treibenn die nachtt thutt er peim maister bleiben, nachdem die vrtten maister in furen jnn auff die herberg hin da Si ein pfundtt mitt $j m$ verschencken aller gsellenn jnn gutt zue dencken darmitt ist $j \mathrm{~m}$ geschenckett aus den bleittens jnn zum thor hinaus So zeuchtt er hin jnn gottes Segenn doch halttens streng darob alwegen wo einer machtt ein bösses stuckh oder prauchtt vnredliche Tückh der wirtt von jungenn vnd von altten verachtt, vnd nichtts von $j m$ gehalttenn das keiner vber firzehen tag On straff bei jm arbeitten mag auch Si jm allentthalb nach schreibenn jm landtt $j n$ vberall aufftreiben bis er sich steltt vnd gar vertregtt Sein Bueß vnd straff leitt vnd erlegtt dardurch die zucht vnnd erberkeytt bey jnn erhalttenn wirtt alzeitt dar mitt jr Rum, grün plue vnd wachs das wunschtt jnn zue Nurmberg Hans Sachß.

\section{Anno Salutis 1543 .}

Hintze, Bd. II, S. 155 u. 156.

Vgl. Demiaris, S. 76 (mit Erklärung von Wörtern !).

Im Jahre 1568 erschien zu Frankfurt am Main von Hans Sach s die oben schon zitierte Eygentlicbe Beschreibung aller Stände auff Erden, etc., mit Holzschnitten von Jost Ammann. Beim Kandelgiesser heisst es : 
Das Zin mach ich im Feuwer fliessen,

Thu darnach in die Mödel giessen,

Kandel, Flaschen, gross und auch klein,

Darauss zu trincken Bier und Wein,

Schüssel, Blatten, Täller, der mass,

Schenck Kandel, Saltzfass und Giessfass,

Oehlbüchsen, Leuchter und Schüsselring,

Und sonst ins Hauss fast nütze ding.

Sehr schlecht zu sprechen auf die Zinngiesser war Abraham a Santa Clara, welcher 1699 in einem in Würzburg erschienen Buche über die Stands-, Amts und Gewerbspersonen schreibt: "aber ihre meisten Wahren dienen der Menschen Gurgel; denn Schüssel, Teller, Becher und Kandel ein Jahrmarkt seyend für das Maul, welches kein Flaschen lieber hat als die zinnene $"$.

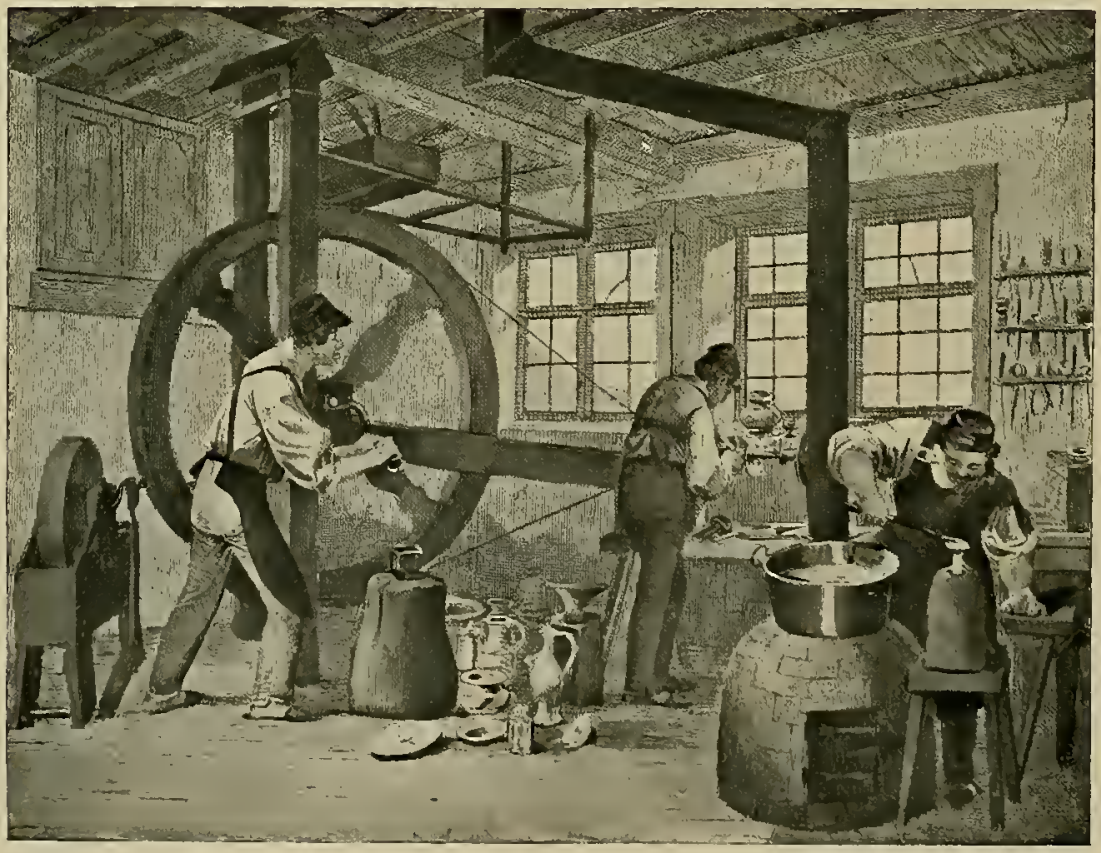






1

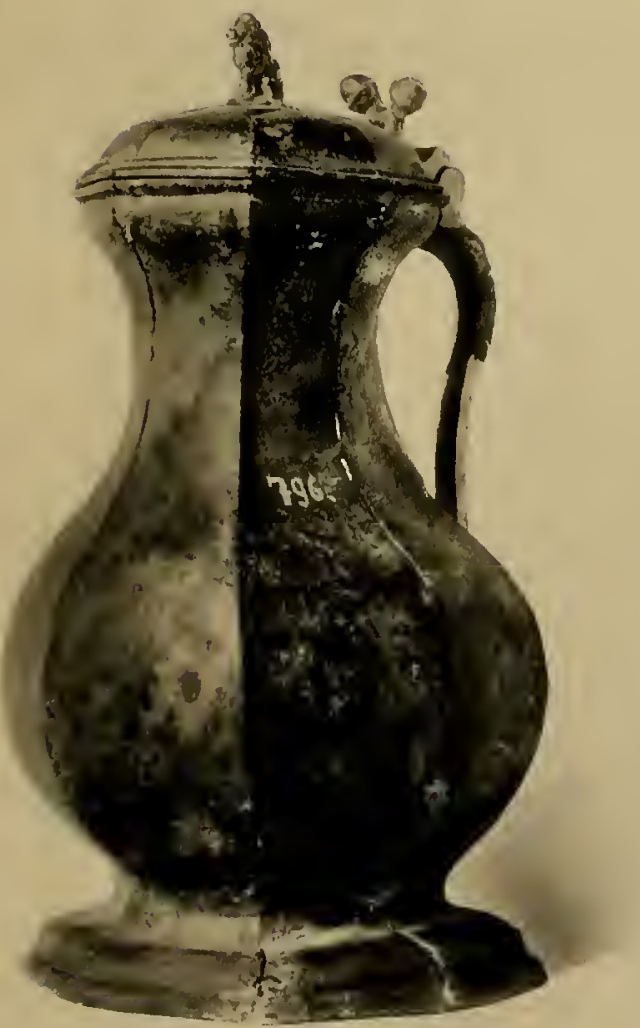

2

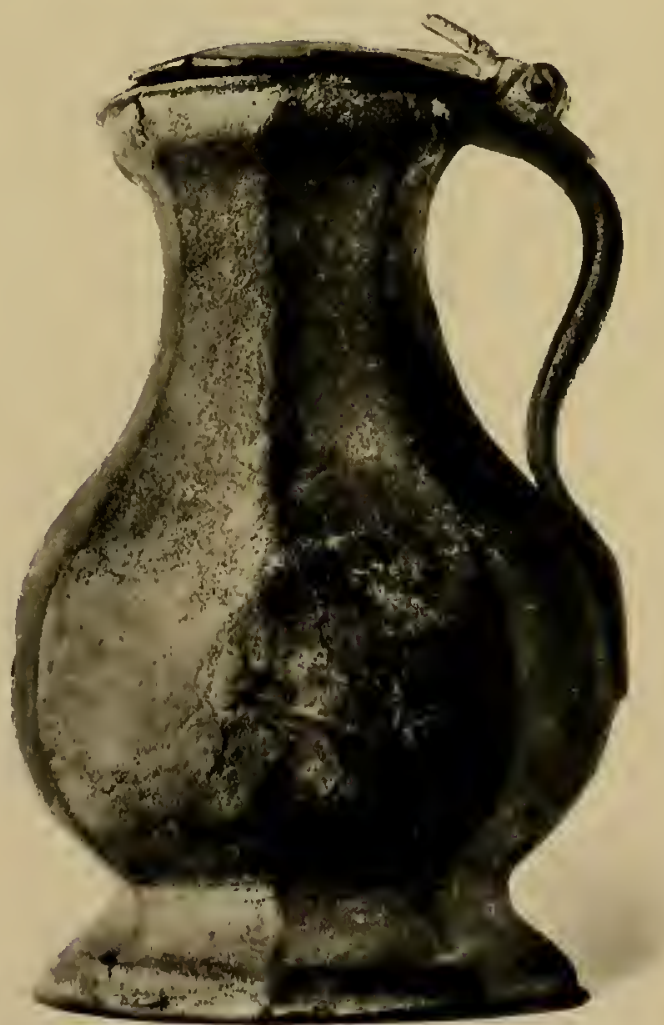

3

1. Gotisches Zinngeschirr von Homberg im Aargau (Seite 33), XIV. Jahrhundert. 2. Gotische Kanne von Homberg (Text S. 33), XIV. Jahrhundert, Höhe 29 cm. 3. Gotische Kanne von Siders (S. 33), XIV. Jahrhundert, Höhe $31 \mathrm{~cm}$. 


\section{Historische Einleitung}

Als Bestandteil der Bronze findet sich das Zinn durch das ganze Bronze zeitalter, also auch bei den Pfahlbauern; als reines Metall oder etwas bleihaltig kommt es viel seltener vor. Doch wurden auch in der Schweiz, so bei Wollishofen und Corcelettes, Tongefässe gefunden, welche mit Zinnbändern oder feinen Zinnstäbchen verziert waren. Entweder wurde der feine Zinnfaden in die eingekratzten Ornamente hineingepresst oder aber in kleinen Löchern befestigt. Solche Gefässe und Scherben befinden sich im schweizerischen Landesmuseum in Zürich ${ }^{1}$. Im Landesmuseum befinden sich auch zivei Zinnrädchen mit vier kreuzförmigen Speichen, ebenfalls von Wollishofen. Herr Michael Speck von $Z u g$ hat seit vielen Jahren zwischen Cham und Zug Ausgrabungen vorgenommen und fand als sehr seltenen Gegenstand einen schweren dicken Ring aus Zinn, mit ganz kleinem Lumen und zwar in der Schicht der Bronzezeit.

Aus der Hallstattperiode stammen Tongefässe mit inkrustirten ${ }^{2}$ Tierfiguren, auch einzelne Figürchen aus einer Zinn-Bleilegierung (Funde aus Frög, Oesterreich). Aus der L a T êne-Zeit stammen römische Zinnfiguren, welche die Minerva (Funde aus Gurina, Obergailtal, Kärnten) oder römische Krieger darstellen (Funde von Mainz im British-Museum).

Aus der gallo-römischen $\mathrm{Z}$ eit stammt eine prachtvolle, zinnerne Gürtelschnalle (abgebildet bei Näf, S. 16), von $34 \mathrm{~cm}$ Länge und $9 \mathrm{~cm}$ grösste Breite, welche sich im Museum von Freiburg befindet. Aus der gleichen $Z$ eit findet man in Frankreich zinnerne Pilgerzeichen und religiöse Insignien (Forrer, L'Etain, S. XIV).

Im frühen Mittelalter gab es in den Kirchen ab und zu neben den gebräuchlichen silbernen und goldenen Gefässen auch zinnerne, besonders Kelche (BAPST, La chronique de Reims, S. 91-105).

Bei Ausgrabungen der im Jahre ${ }_{1} 356$ zerstörten Burg Homberg im Aargau ${ }^{3}$ wurden Zinngegenstände gefunden, so ein kleines, achtseitiges Zinnkännchen von $19 \mathrm{~cm}$ Höhe. Den Deckeldrücker bilden zwei Eicheln. Auf dem Deckel befindet sich ein ovoider Knopf. Der am Halse anliegende Ausguss hat die Form eines Mannskopfes und gab vielleicht die Idee zu den Solothurner Maskaronkannen. Ferner fand sich eine runde Zinnschüssel von $35 \mathrm{~cm}$ Durchmesser, mit horizontalem Rande, ein Tellerchen von $8,5 \mathrm{~cm}$ Durchmesser und ein achteckiger Kannendeckel. Das Hauptstuick aber ist eine achtseitige, $29 \mathrm{~cm}$ hohe Kanne. Auf einem hohlen, ausladenden Fuss sitzt der birnförmige Korpus, welcher oben durch einen flachgewölbten Deckel verschlossen wird. In der Mitte des Deckels sitzt ein kleiner Löwe in Reliefguss. Am Scharnir bilden zwei Eicheln den Deckeldrücker. Der Deckel greift vermittelst eines Hängeplättchens in den obern Kannenrand. (Tafel $I, 1$ u. 2.)

Bei Siders im Wallis wurden ähnliche Funde gemacht. Im Jahre $1906^{4}$ wurde im Pfynwald oberhalb Siders eine zerfallene ähnliche Zinnkanne voll Gold- und Silbermünzen gefunden. Der Korpus war ganz zerfressen und mürbe und ging zum grossen Teil verloren. Besser erhalten war der achtseitige Deckel, auf dessen Mitte ebenfalls ein sitzender Löwe sich befindet. Auf dem geschweiften Fenkel ist in gotischen Majuskeln RO FABRY eingeritzt. Durchmesser der Bodenplatte 14,5 cm.

Im Jahre 1930 erwarb das Landesmuseum ${ }^{\natural}$ in Siders eine ähnliche, aber recht gut erhaltene Kanne von fast gleicher Form. Die Höhe beträgt $31 \mathrm{~cm}$, der Fussdurchmesser 12,7 cm. Der Deckel ist weniger stark gewölbt und liegt dem Rande flach auf. Auf demselben befindet sich weder ein Knopf noch ein Löwe. Der Deckeldrücker besteht aus einer glatten Lamelle;

\footnotetext{
1 Victor Gross, Protohelvètes, Tafel XXII. fig. 15. Landesmuseum Zürich.

2 Les Etains de la collectioo Ritleng à Strasbourg : Robert Forrer, 1905.

3 Dr. A. Gessner-Siegfried, Katalog des Kant. Antiquariums in Aarau. Aarau 1912. S. 121.

+ Zwei gotische Zinokanoen aus dem Wallis. K. Frei. Jahresbericht des schweiz. Landesmuseum von 1930. S. 48 u. ff.
} 
von demselben geht ein flacher, zugespitzter Deckelsteg bis in die Mitte des Deckels. Fuss und Bodenplatte sind ebenfalls achteckig. Auf dem stark geschweiften Henkel steht in gotischen Majuskeln die Inschrift RO ... AR. (Tafel I, 3.)

Beide Kannen von Siders sind gegossen und nicht etwa aus Lamellen zusammengelötet. Bodenrosetten, Stadt- und Meisterzeichen fehlen auf denselben. Ueber den Hersteller kann man nur Vermutungen haben. Ob dieselben von Genf, oder von einem fahrenden Meister aus Frankreich oder aus Basel stammen, ist eine offene Frage. Auffallend ist immerhin die Formgleichheit der Kannen von Homberg und Siders. Man beachte auch die Eicheln am Deckelgriff und den sitzenden Löwen auf dem Deckel, Motive, welche sich noch Jahrhunderte lang finden. Die Kannen von Homberg und Siders stammen aus dem Ende des 14. Jahrhunderts (Erdbeben von Basel 1356 und Einsturz der Burg Homberg; die Münzen in der Kanne von Pfynwald bei Siders stammen aus dem XIII. und XIV. Jahrhundert).

Aus dem Basler Münsterschatzl stammen drei $27 \mathrm{~cm}$ hohe Kannen (Durchmesser des Fusses $13 \mathrm{~cm}$ ) in der Form der Berner Stegkanne mit langer, sechskantiger Ausgussröhre. Doch fehlt der Steg, wie dieses z. B. auch bei den alten holländischen Kannen der Fall ist. Korpus und Hals, ebenso der flache Deckel, sind völlig glatt. Im Kannenboden befindet sich in Reliefguss der Adler des Basler Bischofs Jean de Vienne (1366-1382). Die Kannen sind wahrscheinlich französischen Ursprunges und tragen ein rundes Beschauzeichen (Zeichen $\mathrm{Nr} .374 a, \mathrm{Bd}$. II) mit einem gotischen h. In den Basler Inventaren sind dieselben schon im Jahre 1477 angeführt. Sie sind in zwei Beziehungen von grossem Interesse; zum ersten Mal finden wir eine Bodenrosette und ebenfalls zum ersten Male eine Art Meisterzeichen ( $N r .374 a$, Bd. II). Die Inschriften auf den drei Kannendeckeln lauten: 1) $+\mathrm{S}+\mathrm{O}+$ Puerorum + ; 2) $+\mathrm{S}+$ Oleum + Infirmorum + ; ) + S+ CRISMA +. (Alle in Majuskeln.) (Tafel III, 1.)

Vollrundgegossene Statuetten aus Zinn sind in der Schweiz ausserordentlich selten zu finden. In der Sammlung von Alfred Ritleng zu Strassburg (Robert Forrer, Les Etains de la collection Alfred Ritleng à Strassbourg, Strassbourg, 1905, Tafel I) befand sich, als eines der hervorragendsten Stücke, eine Palmeselfigur, welche aus dem Unterlindenkloster zu Kolmar stammen sollte. Forrer datirt die $20 \mathrm{~cm}$ hohe und $18 \mathrm{~cm}$ lange Figur ins XII-XIV. Jahrhundert.

Zwei in meiner Sammlung sich befindliche Figuren des heiligen Sebastian stammen aus dem Oberwallis. Sie bilden im heutigen $Z$ ustande den Schaft von zwei Kerzenstöcken, wobei unten eine schwere zinnerne Fussplatte und oben am Baum ein Kerzenhalter angebracht wurde. Aus welcher Zeit diese Umänderung stammt, ist wohl kaum zu eruiren, sicherlich aber später, vielleicht erst aus dem XVII. oder XVIII. Jahrhundert. Der heilige Sebastian ist der Patronder Armbrustschützen. Die Figuren hatten ursprünglich wahrscheinlich einen hölzernen Sockel und dienten als Dekorationsstücke in der Schützenstube wie an andern Orten gleiche Statuetten aus Silber. Der von fünf Pfeilen getroffene Heilige ist an einen Baum gefesselt, der erhobene linke Arm aufwärts an einem Ast, die linke Hand hinter dem Rücken an den Stamm des Baumes. Die Darstellungsart der mächtigen Kopflocken, der Hände und Füsse deuten auf das ausgehende XV. Jahrhundert. Diese interessanten gotischen Figuren können ganz gut aus dem Wallis stammen und verraten deutlich französischen Einfluss. (Siehe Tafel II.)

Maasse: Höhe der Figur bis zur ausgestreckten linken Hand $21 \mathrm{~cm}$, bis zur höchsten Stelle des Baumes $24 \mathrm{~cm}$.

In der zeitlichen Reihenfolge kommen nun die frühesten Kannen von Spiez (Bubenbergkanne) und Aeschi, welche noch ins XV. Jahrhundert zurückreichen. Aus dem Anfang des XVI. Jahrhunderts stammen die Ratskannen von Baar. Allen diesen frühen Vertretern ist ein besonderes Kapitel gewidmet.

Von den gewöhnlichen Gebrauchs - Zinngegenständen des XIV. und XV. Jahrhunderts ist so gut wie Nichts erhalten geblieben. Auch aus dem XVI. Jahrhundert sind solche

\footnotetext{
${ }^{1}$ Der Basler Münsterschatz, von R. F. Burckhardt, Basel 1933. S. 175 .
} 
Erzeugnisse noch sehr selten. Es sind Kannen, Platten und Ohrenschüsseln der Genfer Zinngiesser Estienne Charton, Pierre I de La Fontaine, Jean Poncet und Noel Soenori, mit der Jahrzahl 1557 auf dem Meisterzeichen. Aus Schaffhausen stammt eine Glockenkanne mit der Jahrzahl 1582. Das Zinngeschirr des Haushaltes wurde zu oft umgegossen und nur ausnahmsweise konnte ein Stück diesem Schicksal entrinnen. Von den Genfer Gegenständen wurde ein grosser Teil bei Baggerarbeiten in der Rhone gefunden.

\section{Die Stadt- und Gemeindekannen}

Unter ihnen befinden sich die schönsten Erzeugnisse des schweizerischen Zinngiesserhandwerks. Wenn man die ziemlich grosse Anzahl betrachtet, so kann man genau umschriebene Gruppen unterscheiden.

1. Die älteste Gruppe.

2. Die Ausläufer dieser Gattung.

3. Die nordostschweizerische Gruppe.

4. Die Kannen mit linsenförmigem Korpus.

5. Die Bulgen oder Bern-Basler Gruppe.

\section{Die älteste Gruppe}

Die Bubenberg -, Aeschi-und Ba arerkannen bilden eine geschlossene Gruppe von einheitlichem Stil und gleicher Bauart. Der mächtige Fuss ist kegelförmig und trägt, ohne einen Schaft zu bilden, den sphäroidalen, abgeplatteten Korpus. Als Schildform dient die Tartsche, welche als massiges Stück angegossen oder angelötet ist. Die aufgebogene, prismatische Ausgussröhre durchdringt vor ihrem obern Ende einen Tierkopf. Alle besitzen den flachen, kuppelförmigen Deckel, auf dessen Mitte ein Knopf sitzt. Bei der Baarerkanne hatte er ursprünglich einen ornamentalen Aufsatz. Alle drei Stücke besitzen die gleiche seitliche Balkenkonstruktion, an welcher oben der Traghenkel montirt ist. Auch in der Grösse und im Gewicht kommen sie einander nahe (Höhe $42-48 \mathrm{~cm}$ ).

Die Bubenbergkannen stammen aus der Wende des XV.-XVI. Jahrhunderts. Je ein Exemplar ist im Historischen Museum von Basel und im Landesmuseum in Zurich. Sie stanmen aus dem Schlosse von Spiez bei Thun. Die Form ist sehr wuchtig, die Ausführung, auch der Wappenschilder, sehr massig. Auf der einen Seite der Kanne ist der Wappenschild der 1508 ausgestorbenen Familie von Bubenberg, ein querhalbirter Schild mit einem Stern in der obern Hälfte. Auf der andern Seite befindet sich das Wappen von Spiez, ein Spiess. Die prismatische, aufgebogene Ausgussröhre durchbohrt unmittelbar vor ihrem obern Ende einen Tierkopf (Dogge ?). Die Kannen haben eine Höhe von $44 \mathrm{~cm}$; der Durchmesser des Fusses beträgt $22,5 \mathrm{~cm}$. (Tafel III, 2.)

Die Kannen von Aeschi (bei Frutigen) sind im Historischen Museum von Bern und stammen ungefähr aus der gleichen Zeit. Auch in ihrer Form und Ausführung sind dieselben sehr ähnlich. An der Seite der $48 \mathrm{~cm}$ hohen Kannen ist der Wappenschild von Aeschi, eine Bärenpranke. Auf dem Deckel findet man das Zeichen Nr. 506 (Bd. I), also eine französische Lilie ohne Meister-Initialen. Die genaue Zuweisung an einen bestimmten Meister ist deshalb unmöglich. Bevor die Kannen ins Museum gelangten, dienten sie als Wirtschaftszeichen und waren ausserhalb des Wirtshauses aufgehängt. (Tafel IV, 1.)

Die Ratskannen von $\mathrm{Ba}$ ar sind voraussichtlich die ältesten schweizerischen Kannen, welche Beschau- und Meisterzeichen tragen. Der flache kuppelförmige Deckel trägt einen Knopf, welcher von zwei flachen, abgerundeten Scheiben gebildet wird. Davor befinden sich die Marken Nr. 25 (Bd. I), das Beschauzeichen von Zug und das Meisterzeichen des Johannes Vogt. Nach dem Stammbaum von Wickart ist Vogt im Jahre 1450 geboren (oder 1480). Laut 
Bürgerbuch I, Blatt ${ }_{138}$, wird "Hanns Kanntengiesser " 1506 Bürger. In Diebold Schillings Luzerner Chronik von 1513 findet sich auf Fol. 38 eine Kanne mit einem quergeteilten Wappenschild abgebildet, welche unsern Kannen zum Verwechseln ähnlich sieht. Bei den Baarer Kannen fehlt der bronzene Aufsatz auf dem Deckelknopf; doch findet sich eine vierkantige Abbruchstelle. Als Dekoration weisen die mächtigen, $10 \mathrm{~kg}$ schweren Kannen am Fuss, Korpus und Deckel circuläre Rillenpaare auf. Da die Zwischenräume mit eingeschlagenen Punkten dicht ausgefüllt sind, wirken dieselben wie circuläre Bänder und gliedern die glatten Flächen. Zu beiden Seiten des Korpus befindet sich je ein massiger Tartschenschild mit dem Zuger Wappen. Die sechskantige aufgebogene Ausgussröhre durchbohrt vor dem obern Ende einen mächtigen, sehr gut modellirten Löwenkopf. Besonders charakteristisch ist die technische Behandlung der Behaarung des Kopfes und der Mähne. Als Steg dient ein Mannsarm, dessen in alle Details naturalistisch prachtvoll modellirte Hand die Ausgussröhre umfasst. Hinten ist der Arm an dem senkrechten Zinnbalken befestigt, an welchem oben der bewegliche eiserne Traghenkel in einem Ring läuft. Innen im Kannenboden befindet sich ein Medaillon mit dem Crucifixus, Maria und Johannes (siehe die Abbildung auf dem Titelblatt des Bandes I). In der Schilling'schen Luzerner Chronik steht unterhalb obiger Kanne noch eine Glockenkanne mit dem Zugerschild in einem Kühleimer.

Es ist nicht unwahrscheinlich, dass die Kannen von Baar ursprünglich die Ratskannen von Zug waren; um das Jahr 1650 verfertigte Carl Schönbrunner die sechs neuen Ratskannen und bei diesem Anlasse wurden die alten vielleicht nach Baar abgegeben (jetzt in der Sammlung des Verfassers). Die beiden Kannen sind nicht gleich, sondern verhalten sich wie Spiegelbilder. Höhe 41,5 cm; Durchmesser des Fusses $21,5 \mathrm{~cm}$. (Tafel III, 3 u. 4.)

\section{Die Ausläufer der ersten Gruppe}

Die Kannen von Frauenfeld. Sie wurden am Ende des XIX. Jahrhunderts nach Amerika verkauft. Bei Ausführung von Reparaturen wurden in Luzern einige Kopien angefertigt, welche allerdings auch als Wiederholungen Meisterstücke sind, wie alle Werke dieses Kenners und Künstlers. Am Kannenfuss findet man schon deutliche Schaftbildung. Der Korpus ist vom Halse durch eine scharfe Kante getrennt. Die Ausgussröhre ist noch gleich wie bei der alten Gruppe, hat aber am Ende einen Deckelverschluss. Der Steg ist mager und hat schon Anklänge an denjenigen der Berner Stegkannen. Auf dem kuppelförmigen Deckel sitzt ein vollrund gegossener Löwe mit erhobener linker Pranke. Das Traggestell des schön geschmiedeten Henkels besitzt noch die alte, gotische Form. Auf dem schweren Schild befindet sich das in hohem Relief gegossene Wappen der Stadt Frauenfeld. Der untere Rand des Fusses und des Deckels, der obere Rand des Halses weisen reiche Akanthusfriese in feiner Ausführung auf. (Tafel IV, 2.)

Die Kannen der Stadt Baden. Zwei Stück in Privatbesitz. Auf dem breiten Fuss steht ein kurzer Schaft, welcher den mächtigen Korpus trägt. Demselben entsteigt die lange, sechskantige, S-förmig gebogene Ausgussröhre, welche oben in einem Tierkopf endigt. Zu beiden Seiten des Korpus befindet sich je ein grosser Badener Wappenschild in flachem Reliefguss (fehlt bei der einen Kanne an der linken Seite und ist nur eingravirt). Ein fein ciselirter, schmiedeiserner Traghenkel läuft am zinnernen Traggestell, welches auch mit der Ausgussröhre durch einen kleinen Steg verbunden ist. Der flach kuppelförnige Deckel bewegt sich in einem seitlichen Scharnir und besitzt in der Mitte einen starken Knopf. In der Mitte der Innenseite befindet sich in Reliefguss das Wappen Falk mit der Inschrift Casper Falk und im Kannenboden eine Bodenrosette mit einer grossen Renaissance-Vase mit Blumenranken. Der untere Rand des Fusses, des Deckels und der obere Rand des Kannenhalses wird von einem breiten Renaissance-Fries (Akanthusblätter und vertikal gerippte Stäbe) eingefasst.

Höhe der Kanne $41 \mathrm{~cm}$; Durchmesser des Fusses $21 \mathrm{~cm}$. (Tafel IV, 3.)

Auf dem Deckel befindet sich das Stadtzeichen von Baden und das Meisterzeichen eingeschlagen. Wie fast immer bei den ältesten Meisterzeichen, fehlen auch hier die Meister- 
TAFEL II

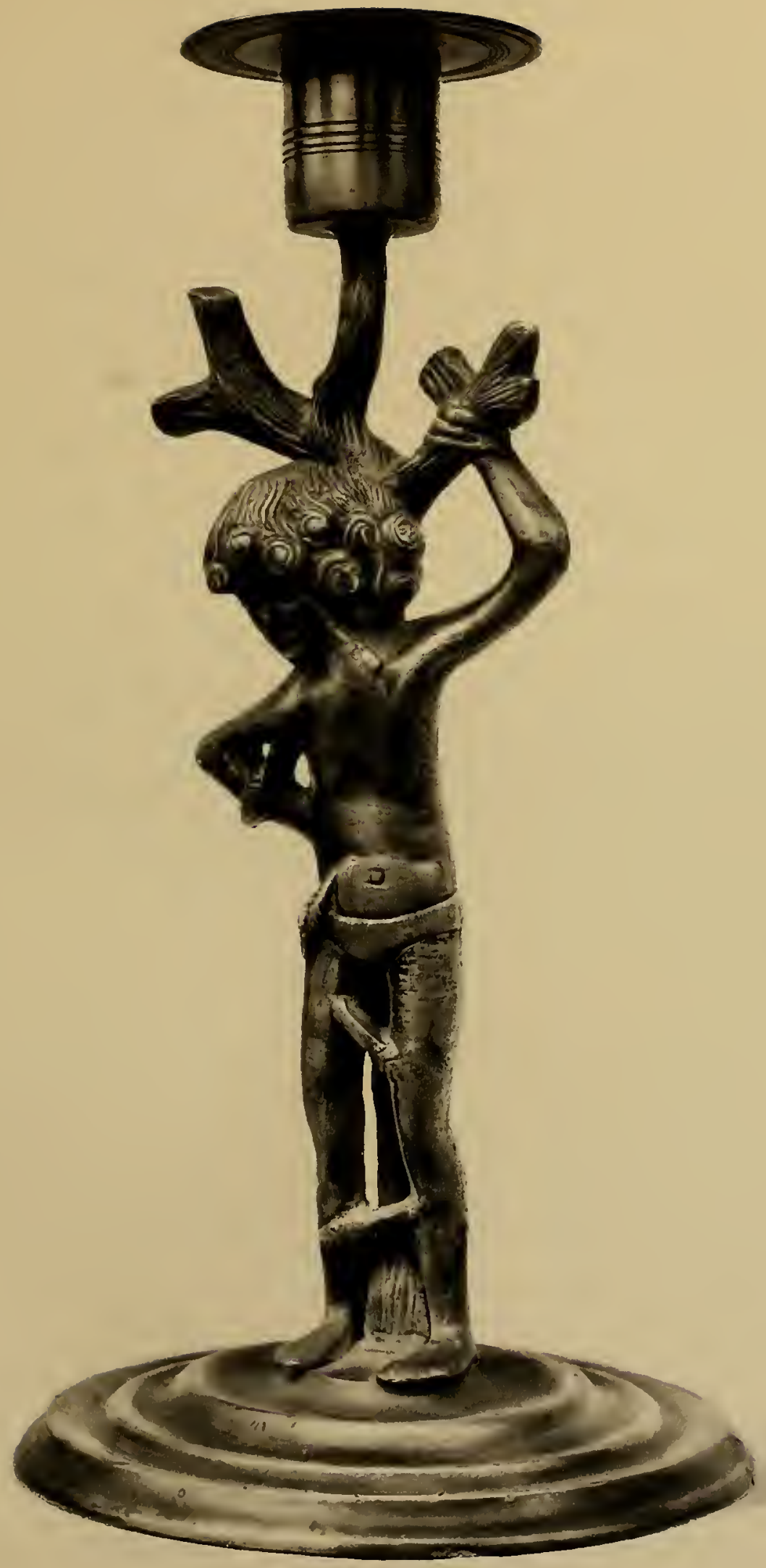

Zinnstatuette des heiligen Sebastian aus dem Ende des XV. Jahrhunderts (Text S. 34). 
Initialen; der Schild enthält über einem Dreiberg einen fünfzackigen Stern und darüber einen plumpen Zinngiesserhammer. Infolge der starken Abnutzung der Zeichnung könnte es sich auch um das deformirte Bild einer Pfeilspitze handeln. In diesem Falle wäre der Zusammenhang mit dem Wappen Falk gegeben.

Die Ratskannen von $\mathrm{Z}_{\mathrm{ug}}$ (sechs Stück im Historischen Museum von Zug), obwohl aus der Mitte des XVII. Jahrhunderts stammend, lehnen sie sich ganz an die alte Form der Baarer Kannen an und wahrscheinlich haben letztere als Vorbild gedient. Immerhin zeigt der Fuss schon Tendenz zur Schaftbildung. Der Schild hat reine Renaissanceform. Der geschuppte Kopf eines Fisches bildet den prächtigen Ausguss. Der Deckel besteht aus zwei über einander liegenden Kuppeln. Die seitlichen Henkelträger sind im untern Teil eingebogen. Das Meisterzeichen Nr. 29 (Bd. I) befindet sich auf dem Fuss der Kannen. Der Zinngiesser Carl Schönbrunner lebte von 1625 bis 1657 . Höhe $40,5 \mathrm{~cm}$; Durchmesser des Fusses $20 \mathrm{~cm}$. (Tafel IV, 4.)

Die Ratskannen von Stein am Rhein. Einzelne Exemplare finden sich im Historischen Museum von Schaffhausen und im Landesmuseum von Zürich. Dem breiten Fuss entsteigt ein dicker Schaft, auf welchem der pokalförmige Korpus ruht. Am obern Rand desselben setzt sich mit fast rechtwinkliger Einziehung der dicke Hals an, welcher sich oben etwas erweitert. In der Mitte des Halses unterbricht ein circulärer Wulst und feine Rillen die glatte Fläche. Auf dem flachen, aus zwei aufeinander gelegten Kuppeln bestehenden Deckel ist ein runder Knopf. Der eiserne, halbkreisförmige, abgekröpfte Henkel läuft an einem gleichen prismatischen Gestänge, wie bei der alten Berner Gruppe ; ebenso verhält such die Ausgussröhre. Ein kleiner Steg verbindet die Ausgussröhre mit dem Traggestell des Henkels. Auf dem seitlich am Korpus angebrachten Schild befindet sich das Wappen von Stein, St. Georg zu Pferd, am Boden der Drache; darüber die Jahrzahl 1655. Auf dem Deckel befindet sich das Meisterzeichen Nr. 149 (Bd. I). Höhe der Kannen $40,5 \mathrm{~cm}$; Durchmesser des Fusses $21-22 \mathrm{~cm}$, je nach der Erhaltung der Kanne. (Tafel V, 1.)

Die Luzerner Kannen, zwölf Stück im Historischen Museum von Luzern. Höhe $56 \mathrm{~cm}$. Sie wurden anlässlich der Erneuerung des Bündnisses mit dem Wallis, 1678 , hergestellt und tragen das Meisterzeichen von Caspar Traber, Nr. 3 (Bd. I). Nur der Fuss, der Korpus und der Deckel sind Zinngiesserarbeit. Die ganze ornamentale Ausstattung, der Wappenschild von Luzern, der als Vogelkopf gebildete Ausguss, die Karyatiden und die Delphine des Traghenkels, besteht aus gelbem Bronzeguss. Die horizontale Gliederung des Fusses, des Korpus und des Halses erfolgt durch circuläre Wülste und Rillen. Der Deckelknopf besitzt drei etagenförmige runde Querscheiben. (Tafel V, 2.)

Die Ratskannen von Murten, im historischen Museum in Murten. Sie besitzen in ihrem ganzen Aufbau die Form der Berner Stegkanne. An der Seite des Korpus befindet sich in Reliefguss das Stadtwappen von Murten, ein steigender Löwe. Die runde, aufgebogene Ausgussröhre endigt in einem Löwenkopf. Eine plumpe Hand an einem auffallend dünnen Arm bildet den Steg. Die Kanne besitzt ausser dem gewöhnlichen hintern Henkel noch einen beweglichen, grossen Träger, welcher an seitlich angebrachten Scharniren läuft. Die Krüge tragen das Meisterzeichen von Pierre Villeneufve, Nr. 532 (Bd. I), welcher 1674-1695 in Neuenburg und nachher in Bern tätig war. Die Kanne besitzt eine Höhe von $41 \mathrm{~cm}$. (Tafel V, 3.)

Die Stadtkannen von Payerne und von Moudon besitzen ebenfalls die Grundform der Berner Stegkanne. Der nach aussen hochgestülpte Fussrand dürfte auf einer spätern Deformation beruhen, vielleicht um ablaufende Weintropfen aufzufangen. Der weite, becherförmige Korpus setzt mit einer scharfen Kante gegen den $\mathrm{Hals}$ ab, welcher oben und unten Friese von Blättern und Perlstäben besitzt. Zu beiden Seiten des Halses ist je ein Schild, mit dem gravirten Stadtwappen, aufgelötet. Die vierkantige, S-förmige Ausgussröhre endigt in einem Tierkopf. Sie wird zwei Mal durch einen Karniss unterbrochen und ist mit gravirten Blattund Blumenranken überzogen. Ein Steg verbindet die Ausgussröhre mit dem Kannenhals. Ausser dem festen zinnernen Handgriff ist auch ein beweglicher eiserner Träger vorhanden, welcher in sehr massiven, gotisirenden Oesen läuft. Der flache, kuppelförmige Deckel 
besitzt als Drücker zwei Tierköpfe. Meisterzeichen sollen nicht vorhanden sein; dagegen befindet sich im Kannenboden, in einer Rosette eingeschlossen, das Bernerwappen in Reliefguss. Alter der Kanne: ca. 1700. Aehnliche Kannen befinden sich in Moudon. (Tafel V, 4.)

\section{Die nordostschweizerische Gruppe}

Die Kannen der Stadt Wyl, sechs Exemplare, wovon eines im historischen Museum von St. Gallen, eines im Landesmuseum in Zürich (zwei im Musée du Cinquantenaire von Brüssel und zwei in einem französischen Provinzialmuseum). Von der breiten Fussbasis schwingt sich der steile konische Schaft zum flachen, aus verschiedenen Kuppeln gebildeten Korpus empor. Die horizontale Gliederung erfolgt durch viele circuläre Perlstäbe (mit rechteckigen "Perlen "). Der hohe, schlanke Hals erweitert sich oben zum pokalförmigen Oberteil. Von der Mitte des Korpus zum obern Kannenrand steigen zwei vertikale, profilirte Säulen, welche einen Querbalken stützen. An diesem läuft der eiserne bewegliche Traghenkel. Der halbkuglige Deckel besteht aus zwei aufeinander gelegten Kuppeln, zwischen welchen wieder ein Perlstab läuft. Die S-förmig gebogene Ausgussröhre beginnt am obern Teil des Korpus, geht dann an den Oberteil der Kanne und schwingt sich nach vorne, indem sie, kurz vor dem Ende, einen Tierkopf durchdringt. Oben am Korpus, rechts und links der Ausgussröhre, befindet sich die eingravirte Jahrzahl 1581 oder 1582. Am Halse sind zwei Schilde angelötet; auf dem rechten der Bär ohne Halsband, auf dem linken das W, das Wappen der Stadt Wyl. Die Höhe der Kanne beträgt 47,2 cm. Sie trägt das Meisterzeichen Nr. 262 a. (Tafel VI, 1.)

Die dekorative Wirkung dieser Kanne ist eine ausserordentliche und der Verlust für Wyl bedauerlich.

Die Kanne der Stadt Rapperswyl. Diese prachtvolle Kanne ist ca. 1910 im Kunsthandel verschwunden. Das Meisterzeichen der $45 \mathrm{~cm}$ hohen Kanne war zur Unkenntlichkeit verschliffen. Durch Vermittlung eines Antiquars konnte wenigstens das Bild des Stückes erhalten werden. Dem breiten Fuss entspringt ein hoher konischer Schaft, welcher den flachen " räbenförmigen " Korpus trägt. Die horizontale Gliederung erfolgt durch circuläre Wülste, Rillen und Rippen. In der Mitte des schlanken, hohen Halses befinden sich ebenfalls circuläre Wülste und davor der Wappenschild von Rapperswil (in Gravirung zwei gestielte Rosen). Der Hals erweitert sich oben zu einer Halbkugel. Auf dem ziemlich hohen, kuppelförmigen Deckel sitzt ein vollrund-gegossener Adler. Der geschweifte Traghenkel geht vom Deckelscharnir zur Mitte des Korpus. (Tafel VI, 2.)

Die Kannen des Zehngerichtenbundes in Davos, sechs Stück im Rathaus in Davos. Dem flachen Fuss entragt ein hoher konischer Schaft. Darauf sitzt ein niedriges, halbkugliges $Z$ wischenstück, auf welchem der flache sphäroidale Korpus ruht. Um den Aequator desselben zieht sich ein flaches, 1,2 cm breites Band, ebenso um die Mitte des hohen Halses. An dessen Vorderseite befindet sich ein grosser Schild mit dem gravirten Wappen des Zehngerichtenbundes und der Jahrzahl 1647. Der Hals erweitert sich oben halbkugelförmig und trägt einen flachen, kuppelförmigen Deckel mit einem hohen Knopf. Der Deckeldrücker ist abgekröpft. Der Henkel hat die gleiche Schweifung wie bei der Berner Kanne. Meisterzeichen des Hertli de Cadenath, siehe Seite 123. (Tafel VI, 3.)

Die Ratskannen der Stadt Bischofszell, zwölf Stück im Museum von Bischofszell. Dem profilirten Fuss entsteigt ein schlanker, oben fast cylindrischer Schaft, auf welchem über einem $Z$ wischenstück der flache sphäroidale Korpus ruht. In der Mitte des Korpus und des Halses befindet sich ein circuläres, profilirtes Band. Vorn in der Mitte des Halses ist der Wappenschild von Bischofszell in schön modellirtem Reliefguss angelötet. Der Hals erweitert sich oben pokalförmig; darauf sitzt der flache, kuppelförmige Deckel mit hohem Knopf. Die Kanne hat eine prismatische Ausgussröhre wie die Berner Stegkannen. Sie steigt vom Korpus an schräg nach vorne bis zur Höhe des Kannenrandes und trägt einen Verschlussdeckel. Ein Steg (auch in Berner Form) befestigt die Ausgussröhre am Anfangsteile des Kannenhalses. 
Die Kannen sind das Werk von Bartholome Riedtmann und tragen das Meisterzeichen Nr. 240 (Bd. I). Sie stammen aus der Zeit um das Jahr 1700. Maasse: Höhe $53 \mathrm{~cm}$; Durchmesser des Korpus 17,3 cm; Durchmesser des Fusses 17,7 cm; Länge der Ausgussröhre $24,5 \mathrm{~cm}$. $\mathrm{D}$ as Meisterzeichen Nr. 240 befindet sich auf dem Deckelchen der Ausgussröhre. (Tafel VI, 4.)

\section{Die Kannen mit linsenförmigem Korpus („Plattflaschen“)}

Die Form dieser Kannen stammt von den Feldflaschen. In der Luzerner Chronik von Diebold Schilling vom Jahre 1513, Tafel 11 des Neudruckes, die Schlacht bei Sempach, trägt eine Marketenderin eine solche Zinnflasche. Urs Graf bringt ${ }_{1515}$ solche Flaschen auf zwei Handzeichnungen. Jost Ammann bringt zwei Stück mit Ketten auf dem bekannten Holzschnitt "der Kandelgiesser " vom Jahre 1568. Auch kleine Pilgerflaschen, welche an Lederschnüren getragen wurden, finden sich in dieser Form. (Tafel XLII, 14.)

Die Kannen des Kleinen Rats von Basel, zwölf Stück im historischen Museum von Basel. Sie dienten zum Ausschank des Ehrenweines bei festlichen Anlässen. Laut Säckel meisterrechnung wurden im Jahre 1638 für 24 Stück an Linder 62 Pfund und 1o Schilling bezahlt. Hans Lukas Linder lebte von 1611 bis 1678 . Auf dem Fuss der Kannen befindet sich das Meisterzeichen Nr. ${ }_{7} 8$ (Bd. I) und daneben eine achteckige Marke mit dem Linderwappen und den Initialen I. L. Der vierkantige, nach oben sich verjüngende Fuss trägt einen linsenoder scheibenförmigen Korpus, in dessen Mitte sich ein rundes Medaillon in Reliefguss befindet, welches das Wappen der Stadt Basel, gehalten von zwei Basilisken, enthält. Der Ausguss ist cylindrisch und mit einem Deckel verschlossen. $\mathrm{Zu}$ beiden Seiten des Halses befinden sich zwei vollrund modellirte Basilisken, welche aus dem Kannenrand herausragen, und deren umgebogene Köpfe die Oesen für die Tragkette bilden. Die zierlichen, sehr dekorativ wirkenden Kannen haben eine Höhe von 41,8-42,2 cm, je nach dem Erhaltungszustande des Fusses. $\mathrm{Ob}$ je 24 Stück vorhanden waren, ist fraglich, da über den Verbleib der restlichen 12 Stück nichts bekannt ist. (Tafel VII, 1.)

Die linsenförmige Wappenkanne mit Bemalung, von Winterthur. Im Besitz des Landesmuseums in $Z$ ürich, gegossen von Antonius I. Graf, von Winterthur (161 7-1686). Der vierkantige, schön profilirte Fuss verjüngt sich nach oben und umfasst mit einem konstruktiven Z wischenglied den senkrecht gestellten, linsenförmigen Korpus. Die kurze cylindrische Ausgussröhre ist mit einem Klappdeckel verschlossen. In der Mitte des Korpus befindet sich je ein aufgemaltes Medaillon und zwar vorne das Hegner Wappen mit der Aufschrift Anna Hegner 1607; auf der Rückseite das Familienwappen des K. Graf. Zu beiden Seiten des Kannenhalses, an der Aussenkante des Korpus, ist je eine Oese angelötet, an welcher die lange Tragkette befestigt ist. (Tafel VII, 2.)

Die Höhe der Kanne misst $36 \mathrm{~cm}$. Auf dem Deckel befinden sich die Meistermarken : das Beschauzeichen von Winterthur und das Meisterzeichen mit dem Wappen Graf und den Initialen A G (Antonius I. Graf, Meisterzeichen Nr. 143 a, Bd. II).

Die grossen linsenförmigen Kannen der Universität Basel. Die vier Stücke im historischen Museum von Basel waren für die vier Fakultäten der Universität bestimmt. Der vierseitige kleine Fuss hat abgekröpfte Ecken und verjüngt sich nach oben. Ohne $Z$ wischenglied sitzt darauf der mächtige, scheibenförmige Korpus, welcher in der Mitte nach aussen ausgebaucht ist. An der Vorderseite ist ein Medaillon in Gelbguss eingesetzt. Dasselbe besteht aus einem Blattkranz, in dessen Innern sich das Wappen der Universität Basel und darunter das Stadtwappen mit der Jahrzahl 1704 befindet. Die Rückseite der Kannen ist glatt. Der cylindrische Hals wird durch einen Holzpfropfen mit rundem Knopf verschlossen. Neben dem Kannenhalse sind Oesen angelötet, in welchen der eiserne, schmale, glatte Traghenkel läuft.

Die (ohne Knopf) $52 \mathrm{~cm}$ hohen Kannen stammen aus der Werkstatt des Simon Grynæus, welcher 1691 zünftig wurde. Sie tragen das Meisterzeichen Nr. 395 (Bd. I). Oberhalb des Fusses, an der Vorderseite des Korpus, befindet sich ein frei beweglicher Eisenring. 
Er dient zur Erleichterung des Einschenkens der in gefülltem Zustande sehr schweren Kanne. (Tafel VIII, 1.)

Die $Z$ ofinger Stadtkannen, vier Stück im städtischen Museum von Zofingen. Der vierseitige, schön profilirte Fuss verjüngt sich nach oben und umfasst mit einem konstruktiven Zwischenstück den linsenförmigen Korpus. Auf dem kreisrunden, ebenen Mittelteil ist das Wappen der Stadt Zofingen aufgemalt (quergeteilter Schild mit den Farben rot-weiss-rot-weiss). Auf dem Korpus sitzt der schlanke, oben etwas erweiterte Hals. Der Deckel besteht nur aus einer flachen Platte, welche an einem Knopf gehoben werden kann. Seitlich neben dem Halse befinden sich angelötete, profilirte Zinnstücke, welche oben das Scharnir tragen, in welchem der starke eiserne Traghenkel läuft. Dieser hat infolge drei starker Ausbuchtungen eine eigenartige Form. Höhe $46 \mathrm{~cm}$. (Tafel VII, 3.)

Die Willisauer Stadtkannen; vier Stück im Besitz der dortigen Theatergesellschaft; davon wurden zwei Exemplare ins Ausland verkauft. Die Form und Ausführung ist gleich derjenigen der Zofinger Stadtkannen. An Stelle des Zofinger Wappens befindet sich dasjenige von Willisau, ebenfalls aufgemalt, ein schwarzer schreitender Löwe auf einem Dreiberg auf rotem Grund. Die Höhe der Kannen ohne Henkel beträgt $46 \mathrm{~cm}$. Alle stammen aus der Werkstatt Hans Müllers von Zofingen (1691-1765). (Tafel VII, 4.)

Die Zofinger Stadtkannen tragen das Meisterzeichen Nr. 481, die Willisauerkannen Nr. 483 mit dem Zofinger-Schild und Nr. 481 (Bd. I).

Die Kannen von Kirchenthurnen (bei Bern). Der linsenförmige Korpus liegt breit dem etwas plumpen Fusse auf. Vorder -und Hinterfläche weisen breite, flache, concentrische Wïlste auf. Der Hals erweitert sich konisch nach oben und ist mit einem flachen, kuppelförmigen Deckel verschlossen, welcher hinten ein Scharnir und in der Mitte einen hohen Knopf besitzt. Der ziselirte, eiserne Traghenkel läuft in eisernen Oesen, welche in ein ornamentirtes Seitenstück eingegossen sind. Der Anschlag des Henkels hat das bekrönte Meisterzeichen zerquetscht. Vielleicht von Daniel Hemmann, gestorben 1750 . Höhe der zwei Kannen 49,5 cm; Durchmesser des Korpus 31,5 cm. (Tafel VIII, 2.)

\section{Die Bulgen}

Die Bulgen dienten sowohl als Gemeindekannen als auch zu kirchlichen $Z_{\text {wecken }}$ (Abendmahlkannen).

Unter einer $\mathrm{Bulg}$ e versteht man eine flache, kofferartige Tasche mit einem länglichen, rechteckigen Boden; der Traghenkel ist fast stets aus Eisen. Die Form ist oft plump und unkünstlerisch. Solche Kannen sind in ziemlich grosser Zahl vorhanden und ich gebe hier nur eine Auslese.

Im Münsterschatz von Bern finden sich mehrere, ganz grosse Exemplare mit schön gravirten Wappen und zum Teil mit dem Meisterzeichen Nr. 506 (Bd. I), welches der Zeit um 1500 entsprechen dürfte.

In der Stadtkirche von $Z$ of ing en befinden sich ebenfalls zwei Riesenstücke von $47,3 \mathrm{~cm}$ Höhe und $31 \mathrm{~cm}$ Fussbreite, auf welcher das Bernerwappen in einem Schild, Form Renaissance, eingravirt ist. Eine Jahrzahl fehlt. Auf der sehr alten Kanne hat Hans Müller einen neuen Hals und Deckel aufmontirt und hiebei sein Meisterzeichen aufgeschlagen, welches also nur für die Reparatur Gültigkeit hat.

Im historischen Muscum von Bern befindet sich eine mächtige Bulge mit der Jahrzahl 1666 ; ihre Höhe beträgt $51 \mathrm{~cm}$ und sie ist eine Arbeit Johannes III Wyss von Bern (1622-1683). Sie ist mit dem Meisterzeichen Nr. 507 (Bd. I) gestempelt und gehört der Gemeinde Lenk (Simmental). (Tafel IX, 1.)

Ebenfalls im historischen Museum von Bern steht eine kleinere, gefälliger gearbeitete Bulge mit dem v. Steiger-Wappen und den Initialen H. ST. Dieselbe ist ein Werk von Samuel Kuhn (1634-1688) von Bern. Sie trägt die Meistermarke Nr. 510 (Bd. I) und ist 3o cm hoch. (Tafel IX, 2.) 
TAFEL III
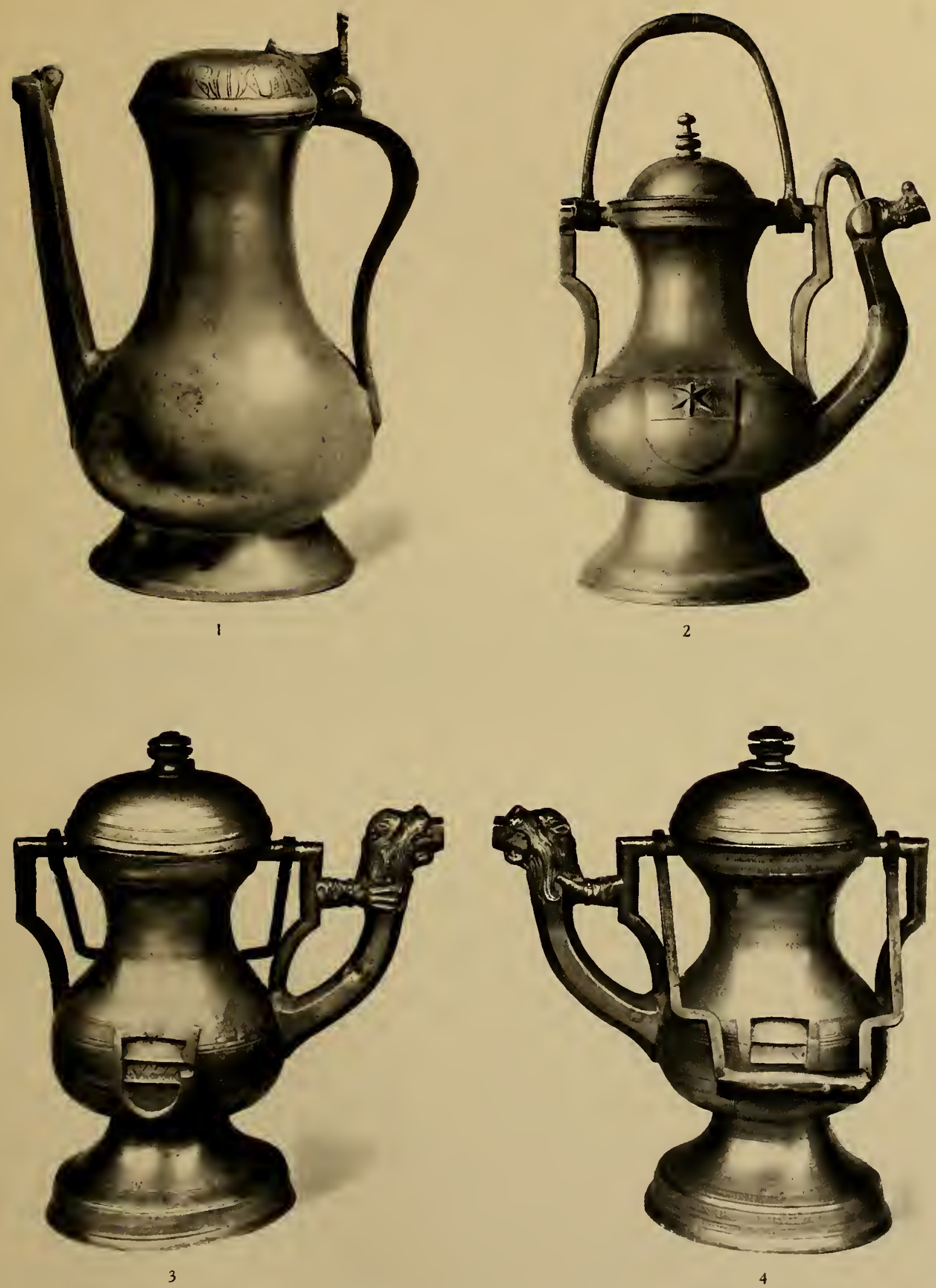

I. Kanne des Basler Münsterschatzes, XIV. Jahrhundert (Text S. 34) Höhe $27 \mathrm{~cm}$. 2. Bubenbergkanne, ca. I500 (Text S. 35), Höhe 44 cm. 3, 4. „Die Baarer Kannen“, ca. 1509-15 (Text S. 35) von Johannes Vogt, Höhe $41,5 \mathrm{~cm}$. 
Eine weitere Bulge mit dem Wappen von Diesbach stammt aus der Werkstatt von Adam Scherer in Bern und Burgdorf (1687 erwähnt). Dieselbe ist $28,5 \mathrm{~cm}$ hoch und besitzt das Meisterzeichen Nr. 586 (Bd. I). (Tafel IX, 3.)

Eine kleine, zierliche Bulge befand sich in der Sammlung L. Gally-v. Mechel in Basel. Auf dem Deckel figurirt die Meistermarke Nr. 515 des Johannes Küpfer von Bern (geb. 1672, tätig ab 1695). Die Vorderseite ist feingravirt, nebst der Jahrzahl 1725 ein Tannenbaum zwischen Stern und Mond. (Tafel IX, 4.)

Vom Meister Joh. Rudolf Grütter von Bern befindet sich im Landesmuseum in Zürich eine 29,5 cm hohe Bulge mit dem Meisterzeichen Nr. 538. An der Vorderseite ist die Kanne mit der Jahrzahl 1704 und einem Familienwappen gezeichnet.

Im Landesmuseum in $\mathrm{Z}$ ürich befinden sich zwei mächtige Stücke aus Neuenburg, der Compagnie des Mousquetaires gehörend. Dieselben sind mit gravirten Neuenburger Wappen vollständig bedeckt. Die eine trägt die Jahrzahl 1650 und ist $53 \mathrm{~cm}$ hoch bei $39 \mathrm{~cm}$ Fussbreite; die andere ist mit der Jahrzahl ${ }_{1} 684$ datirt, ist $54 \mathrm{~cm}$ hoch bei $35 \mathrm{~cm}$ Fussbreite. Hals und Ausguss sind kurz, nach oben erweitert und mit einem flachen, kuppelförmigen Deckel verschlossen. Bei der zweiten Bulge ist die Seitenwand geschweift. Beide Kannen besitzen an den Seitenwänden je zwei Oesen, durch welche ein Lederriemen gezogen ist. Die Tendenz zum Tragen ist also ganz besonders klar und deutlich.

Im historischen Museum zu Burgdorf stehen zwei kleine Bulgen aus der Werkstatt des Johann Arnold Beck in Aarau (1698-1766). Dieselben tragen auf dem Deckel das Meisterzeichen Nr. 440 (Bd. I).

Die Bulgen dienten sehr häufig kirchlichen Zwecken, insbesonders zum Herauftragen des Abendmahlweines. Aus denselben wurde der Wein in die handlichern Abendmahlkannen abgefüllt.

Zum Schlusse erwähne ich als Beispiel einer sehr späten Bulge ein Stück aus dem historischen Museum von Basel. Es stammt von Johann Heinrich Petersohn von Bern (erwähnt 1780-1786). Die 32,5 cm hohe Kanne trägt das Meisterzeichen Nr. 554 (Bd. I), hat eine vom französischen Stil (Louis XVI.) beeinflusste steife Form und einen rechtwinklig abgebogenen Traghenkel.

\section{Die Abendmahlkannen}

In vielen protestantischen Kirchen der Schweiz sind die altehrwürdigen zinnernen Abendmahlkannen noch heute im Gebrauche. Allerdings dient die Bulge kaum mehr diesem Zwecke, weil das Einschenken mit dieser Kanne sehr unbequem ist und oft Wein verschüttet wird. Die Abendmahlkanne hat meist die Form der ortsüblichen Gebrauchskanne; nur sind dieselben viel grösser und haben oft den doppelten bis vierfachen Inhalt. In der Nord-Ostschweiz handelt es sich um zwei- bis viermässige Glocken- oder prismatische Kannen. Dieselben besitzen oft an der Rückseite, nahe dem Kannenboden, einen beweglichen Ring; beim Erfassen desselben kann die Kanne leicht nach vorn gekippt werden. Damit wird das Einschenken mit der sehr gewichtigen Kanne bedeutend erleichtert. Als Beispiele erwähne ich eine mächtige $\mathrm{Ka}$ n ne von Elgg bei Zürich; Höhe der prismatischen, mit Traubenschild verzierten Kanne $44 \mathrm{~cm}$; Durchmesser des Fusses $21 \mathrm{~cm}$. Eine prismatische, sechsseitige $\mathrm{K}$ a nne von $\mathrm{H}$ eris a u zeigt schön gravirte Zeichnungen, der segnende Christus mit dem Kreuz, der am Tor anklopfende Heiland, Blumenranken und die Jahrzahl 1743. Höhe 39,5 cm; Durchmesser des Fusses $21 \mathrm{~cm}$. An Stelle der vordern Kante besitzt die Kanne eine schmale Fläche und kann so auf der festen Unterlage gekippt werden. Eine andere sechsseitige Kanne mit der Jahrzahl ${ }_{17} 61$ trägt am Kannenboden eine angelötete Zinnplatte, über welche der mächtige Krug gekippt werden kann. Eine prismatische Churerkanne von $41 \mathrm{~cm}$ Höhe und $18 \mathrm{~cm}$ Fussdurchmesser hat unten einen Ring zum Neigen der Kanne, ebenso obige Elgger Kirchenkanne. (Tafel X, 1, 2.) 
Die Glockenkannen als Abendmahlkannen haben meistens einen Inhalt von zwei Maass. Aus dem Rheintal stammt eine Glockenkanne mit dem W der Stadt Werdenberg auf dem Schild und einem Feldkircher Meisterzeichen, von $43,5 \mathrm{~cm}$ Höhe und $20 \mathrm{~cm}$ Fussdurchmesser. Ebenso grosse Stücke gibt es in Schaffhausen und St. Gallen. (Tafel X, 3, 4.)

Im Lande Bern und seinen ehemaligen Aemtern haben fast alle Abendmahlkannen die typische Form der Berner Kanne, und zwar mit oder ohne Steg. Wahre Prachtstücke befinden sich in der Stadtkirche von Biel, in Rougemont und im kleinen Museum von Wietlisbach (dabei auch eine Zofinger Kanne). Besonders die doppelmässigen Stegkannen machen einen imposanten Eindruck. Unter den sechs Bieler Abendmahlkannen befinden sich zwei Stücke des Berner Meisters Peter I. Baumgarter (1504-1558 zitirt) oder Peter II Baumgarter (1550-1581 zitirt). Die Form dieser zwei Kannen ist die gleiche, wie diejenige der drei Kannen (mittelalterlich) im Basler Münsterschatz; nur haben die Bieler Kirchenkannen keine Ausgussröhre. Zwei andere Abendmahlkannen von Biel tragen das Beschauzeichen von Neuenstadt und das Meisterzeichen Nr. 580 des David I. Witz (vor 1678), und zwei weitere das Beschauzeichen von Biel und die Meistermarke Nr. 576 (Band II) des Meisters Bendicht Wagner (zitirt 1664-1687). (Tafel XI, 4, 5, 6.)

Die Abendmablkanne von $\mathrm{T}_{w}$ an $\mathrm{n}$ ist $40 \mathrm{~cm}$ hoch und trägt die Jahrzahl ${ }_{1679}$. Auf dem sechsseitig prismatischen Korpus ist ein Schild aufgelötet, der die Widmung trägt. Der cylindrische Hals hat keinen eigentlichen Ausguss und endet oben kreisförmig. Die Kanne hat einen beweglichen, eisernen Traghenkel und trägt das Meisterzeichen des Bieler Meisters David I Witz (in Biel von ${ }^{6} 678$ bis 17o3) Nr. 58o des neuen Blattes Biel (Band II).

Die Abendmahlkanne von Gottstatt bei Biel zeigt den gleichen Aufbau wie die Kanne von Twann und ist ebenfalls $40 \mathrm{~cm}$ hoch. Dagegen trägt sie die Jahrzahl 1706 und stammt von David II Witz (tätig von 1703 bis 1743) mit dem Meisterzeichen Nr. 58 a des neuen Blattes. Im Gegensatz zur Kanne von Twann hat sie einen schnabelförmigen Ausguss mit entsprechendem Deckel. (Tafel XII, х.)

Die Abendmahlkannen von Ligerz. In Form und Arbeit sind die drei Kannen vollständige Unica. Ihr Hersteller ist Alexander Bäschlin (in Biel von $16 \pm 5$ bis 1635 tätig) in Biel. Auf einem hohen Fuss befindet sich der ovoide Korpus, welcher im obersten Teil einen circulären Wulst aufweist, ebenso die Mitte des schlanken Halses. Daselbst sind zwei Schilde aufgelötet, auf welchen sich ein Kreuz auf Dreiberg und die Initialen C D befinden. $\mathrm{Zu}$ beiden Seiten des Halses bilden gebogene Hälse eines Tieres je eine Oese; wahrscheinlich dienten diese Oesen zur Befestigung eines beweglichen Traghenkels. Auf dem flachen Deckel steht ein aus Scheiben zusammengesetzter Knopf. Der rückwärtige feste Henkel hat an der Aussenseite ein reliefirtes Band von Blattranken. Die ganze Oberfläche der Kanne ist mit Linien im Tremolirstich in schöner Anordnung überzogen, so dass eine gute Gliederung der Flächen entsteht. Dadurch erhalten die Kannen ihr eigenartig originelles Aussehen. (Tafel XI, 1, 2, 3.)

Die Form der Stitze kommt bei den Abendmahlkannen selten vor. Die grossen Stitzen wirken plump und schwerfällig; sie kommen in Basel, Schaffhausen und auch Zofingen vor. Ihr Inhalt beträgt 2-3 Maass. (Tafel XIV, 4.)

In der Westschweiz herrscht an den an Bern angrenzenden Landesteilen noch bernischer Einfluss. In Le Landeron waren zrvei ca. 3o cm hohe Bulgen im Gebrauch. Dieselben tragen an der Vorderseite das Stadtwappen, darüber das Sparrenwappen (chevron) von Neuenburg mit der Inschrift LANDERON, unterhalb die Jahrzahl 1721 . Die einzelnen Insignien sind zum Teil vergoldet. Die Kannen besitzen einen beweglichen eisernen Traghenkel und einen flachen, in einem Scharnir laufenden Deckel.

In Le Locle waren zwei Abendmahlkannen in Glockenform im Gebrauch und sie sind wohl einzig in ihrer Art. Hals und Ausguss haben die gleiche Konstruktion wie die Bulgen. Auf dem Deckel sitzt als Griff ein doppelschwänziges Meerweibchen. An der Vorderseite der Kannen befindet sich das Wappen von Le Locle und die Jahrzahl 1706, mit den ein- 
gravirten Buchstaben C L. Der Deckel besitzt das Meisterzeichen von Jean-Jacques Châtelain von Neuenburg ( 1704 zünftig, 1733 gestorben). Die Kannen hatten ebenfalls bewegliche Traghenkel. (Tafel XII, 2.)

Die Abendmahlkannen von Saint-Blaise haben die typische Form der Neuenburgerkannen; nur ist der Deckel hoch-kuppelförmig, mit einem Knopf in der Mitte. Neben dem gewöhnlichen festen Henkel besitzen beide Kannen noch einen beweglichen, eisernen. Das Meisterzeichen mit den Initialen I.F.P gehört wahrscheinlich dem Jean François Perrin (1 728 zünftig, 1748 zuletzt erwähnt). (Tafel XII, 3.)

Die Genfer Abendmahlkannen ' besitzen in Form und Aufbau einen ausgesprochen savoischen Charakter und sie sind heute noch im Gebrauch der Eglise Nationale Protestante. Von den drei Prachtkannen stammen zwei aus der Werkstatt von Léonard Bourrelier (1639 bis 173o) und eine von Pierre Bourrelier (1720-1769).

Das erste Exemplar besitzt einen mächtigen ovoiden Korpus, an welchem hinten ein beweglicher Ring, zum Heben beim Einschenken, angelötet ist. Der relativ kurze, bogenförmige Ausguss hat ganz den Typus der Savoyer-Kannen. Neben dem festen Henkel besitzt die Kanne noch einen beweglichen, welcher in zwei Scharniren läuft. Höhe der Kanne $41 \mathrm{~cm}$. (Tafel XIII, 1.)

Eine zweite, gleich hohe Kanne zeichnet sich durch ihre elegante Form aus. An der Vorderseite des ovoiden Korpus befindet sich ein aufgelöteter Schild mit dem Wappen der Stadt Genf. Der enge Hals erweitert sich oben stark und trägt einen grossen, halbkugligen Deckel. Die Scharnire des eigenartig gebogenen Traghenkels sind oben am Kannenrand angelötet und werden von unten durch zwei profilirte Säulen gestützt, welche dem Korpus aufsitzen. Der gebogene Ausguss ist prismatisch und sehr dick. (Tafel XIII, 2.)

Eine dritte, $50 \mathrm{~cm}$ hohe Kanne, besitzt einen niedrigen, breiten Fuss. Der Mantel des ovoiden Korpus ist in prismatische Flächen gebrochen. Vorne ist der Genfer-Schild angelötet, hinten ein beweglicher Ring zur Erleichterung des Einschenkens. Der kurze Ausguss ist der gleiche wie bei den Savoyerkannen, eine gebogene, vorn knollig verdickte Röhre. Der Traghenkel hat die gleiche Form und einen ähnlichen Unterbau wie die vorige Kanne. Sie trägt die Jahrzahl 1759. (Tafel XIII, 3.)

Die Abendmahlkannen in Lausanne. Die Pfarrei St-François und Saint-Laurent besitzen mächtige, $42-43 \mathrm{~cm}$ hohe Kannen. Auf dem sechsseitig-prismatischen Korpus ist ein massiver Schild aufgelötet. Bei den Kannen von St-François besteht der Ausguss in einem Schwanenhals mit Kopf, welcher dem Korpus entsteigt. Die Kannen von Saint-Laurent haben einen schnabelförmigen Ausguss. Hals, Ausgussteil und Deckel sind bei beiden Kannenformen gleich wie bei den gewöhnlichen Lausannerkannen. Neben dem festen Handgriff besitzen die Kannen noch einen beweglichen, zinnernen Traghenkel, welcher in seitlichen Oesen läuft. Die Kannen tragen das Meisterzeichen von Frédéric Reuchlin von Lausanne ( 75 g Bürger in Prilly) mit der Jahrzahl 1773. - Abendmahlkannen ähnlicher Formen findet man in sehr vielen Kirchen des Waadtlandes. (Tafel XIV, 1, 2.)

In Payerne befinden sich vier ähnliche Kannen; doch besteht der Korpus aus einem Pyramidenstumpf. Weder Meistermarken, noch Bodenrosetten sind zu finden (Mitteilung von Herrn F. Herrmann, Holzbildhauer in Yverdon).

In Grandson weisen die Abendmahlkannen ein ähnliches Meisterzeichen auf wie Nr. 531 (Bd. I). An der Hand eines ausgestreckten Armes hängt eine Waage. Zwischen den Waagschalen befinden sich aber andere Initialen, nämlich D.S (D. Savioz) und darunter die Jahrzahl 1725 (Mitteilung von Herrn F. Herrmann, Holzbildhauer in Yverdon). Der Zinngiesser D. Savioz findet sich im Text über Grandson. Die Kannenform entspricht dem Waadtländer Typ II ; nur ist der Korpus der Kanne im Verhältnis sehr hoch. (Tafel XV, 4.)

${ }^{\prime}$ Die Bilder der Tafeln XIII und XIV, 1-2, verdanke ich dem Entgegenknmmen von Iferrn Ernest Naf in Genf. 
Die Form der oben erwähnten Abendmahlkannen von Lausanne und Payerne findet sich in zahlreichen andern Pfarrkirchen des Kantons Waadt. Anlässlich einer Ausstellung in Lausanne ${ }^{1}$ waren eine grössere Anzahl ausgestellt (im Jahre 1930).

Auf Tafel XV befindet sich eine Auswahl interessanter Abendmahlkannen aus der Gegend von Yverdon und Umgebung. Durch die gütige Mithilfe von Herrn F. Herrmann, Holzbildhauer in Yverdon, erhielt ich die Photos, Angaben und Maasse. Die Beschreibung der einzelnen Kannen ist bei dem betreffenden Zinngiesser zu finden.

\section{Die Formen der gebräuchlichen Zinnkannen}

Auffallend ist vor allem, mit welcher Zähigkeit in der Schweiz an den Altformen festgehalten wurde. Wohl vierhundert Jahre lang ist die Form der Genfer-Walliser Kanne die gleiche geblieben; die Glockenkannen und Stitzen finden sich schon auf Stichen des XV. und XVI. Jahrhunderts; die gleichen Formen sind noch im Anfang des XIX. Jahrhunderts in Gebrauch. Die Berner Kannen in der Kirche von Biel sind von Peter Baumgarter (getauft 1550 , erwähnt bis 1581 ) und noch um 1820 wurden in Bern Stegkannen gegossen.

Auch im XVIII. Jahrhundert fanden die französischen Stilarten bei den Zinngiessern nur sehr langsam Eingang. Es gab auch in den Städten der französischen Schweiz nur vereinzelte Meister, welche bei den Kannen die Formen des Barok, des Louis XV., XVI., und des EmpireStiles anwandten. Eher war dieses bei Tellern und Platten der Fall. Auch in Basel, Bern und Zürich finden sich solche Gegenstände und dieselben sind im Text bei den betreffenden Meistern zu finden. Weitaus der grösste Teil des noch erhaltenen Materials in fremden Stilarten stammt aus dem Auslande. Besonders häufig sind Meisterzeichen von Strassburg, Frankfurt, Paris und London; auch aus Böhmen und Venedig wurden solche Sachen herein gebracht.

Als Haupttypen schweizerischer Zinnkannen, welche im täglichen Gebrauche waren, unterscheide ich folgende Formen. Dieselben halten sich an bestimmte Landesgegenden.

Die zentral- und nordostschweizerische Gruppe :

die Glockenkanne;

die Stitze;

die prismatische Kanne.

Die nordwestschweizerische Gruppe: (Basel, Solothurn und Freiburg):

die Stitze;

die Rundele;

die Freiburger Kanne.

Die Berner Gruppe: (Bern, der Aargau und Neuenburg):

die Stegkanne, Typ. I ;

die Kanne ohne Steg, Typ. II ;

die von Bern beeinflussten Formen der Waadtländer Kannen;

die Neuenburger Kanne.

Die südwestschweizerische Gruppe (Genf, Wallis und Waadt) :

die Genfer Kanne, Typ. I und II ;

die Walliser Kanne, Typ. I, II und III;

die Waadtländer Kanne, Typ. I und II.

\section{Die Glockenkanne}

Wie schon der Name sagt, ist die Grundform dieser Kanne ähnlich derjenigen einer Glocke. Je nach dem Verhältnis der Höhe zum Durchmesser, je nach der Ausladung des untern Teiles, gibt es bei der Glockenkanne viele Varietäten. Im Allgemeinen sind alle schwer und massig. Diesem Uebelstand versuchten die Zinngiesser schon frühe entgegenzutreten. Um

\footnotetext{
'Chappuis Robert, Catalogue de l'Exposition d'objets de culte à la Cathédrale de Lausanne, 1930.
} 

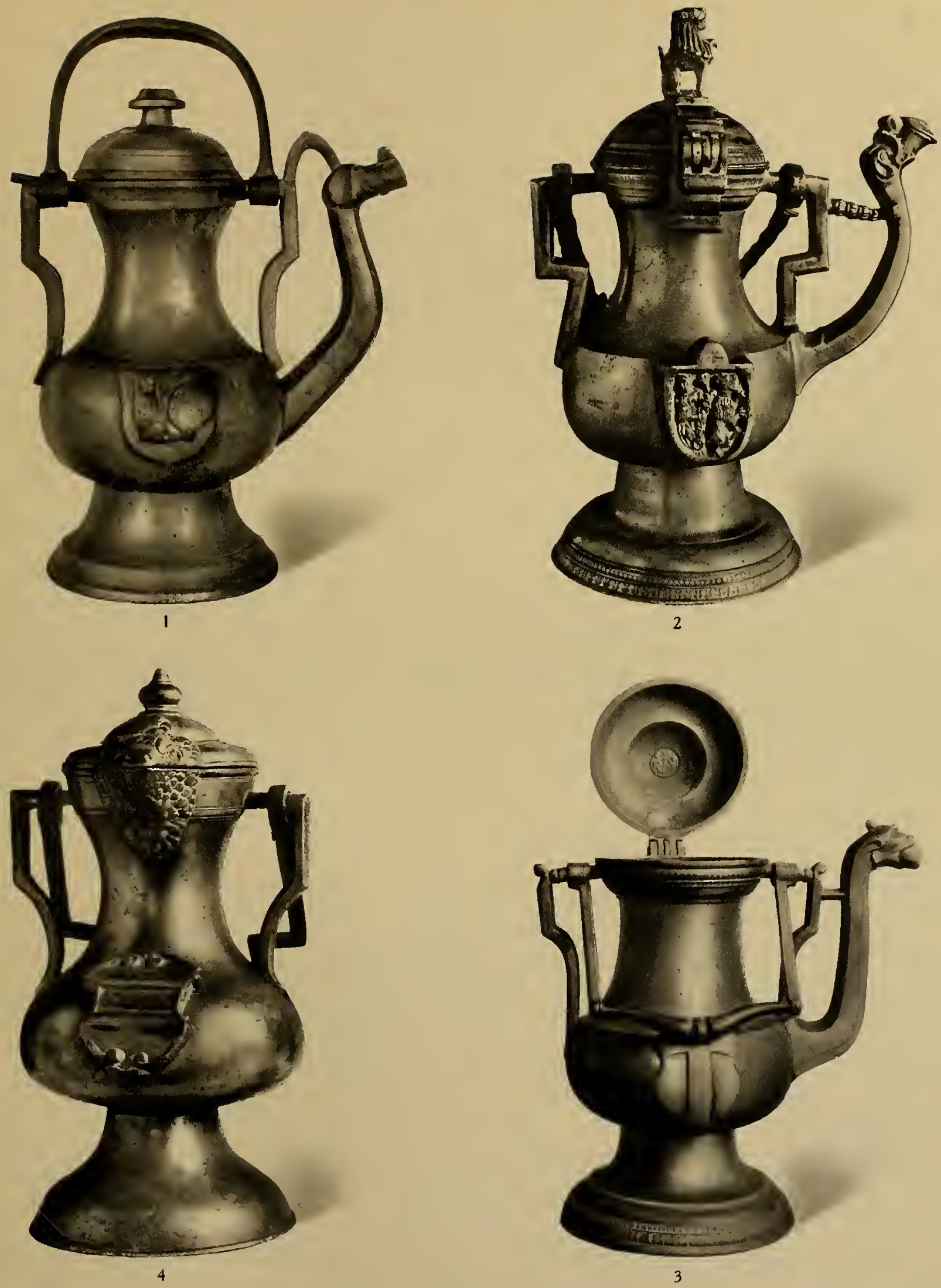

1. Kanne von Aeschi, ca. 1500 (Text S. 35), Höhe 48 cm. 2. Kanne von Frauenfeld, Ende des XVI. Jahrhunderts (Text S. 36). Höhe $40,5 \mathrm{~cm}$. 3. Kanne von Baden, Ende des XVI. Jahrhunderts (S. 36) von Falk, Höhe $41 \mathrm{~cm}$. 4. Kanne von Zug. von Carl Schönbrunner, 1625-57 (Seite 37), Höhe 40,5 cm. 


\section{.}


Einteilung und Gliederung in die glatte Wandung zu bringen, wurden reifenförmige circuläre Wülste (die Weidenreifen der Holzgefässe ?) oder gravirte Rillen angebracht. An der rechten Kannenseite wurde fast ausnahmslos ein kleiner Schild aufgelötet, welcher mit seinen Initialen, Wappen und Jahrzahlen ebenfalls ein wenig zur Dekoration beiträgt. Etwas oberhalb der Kannenmitte setzt die kurze, sechskantige Ausgussröhre an, welche schräg aufwärts bis über die Höhe des Randes führt. Unten sitzt dieselbe mit breiter Basis und scharf begrenzt auf der Wand der Kanne. Das obere Ende der Ausgussröhre trägt ein Scharnir, in welches ein kleines, flaches Deckelchen eingreift; darauf befinden sich meistens die Meisterzeichen. $\mathrm{Ab}$ und zu wurden dieselben auf dem Kannendeckel angebracht. An der Innenseite des Kannenbodens sitzt oft eine Bodenrosette oder ein Wappen in Reliefguss. Die obere Oeffnung der Kanne ist kreisrund und hat an den beiden Seiten (oft auch nur an einer Seite) einen kleinen rechteckigen Ausschnitt zum Einsetzen des Deckelverschlusses, Bajonetverschluss. Der kreisrunde Deckel trägt in seiner Mitte, auf einem konischen Ansatz aufgelötet, einen grossen, senkrechtstehenden Ring, welcher als Handgriff und Träger zugleich dient. Bis zum Jahre 1700 war der Bajonetverschluss der einzige übliche. Nachher kommt häufig der Schraubenverschluss oder Gewindeverschluss zur Anwendung. In den katholischen Gegenden dienen die Glockenkannen heute noch zur Aufbewahrung des Weihwassers und werden jeweilen am Feste der heiligen drei Könige (6. Januar) zur Segnung auf den Altar gestellt. (Tafel XVI, 1.)

Die gebräuchlichsten Grössen der Glockenkannen entsprechen einem Inhalt von 3, 2, 1, $1 \%$ und $1 / 4$ alte Maass (1 Maass = 1,8 Liter). Wir finden dieselben im Gebiet der heutigen Kantone Zürich, Luzern (Uri, Schwyz, sehr selten), Obwalden, Glarus, Zug, Schaffhausen, Appenzell (selten), St. Gallen, Graubünden (nur ein Exemplar bekannt), Aargau, Thurgau.

Die Schaffhauser Glockenkannen besitzen einen hohen Gefässkorpus, die St. Galler Exemplare den niedrigsten und gedrungensten.

Ziemlich selten findet man Glockenkannen ohne Ausgussröhre, z. B. von Zofingerund Schaffhausergiessern. Dieselben haben den Schraubenverschluss. An Stelle der Tragringes befindet sich ein beweglicher, umlegbarer Henkel. Diese Gefässe dienten zur Aufbewahrung von Honig, Oel, Salben u. dgl. und stammen aus dem XVIII. Jahrhundert. (Tafel XVI, 2 ; XXXII, 10-12.)

Als Puppenzinn findet man Kännchen von $5-6 \mathrm{~cm}$ Höhe.

\section{Die Stitze}

Die Stitze ist eine Kanne mit einem cylindrisch-kegelförmigem Korpus. Meistens erweitert sich derselbe wieder ein wenig gegen den obern Rand. Je nach den verschiedenen Orten kommen kleine Variationen vor, welche aber auf das elegante Aussehen der Form von grossem Einfluss sind. So haben die Basler Stitzen einen langen cylindrischen Teil am Korpus und sehen infolgedessen schlanker aus als die gedrungenen Zürcher und Zuger Exemplare. Die Zofinger Stitzen haben oft in der Mitte eine ringförmige Ausbuchtung, einen circulären Wulst. Die definitive Entscheidung der Provenienz bringt aber nur die Meistermarke, welche sich entweder auf dem Henkel oder auf dem Deckel befindet. Je nach der Form des Ausgusses und des Deckels zerfallen die Stitzen in zwei Unterarten, die Schnabelstitzen und die Stitzen ohne Ausgusschnabel. (Tafel XVI, 3, 4.)

Die Schnabelstitze besitzt einen extra gegossenen, entenschnabelförmigen Ausguss, welcher an seiner Unterseite verschiedenartige Einkerbungen aufweist. Der Deckel ist flach kuppelförmig, besitzt vorn einen herzförmigen, den Ausguss deckenden Ansatz und greift in einen Falz des Kannenrandes ein. Bei der Solothurner Bartmannstitze wird der Ausguss durch ein bärtiges Mannsgesicht (Maskaron) gebildet, welches in die Kannenwandung ausläuft. Die Form des Korpus ist vollständig kegelförmig; eine cylindrische Partie fehlt und damit hat die Solothurner Stitze eine völlig eigenartige Form, welche dieselbe von allen andern Stitzen unterscheidet. 
Die Stitze ohne Ausgusschnabel hat oben eine herzförmige Oeffnung, welche dadurch entstanden ist, dass die ursprünglich kreisförmige Oeffnung vorne seitlich zusammengedrückt wurde (wie bei der Walliser und Genfer Kanne). Der ebenfalls herzförmige Deckel liegt dem Kannenrande, welchen er überragt, einfach auf.

Alle Stitzen tragen den Charakter schlichter Einfachheit und weisen nur wenige dekorative Momente auf. Ab und zu trägt der Deckelgriff einige spärliche Verzierungen (Engelköpfe, Akanthusblätter). Auf der Mitte des Deckels sitzt bald nur ein einfacher Knopf, bald eine kleine Traube oder Eichel. Der Kannenleib ist meistens ganz glatt; nur eingravirte circuläre Linien bezwecken eine Andeutung leichter Gliederung. Selten zieren feine ornamentale Gravuren den langen Korpus. Grosse Seltenheiten sind die Maskaronstitzen von Zofingen und Burgdorf mit circulären Ornamentbändern in Reliefguss. An der Innenseite des Kannenbodens befindet sich fast stets eine Rosette oder ein Stadtwappen in Reliefguss. Die Qualität der Legierung ist bei den Stitzen der Innerschweiz oft eine miserable. In den Zuger Ratsprotokollen und in den eigenössischen Abschieden finden sich oft diesbezügliche Reklamationen und (niemals ausgeführte) Strafbestimmungen.

Der Inhalt der Stitzen variirt von 3 Maass bis zu $20 \mathrm{~cm}^{3}$; doch waren die üblichen Grössen 2, 1, 1/2 und 1/4 Maass. Die kleinsten Stitzen waren Messkännchen oder Puppenzinn; die grössten Exemplare findet man bei den Basler und Schaffhauser Stitzen.

Vorkommen: Im Gebiete der heutigen Kantone Zürich, Luzern, Schwyz, Ob- und Nidwalden (sehr selten), Glarus, Zug, Solothurn, Basel, Schaffhausen, St. Gallen (selten), Graubünden, Aargau.

Die sogenannten "Engadiner Stitzen " sind Produkte von Augsburg und sind auf dem Handelswege ins Bündnerland gekommen. Sie waren in Graubünden besonders beliebt, speziell aber im Engadin.

\section{Die prismatischen Kannen}

Weitaus in den meisten Fällen handelt es sich um sechsseitige Kannen; die siebenseitigen sind sehr selten; achtseitige findet man an häufigsten im Bündnerlande, seltener in Stein am Rhein oder in Zug.

Die sechsseitige Kanne, ab und zu "Schraube " genannt, ist ebenso verbreitet wie die Glockenkanne. Bei den hohen Exemplaren ist die Form eher gefälliger als bei den niedrigen. Die Grundform bildet ein senkrecht stehendes, sechsseitiges Prisma, welches meistens auf einem niedern, verschieden profilirten Fusse steht. Während derselbe bei den einfachen BauernKannen oft fehlt, hat derselbe bei den schönen Stücken eine weite Ausladung. Oben schliesst das Prisma mit einer sechsseitigen horizontalen Platte ab, welche ein starkes Gewinde von 4-6 Schraubengängen trägt. Der Ausguss ist genau derselbe wie bei der Glockenkanne; er setzt sich einer Kante an. Die obere Oeffnung ist entweder mit einem Deckelchen verschlossen oder ebenso häufig vermittelst eines Schraubenkopfes, welcher durch eine kleine Kette an der Ausgussröhre festgemacht ist. Infolgedessen kann derselbe nicht zu Boden fallen oder verloren gehen. Der kreisrunde Deckel zeigt inwendig das negative Gewinde zum Verschluss der Kanne und trägt auf einem verschieden hohen und geformten Halse den angelöteten, senkrecht stehenden Ring, gleich wie bei der Glockenkanne. Weil das Gevinde oft hermetisch schliesst, so findet man oft am Deckel ein kleines Loch, welches das Eintreten der Luft gestattet und so ein Ausschenken des Inhaltes ermöglicht. Die Zinnstempel befinden sich entweder auf dem Deckelchen der Ausgussröhre, oder aber an der Oberseite der Kannendeckels. Die prismatischen Kannen stammen eher aus späterer Zeit als die Glockenkannen. Immerhin findet sich auf Tafel 389 des Luzerner Schilling (1513) in der Hand der Marketenderin schon eine prismatische Kanne. (Tafel XVI, 5.)

Die prismatischen Kannen besitzen nur selten einen seitlich aufgelöteten Schild. Auch ist die Dekoration durch Gravuren meist sehr spärlich. Allein auch hier gibt es Ausnahmen; es gibt Churer und Elgger Exemplare, welche vollständig mit Gravuren überzogen sind. 
Eine besonders schöne Abart der sechsseitigen Kanne bilden die Churer Kranzkannen von Heinrich Wilhelm Lange. Derselbe benutzte als Vorbild eine Kanne von H. de Cadenath; allein er baute diese Idee selbstständig aus. Der untere Teil des Kannenleibes ist nach allen Seiten breit ausgeschweift und ruht auf einem weit ausladenden Fuss. Derselbe und auch den Ansatz der Ausgussröhre ist mit stilisirten Akanthusblättern in Reliefguss überzogen und bildet so den (Blätter-) Kranz. Bei den grossen Exemplaren ist auf der rechten Seite ein ziemlich grosser ovaler Schild aufgelötet, welcher durch Ornamente in der Form von Ranken und Weintrauben reich geschmückt ist. Die Ausführung und die Qualität des Materials dieser Kannen ist durchwegs von erster Güte. Die Zinnstempel befinden sich sowohl auf dem Deckelchen der Ausgussröhre wie auf der Unterseite des Kannenbodens. Dass die Kranzkannen sehr gesucht sind und hoch im Preise stehen, bedarf wohl keiner Erklärung. (Tafel XXXIV und XXXV.)

Nach dem Tode Langes kaufte der Zuger Zinngiesser Joachim Michael Keiser, circa 1850, dessen Geschäft und damit auch die Modelle. Er verfertigte nun auch in $Z \mathbf{u g}$ einige Kranzkannen und schlug seinen eigenen Zinnstempel auf. Ich konnte nur drei Exemplare ausfindig machen, davon eines mit Schraubenverschluss der Ausgussröhre (siehe unter Zug). (Tafel XXXV, 1.)

Besonders häufig in der Ostschweiz und in Schaffhausen trifft man neben den Kannen noch prismatische Gefässe ohne Ausgussröhre. Sie dienten zur Aufbewahrung von dickflüssigen Substanzen (Rüböl, Leinöl, Honig, etc.), auch zu kirchlichen $Z$ wecken. Die kleinsten Vertreter dieser Art dienten, mit heissem Wasser gefüllt, als Einlagen und Wärmespender in den Pelzmuffen der guten alten Zeit. (Tafel XXXII, 8, 9, 13, 14.)

Die gebräuchlichsten Grössen waren ähnliche wie bei den Glockenkannen, entsprechend einem Inhalte von 3, 2, 1 und 1/2 alte Maass. Die ganz grossen Exemplare besitzen oberhalb des Bodens einen beweglichen Ring, welcher das Einschenken der schweren vollen Kanne erleichtern soll.

Die prismatischen Kannen findet man im Gebiet der heutigen Kantone Zürich, Luzern, Zug, Aargau, Thurgau, Schaffhausen, St. Gallen, Appenzell, Graubünden und Basel (nur prismatische Gefässe ohne Ausgussröhre).

\section{Die Rundle}

In der Schweiz fand diese Kannenform nur wenige Anhänger; am meisten noch in $\mathrm{B}$ a sel. Hier findet man dieselbe neben der Stitze ziemlich häufig, immerhin in viel geringerer Anzahl als die Stitzen. Auf einem Holzschnitt Jost Ammanns, "der Kandelgiesser ", aus dem Jahre 1568, figurirt diese Kannenform ebenfalls. (Tafel XVI, 7, 8.)

In Solothurn ist die Rundle ziemlich selten zu finden; dieselben stammen von Urs Jaus (erwähnt 1688; gestorben 1731) und Joseph Graff (1685-175o) und auch andern Meistern.

Die Form : Auf einem runden niedrigen Fuss mit starker Einziehung sitzt der bauchige ovoide Korpus und läuft oben in den dicken kurzen Hals aus, welcher sich seinerseits nach oben etwas erweitert. Als Ausguss dient ein verschieden profilirter Schnabel, wie bei den Stitzen. Der geschweifte Handgriff trägt oben ein Scharnir, in welchem der Deckel läuft. Es gibt zweiverschiedene Deckelarten. Meist hat derselbe die Form einer flachen Kuppel, tvelche vermittelst einer senkrecht hängenden Platte in die Kannenöffnung eingreift; vorne ist ein herzförmiger Ansatz zum Verschluss des Ausgusschnabels. Die Oberfläche des Deckels trägt in der Mitte nur selten einen Knopf oder eine Traube; meist ist sie glatt und leer. Die Oberfläche der Kanne ist fast immer glatt; nur am Halse finden sich einige circuläre Rillen. Vorne am Bauche sind oft Initialen, Jahrzahlen, Embleme (Metzerbeil, Bretzeln) angebracht, aber nur in Gravur. In den Rundeln fehlen die Bodenrosetten gänzlich. Der Deckelgriff ist abgekröpft und nach rückwärts gebogen.

Wie bei den prismatischen Kranzkannen, so gibt es auch unter den Basler Rundeln Exemplare, welche am Fuss, am Kannen- und Deckelrand ein reliefirtes Akanthusblatt- 
fries aufweisen. Am Ausgusschnabel befindet sich als eigenes Architecturstück ein fächerförmiger Perlstab.

Auch bei den meist ganz glatten Solothurner Rundeln gibt es seltene Exemplare, deren glatte Leibung durch circuläre Perlstäbe gegliedert wird. Sehr selten sind ferner Rundeln von Solothurn, deren Ausgusschnabel durch den bärtigen Mannskopf (wie bei den Maskaronstitzen) gebildet wird.

Die Basler Rundeln unserer Sammlung stammen von den Meistern : Samuel Burckhardt, 1613-1689; Niklaus I Uebelin, 1648-1722; Simon Grynaeus, 1664-1726; Hans Jakob Wetzel, 1680-1738; Johannes II Linder, 1698-1769; Lukas Wick, 1700-1765; Hans Jakob Grynaeus, zünftig $1723-1753$.

Die Grössen varïren von $18 \mathrm{~cm}$ bis $37 \mathrm{~cm}$ Höhe, entsprechend einem Inhalt von $1 / 2$ bis 4 alte Maass $(4,3,2,1,1 / 2$ und $1 / 4$ Maass).

\section{Die Freiburger Kanne}

Der Korpus hat die Form eines steilen Kegelstumpfes, welcher oben mit einem zirkulären Wulst und Rillen abschliesst. Daran fügt sich der gerade cylindrische Hals, der sich bei einigen Meistern gegen den Rand hin ein wenig erweitert. Der Ausguss ist gleich konstruirt wie bei den Stitzen. Entweder ist derselbe schnabelförmig, wobei der Schnabel über den Wulst hinab bis in den Korpus hineinreicht; oder aber kommt der Ausguss durch Zusammenpressen der runden Oeffnung in eine herzförmige zustande. Bei letztern steigt der obere Kannenrand gegen den Ausguss hin in die Höhe. Der kurze Henkel trägt oben das Scharnir für den Deckel. Der Deckeldrücker ist oft nach hinten abgekröpft und glatt; ab und zu sind auch Eicheln oder ein Akanthusblatt als Deckelgriff vorhanden. Der Deckelsteg ist meist gewellt (wie bei Lausanner Kannen) Bei den Schnabelkannen ist der Deckel flach kuppelförmig und trägt in der Mitte einen gerillten Knopf, einen kleinen Delphin u. dgl. Bei der andern Form liegt der herzförmige Deckel dem Kannenrand glatt auf, indem er denselben gleichzeitig überragt. Oft ist er schön gravirt. Die Meistermarken sind entweder auf dem Deckel oder am Traghenkel. Eigentümlicherweise durfte nur gute Qualitätsware in Freiburg gestempelt werden; daraus erklärt sich die grosse Menge ungestempelter Krüge und Kannen. Meistens fehlt eine Bodenrosette. (Tafel XVI, 11, 12.)

Die Dekoration der Kanne ist sehr spärlich. Circuläre Rillengruppen, kleine Wülste, ein profilirter Stab am Fusse der Kanne, eingravirte Initialen, Jahreszahlen, Wappen sind die einzigen Verzierungen.

Als Seltenheit sei eine $34,7 \mathrm{~cm}$ hohe Kanne erwähnt, deren Korpus durch einen steilen, sechsseitigen Pyramidenstumpf gebildet wird. Der kuppelförmige, sechsseitige Deckel trägt einen grossen Knopf. Der Schnabel läuft über eine Kante. Am Henkel befindet sich das Meisterzeichen Nr. 619 (Bd. I). Durchmesser des Fusses 19,2 cm. (Tafel XLI, 4.)

In Neuenburg verfertigte Jonas Huguenand (erwähnt von 1666-1688) ebenfalls einige Kannen in reinster Freiburgerform; dieselben sind mit datirten Meistermarken versehen, z. B. 1666,1686 .

Die Freiburger Kannen variiren in der Höhe von 13,5 bis $30,5 \mathrm{~cm}$ bei den Schnabelkrannen, und von $14,5 \mathrm{~cm}$ bis $34 \mathrm{~cm}$ bei der Flachdeckel-Form. Der Inhalt beträgt $1 / 8$ bis 2 Maass. Schnabelkannen von $1 / 2$ und $1 / 4$ Maass Inhalt sind sehr selten.

\section{Die Stegkanne.}

\section{Die Berner Kannen}

Auf dem runden, niedrigen Fuss sitzt der zwiebelförmige, schlanke Korpus, welcher oben in den langen Halsteil ausläuft. Letzterer bildet oben eine konische Erweiterung und eine kreisrunde Oeffnung. Diese ist aber bedeutend kleiner als der Querschnitt des Kannenleibes. An der Uebergangsstelle des Leibes in den Hals bemerkt man als charakteristische Eigenschaft 


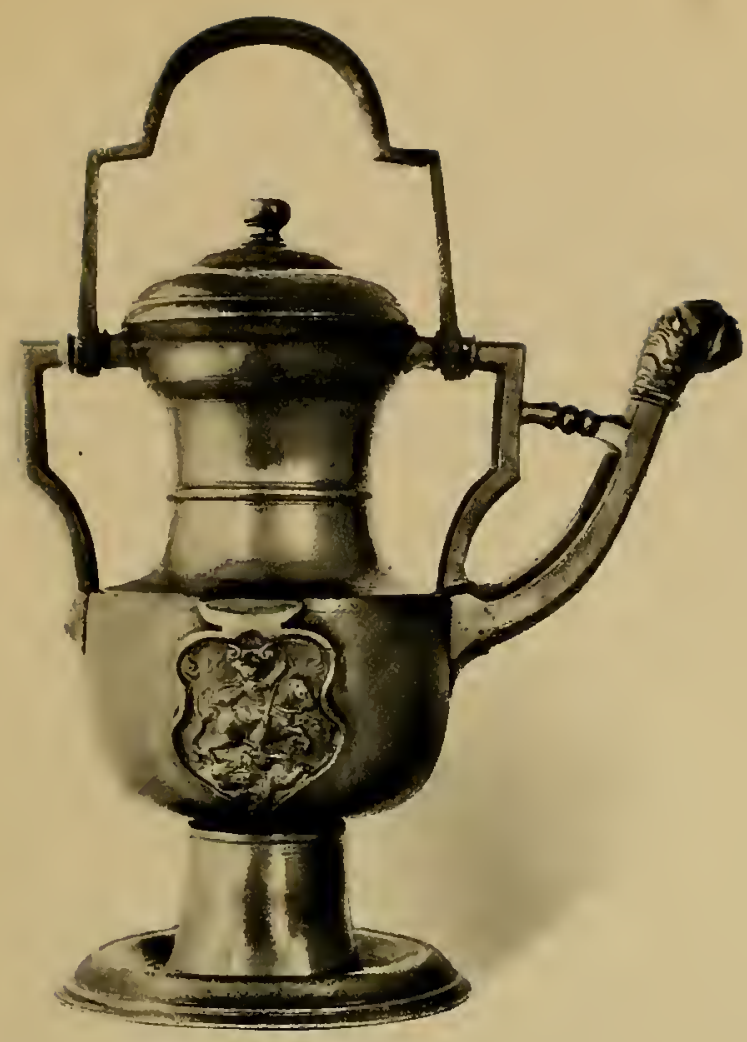

I

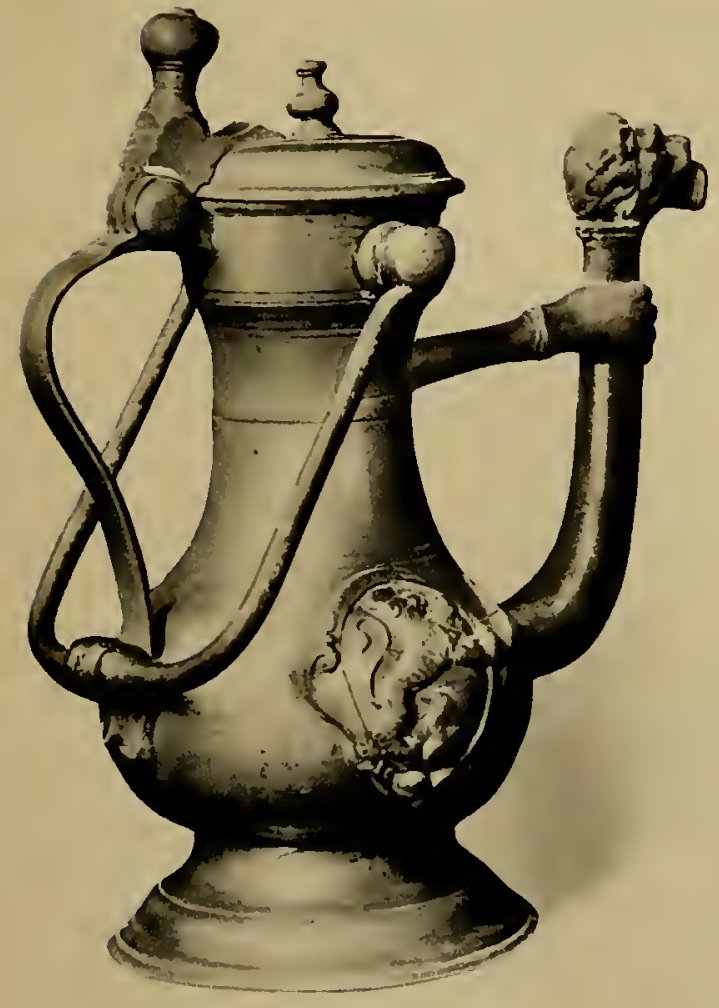

3

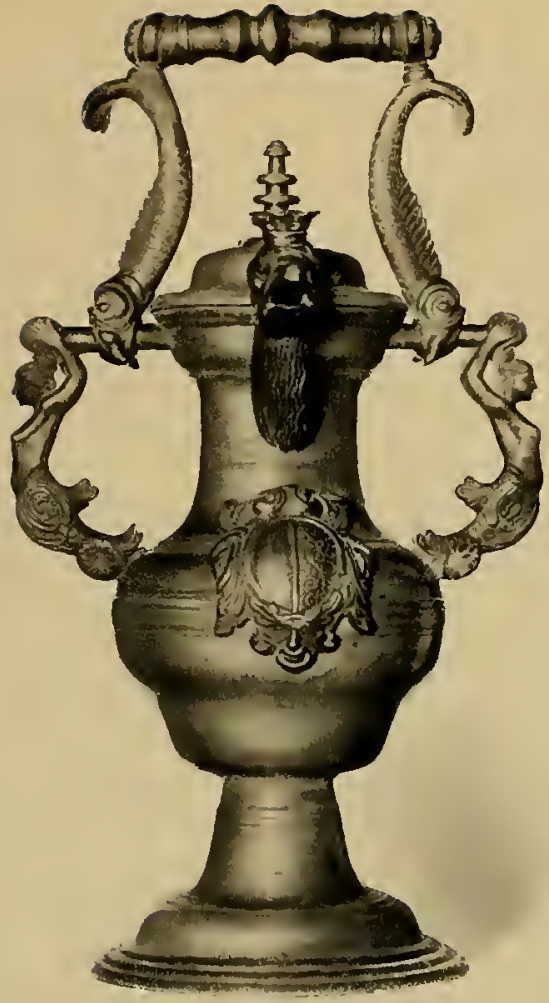

2

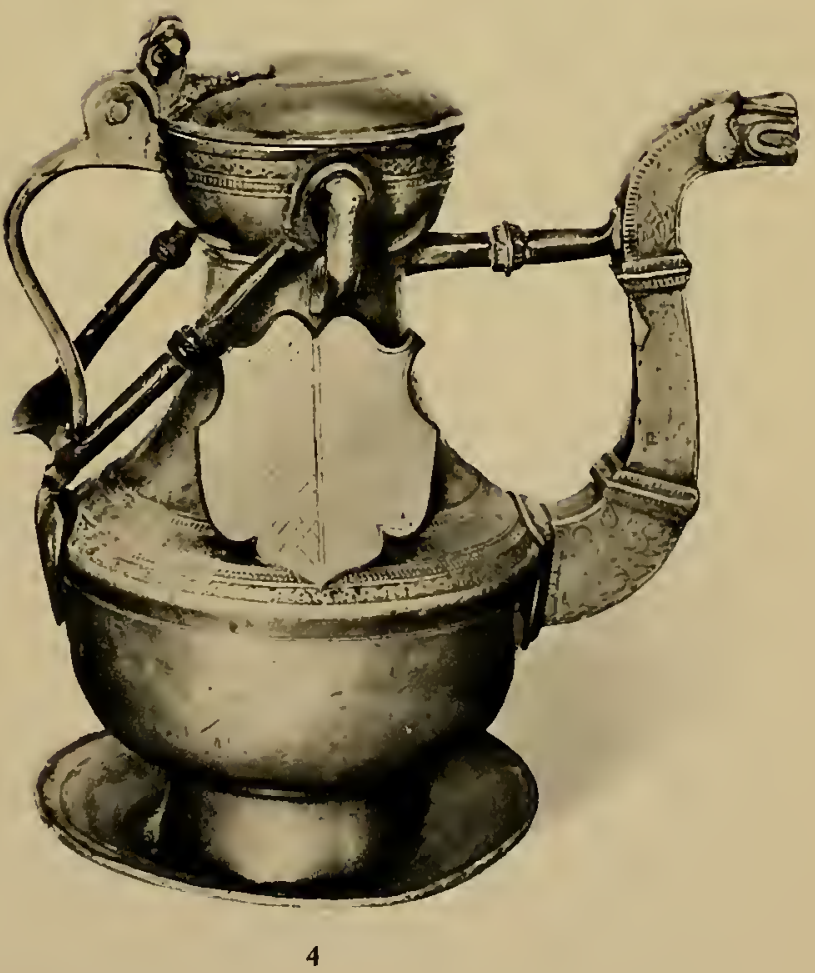

1. Kanne von Stein am Rhein, von Felix Schmid, datirt 1655 (Text S. 37), Höhe $40,5 \mathrm{~cm}$. 2. Kanne von Luzern, von Caspar Traber, erwähnt 1663-1710 (Text S. 37), Höhe $56 \mathrm{~cm}$. 3. Kanne von Murten, von Pierre Villeneufve, erwähnt 1674- ca. 1700 (Text S. 37), Höhe 41 cm. 4. Kanne von Payerne, von ?, ca. 1700 (Text S. 37), Höhe $38,5 \mathrm{~cm}$. 

vier bis fünf parallele, wellenförmige Rippen und in der Mitte des Halses einen ringförmigen, flachen Wulst. Auf dem Korpus befinden sich häufig prachtvoll gravirte Wappen, Blumenranken, Widmungen der Stifter und Jahreszahlen. Das Hauptmerkmal der Stegkanne ist aber die Ausgussröhre. Dieselbe ist sechsseitig-prismatisch und oben durch ein zierliches Deckelchen verschlossen. Sie setzt sich mit ihrem untern Ende, in verbreiterter Basis, in der Mitte des Kannenleibes an und steigt schräg aufwärts bis zur Höhe des Kannenrandes, indem sie sich ein wenig verjüngt. Das obere Ende steht also weit von der Kanne ab und würde bei jeder Gelegenheit verbogen oder beschädigt, wenn es nicht vermittelst eines Querbalkens mit dem obern Teile der Kanne verbunden wäre. Dieses Verbindungsstück heisst Steg und ist nicht horizontal angebracht, sondern steigt gegen die Kanne an. Die Form des Steges ist sehr manigfaltig; er bildet die hauptsächlichste, gegossene Dekoration der Kanne. Bald bildet er einen ausgestreckten Mannsarm im Puffärmel, bald einen schlanken Damenarm im eng anliegenden Kleide; häufig ist der Steg mit Akanthusblättern überzogen; ab und zu besteht er nur aus einem prismatischen oder profilirten Stab, der vorn sich aufrollt. Oft umfasst eine geöffnete zierliche Hand die Ausgussröhre. Der $\mathrm{Henkel}$ hat eine eigentümlich geschweifte Form und trägt oben das Scharnir für den Deckel. Derselbe ist kuppelförmig, bei frühen Exemplaren sehr flach und passt vermittelst einer senkrecht hängenden Platte in den Kannenrand. Der Verschluss ist infolgedessen ein viel vollkommener als beim blossen Aufliegen des Deckels. Auf der Mitte des Deckels sitzt ein verschieden profilirter Knopf, oder eine Eichel und nicht selten ein kleiner Mohrenkopf (Ende des XVIII. Jahrhunderts). Als Deckelgriff dient ein vollrund-gegossenes Akanthusblatt; oft ist nur ein glatter, nach hinten abgekröpfter Drücker vorhanden. Die Meisterzeichen befinden sich meistens auf dem Deckel, seltener am Handgriff. Auf den Schützenkannen wurde stets ein-oder zweimal das Bild eines kleinen Gewehres eingeschlagen. (Tafel XVII, x.)

Stegkannen findet man, ausser in Ber $\mathrm{n}$, auch häufig in Thu $\mathrm{n}$, selten in Biel. In Burgdorf und Neuenstadt fand ich keine. Dagegen waren dieselben in Z ofingen und A ara sehr beliebt, während mir aus Solothurn nur zwei Exemplare bekannt sind; ebenso selten ist diese Kanne in Obwalden. Unter dem Einflusse Berns wurden auch in Lausanne und in Vevey Stegkannen hergestellt, allerdings unter Beibehaltung der waadtländischen Gefässform. Als grosse Seltenheit erwähne ich eine Stegkanne von Orbe im Jura. Dieselbe besitzt, nebst einer sehr originellen Ausgussröhre und einem ganz aparten Steg, einen beweglichen zinnernen Traghenkel. (Tafel XVII, 3, 4.)

Die Stegkannen kommen nur in drei Grössen vor, entsprechend dem Inhalt von 2, 1 und $1 / 2$ alten Maass. Die grössten Exemplare finden sich fast nur als Abendmahlkannen, während die Kannen von einer und $1 / 2$ Maass Inhalt im täglichen Gebrauche waren.

\section{Die Berner Kanne obne Ausgussröhre.}

Die Berner Kanne ohne Ausgussröhre ist ebenso häufig wie die Stegkanne. Die Gefässform ist vollständig die gleiche, doch mit den gleichen, von Ort zu Ort wechsclnden Besonderheiten. So kann man den Uebergang der Berner- zur Neuenburgerform über Biel und Neuenstadt sehr gut verfolgen. Interessant ist ebenfalls die Wanderung gewisser Ornamente. Auf dem Deckeldrücker der Augsburger Kannen findet man häufig einen reliefirten, geflügelten Engelkopf. Dieses Ornament wanderte mit den Zinngiessern nach Schaffhausen und über Zofingen, Solothurn, Biel bis nach Neuenstadt, um hier definitiv aufzuhören. Desgleichen wanderte der mit einem Reliefband geschmückte Henkel von Aarau über Zofingen, Solothurn, Biel bis nach Neuenstadt. Die Grössen dieser B erner Ka nnen entsprechen einem Inhalt von 2, $11 / 2,1 / 4$ und selten sogar $1 / 8$ Maass (ein halbes Quärtchen).

Die Beschreibung der kleinen Eigentümlichkeiten lokaler Natur befindet sich bei den einschlägigen Giesser-Orten. (Tafel XVII, 2.)

Die Berner Kannen wurden in der gleichen Form ebenfalls Jahrhunderte lang unverändert hergestellt, und zwar ist dieses sogar bei der Stegkanne der Fall, welche infolge der schwierigen Reinigung nicht nur unbequem, sondern auch unhygienisch war. 


\section{Die Neuenburger Kannen.}

a) Die Bernerform ohne Steg hat alle dekorativen Momente eingebüsst, so insbesonders jegliche circulären Wellen. Korpus und Hals sind vollständig glatt und weisen nur einige circuläre Linien auf. Doch hat die Kanne bei aller Einfachheit eine vornehme künstlerische Kontur. Die Grössen entsprechen einem Inhalt von 1, 1/2, 1/4 und sehr selten von $1 / 8$ Maass und haben eine Höhe von 32,5-15,8 cm. Die Giessermarken befinden sich auf dem Deckel.

b) Die humpenförmige $\mathrm{K}$ anne gleicht den Hohlmaassen. Der Korpus wird von einem Kegelstumpf gebildet, welchem ein stark eingezogener Hals aufsitzt. Dieser erweitert sich nach oben wieder und geht in einen cylindrischen Ausgussteil über. Der Handgriff trägt das Scharnir für den flachen, herzförmigen Deckel, welcher dem Kannenrand aufliegt. Es finden sich alle Grössen, von 20 gr bis 2 Maass Inhalt. Die Giessermarken sind ebenfalls auf dem Deckel ; die seitlich am Halsteil eingeschlagenen Neuenburger W appen hängen mit der Aichung zusammen. (Tafel XVII, 1 2.)

c) Die Form der Stitze ist sehr selten und findet sich nur beim Meister Jonas Huguenand. (Tafel XVII, 11.)

\section{Die Genfer, Waadtländer und Walliser Kannen}

a) Die gewöhnliche Form, Jer Typ $I$.

Im weinreichen Wallis und in einigen angrenzenden italienischen Tälern mit Walliser Bevölkerung finden sich heutzutage noch zinnerne Weinkannen im Gebrauch, so z. B. im Lötschen- und Eifischtal, im Bezirk Goms und im Saastal. Die charakteristische Form ist ohne weiteres erkennbar. Auf einem niedern, kreisrunden Fusse ruht der Leib der Kanne, in der Form einer oben und unten leicht abgeplatteten Kugel. Bei den kleinen Kannen ist der Korpus ganz glatt; bei den grössern zieren parallele Linien oder ein flacher ringförmiger $\mathrm{W}^{\top}$ ulst den Aequator. Auf den weitbauchigen Leib setzt sich der gedrungene, verhältnismässig dicke Hals, welcher in der Mitte ebenfalls parallele Linien oder den flachen Wulst aufweist. Der Hals erweitert sich oben zum Ausgussteil und zwar fast zur Grösse des Querschnittes der Leibung. Der Ausguss kommt in einfachster Weise dadurch zustande, dass der Rand der ursprünglich kreisrunden Oeffnung seitlich eingepresst wird. Dadurch nimmt dieselbe die typische Herzform an, welcher nun auch der flach aufliegende Deckel entspricht. An der Rückseite der Kanne befindet sich der einfache, meist glatte Henkel, welcher von der Mitte des Kannenleibes bis zum Rande reicht; ab und zu findet man auf demselben Verzierungen. Blumenranken in Ornamentguss. Am obersten Teil des Henkels befindet sich das Scharnir für den Deckel. Letzterer wird von einem vierkantigen, allmälig nach vorn sich verjüngenden Zinnbalken getragen, welcher vermittelst eines Walzengelenkes in das Scharnir eingreift. Ueber demselben bilden Tierköpfe (Widder, Hunde) oder Früchte (Eicheln, Granatäpfel) den Griff. Auf dem Deckel befinden sich die Meisterzeichen und die Qualitätsmarken ( $F$ mit Krone, C, etc.); oft auch eingeschlagene Familien- oder Gemeindewappen, Initialen, Hauszeichen, u.s.w. Die Jahrzahlen sind nicht zuverlässig und entsprechen oft nur der Aichung. Im Innern des Kannenbodens finden sich ab und zu Rosetten, Bourbonenlinien u. dgl.

Die Grösse der Kannen ist sehr verschieden; so variirt die Höhe von 10 bis $40 \mathrm{~cm}$, der Inhalt von $50 \mathrm{~cm}^{3}$ bis zu 7 Liter. Die kleinen Kannen wurden als Trinkgefässe benutzt. Die 1 und 2 Maasskanne war die übliche Grösse in den Wirtschaften. Die kleinsten Exemplare sind Messkännchen.

Oft sind an den Seiten des Ausgussteils Knöpfe oder Oesen angelötet, welche zur Befestigung der zinnernen Ketten oder Traghenkel dienen. Die Ketten stammen meist erst aus dem XIX. Jahrhundert und dienten nur zur Befriedigung einer Mode, zur Dekoration; denn sie sind viel zu weich und zu schwach, um die gefüllte Kanne tragen zu können. Allerdings gibt es auch alte Ketten, deren Glieder die seitliche Naht des Gusses besitzen; in meiner Sammlung finden sich nur einige wenige Exemplare. 

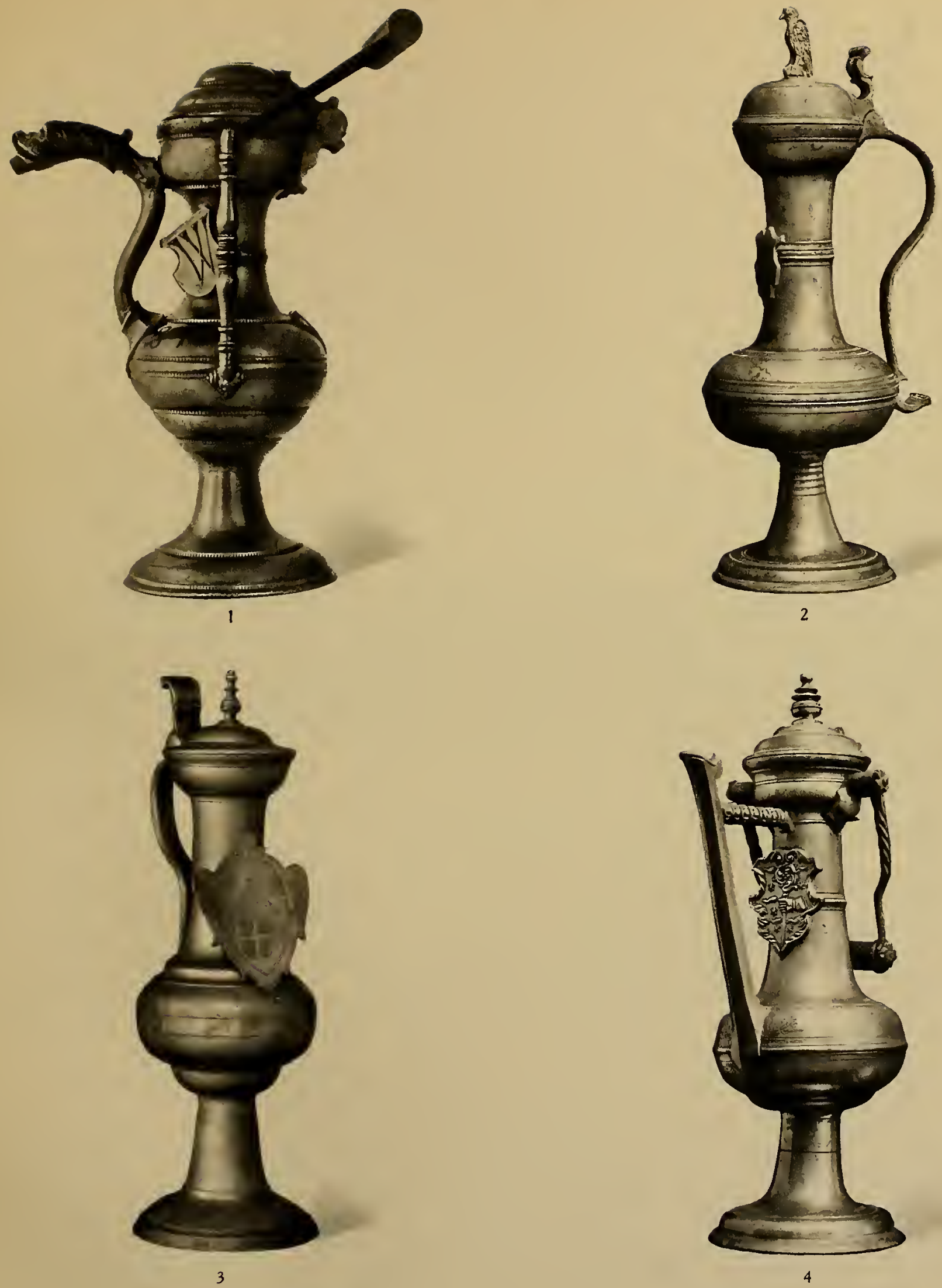

I. Kanne von Wyl, von M.R., datirt 1581 (Text S. 38), Höhe $47,2 \mathrm{~cm}, 2$. Kanne von Rapperswil, von ?, ca. 1600 (Text S. 38), Höhe ca. $45 \mathrm{~cm}$. 3. Kanne von Davos, von Hertli de Cadenath, datirt 1647 (Text S. 38), Höhe $44 \mathrm{~cm}$. 5. Kanne von Bischofszell, von Bartholome Riedtmann, ca. 1700 (Text S. 38), Höhe $53 \mathrm{~cm}$. 

Das Alter dieser Hauptform, Typ I, ist sehr verschieden; im Genfer historischen Museum befinden sich einwandfreie Exemplare mit der Jahrzahl ${ }_{1} 557$ der Ordonnance. In der gleichen Form wurden die Kannen in Genf und im Wallis auch noch im XIX. Jahrhundert hergestellt. Dieses konservative Beibehalten einer Urform ist für die Schweiz charakteristisch. Nur die Proportionen wechseln ein wenig und verursachen kleine Verschiedenheiten zwischen den Genfer, Waadtländer und Walliser Kannen. Die Meistermarken allein sind entscheidend; allein nur insofern mit absoluter Sicherheit, als einwandfrei festgestellt ist, dass der Kannendeckel der ursprüngliche ist. Ich habe unzählige Male gesehen, wie bei den Antiquaren defekte Deckel einfach durch andere ersetzt wurden, welche auf defekten Kannen sich befanden. Bei einigen Zinngiessern findet man Modelle, welche für dieselben typisch sind und diese Modelle geben oft einen ergänzenden Aufschluss. Zur Benutzung solcher Vergleichsmomente bedarf es allerdings grosser Spezialkenntnisse.

$\mathrm{Ab}$ und zu findet man im Handel, aber auch in verschiedenen Museen, Walliser und Genfer Kannen, mit polyedrischem Korpus. Untersucht man dieselben so sieht man zum Erstaunen, dass der Fuss, der Hals, Henkel und Deckel samt den Giessermarken echt und einwandfrei sind; der polyedrische $K$ orpus aber ist neu und einge. setzt. Im germanischen Museum in Nürnberg befand sich seinerzeit eine grosse Serie ansteigender Grössen.

Auch die Kannen mit einem Korpus in Form eines Pyramidenstumpfes sind nur sehr selten echt aus der Zeit und bedürfen genauester Prüfung.

\section{b) Der Typ II der Genfer, Waadtländer und Wallider Kannen.}

Der Fuss der Kanne des Typ I ist weggelassen. Der Korpus ist nicht mehr kugelförmig; er ist fast cylindrisch, nach unten enger werdend, plump, und sitzt vermittelst eines ringförmigen Unterteils direkt auf der Unterlage. Hals und Deckel sind gleich wie bei dem Typ I. Auch bei dieser Form gibt es ganze Serien von verschiedenen Grössen, oft auch mit Ketten, für welche die gleichen Bemerkungen gelten, wie bei Typ I. Auch die ältesten Kannen des Types II sind zeitlich jünger als der Typ I. (Tafel XVII, 6, 7.)

Die Meisterzeichen sind stets auf dem Deckel.

\section{c) Der Typ III.}

Der Typ III findet sich nur im Wallis. Der Korpus hat die Form eines Kegelstumpfes, welcher ohne Hals in den Ausgussteil übergeht. Der letztere, ebenso wie Handgriff und Deckel, hat die gleiche Form wie bei Typ I und II. Korpus und Ausgussteil sind glatt; ab und zu bringen einige circuläre, eingravirte Linien eine Aufteilung der glatten Fläche zustande. Die Deckeldrücker bestehen aus Eicheln oder Granatäpfeln. Die Meisterzeichen sind stets auf dem Deckel. Die kleinsten Exemplare, von 9,5 cm Höhe, dienten als Messkännchen, besonders im Bezirke Goms. Die Maasskanne hat eine Höhe von ca. $25 \mathrm{~cm}$; die $1 / 2$ Maasskanne ca. $20 \mathrm{~cm}$. Obwohl schwerfällig und plump in der Form, sind es doch rassige Kerle. Die angebrachten Ketten stammen stets aus neuester Zeit. (Tafel XVII, 8.)

\section{Die seltenen Kannenformen}

Die seltenen, ungewöhnlichen Kannenformen entsprangen nicht etwa einer blossen Laune oder einem besondern Einfall eines Meisters. Sie sind vielmehr oft das Meisterwerk selbst. Der angehende Meister erhielt den Auftrag, irgend eine ungebräuchliche und ungervöhnliche Form herzustellen, mit welcher er oft nachher nur schlechte Erfahrungen machte. So beschloss die Meisterschaft in Basel vor dem Jahre 1710"; "In Anbetracht, dass die Meisterstücke unbrauchbar und nicht mehr verkäuflich sind, sondern zu einer alten Mode wurden, soll das Meisterstück künftighin nach gangbarer Mode also eingerichtet sein, dass solches einem

\footnotetext{
1 Jobn A. Brown, Seite 82 und Anhang S. 106 Ziff. 28.
} 
Anfänger nützen und verkäuflich sein könne ». Vielleicht bezieht sich dieser Passus auf die Basler Kugelkrüge.

Oft finden sich ausnahmsweise auch ortsfremde Formen: so z. B. in Chur eine Glockenkanne von Johannes Walser, in Zürich eine Stegkanne in Ulmerform von Hans Jakob Steiner, in Solothurn eine Berner Stegkanne von Wilhelm Byss, in St. Gallen eine Stitze von Adrian I. Hiller. Einzelheiten über diese vier in meiner Sammlung sich befindlichen Kannen findet man bei den betreffenden Meistern im speziellen Teil.

In $\mathrm{Gen} f$ und $\mathrm{imW}$ a a $\mathrm{d} t \mathrm{l}$ and gab es grosse Kannen mit einem pris matischen Korpus. In Genf stammen dieselben z. B. von Antoine Boisdechesne, Jean-Antoine Charton; in Vevey von David Angelin, in Lausanne von J. J. Reuchlin. Von den letztern ist je ein Exemplar in meiner Sammlung; ferner eine grosse Kanne mit pyramidenförmigem Korpus des Walliser Meisters PASI.

Die Kugelkrüge. Es sind ungefähr zehn Stück bekannt. Ein Zofingerkrug ist im historischen Museum in Bern; drei Basler Krüge befinden sich im historischen Museum von Basel, sechs in meiner Privatsammlung und zwei in weiterm Privatbesitz (wovon einer ein Zofinger- und einer ein Baslerkrug). Der Krug des bernischen Museums ist im Anzeiger für schweiz. Altertumskunde, 1917, S. 110 , von Architekt Th. Gränicher beschrieben und auch abgebildet. Bei meinen Exemplaren sind drei Stück sehr dünn gegossen. Aus der Wandung wurden Buckel herausgetrieben und die Konturen von aussen wieder hineingepunzt. Die Buckel sind bei zwei Exemplaren vollständig mit gravirten Blumenranken überzogen. Die Krüge stammen von den Meistern Gmünder oder Glinz in St. Gallen, Hans Müller in Zofingen und Simon Grynaeus in Basel. Die genaue Beschreibung befindet sich bei dem betreffenden Meister. Die drei übrigen Kugelkrüge sind dickwandiger gegossen und bedeutend weniger deutlich getrieben oder gehämmert. Zwei derselben sind ebenfalls gebuckelt und einer ist glatt. Ein Stück stammt vom Meister Hans Dietrich Jäger von Brugg, ein Stück vom Meister I. H. H. (vielleicht St. Gallen); das dritte Exemplar besitzt keine Meisterzeichen. (Tafel XVIII, 1-5.)

Die Form dieser Kugelkrüge aus Zinn entstammt sicherlich den gleichzeitigen Steinzeugkrügen der Rheinlande (siehe O. v. FaLke, Das rheinische Steinzeug, Bd. II, Berlin, 1908).

Die importirten, ausländischen $\mathrm{K}$ annen mit ihren eigentümlichen Formen fallen nicht in den Rahmen unsers Buches. Im Uebrigen tragen dieselben ihre eigenen Meistermarken. Besonders häufig sind solche aus Strassburg, Frankfurt, Nürnberg, Augsburg, Paris, Lyon, London, auch aus Sachsen und Böhmen.

\section{Die anderen $Z_{\text {inngegenstände }}$}

\section{Die Maasse}

Die Maasse aus Zinn sind ausschliesslich für Flüssigkeiten bestimmt. Die Grundform derselben ist cylindrisch oder konisch und zwar in dem Sinne, dass die Höhe grösser ist als der Durchmesser. In Genf haben die Maasse die Form einer plumpen Flasche. In Neuenburg, Freiburg, Bern und Solothurn besitzt der Korpus die Forn einer Kegelstumpfes ; darauf sitzt ein stark eingezogener Hals und darüber der cylindrische Ausgussteil. In der Ostschweiz besitzt das Maass die Form einer Vase. (Tafel XIX, 13-17.)

Die Aichung erfolgte entweder durch Anlöten einer kleinen zinnernen Halbkugel an die Innenwand des Gefässes, oder aber durch Ausfeilen eines beidseitigen, rechteckigen Schlitzes. Dieser reicht so weit in die Gefässwandung hinab, bis das genaue Maass erreicht ist. Die zylindrischen und konischen Maasse besitzen einen Handgriff zum Fassen, während ein solcher bei den flaschen- und vasenförmigen fehlt. 


\section{MESSKÄNNCHEN}
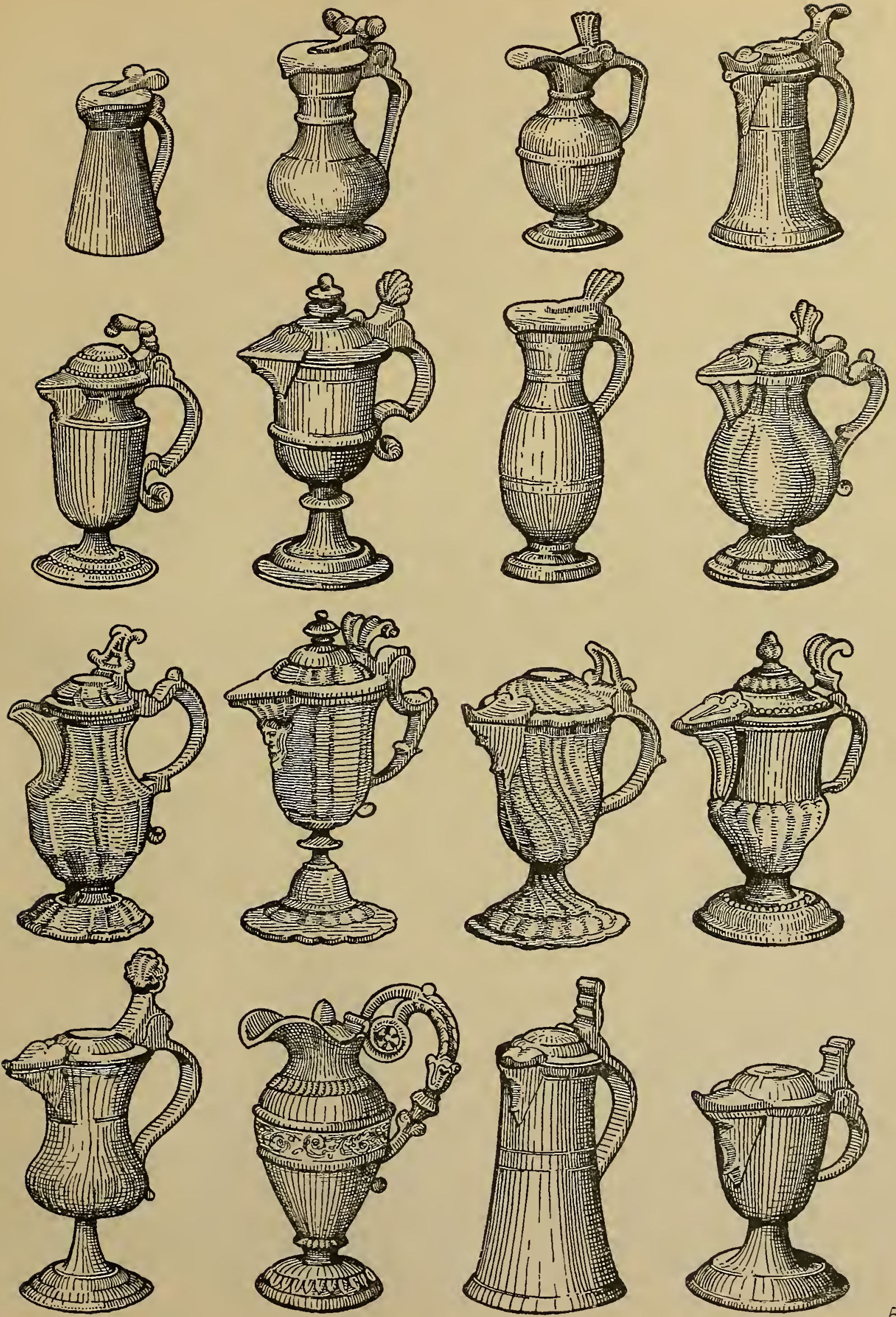


\section{Die zinnernen Flaschen}

Sie besitzen meistens seitliche Oesen am Korpus und am Fusse. Durch dieselben wird eine Schnur oder ein Lederriemen gezogen. Damit haben diese seltenen Gefässe das Kennzeichen einer Feldflasche (ferrière). Man findet dieselben fast nur in der Westschweiz. Die Bestimmung des Ursprungsortes ist leider nur selten möglich, weil die Meisterzeichen sehr oft fehlen. Diese zinnernen Flaschen kommen in allen Grössen vor und varïren in meiner Sammlung in der Höhe von 18,5 bis $34 \mathrm{~cm}$. Sie tragen stets einen Schraubenverschluss, an welchem sich entweder ein beweglicher Henkel befindet oder aber ein fester Griff in Form eines kleinen Delphines, eines sitzenden Löwen u. dgl. (Tafel XIX, 9-12.)

\section{Die Messkännchen}

In den armen Land- und Berggemeinden war die Anschaffung von silbernen Kultgegenständen oft unmöglich. In diesen Fällen war zur Herstellung derselben das Zinn gestattet. Besonders im Wallis findet man häufig Messkännchen in der Form der gewöhnlichen WalliserKanne, und zwar sowohl Typus I wie III. In der Nord- und Zentralschweiz haben dieselben oft die Form der Stitze. Die häufigste Form ist aber die Becherform. Man findet hiebei alle Stilarten vertreten, als Renaissance, Barok, Louis XV., XVI. und Empire. Die Messkännchen haben einen Inhalt von 3o-5o Gramm. Sie tragen auf dem Deckel ein vollrund-gegossenes V (Vinum) oder ein A (Aqua). Oft sind die beiden Buchstaben auf dem Deckel nur eingravirt.

Als Untersatz diente ein ovales Zinnplättchen, dessen Rand selbstverständlich dem entsprechenden Zeitstil entsprach. Wie bei vielen kirchlichen Gegenständen, fehlen oft die Meistermarken. (Siehe die Tafel auf vorgehender Seite).

\section{Die Humpen}

Meistens sind es schwere, cylindrische Gefässe mit einem mehr oder weniger ausladenden Fusse. Der in einem Scharnir laufende Deckel ist kuppelförmig und trägt in der Mitte einen verschiedenartigen Knopf, oft eine vollrund-gegossene Traube oder einen kleinen Delphin Der Deckelgriff ist nach hinten abgekröpft, oft glatt oder mit einem reliefirten Engelkopf, ab und zu durch ein Akanthusblatt gebildet. Das Meisterzeichen befindet sich entweder auf dem bandförmigen Henkel, oder auf dem Deckel, seltener an der Unterseite des Bodens. (Tafel XIX, 1 7.)

Die Bieler Humpen haben einen kuppelförmigen Fuss. Infolgedessen haben dieselben ein eigenartig behäbiges Aussehen. Die glatte Oberfläche des Korpus aller Humpen ist oft reich verziert mit eingravirten Blumenanken, Blatt- und Fruchtgewinden. Dazwischen befinden sich die Initialen der Besitzer, auch deren Wappen und einschlägige Jahrzahlen. Im Innern des Bodens weisen oft die gleichen Rosetten wie in den Kannen auf den Hersteller des Humpens. Gewöhnlich findet man nur zwei Grössen, entsprechend einem Inhalt von 1/2 und 1/4 Maass.

\section{Die Brunnenkesselchen}

Diese eigenartigen Gefässe dienten einerseits zum Auffüllen des Giessfasses, andererseits als Trinkgefäss für die Kinder. Wohl deshalb haben diese Gefässe oft ein ganz abgeschliffenes Mundstück. Dasselbe ist röhrenförmig und hat vorne eine Anschwellung. Weil es in den Häusern keine Wasserleitungen gab, musste das Wasser am Brunnen geholt werden. Das gefüllte Brunnenkesselchen wurde an einem eisernen, oft beweglichen Träger am Buffet aufgehängt. Das bauchige Kesselchen ist mit einem Klappdeckel verschlossen und hat zu beiden Seiten Oesen zur Befestigung des zierlichen schmiedeisernen Traghenkels. In der Mitte des Deckels befindet sich oft als Knopf eine vollrund-gegossene Traube und zu beiden Seiten zieren reliefurte Menschen- und Tiergesichter den Oesenansatz. Die Gefässform ist in der ganzen Schweiz fast überall die gleiche. Nur die St. Gallerkesselchen haben einen stark eingezogenen, 
geschweiften Korpus. Ein Deckeldrücker ist nicht vorhanden; das Oeffnen des Deckels erfolgt durch Heben des Deckelknopfes. - Die Meistermarken befinden sich auf dem Deckel oder an der Unterseite des Bodens. Ebenda sind auch die gravirten Initialen der Besitzer und oft Jahrzahlen; an der Vorderseite des Kesselchens oft auch Wappen. Bodenrosetten im Innern des Bodens sind ebenfalls sehr häufig. (Tafel XX, 18-24.)

Der Inhalt des Kesselchens entspricht ungefähr $1 / 4$ Maass; die Höhe variirt von 12 bis $19 \mathrm{~cm}$. Die kleinsten, mir bekannten Exemplare stammen von Caspar Traber in Luzern.

Im historischen Museum von Basel befinden sich zwei interessante Krüglein von Niklaus Uebelin. Dieselben sind ein Mittelding zwischen Kanne und Brunnenkesselchen. Der röhrenförmige Ausguss ist gleich wie bei letzteren; dagegen ist an Stelle des beweglichen Traghenkels ein feststehender Handgriff aus Zinn, wie bei den Kannen. Wegen der Form und der Abnutzung des Ausgusses dürfte es sich aber doch um eine Abart des Brunnenkesselchens handeln, indem die Kinder daraus trinken mussten. Vielleicht ist diese ungewöhnliche Form auch daher abzuleiten, dass dieselbe eine spezielle Aufgabe bei der Meisterprüfung bildete. In Privatbesitz konnte ich niemals ein solches Exemplar finden.

\section{Die Giessfässer}

In jedem alten Buffet ist in einem eigenen Anbau ein Wassergefäss, dessen Inhalt zum Waschen der Hände diente. Dieser Anbau enthielt häufig als Auskleidung eine verschieden geformte $\mathrm{Zinnnische,} \mathrm{deren} \mathrm{äusserer} \mathrm{Teil} \mathrm{oft} \mathrm{die} \mathrm{ganze} \mathrm{Rückwand} \mathrm{bedeckte.} \mathrm{An} \mathrm{einem}$ starken Eisenhacken hing das Wassergefäss, dessen Form dem denkenden Meister weiten Spielraum liess. Sehr beliebt war von jeher die Form eines aufgerollten Fisches, der Delphin.

Der Delphin ist vielleicht die dekorativste Form des Giessfasses; allerdings wurde der hygienische Moment völlig vernachlässigt. Eine nur einigermassen gründliche Reinigung ist ein Ding der Unmöglichkeit. Der Delphin besteht aus zwei, der Länge nach zusammengelöteten (Tafel XXV, 1.) Hälften; die Lötfuge ist allerdings infolge der Verarbeitung kaum bemerkbar. Oft besteht der ganze Delphin aus Zinn; sehr häufig sind aber die Augen aus rotem Glas; die Einfassung derselben, die Schnauze, die Flossen und der Schwanz aus Messingguss. Im Maul ist der Ausgusshahnen eingelötet; die Füllung mit Wasser erfolgt vom Schwanzteil aus, welcher eine runde Oeffnung aufweist. - Es gibt in der Schweiz mindestens ein Dutzend verschiedener Delphin-Modelle. Leider wurden die Orts- und Meisterzeichen nicht auf den Delphin geschlagen, sondern auf die dazugehörende Zinnische. Nun findet man aber nur sehr selten mehr einen Delphin samt der Nische am ursprünglichen Orte. Meist wurde der Delphin zuerst allein verschachert und oft erst von einer folgenden Generation das Buffet mit der Nische. Infolgedessen ist die Bestimmung der Herkunft des Delphins oft sehr schwierig und nur durch die Modellkontrolle möglich. Dadurch ist der Neufabrikation von Delphinen der Weg leicht gemacht, besonders wenn der Zinngiesser über das Material und die Herstellungsweise orientirt ist. In der Tat gibt es recht viele und zum Teil sehr gute Kopien. (Tafel XXI und XXII, 1, 2, 5.)

Die Zinnis che hat an ihrem Unterteil oft einen Vorbau mit einer kuppelartigen Vertiefung, welche zur Aufnahme des abfliessenden Wassers dient. In der Mitte ist eine Abflussöffnung, welche in ein darunter stehendes Gefäss führt. Infolge dieser Einrichtung ist kein Handbecken notwendig. Im andern Falle findet man ein oft sehr schön getriebenes $\mathrm{k} u \mathrm{p} f$ er $\mathrm{n}$ es $\mathrm{H}$ andbecken oder eine grosse zinnerne Muschel. (Tafel XXI.)

Das Melonen-oder Granatapfel-Giessfass befand sich ebenfalls fast ausnahmslos in einer Zinnische, besonders bei den innerschweizerischen Modellen. In Zug trägt der melonenartige Korpus einen Klappdeckel mit drei Blättern. Der Ausgusshahn steckt in einem kleinen Delphinkopf und hinter demselben befinden sich wieder zwei Blätter. Ab und zu gibt es auch Exemplare, welche zu beiden Seiten der Melone fächerförmig angeordnete Blätter aufweisen. Auch bei dieser Giessfassform ersetzt der zinnerne Vorbau der Nische das Handbecken. (Tafel XXII, 3, 4.) 
Das Giess fass in Eichelform (auch "Birne" genannt) kommt in zahllosen Abarten vor. Oft befindet es sich auch in einer Zinnische; häufiger aber hängt es vermittelst einer Oese an einem eisernen Hacken an der Rückwand des Buffets. In diesem Falle trifft man als Untersatz entweder ein getriebenes kupfernes, oder seltener ein zinnernes Handbecken. Der Ausgusshahn ist in einen zinnernen Fisch- oder Vogelkopf eingegossen. Meistermarken fehlen fast immer. (Tafel XXIII, 1-6.)

Das kastenförmige Giessfass ist bei weitem das häufigste. Man findet es in zahllosen Abarten und in allen Stilformen. (Tafel XXIV, 1-8.)

Das Säulen-Giessfass ist die schönste und dekorativste Art. Je nach dem Zeitalter haben die Säulen Renaissance- oder Barokform (spiralig gewundene Säulen). Der in einen Falz passende Deckel hat die gleiche dachartige Form wie die Reliquare. Als Bekrönung des Deckels sind vollrund gegossene Engelköpfe, Delphine, doppelschwänzige Meerweibchen, Löwen oder Blattornamente aufgelötet I.

Die einfachen Arten des Kastengiessfasses haben eine rechteckige Grundfläche, oft mit gebrochenen Ecken. In andern Fällen ist die ganze Vorderwand geschweift oder in eine Wellenform aufgelöst. Der gleichen Form entspricht der konische aufgesetzte Deckel, welcher als Bekrönung die gleichen dekorativen Elemente aufweist, wie das Säulengiessfass. Die Vorderwand eignet sich sehr gut zur Verzierung mit gravirten Früchte- und Blumengewinden, Wappen, Initialen und Jahrzahlen.

Die Orts- und Meisterzeichen befinden sich meistens an der Rückwand des Deckels, seltener des Kastens. - Das Handbecken ist meistens aus Kupfer; ab und zu findet man auch zinnerne Untersätze, mit den stilistisch gleichen Friesen wie beim Giessfass. Das Handbecken aus Zinn trägt ebenfalls die Zinngiessermarken.

\section{Die Platten und Teller}

Die Breitrandplatte. Der Fundus ist eben oder in der Mitte nur sehr wenig erhöht. Er ist auffallend klein und nicht tief (1-2 cm) im Verhältnis zur Grösse der Platte und des breiten Randes. Derselbe ist oben eben oder steigt nach aussen leicht an. Er ist oft ganz glatt (frühe Exemplare) oder aber hat aussen ein profulirtes Band. Bei den ältesten Platten (z. B. von Jörg Zubler in Zürich) ist der Rand an der Oberseite durch einen prismatischen Stab verstärkt: später ist die Verstärkung an der Unterseite des Randes, in Form eines halbrunden Stabes. Um die Festigkeit der Platte zu erhöhen, wurde dieselbe an der Rückseite gehämmert. Die Hammerstreiche wurden durch die geübte Meisterhand in regelmässigen Kreisen angebracht. Der breite Rand eignete sich besonders gut zur Anbringung von gravirten Wappen, Initialen und Jahrzahlen. Die Meisterzeichen befinden sich bald an der Vorder-, bald an der Unterseite der Platte; infolge des reichlichen Platzes sind sie meist gut eingeschlagen und sehr gut erhalten. Die Breitrandplatten bilden die beste Fundgrube für die ältesten Giessermarken. Die Platten sind meist rund, sehr selten oval. Die Grösse des Durchmessers varïrt von 8 bis $50 \mathrm{~cm}$, bei 3,8 bis $12 \mathrm{~cm}$ Randbreite. Die kleinsten Exemplare dienten als Teller, die mittlern und grossen waren sehr beliebte Schützenfestgaben. (Tafel XVIII, 11, 12; XXVI, 7 9, 11-13.)

Die Gupfplatte. Der Fundus derselben wird durch eine mehr oder weniger tiefe Kuppel gebildet, deren Mitte als Umbo in die Höhe getrieben ist. Die Form nähert sich der Schüssel. Der leicht nach aussen ansteigende Rand ist im Verhältnis zum Durchmesser viel schmaler als bei der vorigen Form. Der Rand ist selten vorne, meistens hinten durch einen Halbrundstab verstärkt. Die Form der Gupfplatte variirt ausserordentlich stark, je nach der Tiefe und Wölbung des Fundus und der Breite des Randes. Die Meisterzeichen sind ebenfalls fast immer sehr gut erhalten. Man findet nicht selten Uebergangsformen zur Breitrandplatte. (Tafel XXVI, 6, 10, 14-16.)

1 Im historischen Museum von Zug befindet sich ein grosses Säulengiessfass aus dem alten Spital. Das interessante Exemplar besitzt zwei Ausgusstïrmchen nebeneinauder. 

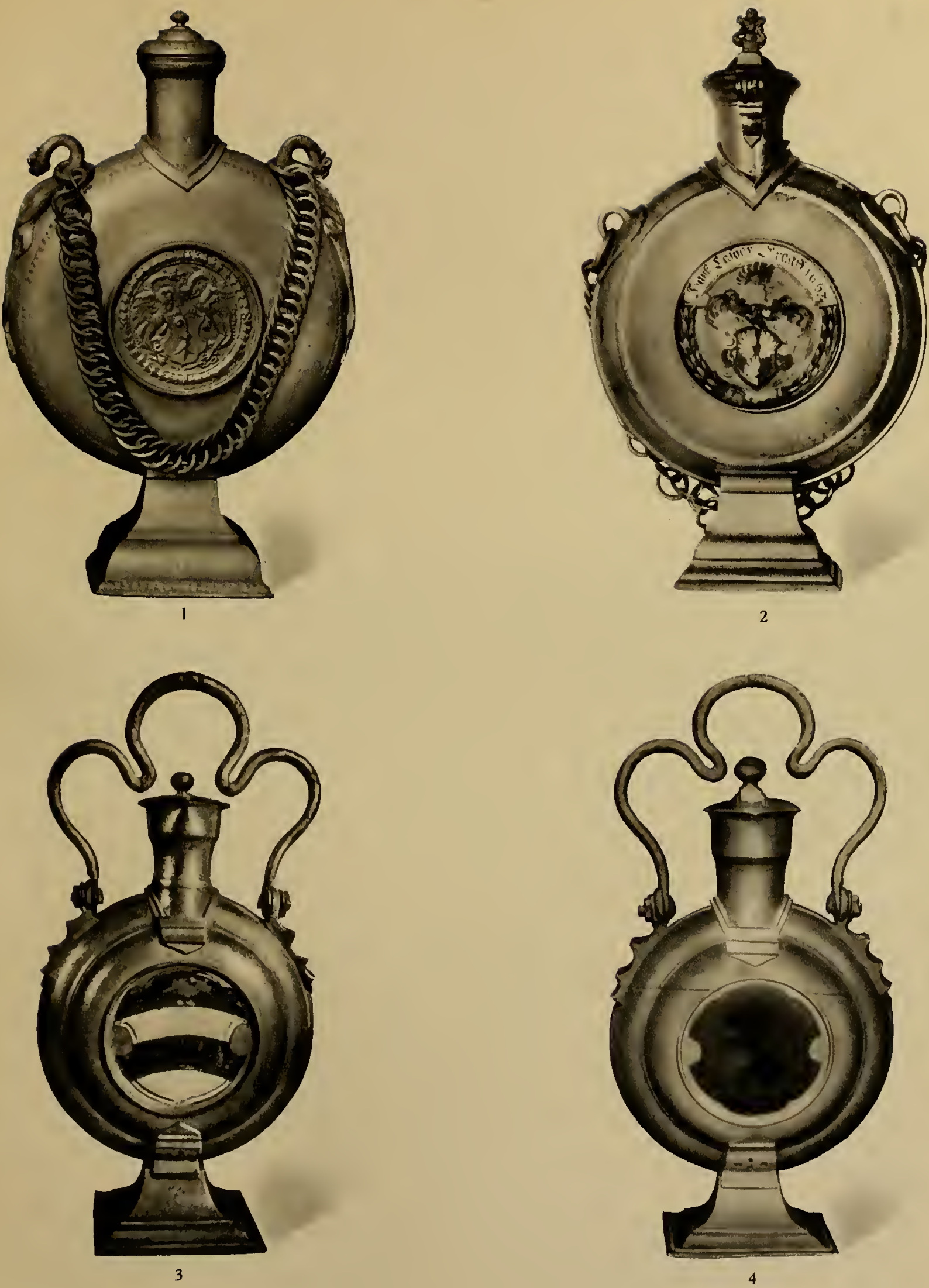

1. Kanne des Kleinen Rats von Basel, von J. Linder, von 1638 (Text S. 39), Höhe 42 cm. 2. Kanne mit den Wappen Hegner und Graf, von Antonius I., Graf, datirt 1667 (Text S. 39), Höhe $36 \mathrm{~cm}$. 3. Kanne von Zofingen, von Hans Müller. $1691-1765$ (Text S. 40), Höhe $46 \mathrm{~cm}$, 4. Kanne von Willisan, von Hans Müller, 169 I-1765 (Text S. 40), Höhe $46 \mathrm{~cm}$. 

Die gewöhnliche Form der spätern Platten hat als Haupteigenschaften den grossen, ebenen Fundus und den relativ schmalen Rand. Der Rand ist nicht eben, sondern leicht nach oben gewölbt und schliesst aussen mit einem verschieden profilirten Karniss ab. Diese Plattenform findet sich in allen Grössen und Stilarten, sowohl kreisrund als oval. Letztere fanden häufig Verwendung als Fischplatten und die kleinen Exemplare als Untersatz für die Messkännchen. Die kleinen runden Stücke dienten als Teller des täglichen Gebrauches.

Die Schüssel entsteht durch Vergrösserung und Vertiefung des Fundus, im Gegensatz zum relativ schmalen Rande, welcher meist profilirt ist. Oft findet man an beiden Seiten Oesen, in denen bewegliche Henkel laufen. Man findet ganze Sätze ansteigender Grössen (z. B. in Zug). Sie dienten in der Küche als Gemüseschüsseln, grössere Exemplare als Hand- und Taufbecken oder als Wasserschüsseln. Auch hier sind alle Stilarten vertreten. Die Rückseite ist nicht selten gehämmert. (Tafel XXVI, 1-5; XVIII, 6, 9, 13.)

Die Wand-oder Dedikationsplatten, oft Tischschoner oder Kuchenplatten genannt, stammen in der Schweiz aus dem XVII. Jahrhundert. Die letzten zwei Benennungen sind völlig ungerechtfertigt. Trotz genauer Untersuchung findet man auf denselben keine Kratzeffekte von Messern (Kuchenplatte) oder Kritzer von schweren Tafelgegenständen (Tischschoner). Es sind runde, zackige oder vieleckige ebene Plaketten. welche kunstvoll gravirt wurden. Sie dienten als Geschenke bei Hochzeiten, Primizenfesten, oder sie wurden von der Stadt selbst als Andenken oder als Anerkennung verschenkt. Diese seltenen und schönen Platten sind also keine Gebrauchsgegenstände, sondern Wandplatten als Erinnerungszeichen. (Tafel XXXI, 1-3.)

Die "Ohrenschüsselchen» (grellet, écuelle). In der einfachsten Form der Spitalschüsselchen findet man sie schon sehr früh. Im historischen Museum von Genf befinden sich aus der Rhone ausgebaggerte Exemplare, welche die Jahrzahl der Ordonnance von 1557 aufweisen. In den Spitälern und Pfrundhäusern waren sie zu Dutzenden vorhanden und dienten zu gleicher Zeit als Teller und als Kaffeeschüsseln. Aus denselben wurde das traditionelle Weizen- und Hafermus (Brei) gegessen, welches in den Spitalrechnungen jahrhundertelang vorkommt, oft mit der humanen Bemerkung, dass die Insassen infolge der reizlosen Kost nicht sterben können. - Die Form des Schüsselchens ist sehr einfach; der Korpus besteht aus einer 4-6 cm tiefen Schale mit flachem Boden. Zu beiden Seiten befinden sich horizontale, blattförmige Handgriffe, die sogen. "Ohren ». Diese hatten, als einzige Dekoration, verschiedenartige Conturen; oft waren sie auch durchbrochen. Die Meistermarken sind entweder auf den Ohren oder am Boden. Nur selten ist ein Deckel vorhanden, welcher drei Kugelfüsse besitzt. Umgekehrt auf den Tisch gestellt, dient er dann als Teller. Diese Form bildet den Uebergang zu den folgenden Schüsselchen.

Die Wöchnerinnen-Schüsselchen. Sie dienten an verschiedenen Orten als übliche Geschenke ins Wochenbett. In Zürich ist der untere Teil fusslos; auf dem Deckel sind drei Kugelfüsse mit Klauen. Die horizontalgestellten "Ohren " sind zur Dekoration verschiedenartig durchbrochen. Auf dem Deckel befinden sich reliefirte Friese von Perlstäben u. dgl. An andern Orten ist die Oberfläche gemäss einer Zeichnung durch Hämmern gebuckelt, wobei die einzelnen Buckel von gepunzten Zickzacklinien eingefasst sind. Die Form kommt besonders in $\mathrm{Z}$ ug und Basel vor. Sowohl das Schüsselchen als der Deckel besitzen je drei Kugelfüsse mit Klauen. An Stelle der "Ohren " sind vertikale gestellte, zierlich durchbrochene Handgriffe mit Engelköpfen und Rankenornamenten vorhanden. Man findet Exemplare im Renaissance-, Barok-, Louis XV und XVI Stil. (Tafel XX, 1-6.)

\section{Weitere Zinngegenstände}

Trinkbecher, Pokale, Zunfthumpen, Gefässe in Form von Tieren (Vögel, Stiere, Affen), Zunftschilder und Embleme, oft in Form eines Buches, eines Schuhes, etc., Helmkannen (aiguières) als Taufkannen mit den entsprechenden Schalen, Suppenschüsseln in allen Stilarten, ebenfalls mit Untersätzen, Tafelaufsätze. 
Pilgerflaschen, Weihwassergefässe (oft mit reliefirter Rückwand), Gefässe für das heilige Oel. Bei den Juden : Sederplatten und Lampen; rituelle Schalen, kleine Fässchen und Becher. - Blumenvasen, Kirchenampeln, Kerzenstöcke; zweiarmige Leuchter, Oellichter, Oellampen mit und ohne Zeitmesser. Rasierbecken, Nachtgeschirre, Waschgarnituren, Senfgeschirre, Salzgefässe, Pfefferbüchsen, Salzfässer, Essig- und Oelbehälter (Karafindl), Eierbecher, Zuckerdosen, Zuckerstreuer, Saucièren, Rechauds für heisses Wasser. Löffel und Vorlegelöffel, Essgabeln, Löffelgestelle, Milch- und Kaffeekannen in allen Stilarten. (Tafel XX, 7-17.)

Apothekerbüchsen, -Gefässe und Maasse (Mensuren). Medizinische Utensilien, wie Spritzen in allen Dimensionen, Sonden, Spatel, Bettschüsseln, Nachtgeschirre in besondern Formen.

Tintengeschirre (Tafel XIX, 18), Zifferblätter für Wanduhren, Tafeln zum Einschlagen der Goldschmiede- und Zinngiessermarken. Die Zierteller in Reliefguss. Zinnerne Kleiderknöpfe. Deckel zu den Fayence- und Glashumpen.

Kinderspielzeug: Zinnsoldaten (siehe bei Aarau), Häuschen, Bäume, Tiere, Puppengeschirr.

\section{Die geographische Verteilung der Kannenformen in der Schweiz und ihre Beeinflussung durch die Stilarten}

Aus dem XIV. Jahrhundert haben wir eine geschlossene Gruppe von vier Kannen (zwei von Homberg im Aargau und zwei aus der Gegend von Siders) welche sich durch ihre einheitliche Form auszeichnen. Trotzdem die Fundorte ziemlich weit auseinander liegen, weisen sie auf ein und denselben Ursprungsort hin. Leider fehlen Marken und Zeichen, doch deutet die Form und der Aufbau der Kannen nach Westen. Sie könnten ganz gut in Genf entstanden sein. Diese Kannenform findet sich später nicht mehr. Sie sind Beispiele frühgotischen Stiles.

Die drei Oelkannen des Basler Münsterschatzes aus dem XIV. oder XV. Jahrhundert verraten ebenfalls französischen Einfluss. In ihrer Form zeigt sich schon der Vorläufer der Berner Stegkanne, nicht nur wegen der langen Ausgussröhre, sondern besonders wegen des Aufbaues des Fusses, welchen man wieder deutlich bei den Kannen des Peter II. Baumgarter in der Kirche von Biel findet.

Die ältesten Kannen des historischen Museums von Bern, die Bubenbergkanne, die Kannen von Aeschi und von Baar ( $Z u g)$ bilden wiederum eine für sich gut umschriebene Gruppe. Ihre Hauptmerkmale sind: der niedrige, kegelförmige Fuss, der mächtige Korpus in der Form einer abgeplatteten Kugel, der Schild in Form der Tartsche und die kreisbogenförmige, prismatische Ausgussröhre. Am Ende derselben befindet sich ein Tierkopf, welcher bei der Baarerkanne eine prächtige Bearbeitung der Haare, der Mähne, besonders auch des Armes und der Hand des Steges aufweist. Diese Kannengruppe bilden ausgesprochene Vertreter des gotischen Stiles. Sie stammen aus der Zeit um 1500.

Die Stadtkannen von Frauenfeld und Baden besitzen noch die gleiche Grundform wie diejenigen der vorigen Gruppe; ebenso ist die Schildform noch tartschenälınlich. Die erstere besitzt auch noch die Ausgussröhre in der Form eines Kreisbogens; bei der Badener Kanne steigt der mittlere Teil der Röhre senkrecht empor. Beide Kannen zeigen aber in den dekorativen Einzelheiten typische Merkmale des Renaissancestiles, besonders prägnant in den Akanthus- und Perlstabfriesen des Fusses, Halses und Deckels. Diese gleichen einander bei beiden Kannen so sehr, dass man an den gleichen Hersteller glauben könnte. Der Kannenfuss ist nicht mehr kegelförmig, sondern besitzt oberhalb der eigentlichen Fussausladung einen niedrigen cylindrischen Teil (Schaftbildung).

Die Zuger und Steiner Ratskannen haben einen Schild im typischen Renaissancestil. Bei der Zugerkanne befindet sich an Stelle des prismatischen Röhrenausgusses ein schön 
gearbeiteter Fischkopf in Reliefguss, mithin schon eine Art von Schnabel-Ausguss. Alle bisher erwähnten Ratskannen haben den eigenartigen, gotischen Aufbau des Traggestelles für den beweglichen eisernen Träger.

Bei den Luzerner Kannen bestehen alle dekorativen Bestandteile, wie der Schild, der Ausguss, der Traghenkel und das Henkelgestell aus gelbem Messingguss, durchweg im reichen Renaissancestil. Die Arbeit des Zinngiessers spielt eine nebensächliche Rolle.

Die Murtener Kannen und besonders die Stadtkannen von Yverdon und Payerne zeigen, neben vielen Renaissance-Elementen, schon deutlich den Einfluss des Barok, insbesonders an der Ausgussröhre. Die Murtner Kannen haben übrigens die typische Form der Berner Stegkanne. Eigenartig plump wirkt die vierkantige, abgekröpfte Ausgussröhre der Kannen von Payerne und Moudon.

Die Ratskannen der Nord-Ostschweiz, nämlich von Wyl, Davos, Rapperswil und Bischoffszell zeichnen sich ebenfalls durch einen einheitlichen Typus aus. Es ist die Form der Schenkkanne mit hohem, fast säulenförmigem Fuss, wie sie in Deutschland sich im Laufe des XVI. Jahrhunderts ausgebildet hatte (Abbildung bei Hintze, Nürnberger Zinn, 1921 , Tafel 1). Auch dieser Kannentyp hielt sich ca. 200 Jahre lang. Die Grundform blieb die gleiche unter Abänderung der Profile, der Schilde und der dekorativen Einzelheiten. Das älteste Stück, die Stadtkanne von Wyl, trägt die Jahrzahl 1581 ; das späteste, die Kanne von Bischofszell, stammt aus den Jahren 1700-1720. Der Meister Bartholome Riedtmann übernahm als Ausguss die lange, prismatische Röhre der Berner Stegkanne. Diese und der baroke Wappenschild contrastiren seltsam mit der alten, spätgotischen Grundform der Kanne.

Die Kannen mit scheibenförmigem Korpus, die sog. "Plattflaschen " finden sich im Bilde schon in der Luzerner Chronik von Diebold Schilling, 1513. Auf der Doppeltafel "Die Schlacht bei Sempach ", Tafel 11 des Neudrucks, trägt eine Marketenderin eine solche Flasche gotischen Stiles. Die 12 Kannen des Kleinen Rates von Basel sind mit RenaissanceOrnamenten in Reliefguss verziert, so die Schilde, die Tragoesen in Form von Basilisken. Die mächtigen 4 Kannen der Universität Basel, datirt 1704, sind schon Vertreter des Barokstiles. Er manifestirt sich deutlich im Aufbau des Fusses. Die Winterthurer Plattflasche des Antonius I. Graf $\left(1617^{-1686)}\right.$ und die ähnlich geformten Stadtkannen von Zofingen und Willisau besitzen in Oel gemalte Familien- und Stadtwappen. Aus Bern stammen wahrscheinlich die Abendmahlkannen von Kirchenthurnen. Diese Kannenform beschränkt sich also auf die Orte Basel, Bern, Zofingen und Winterthur und auf die Zeit von 1513-178o. Auch bei diesem Typus bleibt die Grundform stets gleich; der Zeitstil wechselt und zeigt sich besonders im ornamentalen Teil.

Die Bulgen verändern ihre plumpe Form im Laufe der Jahrhunderte nur unwesentlich. Die ältesten Stücke im Berner Münster stammen aus der Zeit um 150o; die letzten Exemplare (z. B. in Orbe) wurden 1803 hergestellt. Die grossen Flächen eigneten sich sehr gut zur Dekoration mit Gravirungen und - allerdings selten - zur Ornamentierung in Blattvergoldung. Die Verzierungen entsprechen jeweils dem Zeitstil und man findet Stücke in gotischem, Renaissance-, Barok- und Louis XVI.-Stil. Die ältesten Bulgen stammen aus Basel und Bern. Von Bern findet man sie über Burgdorf, Zofingen bis Aarau; nach Westen über Neuenburg bis Orbe, das ja auch unter Bern stand.

Ueberblickt man die erwähnten Ratskannentypen, so kommt man zu folgendem Resultate :

Die Grundform aller vier Typen bleibt konstant und zwar von circa 1500 bis 1800 (1780-18o3), also ungefähr dreihundert Jahre.

Der Stilwechsel vollzieht sich in den Einzelheiten, besonders in den Profilen und dekorativen Elementen. Auch vollzieht sich dieser Wechsel langsamer als die Zeit es erwarten lässt. Mit konservativer Zähigkeit wird am Alten festgehalten. Die Handwerker kopiren nicht etwa die alten Formen; es handelt sich um ein Festhalten der von altersher gewohnten Form. Somit hinkt der Stil der Zeit nach. Dieses Faktum gilt nicht nur für das Zinngeschirr. So z. B. wurden im Bündnerlande durch das ganze XVIII. Jahrhundert hindurch gotische Holztische mit den schönen Blattranken-Ornamenten hergestellt. 


\section{Die Gebrauchskannen}

Alle diese Momente gelten in noch viel höherm Maasse für die Kannen des täglichen Gebrauches. Die Glocken- und prismatischen Kannen haben in der Diebold Schilling'schen Luzernerchronik von 1513 die gleiche Grundform wie um das Jahr 1800 ; desgleichen die Stitzen und Rundeln auf dem Holzschnitte Jost Ammanns von 1568 und die gleiche Kannenform am Ende des XVIII. Jahrhunderts. Kannen im Typ der Genfer und Bernerkanne aus dem XVI. Jahrhundert sind noch im Original erhalten und besonders die Genferkannen sind fast völlig gleich geblieben, nicht nur in der Form, sondern auch in den dekorativen Einzelheiten, z. B. die Widderköpfe am Deckeldrücker. Darum nenne ich diese sechs Typen : Altformen.

Die Beeinflussung der Altformen durch den wechselnden Zeitstil betrifft nur Einzelheiten, besonders die Profile und die dekorativen Momente, z. B. den Schild, den Kannenfuss, den Rand des Deckels, u.s.w.

Die Glockenkannen des XVI. und XVII. Jahrhunderts besitzen einen cylindrischen Korpus, also fast keine Ausladung des Fussteiles; auch befindet sich der Schild oft oberhalb der circulären Wülste; als Verschluss dient stets der Bajonetverschluss. Im XVIII. Jahrhundert wird die Form eleganter infolge der verstärkten und geschweiften Ausladung des Fusses. Um das Jahr 1700 tritt an die Stelle des Bajonetverschlusses häufig der Gewinde-oder Schraubenverschluss ', oft sogar auch an der Ausgussröhre. Die circulären Wülste werden schmaler und zahlreicher und verlieren sich zuletzt in blossen Rillen und eingeritzten Linien. Man hatte vergessen, dass die circulären Wülste eigentlich Weidenreife darstellten. Am Ende des XVIII. Jahrhunderts (Louis XVI.-Stil) findet man als Einfassung des Deckels Perlstäbe.

Die prismatischen Kannen des XVI. und XVII. Jahrhunderts entbehren ebenfalls jeglicher Ausladung des Fussteils. Im XVIII. Jahrhundert wird die Form gefälliger durch eine mehr oder veniger starke Ausladung des Fusses : z. B. die Bündner "Bodenkannen ». Im Anfang des XIX. Jahrhunderts treten die Kranzkannen in Chur auf; die breite Ausladung des Fusses und der Ansatz der Ausgussröhre werden mit einem breiten Akanthusblatt-Fries im Louis XVI.- oder Empire-Stil überzogen. Die Idee der Kranzkanne ist allerdings älter; ich fand eine prismatische Kanne ohne Fuss-Ausladung mit einem Renaissance-Akanthusblattfries von Herkules I de Cadenat aus dem Jahre 1734. Der Fries ist aufgelötet. Die prismatischen Kannen haben stets den Schraubenverschluss und verden deshalb kurzerhand "Schrauben " genannt. Auch diese Kannenform hat bei Exemplaren um das Jahr 1800 herum, oft den Perlstab als Einfassung des Deckels.

Auch bei den Stitzen wird die Formveränderung hauptsächlich durch die zunehmende Ausladung des Fusses verursacht. Infolgedessen erhält die Seitenlinie der Kanne eine verschiedenartige Schweifung und diese bedingt die vielen Abarten der Stitze, je nach dem Orte.

Die Rundele des XVI. und XVII. Jahrhunderts hat stets die gleiche Form beibehalten. In der Mitte und am Ende des XVIII. Jahrhunderts treten unter dem Einfluss des Louis XVI.Stiles ebenfalls Akanthusblattfriese am Fusse, Hals und Deckel der Kanne auf.

Der Berner und Genfer Kannentypus veränderte sich im Laufe der 21/2 Jahrhunderte fast gar nicht und weist damit eine merkwürdige Beharrlichkeit auf.

Die genaue Bestimmung des Alters aller Gebrauchskannen erfolgt durch die Kontrolle des Stadt- und Meisterzeichens.

Die geographische Zuteilung der Altformen befindet sich bei der Beschreibung der Kannentypen. Als Endresultat diene folgendes :

Die Glockenkanne fehlt in Basel, Bern, Solothurn, Graubünden und in der ganzen Südwestschweiz. Die Berner und Genferform kommt in der Central- und Nordostschweiz nicht vor. Die Stitze fehlt vollständig nur im Wallis, Waadtland und in Genf.

\footnotetext{
1 In der Beilage zum Jabrbuch des S. A. C. Band XLIII 1907 erschien eine kleine Monographie "Schweizer Zinnkannen ». Dasclbst findet sich der Passus: "doch finden wir sic (die Glockenkanne) erst nach 173o ". Dicse Jabrzahl bezieht sich nun auf den Schraubenverschluss. Der Setzer hatte drei Zeilen des Manuskripts überhüpft und so den krassen Irrtum verschuldet.
} 

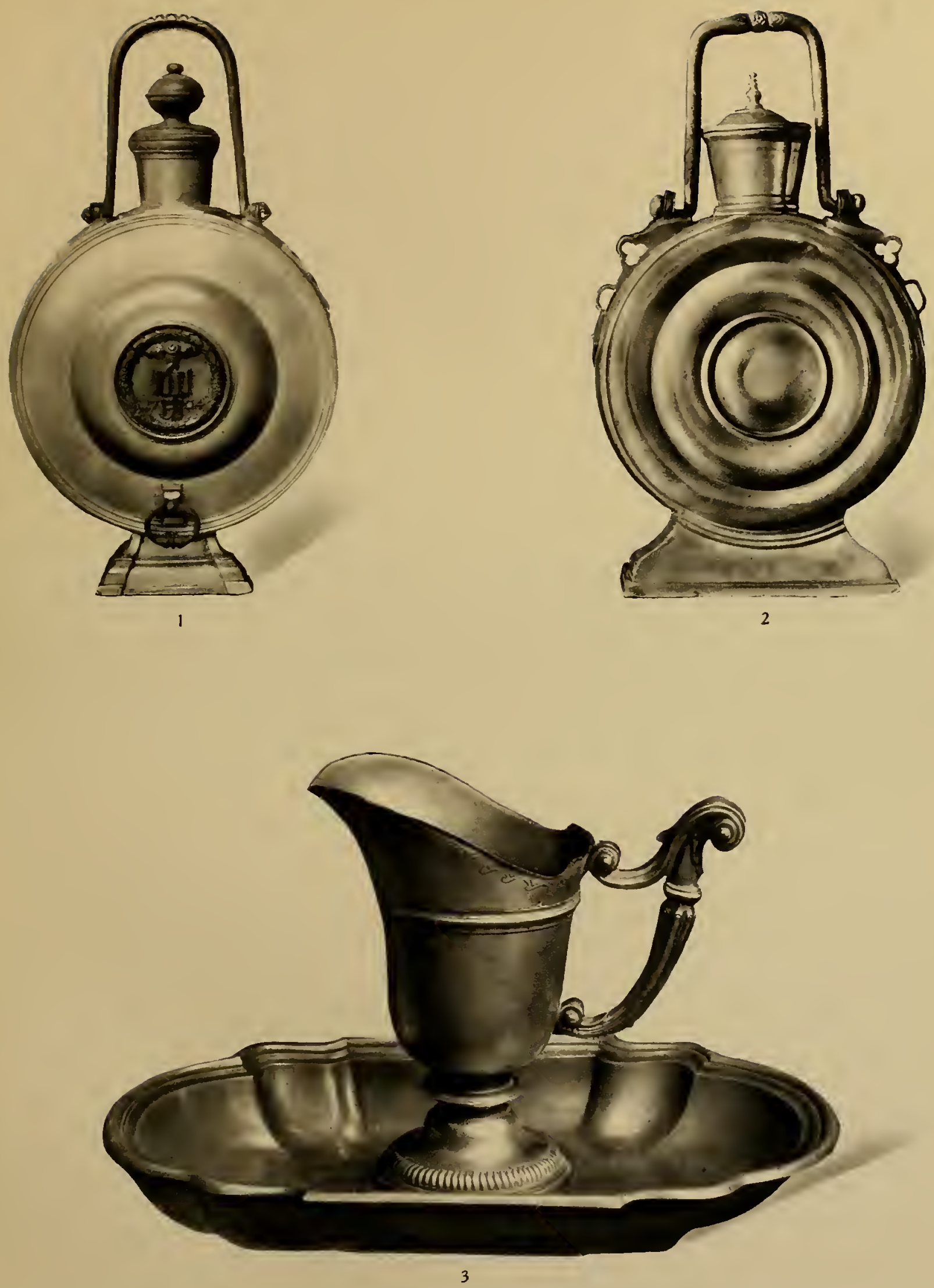

1. Kanne der Universität Basel, von Simon Grynaeus, datirt 1704 (Text S. 39), Höhe $52 \mathrm{~cm}$. 2. Kanne von Kirchenthurnen, von ?, ca. 1700 (Text S. 40), Höhe $49.5 \mathrm{~cm}$. 3. Taufgeschirr von Lukas Wick, 1700-1765, Basel. 

Die Rundelen kommen nur in Basel und Solothurn vor. Die prismatischen Kannen fehlen vollständig in Genf, im Waadtland und Wallis. Die Berner Stegkannen-Form findet sich im Bereiche der heutigen Kantone Bern, Aargau, Solothurn (sehr selten) und Waadt.

\section{Die französischen Stilarten des XVIII. Jahrhunderts}

\section{(Tafeln XXVII, XXVIII und XXIX.)}

In Deutschland und Oesterreich brachten diese Stilarten dem Zinngiesserhandwerk einen gewaltigen Aufschwung; aber nicht im alten Centrum Nürnberg, sondern in Frankfurt am Main, in Augsburg und im böhmischen Karlsbad. Aus diesen Städten kamen bedeutende Mengen von Zinngeschirr auch in die Schweiz. Besonders häufig findet man prächtige Suppenschüsseln und die dazu gehörenden Untersätze, ferner Kannen und Platten, Tafelaufsätze, Confektschalen u.s.w. Die Meistermarken enthalten meistens den vollausgeschriebenen Meisternamen und oft auch die Ortsbezeichnung (siehe E. Hintze, Die deulschen Zinngiesser und ibre Marken, Bd. I-VII).

Bei den Schweizer Zinngiessern fanden diese Stilarten keinen grossen Anklang; nicht einmal in der Westschweiz. Man findet Teller und Platten in den neuen Stilarten, allein im Vergleich zu den Altformen in geringerer Menge. Hintze nennt die Gegenstände des Barok-, Louis XIV.-, XV.- und XVI.-Stiles " $Z$ inn a uf Silberart ", entsprechend dem Silbergeschirr gleichen Stiles. Diese Stilrichtungen hatten das Gute, dass die Zinngegenstände infolge der nach allen Seiten glänzenden gewölbten Flächen fast stets aus Feinzinn hergestellt wurden. In meiner Sammlung befinden sich Teller und Platten von Gabriel II Charton und Jean Charton von Genf; ferner von R. Bosshart, A. und J. Wirz, Rudolf und Friedrich Manz, Lisabeth Manz, Wittwe, von Zürich. In Beromünster befindet sich ein Chorherrenstift; deshalb findet man daselbst oft Messplättchen von den Beromünster-Zinngiessern Franz Anton und Josef Anton Petermann, ebenfalls im Louis XV.- und XVI.-Stile.

Die Gegenstände im Empire- und Biedermeierstil dagegen zeichnen sich durch eine sehr schlechte Zinn-Bleilegierung aus; sogar Zinn und Blei zu gleichen Teilen wurde häufig verwendet. Die schlechte Qualität des Zinngeschirrs half mit, dem ohnehin abnehmenden Zinngiessergewerbe den Todesstoss zu versetzen. Die Leute verloren jegliche Freude an dem schwärzlichen Geschirr (und so geht es heutzutage sogar dem Sammler).

\section{Die Zinnfälschungen}

Nomina sunt odiosa. Ich will bei den Tatsachen bleiben, soweit sie die Schweiz betreffen. Um zu entscheiden, ob ein Zinngegenstand " echt aus der Zeit " sei, bedarf es in allererster Linie einer genauen Kenntnis der Orts- und Meisterzeichen. Allerdings gibt es auch ungestempelte echte Zinnwaren; allein diese bieten dem richtigen Sammler niemals die gleiche Befriedigung wie solche mit echten und guterhaltenen Zeichen. Der Band I und die dem Band II beigefügten, seit 1920 gefundenen Marken, geben wohl die wichtigsten Aufschlüsse. Die Untersuchung der Marken erfolgt mit Hilfe einer guten Lupe. Entsprechend dem Alter ist stets eine " natürliche Abnutzung " vorhanden, welche infolge der häufigen, sorgfältigen Reinigung völlig gleichmässiger und feiner Natur ist. Die "natürliche Abnutzung " bietet dem Fälscher die grössten Schwierigkeiten. Beim imitirten Stempel sind die tiefer gelegenen Partien noch scharf und glänzend, wenn auch die oberflächlichen Conturen abgeschliffen sind. Ferner treten die Fälschungen stets schubweise auf. Auf einmal gibt es z. B. viele gleiche Zürcherstitzen oder Thuner-Stegkannen mit schlecht geschnittenen, oft unscharfen Meistermarken oder mangelhaften Städtewappen.

An den echten Zinngegenständen sind die Zinnmarken oft unvollständig eingeschlagen, oft kaum die Hälfte. Nur die genaueste Stempelkenntnis ermöglicht in diesen Fällen die richtige Orts- und Meisterbestimmung. Besonders schwierig ist dieselbe bei den Engelmarken, obwohl 
auch hier die Zeichnung des Engels hundertfach wechselt. Man untersuche dann das Verhältnis der Buchstabenstellung zu Einzelheiten, z. B. zu den Flügeln des Engels; ferner untersuche man : wo fängt die Umschrift an ? bei welchen Détails sind die Punkte oder Sternchen ?

Nach der Untersuchung der Meisterzeichen kommt die allgemeine Untersuchung des Gegenstandes. Oft ist die Qualität der Zinn-Bleilegierung eine schlechtere; oft ist die Farbe der Patina auffallend schwarz und "gemacht ». Bei den Fälschungen sind die Konturen scharf und eckig; die Verarbeitung der Gusszapfen und Nähte, ferner besonders der Lötstellen, ist eine flüchtige, schlechte : kurz es fehlt die alte fachmännisch-genaue Verarbeitung. Die heutigen Arbeitslöhne sind zu hoch, als dass ein Zinngegenstand sich der grossen Mühe lohnt, im Gegensatz zu den silbernen Falsificaten. Bei den Zinnkannen gibt die Untersuchung der Bodenrosetten aufschlussreiche Resultate.

Nach ausgedehntem Studium der Materie erkennt man bald, dass jeder einzelne Meister seine speziellen Eigentümlichkeiten hatte, oft nur in Kleinigkeiten. Damit kommt man zum Hauptpunkt: das Studium guter Originale allein verschafft alle nötigen Kenntnisse, falls der Sammler über ein gewisses «fast angeborenes» Gefühl verfügt. Bei allen Antiquitäten ist es unumgänglich notwendig, möglichst viele gute Originale zu besichtigen und zu studiren. Mankann die Patina der verschieden guten Legierungen nicht beschreiben, man muss sie sehen. Raffinirte Zinnkenner betasten das Zinngeschirr beim Untersuchen; in der Tat, keine schlechte Methode. Wenn ich an irgend einem Punkte stutzig werde, kaufe ich den Gegenstand nicht; denn stets ist dieses unbestimmte Gefühl des Zweifels die Resultante unterbewusster Summierungen der unsichern Momente. Eine einwandfreie alte Kanne packt den Kenner auf den ersten Blick.

$\mathrm{Zu}$ den schlimmsten Fälschungen gehören die Zusammensetzungen aus alten Bruchstücken. Noch in den Jahren 1890-1 900 waren die "Walliser Kannen ", unter welchem Namen ausser den Wallisern auch die Genfer und Waadtländerkrüge gehandelt wurden, so häufig, dass niemand an eine Fälschung dachte. Meist war nur der Korpus verbeult; Fuss, Hals und Deckel samt dem Henkel waren noch gut. Also schnitt man den Korpus heraus und ersetzte ihn nicht etwa durch einen gleichgeformten, sondern der Seltenheit wegen, durch einen polyedrischen. Ein alter Walliser Händler sagte mir einmal, er habe eine einzige, echte Walliserkanne mit einem solchen Korpus gesehen; ich habe niemals ein echtes Stück finden können. In deutschen und sogar in schweizerischen Museen findet man oft ganze Serien (von 1/2-4 Maass), dieser wunderlichen Gesellen. Selten findet man echte Genf-Walliser Kannen mit einem Ko rpus in Form eines Pyramidenstumpfes oder eines 6-8 seitigen Prismas. Auch hier findet man wieder oft Exemplare, bei welchen ein neuer Korpus an einen alten Kannenhals angelötet wurde. Meist verrät die unverhältnismässige Grösse des Korpus das Falsificat; oft differiren die Legierungen der zusammengesetzten Teile. (Tafel XLVIII.)

Die zur Dekoration an den Kannen angebrachten Ketten sind fast ausnahmslos eine neue Zutat. Der Fremdenverkehr hatte diese "Mode " direkt gezüchtet. Ich habe vielleicht 10-1 2 Kannen gesehen mit Ketten " echt aus der Zeit ». Alle Ketten " à la Pferdezaum " sind falsch, resp. neu.

Eine weitere Zusammensetzung findet sich bei den grossen Pokalen, deren Korpus eine alte Kirchenampel bildet. Der angefügte Fuss entspricht den stilistischen Kenntnissen des Fälschers.

$\mathrm{Zu}$ den Fälschungen sind auch die "Veredlungen " zu rechnen. Auf die glatten Vorderflächen von echten Giessfässern, auf den breiten Rand alter, grosser Platten, auf glatte Kannenpartien, werden Ornamente in Reliefguss, Madonnen, Medaillen aufgelötet " zur Dekoration ". In der Schweiz kommt dies Methode bei den alten Meistern so gut wie niemals vor.

Reliefirte Zinnteller gibt es in der Schweiz nur vier Arten. Auch diese wurden nachgeahmt; doch sind die Conturen meist unscharf; ferner sind die Copien viel dicker und schwerer. Die Abdrehung der Hinterseite ist nicht sorgfältig ausgeführt. Bei den Relieftellern ist grösste Vorsicht am Platze, weil sich nur die besten Fälscher an sie heranmachten. Leider verschacherte der Fremdenverkehr viele solcher Produkte ins Ausland, nicht zum Vorteil schweizerischer Ehrlichkeit. 
Wohl jeder Sammler ist mehrere Male hereingefallen. Man lernt nie mehr, als in diesen Fällen. Ausgedehnte Studien und Kenntnisse sind der beste Schutz; an alles denken und nichts vergessen ! Nach dem Kaufe ist die Erkenntnis zu spät.

\section{Die Kopien}

Wenn der moderne Zinngiesser Zinngegenstände nach alten Originalen lropirt und dann sein eigenes Meisterzeichen darauf schlägt, so handelt er korrekt und niemand wird etwas einwenden. Viele Leute verlangen tadellose Zinnkannen nur zur Dekoration der WohnungsEinrichtung. Im Original sind solche unerhältlich; also werden dieselben neufabrizirt. In vielen grössern Städten der Schweiz gibt es ausgezeichnete Meister, welche den Bedarf decken.

In den letzten Jahrzehnten haben viele Schützengesellschaften Zinnkannen als Schützengaben anfertigen lassen. Dieselben verraten meist den tadellosen, fachmännisch ausgebildeten Meister, welcher seinen Auftrag in allen Teilen kunstgerecht ausgeführt hat. Falls der Besteller mit dem Preise nicht knausert, so ist auch die Legirung des Materiales eine erstklassige ; sonst gilt auch hier der Spruch, den ich auf einer Schaffhauser Kanne von 1792 fand : Wie das Gelt, so die Waar (Marke Nr. 211, Tafel X, Bd. I).

Das Kopiren alter Ratskannen (von Luzern, Zug) ist als bedauerlich zu bezeichnen und verdankt ihre Entstehung meist einer Indiskretion bei der Ausführung von Reparaturen oder der Gleichgültigkeit der den Auftrag gebenden Behörden.

\section{Der Zinnsammler}

Gute Zinnsammlungen sind auch in der Schweiz recht selten, sogar in den Museen. In Basel, Bern, St. Gallen und Genf ist das lokale Zinn recht gut vertreten, ebenso in einigen Privatsammlungen von Genf, Neuenburg, Solothurn, Bern und Basel. Für das Gebrauchszinn verwenden die Privatsammler viel grössere Sorgfalt und ihre Kollektionen stehen qualitativ viel höher als diejenigen der öffentlichen Sammlungen. Im Landesmuseum in Zürich ist der sehr reichhaltige und gute Bestand an Zinn im ganzen Bau zerstreut. Die Kannen und Platten dienen mehr dekorativen $Z$ wecken. In allen Museen sollten alle Falsifikate, Compilationen und "Veredlungen" entfernt werden.

In diesen wenigen Sätzen sind auch die Ratschläge zur Gründung und zum Ausbau einer Privatsammlung enthalten. Man kann sich als Sammler auf die Zinngegenstände eines Ortes beschränken.

Die Lokalsa mmlung umfasst alle erreichbaren Gegenstände eines Ortes unter Berücksichtigung aller Zinngiesser und deren Marken. Auch die Stilarten sollen ihren Platz finden. Nach gründlichem Studium der Orts- und Meisterzeichen findet man bei den schweizerischen Antiquaren überall noch gute Stücke. Am billigsten sind gute Gegenstände niemals am Ursprungsort, weil das Lokalinteresse die Preise hochhält. Der ortsansässige Sammler muss daselbst meist zu viel bezahlen. Das beste und billigste Zuger Zinn habe ich in Luzern, Zürich und Basel gekauft. Einzelne Stücke in Privatbesitz sind meist fast unerhältlich, wveil der Besitzer an den einzigen Gegenstand gewohnt ist und ihn darum für sehr kostbar hält. Oft wird auch Pietät simulirt, um den Preis zu steigern oder sogar die Grossmutter als Zeuge herbeigeholt. Man hüte sich vor der "Story ". Kann man dann endlich einmal den Gegenstand kaufen, so reut es nachher den Besitzer und er erzählt überall, man hätte ihm denselben viel zu billig "abgenommen ». Darum lässt man viel besser solche einzelne Gegenstände durch einen zuverlässigen Händler kaufen. Man kommt hiebei billiger und besser zum Ziele, weil der Berufshändler den Einkauf besser versteht und keine privaten Rücksichten zu nehmen hat. Gegenwärtig stehen die Preise im Antiquitätenhandel ziemlich tief; der kluge Sammler soll nicht warten bis die Zinnmode wieder an die Reihe kommt. Ein rascher Entschluss hat mir schon manches gute Stück gebracht, welches ich nachher niemals mehr gefunden habe. 
Andere Sammler befassen sich nur mit bestimmten Gegenständen, z. B. Kannen, Platten, Leuchter u. dgl. Dadurch wird die Ausdehnung des Sammelgebietes bedeutend grösser, besonders wenn alle Grössen und Formen einbezogen werden. Dazu braucht es ausser Kenntnissen, Findigkeit und Glück noch einen guten Geldbeutel. Solche Sammlungen sind sehr vielseitig und interessant. Am besten beschränkt man sich auch in diesem Falle auf die Schweiz; sonst entsteht ein uferloses Kunterbunt.

Die Neuanlage einer allgemeinen schweizerischen Sammlung ist wohl kaum mehr möglich, weil die besten Stücke schon in festen Händen sind.

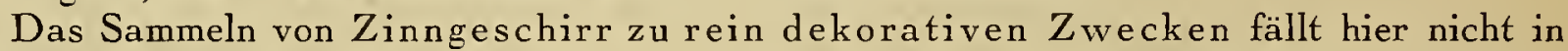
Betracht. In diesem Falle kommt es auch nicht auf die Echtheit der Gegenstände an; denn gute moderne Kopien erfüllen den gleichen Zweck. Es gibt ja heute noch wirklich gute Meister in Zürich, Luzern, Schaffhausen, Bern, Vevey, Visp, Leuk, u.s.w.

Die Reparaturen. Gegenstände aus dem XV. und XVI. Jahrhundert soll man niemals blank reinigen. Man lasse die Patina, das Zeichen des hohen Alters. Kleine Löcher und Beulen stören bei den ältesten Gegenständen ebenfalls nicht. Man beschränke sich auf die Entfernung des Schmutzes und des Kalkes. Falls Zinnpest besteht, so verlangt deren Beseitigung gründliche Kenntnisse (siehe unter " Zinnpest "), sonst kann ein besonders altes Stück zugrunde gehen. - Die jüngern Zinngegenstände, besonders des XVIII. Jahrhunderts, kann man repariren lassen, doch nur bei einem guten Fachmann, bei einem modernen Zinngiesser. Auch in diesen Fällen soll die Reparatur nicht zu weit gehen. Besonders zu verpönen ist die Politur mit Maschinen. Auch ein antiker Gegenstand, in Hochglanz polirt, hat für den richtigen Sammler den Wert verloren; besonders wenn bei diesen Prozeduren auch noch die Meisterzeichen verschliffen wurden. Man untersuche jeden reparirten Gegenstand auf das Genaueste und achte besonders darauf, ob keine alten Zinnmarken in ungestempelte echte Zinngegenstände eingesetzt wurden. Ferner hüte man sich vor den Zusammensetzungen alter Fragmente und vor den "Veredlungen », z. B. vor aufgelöteten reliefirten Figuren u. dgl. Dem zusammengesetzten Gegenstand fehlt stets die stilistische Einheit.

Bei den Genfer, Waadtländer und Walliser Kannen lässt man die neuen Ketten (in Form der Pferdezaumketten) am besten vieder entfernen. Die schöne Kannenform tritt dann wieder besser zutage.

Das Reinigen des Zinngeschirrs. Vor Allem muss der oft Jahrzehnte alte Schmutz mit heissem Seifenwasser und Bürste entfernt werden; die Bürste soll nicht zu hart sein. Eine Metallbürste oder Stahlspähne dürfen niemals verwendet werden, vveil sonst unzählige Kratzer entstehen. Stets muss mit viel heissem Wasser nachgespült werden. - Wiener Kalk, Sigolin und Geolin verwende man nur recht spärlich und entferne ihre Spuren aus Ritzen, Rillen und Ecken auf das sorgfältigste, weil nach dem Trocknen die weiss-ausgefüllten Stellen einen sehr schlechten Eindruck machen. Am besten nimmt man hiezu eine feine steife Borstenbürste. Nach Entfernung aller Unreinigkeiten reibe man das Geschirr mit zusammengekrülltem Zeitungspapier lange und kräftig ab; so erhält man den schönen, matten und seidigen Glanz.

Das Reinigen mit Salzsäure-Wasserlösungen bedarf grosser Uebung, sonst ist bald grosser Schaden angerichtet, besonders in den Lötfugen. Ist das Zinngeschirr einmal sorgfältig gereinigt, so bleibt es - im Gegensatz zum Silber - Jahre lang blank und muss nur vom Staub befreit werden. Muss man es wieder reinigen, so bediene man sich der uralten Methode mit Seifenwasser und Schachtelhalmen. Letztere nennt man häufig "Zinnkraut ". Diese Reinigungsart eignet sich auch sehr gut für das moderne Dekorationszinn. Das Nachreiben mit Zeitungspapier gibt auch hier unerwartet schöne Resultate. 
TAFEL IX


1. Bulge der Kirchgemeinde Lenk, von Jakob III. Wyss, Bern, datirt 1666 (Text S. 40), Höhe $51 \mathrm{~cm}$. 2. Bulge mit dem Wappen von Steiger, von Samuel Kuhn, Bern, 1634-88 (Text S. 40), Höhe $30 \mathrm{~cm}$. 3. Bulge mit dem Wappen von Diesbach, von Adam Scherer, Bern, erwähnt 1687 (Text S. 41), Höhe $28.5 \mathrm{~cm}$. 4. Bulge in Basler Privatbesitz, von Johannes Küpfer, Bern, erwähnt 1695 (Text S. 41), Höhe $26 \mathrm{~cm}$. 



\section{$\mathrm{Al}_{\text {phabetisches }}$ Meisterverzeichnis der schweizerischen Zinngiesser}

A.

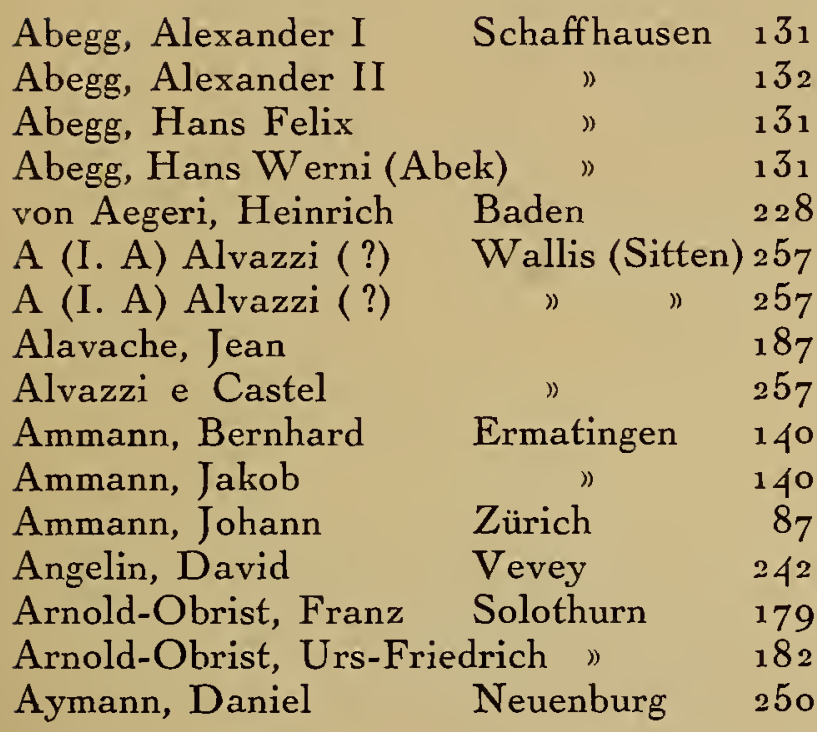

B.

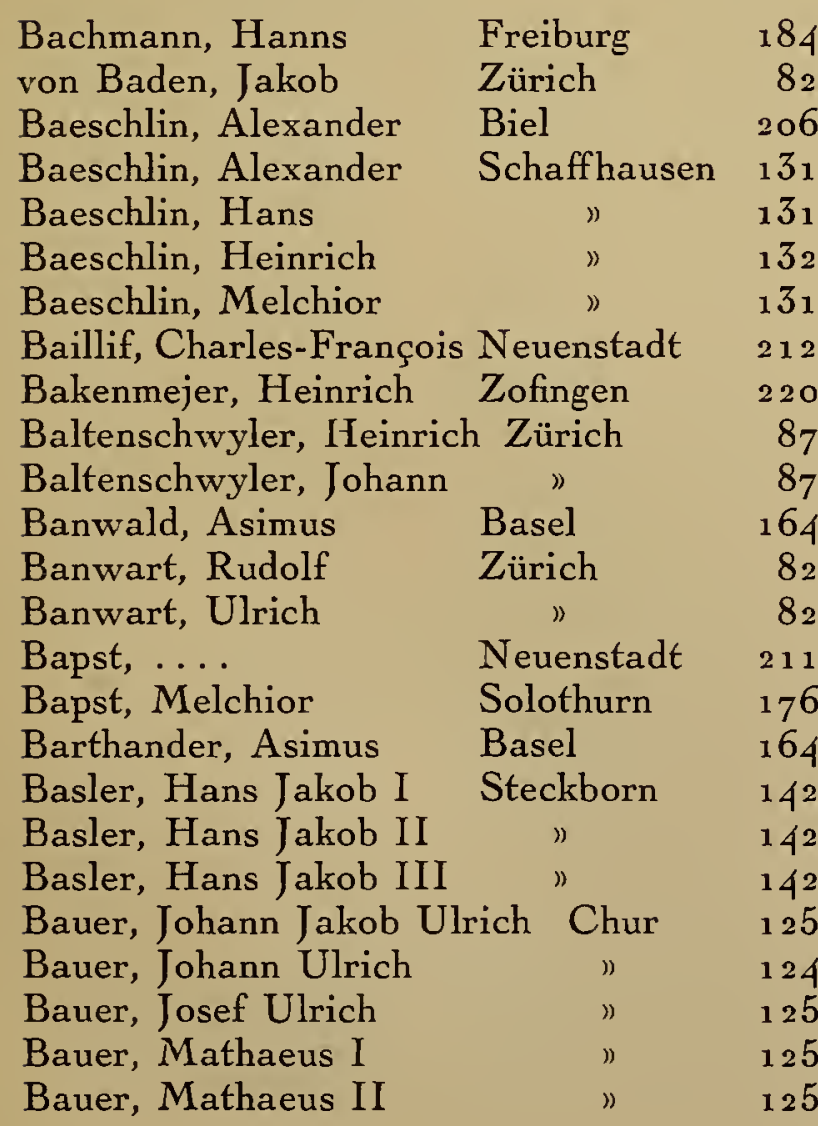

Baumgarter, Adrian

Baumgarter, Niklaus I

Baumgarter, Niklaus II

Baumgarter, Peter I

Baumgarter, Peter II

Beck, Christoffel Jakob

Beck, Johann Arnold

Beck, Johann Jakob

Beck, Martin

Beneti, Georg

Benker, Erhart

Benker, Hans Rudolf

Benker, Jonas

Bergmatter, ....

Berlocher, Hans Jakob

von Bern, Jörg

Bernard, Guérrin

Bernhard, Adam

Bernhard, Adam

Bianca, Della, Lorenzo

Bianca, Della, Louis

von Biel, Adam

von Biel, Adam

Biermann, Hans Cunrat

Biermann, Johann Ernst

Bigiuli, Sébastien

Blasi, Franz

Boden, Niklaus

Bodmer, Hans Cunrat

Bodmer, Hans Ulrich

Bodmer, Samuel

Boenger, Zacharias I

Boenger, Zacharias II

Boenger, Zacharias III

Boertly, Hanns

Boesch, Hans Heinrich

Boesch, Johannes

Boine, Olivier

Boisdechesne, Antoine

Bomonti, A.

Bon, Jean

Boner, Ulrich

Bonhôte, Abram

Bonhôte, François

Bonvespre, Abraham
Bern $\quad 193$

1) 192

) 193

" 192

" 193

Basel $\quad 166$

Aarau 214

Basel $\quad 166$

Aarau $\quad 215$

Lausanne $\quad 236$

Diessenhofen 144

" 144

Luzern 144

Rheineck $\quad 154$

Freiburg $\quad 184$

185

Solothurn $\quad 175$

Neuenstadt 211

Wallis (Visp) 258

" $\quad 259$

Biel 206

Solothurn $\quad 175$

Basel $\quad 165$

Freiburg $\quad{ }_{187} 87$

Obwalden 118

Freiburg $\quad 184$

Zürich $\quad 86$

") 86

Bern $\quad 196$

St. Gallen $\quad 147$

147
11

Zürich $\quad 82$

Rheineck $\quad 154$

") 154

Freiburg $\quad 184$

Genf 230

Bern 202

Bulle (Freib.) ${ }_{1} 87$

Zürich $\quad 82$

Neuenburg $\quad 250$

250

248 
Bonvespre, Henry

Borel, Erhard

Borel-Fabry

Borel, Jean-Jacques

Borlier, Heinrich

Borocho, Peter

Bosshart, Hans Conrad Zürich

Bosshart, Hans Heinrich "

Bosshart, Hans Jakob I "

Bosshart, Hans Jakob II "

Bosshart, Hans Rudolf "

Bosshart, Hans Ulrich "

Bosshart, Jakob

Bosshart, Konrad

Bourrelier, Jean

Bourrelier, Léonard I

Bourrelier, Melchisédec

Bourrelier, Pierre

Boyve, Abram

Boyve, Daniel

Boyve, David

Boyve, François

Boyve, Frédéric

Boyve, Jakob

Boyve, Jérémias

Boyve, Josué

Boyve, Josué

Boyve, Noë

Boyve, Samuel

Boyve, Simon

Brachner, Heinrich

Brakh, Martin

Brandschorer, Paul

Breitinger, Wilhelm I

Breitinger, Wilhelm II

von Bremgarten, W.

Bremme (Bremi), Ulrich Zürich

Breny, Johann Heinrich Rapperswil

Breny, Kleinhans

Breton, Jean

Bridler, Johann Baptist

Broije, Samuel Joseph

Brombach, Christoffel

Brunet, Jakob

Bucher, Hans

Bumann, Zacharias

Burde, Burdi, Jacques

Burger, Hans Rudolf

Burguner, ....

Bern

Neuenburg

")

Bern

Bremgarten

Luzern

(Beromünster)

Zürich

'Luzern

Neuenburg

Bischofszell

Estavayer

Basel

Genf

Obwalden

Schaffhausen

Freiburg

Basel

Neuenstadt

Burkardt, Johann Albrecht Freiburg
251

206

202

89

89

89

89

89

89

88

89

231

230

231

231

249

249

249

249

249

249

249

249

196

249

249

249

195

218

166

112

87

87

110

83

159

159

249

139

188

166

231

118

131

184

168

211

186
Burkhardt, Hans Rudolf Basel

Burkhardt, Rudolf

Burkhardt, Samuel

Buschi, Hans

Byss, Wilhelm

B. (A. I. B.)

B. (F. B.)

B. (G. B.)

B. (HH. B.)

B. (I. B.)

B. (I. B.)

B. (I. B.)

B. (I. B.), Jean Bon

B. (I. B.)

B. (H. R. B.)

B. (R. B.)

B. (P. B.)

")

Freiburg $\quad 184$

Solothurn $\quad 177$

Appenzell $\quad{ }_{162}$

Freiburg $\quad 184$

Wallis $\quad 256$

Stein a. Rhein 98

Appenzell $\quad \mathbf{1 6 2}_{2}$

Wallis $\quad 256$

Neuenstadt 212

Freiburg (Bulle) 188

$\begin{array}{ll}\text { Solothurn } & 178\end{array}$

Thun 203

) 203

c.

246

de Cadenath, Hans Luzi I Chur 123

de Cadenath, Hans Luzi II " 124

de Cadenath, Hans Luzi III " 124

de Cadenath, Herkules I " 124

de Cadenath, Herkules II

de Cadenath, Hertli

Cane, F.

Cane, G.

Cane, $\mathrm{P}$.

Cane M. F. P. Fratelli

Cantin, ....

Castel, Joseph

Castelmur, G.

Chaillet, Théodore

Challandat, Pierre

Charton, Antoine I

Charton, Antoine II

Appenzell

124

123

162

162

162

162

Charton, Estienne

Charton, Gabriel I

Freiburg

186

Charton, Jean I

Charton, Jean II

Wallis, Sitten 257

Chur

122

Neuenburg 249

Freiburg $\quad 184$

Genf 231

Charton, Jean-Antoine

Charton, Marc

Châtelain, Claude

Châtelain, Jean-Jacques

Chattonay, Jakob

)

231

230

232

232

232

231

232

Chevalier, Jean

Classen, Abram-Isaac

Classen, Frédéric-Antoine "

250

250

Classen, Louis-Auguste

Claude, Pierre-Paul

"

Neuenburg

189

Constançon, Jakob

Genf

Correvon, Pierre-Marc

Neuenburg
248

${ }_{23} 3$

232

232

250

232

250 


\begin{tabular}{|c|c|c|c|c|c|}
\hline Cougnard, Pierre & Genf & 232 & Favarger, Jonas & Neuenburg & 248 \\
\hline Crissier, Hanns & Freiburg & 184 & Fechter, Wolf & St. Gallen & 146 \\
\hline \multirow[t]{2}{*}{ Crissier, Hanns } & Murten & 189 & Fehr, Adam & Frauenfeld & 138 \\
\hline & & & Fehr, Daniel & St. Gallen & 148 \\
\hline \multirow{2}{*}{\multicolumn{2}{|c|}{ D. }} & & Fels, Conrad & $n$ & 147 \\
\hline & & & Finsterling, Cyrill & ) & 147 \\
\hline Daller, Hans Jakob & Bischofszell & 139 & Fisch, Johann Georg & Aarau & 214 \\
\hline Dappaz, Louis & Lausanne & 234 & Fisch, Johann Heinrich & $»$ & 215 \\
\hline Debong, Hartmann & Delsberg & 212 & Fizaula, David & Murten & 89 \\
\hline Decarli, .... Gla & ad bei Morges & 246 & Flügel, Salomon & Bern & 96 \\
\hline Diaceri, E. & Bern & 202 & Foppell, Cunrat & Zofingen & 20 \\
\hline de Diesse, François & Neuenburg & 249 & Forrer, Abraham & Winterthur & $9^{6}$ \\
\hline Dietzi, Lienhart & Bern & 197 & Forrer, David & $"$ & 97 \\
\hline$r$, Isaac & Glarus & 121 & Forrer, Heinrich & $"$ & 96 \\
\hline Dittlinger, Heinrich & Bern & 192 & Fracheboud, Franz & Freiburg & 85 \\
\hline Dittlinger, Jakob I & $n$ & 195 & Frantz, Philippe & $\eta$ & 84 \\
\hline Dittlinger, Jakob II & ” & 195 & eysy, .... & Orbe & 244 \\
\hline Doret, Philippe-Benjami & n Vevey & 242 & Frenk, Conrad & St. Gallen & 146 \\
\hline $\mathrm{Du} . . .$, Jakob & Luzern & 112 & Freudweiler, Joh. Jakob & I Zürich & \\
\hline Dub, Claus & Basel & 164 & Freudweiler, Joh. Jakob & II & 90 \\
\hline Dubourg, Jean & Vevey & 237 & Frey, Jost Münster in & n Berner Jura & 212 \\
\hline Duperron, Henri-Franço & is Neuenburg & 249 & Freytag, Hans Jakob & Zürich & 87 \\
\hline Dürler, Anton & St. Gallen & 150 & Fridenrich, Hans & Basel & 165 \\
\hline & & & arich, Hans Jakob & $n$ & 165 \\
\hline $\mathrm{E}$ & & & enrich, Jakob & 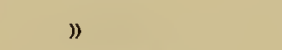 & 165 \\
\hline & & & nger, Fridolin & Rappe & 159 \\
\hline Eberhart, Hans Freidric & h Biel & 208 & Friederich, Jakob & St. Gallen & 147 \\
\hline Ebneter, Hans Jakob & Basel & 167 & Friedrich, Diebold & Basel & 164 \\
\hline Eckart, Cunrat & Zürich & 228 & Frikart, Daniel & Zofingen & 227 \\
\hline Eckert, Christoffel & Baden & 82 & Frölich, Hans Rudolf & Brugg & 217 \\
\hline L'Ecuyer, Jean Jacques & Neuenburg & 250 & Frölich, Johann Rudolf I & $1 "$ & 217 \\
\hline Ehrhart, Franz & Wyl & 157 & Frölich, Johann Rudolf I & II $"$ & 217 \\
\hline Eiselin, Jakob & Bern & 200 & Frossard, Samuel & Moudon & $24^{5}$ \\
\hline Engelhart, Peter I & $\eta$ & 195 & Fuchs, Lienhard & Bern & 194 \\
\hline Engelhart, Peter II & $\eta$ & 195 & Furer, Johann Heinrich & Winterthur & 97 \\
\hline Enok, Hanns & Zürich & 82 & F. (I.R.F.) & Freiburg & 187 \\
\hline Entli, Michel & Luzern & 110 & F. (S. H. F.) & Stein a. Rhein & $9^{8}$ \\
\hline
\end{tabular}

Ertzberger, Willi $\quad$ Freiburg 184

Eschaux, Virgil Lausanne 234

Etli, Franz Obwalden 119

Etli, Hans Josef " 118

Etzweiler, Hanns Jakob Stein a. Rhein 98

Etzweiler, Johann Caspar " $\quad 98$

$\begin{array}{lll}\text { E. (H. I. E.) } & \text { Sargans } & \mathbf{1 6 1} \\ \text { E. (H. I. E.) } & \text { Herisau } & \mathbf{1 6 2} \\ \text { E. (I. C. E. } & \text { Appenzell } & \mathbf{1 6 2}\end{array}$

F.

Faesch, Gustav Heinrich Basel

Ganting, Abraham

G.

Gacci, .... Wallis $\quad 256$

Galdi, Oswald (od. Guldi) 193

Galinger, Wilhelm Wyl $\quad$ 56

Gallot, Henry Neuenburg 250

Gallot, Jacques

Gamba, Gotardo

Gamba, Gotardo

Gamba, Gotardo

Falk, Johann u. Caspar Baden 228

Fassnacht, Antoni

Solothurn $\quad 175$

Ganting, Jakob

") 249

Tessin $\quad 259$

Uri $\quad 117$

Schwyz $\quad 115$

Bern 198

Gasser, Jakob " 192

Gasser, Johann " 192 


\begin{tabular}{|c|c|c|c|c|c|}
\hline Gaudet, Frédéric & Neuenburg & 249 & Gugger, Johannis & Solothurn & 176 \\
\hline Gaudy, Abraham & Genf & 232 & Gugk, Hanns & Zürich & 82 \\
\hline Gaudy, Etienne & $"$ & 232 & Guillebert, Jean-Henry & Neuenburg & 250 \\
\hline Gebhart, Geronimus & Basel & 165 & Guldi, Oswald & Bern & 193 \\
\hline Genelat, Samuel & Zofingen & 225 & Guldin, Melchior & St. Gallen & 146 \\
\hline George, Jaques & & ${ }_{1} 87$ & Gyr, Hans & Freiburg & 184 \\
\hline Gerster, Hans & Bern & 193 & G. (I. B. G.) & Wallis & 256 \\
\hline Giezendanner, Georg & Lichtensteig & 160 & G. (I. G.) & ) & 256 \\
\hline Gippa, frères & Vevey & 243 & G. (P. A. G.) & ) & 256 \\
\hline Girtanner, Friedrich & St. Gallen & 149 & G. (W. G.) & Solothurn & 178 \\
\hline Girtanner, Hieronimus & ” & 146 & \multirow{2}{*}{\multicolumn{3}{|c|}{$\mathrm{H}$. }} \\
\hline Girtanner, Joachim I & $n$ & 149 & & & \\
\hline Girtanner, Joachim II & ) & 149 & Halder, David & St. Gallen & 152 \\
\hline Girtanner, Joachim III & 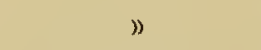 & 149 & Halder, Friedrich & $n$ & 152 \\
\hline Girtanner, Johannes & $\eta$ & 149 & Halder, Jakob & ) & 148 \\
\hline Girtanner, J. & Lichtensteig & 160 & Hamberger, Samuel I & Zürich & 84 \\
\hline Glaner, Caspar & Bern & 194 & Hamberger, Samuel II & $n$ & 84 \\
\hline Glaner, Samuel & ) & 195 & Har, Antoni & Bern & 193 \\
\hline Glaser, Hans & Luzern & 109 & Harlapp, Cunrat & Aarau & 213 \\
\hline Glinz, Jakob & St. Gallen & 149 & Harlapp, Melchior & 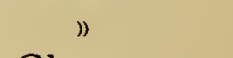 & 213 \\
\hline Gloggner, Beat Ludwig & Luzern & 110 & Harnist, Johann & Chur & 123 \\
\hline Gloggner, Franz & ) & 111 & Harnist, Otto & ) & 123 \\
\hline Gloggner, Josef & ) & 111 & im Hasle, Hans & Luzern & 109 \\
\hline Gmünder, Jakob I & St. Gallen & 149 & Haussknecht, Heinrich & St. Gallen & 152 \\
\hline Gmünder, Jakob II & » & 149 & Hayoz, Josephe & Freiburg & 186 \\
\hline Gmünder, Johann & ” & 149 & Heid, Hans & $n$ & 184 \\
\hline Goldner, Alexandre & Lausanne & 236 & \multicolumn{3}{|c|}{ Heidegger, Hans Heinrich Zürich } \\
\hline Goldner, Charles-Christo & Orbe & 244 & Heller, Hans Caspar & Winterthur & 97 \\
\hline Goldner, Charles-Gabriel & ) & 245 & Hemmann, Daniel & Bern & 199 \\
\hline Goldner, Louis & Vevey & 243 & Hemmet, Friedrich Nikl & Biel & 210 \\
\hline Goncet, Pierre & Waadt & 241 & Hempel, Christoffel I & Chur & 122 \\
\hline Gottschalk, Johann Wilh & Aarau & 215 & Hempel, Christoffel II & $n$ & 123 \\
\hline Graf, Antonius I & Wrinterthur & 96 & Henman, .... & Zürich & 82 \\
\hline Graf, Antonius II & ") & 96 & Hentz, .... & Bern & 192 \\
\hline Graf, Hans Heinrich & $"$ & 96 & eli, David & Neuenburg & 248 \\
\hline Graf, Hans Rudolf & ) & 96 & Henzeli, Jacques & ” & 248 \\
\hline Graf, Hans Ulrich & $\eta$ & 96 & Herbst, Thomas & Freiburg & 184 \\
\hline Graff, Christoph & Solothurn & 178 & Herbst, Ulli & 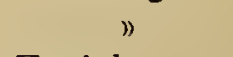 & 184 \\
\hline Graff, Joseph & ) & 179 & Herer, Paulus & Zürich & 82 \\
\hline Graff, Urs Victor & ") & 182 & Herd, Hans & Freiburg & 184 \\
\hline Grailliex, Jakob & Freiburg & 184 & Herfart, Baschi & Luzern & 109 \\
\hline Grineus, Philipp & Basel & 164 & Herfart, Benedict & $"$ & 109 \\
\hline Griner (Grineus?) Jakob & $\eta$ & 165 & Herrmann, Rodolphe & Neuenburg & 250 \\
\hline Gritz, Heinrich & Solothurn & 178 & Heydegger, Hans & Zürich & 83 \\
\hline Gritz, Niklaus & ) & ${ }_{180}$ & Hiller, Abraham & St. Gallen & 151 \\
\hline Gritz, Philipp & ) & 181 & Hiller, Adrian I & " & ${ }_{1} 5_{1}$ \\
\hline Grob, Hans Jakob & Zïrich & 87 & Hiller, Adrian II & $»$ & 152 \\
\hline Grob, Jakob & $n$ & 87 & Hiller, Gallus & $"$ & 147 \\
\hline Grob, Rudolf & $\mathrm{W}^{T}$ interthur & 96 & Hiller, Heinrich I & $"$ & 151 \\
\hline Grütter, Johann Rudolf & Bern & 197 & Hiller, Heinrich II & $n$ & 151 \\
\hline Grynaeus, Hans Jakob & Basel & 169 & Hiller, Heinrich III & 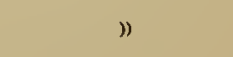 & 151 \\
\hline Grynaeus, Simon & " & 168 & Hiller, Heinrich IV & ) & 151 \\
\hline
\end{tabular}


Hiller, Josua

Hiller, Othmar

Hiller, Sebastian

Hiller, Silvester

Hindenlang, Peter

Hitz, Daniel

Hoechner, Johann

Hoffer, Moritz

Hoffmeister, Jakob

Holzhalb, Anderes

Holzhalb, Hans

Hornberg, Hans

Hoscheller, Johann

Hotinger, Gotthard

Hottinger, Hans I

Hottinger, Hans II

Huber, Hans

Huber, Hans Cunrat

Huber, Marx

Huber, Werni

Huebsch, Niclaus

Huebsch, Nicolas

Huepschi, Dietrich

Huepschlin, Dietrich

Huersch, Johann

Hug. ....

Hug, ....

Huguenaud, Jonas

Huguenaud, Samuel

Humler, Thomas

Hummel, Michael

Hunziker, Hans Heinrich

Huntzikerin, Frau Maria

Huober, Beat

Hurter, Hans Conrad

Hurter, Hans Jakob

H. (H. A. H.)

H. (H. I. H.)

\section{I, J.}

Jaeger, Hans Dietrich I Brugg

Jaeger, Hans Dietrich II

Jaeger, Johann

Jaus, Franz Josef

Jaus, Josef Anton

Jaus, Urs

Jeger, Bendicht

Jeger, Heinrich

Jenetti, J. M.

Iselin, Andreas

Iselin, Hans I.ux od. Johannes

Wyl

Chur

"

)

Basel

"

Bern

Basel

Bern

Bern

Basel
St. Gallen

148

147

152

Rheineck

Zofingen

Zürich

Luzern

Schaffhausen

Zürich

Zürich

Luzern

Neuenburg

Solothurn

148

156

126

154

222

87

83

84

109

135

165

84

84

195

84

165

110

192

248

175

Zofingen 225

Solothurn $\quad 175$

Bern $\quad 192$

Neuenburg $\quad 248$

Zofingen

Zofing

Aarau

165

213

Basel 165

Schaffhausen $\quad 133$

Rorschach 133

${ }_{1} 55$

155

" 155

Solothurn $\quad 181$

178

206

$\begin{array}{ll}\text { ") } & 206 \\ & \mathbf{1 3 8}\end{array}$

168

Basel 166
Isenring, Michael

Wyl

157

I. (P. A. I.)

Freiburg

186

$\mathrm{K}$.

Kapeller, Hans Ulrich Frauenfeld $\quad{ }_{13}$

Kapfmann, Jakob St. Gallen 146

Keiser, Beat Jakob, Josef Anton Zug 105

Keiser, Carl Oswald

Keiser, Jakob David

Keiser, Joachin Leonz

Keiser, Joachim Michael

Keiser, Oswald

Keiser, Wolfgang Leonz

Keller, Franz

Keller, Hans Conrad

Keller, Hans Joachim.

Keller, M. Jakob

Klein, Antoine

Klein, Herrmann

Klein, Jakob

Koch, Adam

Koch, Crispian

Koelner, Jakob

Koerner, Hans Rudolf

Kolb, Hans

Koler, Rudolf

Kolmar, Johannes

Kolmar, Johann Jakob I

Kolmar, Johann Jakob II

Kolmar, P.

Krackh, Baptista

Krentzli, Sebastian

Krieg, Lienhart

Krittli, Hans

Baden $\quad 228$

Weinfelden 143

" 143

Aarau $\quad 213$

Freiburg $\quad 185$

Basel 171

1) 164

Wyl $\quad 155$

1) $\quad 155$

Biel $\quad 206$

Zürich 83

Bremgarten $\quad 218$

Bern 193

Schaffhausen $\quad{ }_{1} 33$

Krüger, Guillaume Wrerner ${ }^{r}$ (a)

Kuechlin, Hans Jakob Diessenhofen 144

Kuhn, Samuel

Kunz, Caspar I

Kunz, Caspar II

Kunz, David

Küpfer, Johannes

Küpfer, Peter

Bern $\quad 195$

St. Gallen 147

Zug 102

Zofingen 221

Pruntrut 212

" 148

147

Bern 195

" 195

L.

Labhardt, Hans Heinrich Steckborn 142

Lachmund, Julius Zürich 90

Lacombe, Jean-François-Louis I Genf $\mathbf{2 3 2}$

Lacombe, Jean-Henry Genf 233

Lacombe, Louis I Lausanne $\quad \mathbf{2 3 6}$

Lacombe, Maurice-Louis II Genf 233

Lacombe, Philippe Genf $\quad 232$ 
Lacombe, Philippe

Lausanne

de Lafontaine, Estienne Genf

de Lafontaine, Pierre I "

Lambert, Franz Bern

Lambert, Franz Felix Solothurn

Lambert, Josef

Lambert, Urs Victor

Lambert, Victor

Lang, Johann Friedrich

Lang, Johann Friedrich Burgdorf

Lange, Heinrich Wilhelm Chur

Langenhart, Michael

Larget, Pasquier

Laufer, Daniel

Laufer, Jakob

Lauffer, Jakob

Lauffer, Jakob Friedrich

Leemann, Hans

Lichtenhan, Mathaeus

Lienhart, Abraham

Lienhart, Adam

Lienhart, David

Lienhart, Sebastian

Linder, Hans Lukas, od. Johannes I

Linder, Johannes II

Linder, Johannes III

Linder, Niklaus I

Linder, Niklaus II

Liouna, Jean

Locher, Jakob

Lochmann, Apollinarius

Lochmann, Hans

Loew (Löw), Abraham

Lombard

Ludwig, Mathaeus

Lüthert, Xaver

Wyl

Neuenburg $\quad 248$

Zofingen 222

222

Eglisau

Zürich
Basel
Bern
"
"
"

Basel

"

")

")

"

Lausanne

St. Gallen

Basel

")

Burgdorf

Lausanne

Chur

Luzern

Luthiger, Josef Wolfgang

L. (I. L.)

Zug

Freiburg

M.

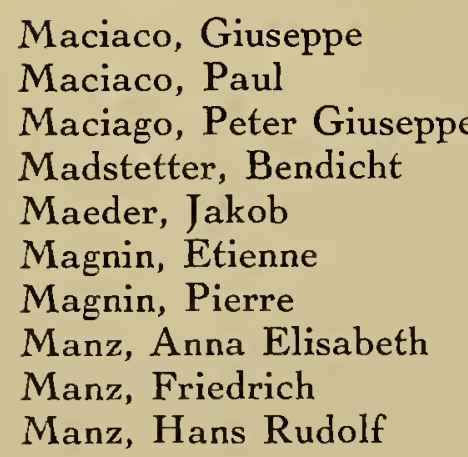

Wallis (Brig) ${ }_{258}$

" 258

Biel 206

Basel $\quad 165$

Vevey

Zürich

)

))
258
258

201

182

181

182

182

226

204

126

57

98

$9^{8}$

83

165

196

194

194

195

166

170

$17^{\circ}$

168

169

234

147

165

165

204

235

123

112

103

187

240

241

90

90

9o
Manz, Johann Caspar Zürich

89

Manz, Magdalena Elisabeth " 9o

Marti, Johannes Glarus 121

Martin, Meister Solothurn $\quad{ }_{175}$

Marty, Rudolf

Biel

206

Marx, Barthlime

Wyl

157

Matschi, Hans

Meier, Kilian

Meier, Hans Georg

Zofingen 220

Meley, Jakob Friedrich

Merz, ....

Merz, Joachim

Meyer, Hans

Meyer, Hans

Meyer, Jakob Hans

Meyer, Jakob I

Meyer, Jakob II

Meyer, Ludwig

Meyer, Wolfgang

Meyle, Hans Felix

Michel, Meister

Michel, Martin

Michod, David

Basel

164

169

Bern 201

Luzern 110

St. Gallen $\quad \mathbf{1 5 2}$

Zürich 83

Stein a. Rhein $9^{8}$

98

Schaffhausen ${ }_{1} 35$ (Hallau)

" 35

Solothurn $\quad 181$

Michod, J.-François von Miltenberg, Hans

Mittelholzer, Caspar

179

Zürich $\quad 87$

Luzern $\quad 109$

Freiburg $\quad 186$

Yverdon $\quad 243$

") 244

Bern 192

Moerigkoffer, Hans Jakob I Frauenfeld ${ }_{13} 3$

Moerigkoffer, Hans Jakob II " 138

Moos, Joachim $\quad$ St. Gallen 147

Mor, Sigmund

Morat, ....

Morel, Jacques I

Luzern $\quad 109$

Freiburg $\quad 184$

Morel, Jacques II

Morel, Jacques II

Morel, Jean François II "

Morel, Pierre "

Moret, François

Moriggi, Charles I

Moriggi, Charles II

Moriggi, Dominico

Moriggi, Louis-Charles

Morigi, Achille

Morigi, Charles I

Morigi, Dominico

Moser, Andreas

Motheux, Mathurin

Motta, Jean Henry

Müeg, Hans Wilhelm

"

187

Vevey 243

) 243

Müeg, Wilhelm

Müg, Niklaus

Müller, Andreas

Müller, Christoffel
243

243

Neuenburg $\quad 251$

252

251

Schaffhausen $\quad 134$

Neuenburg $\quad 250$

250

Zürich 83

83

83

Zug

103

Freiburg $\quad 187$ 


Müller, Daniel
Müller, Hans
Müller, Heinrich
Müller, Hans Melchior
Müller, Jakob Martin
Müller, Johann Rudolf
Müller, Lienhart
Müller, Melchior
Müller, Michael
Müller, Oswald
Müller, Peter
Müller, Peter Roman
Müntschi, Hans
Müög, Hans Wilhelm
Murer, Hans Cunrat
Murrer, Salomon
Mury, ...
M. (I. M.)
M. (I. M.)
M. (L. M.)

$\begin{array}{lr}\text { Zofingen } & 223 \\ \text { Zug } & 224 \\ \text { Wyl } & 103 \\ \text { Zug } & 157 \\ \text { Zofingen } & 103 \\ \quad \text { " } & 225 \\ \text { Frauenfeld } & 221 \\ \text { Zofingen } & 137 \\ \text { Zug } & 221 \\ \text { Freiburg } & 103 \\ \quad \text { " } & 186 \\ \text { Biel } & 186 \\ \text { Zürich } & 206 \\ \quad \text { " } & 83 \\ \quad \text { ” } & 86 \\ \text { Uri } & 86 \\ \text { Bischofszell } & 116 \\ \text { Freiburg } & 139 \\ \text { Wallis } & 187 \\ & 258\end{array}$

N.

Naffzger, Franz Ludwig Naffzger, Franz Ludwig II

Niklaus, .... Meister

Niklaus, .... Meister

Nötiger, David

Nuikom, Heini

O.

\begin{tabular}{|c|c|c|}
\hline & & \\
\hline Oberist, Heinrich & Zürich & 83 \\
\hline Oberist, Wilhelm & $n$ & \\
\hline Oberkan, Hans Jakob & ) & 8 \\
\hline Oechsli, Micheal & Schaffhausen & 130 \\
\hline Oechslin, Johann Alexar & der & 3 \\
\hline Oehri, Paul & Chur & 23 \\
\hline Oeninger, RudoIf & Zürich & 0 \\
\hline Offenburg, Gangwolf & Schaffhausen & \\
\hline $\mathbf{F}$ & & \\
\hline Paillard, Jean & Yverdon & \\
\hline Pankraz, ... Meister & Luzern & \\
\hline Pasi, .... & Wallis & \\
\hline Pastori, Charles-Joseph & Biel & \\
\hline Paul, Nicolas & Genf & \\
\hline Peroulla, Germain & Freiburg & \\
\hline Perret, Joseph & " $118 \mathrm{u}$ & \\
\hline Perrin, François & Neuenburg & \\
\hline Perrin, Josué & ” & \\
\hline Perrin, Louis & $\eta$ & 25 \\
\hline Perrin, Louis fils & $\eta$ & \\
\hline
\end{tabular}

\begin{tabular}{|c|c|c|}
\hline Peter, Gottlieb & Elgg & \\
\hline Peter, Heinrich & ) & \\
\hline Petermann, Franz Anton & Beromünster & \\
\hline Petermann, Jean & Neuenburg & 24 \\
\hline \multicolumn{3}{|c|}{ Petermann, Josef Leodegar Beromünster } \\
\hline Petersohn, Johann Heinr & Bern & \\
\hline Pfänder, Johannes I & Schaffhausen & \\
\hline Pfänder, Johannes II & 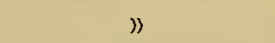 & \\
\hline Pfeifer, Johannes & Rheine & \\
\hline Pflum, Veith & Schaffl & \\
\hline er, Lorentz & Basel & \\
\hline Ple & Yverdon & \\
\hline t, Jean & Genf & \\
\hline , Laurent & Leuk (Wallis) & \\
\hline Levin & ) & \\
\hline Preisig, Jakob & St. Gall & \\
\hline Pury, Jean & Neuenburg & 2 \\
\hline P. (A. P.) & Wallis & \\
\hline
\end{tabular}

R.

Rainsperg, Hans Rapperswil $\quad{ }_{159}$ Rapin, Jean, od. Isaac Daniel Payerne 245 Rechberger, Cunrat Zürich 82 Reimann, Franz Rapperswil $\quad 159$ Reiner, Sebastian $\quad$ St. Gallen 148 Respini, Andrea $\quad$ Tessin $\quad 259$ Respini, Giosep ” $\quad 259$ Respini, Fratelli " $\quad 259$ Reuchlin, Jean-Jacques Lausanne $\quad 235$ Reuchlin, Frédéric " 236 Reutiner, Hector $\quad$ St. Gallen 148 Reutiner, Johannes „ 147 Rey,.... Monthey (Wallis) ${ }_{2}^{257}$ Reysberger, Veltin Freiburg 184 Rickenmann, .... Rapperswil $\quad 159$ Riedtmann, Bartholomä Bischofszell 139 Rieter, Jakob Winterthur 97 Roder, Johann Samuel Bern 200 Roder, Ludwig " 200 Roggwyler, Batt Jakob Luzern 110 Rordorf, Hans Rudolf Zürich 83 Rossi, Gio. Ant. Tessin $\quad 259$ Rossier, André Genf $\quad 233$ Rossier, André Morges 245 Rothenfluh, Jakob Rapperswil $\quad 159$ Rötteler, Bertschi Zürich $\quad 82$ Royaume, Jehan Genf $\quad 234$ Royaume, Pierre I " 233 Royaume, Pierre II " $\quad 233$ Royaume, Pierre III " 233 Roze, Pierre Ruch, Balthasar
234

120 


\begin{tabular}{|c|c|}
\hline Ruchti, Conrad & Solothurn \\
\hline Rudolf, Daniel I & Zofingen \\
\hline Rudolf, Daniel II & ) \\
\hline Rudolf, David I & ) \\
\hline Rudolf, David II & ) \\
\hline Rudolf, Hans Heinrich & $n$ \\
\hline Rudolf, Hans Ulrich & $»$ \\
\hline Rudolf, Jakob & 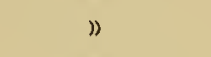 \\
\hline Rudolf, Michael & $\eta$ \\
\hline Rudolf, Moritz I & $\eta$ \\
\hline Rudolf, Moritz II & ) \\
\hline Rudolf, Samuel & $n$ \\
\hline Rue, Joseph & Estavayer \\
\hline Rumpler, Elias & Zofingen \\
\hline von Rütte, ChristoffeI & Bern \\
\hline von Rütte, David & » \\
\hline von Rütte, Samuel & $n$ \\
\hline Rütter, Peter & Zürich \\
\hline Rychwin, Jakob & Luzern \\
\hline Ryf, Hans & Biel \\
\hline R. (F. R.) & Bern \\
\hline R. (H. R.) & $\eta$ \\
\hline R. (M. R.) & St. Gallen \\
\hline
\end{tabular}

S.

Sachs, Friedrich Schaffhausen 130

Sancson od. Samson, ... Neuenburg 248

Sandoz, Abram. Môtiers-Travers 252

Savioz, David od. Daniel Grandson 246

Scaglia et Gippa Vevey 243

Scaglia

Secrétan, Estienne

Seiler, Leonhard

Seiler, Leonhard

Seiler, Lienhart

Senn, Johannes

Senn, Ursus

Sesiani, ....

Sessiani, Anton

Setzstab, Eucharius

Seyller, Josef

Simaval, Pier Tonii

Sior, Jean

von Sitten, Hans

Soenori, Noel

Yverdon

Vevey

Basel

Liestal

Bern

Liestal

")

202

138

Zürich

Wyl

Wallis

255

Solothurn $\quad 175$

Genf $\quad 230$

Sommerauer, Hans Felix I Zürich 86

Sommerauer, Hans Felix Il " 86

Sommerauer, Hans Georg " 86

Sommerauer, Heinrich

Spälti, Hans Jakob I

Spälti, Hans Jakob II
Glarus

1) 86

120

121
Spälti, Heinrich

Glarus

Spengler, Bartlime

Spengler, Caspar

Spitzli, ....

Spitzli, Bernardi

Sprüngli, Ulrich

St. Gallen 147

121

Sulzberger, Adam

Sulzberger, Hans Caspar

Sulzer, Emanuel

Wyl 147

))

156

Zürich 83

Frauenfeld $\quad 137$

Sulzer, Hans Caspar I " 97

Sulzer, Hans Caspar II " 97

Sulzer, Hans Jakob $\quad$ " 97

Sulzer, Johannes I " 97

Sulzer, Johannes II " 97

Sulzer, Johann Heinrich " 97

Sunnenberg, Niklaus Luzern 110

Suochdentrunk, Andreas Basel 164

Surd, Joannes Wallis 254

Sutermeister, Johann Heinrich Zofingen 227

S. (A. S.) Wallis 255

S. (B. S.) Solothurn 179

S. (H. S.) Schwyz 114

S. (I. S.) Bern 197

S. (I. S.) Wallis ${ }_{2} 55$

S. (P. S.) Waadt od. Wallis 255

Sch.

Schaerer, Adam

Schaerer, Adam

Schaffner, Josef Fidel

Schalch, Beat

Schalch, Cunrat

Schalch, Hans

Schalch, Hans Caspar

Schalch, Hans Conrad I

Bern

Burgdorf $\quad 204$

Schalch, Hans Conrad II

Solothurn

182

Schaffhausen 130

131

131

133

133

Schalch, Hans Heinrich

134

133

Schalch, Johann Conrad I " 133

Schalch, Johann Conrad II " 134

Schalch, Johann Conrad III " 134

Schalch, Salomon " 134

Schaler, Hanns Luzern 109

Schallbretter, Franz, Xaver " 111

Schallbretter, Josef Wendel " 112

Schaltenbrand, Melchior Schaffhausen $13_{1}$

Schaltenbrand, ....: Bern 193

Schaufelberger, Hans Jakob Zürich 84

Schaufelberger, Hans Ulrich " 84

Schellenberg, Hans Caspar Winterthur 96

Schellenberg, Hans Rudolf " $\quad 96$

Scher, .... Meister Wyl $\quad{ }_{157}$ 
Scherer, Bernhardin

Scherer, Diethelm

Schinz, Hans Caspar

Schinz, Hans Rudolf

Schirmer, Hans Jakob

Schirmer, Joachim I

Schirmer, Joachim II

Schlatter, Heinrich

Schlep, Hans

Schlumpf, Hans Joachim

Schmid, Felix

Schmid, ....

Schmid von Grüneck

Schmid, Hans

Schmid, Jakob

Schmid, Jakob

Schmid, Kuret

Schmid, Oswald

Schmid, Stoffel

Schmidt, Conrad

Schneck, Johann Jakob

Schnewli, Benedikt I

Schnewli, Benedikt II

Schnewli, Hans Conrad

Schnider, Hans

Scholer, Emanuel I

Scholer, Emanuel II

Scholer, Hans Jakob

Scholer, Jakob Christoph

Schönbrunner, Carl Zug

Schönbrunner, Carl Josef "

Schönhand, Hanns

Schor, Herrmann

Schwaller, Josef

Freiburg

Basel

Solothurn

Schwaller, Josef Anton

Schwaller, Niklaus Josef

Schwaller, Victor Josef

Schwarz, Hans Andreas

Schwendimann, Hans

Schwendimann, Ludigari

\section{St.}

Stadler, Franz Josef

Uri

Stadler, Peter

Basel

Stadlin, Caspar Michael Bern

Städelin, Caspar

Städelin, Hans Jakob

Städelin, Leonhard J.

Städinger, Niklaus

Stähelin, David

Stähelin, Georg

(1)

Schwyz

"

"

Schaffhausen

St. Gallen
Luzern 109

St. Gallen 147

Zürich $\quad 86$

148

147

148

139

164

150

Stein a. Rhein 98

Aarau $\quad 213$

Chur $\quad 123$

Eglisau

)

Zürich

$"$

Rapperswyl $\quad \mathbf{1 5 9}$

Basel 171

Stein a. Rhein 98

Basel

))

)

Stamma, Martin

Schaffhausen 130

Steiger, Hans Heinrich

Steiger, Jakob I

Steiger, Jakob II

Steiger, Jakob III

Steiger, Jakob IV

Steiger, Johann Conrad

Steiger, Johann Jakob

Stein, Peter

Steinbrecher, Hensly

Steiner, Caspar

Lichtensteig

160

160

160

160

${ }_{161}$

160

161

Steiner, Hans Cunrat I

Rorschach $\quad \mathbf{1 5 5}$

Freiburg $\quad 184$

Zürich $\quad 85$

Steiner, Hans Cunrat II

Steiner, Hans Jakob

Steiner, Tobias

Steinli, Hector

Stetter, Alexius

»

85

85

85

Stooss, AlbrechtEmanuel

Stor, Antonius

Stor, Jehan

Storno, Antonii

Storno, Joseph

von Strassburg, Hans

Streckeisen, Emanuel I

Streckeisen, Emanuel II

Streiff, Fridolin

Streiff, Hans Heinrich

Streiff, Herkules

Strübin, Johann

Strübin, Josef

Strübin, Josef

Strübin, Niklaus

Strübin, Peter

Strübin, Peter

Stumpf, Hans Rudolf

Winterthur

St. Gallen

Basel

97

152

164

197

255

255

255

255

82

170

170

121

121

121

169

165

172

169

169

181

180

182

181

221

109

110

116

165

201

114

114

114

131

148

150

$\begin{array}{cr}\text { " } & 165 \\ \text { Liestal } & 172 \\ \text { Basel } & 169 \\ \quad \text { N } & 169 \\ \text { Liestal } & 172 \\ \text { Zürich } & 84\end{array}$

T.

Taeschler, Josua Zofingen 220

Taeschler, Zacharias St. Gallen 148

Täucher, Hans Heinrich Zürich 84

Terraillon, Henry Neuenburg 248

Teucher, Hans Melchior Frauenfeld $\quad 138$

Teucher, Heinrich " $\mathbf{1 3 8}$

Thomann, Hans Heinrich Zürich 86

Thonnet, Charles Neuenburg 251

Thumysen, Hans Georg Zürich $\quad 87$

Thurnheer, Jakob Weinfelden 143

Thurnheer, Johann Jakob " 143

Thyss, Adam Lienhart Bern 198

von Tirez, Hans

Freiburg

Tonietti, Gio. Thomas Wallis

184

257 
Tonietti, Jan. Thomas Wallis

de la Tour, Jean-Baptiste Murten

Touvenin, Jaques

Traber, A.

Traber, Caspar

Trachsler, J. Heinrich

Tratz, Paulus

Trechsel, Hans I Balthasar "

Trechsel, Hans II Balthasar :"

Tressel, Daniel

Triboltinger, Niklaus

Trutz, Albrecht

Trutz, Johannes

Tscharandi, Benedikt

Tschiepo, Hans Ulrich

Tschiepo, Niklaus

Tschiepo, Peter

Tschödeli, Ludi

U.

Uebelin, Niklaus I
Uebelin, Niklaus II
von Ulm, Jörg
Urech, Hans
Utain, ....
Utin, André
Utin, Jean Jacques Samue
Utin, Jehan
von Utzingen, Heini
U. (Utin)
U. U. (Utin)

$\begin{array}{ll}\text { Basel } & 167 \\ \quad " & 170 \\ \text { Biel } & 206 \\ \text { Liestal } & 172 \\ \text { Vevey } & 239 \\ \quad " & 238 \\ \text { el } " & 239 \\ \quad " & 238 \\ \text { Luzern } & 109 \\ \text { Vevey } & 240 \\ \quad \prime & 240\end{array}$

V.

Valin, Jakob

Variolly, Vincent

Villeneufve, Pierre

Villeneufve, Pierre

Villeneufve, Pierre

von Vivis, Peter

Vogt, Hans Peter

Vogt, Johannes

Vogt, Wolfgang

Vonwiller, Jakob

V. (M. V.)

W.

Waegele, ....

Wagner, Bendicht

Wagner, Daniel

Bern
Zürich
Wyl
»

Solothurn

Freiburg

")

Luzern

246

110

110

100

82

83

83

197

82

156

156

178

184

184

184

109

$\begin{array}{ll}\text { Genf } & 234 \\ \text { Martigny } & 257 \\ \text { Freiburg } & 184 \\ \quad \text { und Murten } & 189 \\ \text { Neuenburg } & 248 \\ \text { Bern } & 197 \\ \text { Freiburg } & 184 \\ \text { Zug } & 102 \\ \text { " } & 102 \\ \text { " } & 102 \\ \text { St. Gallen } & 150 \\ \text { Freiburg } & 187\end{array}$

Diessenhofen 144

Biel

208

Bern
Walser, Johannes

Chur

Zürich

123

Waser, Heinrich

Waser, Jakob

Waser, Johannes I

Waser, Johannes II

Waser, Jost

Waser, Remigi

Wasmer, Brandolf

》)

Wasmer, Daniel

)

86

David François Neuenburg

attel, David François Neuenburg $\quad 250$

Wattel, Jacques

)

Zürich

250

Weber, Daniel

Luzern

88

Weber, Gladi

Zürich $\quad 88$

110

Weber, Johannes

Wegmann, Hans Heinrich Baden 228

Wehrli, Friedrich

Aarau

215

Wehrli, Johann Rudolf

")

215

Weichel, Johann Herrmann Rapperswil ${ }^{5} 59$

Weiss, Hans

Glarus

120

Weissbrod, Peter

Bern

Weldtin, Meinrad

Wyl

Werdmüller, Jakob

Werlin, Jerg

Werlin, Lienhart

Werlin, Onophrion

Wetter, Georg

Wetzel, Hans Jakob

Wetzstein, Hans

Weyermann, Hans

Wick, Bernhard

Wick, Josef

Wick, Lukas

Wick, Stoffel

156

Widenmann, Abraham

Widmer, Diethelm

Wiedemann, Alfons

Wiedemann, Franz Josef

Wiedenhuber, Hans

Wiell, ....

von Wil, Hans

Wirz, Andreas I

Wirz, Andreas II

Wirz, Hans Caspar

Wirs, Hans Cunrat

Wirz, Hans Jakob

Wirz, Heinrich

Wirz, Salomon

Witz, David

Witz, David I

Witz, David II

Witz, David III

Witz, Hans Caspar
Zürich

Basel

Basel

St. Gallen

Basel

Rapperswil $\quad 159$

Bern

Basel

(D)

Wyl

Winterthur

83

${ }_{164}$

164

164

148

168

194

169

167

$17^{\circ}$

156

") $\quad 96$

Schaffhausen $\quad \mathbf{1 3 6}$

St. Gallen $\quad 146$

Solothurn $\quad 176$

Luzern 109

Zürich 85

85

84

84

85

84

85

Neuenstadt 212

Biel

208

209

209

208 


\begin{tabular}{|c|c|c|c|c|c|}
\hline Witz, Hans Peter & Biel & 209 & W. (A. M. W.) & Gossau & 161 \\
\hline Witzig, Hans Heinrich & $"$ & 210 & W. (H. W.) & Aarau? & 214 \\
\hline Wolfrad, Johannes & Zürich & 82 & W. (H. I. W.) & Aarau? & 214 \\
\hline Wüger, Andreas I & Steckborn & 141 & & & \\
\hline Wüger, Andreas II & ) & 141 & \multirow{2}{*}{\multicolumn{3}{|c|}{ Y. }} \\
\hline Wüger, Andreas III & » & 141 & & & \\
\hline Wüger, Andreas IV & $n$ & 141 & Ysenbart, Hanns & Freiburg & \\
\hline Wüger, Andreas V & $n$ & 141 & & & \\
\hline Wüger, Andreas VI & ” & 141 & & & \\
\hline Wüger, Johannes I & 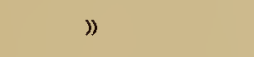 & 141 & Z. & & \\
\hline Wüger, Johannes II & $\eta$ & 141 & & & \\
\hline Wüger, Johannes III & $n$ & 141 & Zanoni, Antoine & Tessin & 259 \\
\hline Wuilleret, Adam & Freiburg & 184 & Zehender, J. & Bern & 9 \\
\hline Wuilleret, Anthoni & $"$ & 184 & Zhann, .... & Basel & \\
\hline Wüscher, Adam & Schaffhausen & 131 & Ziegler, Hans & Schaffhausen & 13 \\
\hline Wüscher, Benedikt & ” & 132 & Ziegler, Hans Caspar & Zürich & 9 \\
\hline Wüscher, Hans Adam I & $"$ & 132 & Ziegler, Margreth & $»$ & 9 \\
\hline Wüscher, Hans Adam II & $n$ & 132 & Zimmermann, Johannes I & ” & \\
\hline Wüscher, Hans Adam III & $I$ & 132 & Zimmermann, Johannes I & I $》$ & \\
\hline Wüscher, Laurenz & $n$ & 132 & Zimmermann, Jakob Anto & on Rappers & 15 \\
\hline Wüst, David & Zürich & 86 & Zingg, Hans Gabriel & St. Gallen & $r$ \\
\hline Wyss, Antoni & Solothurn & 176 & Zingg, Hans Jakob & $"$ & \\
\hline Wyss, Antoni & Bern & 193 & Zingg, Jakob & $"$ & o \\
\hline Wyss, Hans & Zürich & 82 & Zollikofer, Hans Josef & 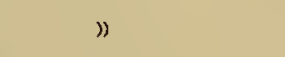 & 15 \\
\hline Wyss, Jakob I & Bern & 193 & Zollikofer, Jakob Lauren & $"$ & 148 \\
\hline Wyss, Jakob II & $»$ & 193 & Zollikofer, Rupprecht & $"$ & 15 \\
\hline Wyss, Jakob III & ” & 193 & Zschan, Martin & Basel & 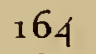 \\
\hline Wyss, Samuel I & $n$ & 194 & Zubler, Jörg & Zürich & \\
\hline Wyss, Samuel II & 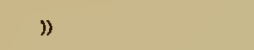 & 194 & Zweifel, David & Glarus & 12 \\
\hline Wyss, Samuel III & $"$ & 194 & Zwinger, Hans Caspar & Bischofszell & \\
\hline W. (A. W. (Wiell ?)) & Solothurn & 176 & Z. (I. P. Z.) & Wallis & \\
\hline
\end{tabular}




\section{Alphabetisches Ortsverzeichnis}

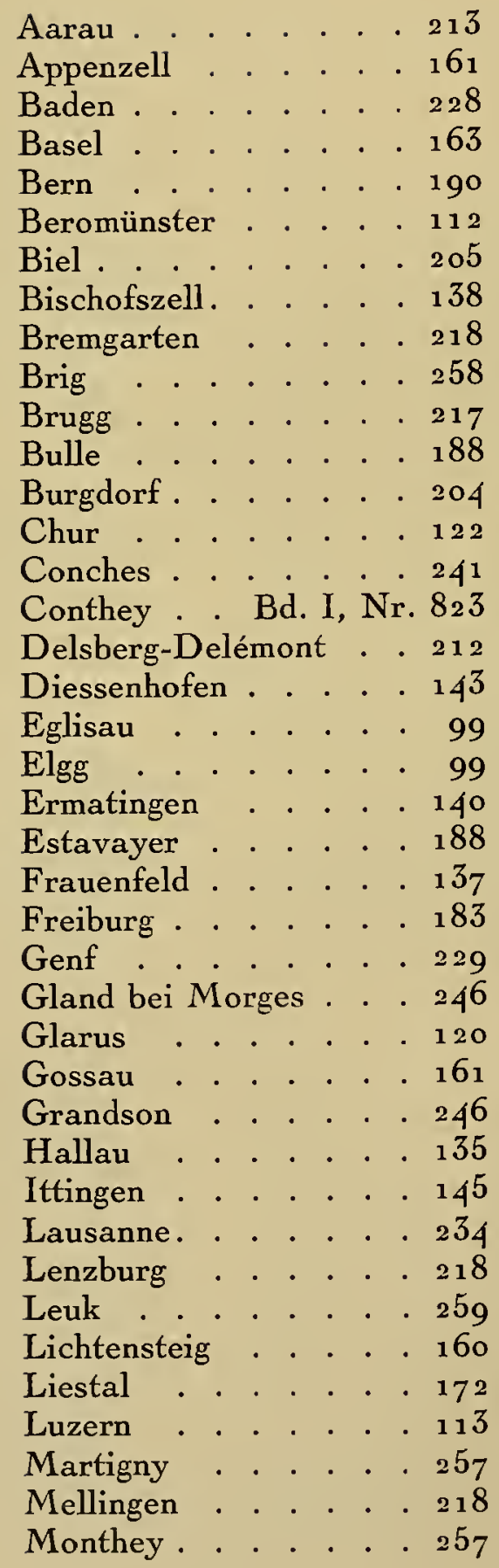

Morges . . . . . . 245

Môtiers-Travers . . . $\mathbf{2 5 2}$

Moudon . . . . . . . 245

Münster im Jura . . . 212

Murten . . . . . . . 189

Neuenburg . . . . . . 247

Neuenstadt . . . . . . 211

Nidwalden . . . . . 117

Obwalden . . . . . 118

Orbe . . . . . . 244

Payerne . . . . . . 245

Pruntrut . . . . . . 212

Rapperswil . . . . . 158

Rheinau . . . . . . . 99

Rheineck . . . . . 254

Rorschach . . . . . 155

St. Gallen . . . . . . 145

Sargans . . . . . . $16_{1}$

Schaffhausen . . . . 128

Schwyz . . . . . . . 113

Siders-Sierre . . . . . 231

Sitten . . . . . . . 252

Solothurn . . . . . . 173

Steckborn . . . . . . 140

Stein am Rhein . . . . 97

Tessin . . . . . . . . 259

Thun .. . . . . 202

Uri . . . . . . . . 115

Uznach . . . . . . 154

Vevey . . . . . . . 237

Visp. . . . . . . . 258

Wallis ... . . ${ }_{252}$

Weinfelden . . . 142

Wettingen . . . . 218

Winterthur . . . . 95

Wyl. . . . . . . 155

Yverdon . . . . . . 243

Zofingen . . . . . 218

Zug . . . . . . . 101

Zürich . . . . . 80 


\section{Verzeichnis der Tafeln}

I. Zinngeschirr aus dem XIV. Jahrhundert (Ausgrabungen).

II. Zinnstatuette des heiligen Sebastian, ca. 1500 (Wallis).

III. Kannen um das Jahr 15 oo (Münsterschatz Basel, Bubenberg- und Baarerkannen).

IV. Kannen von Aeschi, Frauenfeld, Zug, Baden (Ratskannen).

V. Kannen von Stein, Luzern, Murten, Payerne (Rats- und Abendmahlkannen).

VI. Kannen von Wyl, Rapperswil, Davos, Bischofszell (Ratskannen).

VII. Kannen von Basel, Winterthur, Zofingen, Willisau (Rats- und Gemeindekannen).

VIII. Kannen von Basel, Kirchenthurnen, Taufgeschirr (Universitäts- u. Kirchenkannen).

IX. Vier Bulgen von Bern (Gemeinde- und Patrizierkannen).

X. Abendmahlkannen der Nordostschweiz (prismatische und Glockenkannen).

XI. Abendmahlkannen von Ligerz und Biel.

XII. Abendmahlkannen von Gottstatt, Le Locle, Saint-Blaise, Boudry.

XIII. Abendmahlkannen von Genf.

XIV. Abendmahlkannen von Lausanne, Neuenburg, Zofingen.

XV. Abendmahlkannen v. Yverdon, Romainmôtier, Grandson, Orbe, Rovray, Yvonand.

XVI. Typen der Gebrauchskannen (Glocke, Stitze, prismatische Kanne, Rundele, Solothurner und Freiburger Stitze).

XVII. Typen der Gebrauchskannen (Bern, Waadt, Genf, Wallis, Neuenburg).

XVIII. Kugelkrüge; getriebenes und geschlagenes Zinn. Kannen von Glarus und Zürich.

XIX. Humpen, Flaschen, Maasse, Tintengeschirr.

XX. Wöchnerinnen-Schüsselchen, kleine Zinngegenstände, Brunnenkesselchen.

XXI. Grosser Delphin mit zinnernem Untersatz.

XXII. Delphine in Nischen, Kugelgiessfässer mit Handbecken.

XXIII. Birnen- und eichelförmige Giessfässer.

XXIV. Säulen- und Kasten-Giessfässer.

XXV. Guss-Modelle aus Ton und Bronze.

XXVI. Henkelschüsseln, Schüsseln, Breitrandteller und -Platten, "Gupfplatten ".

XXVII. Zinngeschirr in den französischen Stilarten des XVIII. Jahrhunderts.

XXVIII. Zinngeschirr in den französischen Stilarten des XVIII. Jahrhunderts.

XXIX. Taufkannen aus Habkern und Luzern, Taufschale.

XXX. Zürcher Gebrauchskannen : Stitzen, Glocken- und prismatische Kannen.

XXXI. Dedikations- und Schützenplatten.

XXXII. Zuger Gebrauchskannen. Glocken- und prismatische Gefässe ohne Ausgussröhre.

XXXIII. Kannen von Unterwalden, Schwyz und Luzern.

XXXIV. Churer Kannen.

XXXV. Zuger und Churer Kranzkannen. Gravirte Churer Quartkannen.

XXXVI. Schaffhauser Kannen; Thurgauer Kannen (Bischofszell, Steckborn, Weinfelden, Diessenhofen und Frauenfeld).

XXXVII. St. Galler und Appenzeller Kannen.

XXXVIII. Die schweizerischen Reliefteller (St. Gallen, Wyl, Wallis).

XXXIX. Kannen von Basel und Solothurn.

XL. Solothurner Kannen; gravirte Zuger und Basler Stitzen.

XLI. Kannen von Freiburg und Bern.

XLII. Kannen von Thun und Biel.

XLIII. Die verschiedenen Formen des Steges der Berner Kannen.

XLIV. Seltene Zofinger und gravirte Berner Kannen.

XLV. Kannen von Aarau, Brugg und Zofingen.

XLVI. Kannen von Neuenburg, Neuenstadt und Genf.

XLVII. Waadtländer Kannen (Vevey, Lausanne, Orbe).

XLVIII. Wallis. Kannen. - Falsifikate u. Kompilation. (Wallis., Genf. u. Bern. Kannen). 



\section{ZWEITER TEIL}

\section{A. DIE NORDOSTSCHWEIZ}

Zürich : Zürich.

Winterthur.

Stein am Rhein.

Eglisau.

Rheinau.

Elgg.

Zug.

Luzern : Luzern.

Beromünster.

Schwyz.

Uri.

Unterwalden: Nidwalden.

Obwalden.

Glarus.

Graubünden.

Schaffhausen.

Thurgau :

Frauenfeld.

Bischofszell.

Ermatingen.

Steckborn.

Weinfelden.

Diessenhofen.

St. Gallen : St. Gallen.

Rheineck.

Rorschach.

Wyl.

Rapperswil.

Lichtensteig.

Appenzell.

Sargans, Gossau. 


\section{ZÜRICH}

Schon im ausgehenden Mittelalter hatte das $\mathrm{Z}$ unftwesen in Zürich eine mächtige und glanzvolle Stellung erlangt. Die günstige Lage der Stadt war wie geschaffen für eine starke Entwicklung des Handels und damit auch der Gewerbe. Die Kannengiesser gehörten zur Schmiedenzunft. Die "Geschichte der Zunft zur Schmiden in Zürich, 1336-19121", von Dr. Friedrich Hegi, gibt uns reichen Aufschluss über diese $Z$ unft und auch für das Zunftwesen in Zürich überhaupt. Schon im ersten geschwornen Brief vom 16. Juli 1336, welcher die erste Zunftverfassung Zürichs bildet, werden an siebenter Stelle die Schmiede, Schwertfeger, Kantengiesser, Gloggner, Spengler, Sarwürker, Scherer und Bader angeführt. Diese bilden, neben den übrigen zwölf Zünften, eine Zunft und haben ihr Panner. Das Zinngiessergewerbe war schon tüchtig entwickelt. Von namentlich genannten Meistern seien folgende erwähnt: 1357 Henman, 1362 Rudolf Banwart, 1371 Johannes Wolfrad und Ulrich Boner. Letztere drei Meister stellten die erste technische Zinngiesser-Ordnung auf. Dieselbe ist datirt vom 12. Juli ${ }^{1} 3_{71}$ und wurde den Zunftmeistern Heinrich Wider und Heinrich Wetzel, dem Bürgermeister Rüdiger Maness, dem Rat und den übrigen Zunftmeistern zur Bestätigung vorgelegt. Diese Verordnung bezweckte in erster Linie, einen zu hohen Bleizusatz und die dadurch bedingten Erkrankungen zu verhindern. Innerhalb sechs Meilen um die Stadt musste diese " $Z$ ürcher Probe " gehalten werden. Sie bestand in einer Mischung von 4 Pfund Zinn und 1 Pfund Blei.

Da die einheimischen Meister der Nachfrage kaum genügten, so vvurden gerne a u s wärtige Zinngiesser ins Bürgerrecht und in die Zunft aufgenommen. So meldet das Bürgerbuch folgende Aufnahmen ins Bürgerrecht: 1394 Bertschi Rötteler von Uster, 1398 Rudolf Oeninger, 1419 Hans von Strassburg, 1425 Niklaus Triboltinger aus Konstanz, 1437 Peter Herer von Rottweil, 1442 Ulrich Banwart, 1453 Hans Börtly von Nürnberg, 1456 Hans Gugk, 1484 Cunrat Eckart von Frankfurt, 1542 Niklaus Müg von Schaffhausen, u.s.w., alle sind Zinngiesser.

Da die Kannengiesser ausser den Kannen beinahe alle Ess- und Trinkgeschirre anfertigten, trat an die Stelle des alten Namens schliesslich die Bezeichnung Zinngiesser.

Um sich einen Begriff zu machen über die Verbreitung des Zinngeschirrs im $\mathrm{XV}$. und XVI. Jahrhundert, zitire ich einige amtliche Inventare 2 aus dieser Zeit. Dasjenige von $\mathrm{Hans}$ Waldmann aus dem Jahre 1489 erwähnt an Zinngeschirr: 39 Paar Platten und Schüsseln, 10 Kannen und 23 Kerzenstöcke. Sein Zeitgenosse, der Zürcher Schmiedmeister Hans Thumysen, hinterliess bei seinem Tode "ein zinnyn giess, 17 zinnyn blatten und 4 Kanten ». Rudolf Rubli, der Gastwirt zum "Schwert » in Zürich, besass Zinngeschirr im Gewicht von einem Zentner. Der im Jahre 1545 verstorbene Kaspar Bluntschli besass an Zinngeschirr : " 11 blatten gross und klein, 1 Vischteller, 17 kleine Teller, 10 Kanten und Stitzen, 21 Schüsseln gross und klein, 4 Salzbüchsli, 2 Senfkentli, 2 Fleschen, 1 Giessfass ". Im Inventare Marx Eschards werden erwähnt : 1 Schützenblatten, 2 Zipfelschüsslen, 4 Salzbüchsli, das ich mit der Armbrust gewunnen, 13 blatten, 7 schüsslen, 2 welschstitzen hab ich mit der Büchsen zo Losanne gewunnen, 21 Schüsslen gross und klein, 4 Salzbüchsli, 2 Senfkentli, 2 Fleschen, 1 Giessfass, 2 Stitzli hab ich auf dem blatz (Zürich) mit der Büchs gewunnen an der Kilchwy 1568 \%.

Im Inventar" aus dem Ritterhaus Bubikon vom Jahre 1528 finden wir: "An Zinÿ geschirr Item 5 köpffig Kanntten - Item 1 mässigi Kanntten — Item 4 halbmässig Kanntten

1 Geschichte der Zunft zur Schmiden in Zürich von Dr. Friedrich Hegi, Zürich 1912. S. 18, 162 und folgende. Th. G. Gränicher. S. 39 .

${ }^{3}$ Anzeiger für schweiz. Altertumskunde, Jahrgaog 1910, S. 250. Mitteilung von Armio Eckinger. 
TAFEL X


1. Kanne von Elgg, Höhe $44 \mathrm{~cm}$, von Heinrich Peter, erwähnt von 1807-33 (Text S. 41 und 100). 2. Kanne von Herisau, Höhe 39,5 cm, von ?, datirt 1743 (Text S. 41). 3. Kanne von Werdenberg-Montfort, von ?. (Text S. 42 ), Höhe $43,5 \mathrm{~cm}$. 4. Kanne von Schaffhausen, von ?, datirt 1582 (Text S. 42), Höhe $42 \mathrm{~cm}$. 

oder stürzyn - Item 4 giessfass und ein Küepffy birky - Item 10 grosse Platten und 3 kleineri Platten - Item ein Kellt wasserkessel lytt in des herren Kammer ".

Im Inventar des Badehauses "Hinterhof " zu Baden' vom Jahre 1435 figurirt der Passus : " 13 stuk an zinninem geschirr, darunter ist ein häfeli und kessely wegend $51 \&$ zu $31 / 2$ ß $»(H$. Zeller-Werdmüller).

Im Verzeichnis des Hausrates des Landvogteischlosses zu Baden ${ }^{2}$ unter Gilg Tschudi vom 14. Mai 1551 , kommt an Zinngeschirr vor : "Item ein zwey mässige Kannten, drey mässige Kannten, eine anderthalb mässige Kannten, eine mässige Kannten, zwey stintzli, vier schennk stintzen, eine grosse fläschenn, fünf saltz fässly, 21 zinninne tällerle, 3 visch täller, 26 blattenn klein und gross, 2 kleyn zinnin täller, x brunnen Kessy " (Dr. Walter Merz-Diebold).

Eine ganz erhebliche Rolle für das Zinngiessergewerbe spielten die Bestellungen der Regierung für Schützengaben. Anfänglich bestanden die Gaben nur in Platten für die Knaben; später erhielten auch die erwachsenen Schützen Gaben und zwar sowohl Platten als auch Kannen. Die Bestellungen nahmen bald einen sehr erheblichen Umfang an. Den besten Aufschluss geben darüber die Seckelmeisterrechnungen ${ }^{3}$. Wir entnehmen denselben einige Beispiele :

15o3: ${ }_{1} 3$ \& 1 B dem Kantengieser umb züg zun platten den Knaben zum afentüren.

1504: 24 \& dem Cunrat Rechberg umb schüsslen den Knaben zu affentüren.

1507 : 27 \& 2 B $6 \partial$ Cunratt Rechberger um 731/2 \& ziny schüsseln den Knaben zu abenturen zu schiessen.

1510: 23 \& 2 B Kunrat Rechberger umb 63 \& blatten den Knaben zu affenthüren.

1531 : $4 \& 6$ \& $8 \partial$ gen Eucharius Setzstabenn umb ein dotzet schies blettli, actum 6 tag Aprellen im 32 Jar.

$4 \& 4$ B Hannsen Wisen umb ein dotzet schiess blettli.

$4 \&$ \& $B$ Jacoben Schmid umb ein totzet schiess blettli.

$4 \& 4 \beta$ aber dem Setzstaben ein totzet.

$4 \& 6$ aber ime umb ein totzet schiess blettli.

$4 \& 7$ \& $6 \partial$ aber ime umb totzet schiess blettli.

$2 \& 9$ aber Hanus Wyssen um 7 schiess blettli.

16 B Carius Setzstaben umb 2 schiess Blettli.

Da nun seit diesem Jahre auch den Erwachsenen Zinnplatten als Schützengaben verabfolgt werden, nimmt der Bedarf einen immer grösser werdenden Umfang an. Im Jahre 1601 bestellte die Obrigkeit " 42 Dutzend Schiessblättli, wogend 672 \& ". Vier Kannengiesser lieferten diese 504 Platten zu 11 Schilling das Stück. Im Jahre 1651 wurden 55 Dutzend Blättlein "den Knaben zu verschiessen " gespendet. Die 66o Stück wogen 814 \& und kosteten 16 Schilling das Stück. Sieben Zinngiesser teilten sich in die Arbeit. Im Jahre 1700 lieferten acht Kannengiesser 646 Platten, für welche 88 o \& Zinn gebraucht wurden. Obwohl im Ganzen Tausende solcher Platten und Teller ausgeteilt wurden, so sind dieselben, und zwar besonders die frühern Exemplare, recht selten geworden. Die Schützenplatten haben nebst dem Stadtund Meisterzeichen noch einen besondern Schützengabenstempel, welcher am Rande des Tellers eingeschlagen wurde. Die Zeichnung des Stempels besteht in einer Armbrust mit einer wechselnden Jahrzahl. Die mir bekannten Schützengabenstempel entsprechen den Nrn. 848, 849 und 850 in Band I. Weil diese Schützenteller so selten sind, findet man im Altertumshandel häufig Exemplare, welchen trotz der Echtheit des Tellers ein neuer Schützenstempel aufgeschlagen ist.

Eine Kanne mit einem Schützengabenzeichen von $Z$ ürich habe ich nicht auffinden können.

Wappen und Siegel der Zinngiesser. Es existiren zwei Siegel, ein älteres kleineres und ein grösseres neueres. Im Wappen befindet sich in der Mitte eine Glocke und rechts und links davon ein Zinnkrug in der Form eines Humpens oder einer Aiguière.

\footnotetext{
4 Neue Folge, Band II, Seite 49.

2 Anzeiger für schweiz. Altertumskunde, 1895, XXVIII. Jahrgang, S. 497.

${ }^{3}$ Anzeiger für schweiz. Altertumskunde, Jahrgänge 1907 und 1908 : Notizea zur Geschichte des zürcher. Waffenwesens. Zusammeogestellt von Dr. R. Wegeli.
} 


\section{Die Zürcher Zinngiesser ${ }^{1}$}

Henman, Kanntengiesser, steuert 1357 in die Wacht Linden.

Banwart, Rudolf, Kannengiesser, oft genannt in den Zürcher Steuerbüchern von 1357-1376 und im Personenregister unter dem Namen Banwart und Kannengiesser. Im Jahre 1388 blieb er zu Hause und machte den Kriegszug nach Baden nicht mit. Stellt ${ }_{13} \mathbf{7}_{1}$ die erste technische Kannengiesser-Ordnung auf.

Wolfrad, Johannes, Kannengiesser, wohnte 1369 in der Wacht Linden im Schwendenkeller (Steuerbücher I, S. 219, Nr. 10). Er ist ebenfalls an der Aufstellung der ersten technischen Kannengiesser-Ordnung beteiligt.

Boner, Ulrich, (Uli), Kannengiesser, stammt aus Winterthur (Stadtbuch Zürich I, S. 383 und Hegi, S. 383, Nr. 198). Er ist ebenfalls bei den vier Meistern, welche im Jahre 1371 die erste technische Zinngiesser-Ordnung aufstellten.

von Baden, Jakob, Kannengiesser. Er ist identisch mit dem in den Steuerbüchern genannten Jakob Jaehli oder Jaeli (Personenregister zum Steuerbuch I). Er wohnte 1376 am Neumarkt. Er ist der vierte Meister, welcher ${ }_{13} 3_{1}$ die erste technische Zinngiesser-Ordnung aufstellte.

Rötteler Bertschi, von Uster, der Kannengiesser, receptus als Bürger von Zürich 28. November 1394 (Bürgerbuch I, S. 16).

Oeninger, Rudolf, der Kannengiesser, receptus in civem 15. August 1398 (Bürgerbuch I).

von Strassburg, Hans, der Kannengiesser, receptus als Bürger feria secunda ante festum Katherinae virginis 1419 (Bürgerbuch).

Triboltinger, Niclaus, von Konstanz, der Kannengiesser, receptus in civem quarta feria post dominicam invocavit 1425 (Bürgerbuch).

Herer, Paulus, von Rottweil, der Kannengiesser, rec. in civem uff mentag vor Sant Gregorientag 1437 , dedit florenos 3 pro civilegio (Bürgerbuch).

Banwart, Ulrich, der Kantengiesser, receptus in civem uff mentag vor St. Ulrichstag anno 1442 et gratis (Bürgerbuch).

Börtly Hanns, Kannengiesser von Nürnberg, receptus in civem uff samstag nach sant Marsetag 1453 , dedit $3 \mathrm{fl}$.

Gugk, Hanns, der Kannengiesser, receptus in civem uff donrstag post Jacoby 1456 , dedit 2 flor.

Enok, Hanns, Kantengiesser, verfertigte 1467 die Fähnchen mit des Gotteshauses und des Abts Schildern auf den Einsiedlerweg zu Zürich (G. v. Wyss, Geschichte der Ablei Zürich, S. 443).

Eckart, Cunrat, von Frannckfurt, der Kannengiesser, rec. est in civem zinstag nach Inventionis Crucis a. 1484 . Dedit 3 guldin.

Tratz, Paulus, der Kannengiesser von Ingelstat; rec. in civem et juravit mitwuchen nach Theodori 1488 , gratis, als er miner herren werchmeister worden ist den turm zu tecken am Grossenmünster.

Rechberger, Cunrat, Kanttengiesser, der Freund G. Edlibachs (Chronik, S. 261). Liefert viele Schützenplatten in den Jahren $1504,1507,1510$ und 1511.

Setzstab, Eucharius, figurirt unter den schon verhandenen Zünftern in dem ${ }_{153}$ beginnenden Zünfterverzeichnis als "Carius Setzstab ». Im Jahre 1520 trägt er zum Bau der Zunftstube bei (Dr. Hegr, Geschichte der Schmiedenzunft, S. 361). Er war ein Hauptlieferant von Schützenplatten in den Jahren $1531,1532,1534$ und 1535.

Wyss, Hans, Zinngiesser, figurirt im Zunftverzeichnis von ${ }_{1532}$ uff. bereits als Zünfter "Hanns Wyss ». Liefert viele Schützenplatten an die Schützenfeste der Jahre 1531, $1532,1534,1535,1537,1541$.

\footnotetext{
1 Geschichte der Zunft zur Schmiden in Zürich. Dr. Friedrich Hegi, 1912, S. 162 u. ff. und S. 220 , Anmerkungen.

Zettel-Notizen von Dr. Friedrich Hegi aus dem Bürgerbuch I, Zürich, aus den Steuerbüchern $1357 / 76$, aus dem Zunftarchiv der Schmidenzunft.

Anzeiger für schweizerische Altertumskunde, Jahrgang 19n7, 1908 und ff. Notizen zur Geschichte des zürcher. Waffenwesens. Zusammengestellt von Dr. R. Wegeli, Seite 163, 253, 362 im Jahrgang 1907. Seite 72, 165, 257 und 344 im Jahrgang 19o8. Ausziigc aus den Seckelmeister-Rechnungen.
} 
Schmid, Jakob, ist erwähnt als Zünfter im Zunftverzeichnis von 1532 und wird in diesem Jahre Zwölfer. Auch kommt er in der Baurechnung zum Zunftstubenbau von 1520 vor. Er liefert Schützenplatten und Kannen in den Jahren $1531,1532,1535,1537,1538,1539,1541,1542$, 1543 .

Schmid, Stoffel, Sohn des vorigen Schmid Jakob, liefert Schützenplatten in den Jahren 1537 und 1541. Starb 1541. Seine Frau liefert als Wittwe noch im Jahre 1542.

Rordorf, Hans Rudolf, Kantengiesser, erkauft der Zunft Grächtigkeit uff den 25 . Tag September 1536, um $14 \&$ und $10 B$. für Wachs, und $5 \mathrm{~B}$ den Meistern und dem Stubenknächt Ein B. Er ward Zwölfter, 155o, und Amtmann zum Augustinern (Zünfter-Verzeichnis). Er liefert Schützenplatten in den Jahren $1537,1538,1539,1542,1543,1545,1546,1547$, 1548. Er war ein Pröbler und erfinderischer Kopf. Er starb in Lyon im Jahre 1570 (Hegi, S. 163 ).

Müg, Niklaus, von Schaffhausen, der Kanntengiesser, ist umb io rynische gulden zu burger uffgenomen, die hat er bezalt und den burgereyd geschworen mittwuchs nach Judica a. di ${ }_{1542}$ (Bürgerbuch). Erkauft am Palmtag 1542 der Zunft Grächtigkeit um 2o \& 16 B für alle Ansprach als Niclaus Müö (Zünfterverzeichnis). Beschwört 1552 die neue Zinngiesserordnung (HEGI, Geschichte der Schmiedenzunft, S. 164). Er liefert Schützenplatten in den Jahren $1543,1546,1548,1549$.

Heydegger, Hans, erkauft der Zunft Grächtigkeit St. Othmarstag 1539 um 14 \& und 1o B um Wachs, den Meistern 5 B und dem Stubenknecht 1 B. Er beschwört 1552 die neue Kannengiesserordnung (HEGI, S. 164). Er liefert Schützenplatten in den Jahren $1541,1542,1543$, $1546,1548,1549$.

Werdmüller, Jakob, Kantengiesser, erneuert der Zunft Grächtigkeit den 11. Mai 155o un $18 \&$ und $5 \beta$ den Meistern und 1 B dem Stubenchnächt. Er beschwört 1552 die neue Kannengiesserordnung.

Schmid, Kuret, Kantengiesser, erkauft der Zunft Grächtigkeit um 16 \&. Ward Stadtknächt, ward Zivölfer 1555.

Schmid, Oswald, Kantengiesser, erneuert der Zunft Grächtigkeit 1564 um 9 \&. Er wird 1568 erwähnt beim Umtausch alten Zinngeschirrs gegen neues (HEGI, S. 163).

Bremme, (Bremi), Ulrich, Kantengiesser und Tüöchler, erneuert der Zunft Grächtigkeit um $23 \& 16$ \& 1569 .

Holzhalb, Anderes, Kantengiesser, erkauft der Zunft Grächtigkeit um $23 \&$ den 9. Heumonat 1564 .

Meyer, Hans, Kantengiesser, erneuert der Zunft Grächtigkeit um 9 \& den 2. Hornung 1566. Heidegger, Hans Heinricb, Kantengiesser, erneuert der Zunft Grächtigkeit um 9 \& 1568.

Müö (Müeg), Hans Wilhälm, Kantengiesser, erneuert der Zunft Grächtigkeit um 9 \& 1572. Er ward Zwölfer.

Sprüngli, Ulrich, Kantengiesser, erkauft der Zunft Grächtigkeit um 23 \& 16 B 1577 .

Oberkan, Hans Jakob, Kantengiesser, erkauft der Zunft Grächtigkeit um 23 \& 16 B, 1583.

Körner, Hans Rudolf, Kantengiesser, erneuert der Zunft Grächtigkeit um 9 \&, 1584 .

Oberist, Wilhälm, Kantengiesser, erkauft der Zunft Grächtigkeit um 23 \&, 1562. Er liefert einen zinnernen Leuchter in die Zunftstube im Jahre 1571 (HeGi, S. 163).

Oberist, Heinrich, Kantengiesser, erneuert der Zunft Grächtigkeit um 9 \&. 1589. Er ist geboren 1564, getraut 1589 mit Anna Thumysen. Seine drei Kinder sind jung gestorben.

Trechsel, I Hans Balthasar, Kantengiesser, erneuert der Zunft Grächtigkeit um 9 \&, 1591 .

Trechsel, Ir Hans Balthasar, der Kantengiesser, erneuert der Zunft Grächtigkeit den 23. Juni 1636 und zahlt dafür $12 \&$.

Leemann, Hans, Kantengiesser, erneuert der Zunft Grächtigkeit um 12 \& den 8. Wynmonat 1605. Er starb zu Venedig im Krieg.

Müey, Wilhälm, der jung Kantengiesser, erneuert der Zunft Grächtigkeit um 12 \& den 28. Jenner 1611 . 
Zubler, Jörg, Kantengiesser, erneuert der Zunft Grächtigkeit um 12 \& den 25. Wynmonat 1612. Er wurde Zwölfter 1640. Er lieferte auf Befehl des Pflegers Röuchli im Jahre 1615 Zinngeschirr auf die Zunft. Im Jahre 1640 goss er $75 \&$ altes Zinngeschirr um und lieferte neues. Auch reparirte er alte Zinngegenstände (HEGI, S. 163). Nach 165o lieferte er auch Schützenplatten. Nach seinem Tode führte seine Wittfrau das Geschäft weiter; sie war eine Anna Sulzer. Meister Zubler starb am 14. Januar ${ }_{1641}$ und wohnte im Hause zum Tanz, Metzgergasse Nr. 3.

Die Wittwe Anna Zubler und spätere Anna Corrodi-Sulzer lieferte ${ }_{1650}$ und ${ }_{1} 651$ grosse Mengen Schützenplatten. Im Jahre 1671 kommt sie nicht mehr vor.

Jörg Zubler und seine Wittfrau führten die Giessermarke Nr. 8o, Bd. I.

Von Zubler's Arbeiten sind nur wenige Stücke bekannt.

Kleines breitrandiges rundes Plättchen, $19 \mathrm{~cm}$ Durchmesser, 4,8 cm Randbreite. (Kunsthandel in Luzern).

Runde Gupfplatte mit vorn verstärktem Rand. Durchmesser $38 \mathrm{~cm}$, Randbreite 6, $2 \mathrm{~cm}$. Reich gravirt. (Tafel XXVI, 15.$)$

Gleiches Stück von $35 \mathrm{~cm}$ Durchmesser.

Huber, Hans Cunrat, Kantengiesser, erkauft der Zunft Grächtigkeit um 3o \& den 14. Hornung 16,3 .

Hottinger, I Hans Caspar, Kantengiesser, erkauft der Zunft Grächtigkeit um 3o \& den 11. Herbstmonat ${ }_{1614}$. Er wurde Kohlenmeister, war Lieutenant in Frankreich. Er führte als Zinngiesserzeichen Nr. 95 (Bd. I).

Hottinger, II Hans Caspar, Kantengiesser, erneuert der Zunft Grächtigkeit den 8. Christmonat 1644 um $12 \&$.

Er führte wahrscheinlich auch die Zinngiessermarke Nr. $9^{5}$ (Bd. I).

Stumpf, Hans Rudolf, der Kantengiesser, erkauft der Zunft Grächtigkeit den 28. Augsten 1617 um 3o \&. Er wurde Stadtknächt und kam in Spital.

Täucher, Hans Heinrich, der Kantengiesser, erkauft der Zunft Grächigkeit um 3o \& den 10. Heumonat 1620 .

Schaufelberger, (Schuffelberger), Hans Ulrich, erkauft der Zunft Grächtigkeit den 12. Wynmonat 1626 um 30 \&.

Schaufelberger, (Schuffelberger), Hans Jakob, Zinngiesser, erneuert die Zunftgrächtigkeit den 16. Herbstmonat 1663 mit $12 \&$.

Holzhalb, Hans, der Kantengiesser, erkauft der Zunft Grächtigkeit den 3o. Mai ı63o um 3o \&. Starb 1635.

Rütter, Peter, der Kantengiesser, 1637 uff den 19 Januarii habent myn Herren die Zunftmeister, Herr Rathsherr und wir Zwölf Petern Rütter, jetzigen Wirth zur Cronen, synen Sohn Peter Rütter, dem Kantengiesser, uss sonderbahren Gnaden, wylen der Vatter auch allhie zünftig gewesen und der Zunft Grächtigkeit nit uffgäben, bewilliget und zugelassen, dass derselbig dieser Zunftgrächtigkeit mit 20 \& Gelts zugleich kauffen und ernöweren möge.

Hamberger, I Samuel, der Kantengiesser, kauft der Zunft Grächtigkeit den 12. Aprilis 1637 und zahlt dafür 3o \&. Er wurde Zivölfter ${ }_{1654}$ und Grosskeller am 3o. Dezember 1658. Er starb im Jahre 1670 .

Hamberger, II Samuel, der Zinngiesser, H. Ratsprocurator Hambergers ehelicher Sohn, hat den 17. Augstmonat 1702 die Zunftgrächtigkeit erneuert mit 12 \&.

Wirz, Heinrich, der Kantengiesser, erkauft der Zunft Grächtigkeit den 1. April 1633 um 3o \&. Er war geboren 1609 und starb im Jahre 1665 (Stammbaum der Wirz b. Frau Prof. Wirz). Er war Kohlenmeister, Zwölfer und Grossweibel. Im Jahre ${ }_{1643}$ lieferte er "Guss und Eichel fürs Buffet in Gigers Gemach im Zunfthaus (HegI, S. 163).

Wirz, Hans Cunrat, Zinngiesser, der Sohn des Vorigen, lebte von 1639 bis 1697 . Erneuert die Zunftgrächtigkeit den 27. November ${ }_{1662}$ mit 12 \&. Er war auch Ratsschreiber.

Wirz, Hans Caspar, der Kantengiesser, Sohn des Vorigen, lebte von 1666-1733. Erneuert die Zunftgrächtigkeit den 24 . Octobris 1688 mit $12 \&$. 



1-3. Abendmahlkannen von Ligerz, von Alex. Bäschlin, Biel, 1615-35 tätig (Text S. 42). 4. Abendmahlkanne von Biel, von David l. Witz, in Neuenstadt vor 1678 (Text S. 42 und 212). 5. Abendmahlkanne von Biel, von Bendicht Wagner, in Biel tätig 1664-87 (Text S. 42 und 208). 6. Abendmahlkanne von Biel, von Peter ll. Baumgarter in Bern, erwähnt 1550-8! (Text S. 42 und 193). 

Sein Sohn Hans Caspar wurde nicht Zinngiesser.

Er führte das Meisterzeichen Nr. 102 und 103 (Bd. I).

Gegenstände : Melonengiessfass im schweizerischen Landesmuseum. Zackige

Wandplatte im historischen Museum in Basel.

Wirz, I Andreas, Zinngiesser. Er wurde geboren am 6. Juni 1703 und starb am 23 . Mai 1792. Der Einkauf in die Zunft erfolgte im Jahre 1728. Er war ein sehr produktiver Zinngiesser; daneben war er Inspector der Feuerwerker, Zwölfer, seit 1769 Ratsherr, von 1769-81 Obervogt von Wettswil, 1777 Spitalpfleger (Bürger-Register der Stadt Zürich).

Er führte die Meistermarken Nr. 97 und 98 (Bd. I).

Gegenstände: Sechsseitig prismatische 2 Maass-Kanne mit Schraubenverschluss, Marke Nr. 98 auf dem Deckel der Kanne. Am Ausgussrohr ist ein kleiner Delphin angelötet zur Befestigung des Kettchens. An Stelle der Bodenrosette befinden sich feine concentrische Kreise. Höhe der Kanne 36,5 cm. Gravirte Jahrzahl 1745.

Barokteller mit gewelltem Rand; Marke Nr. 98 ohne römische Zahlen. Durchmesser $25 \mathrm{~cm}$. (Tafel XXVII, 11.)

Wirz, Hans Jakob, Zinngiesser; er wurde geboren am 25. Januar 1795 und starb am 6. März 1885. Sein Vater war Färber.

Er führte die Zinngiessermarken Nr. 104 und 105 (Bd. I).

Gegenstände : runder Barokteller mit gewelltem Rand; Durchmesser $25,3 \mathrm{~cm}$. Meistermarke Nr. 1 o5. (Tafel XXVII, 11.)

Wirz, Salomon, Zinngiesser, Sohn des I. Andreas Wirz, Zinngiesser. Er wurde geboren am 7. September 1740 und starb am 6. August 1815. Er erneuerte die Zunft im Jahre 1761; er war Zunftschreiber im Jahre ${ }_{1769}$ und im Jahre 1789 Amtmann am Kappelerhof.

Nr. 99 und 1 oo (Bd. I) sind seine Meisterzeichen.

Gegenstände: Glockenkanne von einer Maass Inhalt; Bajonetverschluss. Höhe $29 \mathrm{~cm}$. Bodenrosette Nr. 165. Meisterzeichen Nr. 100 auf dem Ausgussdeckelchen. Ferner viele $\mathrm{S}$ chützenteller.

Wirz, II Andreas, Sohn des vorigen Zinngiessers Salomon Wirz; er wurde geboren am 3. Mai ${ }_{1767}$ und starb am 19. November 1813 ohne Nachkommen. Erneuert die Zunft 1792.

Er führte als Meisterzeichen Nr. 101 (Bd. I).

Gegenstände: Wöchnerinnenschüsselchen mit Ohren. Auf dem Deckel doppelter Perlstabfries und drei Klauenknöpfchen. (Tafel XX, 3.)

Grosses Plateau mit beweglichen Traghenkeln. Sechs knopfförmige Füsse. Durchmesser $54,5 \times 43,5 \mathrm{~cm}$.

Steiner, I Hans Conrat, der Kantengiesser, erkauft der Zunft Grächtigkeit den 7. Jenner 1641, zalt dafür 3o \&. Meisterzeichen Nr. 75 (Bd. I).

Gegenstand: grosse Breitrandplatte, Durchmesser $35 \mathrm{~cm}$; Randbreite $9,7 \mathrm{~cm}$. Am Rande das Meisterzeichen Nr. 75. (Tafel XXVI, 11.)

Steiner, Hans Jakob, der Zinngiesser, hat die Zunftgrächtigkeit erneuert uff den 3o. November 1671 mit $12 \&$.

Er führte das Meisterzeichen Nr. 77 (Bd. I).

Gegenstand: Stegkanne in der Ulmer-Form. Höhe $31 \mathrm{~cm}$. Auf dem Deckel Etagenknopf. Auf dem Traghenkel das Meisterzeichen Nr. 77 (Bd. I). Wahrscheinlich das "Meisterwerk". (Tafel XVIII, 18.)

Steiner, II Hans Conrat, der Zinngiesser, ernöüert der Zunftgrächtigkeit den 19. Octobris 1681 und zalt 12 \&.

Er führte das Meisterzeichen Nr. 76 (Bd. I).

Gegenstände: Taufschüssel aus der Auction Angst mit der Jahrzahl 1685. Ferner eine Kuchenplatte im schweizerischen Landesmuseum in Zürich.

Steiner, Caspar, der Zinngiesser, hat die Zunftgrächtigkeit erneuert den 3o. Novembris ${ }_{16} 6_{1}$ mit 12 \&. Meistermarke unbekannt. 
Schinz, Hans Caspar, der Kantengiesser, erkauft der Zunft Grächtigkeit den 7. Christmonat ${ }_{1645}$ um 3o \&. Im Jahre 165 o lieferte er das ein pfundschwere Giessfass in die kleine Stube des Zunfthauses (Hegr, S. 163). Er war der Sohn des Pfarrers Caspar Schinz. Er wurde geboren am 7. Mai 1620 und starb im Jahre 1665.

Schinz, Hans Rudolf, der Zinngiesser, erkauft der Zunft Grächtigkeit den 29. Septembris 1664 mit 3o \&. Er war der Sohn des Pfarrers Johannes Schinz und war geboren im Jahre 1640. Im Jahre 1665 heiratete er Dorothea Meyer, welche als Witwe sich im Jahre ${ }_{1671}$ wiederum mit dem Zinngiesser Georg Thumysen (1647-1700) verehelichte. Hans Rudolf Schinz hatte keine Söhne.

Bodmer, Hans Ulrich, der Kantengiesser, erkauft der Zunft Grächtigkeit den 26. Hornung 1652. Zalt dafür 3o \&.

Bodmer, Hans Gunrat, der Zinngiesser, hat die Zunftgrächtigkeit erneuert Donstag den 27. Wintermonat 1679 mit $12 \&$.

Murer, Hans Cunrat, der Kantengiesser, erkauft der Zunft Grächtigkeit den 2o. Mai 1652. Zalt darfür 3o \&.

Murrer, Salomon, der Zinngiesser, Herrn Obmann Salomon Murrers dess Sattlers und Amtmann im Cappelerhoff ehelicher Sohn, erkauft der Zunft Grächtigkeit den 6. Juny 1716 mit 3o \&.

Sommerauer, Hans Georg, der Kantengiesser, erkauft der Zunft Grächtigkeit den 26. Hornung 1652. Zalt darfür 3o \&. Er war Obmann der Zinngiesser und starb am 31. Oktober 1697. Er führte das Meisterzeichen Nr. 73 (Bd. I). Als eine Variante führte er die 2 Stempel (Orts- und Familienwappen) auch getrennt.

Sommerauer (Summerauer), I Hans Felix, der Kantengiesser, hat die Zunftgrächtigkeit erneuert Mitwochs den 6. Dezembris 1676 mit 12 \&. Meistermarke Nr. 74 (Bd. I). Starb am 22. April 1714 .

Gegenstand: Breitrandteller von $24 \mathrm{~cm}$ Durchmesser. Randbreite $6,3 \mathrm{~cm}$.

Sommerauer, Heinrich, der Zinngiesser, hat die Zunftgrächtigkeit ernöuwert Mittwochs den



73 a 17 Novembris 1680 mit 12 \&. Er starb am 26. Oktober 1726. Er führte als Meisterzeichen Nr. 73 a (Bd. II).

Gegenstand: Maastitze ohne Ausgusschnabel; Höhe mit dem Deckelgriff $29 \mathrm{~cm}$. Am Griff reliefirter Engelkopf. Am Henkel die Meisterzeichen Nr. 73 a (Bd. II). Im Kannenboden eine eingesetzte, neunteilige Rosette (Nr. 16o a, Bd. II). Tafel XXX, 5.

Summerauwer, II Hans Felix, der Zinngiesser, dess Hans Felix Summerauwers dess Zinngiessers ehelicher Sohn, ernöuwerte der Zunft Grächtigkeit Dinstags den 2. Septembris 1721 mit 12 \&. Führte das gleiche Meisterzeichen Nr. 74 (Bd. I) wie sein Vater.

Waser, Jakob, der Kantengiesser, erkauft der Zunft Grächtigkeit den 6. Decembris ${ }_{1660}$ mit 3o \&.

Waser, I Johannes, der Zinngiesser, ernöuert der Zunftgrächtigkeit uff den 29. April 1686 mit 12 \&. Er war im Jahre 1665 geboren und starb am 9. Dezember 1731. Er war Obmann und Artilleriehauptmann.

Waser, II Johannes, der Zinngiesser, Herrn Obmann Johannes Wasers des Zinngiessers ehelicher Sohn ernöuwert der Zunftgreechtigkeit Donstags den 25. Novembris $A^{0}{ }_{1717}$. Er war am 1o. Oktober 1697 geboren und starb am 4. Dezember 1756. Seine Tochter Ursula (1733-1756) heiratete im Jahre ${ }_{17} 55$ den Zinngiesser Konrad Bosshart (1727-1795).

Waser, Heinrich, Zinngiesser, lebte von 1743 bis 1801 . Als Meisterzeichen führte er Nr. 82 (Bd. I).

Gegenstand: Breitrandplatte von $3_{1} \mathrm{~cm}$ Durchmesser bei $8 \mathrm{~cm}$ Randbreite.

Thomann, Hans Heinrich, der Kantengiesser, erkaufft der Zunft Grächtigkeit den 24. Aprilis 1661 mit 3 o \&.

Wüst, David, der Zinngiesser, hat die Zunftgrächtigkeit erkauft Mittwochs den 3. Octob. 1666 mit 3o \&. 
Thumysen, Hans Georg, der Zinngiesser, hat die Zunftgerechtigkeit erkauft auf 3. Juli 1671 mit 3o \&. Er war im Jahre 1647 geboren und wurde 1671 getraut mit Dorothea Meyer, der Wittwe des Zinngiessers Rudolf Schinz. Er starb vor dem Jahre 170o. Seine Meisterzeichen sind Nr. 69 und 70 des Band I.

Gegenstände: Kuchenplatte im Landesmuseum in Zürich.

Schützenplatte mit Gupf. Vorn verstärkter Rand. Durchmesser $24,5 \mathrm{~cm}$; Gupfdurchmesser 16,7 cm. Gupftiefe $3 \mathrm{~cm}$. Auf dem Schützenzeichen die Jahrzahl 1650. (Tafel XXXI, 4.)

Breitrandiger Teller.

Baltenschwyler, Johannes, der Kantengiesser, hat die Zunftgrächtigkeit erkauft den 5. Novembris 1672 mit 3o \&. Er wurde geboren am 11. November 1649 ; verheiratete sich 1672 mit Anna Hirzel. Er wohnte im Haus zur Büchs, am Rennweg Nr. 6; im Jahre 1699 wird er Obmann der Zinngiesser. Er starb im Januar 173o. Sein Vater Ludwig war Pfarrer in Dielsdorf. Als Meisterzeichen führte er Nr. 81 (Bd. I). Im Jahre 1700 lieferte er viele Schützenplatten und zwar 116 Pfund.

Gegenstand: grosse Breitrandplatte. Durchmesser $35,3 \mathrm{~cm}$, Randbreite $8 \mathrm{~cm}$. Am Rande viele feine concentrische Rillen. Das Meisterzeichen $\mathrm{Nr}$. 81 befindet sich an der obern Seite des Randes.

Baltenschwyler, Heinrich, der Zinngiesser, hat die Zunftgrächtigkeit erneuert uff Mittwochs den 18. März 1696 mit 12 \&.

Grob, Hans Jakob, der Kantengiesser, Herrn Obmann Hans Jakob Groben des Kupferschmieds ehelicher Sohn, hat den 24. Novembris 1707 die Zunftgrächtigkeit erneuert mit 12 \&. Meistermarke Nr. $7_{1}$ (Bd. I). Kleiner Breitrandteller mit Schützenstempel 1695 . (Sammlung Hirsbrunner Luzern).

Grob, Jakob, Kantengiesser, Erneuerung der Zunft-Grächtigkeit 1733 (oder 1734 ?).

Breitinger, I Wilhälm, der Zinngiesser, Herrn Hans Caspar Breitingers selgen, gewesenen Pfarrers in Münch-Altorff ehelicher Sohn, erkauft der Zunft Gerechtigkeit den 6. Junii 1716 mit 3o \&. Er wurde geboren im Jahre 169. Er starb im Spital am 29. November 1767. Er führte die Meisterzeichen Nr. 78 und 79 (Bd. I). Bodenrosette Nr. 160.

Gegenstände : Kleines Tellerchen mit sehr schmalem Rand. Durchmesser 19,1 cm.

Maasstitze ohne Schnabel; Bodenrosette Nr. $160 a$; Höhe 3r,5 cm. Auf dem Deckel etagenförmiger Knopf.

Breitinger, II Wilhelm, Zinngiesser. Erneuerung der Zunft 1739 (oder 1738) mit 12 \&. Er war der Sohn des Vorigen und war geboren im Jahre 1717; er starb kinderlos im Spital im Jahre ${ }_{1769}$. Gleiche Meistermarken wie der Vater, I. Wilhelm.

Gegenstand: Grosser $\mathrm{H}$ umpen mit etagenförmigem Knopf auf dem Deckel. Deckelgriff fehlt fast vollständig. Höhe des Humpens $20 \mathrm{~cm}$. Durchmesser des Fusses $14 \mathrm{~cm}$.

Freytag, Hans Jakob, der Zinngiesser, Herrn Andreas Freytags, Pfarrers zu Wyl uff dem Rafzerfeldt ehelicher Sohn, erkauft der Zunft Grächtigkeit Montags den 27. Februarii 1719 mit 3o \&. Im Jahre 1724 wird Hans Jakob Freytag wegen zu schlechter Zinn-Bleilegirung trotz Appellation gestraft und zwar mit 12 \& Busse und 8 \& Bottgelder (Hegi, S. 165). Meisterzeichen Nr. 72 (Bd. I).

Gegenstand: 2 Maass-Glockenkanne mit Bajonetverschluss; Marke Nr. 72 auf dem Ausgussdeckelchen. Auf dem Schild die Initialen H ST und die Jahrzahl 1742. Deckelsicherung durch einen Scharnirverschluss. Eingesetzte Bodenrosette. Höhe $36 \mathrm{~cm}$.

Meyle, Hans Felix, der Zinngiesser, Herrn Hs Rudolf Meilins seligen dess Eysenkrämers ehelicher Sohn, ernöuwert die Zunftgrächtigkeit auf den 25 . Novembris 1717 mit 12 \&.

Hoffmeister, Jakob, Einkauf zu den Zinngiessern.

Ammann, Johannes, Zinngiesser, kauft sich 1765 in die Zunft ein. Gehört der sogenannten Reithaarlinie der Ammann von Zürich an (siehe Stammtafel im Ammann-Werk). Er ist geboren am 11. September 1740 und gestorben am 13. Februar 1800. Er führt als Meister- 
marke Nr. 96 (Bd. I). Seine erste Frau war Anna Regula Bosshart, die Tochter des Zinngiessers Jakob Bosshart (1702-1863). Er war auch Zoller.

Gegenstand: gewöhnlicher, schmalrandiger Teller.

Weber (Waeber), Johannes, Zinngiesser, Sohn des Weber, Rudolf, Goldschmied; er wurde geboren am 28. Juni ${ }_{1713}$, kaufte sich in die Zunft ein ${ }_{1739}$. Er starb am 1. November 1788. Seine Arbeiten sind ebenso häufig als gut. Er zählt mit zu den besten Zinngiessern Zürichs. Seine Meisterzeichen sind Nr. 106, 107, 108 und 109 (Bd. I). Er besass auch eine Marke mit der Krone für Arbeiten in Feinzinn, Nr. 108 (Bd. I).

Gegenstände : Grosser H umpen mit gerilltem Knopf auf dem Deckel, Meistermarke 107 ; reich gravirt. Deckelgriff fehlt. Höhe $21 \mathrm{~cm}$. (Tafel XIX, 3.)

$1 / 4$ Maass Schnabelstitze mit etagenförmigem Deckelknopf; gravirte Initialen $\mathrm{H} \mathrm{C} \mathrm{K}$. Höhe $17 \mathrm{~cm}$. (Tafel XXX, 1.)

Sechsseitig prismatische Schraubkanne von 2 Maass Inhalt. Meistermarke Nr. 107. Auf der rechten Seite des Kannenleibes die gravirte Jahreszahl 1766. Ausgussröhre mit Schraubenverschluss. Höhe mit Ring $37 \mathrm{~cm}$. (Tafel XXX, 12).

$1 / 2$ Maas Schnabelstitze mit etagenförmigem Deckelknopf. Am Henkel die Meistermarke 107 ; Bodenrosette 162 . Höhe $23,5 \mathrm{~cm}$.

$1 / 2$ Maass Stitze ohne Schnabel, mit gerilltem Knopf auf dem Deckel, Bodenrosette Nr. 162 ; Höhe $23,5 \mathrm{~cm}$. (Tafel XXX, 6).

Wöchnerinnen-Schüsselchen mit horizontalen "Ohren ", Meistermarke Nr. 106 inwendig am Boden. Auf dem Deckel 3 Klauenfüsse. Durchmesser mit den Ohren 18,7 cm. Durchmesser des Bodens $9 \mathrm{~cm}$. (Tafel XX, 4.)

Gewöhnliche schmalrandige Teller.

Weber, Daniel, Zinngiesser, der Sohn des Vorigen. Er wurde am 28 . April ${ }_{17} 51$ geboren; er erneuerte die Zunft 1771, war Verwalter des Waisenhauses 1787, Zunftmeister 1796 und $1797^{1}$, Amtmann zu Rüti 181 o. Er starb am 16. Juni 1828. Seine Meistermarke entspricht der Nr. 110 (Bd. I).

Gegenstände: Glockenkannen von I Maass Inhalt.

Zimmermann, I Johannes, Zinngiesser, Sohn des Hans Conrad, Pfarrers in Egg (1671-174.), wurde geboren im Jahre 1716 , erneuerte die Zunft 1740 oder 1741. Er starb 1789.

Meisterzeichen Nr. $111,112,113$ und 114 (Band I).

Zimmermann, II Johannes, oder Jean, Zinngiesser, Sohn des Vorigen. Er ist im Jahre 1744 geboren, erneuerte die Zunft im Jahre 1769 und starb 1822. Er hatte drei Töchter. Die älteste, Namens Elisabeth, heiratete 1801 den Zinngiesser Hans Caspar Ziegler (17761814); die jüngste, Namens Anna Barbara, verehelichte sich im Jahre 1807 mit Heinrich Emmanuel Freudweiler, dem Vater des Zinngiessers Joh. Jakob Freudweiler (1810-1840). Johannes II Zimmermann führte die Meisterzeichen Nr. 115 und 116 (Band I). Wahrscheinlich auch im Anfang die Meisterzeichen seines Vaters Nr. 111, 112, 113 und 114. Gegenstände : 1 Maass Stitze ohne Schnabel; Meistermarke 112 auf dem Traghenkel; Bodenrosette Nr. 166. An der Vorderseite gravirter Blattdekor mit den Initialen EBR. Höhe $30 \mathrm{~cm}$.

1/4 Maass Schnabelstitze mit gerilltem Deckelknopf. Meisterzeichen Nr. 11 rosette 166 . Höhe $17,5 \mathrm{~cm}$.

1 Maass Schnabelstitze, auf dem Traghenkel die Meistermarke Nr. 112 ; Bodenrosette 167. Gravuren: $M M B$ 1786. Höhe $31 \mathrm{~cm}$.

$1 / 4$ Maass Stitze ohne Schnabel mit gerilltem Deckelknopf. Am Traghenkel das Meisterzeichen Nr. 112 . Höhe $17 \mathrm{~cm}$.

Bosshart, Jakob, Zinngiesser, geboren am 11. Februar 1702, gestorben am 1 o. Dezember 1763 . Er war Stubenverwalter zur Schmieden. Sein Meisterzeichen ist wahrscheinlich Nr. 85 (Band I). Gegenstand: Zürcher Schützenteller.

${ }^{1}$ (Hegi S. $3_{70 .)}$ 
Bosshart, Konrad, Zinngiesser, Sohn des Vorigen Jakob Bosshart, wurde geboren am 1 2. Oktober 1727; heiratete 1755 Ursula Waser, die Tochter des letzten Zinngiessers aus dem Geschlechte der Waser. Er starb am 22. Februar 1795. Im Militär war er Hauptmann. In die Zunft zur Schmieden trat er im Jahre ${ }_{17} 52$ oder 1753.

Bosshart, Hans Heinrich, Zinngiesser, ebenfalls ein Sohn des Jakob Bosshart, wurde geboren am 27. Januar 1732; er erneuerte die Zunft im Jahre 1757; wurde auch Stubenverwalter der Schmiedenzunft. Er starb am 15. September 1788. Er war ein sehr produktiver und guter Zinngiesser. Er führte die Meisterzeichen Nr. 86, 87 und 88 (Band I); ebenfalls einen Stempel mit der Engelmarke.

Gegenstände : 1/4 Maass Stitze ohne Schnabel mit Traube auf dem Deckel; Meisterzeichen Nr. 87. Gravirte Initialen RK. Höhe $18,5 \mathrm{~cm}$.

Rokkokoteller mit Engelmarke.

1 Maass Schnabelstitze mit Traube auf dem Deckel. Auf dem Henkel das Meisterzeichen Nr. 86; Bodenrosette 161; gravirter Blumendekor und SL 1776 . Höhe 3o $\mathrm{cm}$. (Tafel XXX, 3).

$1 / 2$ Maass Schnabelstitze; auf dem Henkel das Meisterzeichen Nr. 88; Bodenrosette 161. Höhe 23,7 cm. (Tafel XXX, 2.) Traubenknopf.

$1 / 4$ Maass Schnabelstitze mit gerilltem Knopf auf dem Deckel; Meisterzeichen Nr. 87. Gravirte Initialen HB. Höhe $16,7 \mathrm{~cm}$.

Bosshart, Hans Conrad, Zinngiesser, Sohn des Conrad Bosshart, Hauptmann, wurde geboren am 11. Sept. 1768 und starb am 9. Sept. 1820. Er führte das Meisterzeichen Nr. 89 (Bd. I). Gegenstand: Humpen mit Traube auf dem Deckel. Am Henkel die Marke Nr. 89. Gravirte Initialen und Jahreszahl E B H 1762. Höhe ${ }_{2} 3 \mathrm{~cm}$. (Tafel XIX, 4.)

1 Maass Glockenkannen.

Bosshart, I Hans Jakob, Zinngiesser, Bruder des Vorigen, wurde geboren am 5. Januar 1773, trat bald in französischen Militärdienst und ist seit 1800 verschollen.

Wahrscheinlich hatte er als Meisterzeichen Nr. 91 .

Gegenstand: Grosser Humpen mit Traube auf dem Deckel. Auf dem Henkel Marke Nr. 91. Bodenrosette Nr. 163 . Höhe $20 \mathrm{~cm}$.

Rokkokoteller.

Bosshart, II Hans Jakob, Zinngiesser, Sohn des Hans Heinrich Bosshart, wurde geboren am 28. August 1757; war 1778 Zünfter; starb am 26. Dezember 1839 . War auch Holzmesser. Er führte die Meisterzeichen Nr. 92 und 93 (Bd. I).

Gegenstände : 1/2 Maass Glockenkanne mit Bajonetverschluss, Meisterzeichen Nr. 92 ; Bodenrosette 164. Höhe 22,5 cm. (Tafel XXX, 13.)

Brunnenkesselchen mit Traube auf dem Deckel. Meisterzeichen Nr. 92. Fratzenköpfe am Ausguss und an der Basis des Traghenkels (aus Eisendraht). Der Deckel greift in einen Falz ein. Höhe $18 \mathrm{~cm}$. Durchmesser des Fusses 12,5 cm. (Tafel XX, 20.)

Bosshart, Hans Ulrich, Zinngiesser, Bruder des Vorigen, wurde geboren am 1. Juni 1763; er erneuerte die Zunft 1786. Er starb am 9. September 1822 ohne männliche Nachkommen. Sein Meisterzeichen entspricht Nr. 90 (Bd. I).

Gegenstand: Schmalrandteller mit Schützengabenzeichen. (Tafel XXVII, 12.)

Bosshart, Hans Rudolf, Zinngiesser, der Sohn des II Hans Jakob Bosshart; er wurde geboren am 28. November 1787 und starb kinderlos am 31 . August 1852 .

Als Meisterzeichen führte er Nr. 94 (Bd. I).

Gegenstand: Schmalrandiger Teller; Durchmesser $23,5 \mathrm{~cm}$; Meisterzeichen Nr. 94 an der Unterseite des Tellers. Gravirte Initialen HH I.

Manz, Johann Gaspar, Zinngiesser, wurde geboren im Jahre 1741 ; kaufte sich in die Zunft ein im Jahre 1765 und wurde 1779 wegen Diebstahls enthauptet. Seine Meisterzeichen entsprechen den Nr. $117,118,119$ und 120 (Bd. I). 
Gegenstände : eine sechsseitig prismatische $\mathrm{K}$ anne von 1 Maass Inhalt mit Schraubenverschluss. Marke Nr. 118 auf dem Deckel der Kanne. An der rechten Seite der Kanne die gravirte Jahrzahl $177^{5}$ und die Initialen F. K. Höhe $3_{1} \mathrm{~cm}$.

Glockenkannen von 2 Maass, Stitzen, Humpen.

Manz, Anna Elisabeth, geborne Ulrich, die Wittwe des Johann Caspar Manz, führte nach harten Kämpfen mit den Zunftgenossen das Geschäft ihres Mannes weiter und zwar bis 1803 , also ca. 25 Jahre.

Ihre Meisterzeichen sind die Nr. 121,123 und 125 .

Gegenstände: Ovale Barok-Fischplatte; Meisterzeichen 121 . Durchmesser $30 \times 22 \mathrm{~cm}$.

Schmalrandiger Teller von 26,7 cm Durchmesser; Meisterzeichen 123 . (Tafel XXVII, 16.) 1/4 Maass Schnabelstitze mit Traube auf dem Deckel ; am Henkel Marke Nr. 125 , Bodenrosette Nr. 168. Gravirte Initialen B. S. H.

Prismatische Kannen. Henkelschüsseln. Giessfässer.

Manz, Hans Rudolf, Zinngiesser, wurde im Jahre 1771 geboren; er erneuerte die Zunft im Jahre 1794 und starb im Jahre 1829.

Er führte die Meisterzeichen Nr. 127, 128, 129, 130, 131, 132 und 133 (Bd. I).

Gegenstände : 1 Maass Schnabelstitze mit grosser Traube auf dem Deckel; Meisterzeichen $\mathrm{Nr} .{ }_{1} 3_{1}$ auf dem Traghenkel. Bodenrosette Nr. 169. Fuss der Kanne mit starker Ausladung. Höhe $31,5 \mathrm{~cm}$. Gravirte Jahrzahl 1806. (Tafel XXX, 4.)

Ovale Plättchen mit doppeltem Perlstab am Rand; Durchmesser 25,5 X $19 \mathrm{~cm}$. Meisterzeichen Nr. 128 am Boden. Initialen HK ST. (Tafel XXVII, 14.)

Glockenkannen. Giessfässer. Biedermeier-Gemüseschüsseln mit Henkelgriffen.

Manz, Friedrich, Zinngiesser, wurde im Jahre 1810 geboren und starb 1882 . Im Jahre $183_{2}$ heiratete er Magdalene Elisabeth Weber (1812-1880). Er war Major, Sekretär der städtischen Armenpflege.

Seine Meisterzeichen entsprechen den Nr. 134 und 135 (Bd. I).

Gegenstand: Ovales Plättchen mit Akanthusfries am Rand; Meisterzeichen Nr. 135.

Durchmesser $24,7 \times 18,3 \mathrm{~cm}$. (Tafel XXVII, 18.)

Kleine Messtitzchen (Historisches Museum Basel).

Manz, Magdalena Elisabeth, führte die Meisterzeichen Nr. 122 und 124. Als Wittwe des Friedrich Manz, 1812-188o, führte sie das Geschäft nur kurze Zeit.

Freudweiler, I Johann Jakob, Zinngiesser, wurde im Jahre 1810 geboren und starb 1840. Sein Meisterzeichen entspricht Nr. 137.

Freudweiler, II Johann Jakob, Zinngiesser und später Spielwarenhändler, wurde im Jahre 1835. geboren und starb 1877 .

Das Meisterzeichen Nr. 137 war auch das seinige.

Ziegler, Hans Kaspar, Zinngiesser, der Sohn des Kornhausmeisters, wurde am 11. Mai 1776 geboren und starb ohne männliche Nachkommen am 19. November 1814 .

Als Meisterzeichen führte er die Nr. 138, 139 und $139 a$ und $b$.

Gegenstände: Glockenk annen, Brunnenkesseli.

Ziegler, Margarethe, Wittwe des Hans Kaspar Ziegler, Zinngiesser, führte das Geschäft ihres Mannes weiter und zwar von 1814 bis 1837 .

Sie führte als Meisterzeichen die Nr. 140 und 141 (Bd. I).

Gegenstände: Giessfässer, Teller, Glockenkannen.

Lachmund, Julius, Zinngiesser, wurde geboren im Jahre 1801 , verheiratete sich 1835 und starb im Jahre 1874 .

Er führte das Meisterzeichen Nr. 136 (Bd. I). Sein Geschäft befand sich im "Wettingerhaus " unter den Bögen, also nahe bei der Zunft zur Zimmerleuten. 


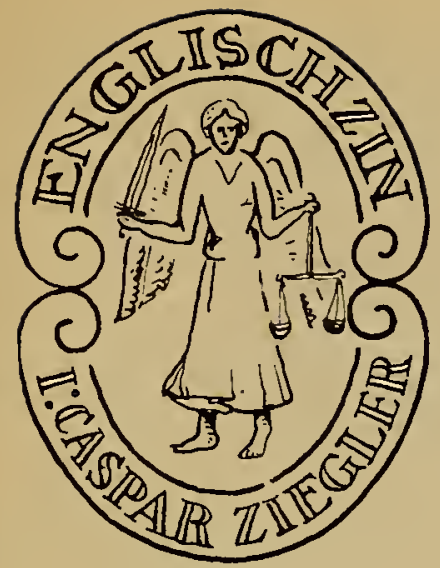

139 a

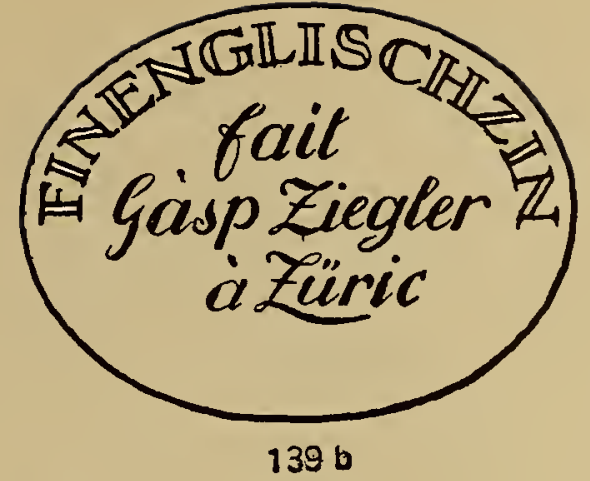

$139 \mathrm{~b}$

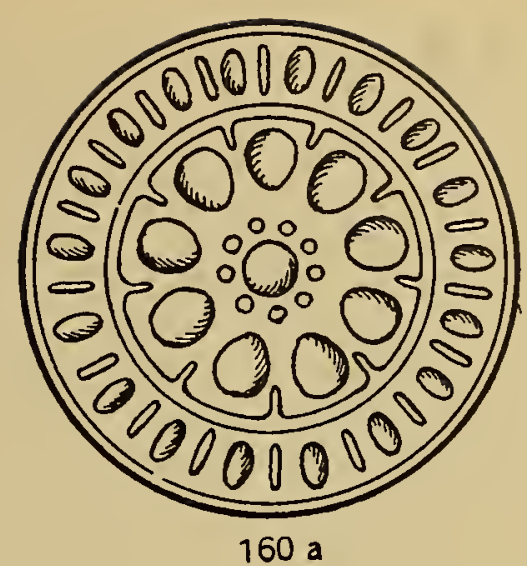

160 a

\section{Die zürcherischen $Z$ inngegenstände}

Im Allgemeinen ist $\mathrm{zu}$ bemerken, dass wohl infolge der straffen Zunftdisciplin die Qualität der Zinngegenstände in Bezug auf den Bleigehalt als eine gute bezeichnet werden darf. Die ältesten, noch erhaltenen Zinngegenstände entsprechen ziemlich genau der alten $Z$ ürichprobe. Von ca. 1700 ab gibt es aber viele Zinngiesser, welche, wohl auf Bestellung hin, viel weniger Blei verwendeten. Diese verfertigten eine Ware, welche sich jahrelang silberweiss erhält. Trotzdem tragen diese Zinnsachen die gleiche Abstempelung wie die qualitativ viel schlechtern. Für Arbeiten in Fein zin n war als Zusatzstempel eine Krone vorgeschrieben. Wir haben dieselbe nur bei einem einzigen Zinngiesser, bei Meister Johannis Weber oder Waeber, gefunden.

Zürcher Zinnwaren vor dem Jahre 1600 habe ich niemals finden können. Dieselben sind zu Grunde gegangen oder sind umgeschmolzen worden.

Die ältesten bekannten Gegenstände sind Breitrand-oder "Gupf "-Platten; infolge des reichlichen Platzes sind die Giesserzeichen auch meist gut erhalten. Eine Stitze von Sommerauer oder eine Stegkanne von Hans Jakob Steiner gehören zu den grössten Raritäten.

Auffallenderweise gibt es keine Ratskannen der Stadt Zürich.

\section{Die Kannen}

Wir finden drei Typen in Zürich. Wegen der mächtigen Entwicklung des Zinngiesserhandwerkes und nicht zum wenigsten infolge des hochentwickelten Kunstsinnes der Bevölkerung weisen alle drei Typen derartig gute Proportionen auf, dass ich alle drei Kannenformen als Grundtypen für die gesamte Nordostschweiz aufstelle. Es sind diese : die Glockenkanne, die Stitze und die 6-8 seitige prismatische Kanne.

Die Glockenkanne. - Es gibt vier gebräuchliche Grössen, je nach dem Inhalt von 2, 1, 1/2 und $1 / 4$ Maass. Die häufigsten Kannen halten 1 oder $1 / 2$ Maass. Es gibt aber auch $Z_{\text {wischen- }}$ grössen, so z. B. $1 \frac{1 / 2}{2}$ Maass. Der Deckel trägt einen senkrecht gestellten Tragring. Der Verschluss des Deckels erfolgt entweder durch einen Bajonetverschluss oder aber durch ein Schraubengewinde. Ebenso gibt es zwei Arten von Verschlüssen der Ausgussröhre. Bei der einen Art besteht ein Deckelchen, welches in einem Scharnir läuft; die andere Art hat den Schraubengewinde-Verschluss. In letzterm Falle befindet sich aussen am Verschluss ein Knopf, an welchem eine kleine Kette befestigt ist, welche ihrerseits an einem kleinen Delphin hängt. Letzterer ist an der Basis der Ausgussröhre angelötet. Der Leib der 
Kanne ist cylindrisch und ist gegen den Fuss etwas erweitert. Durch diese Ausladung wird die gefällige Form bedingt. Jeder Meister hat sein eigenes Modell, das seinen Formensinn kennzeichnet. An der rechten Seite der Kanne befindet sich meistens ein aufgelöteter Schild, welcher bestimmt ist, gravirte Wappen, Initialen oder Jahrzahlen aufzunehmen. Die Zinn giessermarken befinden sich entweder auf dem Deckelchen der Ausgussröhre oder auf dem Deckel oder am Boden der Kanne. An der Innenseite des Kannenbodens sind die Rosetten oder Plaquetten verschiedenster Art angebracht, z. B. das Schweisstuch mit dem Antlitz Christi, Figurinen u. dgl. Diese Bodenstücke sind meist zeichnerisch sehr schön und auch ausserordentlich manigfaltig. Jeder Meister hat seine eigenen Formen und deshalb soll die Bodenrosette und die Giessermarke zusammenstimmen. Darum ist es auch möglich, aus der Bodenrosette den Zinngiesser zu eruiren.

Bei den Kannen von 2 Maass Inhalt, deren Deckel einen Bajonetverschluss aufweist und infolgedessen leicht abfällt, besteht eine Sicherung in der Form eines Scharnirs. Wenn dieses geschlossen ist, so ist die Drehung des Deckels unmöglich und damit auch das Abfallen.

Der Kannenleib der zürcherischen Glockenkannen ist glatt und weist keine circulären Wülste auf. Dagegen sind circuläre Rillen eingedreht, welche der sonst glatten Kanne einige Gliederung verleihen.

Der an der rechten Kannenseite befindliche Schild hat sehr verschiedene Formen und entspricht dem Stile der Zeit.

Um die Basis der Ausgussröhre herum findet man fast immer einfache gravirte Ornamente als Einfassung, oft nur im Tremolirstich als Zackenband, oft aber auch Girlanden und verschiedene Pflanzenmotive.

Die Stitze. - Diese Form wurde nur in der Stadt Zürich, nicht aber in den Municipalstädten, angefertigt. Irgend eine amtliche Vorschrift für dieses Privilegium der Stadt Zürich habe ich nicht auffinden können; und doch kennt man keine Stitzen der Municipalstädte Winterthur, Stein, Eglisau; auch in Rheinau und Elgg kommen sie nicht vor.

Die Stitzen kommen in drei Grössen vor, als 1, 1/2 und 1/4 Maass-Kanne. Man unterscheidet zwei Arten: die Stitze mit oder ohne schnabelförmigem Ausguss. Die Schnabelstitzen besitzen einen relativ grossen, kräftig modellirten Ausguss-Schnabel, welchem, am Deckel angelötet, ein passender Verschluss entspricht. Die Stitzen ohne schnabelförmigen Ausguss sind am offenen Teile, und zwar gegenüber dem Traghenkel, seitlich zusammengepresst, so dass das Lumen eine herzförmige Gestalt annimmt. Dementsprechend hat natürlich auch der Deckel die Herzform. Diese Stitzenform scheint die ältere zu sein; wenigstens finden wir dieselbe schon beim Meister H. F. Sommerauer.

Die Schnabelstitzen sind dekorativer und haben auch eine elegantere Form. Auf dem Deckel beider Stitzenformen befindet sich ein knopfförmiges Gebilde. Es gibt drei Arten solcher Deckelknöpfe : die vollrundgegossene Traube, der aus etagenförmigen Scheibchen zusammengesetzte Knopf und der gerillte, kegelförmige Knopf. Die einzelnen Giessermeister bevorzugten diese oder jene Form und verwendeten dann die betreffende fast allein.

Die Ausladung des Kannenfusses wechselt erheblich bei den verschiedenen Meistern und verleiht dem Krug bei richtiger Proportion die eigentliche Eleganz. Die schönsten Formen finden wir bei den Stitzen von Johannes Weber, Hans Heinrich Bosshart und den verschiedenen Manz. Ueberschlank sind die Stitzen der Breitinger.

Die $M$ eisterzeichen befinden sich bald auf dem bandförmigen Traghenkel, bald auf dem Deckel bei den Stitzen ohne Schnabel und seltener an der Unterseite des Kannenbodens. Die gravirten Jahrzahlen, Initialen oder Pflanzenornamente schmücken die vordere Kannenseite unterhalb des Ausgusses. Diese Gravuren sind stets einfach gehalten und bestehen in Blumenzweigen und Blattornamenten, welche die Besitzerinitialen oder die Jahrzahl einschliessen.

Die priumalische Kanne. - Die vier gebräuchlichsten Grössen entsprechen einem Inhalt von 2, 1, 1/2 und 1/4 Maass. Der Deckel mit dem Tragringe verschliesst die Kanne stets vermittelst eines Schraubengewindes; ebenso verhält es sich mit dem Verschluss der Ausguss röhre. Wie bei der Glockenkanne wird der Gewindeverschluss mit einer kleinen Kette an der 
Kanne befestigt, um nicht verloren zu gehen. An Stelle einer Oese befindet sich am Kannenleibe ebenfalls eine kleine, aufgelötete Delphinfigur. Der Fuss der Kanne zeigt, je nach dem Giesser, eine kleine oder grössere profilirte Ausladung. Dadurch wird die Form und Schönheit des Kruges wesentlich beeinflusst. Die Meistermarke befindet sich auf dem Deckel oder an der Unterseite des Kannenbodens. Die stadtzürcherischen prismatischen Kannen haben keinen aufglöteten Schild; die Initialen, Jahrzahlen, Wappen oder dekorativen Figuren befinden sich stets in der Mitte der rechten Kannenseite. Um das Einschenken zu erleichtern, befindet sich in der Mitte des Deckels ein gebohrtes Luftloch. Die seltensten Stücke sind die kleinen 1/4 Maas-Kännchen; darum sind bei denselben die Fälschungen am häufigsten. Eine besondere Art der Fälschung besteht darin, dass an die häufigen Schaffhauser Schraubfläschchen eine Ausgussröhre angelötet wird, und ebenso auf den Deckel ein senkrecht stehender Tragring.

\section{Die zürcherischen Humpen}

Die grossen, massigen Zinnhumpen sind eine Spezialität Zürichs. Der Inhalt beträgt meistens $1 / 2$ Maass. Der auf breit ausladendem Fusse stehende Korpus ist fast cylindrisch und erweitert sich nach oben nur bei den ältern Exemplaren, z. B. von Breitinger und Hans Conrad Bosshart. Der Deckelknopf kommt in den gleichen drei Formen vor wie bei den Stitzen, also die vollrundgegossene Traube, der Etagenknopf und der kegelförmige gerillte Knopf. Die Meisterzeichen befinden sich meistens auf dem bandförmigen Traghenkel, selten unten am Boden. Die Humpen sind oft vollständig überzogen mit prächtigen, eingravirten Blatt- und Blumenornamenten, welche von den kunstfertigen Händen der Goldschmiede auf Bestellung angebracht wurden. In seltenen Fällen besitzen die Humpen auch eine Bodenrosette.

Weitere Détails siehe bei den Zinngiessern W. Breitinger, Hans Conrad Bosshart, Hans Jakob Bosshart und Johannes Weber (oder Hans Weber).

\section{Die Wöchnerinnen-Schüsselchen}

Diese seltenen Zinnobjekte sind relativ klein und haben zu beiden Seiten horizontal gestellte, blattförmige, flache Handgriffe, sogenannte "O h r e n ". Dieselben sind verschiedenartig durchbrochen und wirken als Ornamente. Auf dem Deckel, welcher in einen Falz eingreift, sind drei von Klauenfüssen gehaltene Kugeln angelötet, so dass der Deckel umgekehrt darauf gestellt werden kann und als Tellerchen dient. Am Boden haben die zürcherischen Exemplare keine Füsschen. An Stelle der Klauenknöpfe findet man ab und zu aufgelötete kleine Delphine wie an den Giessfässern und dieselben stammen auch aus der gleichen Gussform. Der Deckel ist entweder schön profilirt oder weist einen oder mehrere Perlstäbe auf. Die Meistermarken sind entweder inwendig am Boden oder oft auch an den "Ohren " eingeschlagen.

Die Wöchnerinnen-Schüsseln waren ein beliebtes Geschenk bei der Erstgeburt und wurden kaum zum Gebrauche verwendet. Wenigstens finden sich an denselben keine Gebrauchsspuren. Weber.

Beschriebene Exemplare findet man bei den Zinngiessern Andreas Wirz und Hans

\section{Die Giessfässer und Handbecken}

Am häufigsten findet man die flachen, prismatischen Gefässe in Kastenform mit zwei seitlichen Traggriffen und zwar auch heute noch in den Bauernbuffets. Der abnehmbare Deckel liegt in einem Falz und ist kuppelförmig. Als Deckelgriffe dienen zwei oben angelötete Delphinchen, Meerweibchen, Hunde, Löwen u. dgl.; nicht selten ist auch ein vollrund gegossenes Akanthusblatt. Am untern Teil des Giessfasses ist ein kleiner Hahnen angebracht zum Ablassen des Wassers (aus Gelb- oder Rotguss). An der Vorderseite findet man die 
Initialen, Jahrzahlen, Besitzerwappen, Blattornamente, u.s.w. Die Meistermarken fehlen selten und sind an verschiedenen Stellen zu finden, oft am Deckel, oft am Unterteil.

Ebenfalls ziemlich häufig findet man die Giessfässer in der Form einer sehr verschieden gestalteten Eichel (Eichelgiessfass). Der Deckel läuft in einem Scharnir und trägt einen Knopf. Der nach vorne gebogene Ausguss endigt meist in einem Delphinkopf mit Flossen, in dessen Rachen ein Hahnen eingesetzt ist. Die Meistermarken fehlen leider fast immer, weil dieselben an den zinnernen Nischen angebracht waren.

Die schönste und seltenste Art des Giessfasses ist der sogenannte Delphin. Es ist dies ein Gefäss in der Form eines sich windenden Fisches. Die Flossen und Augen sind oft aus Messingbronze, oft aus Zinn; die Augen bei den besten Exemplaren aus rotem Glas. Dem Rachen des Fisches entragt der verschieden geformte Ausgusshahn aus Messingbronze. Das Wasser wurde vermittelst des Brunnenkesselchens hinter der Schwanzflosse eingegossen. An der Hinterseite des Delphins befindet sich eine massive Oese zum Einhängen in ein Winkeleisen. Die Zürcher Delphine sind glatt, ohne Muskelwülste und ziemlich schlank im Gegensatz z. B. zu den kurzen und plumpen Exemplaren von Rheinau .

Wie den Eichelgiessfässern, so fehlen auch den Delphinen jegliche Meisterzeichen und zwar aus dem Grunde, weil dieselben stets nur an der zugehörigen Zinnische angebracht wurden. Leider wurden meist die Delphine allein veräussert und damit unbewussst ausserordentlich entwertet. Die oft vorkommenden Falsificate sind sehr gut copirt und sehr schwierig zu erkennen. Nur wer jahrelang und mit grösstem Misstrauen ausgerïstet, in Zinn gesammelt hat, vermag ein relativ sicheres Urteil abzugeben. Delphine mit der zugehörigen Originalnische sind ungeheuer selten, weil eben der absolut sichere Nachweis der Zusammengehörigkeit sehr schwer zu erbringen ist. Es ist meist nur das Privilegium alten Familienbesitzes oder der Exemplare in Kirchen, Rathäusern u. dgl.

Bei den Zinnischen gibt es zwei Formen. Bei den guten Stücken entragt die Nische einer rechteckigen Rückwand, auf der sich die Meisterzeichen befinden, ebenso die Wappen, Initialen, u.s.w. Bei der weniger guten Form ist die Nische nur bandförmig, in der Breite von 2-5 cm, eingefasst und in die Holzfassung eingesetzt. Bei der ersten Form ist also auch die glatte Rückwand aus Zinn und nicht blos die Nische allein.

Die zinnernen Handbecken, welche ebenfalls selten sind, haben keine bestimmte, typische Form. Sie tragen an der Rückwand fast stets die Meistermarken. Die Seltenheit beruht auf dem Umstand, dass kupferne Handbecken viel beliebter und billiger waren als diejenigen aus Zinn.

\section{Die Brunnenkesselchen}

Diese kleinen Gefässe von ca. 1/2 Maass Inhalt pendeln an einem eisernen Traghenkel und hingen an einem kleinen, schmiedeisernen Träger am Buffet und zwar zur Seite des Giessfasses. Sie dienten zum Auffüllen des Giessfasses und auch als Trinkgefäss für die kleinen Kinder. $\mathrm{Zu}$ beiden Seiten des Korpus sind vollrund gegossene Fratzenköpfe angelötet, an denen die Oesen für den Traghenkel befestigt sind. Die Ausgussröhre, welche inwendig bis an den Boden des Gefässes reicht, durchbricht ebenfalls einen Maskaron und entragt noch 2-3 cm dessen Rachen. Der äusserste Teil ist oft stark abgenutzt vom Trinken der Kinder und im Querschnitt fast oval anstatt rund. Der in einem Scharnir laufende Deckel trägt als Knopf wiederum entweder eine Traube oder einen Rillen- oder Etagenknopf. Der Fuss des Korpus hat eine ziemlich starke Ausladung. Die Meisterzeichen fehlen fast niemals und sind entweder an der Unterseite des Bodens oder in- oder auswendig am Deckel. Vgl. die Angaben bei Meister Hans Jakob II Bosshart.

\section{Platten und Teller}

Dieselben weisen keine für Zürich typischen Eigenschaften auf; die Meistermarke allein entscheidet die Zugehörigkeit. Einfach und sehr gut wirken die Breitrandplatten, welche in Zürich ganz glatt sind; nicht einmal am Rande findet man irgendwelche Profilirung oder gar 
Rillen. Eine wenig beachtete Eigentümlichkeit ist die Randverstärkung zur Verhütung des Umbiegens. Ein halbcylindrischer Zinnwulst an der Rückseite der Breitrandplatte verleiht also die erhöhte Festigkeit gegen das Abbiegen des weichen Zinnes. Die Giessermarken sind an der Oberseite des Plattenrandes und infolge des reichlichen Platzes sehr gut eingeschlagen und darum auch gut erhalten. Auf diesen und den sogen. "Gupfplatten " findet man die ältesten bekannten zürcherischen Zinngiesserzeichen, z. B. von Jörg Zubler, Hans Conrad und Hans Jakob Steiner, Hans Caspar Hottinger, Hans Georg Thumysen und Felix Sommerauer. Unter "Gupfplatte " verstehen wir eine schmalrandige, runde Platte mit grossem, kuppelförmigem Fundus, dessen Mitte wieder nach oben hochgetrieben ist. Bei den ältesten Gupfplatten von Jörg Zubler befindet sich die Randverstärkung an der Oberseite der Platte. Erste Kenner sind der Ansicht, dass Platten mit oberer Randverstärkung die älteste bekannte Plattenform darstellen, nicht nur für die Schweiz, sondern für alle europäischen Länder. Ich halte diese Ansicht ebenfalls für die richtige.

Vom XVIII. Jahrhundert an weisen Teller und Platten am Rande die Form des entsprechenden Stiles auf. Sehr dekorativ wirken die runden und ovalen Platten im Louis XIV.-, XV.- und XVI.-Stile. Das Meisterzeichen bildet auch hier den Heimatschein.

Die Platten mit den Schützengabenzeichen Nr. 848, 849 und 850 (Bd. I) sind sehr selten, besonders die Breitrand- und Gupfplatten. Ich kenne solche von Jörg Zubler, Hans Georg Thumysen, Felix Sommerauer; etwas häufiger sind die schmalrandigen Teller von Salomon Wirz, Johannes Weber, Hans Conrad Bosshart. Fälschungen durch Stempelung alter echter Teller sind häufig; man findet sogar vollständig neu gegossene Exemplare.

Im XVII. und frühen XVIII. Jahrhundert war es Sitte, bei feierlichen Anlässen eine eigene Art flacher Platten zu schenken. Dieselben haben keine Randerhebung und sind entweder polygonal oder zackig, in allen denkbaren Formen. Man findet darauf in prächtiger Gravur Alliance-Wappen, Städte- und Vogteienwappen mit den Namen der gnädigen Herren, umgeben von Blatt- und Blumenranken. Es handelt sich um ausgesprochene Geschenkplatten, welche mittelst einer runden Oeffnung an der Wand aufgehängt wurden und zum Schmucke dienten. Man trifft oft den Ausdruck "Kuchenplatten "; allein man findet auf keinem dieser prächtigen Stücke irgend eine Spur eines Messerschnittes und dies wäre doch unvermeidlich gewesen. Auch könnte man die mit einem Kuchen beladene randlose Platte nicht leicht vom Tische abheben, weil man sie nicht fassen kann.

\section{Verschiedene andere Zinngegenstände}

Mit zürcherischen Meisterzeichen versehen, haben wir gefunden : Suppenschüsseln verschiedener Stilarten, Gemüseschüsseln, Salzgeschirrchen, Senfbehälter, Essig- und Oelgefässe, Zwiebelgefässe, Tintengeschirre, Messtitzchen, Trinkbecher, Löffel aller Grössen, Löffelgestelle, Oellampen, Kerzenstöcke, Suppenteller, u.s.w.

\section{Die Municipalstädte}

Ausserhalb der Stadt Zürich war die Ausübung des Zinngiesserberufes nur in den privilegirten Municipalstädten Winterthur, Stein am Rhein und Eglisau gestattet. In Rheinau ${ }^{\prime}$ gab es fast immer fahrende Zinngiesser und der Abt hatte dafür zu sorgen, dass die in Zürich geltenden Vorschriften auch daselbst eingehalten wurden. Die eigenartigen Verhältnisse in $\mathrm{El} \mathrm{g} \mathrm{g}$ werden bei den dortigen Zinngiessern behandelt.

\section{WINTERTHUR}

Die Winterthurer Zinngiesser waren an die gleichen technischen Vorschriften gebunden wie die Meister der Stadt Zürich. Neid und Missgunst sorgten für das Einhalten der Kontrolle. So erklärte der Rat von Zürich auf Reklamationen hin im Jahre $1642^{1}$ die neue

I F. Hegi, Geschichte der Zunft zur Schmiden, Seite 165. 
Giesserordnung als auch für Winterthur verbindlich. Im Jahre ${ }_{1} 6_{71}{ }^{1}$ wurde von neuem angeordnet, dass auch in den Municipalstädten die zürcherische Zinnprobe von 1371 einzuhalten sei. Die Zahl der bekannten Zinngiesser ist eine ziemlich bedeutende und es folgen hiemit die Namen und Daten nach den Aufzeichnungen des Herrn Dr. K. Hauser, Archivordner der Stadt Winterthur.

Grob, Rudolf, Kantengiesser, geboren den 22. März 1574, verheiratet 1596 , gestorben den 16. September 1638.

Widenmann, Abraham, Kantengiesser, geboren den 6. April 1606; gestorben den 22. September 1629 .

Widmer, Diethelm, Zinngiesser, geboren den 2. April 1640; gestorben den 5. Juni 1694 .

Graf, I Antonius, Kantengiesser, führte das Meisterzeichen Nr. 143 a (Bd. II), geboren den

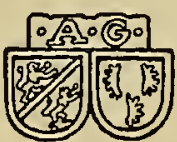

143 a 23. September 1617 ; wohnhaft am Untertor; war ${ }_{1669}$ Stadtrichter und ${ }_{16} 69$ Amtmann auf Schloss Wyden. Er heiratete ${ }_{1641}$ und starb am 17. Januar 1686 .

Gegenstand: Linsenförmige Kanne im Landesmuseum Zürich, mit den aufgemalten Wappen Hegner und Graf. Datirt 1667. Höhe $36 \mathrm{~cm}$. Auf dem Deckel Beschauzeichen von Winterthur und Meisterzeichen mit dem Wappen Graf und den Initialen A. G. Abbildung der Kanne Tafel VII, 2.

Graf, Hans Heinrich, Zinngiesser, der Sohn des Vorigen; geboren den 17. Mai 165o; steuerte $168817 ß$; er steuerte 1693 nicht mehr und war wahrscheinlich fortgezogen. Er wohnte an der Metzggasse.

Graf, II Antonius, Zinngiesser, ebenfalls ein Sohn des Antonius I Graf; geboren am 22 . Juni 1662; heiratete am 6. Mai 1689 ; war 1719 Grossrat, Weinschätzer. Er starb am 26. Mai 1726. Er wohnte am Untertor.

Graf, Hans Ulrich, Zinngiesser; geboren als Sohn des Antonius II Graf den 1o. Oktober 1697 ; verheiratet 1727. Er starb am 16. August 1761. Er wohnte am Untertor.

Graf, Hans Rudolf, Zinngiesser, jüngster Sohn des Vorgenannten und Bruder des berühmten Kunstmalers Anton Graf in Dresden. Er wurde geboren am 26. März 1741, heiratete im Jahre 1764 und starb am 8. Mai 1796 ohne männliche Nachkommen.

Er führte das Meisterzeichen Nr. 143 (Bd. I).

Gegenstand: Kleinste Glockenkanne mit Bajonetverschluss. Höhe $20,5 \mathrm{~cm}$. Meisterzeichen Nr. 143 auf dem Ausgussdeckelchen. Bodenrosette Nr. 172. Spärliche Gravuren an der Basis der Ausgussröhre.

Schellenberg, Hans Caspar, Zinngiesser, geboren am 2. April 1648, heiratete am 1o. August 1674 ; gestorben am 9. Januar 1692 .

Schellenberg, Johannes oder Hans, Zinngiesser, geboren am 24. März 1762, heiratete am 24. Februar 1788; gestorben am 2. Februar 1831.

Er führte die Meistermarke Nr. $14^{8}$ (Bd. I).

Gegenstände: Glockenkanne mit Bajonetverschluss von 1 Maass Inhalt. Höhe ${ }_{28,5} \mathrm{~cm}$. Auf dem Schild die Initialen $M$ GW. Marke 148 .

Glockenkanne mit Bajonetverschluss von $1 / 2$ Maass Inhalt. Höhe $23,5 \mathrm{~cm}$. Auf dem Ausgussdeckelchen die Meistermarke 148. Auf dem Schild die Initialen H. V. Ohne Bodenrosette.

Glockenkanne mit Bajonetverschluss von $1 / 4$ Maass Inhalt. Höhe $21 \mathrm{~cm}$. Meisterzeichen Nr. 148 auf dem Ausgussdeckelchen. Auf dem Schild die Initialen HR.G.W.1804.

Forrer, Abraham, Zinngiesser und Ochsenwirt, geboren am 23. Oktober ${ }_{16} 6_{0}$; verheiratet am 3. März 1691; gestorben am 29. Januar 1702.

Forrer, Heinrich, Kantengiesser, geboren den 18. Mai 1748, verheiratet am jo. Juli 1775 ; gestorben am 4. Januar 18ı. Wohnhaft "zur hohen Eich ", am Obertor.

Seine Meisterzeichen sind Nr. 145,146 und 147 (Bd. I).

1 F. Hegi, Geschichte der Zunft zur Schmiden, S. 165. 


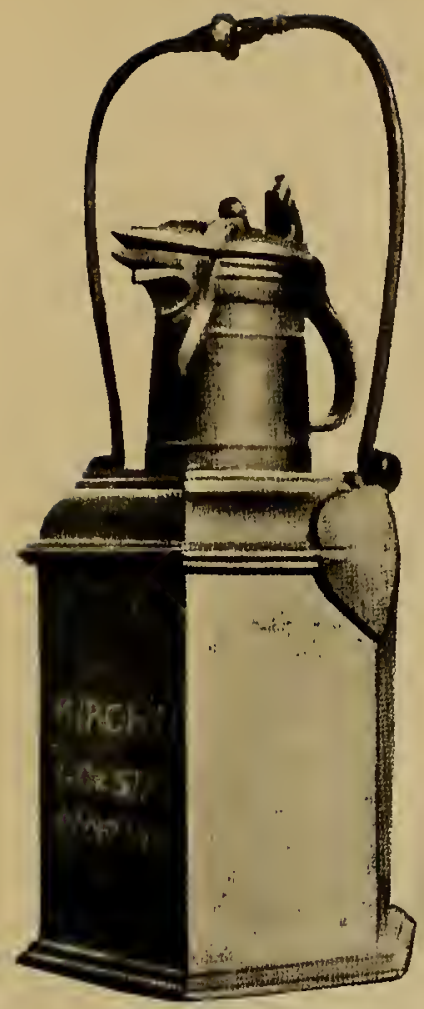

1

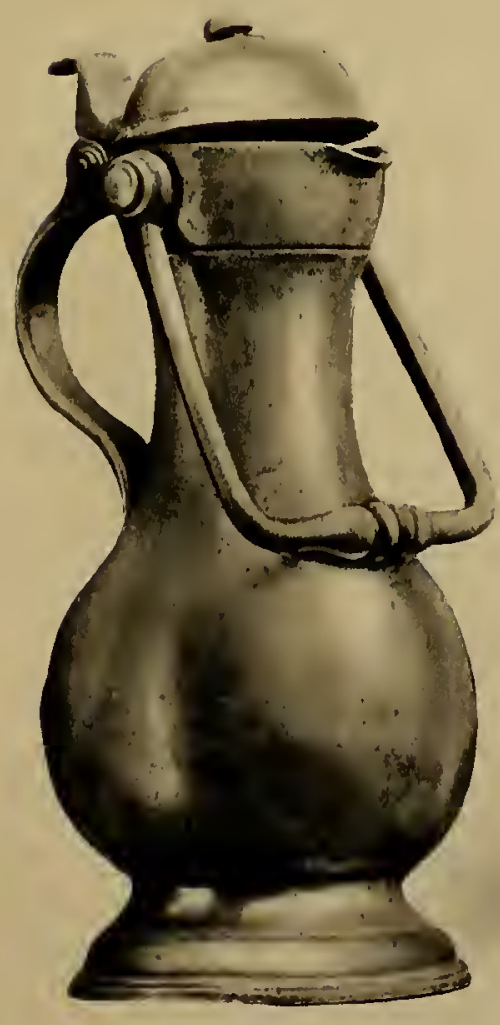

3
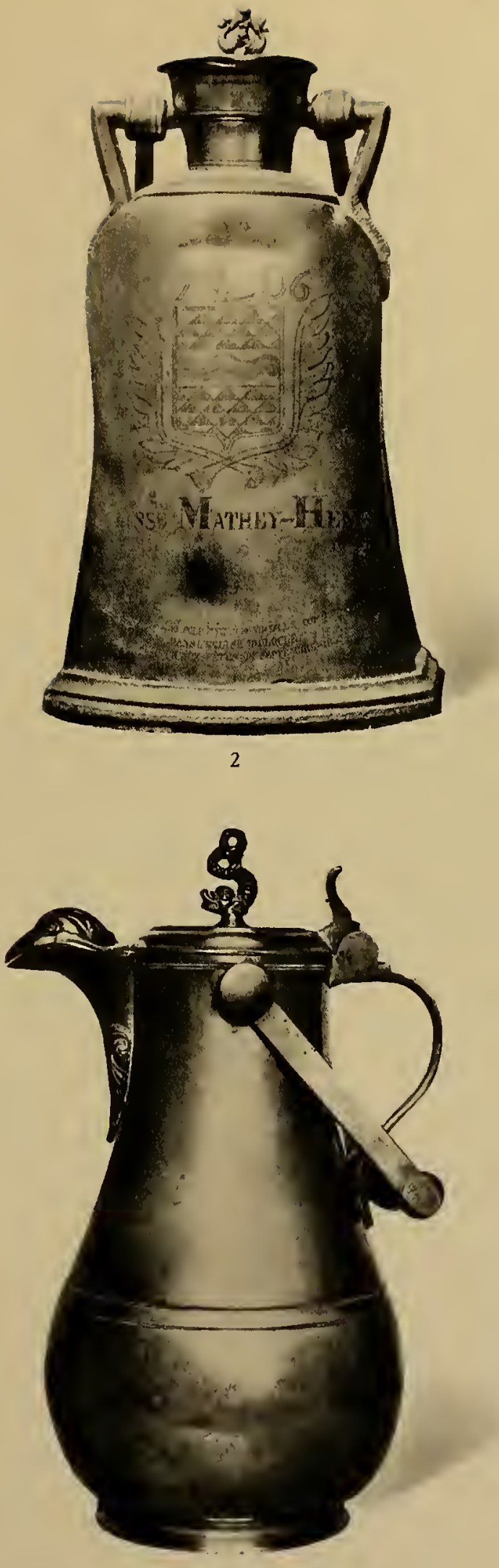

4

1. Abendmahlkanne von Gottstatt, von David II. Witz, tätig 1703-43 (S. 42 und 209). 2. Abendmahlkanne von Le Locle, datirt 1706, von J. J. Châtelain, Neuenburg (S. 42 und 250). 3. Abendmahlkanne von Saint-Blaise, von J. F. Perrin, Neuenburg, tätig 1728-48 (S. 43 und 250). 4. Abendmahlkanne von Boudry, von L. Perrin, Sohn, Neuenburg, tätig ab 1799 (S. 251 ). 

Gegenstand: Glockenkanne mit Bajonetverschluss von $1 \frac{1 / 2}{2}$ Maass Inhalt. Auf dem Ausgussdeckelchen das Meisterzeichen Nr. 147. Höhe $33 \mathrm{~cm}$. Keine Bodenrosette. Auf dem Schild die Initialen M.F.F. Dekorative Gravirung um die Basis der Ausgussröhre.

Forrer, David, Zinngiesser, Sohn des Vorigen, Heinrich Forrer, wurde am 15 . Juni 1788 geboren und starb am 16. Oktober 1876. Er wohnte ebenfalls im Haus " zur hohen Eich " am Obertor.

Steiner, Tobias, Zinngiesser, wurde geboren am 26. September 1700, verheiratete sich am 8. Juli 1732 und starb am 20. August ${ }_{177}$. Er wohnte im Haus zum Engel und am Markt. Er führte als Meisterzeichen wahrscheinlich $\mathrm{Nr}$. 142 (Bd. I).

Gegenstand: Glockenkanne von 1 Maass Inhalt.

Sulzer, I Hans Caspar, Zinngiesser, wurde am 4. Oktober ${ }_{1} 6_{72}$ geboren und starb unverheiratet am 5. November 1714 .

Sulzer, II Hans Gaspar, Zinngiesser, wurde am 27. Dezember ${ }_{1} 678$ geboren, verheiratete sich am 10. Oktober 1698 und starb am 24. März 1720 als Pfründer im Spital.

Sulzer, I Johannes, Zinngiesser, wurde am 11 . Februar 1690 geboren, verheiratete sich am 21. Juni 1716 und starb am 3o. Mai 1773. Er wohnte "z. Ochsen », war Obmann, Wagmeister 1745 .

Sulzer, Hans Jakob, Zinngiesser, wurde am 16. Oktober 1717 geboren; er wohnte im "Steineck " und starb am 28. Mai 1752. Er war der Sohn des vorgenannten Zinngiessers Johannes I Sulzer.

Sulzer, II Johannes, Zinngiesser, wurde am 20. Januar 1699 geboren, er wohnte im Hause zur "Sonnenuhr " und starb am 19. Dezember 1758.

Sulzer, Emmanuel, Zinngiesser, wurde geboren am 11. Januar 1724 , verheiratete sich am 25 . Juli 1749; er wohnte im Haus zum "Gamsberg " und starb am 5. Dezember 1786.

Sulzer, Johann Heinrich, Zinngiesser, wurde am 23. Oktober 1796 geboren und starb unverheiratet am 18 . November 1818 .

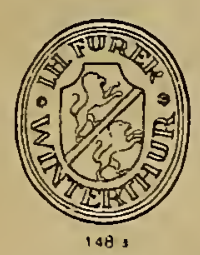

Furer, Johann Heinrich, Zinngiesser, wurde am 16. August 1812 geboren; er verheiratete sich am 19. Juni 1843 . Todesdatum unbekannt.

Er führte die Meistermarke Nr. 148 a. (Bd. II).

Gegenstand: Glockenkanne mit Bajonetverschluss von 2 Maass Inhalt. Meisterzeichen auf dem Ausgussdeckelchen. (Sammlung C. Hirsbrunner, Luzern.)

Heller, Hans Caspar, Zinngiesser, wurde am 13. Januar 1737 geboren. Todesjahr unbekannt.

Rieter, Jakob, Zinngiesser, wurde am 20. März 1750 geboren, verheiratete sich am 25 . Juli ${ }_{1784}$ (wieder geschieden 1793 ) und starb in sardinischen Diensten am 23. Oktober 1796. Er führte das Meisterzeichen Nr. 144 (Bd. I).

Gegenstand: Glockenkanne mit Bajonetverschluss von $1 / 2$ Maass Inhalt. Höhe ${ }_{26,3} \mathrm{~cm}$. Keine Bodenrosette. Auf dem Schild die Initialen HR.B.1792. Schild mit profilirtem Rand. Spärliche Gravirung um die Basis des Ausgussrohres. Meistermarke Nr. 144 auf dem Deckelchen der Ausgussröhre.

Die Winterthurer Zinngegenstände haben die gleichen Formen wie diejenigen der Stadt Zürich. Bei den Glockenkannen fehlt meistens die Bodenrosette. Stitzen habe ich niemals gesehen. Teller, Platten, Giessfässer, u.s.w. haben keine für Winterthur charakteristische Eigenschaften. Die Ortsbestimmung ist also nur aus dem Meisterzeichen möglich. Voraussichtlich finden sich viele Zinngegenstände von Meistern, deren Marken mir nicht zu Gesicht gekommen sind und zwar besonders deshalb, weil dieselben ja aus dem XVIII. Jahrhundert stammen. Die prismatischen Winterthurer Kannen sind ziemlich selten.

\section{STEIN AM RHEIN}

Diese prächtige Stadt gehörte ebenfalls zu den zürcherischen Municipalstädten und unterstand den gleichen Ordnungen wie Winterthur. Das Zinngiessergewerbe war entspre- 
chend der Kleinheit der Stadt niemals von grösserer Bedeutung. Ausserordentlich interessant sind die Ratskannen, datirt 1655, und gegossen von F. Schmid. (Tafel V, 1.)

S.H.F. führte als Meistermarke die Initialen in Hauszeichenform. Der einzige bekannte Gegenstand ist eine sechsseitige Schraubflasche mit Facettirung (Sammlung Baurat Manz in Stuttgart). (Siehe Hintze, Bd. VII, Nr. 2382.)

Schmid, Felix, verheiratet mit Elsbetha Brennwald, 1 der Giesser der vier Stadtkannen von Stein. Höhe $40,8 \mathrm{~cm}$. Durchmesser des Fusses 21,2 cm. (Drei Stücke im historischen Museum von Schaffhausen und eines im Landesmuseum in Zürich.) Er führte das Meisterzeichen Nr. 149 (Bd. I). Die Kannen sind 1655 entstanden und tragen diese Jahrzahl. (Tafel $\mathrm{V}, 1$.

Etzweiler, Johannes Caspar, Kantengiesser; sein Name findet sich im Steiner Burgerrodel vom Ende des XVII. Jahrhunderts. Sein Meisterzeichen entspricht Nr. 150 (Bd. I) und findet sich auf einer prachtvollen grossen Glockenkanne von 3 Maass Inhalt mit Bajonetverschluss und Verschlussklappe zur Verhütung der Drehung des Deckels. Auf dem grossen, eigenartig geformten Schilde ist die Jahrzahl 1684 und die Initialen H. C. EW., welche also dem Namen des Giessermeisters selbst entsprechen. Daneben finden sich die Buchstaben A. S., welche vielleicht den Namen der Frau anzeigen. Die Höhe der Kanne beträgt $40 \mathrm{~cm}$. Das Meisterzeichen Nr. 150 befindet sich auf dem Deckelchen der Ausgussröhre, welche an der Basis mit fein gravirten Blumenornamenten umgeben ist. Bodenrosette Nr. 170 (Bd. I). Am Korpus flache, fast in der Oberfläche verschwindende, breite Wülste. (Tafel XXX, 11.)

Etzweiler, Hans Jakob, Zinngiesser, wird im Burgerrodel $¹ 734$ und 1764 erwähnt. Er führte das Meisterzeichen Nr. 151 .

Gegenstand: Sechsseitig-prismatische Kanne, vollständig mit feinen Blatt- und Blumenornamenten gravirt. Inhalt $1 / 2$ Maass. Höhe mit dem Ring $33 \mathrm{~cm}$. Auf dem Schild das Wappen von Zürich. Meisterzeichen Nr. ${ }_{151}$ auf dem Deckelchen der Ausgussröhre.

Schnewli I, Benedict, führte das Meisterzeichen Nr. 157, welches die Jahrzahl 1684 trägt. Er war vom 24. März 1679-1682 bei Andreas I Wüger in Steckborn Lehrling; wahrscheinlich wurde er 1684 Meister.

Gegenstand: Sechsseitig-prismatische Kanne in der Sammlung Gally-v. Mechel in Basel.

Schnewli, Hans Conrad, Zinngiesser, wird im Burgerrodel $\supseteq$ in den Jahren 1734 und 1768 erwähnt. Meisterzeichen Nr. 152 (Bd. I).

Gegenstände: Glockenkanne mit Bajonetverschluss von $1 / 2$ Maass Inhalt. Höhe $26 \mathrm{~cm}$. Am obern und untern Teile des Korpus schmale circuläre Wülste. Schild ohne Zeichen. Auf dem Ausgussdeckelchen das Meisterzeichen Nr. 152. Gravirte Ornamente um die Basis der Ausgussröhre.

Glockenkannen mit den Jahrzahlen 1741, 1751.

Sechsseitig-prismatische Kanne im Landesmuseum in Zürich.

Schnewli II, Benedict, Zinngiesser, wird im Burgerrodel 1784 und 1786 erwähnt und zwar als Sohn des vorigen Hans Conrad Schnewli. Seine Meisterzeichen sind Nr. 153 und 154 . Gegenstand: Glockenkanne von 1/2 Maass Inhalt mit der Jahrzahl 1795.

Meyer, Hans, Zinngiesser, wird im Burgerrodel im Jahre 1764 erwähnt. Er führte das Meisterzeichen Nr. 155.

Meyer, Jakob, Hans Zinngiesser, ist im Jahre 1779 im Burgerrodel erwähnt. Sein Meisterzeichen entspricht Nr. 156.

HH. о. B., Unbekannter Meister am Ende des XVIII. Jahrhunderts. Meisterzeichen Nr. 158. Auf einer sechsseitig-prismatischen Kanne mit der gravirten Jahrzahl 1807. (Im Antiquitätenhandel bei C. Hirsbrunner, Luzern, 1928.)

1 Haushaltungsregister (1650) E II $224 \mathrm{Nr} .19$ in Stadtarchiv Zürich.

2 Burgerrodel der Stadt Stein. Mitteilung von Dr. Jur. F. Rippmann in Stein. 
Die Steiner Glockenkannen unterscheiden sich von den zürcherischen durch die circulären Wülste, welche auf die Nachbarschaft von Schaffhausen und des Thurgau hinweisen. Die sechsseitig-prismatischen Kannen sind bedeutend schlanker als die zürcherischen. Häufig findet man Kannen und Platten, welche nur das Stadtzeichen von Stein, Nr. 159, tragen und kein Meisterzeichen. Es gibt auch achtseitige prismatische Kannen, meistens mit einem Schilde an der rechten Seite.

Die Ratskannen von Stein am Rhein (drei im historischen Museum von Schaffhausen, eine im schweizerischen Landesmuseum in Zürich). Höhe $40,8 \mathrm{~cm}$. Durchmesser des Fusses $21-22 \mathrm{~cm}$ je nach dem Erhaltungszustand. Der flache kuppelförmige Deckel trägt in der Mitte einen flachen, runden Knopf. In der Mitte des dicken Halses ist ein circulärer Wulst und feine Rillen. Auf der Seite des becherförmigen Korpus befindet sich der Wappenschild von Stein, der berittene hl. Georg mit dem am Boden liegenden Drachen und die Jahrzahl 1655. Die gebogene, sechskantige Ausgussröhre endigt in einem Tierkopf und ist vermittelst eines kurzen Steges mit dem Henkelträger verbunden. Der eiserne halbkreisförmige Traghenkel geht mit einer Abkröpfung an den Henkelträger, an welchem er in einem Ring frei beweglich ist. (Tafel V, 1.)

\section{EGLISAU}

Die Kirchenbücher ' von Eglisau erwähnen nur wenige Kantengiesser; auch sind Zinngegenstände, besonders vor der Mitte des XVIII. Jahrhunderts, ziemlich selten zu finden.

Schmid, Hans, Kantengiesser, geboren 1632.

Schmid, Jakob, Kantengiesser, getauft 1672 .

Lauffer, Jakob, Gussmeister, geboren am 24. April 1681. Ob er Zinngiesser war, ist fraglich. Lauffer, Jakob Friedrich, Zinngiesser, geboren am 24. November 1804. Er führte das Meisterzeichen Nr. 177 (Bd. I).

Gegenstände: Glockenkannen von 1 Maass Inhalt. (Im Antiquitätenhandel in Zürich.)

Sechsseitig-prismatische Kannen von $1 / 2$ und 1 Maas Inhalt. (Im Antiquitätenhandel in Zürich.)

\section{RHEINAU}

Wahrscheinlich betätigten sich in Rheinau nur fahrende Zinngiesser; Namen konnten nicht aufgefunden werden und damit auch nicht einwandfrei gesicherte Zinngegenstände.

Im Jahre 1642 befahl der Rat von Zürich dem Abt von Rheinau, die dortigen Fremden ebenfalls zur Beobachtung der Zinngiesser-Ordnung anzuhalten \%. Am ${ }_{16}$. November 1646 reklamirt Burgermeister und Rat von Schaffhausen beim Abt Bernhard zu Rheinau, dass sein Zinngiesser geringeres Zinngeschirr mache und verkaufe. Der Abt bestreitet diese Vorwürfe in seiner Antwort vom 10. Dezember $1646^{3}$.

Infolge der Nähe der Zurzacher Messe ist es nicht verwunderlich, wenn fahrende Giesser nach Rheinau und Eglisau kamen und daselbst zeitweise arbeiteten. Man nannte dieselben "Galangger " (Italiener oder aus dem Val Calanca?).

\section{ELGG}

Obwohl Elgg nicht Municipalstadt war, besass der Ort schon vor 1798 eigene Zinngiesser. In der Geschichte der Stadt, Herrschaft und Gemeinde Elgg, von Kaspar Hauser, Lehrer in Winterthur, 1895, findet sich auf Seite 473-476 der Passus " der Junge des Fähnrich Schöchli in Elgg wollte Zinngiesser werden; aber die Zinngiessermeisterschaft von Zürich verwehrte ihm, dieses Handwerk zu erlernen, da in Elgg noch nie ein Kantengiesser gewesen sei (also vor

1 Kirchenbücher von Eglisau. Mitteilung von Herrn A. Hauser, Zivilstandsamt Eglisau.

${ }^{2}$ F. Hegi, Geschichte der Zunft zur Schmiden in Zürich.

${ }^{3}$ Missinnsbuch 1646 , S. 302. 
1749). Vogt und Rat beschlossen, eine Abordnung, bestehend aus Statthalter Huber und Ratsschreiber Trachsler zu Bürgermeister Fries nach Zürich zu schicken, damit... "er Elgg bei seinen Freiheiten schütze, und gelangten zum Ziele. " Laut Mitteilung des Staatsarchivs des Kantons Zürich findet sich weder im Ratsmanual, noch in den Ratsurkunden und im Aktenregister der Jahre 1748 und 1749, eine Erwähnung obigen Vorfalles. In der Plattenordnung vom 15. April 1756 findet sich die Bestimmung, dass den Knaben jedes Jahr eine zinnerne Platte zu verabfolgen sei .

Trachsler, J. Heinrich, Zinngiesser, ist im Burgerschaftsrodel 2 von 1780 als Zinngiesser er-

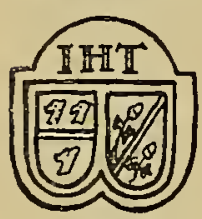

$176^{\mathrm{s}}$

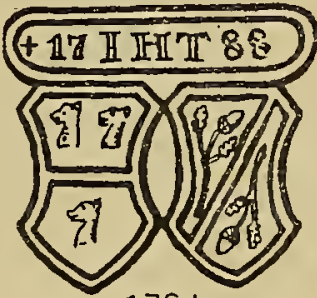

$176 \mathrm{~b}$ wähnt. Er besass zwei Meisterzeichen, Nr. 184 und 185 (Bd. I) (irrtümlich unter Schaffhausen eingereiht) Nr. $176 \mathrm{a}$ und $176 \mathrm{~b}$ (Bd. II). Die Bärenköpfe des Elgger Wappen sind kaum als solche erkennbar. Auf dem grössern Zeichen Nr. 184 befindet sich die Jahrzahl 1788 . Auch gibt es einwandfrei datirte Kannen von 1784 bis 1804 .

Gegenstände: Sechsseitig-prismatische Kanne mit Schraubenverschluss am Deckel und Ausgussrohr. Inhalt $1 / 4$ Maass. Höhe 23,5 cm. Marke Nr. 185 auf dem Deckel. An den beiden Vorderseiten prachtvolle gravirte Blatt- und Blumenornamente. An der rechten Seite der Kanne die Initialen L. B. SP. 1784 . (Tafel XXX, 14.)

Glockenkanne mit Bajonetverschluss von $1 / 2$ Maass Inhalt. Am obern Teil des Korpus fünf schmale circuläre Wülste. Auf dem Deckelchen der Ausgussröhre das Meisterzeichen Nr. 185. Um die Basis der Ausgussröhre herum gravirte Blattranken. Bodenrosette Nr.2 12. Auf dem Schild die Initialen L. B. F. 1804 . Höhe $27,5 \mathrm{~cm}$.

Peter, Heinrich, Zinngiesser, unterzeichnet eine Urkunde am 9. März 1807 mit "Heinrich Peter, Zinngiesser " (Mitteilung von Herr Gemeindegutsverwalter Julius Spiller). Lieferte 1833 an die Kirche von Wiesendangen (Anzeiger $f$. schweizer. Altertumskunde, Bd. 1916, S. 128). Er führte die Meisterzeichen Nr. 174 und 175. Auch besass er eine hübsche Bodenplakette (Nr. ${ }_{7} 6$, Bd. I) mit den Initialen J H P.

Peter, Gottlieb, der Sohn des Vorigen, wird als Zinngiesser bezeichnet. Laut Familienregister des Civilstandsamtes von Elgg" wurde er am 3. Januar 1815 geboren und starb am 2o. Oktober 1844 . Er führte die Meisterzeichen und Bodenplakette seines Vaters, weshalb die Provenienz der Gegenstände nicht auseinander gehalten werden kann.

Gegenstände der beiden Zinngiesser Peter :

Sechsseitig-prismatische Kirchenkanne mit Schraubenverschluss; auf dem Ausgussdeckelchen die Meistermarke Nr. 175. Hinten, nahe dem Kannenboden, ein beweglicher, ringförmiger Griff zum Heben beim Einschenken. An der rechten Seite grosser Schild mit Traube; Initialen G. M. I. Höhe $44 \mathrm{~cm}$. (Tafel X, 1.)

Sechsseitig-prismatische Kanne von a Maass Inhalt mit Schraubdeckel; auf letzterem das Meisterzeichen Nr. 175. An den zwei Vorderflächen prächtig gravirte Blumenranken. Auf dem Schild mit Traube die Initialen H. B. 1803. Diese Kanne ist also sicher von Heinrich Peter. An Stelle der Bodenrosette ist beinahe der ganze Gustav-Adolf Teller eingesetzt (Nürnberg). Höhe $36 \mathrm{~cm}$. (Tafel XXX, 1о.)

Sechsseitig-prismatische Kanne von 1/4 Maass Inhalt mit Schraubendeckel. An den beiden Vorderflächen schöne Rankengewinde. Kein Schild. Meisterzeichen Nr. 174. An der rechten Seite die Initialen S. B. 1809 . Höhe $29 \mathrm{~cm}$. (Tafel XXX, 8.)

Glockenkanne mit Schraubdeckel von a Maass Inhalt. Am Korpus oben und unten zahlreiche Wülste (ähnlich bei J. H. Trachsler). Auf dem Ausgussdeckelchen die Meistermarke Nr. 174. Höhe $33 \mathrm{~cm}$. Auf dem Schild die Initialen H G S 1811. 
TAFEL XIII
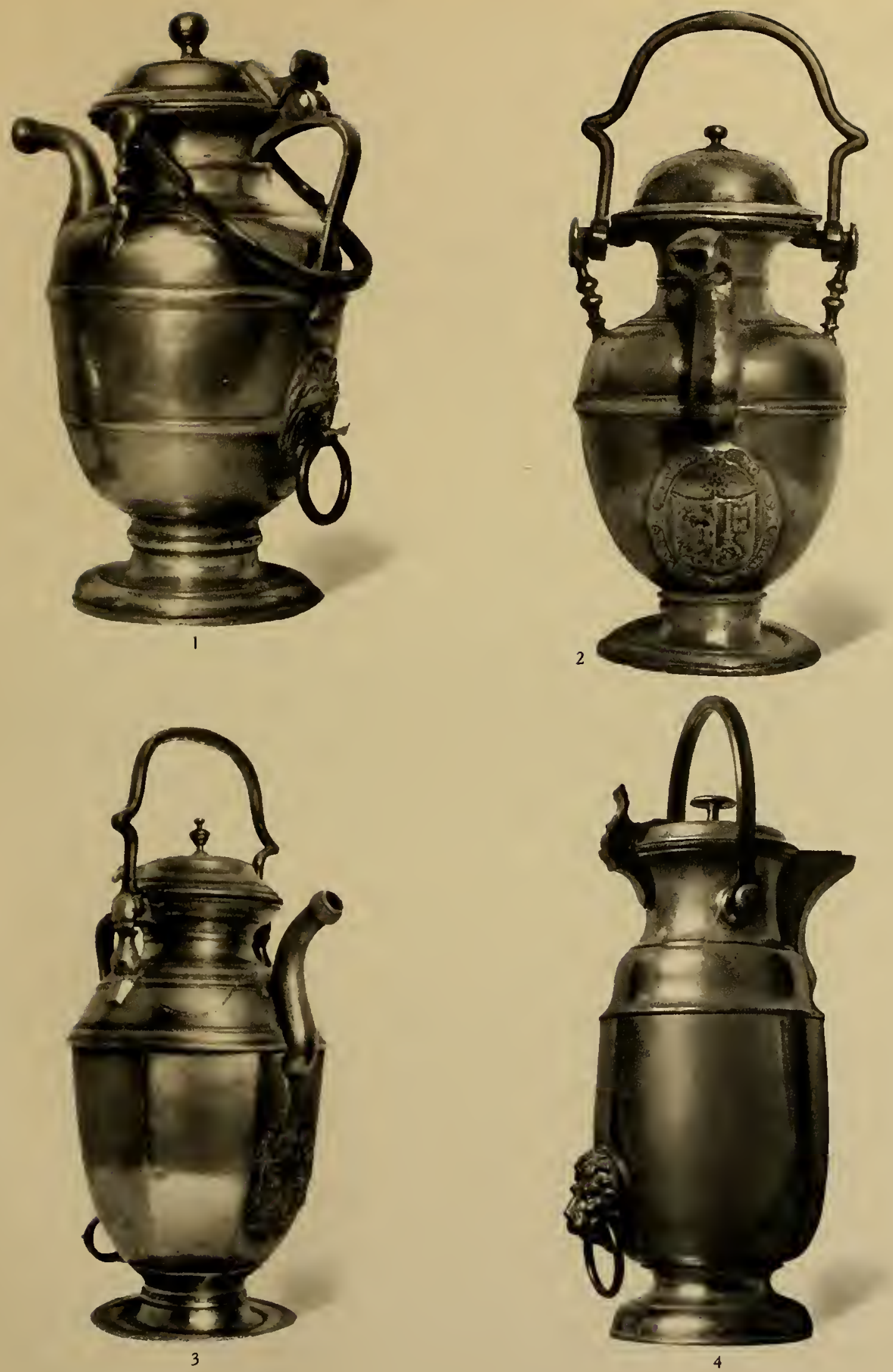

1. Abendmahlkanno von Genf, Höhe $41 \mathrm{~cm}$, von Léonard Bourrelier, Genf, 1639--1730 (Text S. 43). 2. Abendmahlkanne von Genf, Höhe $41 \mathrm{~cm}$, von Léonard Bourrelier, Genf, 1639-1730 (Text S. 43). 3. Abendmahlkanne von Genf, Höhe $50 \mathrm{~cm}$, von Pierre Bourrelier, Genf, datirt 1759 (Text S. 43). 4. Abendmahlkanne von Genf, Höhe $37 \mathrm{~cm}$, von Lacombe, Genf, 19. Jahrhundert (Text S. 232). 

Glockenkanne mit Schraubdeckel und Deckelchen auf der Ausgussröhre. Inhalt $11 \frac{2}{2}$ Maass. An Stelle der Wülste circuläre Rillen. Auf dem Ausgussdeckelchen das Meisterzeichen Nr. 174. Bodenplakette 176. Auf dem Schild die Jahrzahl 1822. Höhe $38 \mathrm{~cm}$.

Glockenkanne mit Bajonetverschluss von $1 / 2$ Maass Inhalt. Auf dem Ausgussdeckelchen das Meisterzeichen Nr. 174. Höhe $27 \mathrm{~cm}$. Schild leer. Bodenplakette 176. Circuläre Rillen am Korpus.

Glockenkanne mit Schraubverschluss am Deckel und am Ausguss. Vier Kannen in verschiedener Grösse : $28,5 \mathrm{~cm}, 30,5 \mathrm{~cm}, 33 \mathrm{~cm}$ und 36,5 cm hoch. Der Ausgussdeckel trägt eine kleine Traube zur Befestigung des Kettchens, welches bis zur Basis der Ausgussröhre reicht. Daselbst befindet sich ein Klauenfuss mit einer kleinen Kugel, an welcher das Kettchen wiederum befestigt ist. (Tafel XXX, 9.)

Glockenkanne mit Schraubdeckel ohne Ausgussröhre. In der Mitte des Deckels ein beweglicher Tragring, daneben zwei Mal das Meisterzeichen Nr. 175. Bodenplakette Nr. 176. Höhe $24 \mathrm{~cm}$. (Tafel XXXII, 12.)

Die Elgger Kannen nehmen eine Sonderstellung ein. Abgesehen davon, dass die Arbeit eine technisch meisterhafte ist, weisen einzelne Kannen besonders die prismatischen, Eigenschaften auf, welche nach $\mathrm{Chur}$ weisen. So haben die aufgelöteten Schilder mit der Traube die gleiche Modellirung wie die Kannen des J. U. Bauer in Chur. Auch die Profilirung des Kannenfusses ist eine sehr ähnliche. Am Rande des Deckels findet man bei den Elgger Kannen oft Perlstäbe, aber nur bei den beiden Peter, niemals bei Trachsler.

Die Elgger Glockenkannen sind viel schlanker als die Zürcherglocken. Die Ausladung des Fusses ist eine stärkere und erhöht damit noch die Schlankheit. Der Schraubenverschluss ist bei den Glockenkannen der übliche ; der Bajonetverschluss ist sehr selten, sowohl bei Trachsler als auch bei Peter.

Merkwürdige Gefässe sind die Glockenkannen ohne Ausgussröhre. Es ist nicht leicht, damit einzuschenken. Wahrscheinlich dienten sie für dickflüssige Substanzen, z. B. Oel oder Honig. (Tafel XXXII, 11.)

Bd. I).

Im Innern des Kannenbodens befinden sich oft interessante Bodenplaketten (Nr. ${ }_{7} 6$,

\section{ZUG}

Trotz der Kleinheit und der relativ geringen Bedeutung Zugs blühte daselbst das Zinngiessergewerbe ganz erheblich und erreichte auch einen hohen Grad der Vollkommenheit. Infolge der geringen Entwicklung des Zunftwesens gehörten die weniger häufigen Handwerke meistens zu einer ursprünglich rein kirchlichen Bruderschaft. Dieses war auch bei den Zinngiessern der Fall. Sie gehörten also nicht etwa zur Schmiedenzunft wie anderorts, sondern waren in allen Zünften und Bruderschaften verteilt. Laut Bürgerbuch I, Blatt Nr. 138, rvird ein Zinngiesser als Bürger aufgenommen : " $\mathrm{H}$ ann s Kanntengiesser, ....., sindt burger worden im 1506 jar ". Es handelt sich wahrscheinlich um Johannes Vogt, den Verfertiger der Baarer Ratskannen mit den eingegossenen 1/2 Dicken aus dem Jahre 1568.

Der Rat von Zug befasste sich nachweisbar schon 1570 mit den Zinngiessern und zwar bei Aufnahme des Kannengiessers Sebastian Krentzli, indem sie demselben vorschrieb, die Zürichprobe zu halten. Ratsprotokoll von 1570 : "Sainstag vor St. Gallustag. Uff obgenannten Tag hand $M . H$. vergunne Baschi Krenztli, dem Khantngiesser sich allhier zu setzen, soll zu Inzug geben 5 gld und das geschir uff Zürich prob. " Des weitern ist vermerkt, dass für den Fall er sich nicht nach ihrem Gefallen verhalte, $M$. Herren die fremden Kantengiesser wieder hier arbeiten lassen nach ihrem Gutdünken. 
Laut Ratsprotokoll Nr. 8, fol. 101, gab im Jahre 1665 der Zinngiesser Jakob Marti Müller den Anstoss zur Aufstellung einer Zinnprobe : 1665, August 14. Die Zinn probe wird festgestellt, dass unter 4 \& gut und lauther Zinn nicht mehr als 1 \& Blei dürfe genommen werden. Dieser Beschluss bedeutet also die Annahme der alten Zürichprobe von 137 o.

Wie früh auch in Zug Zinngeschirr im Gebrauche war, beweist ein Inventar ${ }^{1}$ aus der Burg in Zug. Der 1422 in Arbedo gefallene Junker Petermann von Moos von Luzern hinterliess seinem Sohne Walter an Zinngeschirr : 3 halbviertlig Kannen, 2 halbmessig Kannen, 6 messig Kannen, 12 hefen, 6 Kesse, 6 blatten, 28 zinenschüsslen....

\section{Die Zinngiesser}

Vogt, (-Räber), Johannes, Kantengiesser, wurde ca. 1480 geboren. " Hanns Kanntengiesser .... sindt burger worden im 1506 jar (Bürgerbuch I. Band, Blatt 71, Nr. 138). Das Todesdatum ist unbekannt. Er führte das Meisterzeichen Nr. 25 (Bd. I). Die einzigen erhaltenen Gegenstände sind die beiden Baarer Ratskannen. Die Beschreibung findet sich am Schlusse bei den Zinngegenständen. An der Innenseite des Kannendeckels befindet sich je $1 / 2$ Dicken mit der Jahrzahl (15)68. Höhe $41,5 \mathrm{~cm}$; Durchmesser des Fusses $21,5 \mathrm{~cm}$. (Tafel III, 3, 4.)

Vogt, Hans Peter, Kantengiesser. Geburtsdatum unbekannt; starb am 14 . November 1648. Er war der Grossvater des Zinngiessers Wolfgang Vogt-Brandenberg.

Er führte das Meisterzeichen Nr. 26 (Bd. I). Bodenrosette Nr. 62.

Gegenstand: Stitze ohne Schnabel von $1 / 4$ Maas Inhalt. Die Bodenplakette ist merkwürdig in der Darstellung des Christus (Nr. 62). Privatbesitz in Zug.

Vogt, (-Brandenberg), Wolfgang, Zinngiesser, wurde geboren am 26. Februar 1652. Laut seinem Tagebuch ${ }^{3}$ ging er am 12. März 1668 nach Zürich " auf die Wanderschaft uff dem Kantengiesser handtwerkh ". Am 21. April 1670 heiratete er Marianne Brandenberg und wohnte am Fischmarkt. Auch betrieb er eine Eisenhandlung und war eine Zeitlang Stadtschreiber (1687-17o3); er resignirte im Jahre 1703 und starb am 17. März 1717 .

Sein Meisterzeichen entspricht Nr. 27 in Band I.

Gegenstände: Zinnische mit Eichelgiessfass. Meisterzeichen Nr. 27.

Grosse Gupfplatte von $32 \mathrm{~cm}$ Durchmesser, Randbreite 4,7 cm. Rand vorn verstärkt. Gupftiefe 3,5 cm. Meisterzeichen Nr. 27. Am Rand Initialen F. P. I. (Tafel

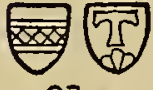
XXVI, 14.) Kubisches Reliquienkästchen aus einem Altar, 5,8 cm Seitenlänge. Am Deckel und Boden Spuren der Verschliessung mit Draht. Auf dem Deckel und an einer Seite Goldschmiedmarke Vogt. Nr. 27 a (Tafel XX, 7.) Breitrandplatte, Durchmesser $34 \mathrm{~cm}$; Randbreite $7,8 \mathrm{~cm}$, Rand hinten verstärkt. Meistermarke Nr. 27, darunter kleine Goldschmiedmarke.

Gupfteller, Durchmesser $25,4 \mathrm{~cm}$; Randbreite $5 \mathrm{~cm}$. Meisterzeichen Nr. 27 und Eigentumsstempel in Octogonform mit dem Wappen Suter.

Krentzli, Sebastian, Kanntengiesser, wird heute Kränzlin geschrieben und ist im Zuger Ratsprotokoll zitirt am "Samstag vor St. Gallustag 1570 ». Er führte das Meisterzeichen Nr. 28.

Gegenstand: Zinnische mit der Marke Nr. 28; darin ein einfaches Eichelgiessfass (Privatbesitz in Ober-Aegeri).

Schönbrunner, Carl, Kanntengiesser, lebte von 1625 bis 1657 . Meisterzeichen Nr. 29.

Die Ratskannen von $\mathrm{Zug}$. Das Meisterzeichen Nr. 29 befindet sich auf dem Fuss der Kannen. Die ornamentale Ausführung des Ausgusses und des Zuger Wappenschildes ist

1 Th. von Liebman. Anzeiger für schweiz. Altertumskunde. Neae Folge Band III. S. 306 u. 307.

2 Alle Daten der Zinngiesser stammen aus den Stammbäumen von R. D. Pfarrbelfer P. A. Wickart, Zug.

3 Besitzer : Herr Lnuis Bossard, Nuegase, Zug. 
sehr gut. Bei vier Kannen befindet sich innen am Boden ein Medaillon mit dem Crucifixus, ähnlich wie bei den Baarer Kannen ; bei zwei Kannen nur eine Bodenrosette. Höhe $40.5 \mathrm{~cm}$, Durchmesser des Fusses $20 \mathrm{~cm}$. (Tafel IV, 4.)

Schönbrunner, Carl Josef, Sohn des Vorigen, lebte von ${ }_{1} 65_{1}$ bis ${ }_{1689}$. Meisterzeichen Nr. 3o. Gegenstand: Glockenkanne mit Bajonetverschluss von 1 Maass Inhalt. Meisterzeichen $\mathrm{Nr}$. 3o auf dem Deckelchen der Ausgussröhre.

Müller, Jakob Martin Zinngiesser, wohnte 1627 am Fischmarkt. Laut Ratsprotokoll 8, Seite 101, gab er im Jahre 1665 den Anstoss zur Aufstellung der Zinnprobe. Laut Künstlerlexikon bezahlt ihm das Kloster Engelberg im Jahre 1687 einen Posten Zinngeschirr.

Er führte die Meisterzeichen Nr. 31, 32 und 33.

Gegenstände : Gupfplatte von $36 \mathrm{~cm}$ Durchmesser, Randbreite $5 \mathrm{~cm}$. Rand hinten und vorn verstärkt. Meisterzeichen Nr. 31 und daneben der Eigentumsstempel Zimmermann im Octogon. Daneben gravirt I. W. und eine Sichel.

Gupfplatte von $27,3 \mathrm{~cm}$ Durchmesser; Randbreite $5,2 \mathrm{~cm}$; Tiefe des Gupfes $3,5 \mathrm{~cm}$. Meisterzeichen Nr. 3 I (vielleicht WM ?).

Gupftellerchen von 17,8 cm Durchmesser und 3,6 cm Randbreite. Besitzerstempel S im Achteck. Meisterzeichen Nr. 33. (Tafel XXVI, 17.)

Müller, Oswald, Zinngiesser, kaufte am 4. April ${ }_{163}$ das Haus Nr. 48 in der Altstadt Obergasse!. Im Jahre ${ }_{1} 646$ gehörte es den Erben des Zinngiessers. Meisterzeichen Nr. 34 .

Gegenstand: Im Landesmuseum in Zürich zwei Dedicationsplatten.

W. M. Müller, W. oder Meister W. M., führte das Meisterzeichen Nr. 34 a (Bd. II).

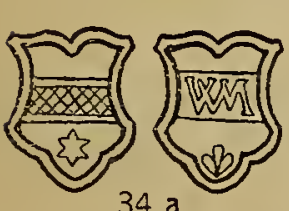

34 a

Gegenstand: Gupfplatte von $27,5 \mathrm{~cm}$ Durchmesser; Randbreite $5,6 \mathrm{~cm}$. Rand unten verstärkt. Rand oben ganz glatt. Beschauzeichen Zug und Meisterzeichen Nr. 34 a auf der Mitte desselben. Tiefe des Gupfes 3,5 cm (vom Tellerrand gemessen).

Müller, Heinrich, Zinngiesser, wohnte im Jahre ${ }_{1654}$ am Fischmarkt Nr. 78 !. Meisterzeichen und Gegenstände unbekannt.

Müller, Andreas, Kantengiesser, wohnt im Jahre 1654 in der Altstadt Obergasse Nr. 40" (nachher Kupferschmied Müller). Meisterzeichen und Gegenstände unbekannt.

Luthiger, Josef Wolfgang, Zinngiesser, wurde am 19. August ${ }_{172} 8$ geboren, verheiratete sich am 25. September 1752 mit Marianne Heinrich von Aegeri. Er war ziemlich liederlich, ein Pintenwirt, ging im Jahre ${ }_{17} 56$ in französische Dienste und kam nicht mehr heim. Meisterzeichen Nr. 35.

Gegenstände : gewöhnliche schmalrandige Teller.

Keiser, Oswald, Kantengiesser, Grossonkel des folgenden Carl Oswald Keiser, wurde geboren ? und starb am 29. Oktober $1644^{3}$.

Er führte das Meisterzeichen Nr. 36.

Gegenstände: Schnabelstitze mit Etagenknopf von 1 Maass Inhalt. In der Mitte der Leibung ein flacher, profilirter, circulärer Wulst. Unter dem Schnabel ein gravirtes Heinrichwappen zwischen den Initialen S. H. Deckel sehr flach; auf dem Ausgusschnabel rautenförmiger Deckel. Höhe der Kanne $31 \mathrm{~cm}$. Meisterzeichen Nr. 36. Bodenrosette Nr. 54 . (Tafel XXXII, 3.)

Breitrandplatte von $32,5 \mathrm{~cm}$ Durchmesser und 7,3 cm Randbreite. Aussen am Rand $12 \mathrm{~mm}$ breiter profilirter Streifen. Gravur: H. I. W. Marke Nr. 36.

Breitrandteller von 25,5 cm Durchmesser und 5,6 cm Randbreite, aussen ein $12 \mathrm{~mm}$ breiter fein gerillter Streifen. Meisterzeichen Nr. 36.

Schnabelstitze von $1 / 2$ Maass Inhalt. Auf dem Deckel ein Etagenknopf. In plumper Gravirung F B Z mit Zehnderwappen. Meisterzeichen Nr. 36, Bodenroseete Nr. 54. Höhe $23,5 \mathrm{~cm}$.

\footnotetext{
1 Hausbesitzer-Verzeichnis von Herrn Victorin Lutiger, Zug.

2 Hausbesitzer-Verzeichnis von Herrn V. Luttiger, Zug.

3 Stammbäume von R. D. Pfarrbelfer P. A. Wickart, Zug.
} 
Stitze ohne Schnabel von $1 / 4$ Maass Inhalt; auf dem Deckel ein Etagenknopf. Vorn Initialen I. I. H. Hinten unten am Traghenkel eine flache, gegossene Fratze. Meisterzeichen Nr. 36 . Höhe $16,5 \mathrm{~cm}$.

Zwei Schnabelstitzen von $1 / 4$ Maass Inhalt, Bodenrosette Nr. 53 . Höhe 17 cm. (Tafel XXXII, 7.)

Zwei Breitrandteller, Durchmesser $22 \mathrm{~cm}$, Randbreite $5 \mathrm{~cm}$, ganz glatt.

Keiser, Carl Oswald, Kantengiesser, wurde am 2. November 1663 getauft und starb am 31. März 1737 .

Er führte das Meisterzeichen Nr. 37.

Gegenstände: Breitrandplatte von $32,4 \mathrm{~cm}$ Durchmesser und $7,2 \mathrm{~cm}$ Randbreite. Aussen am Rande $12 \mathrm{~mm}$ breiter, stark profilirter Streifen. Meisterzeichen Nr. 37 .

Breitrandplatte von $32,2 \mathrm{~cm}$ Durchmesser und 7,2 cm Randbreite; aussen am Rande ein $12 \mathrm{~mm}$ breiter Streifen von feinen Rillen.

Zwei Breitrandteller von $22 \mathrm{~cm}$ Durchmesser und $5 \mathrm{~cm}$ Randbreite; aussen ein $10 \mathrm{~mm}$ breiter Streifen feiner Rillen.

Keiser, Jakob David, Kantengiesser, wurde am 25. November ${ }_{1} 696$ getauft und starb am 3o. April 1776.

Er führte das Meisterzeichen Nr. 38.

Gegenstände: Breitrandplatte von 31,5 cm Durchmesser; Randbreite 7,5 cm; am Rande $9 \mathrm{~mm}$ breit profilirt. Meistermarke Nr. 38. Am Rand die Initialen M. (M L).

Glockenkanne mit Bajonetverschluss von $1 / 2$ Maass Inhalt. Auf dem Ausgussdeckelchen die Marke Nr. 38. Bodenrosette Nr. 57. Höhe $24 \mathrm{~cm}$.

Schnabelstitzen mit Traubenknopf von $1 / 2$ Maass Inhalt (2 Exemplare). (Tafel XXXII, 6.) Am Henkel Marke Nr. 38. Ganz mit Gravuren überzogen: Josua und Kaleb. Oben ein Fries mit Löwen und der Jahrzahl 1754. Höhe 22,5 cm. Rosette Nr. 56 und 53. (Tafel XL, 3.)

Glockenkanne mit Bajonetverschluss von 2 Maass Inhalt. Auf dem Schild die Jahrzahl 1735. Bodenrosette Nr. 54 . Höhe $34,5 \mathrm{~cm}$.

Schnabelstitze mit Etagenknopf von I Maass Inhalt. Marke Nr. 38 am Henkel. Bodenrosette Nr. 54. Höhe $32,5 \mathrm{~cm}$. In der Mitte der Leibung zwei flache, circuläre Wülste. (Tafel XXXII, 5.)

Gupfplatte von 28,4 cm Durchmesser; Randbreite $6 \mathrm{~cm}$; am Rande 1,2 cm breite, profilirte Zone. Gravirte Initialen F I F zwischen Rollen-Ranken.

Grosse Zinnische mit Eichelgiessfass im Kaplaneihaus an der Grabenstrasse in Zug.

Keiser, Wolfgang Leonz, Zinngiesser, der Bruder des Vorigen, wurde am 1. November 1703 getauft und starb am 7. August 1750.

Seine Meisterzeichen entsprechen den Nr. 39, 40, 41, 42 und 43 des Band I.

Gegenstände: Breitrandteller von 24,4 cm Durchmesser und 5,2 cm Randbreite; aussen 1,5 cm breit stark profilirt. Am Rande gravirtes Doppelwappen Keiser-Uttinger. Unten am Boden die Meisterzeichen Nr. 40 und 41 .

Zwei Breitrandteller von $22 \mathrm{~cm}$ Durchmesser; Randbreite $5 \mathrm{~cm}$; aussen I cm breit fein gerillt. Unten am Boden das Meisterzeichen Nr. 39.

Stitze ohne Schnabel, mit Traube auf dem Deckel, von $1 / 2$ Maass Inhalt. Am Henkel die Marke Nr. 39. Bodenrosette Nr. 53. Höhe $22 \mathrm{~cm}$.

Breitrandteller von $25 \mathrm{~cm}$ Durchmesser und $6,3 \mathrm{~cm}$ Randbreite, aussen $2 \mathrm{~cm}$ breit tief profilirt. Meistermarke Nr. 4o. Am Rand das gravirte Doppelwappen Keiser-Uttinger. (Tafel XXVI, 7.)

Tintengeschirr mit Marke Nr. 41. (Tafel XIX, 18.)

Melonengiessfass mit dem Meisterzeichen Nr. 42. Gewöhnlicher Schmalrandteller mit der Marke Nr. 42. 

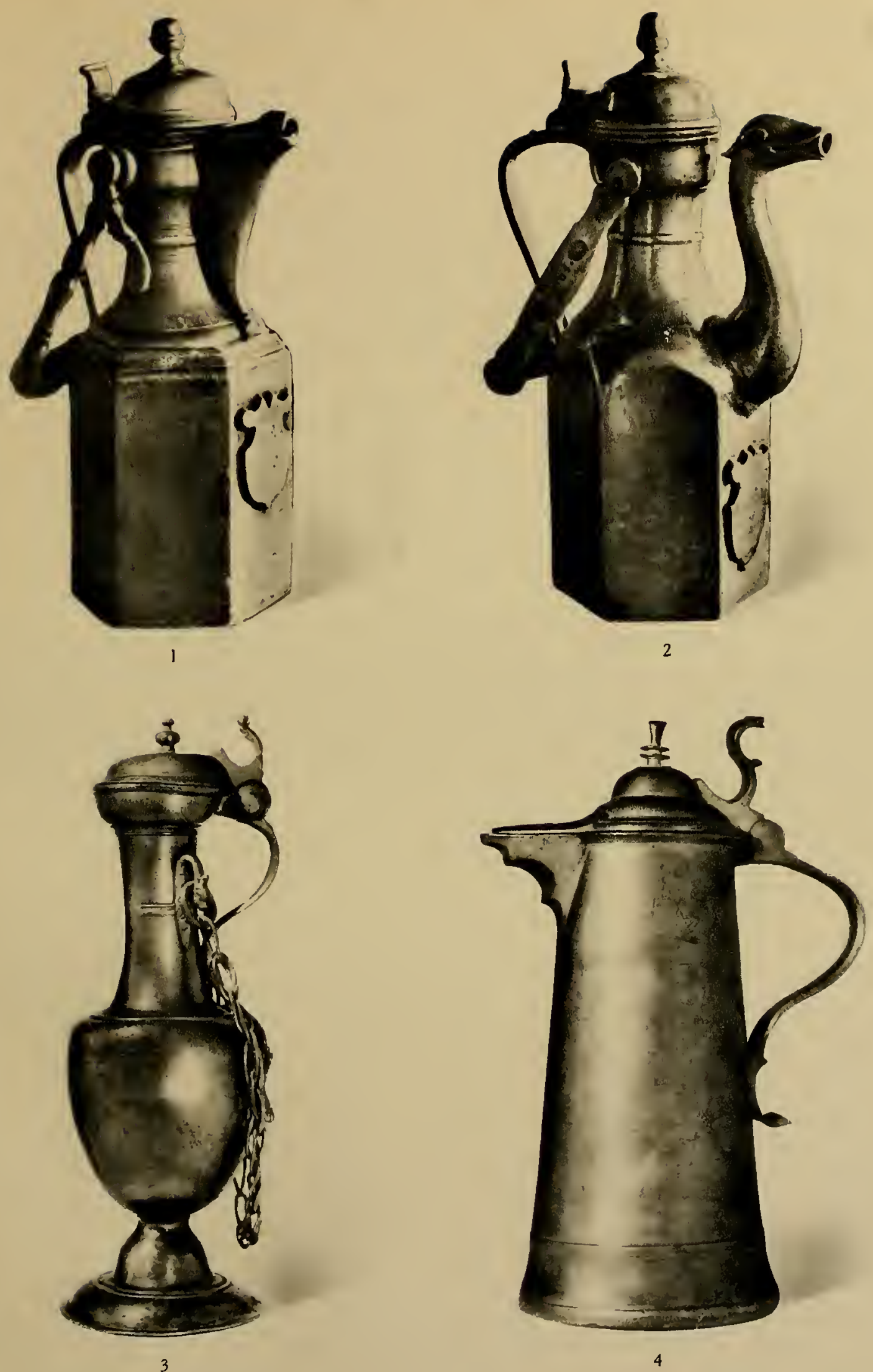

1. Abendmahlkanne von Lausanne (St. Laurent), Höhe $43,5 \mathrm{~cm}$, von F. Reuchlin, Lausanne, 1759-? (S. 43 und 236). 2. Abendmahlkanne von Lausanne (St. François), Höhe $42,5 \mathrm{~cm}$, von F. Reuchlin, Lausanne, 1759-? (S. 43 und 236) 3. Abendmahlkanne, von Pierre Villeneulve, tätig 1671-1700; Kanne im L. M. Zürich (S. 197 und 248). 4. Stitze (L. M. Zürich). Höhe $35 \mathrm{~cm}$, von Hans Ulrich Rudolf, Zofingen, 1598-1646) (S. 221). 
Keiser, Joachim Leonz, Zinngiesser, war der Sohn des Zinngiessers Jakob David Keiser; er wurde am 3o. August 1728 getauft und starb am 26. April 1809. Er war der produktivste aller Zuger Zinngiesser.

Er führte die Meisterzeichen Nr. 44 und 45 (Bd. I).

Gegenstände: Schnabelstitze, mit Traube auf dem Deckel, von $1 / 2$ Maass Inhalt. Am Henkel die Meistermarke Nr. 45. Höhe 22,5 cm. Bodenrosette Nr. 6o. Gravirte Initialen I. G. ST.

Fünf Salatschüsseln mit beweglichen Henkeln (Tafel XXVI, 1-3). Drei Wöchnerinnenschüsselchen mit Meistermarke Nr. 45 auf dem Deckel oder unten am Boden. (Tafel XX, 1.)

Schnabelstitze, mit Deckeltraube, von $1 / 2$ Maass Inhalt. Marke 45 ; Bodenrosette Nr. 60. Stitze ohne Schnabel mit Etagenknopf auf dem Deckel, Marke 45 ; Bodenrosette Nr. 58. Höhe $15,5 \mathrm{~cm}$. Inhalt $1 / 4$ Maass. (Tafel XXXII, 1.) - Schnabelstitze von $1 / 4$ Maass, G F B 1775 .

Glockenkanne mit Bajonetverschluss von 1 Maass Inhalt. Bodenrosette Nr. 59; Höhe $29,2 \mathrm{~cm}$. Auf dem Schild gravirte Initialen MF. A. K. 1794. - Gleiche Glockenkanne mit den Initialen H. I. L. 1776 . Höhe $28,5 \mathrm{~cm}$.

Glockenkanne mit Bajonetverschluss von 2 Maass Inhalt. Bodenrosette Nr. 61. Höhe $36 \mathrm{~cm}$. Auf dem Schild die Initialen X. ST. 1806. - Ebensolche mit I. A. H. 1788 und Hedigerwappen. - Ebensolche mit B C B ${ }_{17} 67$. (Tafel XXXII, 4.)

Bauchige Kaffeekanne, $25 \mathrm{~cm}$ hoch; die Marke Nr. 45 innen am Kannenboden.

Breitrandplatte von $37 \mathrm{~cm}$ Durchmesser und $8,2 \mathrm{~cm}$ Randbreite. Fundus in der Mitte hochgetrieben. Marke Nr. 45. - Brunnenkesselchen mit Rillenknopf. (Tafel XX, 19, 21.) Zwei sechsseitig-prismatische Kannen von 2 Maass Inhalt mit Schraubdeckel; Marke Nr. 45 auf dem Deckel. Ausgussröhre mit Schraubverschluss. Höhe $37 \mathrm{~cm}$.

Ohrenschüsselchen mit Deckel und drei Klauenfüssen darauf. Breite 24,8 cm. (Tafel $\mathrm{XX}, 6$.

Grosses Säulengiessfass mit gewundenen Säulen. Auf dem Deckel Zugerwappen in Reliefguss. Zwei Ausgusshahnen. Aus dem alten Spital. (Im historischen Museum Zug.)

Keiser, Joachim Michael, Zinngiesser, der Sohn des vorigen Joachim Leonz Keiser, wurde am 8. Januar 1775 getauft und starb am 13. April 1853. Er besass in Chur um 1850 herum eine Filiale, indem er den Nachlass des Churer Zinngiessers Wilhelm Lange erwarb und damit auch dessen Modelle und Matritzen.

Er führte das Meisterzeichen Nr. 46.

Gegenstände: Giessfass mit seitlichen Handgriffen im Rokkokostil. (Tafel XXIV, 5.)

Granata pfel-Giessfass mit Flügeln und drei Blättern auf dem Deckel und zwei Blättern am Ausgussrohr mit Delphinkopf. Im letztern ist der Messingbroncehahn eingelötet. (Privatbesitz in Zug.)

Zuger "Kranzkanne ", nach dem Churer Modell gegossen. Marke Nr. 46 auf dem Deckelchen der Ausgussröhre und unten am Boden. Der Boden der Kanne ist ganz flach, im Gegensatz zu dem hochgetriebenen der Churer Kanne. Auf dem Schild das Wappen von Beromünster. Keine Bodenrosette. Höhe $34 \mathrm{~cm}$. (Tafel XXXV, 1.)

Glockenkanne mit Bajonetverschluss von I Maass Inhalt; keine Bodenrosette. Auf dem Schild die Initialen B. Z.

Schnabel-Kaffeekanne mit kuppelförmigem Deckel und Holzgriff. Meisterzeichen Nr. 46 an der Innenseite des Bodens. Höhe $20 \mathrm{~cm}$.

Keiser, Beat Jakob Josef Anton, Zinngiesser, wurde am 8. März 1821 getauft und starb am 23. Mai 1897 in seinem Hause in der Altstadt Untergasse. "Keiser Beat Jakob, 21 Jahre alt, Heimat Zug. Wanderbuch vom 1 o. Juni 1842. Meldet sich an bei Zinngiesser Heinrich Wilhelm Lange 1846 Juni 16.; ab : 1844 Juni 8. (Chur. Wanderbuch). 
Er führte das Meisterzeichen Nr. 47 in doppelter Grösse der Zeichnung.

Gegenstände: Zwölf Tellerchen von 17,5 cm Durchmesser; Randbreite 2,5 cm. Die Meistermarke Nr. 47 befindet sich an der Unterseite des Bodens.

$\mathrm{Z}$ wölf Trinkbecher, $7,2 \mathrm{~cm}$ hoch; oberer Durchmesser $7,1 \mathrm{~cm}$. Form nur wenig nach oben konisch sich ausweitend. Oberer Rand verdickt.

Zehn Ohrenschüsseln, davon einige mit Deckel. Breite mit den Ohren 22,5 cm, ohne Ohren $15 \mathrm{~cm}$. Tiefe $4 \mathrm{~cm}$.

\section{Die zugerischen Zinngegenstände}

Die Erzeugnisse der Zuger Zinngiesser gehören zu den besten dieses bis zur Kunst entwickelten Handwerks. Die ältesten erhaltenen Zinngegenstände sind die zwei Ratskannen von Baar. Sie stammen vom Meister Johannes Vogt (Meisterzeichen Nr. 25) und.gehören zu den ältesten bekannten Kannen der Schweiz. Diese mächtigen, $10 \mathrm{~kg}$ schweren Kolosse, weisen in der Gesamtform und in den Einzelheiten ausgesprochen gotische Momente auf. Zu beiden Seiten des Kannenbauches befindet sich ein gegossener Zuger-Schild in Tartschenform. Der eiserne Henkel ist an grossen Zinnhenkeln befestigt. In der Mitte des Kannenbodens ist eine Plakette eingelötet, welche in gotischem Stile den Crucifixus mit Maria und Johannes darstellt (Abbildung auf dem Titelblatt des I. Bandes). Der massive Deckel ist kuppelförmig und mit einem sehr voluminösen Scharnir am Korpus befestigt. Dem etagenförmigen Deckelknopf war früher noch ein Stück aufgelötet, das aber abgebrochen ist. Auf dem. Deckel befinden sich auch die Zinnmarken und zwar das Stadt- und das Meisterzeichen (Nr. 25, Bd. I). In die Mitte der Innenseite des Deckels ist ein halber silberner Dicken von Zug mit der Jahrzahl (15)68 eingegossen. Besonders bemerkenswert ist die Konstruktion des Ausgusses. Die sechsseitig prismatische, im Bogen aufsteigende Ausgussröhre wird durch einen vollrund gegossenen Mannsarm mit dem Kannenleib verbunden. Die ausgespreizte Hand umfasst den Hals des Löwenkopfes, welcher den Ausguss bildet. Dem Rachen entragt noch ein kleines Stück der sechskantigen Ausgussröhre. Die stilistische Behandlung der Haare und der Mähne des Löwenkopfes ist rein gotischen Stiles und ebenso die Modellirung der Hand samt den Fingern. Die Maasse der Kannen sind folgende: Höhe bis zum Deckelknopf $41,5 \mathrm{~cm}$; Durchmesser des Fusses $21,5 \mathrm{~cm}$; Durchmesser des Deckels, welcher dem Korpus bündig aufliegt, 17,4 cm.

Im Rathause von Zug (historisches Museum) befinden sich sechs prächtige Ratskannen aus der Werkstatt Carl Schönbrunners. Die Meisterzeichen befinden sich am Fusse der Kannen (Nr. 29, Bd. I). Bemerkenswert schön ist die Ornamentirung des massiven Zugerschildes zu beiden Seiten der Kannen und prachtvoll ist die Modellirung des schnabelförmigen Ausgusses. Im Kannenboden ist bei vier Exemplaren eine Plakette eingelötet, welche derjenigen der Baarer Ratskannen sehr ähnlich ist; bei den zwei andern Kannen befindet sich an der Stelle der Plakette eine einfache Rosette. Die Echtheit dieser zwei Exemplare bedarf unbedingt einer genauen Prüfung. (Tafel IV, 4.) Die Höhe beträgt $40,5 \mathrm{~cm}$.

Der $Z$ uger Delphin ist sehr gut in der Form, ziemlich schlank und ganz glatt, also ohne Musculaturwülste. Ebenso kunstreich gearbeitet sind die Granatapfel- und Melonengiessfässer. Von beiden gibt es zwei Arten, mit drei oder fünf Blättern und Flügeln. Alle diese Wasserbehälter stammen von den Meistern Wolfgang Leonz und Joachim Michael Keiser und sind eigentliche Raritäten. Die Säulengiessfässer mit Renaissance- oder Barocksäulen kommen in verschiedenen Abarten und Grössen vor. Sie wirken sehr dekorativ und sind ebenfalls recht selten geworden. (Tafel XXIV, 4.) Eine weitere zugerische Specialität sind die prächtigen Wöchnerinnen-Schüsselchen von Joachim Leonz Keiser. Durch ihre massive Ausführung und die feine Modellirung der vertical gestellten Henkel differiren sie erheblich von den Basler Modellen. Man findet Exemplare im Barok-Stil und auch solche mit Anlklängen an den Louis XV.-Stil. Dieselben haben je drei Klauenfüsschen am Boden und auf dem Deckel. 
An Stelle horizontaler Ohren (v. Zürich) sind vertikal gestellte Handgriffe mit kunstvollen Ranken und Engelköpfen. (Tafel XX, 1.)

Eigenartig sind auch die buffetartigen Tintengefässe des Wolfgang Leonz Keiser. (Tafel XIX, 18.)

Als weitere Gegenstände finden wir alle Arten Platten, Teller, Ohrenschüsseln, Schalen mit beweglichen Henkeln, Brunnenkesselchen, Kerzenstöcke, Oellämpchen, Trinkbecher, Weihwassergefässe. Von letztern gibt es eine besonders schöne Art, bei welcher eine kunstvoll reliefirte Madonnafigur die Rückwand bildet. (Tafel XX, 12, 9, 10.)

\section{Die Kannen}

Die Glockenkanne ist die häufigste Form der Zugerkannen. Immer besitzt der Deckel einen Bajonetverschluss, niemals einen Schraubenverschluss. Der Inhalt beträgt 2, 1 und $1 / 2$ Maass. Die Form differirt nicht von der zürcherischen; ebenso finden sich ähnliche circuläre Rillen am Kannenleibe und ziemlich häufig im Oberteile ein flacher circulärer Wulst. Auf dem Schild findet man ebenfalls Initialen, Jahrzahlen, Wappen, u.s.w. Ueber die Bodenrosetten gibt Tafel III in Band I genügenden Aufschluss.

Die Stitze kommt in beiden Formen vor, also mit und ohne schnabelförmigem Ausguss; die Schnabelstitzen sind aber viel häufiger. Während die zürcherischen Exemplare ganz glatt sind, weisen die zugerischen Kannen immer circuläre Rillen oder (seltener) Wülste auf; dadurch wird eine Gliederung des einfachen Leibes erzielt. Dagegen ist die Zugerstitze plumper als die zürcherische, und zwar besonders wegen der schwachen Ausladung des Fusses. Die vorkommenden Grössen entsprechen einem Inhalt von $1,1 / 2,1 / 4$ und $1 / 8$ Maass. Die 1 Maass und $1 / 4$ Maass-Stitzen sind selten.

Die sechsseitig-prismatischen $\mathrm{K}$ annen sind sehr selten und stammen alle aus der Werkstatt von Joachim Leonz Keiser (vier bekannte Exemplare). Die etwas plumpen Kannen von 2 Maass Inhalt haben sowohl am Deckel als auch an der Ausgussröhre einen Schraubenverschluss. Das Meisterzeichen befindet sich am Rande des Deckels. Bodenrosette fehlt.

Eine eigenartige Erscheinung ist das Vorkommen von Churer Kranzkannen mit zugerischen Zinngiesserzeichen. Auch hiefür wurde der Schlüssel gefunden. Der letzte zugerische Zinngiesser Beat Jakob Josef Anton Keiser arbeitete vom 10. Juni 1842 bis 8 . Juni 1844 bei dem Zinngiesser Heinrich Wilhelm Lange in Chur, dem Hersteller der Churer Kranzkannen. Dann übernahm Joachim Michael Keiser im Jahre 1848 das Geschäft des verstorbenen Meisters Lange und führte dasselbe ca. 5 Jahre lang als Filiale des Zugergeschäftes weiter. Die drei bekannten Kranzkannen mit zugerischen Giessermarken tragen den Stempel Nr. 46 mit den Initialen I. M. K. Bei zwei Exemplaren befindet sich je ein Zeichen auf dem Deckelchen der Ausgussröhre und an der Unterseite des Kannenbodens. Das andere Exemplar hat einen Schraubenverschluss an der Ausgussröhre und deshalb ist das Meisterzeichen nur an der Unterseite des Kannenbodens. Die zugerischen Kranzkannen haben einen ganz ebenen, flachen Boden, im Gegensatz zu dem kuppelförmig in den Kannenleib hineinragenden Boden der Churer Kannen. Im Nachlasse des letzten Zinngiessers mit Namen Keiser fand sich auch eine Original-Stahlmatritze des Engelstempels Heinrich Wilhelm Langes. (Tafel XXXV, 1.)

\section{Geschenk- und Dedicationsplatten}

Diese seltenen Platten haben ähnliche Formen wie die zürcherischen. Leider fehlen oft die Meisterzeichen. Im Landesmuseum in Zürich befinden sich zwei Exemplare des Zuger Meisters Oswald Müller. (Tafel XXXI.)

Aus dem Jahre ${ }^{6} 61$ datirt eine dicke sechseckige Platte, welche bis auf ein Eckstück bei einem Brande zugrunde ging. Es existiren nun davon einige sehr gut geratene Rekonstruc- 
tionen, welche dem Original täuschend ähnlich sehen. Die Umschrift lautet: " Die löbliche Statt Zug sampt den Regieren Räthen ». Die Gravirung besorgte ein Goldschmied W. R. Wahrscheinlich handelt es sich um Wolfgang Rogenmoser, welcher 1604 der Lukasbruderschaft in Zug angehörte und am 17. März 1642 starb. In der Mitte der Platte ist ein von zwei Löwen gehaltenes Doppelwappen der Stadt Zug; unterhalb desselben befinden sich die Wappen der sechs Vogteien und die Jahrzahl 1641. Um den Rand der Platte zieht sich ein Schriftband mit den Namen und Wappen der regierenden Räte, der Weibel und Stadtschreiber. Durchmesser $36,5 \mathrm{~cm}$. (Tafel XXXI, 3.)

Eine grosse prachtvoll-gravirte Zackenplatte wurde von den Eltern Signer-Blunschi ihrem Sohne Johann Georg Signer, Stadtpfarrer von $Z_{u g}$, gestiftet. In der Mitte befindet sich das Alliancewappen der Eltern, Signer und Blunschi, von Engeln gehalten und mit dem Prothonotariushut überdacht. Rund herum windet sich das Schriftband mit dem Text: "H. Johann Georg Signer der H. Schrift Doctor, Apostolischer Prothonotarius des Ehrwürdigen Capitels Zug und Bremgarten demnuss Pfarr Herr der Statt Zug 1674 ". Der Graveur zeichnet mit W und dem Vogtwappen; es handelt sich also wahrscheinlich um Wolfgang Vogt, Zinngiesser (1652-1717). Die Zacken und Randlappen sind mit Blatt- und Fruchtornamenten ausgefüllt. Durchmesser der Platte $34,3 \mathrm{~cm}$. (Tafel XXXI, 2.)

\section{LUZERN}

Luzern stand bis zur französischen Revolution unter einem ausgesprochen aristokratischen Regiment. Die Handwerker in den Zünften hatten wenig mitzusprechen; auch förderten die gnädigen Herren zu sehr die grossen $M$ ärkte, an welchen viele auswärtige Meister teilnahmen und den Ansässigen den Absatz verkürzten. Luzern sollte die Urkantone mit Zinngeschirr versorgen und nun treffen wir auf der "Määss " und den drei grossen Jahrmärkten die Zinngiesser von Zofingen, Zug, Zürich und Basel. Darum funden wir zum Beispiel im Lande Uri fast nur Basler Zinngeschirr neben wenigen Stücken schwyzerischen Ursprungs. In Obwalden genügten die beiden Etli von Sachseln dem Bedarf. Dadurch wurden die Luzerner Meister in ihrer Produktion stark gehemmt. Luzerner Zinnsachen sind heutzutage viel seltener als solche aller umgebenden Städte. Die Kannengiesser von Luzern gehörten zur Schmiedenzunft '.

Die älteste Kannengiesserordnung stammt aus dem Jahre 1418 , der erste Kannengiesser-Eid von 1422. Die zweite Ordnung wurde am 28. August 1556 erlassen und 1559 noch verschärft. Die älteste $Z$ innprobe für gewöhnliches $Z$ inn war $5: 1$. Im Jahre 1559 wurde die Zürcherprobe 4: 1 angenommen. Der Verkauf von Zinngeschirr war nur den einheimischen und den zünftigen Meistern der umgebenden Städte gestattet, nicht aber den Stümpern. Letztere durften auch keine Flickarbeiten ausführen; auch durften die fahrenden Zinngiesser nur an den grossen vier Märkten Geschirr feilhalten (Brown, S. 40). Zum grossen Schaden für den Handel mit Zinngeschirr wurde im Jahre 1689 die Legirung $2: 1$ gestattet und längere Zeit beibehalten. Solche Zinngegenstände (mit der Legirung 2:1) wurden rasch schwarz und unansehnlich; auch sind dieselben zu weich und sind rasch verbeult. Diese Momente brachten die Luzerner Produkte in Misskredit und öffneten der Konkurrenz Tür und Tor. Die Innerschweizer kauften lieber das haltbare Basler- und Zürcher-Zinn als das — wenn auch billigere - rasch schwarz werdende Luzerner Produkt.

Trotzdem die archivalischen Nachrichten bis ins Jahr 1365 zurückgehen, gibt es nur 3o Luzerner Meister; es war also meist nur ein Kannengiesser tätig. Nur A. und C. Traber

1 Die archivalischen Nachrichten verdanke ich llerrn Staatsarchivar P. V. Weber in Luzern. 


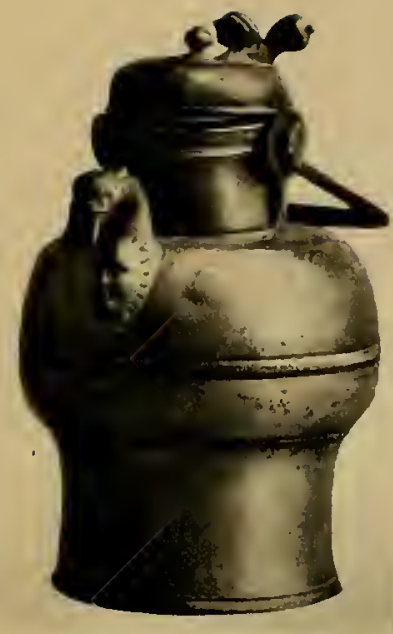

1

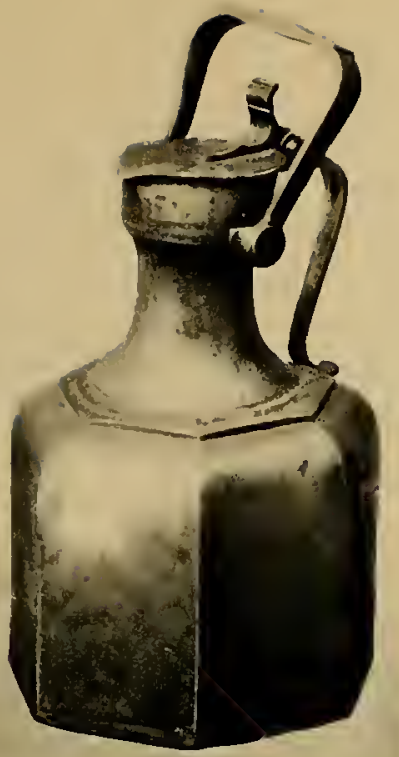

2

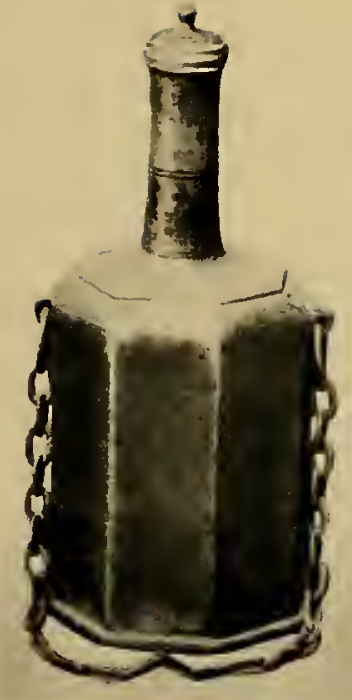

3

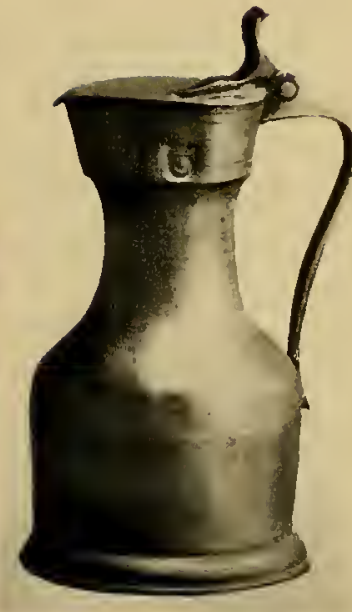

4



5

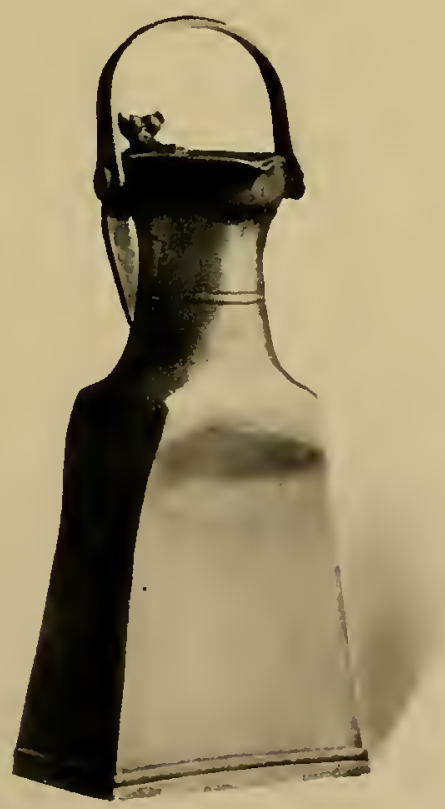

6

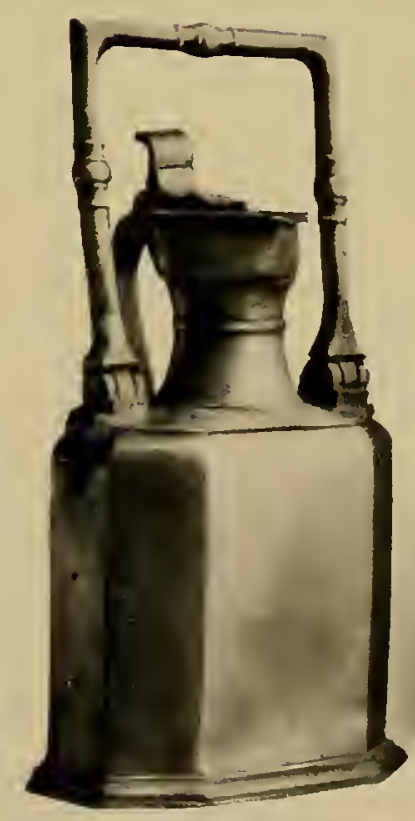

7

1. Abendmahlkanne von Yverdnn, Höhe $43 \mathrm{~cm}$, von Meister 1. B.-D..., (Text S. 244). 2. Abendmahlkanne von Romainmôtier, Höho 35 cm, van J. J. Reuchlin, Lausanne, tätig ab 1759 (Text S. 235). 3. Abendmahlkanne von Romainmôtier, Höhe $36 \mathrm{~cm}$, von D. Freneysy, Orbe, erwähnt 1711 (Text S. 244). 4. Abendmahlkanne von Grandson, Höhe $30.5 \mathrm{~cm}$, von D. Savioz, Grandson, 1725 (Text S. 246). 5. Abendmahlkanne von Orbe, Höhe $42 \mathrm{~cm}$, von Charles-Christophe Goldner, Orbe, 1736-1809 (Text S. 244). 6. Abendmahlkanne von Rovray, Höhe $38 \mathrm{~cm}$, von Meister P. B. (Text S. 246). 7. Abendmahlkanne von Yvonand, Höhe $33 \mathrm{~cm}$, von Jaques Touvenin, 1727. Frankreich (Text S. 246). 

und Franz Xaver Schallbretter lieferten Zinngeschirre, welche qualitativ über dem Durchschnitt stehen; alle andern Meister lieferten, so weit die Gegenstände noch erhalten sind, nur gewöhnliche Ware.

\section{Die Zinngegenstände}

Die Luzerner Kannen sind entweder Stitzen oder Glockenkannen; in der Stadt Luzern konnte ich keine prismatischen Kannen finden, wohl aber in Beromünster. Alle Kannen haben keine für Luzern besondere Form und sind also nur am Meisterzeichen zu erkennen; ebenso die Teller und Platten.

Die zwölf grossen Prunkkannen von Caspar Traber, wurden anlässlich des Schutzbündnisses mit dem Lande Wallis, ${ }_{1678}$, bestellt. Allerdings besteht nur ein Teil des Fusses, der Korpus und der Deckel aus Zinn; der Schild, die Fassung des Fusses, die Karyatiden, die Delphine und der Henkel sind aus Messingbronze. Leider wurden am Ende des XIX. Jahrhunderts eine grössere Menge von Kopien hergestellt, welche nun ab und zu an den Auktionen auftauchen. (Tafel V, 2.)

Das Delphin-Modell von Franz Xaver Schallbretter zeichnet sich durch seine einfache Schönheit vor allen andern Schweizer-Modellen aus. Auch die Form der Zinnische ist prachtvoll; meist findet man in den Ecken feingravirte Familienwappen. (Tafel XXII, 2.)

\section{Die Luzerner Zinngiesser}

Die ausgezeichneten Angaben von Herrn Staatsarchivar P. X. Weber in Luzern ermöglichten die Aufstellung einer grossen Reihe von Luzerner Meistern, welche bis anhin vollständig unbekannt waren.

Rychwin, Jakob, " der Kantengiesser ist zum burger angenommen um 1 Mark Silber, hat der statt ze burgrechtgeld geben 2 Harsthörner" 1365 (Geschichtofreund, Bd. 74, 221). Die berühmten Luzerner Kriegshörner erschollen vielleicht in der Schlacht bei Sempach.

Bergmatter, ..., 1428, von Kannen ze machen (Umgeld).

Schaler, Hans, 1431 , der Kannengiesser am Kornmarkt (Ratsbuch IV 286).

Pankraz, $1433-37$, um Kannen ze bletzen, um hanthaben an Kannen (Umgeld).

Glaser, Hans, 1452, der Kannengiesser von Dinkelsbühl. Burgerrecht (Geschichtofreund, Bd. 75,314$)$.

von Utzingen, Heini, $144^{2-1470}$, Kantengiesser (P. X. Weber, aus der Geschichte des Luzerner Weinmarktplatzes, 1928 , S. 25).

Hornberg, Hans, 1457 , von St. Gallen, Kantengiesser, Burgerrecht (Geschichtofreund, Bd. 75, 316). Scherer, Bernhardin, 1473-1500, Zinngiesser, hantbüchser, zinnkannen, schüsslen (Umgeld). 1480 der statt kannen ze fegen 8 schilling. 1484 um 1 giessfassbecki uf das rathus 2 pfund (Umgeld).

im Hasle, Hans, der Kantengiesser, 1487-1491 (Geschichtofreund 19, S. 3o9, Steuerrodel), Abschnitt Mühlengasse.

Herfart, Benedikt, 1505-1532, der Kantengiesser aus Schlesien, Fischmarkt, Burgerrecht ${ }_{1} 506$ (Burgerbuch und Hintersässen).

Michel, ..., der Kantengiesser, 1515 (Umgeld).

Tschödeli, Ludi, $1545-1547$ (Umgeld).

von Wil, Hans, 1546 (Umgeld).

Herfart, Baschi, Kantengiesser, $1578-1583$. (Umgeld)

Mor, Sigmund, 1585 , Kannen ze fägen (Umgeld).

Schwendimann, Hans, ${ }_{1603-1620}$ (Kaufsprotokoll 82). Er führte das Meisterzeichen Nr. 15 (Bd. I). 
Gegenstand: Runde Gupfplatte, Durchmesser $25 \mathrm{~cm}$; Randbreite 4,5 cm. Tiefe des Gupfes $3 \mathrm{~cm}$. Am Rand des Gupfes vier circuläre Rillen. Oben am Rand das Meisterzeichen Nr. 15. Rand unten verstärkt. An der Unterseite Spuren des federnden Dreheisens. Birnförmiges Giessfass, mit Meisterzeichen $\mathrm{Nr}$. 15, auf welchem der $\mathrm{H}$ vor dem $\mathrm{S}$. deutlich ist. (Antiquitäten-Handel in Luzern, Mitteilung von Dr. B. Th.)

von Bremgarten, Werner und Söhne. ) 1613 Burgerrecht (II. Bürgerbuch).

Huber, Werni, 1619, Kantengiesser (Säckelmeister-Rechnung).

Merz, ..., 1638, Kannengiesser (Landvogtei P.).

Rogǵwiler, Batt Jakob, Kannengiesser, 1641 (Akten Zinngiesser).

Schwendimann, Ludigari, 1641-1644, Kannengiesser; erwähnt $165_{2}$ als Mitunterzeichner einer Schrift der aufrührerischen Bauern (Schweiz. Künstler Lexikon III, S. 100).

Weber, Gladi sel. Wittwe Anna Arnet, 1679.

Sunnenberg, Niklaus, Goldschmied und Zinngiesser, tätig um 165o (Schweiz. Künstler Lexikon III, S. 288).

Traber, A..., führte das Meisterzeichen Nr. 12.

Gegenstand: Giessfass mit zwei Säulen, mit engen circulären Wülsten. Höhe $35,5 \mathrm{~cm}$; Breite $21 \mathrm{~cm}$; Tiefe 11,8 cm. Am obern Ende der Säulen sind Löwenmasken aufgelötet. Der aufstülpbare Deckel hat die Form eines geschweiften Daches wie bei einem Reliquar. Vorne am Deckel das Meisterzeichen Nr. 12 mit den Initialen A T (Traber), dazwischen ein Henkelkrug. Zeichnung also wie bei Caspar Traber (siehe der Folgende). (Tafel XXIV, 2.)

Traber Caspar, Zinngiesser, erwähnt 1701, 1710 (Säckelmeister-Rechnung). Ein Caspar Gottfried Traber ist 1663 geboren (Schweiz. Künstler-Lexikon). Er führte das Meisterzeichen Nr. 13. Es befindet sich auch auf den zwölf Prachtkannen von Luzern, welche im Jahre 1678 zur Erinnerung an das Schutzbündnis mit dem Lande Wallis angefertigt wurden. Trabers Arbeiten sind ausgezeichnet gute Werke.

Gegenstände: Breitrandplatte. Durchmesser $33 \mathrm{~cm}$ bei $7,5 \mathrm{~cm}$ Randbreite. Rand an der Unterseite verstärkt; an der Oberseite ein $1 \mathrm{~cm}$ breites profilirtes Band. Am Rande das Meisterzeichen Nr. 13 ; daneben ein eigentümliches Zeichen in Kreuzform.

Gupfplatte. Durchmesser $26 \mathrm{~cm}$ bei $6 \mathrm{~cm}$ Randbreite; Tiefe $3,5 \mathrm{~cm}$. Rand unten verstärkt. Oben, 1,7 cm vom Rand entfernt, eine circuläre Rille; im Gupf zrvei circuläre Rillen. Oben am Rande das Meisterzeichen Nr. 13.

Breitrand-Teller. Durchmesser $19,2 \mathrm{~cm}$ bei $4,5 \mathrm{~cm}$ Randbreite. Rand unten verstärkt, oben ein 1,5 cm breites, schön profilirtes Band. Am Rand das Meisterzeichen Nr. 13. (Tafel XXVI, 16.)

Prachtkannen von Luzern, 12 Stück. Höhe $56 \mathrm{~cm}$. Die Form und der Aufbau der Kanne ist sehr gefällig und elegant. Der grösste Teil der kunstgewerblichen Arbeit besteht aber in Gelbguss (Messingbronze) und zwar der Luzerner Schild, die Karyatiden, die Seitenhenkel und die Delphine des Traghenkels. Die Zinngiesserarbeit beschränkt sich also auf den Kannenleib und den Deckel, welche deutlich auf Nürnberger Modelle hinweisen. (Tafel V, 2.)

Entli, Michael, Zinngiesser, führte das Meisterzeichen Nr. 14. Er wurde im Jahre 1659 geboren, ist seit 1694 verheiratet und wird zuletzt erwähnt 1710 .

Gegenstand: Breitrandplatte. Durchmesser $31 \mathrm{~cm}$ bei $7,5 \mathrm{~cm}$ Randbreite. Rand unten verstärkt. Tiefe circuläre Rille $1 \mathrm{~cm}$ vom Rand entfernt. Der Fundus der Platte stammt von einer andern und trägt ein Meisterzeichen mit den Initialen $H$. C. Das Meisterzeichen Nr. 14 befindet sich oben am Rande; ein sprechendes Wappen, eine Ente auf Dreiberg; der Buchstabe $M$ ist noch deutlich erkennbar, vom $E$ nur ein Teil.

Gloggnner, Beat Ludwig, Zinngiesser, führte das Meisterzeichen Nr. 20; als erster Gloggner, ohne Initialen; zwei verschiedene Stempel : das Luzerner- und das Gloggnerwappen. Dem ersten Zinngiesser Namens Gloggner waren die Initialen unnötig. Der Meister wird im Jahre 1710 erwähnt. 
Gegenstand: Schnabelstitze. Höhe $17,8 \mathrm{~cm}$; Durchmesser des Fusses 10,6 cm. Inhalt 1/4 Maass. Deckeldrücker abgekröpft. Deckel flach-kuppelförmig, mit kleiner Erhöhung in der Mitte. Auf dem bandförmigen Henkel das Meisterzeichen Nr. 20. Oben und unten am Korpus je ein breites, tief-eingedrehtes Rillenpaar. Vorne die gravirten Initialen F. I. S. (Tafel XXXIII, 8.)

Glockenkanne mit Bajonetverschluss von 1 Maass Inhalt mit dem Meisterzeichen Nr. 20. Bodenrosette Nr. 24 .

Breitrand-Platte, am $7 \mathrm{~cm}$ breiten Rand das Meisterzeichen Nr. 20. Durchmesser der Platte $32 \mathrm{~cm}$. (Sammlung C. Hirsbrunner in Luzern.)

Gloggner, Franz, Zinngiesser, führt als Meisterzeichen Nr. 21, 22 und 22 a (Bd. II). Er wird

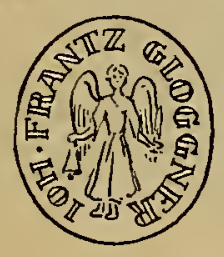

22 a in den Jabren 1757-1771 erwähnt (Akten Fischerstatt). Wahrscheinlich arbeitete er mit Josef Gloggner zusammen und dann benutzten beide zusammen den Stempel Nr. 21. Es gibt auch einen Engelstempel mit der Umschrift IOH * FRANTZ * GLOGGNER (Nr. $22 a$, Bd. II).

Gegenstände : Sechsseitige, prismatische Kanne mit Schraubverschluss. Auf dem Deckel das Meisterzeichen Nr. 22. Höhe $38 \mathrm{~cm}$; Durchmesser des Fusses 16,2 cm. An der rechten Kannenseite der reliefirte Schild nach dem Modell des Hans Luzi Cadenath von Chur. Auf dem Schild die gravirten Initialen $\mathrm{P}$ und $\mathrm{ML}$ 1786. Die sechskantige Ausgussröhre ist vermittelst einer eigentümlichen oval-spitzigen Platte am Korpus angelötet. An den zwei Vorderflächen der Kante gravirte Blätter und Trauben. Die Kanne ist vielleicht eine Zusammensetzung.

Runde Gemüseschale mit dem Meisterzeichen Nr. 22, in der Sammlung von L. Gally in Basel.

Zinn-Kruzifix, $16 \mathrm{~cm}$ hoch, nit Engelmarke Nr. 22 , Umschrift : Joh. Frantz Gloggner. Privatbesitz Dr. B. Th., Luzern.

Gloggner, Josef, Zinngiesser, führte das Meisterzeichen Nr. 21. Er wird als Zinngiesser im Jahre 1765 erwähnt (Säckelmeister-Rechnung). Wahrscheinlich arbeitete er, wenigstens zeitweise, mit Franz Gloggner zusammen.

Gegenstände: Glockenkanne mit Bajonetverschluss; Höhe $28,8 \mathrm{~cm}$; Durchmesser des Fusses 14,2 cm. Meisterzeichen Nr. 21 auf dem Deckelchen der Ausgussröhre. Auf dem Schild die gravirten Initialen C N E - I T. (Tafel XXXIII, 6.)

Stitze ohne Schnabel; Höhe $22 \mathrm{~cm}$; Durchmesser des Fusses $12,3 \mathrm{~cm}$. Deckeldrücker abgekröpft. Auf dem flachen, herzförmigen Deckel vier starke circuläre Wülste. In der Mitte das Meisterzeichen Nr. 21. Oben und unten am Korpus je ein circuläres Rillenpaar. Innen am Boden die Rosette Nr. 24. (Tafel XXXIII, 7.)

Taufschale, rund; Durchmesser $34,5 \mathrm{~cm}$; Randbreite $4 \mathrm{~cm}$; Tiefe $5,3 \mathrm{~cm}$. Am Rande das Meisterzeichen Nr. 21. Im flachen Boden befindet sich ein kunstvoll gravirter Falke auf einem Blumenzweig. Die Seitenwand ist radiär gebuckelt, wobei die Rippen bis zum Rand hinauf reichen (16-teilige Wandung). Der Rand des Fundus und der Schüsselrand ist mit gepunzten und gravirten Ranken überzogen. - Der Taufkrug ist helmförmig, auf einem breiten Fuss mit Perlstab. Der Korpus wird durch einen circulären, schönen Profilstab geteilt. Unterhalb desselben sind prächtig gravirte Ranken von Blättern, Blumen und Früchten; ebenso oberhalb demselben. Auf den obersten $Z$ weigen sitzt zu beiden Seiten des Ausgusses je ein Falke (Wappen der Familie Falk in Luzern). Reliefirter geschweifter Traghenkel. Höhe des Kruges $22 \mathrm{~cm}$. Durchmesser des Fusses 10,7 cm. (Tafel XXIX, 2, 3.)

Schallbretter, Franz Xaver Leodegar, Zinngiesser, führte die Meisterzeichen Nr. 16, 17 und eventuel auch Nr. 19. Er wurde im Jahre 1725 geboren, heiratete 1647 und ist noch von 1751-59 nachweisbar (Geschichtsfreund 15, 196). Bodenrosette Nr. 23 .

Gegenstände: Stitze ohne Schnabel. Höhe $22.8 \mathrm{~cm}$; Durchmesser des Fusses $12,2 \mathrm{~cm}$. Inhalt $1 / 2$ Maass. Der herzförmige flache Deckel hat in der Mitte eine kleine, kegelförmige Erhöhung, davor das Meisterzeichen Nr. 16. Im Boden die Rosette Nr. 23. Vorne am Korpus die gravirten Initialen I. S. H. (Tafel XXXIII, 5.) 
Wandnische mit Delphin. Höhe der Nische $69,5 \mathrm{~cm}$; Breite $48,2 \mathrm{~cm}$; Tiefe am Rand $37,2 \mathrm{~cm}$. Die Nische hat einen breiten profilirten Rand; in den beiden obern Ecken je ein grosses, feingravirtes Familien-Wappen. In der Mitte befindet sich das Meisterzeichen Nr. 17. Die Kuppel der Nische wird vom Unterteil durch einen breiten Profilstab getrennt. Im Unterteil hängt an einem starken eisernen Hacken der prachtvolle Delphin . Derselbe hat Messingflossen und in Messing gefasste rote Glasaugen. Als Ausgusshahn dient ein drehbarer Bügel. Der Unterteil der Nische besteht in einem tellerförmigen Wassersammler mit Ablaufrohr in der Mitte. Länge des Delphins $44 \mathrm{~cm}$. - Die Zinnische befindet sich nich in der ursprünglichen Holzfassung. Stammt aus Ober-Aegeri. (Tafel XXII, 2.)

Humpen mit dem Meisterzeichen Nr. 19, im Antiquitätenhandel C. Hirsbrunner, Luzern. Schallbretter, Jos. Wendel Adam, Zinngiesser, Sohn des vorigen Franz Xaver; erwähnt 1766-1778 (Säckelmeister-Rechnung, Akten Schmiede). Er wurde im Jahre 1749 geboren und 1766 ledig gesprochen.

Meisterzeichen und Gegenstände nicht bekannt.

Du..., Jakob, Zinngiesser, erwähnt 1775 (Akten Schmiede).

Lüthert, Xaver, Zinngiesser, erwähnt ${ }_{177}$ (Akten Schmiede).

\section{BEROMÜNSTER}

Brandschorer, Paul, Zinngiesser aus dem Tirol, erwähnt ${ }_{1} 679$ (Mitteilung von Herrn P. X. Weber, Staatsarchivar, Luzern). Sein Sohn Jost Laurenz wird um 1700 als Hintersäss aufgenommen (BRUn, Schweiz. Künstler-Lexikon IV, S. 64).

Meisterzeichen und Gegenstände sind nicht bekannt.

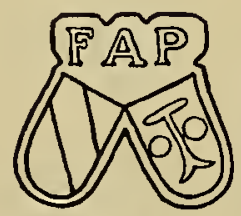

24 a

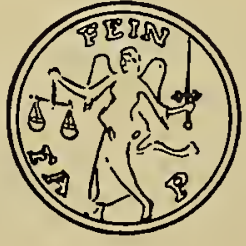

$24 \mathrm{~b}$

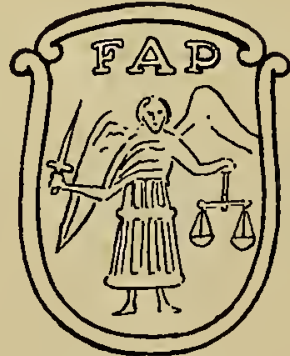

$24 \mathrm{c}$
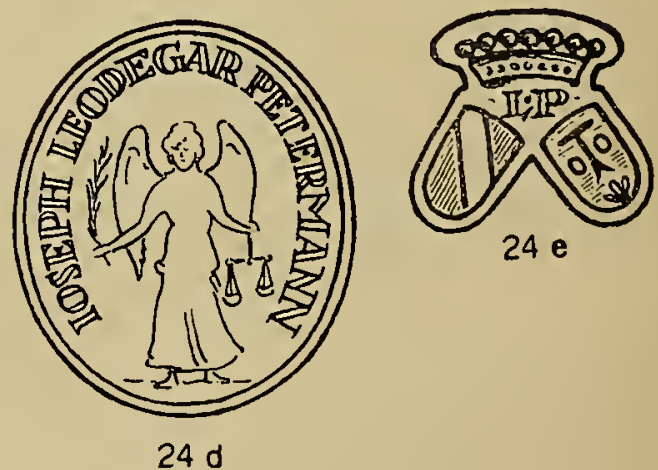

$24 \mathrm{e}$

Petermann, Franz Antoni, Zinngiesser, führte die Meisterzeichen Nr. $24 a, 24 b, 24 c$. Er wird im Rodel der Lukasbruderschaft, welche im Jahre 1685 erneuert vvurde, erwähnt und zwar unter dem Jahr 1748: Meister Antoni Petermann, Kantengiesser und Frau Clementia Kurtz (Mitteilung von Herrn Dr. E. Müller-Dolder, Beromünster).

Gegenstände : Kannen und Platten in der Sammlung von Herrn Dr. E. MüllerDolder).

Giessfass mit aufgestülptem Deckel. Höhe 33,7 cm. Breite am Fuss $21,2 \mathrm{~cm}$. Tiefe $10,4 \mathrm{~cm}$. Als Bekrönung des Deckels ein Blattornament. Das ganze Giessfass ist mit Gravuren überzogen (Musikanten, zwei Verlobte, etc.). Vorn das Beschauzeichen von Uri Nr. 2 (Bd. I). (Ein gleiches Giessfass mit dem Meisterzeichen Nr. $24 b$ in Zuger Privatbesitz.) (Tafel XXIV, 8.) 

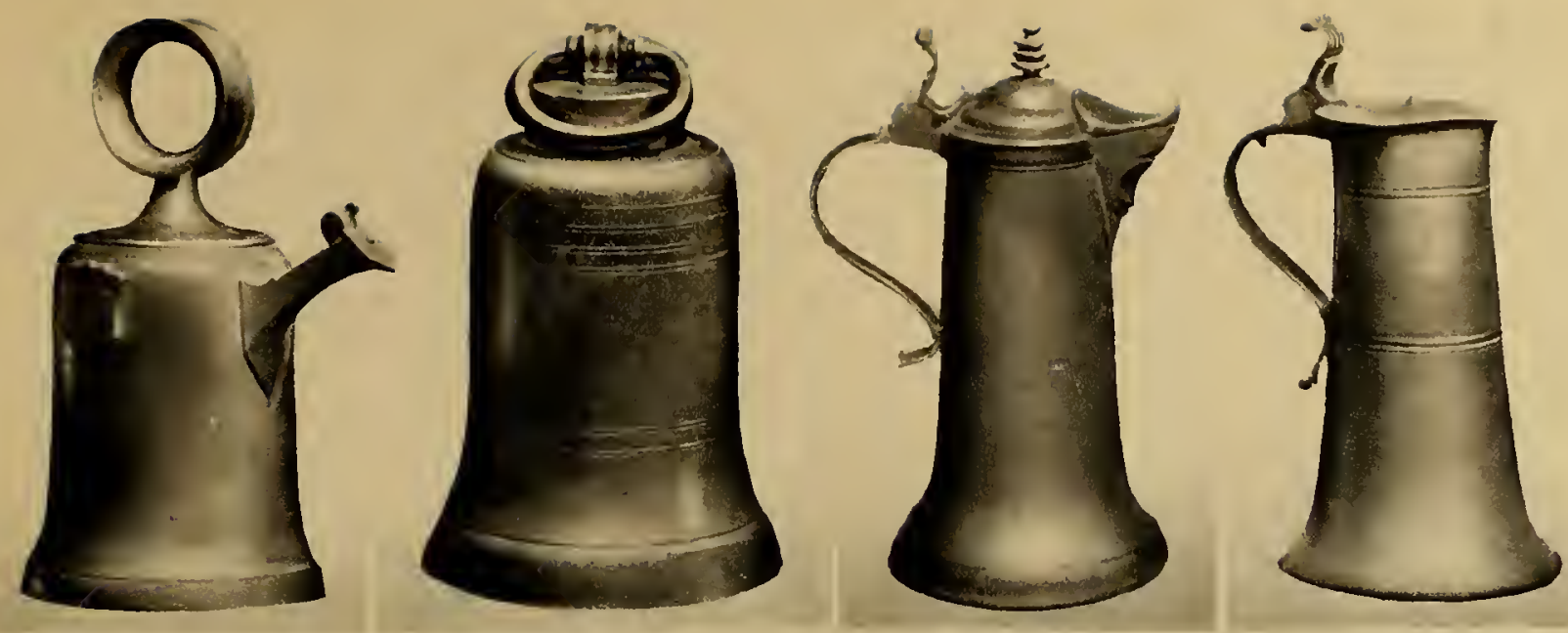

2

3

4
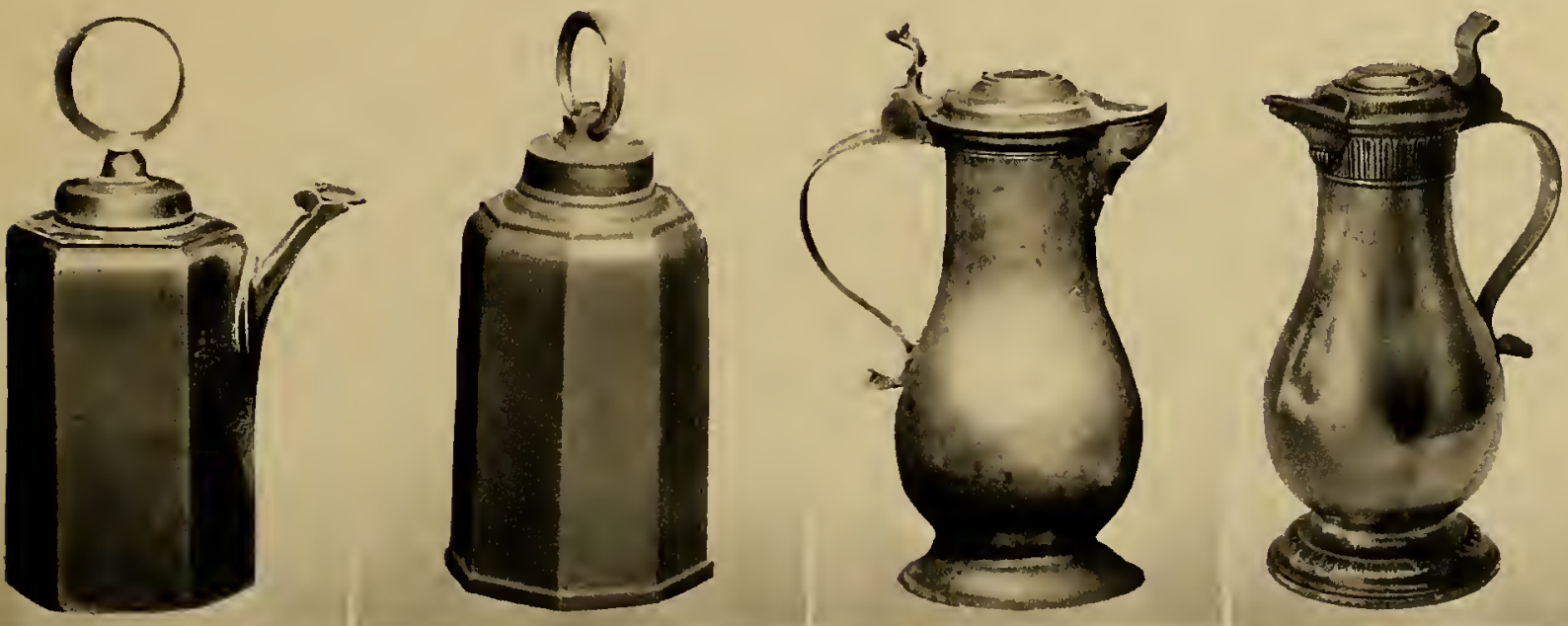

5

6

7

8



9

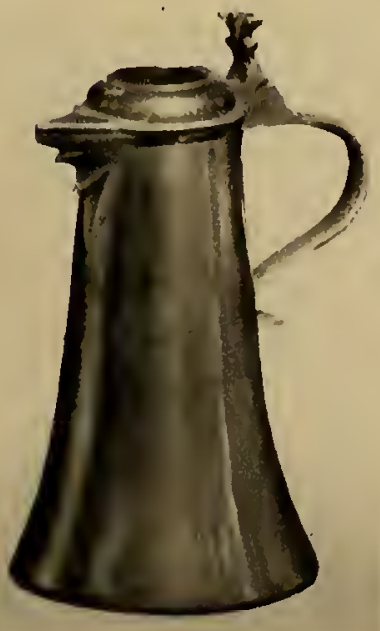

10

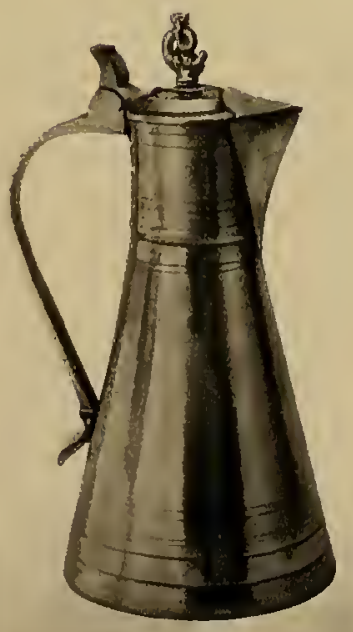

11

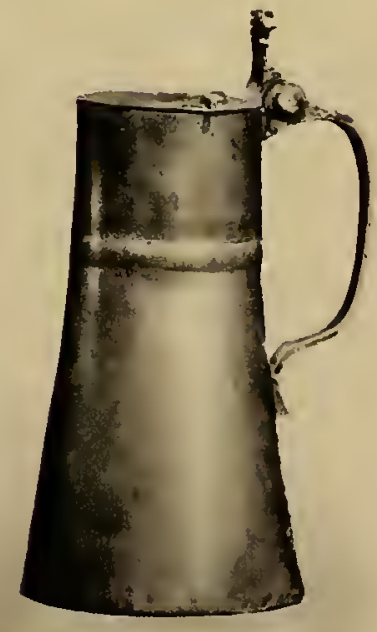

12

Kannentypen: 1, 2. Glockenkannen. 3, 4. Stitzen mit und ohne Schnabel. 5,6. prismatische Kannen. 7, 8. Rundeln. 9, 10, Solothurner Stitzen. 11, 12. Freiburger Stitzen. 

Petermann, Joseph Leodegar, Zinngiesser, führte die Meisterzeichen Nr. $24 \partial$ und 24 e. Er ist im Rodel der Lukasbruderschaft im Jahre 1748 ebenfalls eingetragen : Leodegari Petermann und Frau Anna Maria Gertzig.

Gegenstände: Glockenkannen, prismatische sechsseitige Kannen, in verschiedenen Grössen, ferner Weihwasserkesselchen, Messkännchen auf ovalen Platten, Giessfässer, Handbecken, Schüsseln, Teller und Becher in der Sammlung von Dr. E. Müller in Beromünster.

Ovale Messplättchen im Louis XV-bis Biedermeier-Stil. (Tafel XXVII, 13, 15.)

\section{SCHWYZ}

Zinngegenstände aus dem Lande Schwyz gehören zu den grössten Seltenheiten. Die wenigen nachweisbaren Meister stehen auf einer mittlern Stufe; ein einziger, Leonhard Städelin, lieferte prachtvolle Arbeiten. Ich habe im Ganzen nur vier Meister nachweisen können, von denen sich Gegenstände erhalten haben. Bei drei Zinngiessern sind stets zwei Zinnmarken vorhanden, das Landeswappen von Schwyz und der Schild mit den Initialen des Giessers. Beim Landeswappen ist das Kreuz bald in der linken, bald in der rechten obern Ecke angebracht.

Dass auch in Schwyz die wohlhabenden Leute über reichliches Zinngerät verfügten, sei an Hand des Erbschaftsrodels des am 17. August 1697 verstorbenen Landammanns Jakob Weber veranschaulicht '. Er hinterliess an Zinn 63o Pfund; dazu 16 kleine und grosse Platten, 14 Teller, 2 Flaschen mit Gläsern, 4 Maasskannen, 1 Zweimaasskanne, 1 Suppenplatte, 1 Giessfass mit Weihwasserkesselchen (!), 2 Nachtgeschirr, 1 Rössli, 1 Schlanggenblättlein, 1 Quartstintze und ein Salzbüchslein.

Die Daten über die Zinngiesser sind etwas lückenhaft, weil die Eintragungen in den Tauf- und Sterbebüchern die gleichen Lücken aufweisen . Ferner sollen Zinngiesser des Namens Städelin in Steinen, Steinerberg und Lowerz gearbeitet haben. Des weitern findet man im Kanton Schwyz ab und zu Platten und Kannen mit dem Stempel des Gottardo Gamba, der wahrscheinlich ein fahrender Giesser war und darum das Schwyzer Standeswappen nicht anbringen durfte. Seine Arbeiten sind recht gut, besonders die gewellten Giessfässer, die prismatischen Kannen und die Messkännchen.
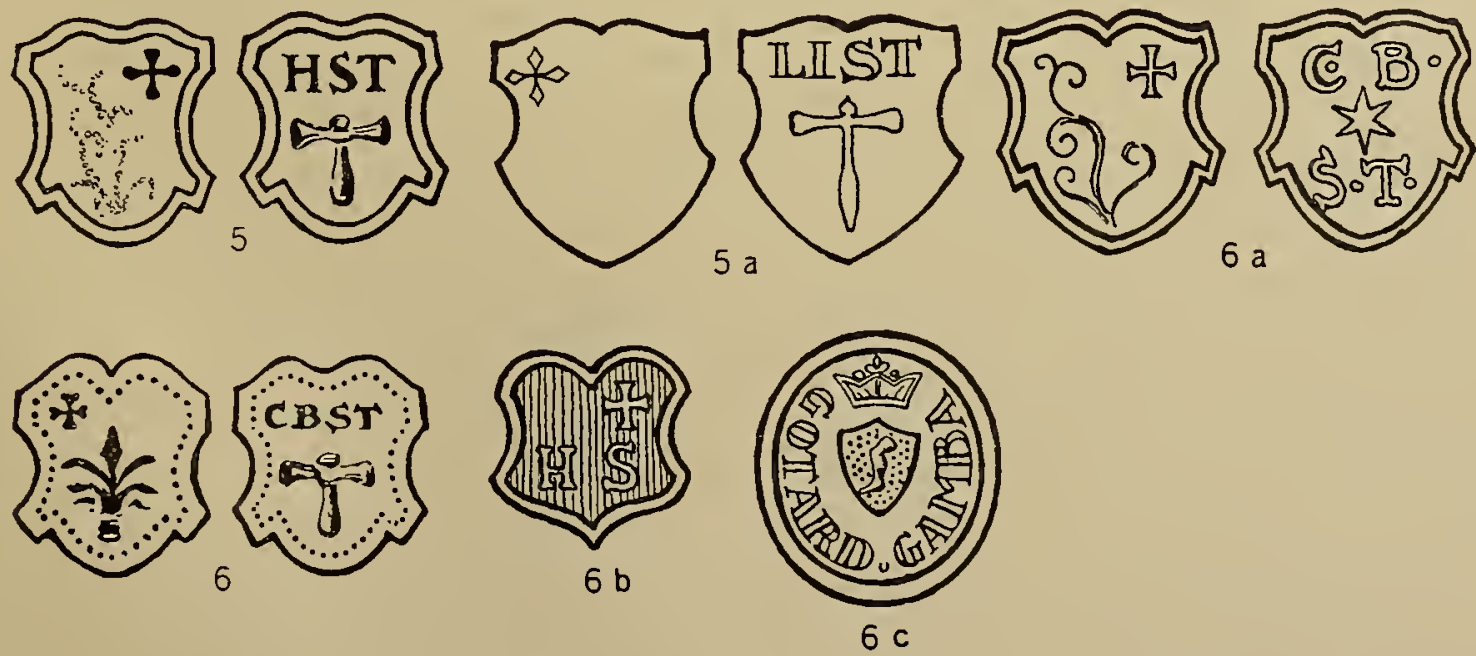

I Dr. C. Benziger. Aus dem Nachlass des Landammann Jakob Weber van Schwyz ( $\left.{ }_{1} 1697\right)$. Anzeiger für schweiz. Altertumskunde. ig14, S. $159^{-161 .}$

2 Mitteilungen von Herrn Staatsarchivar P. Fridolin Segmüller aus dem Tauf- und Sterbebuch der Gemeinde Schwyz. 


\section{Die Zinngiesser}

Meister L.I.ST. In Betracht fallen:

Leonhard J., Städelin, geboren 1618 , Nov. 25 .

Leonhard Städelin, Goldschmied, gestorben 1689 , Jan. 29.

Die Lebens- und Wirkungszeit ist also die gleiche. Sein Meisterzeichen ist Nr. 5 a.

Gegenstände : Mächtige Zinnische mit Giessfass in Eichelform aus einem tannenen

Buffet in Schwyz. Das Material und die Arbeit sind allerersten Ranges. Das Gewicht beträgt $26 \mathrm{~kg}$. Die Höhe der Rückwand $84,2 \mathrm{~cm}$, die Breite $50,7 \mathrm{~cm}$, die Tiefe bis zum vordern Rand des Unterteiles 43,5 cm. Die Zinnmarke Nr. 5 a befindet sich an der Vorderwand, oberhalb der höchsten Stelle der Nische. Im Schwyzer Wappen befindet sich das Kreuzchen in der linken obern Ecke. Leider ist dieser Wandbrunnen, in ein anderes Buffet eingebaut, nach Amerika verkauft worden. (Tafel XXIII, 5.)

Stitze von $1 / 2$ Maass Inhalt, ohne Schnabel. Meisterzeichen Nr. $5 a$ an der Spitze des herzförmigen Deckels, welcher in der Mitte kuppelförmig in die Höhe getrieben ist. Am Kannenleib befinden sich circuläre Rillen, aber keine Gravirungen. Keine Bodenrosette. Höhe $24,8 \mathrm{~cm}$. (Tafel XXXIII, 3.)

Städelin, Caspar, Sohn des Johann Balthasar Städelin, wurde geboren am 24. März 1665. Das Todesdatum ist unbekannt.

Er führte das Meisterzeichen Nr. 6 und 6 a mit den Initialen C B ST. Im Landeswappen ist das Kreuzchen in der linken obern Ecke. Es gibt zwei Varianten des Meisterzeichens mit verschiedenen Stellungen der Initialen; bei der zweiten ist das Kreuzchen in der rechten obern Ecke.

Gegenstände: Säulengiessfass, Höhe $32,5 \mathrm{~cm}$; Breite $17 \mathrm{~cm}$; Tiefe $10 \mathrm{~cm}$. Die Giesserzeichen befinden sich an der Vorderseite des hausdachartigen Deckels. Auf letzterm ist ein knaufartiger Griff angelötet, welcher in gleicher Wiederholung zu beiden Seiten des Giessfasses als Traggriff dient. (Tafel XXIV, 1.)

Stitze ohne Schnabel von 1/2 Maass Inhalt. Das Meisterzeichen ohne das Landeswappen befindet sich auf dem herzförmigen Deckel, Variante Nr. 6 a. Im Boden eine fünfteilige eingelötete Bodenrosette. Höhe $24,9 \mathrm{~cm}$ bis zum Deckelgriff; bis zum Kannenrande $21,2 \mathrm{~cm}$. Durchmesser des Fusses $11,2 \mathrm{~cm}$. (Tafel XXXIII, 4.)

Runde, tiefe Schüssel von 3o cm Durchmesser und 5,3 cm Tiefe. Die Marken befinden sich an der obern Seite des schmalen Randes und zwar das Meisterzeichen Nr. $6 a$ wie auf voriger Stitze und das Landeswappen (Kreuzchen in der rechten obern Ecke). An der gegenüberliegenden Seite des Randes findet man das Beschauzeichen von Uri mit der gravirten Jahrzahl 1735 (Variante des Beschauzeichens Nr. 4).

Städelin, Hans oder Hans Jakob, Zinngiesser; in Betracht kommen entweder Johann Städelin, geboren am 4. Mai 1666 oder Hans Jakob Städelin, gestorben 1726. Letzterer ist der wahrscheinlichere wegen einer datirten Breitrandplatte. Er führte das Meisterzeichen Nr. 5 (Bd. I). Der Wappengrund ist mit einer feinen, damastartigen Zeichnung ausgefüllt. Das Kreuzlein im Schwyzerwappen ist in der rechten obern Ecke.

Gegenstand: Grosse Breitrandplatte von $37,3 \mathrm{~cm}$ Durchmesser und 7,5 cm Randbreite. Auf dem Rande befindet sich ein etwas unbeholfen gravirtes Wappen zwischen der Jahrzahl 1710 .

Meister, H. S., Der Name konnte nicht eruirt werden; er ist ein unbedeutender Handwerker, von welchem nur schmalrandige Teller von 22,2 cm Durchmesser erhalten sind. Das Meisterzeichen Nr. $6 b$ resp. die Initialen sind mit dem Landeswappen vereinigt, in der Weise, dass sich im untern Teile des Schwyzerwappens (Kreuz in der rechten obern Ecke) die Initialen H. S. befinden. Die Meistermarke ist an der untern Seite des Tellerbodens angebracht. 
Gamba, Gottardo, ein fahrender Zinngiesser, hat viel im Lande Schwyz gearbeitet; er lebte, dem Stile seiner Arbeiten nach, Ende des XVIII. und Anfang des XIX. Jahrhunderts. Von Geburt war er wahrscheinlich ein Tessiner.

Er führte das Meisterzeichen Nr. $6 c$. Kein Schwyzer Wappen.

Gegenstände, welche in Schwyz aufgefunden wurden: Glockenkanne mit Bajonetverschluss von 1 Maass Inhalt. Auf dem Ausgussdeckelchen das Meisterzeichen Nr. 726. Keine Bodenrosette. Herzförmiger Schild mit den Initialen A M G ${ }_{18}$. Korpus glatt, nur zweimal je drei feine circuläre Linien. Um die Basis der Ausgussröhre spärliche Gravirung im Tremolirstich. Höhe $28,7 \mathrm{~cm}$. Durchmesser des Fusses 14,4 cm. (Tafel XXXIII, 14.)

Gewelltes Giessfass, 5 Wellen. Auf dem nach oben sich verjüngenden, ebenfalls fünffach gewellten Deckel und zu beiden Seiten als Handgriffe je eine dünnwandige, hinten concave Palmette. Am untern Rand des Giessfasses und am untern und obern Rand des Deckels je ein profilirtes Band. Oberhalb des Ausgusshahnens ein hohes, spitzes, reliefirtes Blatt. Höhe $35,2 \mathrm{~cm}$. Breite $24 \mathrm{~cm}$ (ohne die Handgriffe). Hinten unten am Deckel bei dem Exemplar im Kurhaus Bad Seewen die Meistermarke Nr. 726 . (Tafel XXIV, 7.) Messkännchen, becherförmig mit schnabelförmigem Ausguss. Auf dem Deckel je ein $\mathrm{V}$ (Vinum) und ein A (Aqua) gravirt. An der Innenseite des Deckels die Meistermarke Nr. 726. Fuss verhältnismässig sehr breit. Höhe 10,2 cm. Durchmesser des Fusses $6,8 \mathrm{~cm}$. Prismatische, sechsseitige Schraubkanne von 2 Maass Inhalt; ebenfalls die Meistermarke Nr. 726 . (Sammlung L. Gally, Basel.)

Der Eigentumstempel des Klosters Einsiedeln besteht in einer kreisförmigen Marke mit zwei Raben, Nr. $6 \partial$.

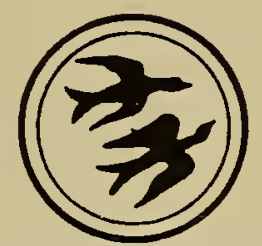

Kloster Einsiedeln

$6 \mathrm{~d}$

\section{URI}

Das Land Uri war zu allen Zeiten sehr arm an Kantengiessern. Seit dem Jahre ${ }_{1502}$ bestand in Altdorf eine Gesellschaft zum Regenbogen', welche später nach ihrem Schutzpatron auch Antonius-Bruderschaft genannt wurde. Die Einzelmitglieder hiess man "Antoniner". Aus einem Statut vom 17. Januar 1737 ergibt sich, dass diese Bruderschaft sich hauptsächlich aus Feuerarbeitern zusammensetzte. Als dieselben sich im Jahre $176_{2}$ als Zunft organisirten, wurden als zünftige Mitglieder genannt die "Feuerarbeiteren, Schlosser, Büchsenschmidt, Uhrenmacher, Windt- oder Löthmacher, Kupferschmidt, Huofschmidt, Waaffen- oder Hammerschmidt und Glasser, auch andere ehrliche Meister ».

Wichtige Aufschlüsse gibt auch das "Satzungsbuch" des Landrates von Uri. So findet sich eine Verordnung über das Gewerbe der Niedergelassenen oder Hintersässen vom Jahre 1553 und darin wird als Handwerk auch aufgezählt "Cantengiesser ». Im Militär-

${ }^{1}$ Sämtliche historischen Angahen entstammen den Mitleilnngen des Hochw. Herrn Dr. Eduard Wymann, Staatsarchivar in Altarf. 

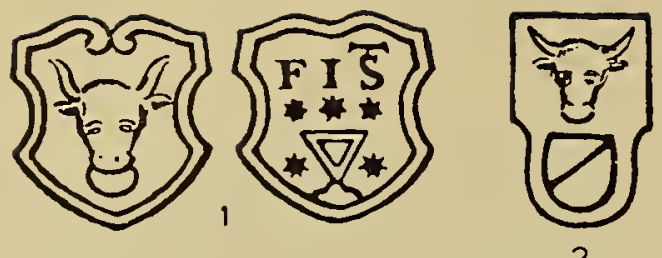

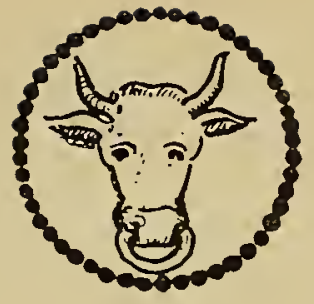

3

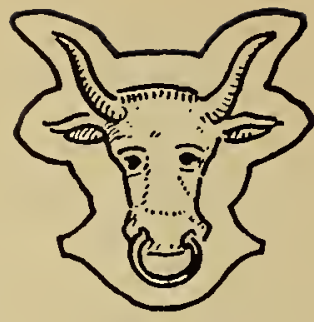

4

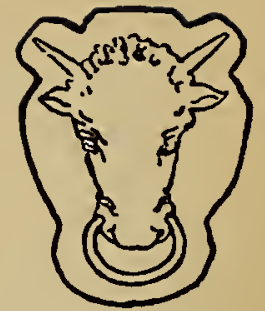

4 a

Rodel von 1596-1600 findet sich kein Kantengiesser. Dagegen steht im MilitärRodel von 1655 in der dritten Rotte unter den "Halbartenträgern " von Altdorf : "Meister Hans Kantengiesser ". Im obgenannten Satzungsbuch " ist Seite 149 eine Verordnung des Landrates vom 17. Januar 1668 , welche sich stellenweise auf ältere Ordnungen beruft und bezüglich der "Kantengüesser " verfügt: "Dessgleichen auch der Kantengüesser, die sollend guot Zürich-

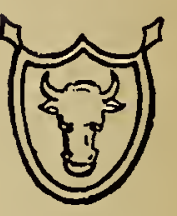

$4 \mathrm{t}$ prob machen und jeder sein Zeichen daruff schlagen, alldass by Vermydung meiner gnädigen Herren Straf und Ungnad und von grober Arbeit nit mehr dan $B 4$ vom \&, von fryer Arbeit aber $B 5$ nemmen mögen by GI. 5 Buoss ». Damit ist also auch für das Land Uri die Zürichprobe maassgebend und verbindlich, auch wenn es Mühe hält, fortwährend auch nur einen Zinngiesser nachzuweisen. In der Altdorfer Kirchenrechnung von 1669-1671 findet sich die Notiz : " den 3o. Meyen (1670) dem Kantengüesser zalt, dass er ein Zinis Meyenkrüglin glöttet Schilling 4 ". Damit ist also die Anwesenheit eines solchen Meisters nachgewiesen. In den Mitglieder-Verzeichnissen der St. Barbara-Bruderschaft zu Altdorf findet sich der Passus : 1676-1678 wurde aufgenommen : "Meister Baptista Krackh, der Kantengiesser ". Schon 1696 erscheint er nicht mehr unter den "Lebendigen ". Sub 1698-1700 wird wie oben aufgenommen "Frau Maria Salome Huntzigkerin, die Kantengiseri ". Unter 1700-1702 wurde in die St. Barbara-Bruderschaft aufgenommen "Johanna Mury dess Kanthengiessers seligen Dochter ». In den Totenlisten sind keine der Obigen zu finden, weil sie wohl auswärts gestorben sind. Im Urner Kriegsrodel von ${ }_{7} 55$ findet sich kein Kannengiesser.

Die Lebensdaten des Zinngiessermeisters Franz Josef Stadler ${ }^{2}$ sind einstweilen nicht eruirbar, doch weisen die erhaltenen Teller und Schüsseln auf die Mitte des XVIII. Jahrhunderts. Er führte das Meisterzeichen Nr. 1 (Bd. I).

Gegenstand: drei gewöhnliche, schmalrandige Teller von 22,5 cm Durchmesser und $3,2 \mathrm{~cm}$ Randbreite, mit den gravirten Initialen I. K. Z. - Zwei tiefe runde Gemüseschüsseln.

Es ist nun zweifellos, dass der Bedarf von Zinngeschirr jeder Art auf dem Handelswege gedeckt werden musste. Nach dem vorliegenden Material geschah dies besonders von Basel, Zürich, Zug und Luzern aus. Die mit den entsprechenden Meistermarken versehenen Gegenstände wurden in Altdorf controllirt und mit dem Urnerwappen und der Jahrzahl abgestempelt. Es bestand also eine amtliche Controlle. Auffallenderweise finden sich keine Kannen mit diesem Controllstempel, sondern blos Teller, Platten und Schüsseln. Es sind mir fünf verschiedene Urner Controllstempel durch die. Hände gegangen (Nr. 2, 3, 4, 4 a und $b, \mathrm{Bd}$. I). Er befindet sich immer zwischen der ersten und zweiten Hälfte der Jahrzahl.

Gegenstände: Runde Basler Gemüseschüsseln von Niklaus Uebelin und Emanuel Scholer mit den eingeschlagenen Jahrzahlen 1754, $1762,177^{8}$ und dem Controllstempel Nr. 4 (Bd. I).

Grosse Schwyzer Schüssel von 3o cm Durchmesser und $5,3 \mathrm{~cm}$ Tiefe, des Meisters Caspar Johann Balthasar Städelin; die Jahrzahl 1735 ist eingravirt neben dem Stempel Nr. $4 a$. - Auf einem Zürcher Teller des Meisters Hans Jakob Bosshart befindet sich ein neuer Controllstempel im Empire-Stile, Nr. 4 b. - Auf einem Giessfass des Meisters A. Petermann von Beromünster figurirt der Stempel Nr. 2 (Bd. I und II). (Tafel XXIV, 8.)

1 Urner Neujahrsblatt 1907. S. 15 und 22.

* Urner Neujahrsblatt 1916 . S. 14 . 


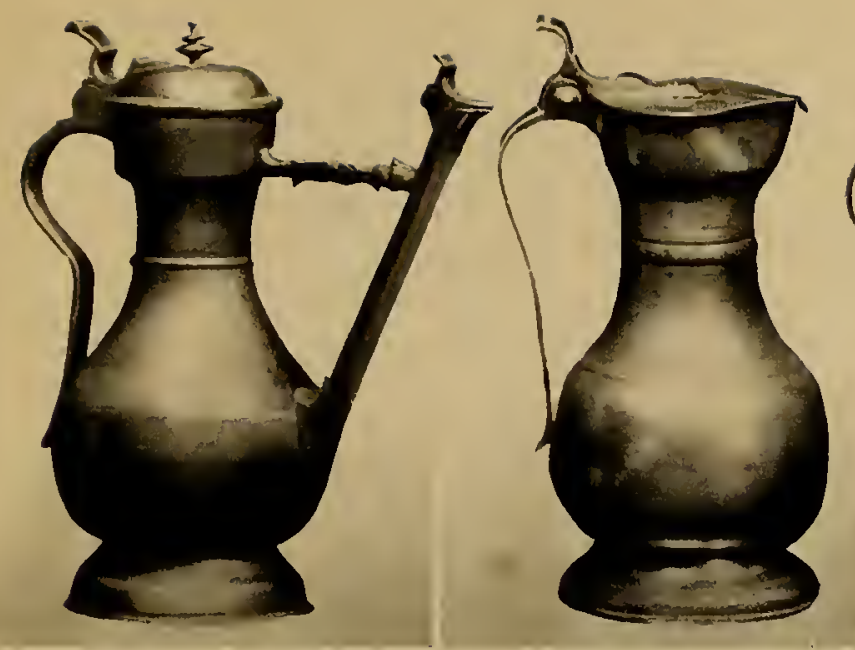

2

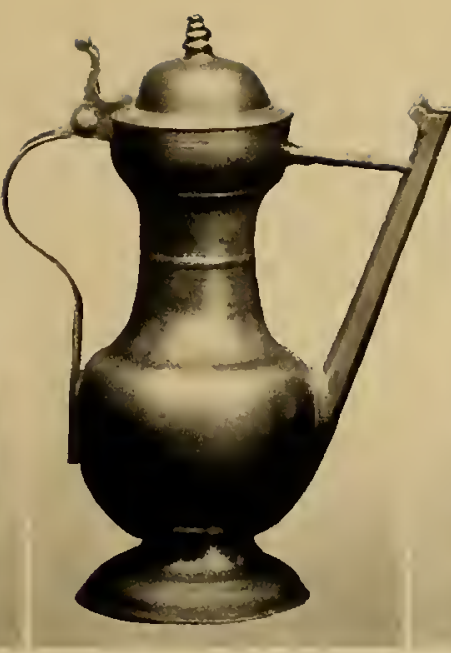

3

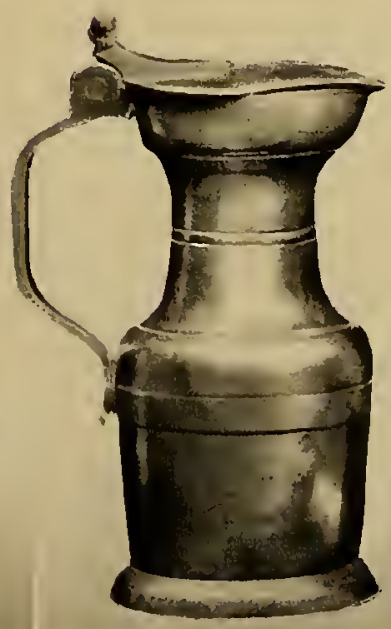

7

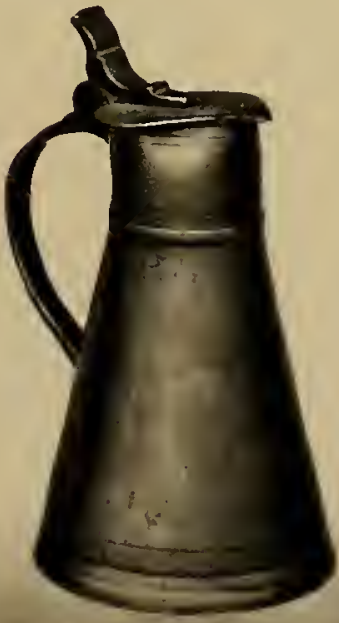

11

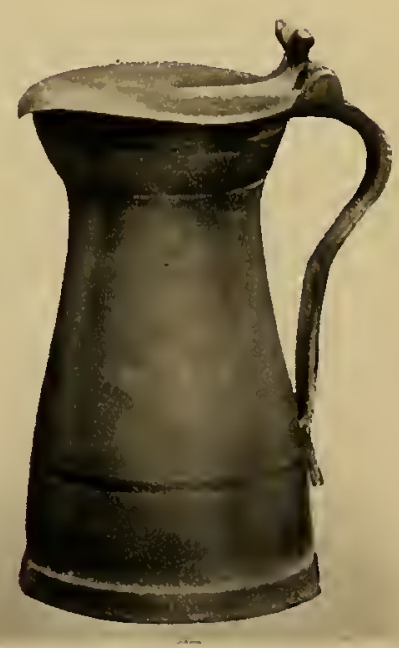

8

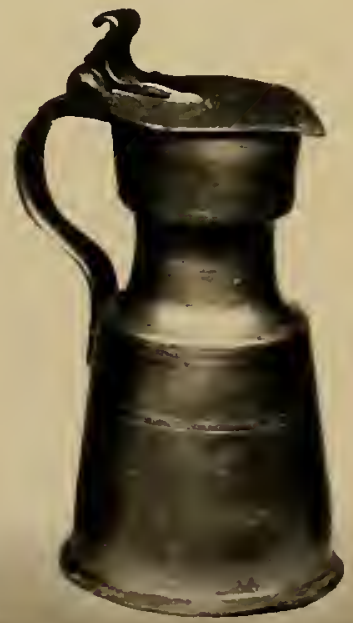

12

Kannentypen: 1, 2. Berner Stegkannen Typ 1 und Typ II. 3. Stegkanne von Vevey 4. Stegkanne von Lausanne. 5, 9, 10. Genf, Waadt, Wallis Typ 1. 6, 7. Typ II. 8. Typ III. 11, 12. Neuenburger Kannen. 

Auch fanden sich im Lande Uri, als dem Durchgang nach Italien, zahlreiche wandernde Zinngiesser ein, sogenannte "Fecker ", "Galangger ", auch Kesselflicker, Spengler, welche auf offener Strasse ihre Gewerbe betrieben. Sie machten nicht nur Gelegenheits-Reparaturen, sondern auch neue Gegenstände, besonders kleinere Stücke wie z. B. Weihwasserkesselchen, kleine Teller, Schüsselchen, Ohrenschüsseln. Meistens besassen diese Art Giesser keine Meistermarken; es kommen aber auch Ausnahmen vor wie z. B. Gottardo Gamba, dessen Erzeugnisse allerdings eine gute Qualität besitzen und den Vergleich mit den Produkten zünftiger Meister aushalten. Er führte das Meisterzeichen $\mathrm{Nr} .6 c$.

\section{NIDWALDEN}

Alle Zinngegenstände, besonders Kannen, sind ziemlich selten zu finden. Die Arbeit und Qualität des Materiales lassen fast immer sehr zu wünschen übrig. Oft findet man flache, niedrige Zinnteller, welche ausserordentlich stark bleihaltig sind. Die alten Landbücher enthalten keine Vorschriften über die Zusammensetzung des Zinnes. Nur zwei Zinngiesser sind urkundlich nachweisbar. "Am 21. Dezember 1763 sind von der Dorfleuten-Gemeinde von Stans dem Kantengiesser Jos. oder Jost Waser das Dorfrecht nach neuem Artikel um ein Lagel Wein verehrt " (Dorfleuten-Protokoll Stans '). Im Verzeichnis von ${ }_{1768}$ sind mit Obigem als Dorfleute eingetragen dessen Vater Franz Remigi Waser und sein zweiter Sohn Franz Josef. Alle stammen von Wolfenschiessen.

Franz Remigi Waser, zitirt 1768, führte die Meistermarke Nr. 7 (Bd. I) und $7 b$ mit den Initialen F. R. W. neben dem Einhorn. Oft bringt er nur die Initialenmarke der Nr. 7 an und $a b$ und zu auch nur das Landeswappen der $\mathrm{Nr} .7$.

Gegenstände: Runde, schmalrandige Teller und Platten aller Grössen. Letztere tragen oft nur die Initialenmarke; die kleinen Teller 2 oft nur das Landeswappen, den Doppelschlüssel $(7 a)$. In Buochs befindet sich in einem Buffet ein Giessfass mit der Meistermarke Nr. 7 und ebenso in einer Privatsammlung in Genf (Prof. R. Weber).

Jos oder Jost Waser, Kantengiesser von Wolfenschiessen, seit ${ }_{17} 63$ Mitglied der Dorfleute in Stans.

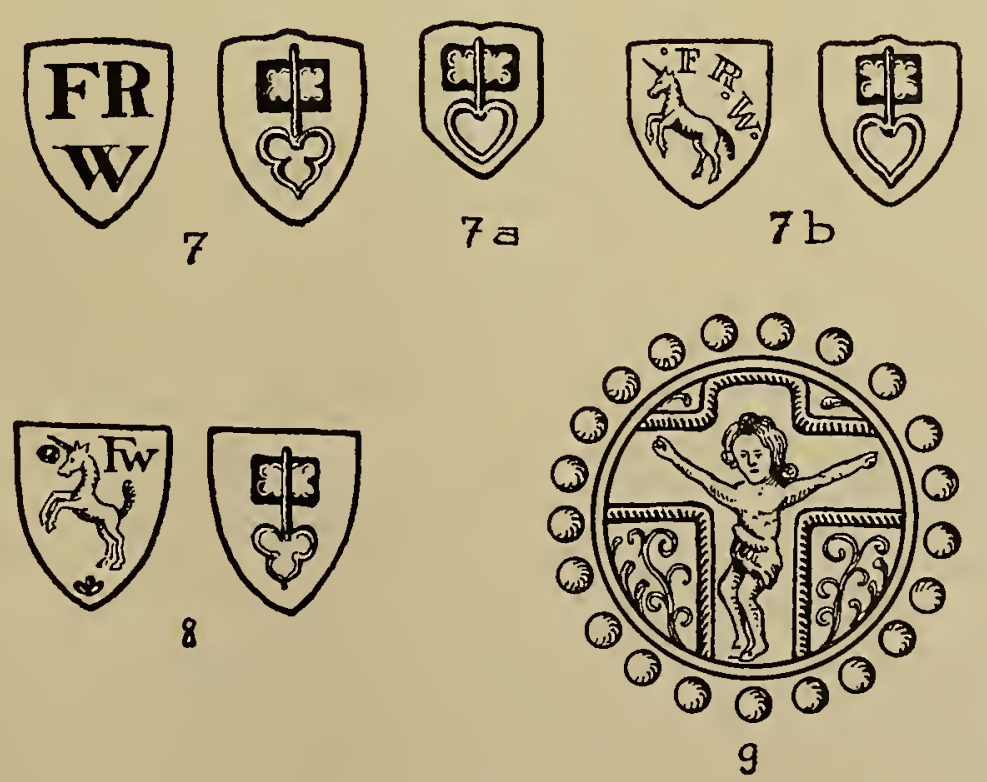

'Mitteilung von Herrn Staatsarchivar Dr. R. Durrer in Stans.

2 Sammlung von Herrn Josef v. Flüe, Sachseln. 
Gegenstände: Stitze, massives Stück. Höhe bis zum Rande $13,4 \mathrm{~cm}$, bis zum Deckelgriff $16,7 \mathrm{~cm}$. Durchmesser des Fusses 10,6 cm. Auf dem Deckel befinden sich die gleich angeordneten, circulären Wülste wie bei den Stitzen des ersten Gloggner von Luzern. Im Kannenboden ist die Plaquette Nr. 9 (Bd. I und II) eingesetzt. Am untern Ende des Traghenkels ist eine reliefirte Maske angebracht. Auf der Mitte des Deckels ist die Meistermarke Nr. 8 eingeschlagen; die Initialen lauten aber I W und nicht F W. (Tafel XXXIII, 1.) In der Sammlung von Dr. Etlin, Sarnen, befindet sich eine prächtige, reliefirte Strassburger Wöchnerinnen-S chüssel, auf welche J. Waser einfach seine Zinngiessermarke eingeschlagen hat.

Runde Teller und Platten in verschiedener Grösse.

\section{OBWALDEN}

Die Obwaldner Landbücher enthalten keine Bestimmungen über das Zinngiessergewerbe, auch nicht über die Zusammensetzung der Zinn-Blei-Legirung. Wahrscheinlich waren es anfänglich nur fahrende Giesser, welche das spärlich bevölkerte Land mit Zinngeschirr versorgten. Der bekannte Lokalhistoriker Pfarrhelfer Anton Küchler befasste sich in einer Abhandlung im Obwaldner Volksfreund, 1883, Nr. 21, mit den einheimischen Zinngiessern. Ohne Quellenangabe meldet er, dass im Jahre ${ }_{1634}$ die Melchtaler Schützen bei einem Zinngiesser Hans Beret Platten giessen liessen. Aus dem Jahre 1645 stammt ein Zitat, nach welchem die 24 Platten, welche bisher alle in Sarnen verschossen wurden, auf sämtliche Gemeinden zu verteilen seien. Es ist bisher noch niemals ein Schützenteller mit dem Obwaldner Stempel gefunden worden. Weiter erwähnt Herr Küchler aus dem Jahre 1655 einen Zinngiesser Hans Bucher und aus dem Jahre 1695 einen Franz Blasi aus Freiburg. Von allen bis anhin erwähnten Zinngiessern kennt man weder Gegenstände noch Meisterzeichen '.

Etli, Hans Josef, im Stammbaum ${ }^{2}$ ausdrücklich als Zinngiesser bezeichnet, wurde im Jahre 1721 im Hause seines Vaters Peter Anton Etli in der Hofur geboren. Schon im Jahre 1749 ist er als tätiger Zinngiesser in Kerns nachzuweisen. Der Flüelikastenvogt rückvergütet in diesem Jahre an den Ranftsigrist 2 Gl. 31 Sch. und 3 A., welche Summe derselbe an den Kannengiesser Etli wegen eines neuangefertigten Giessfasses in die Sakristei und für einen angeschafften Weihwasser-Wadel zusammen ausgelegt hatte.

Meister Hans Josef Etli war ein ausgezeichneter Fachmann; Küchler berichtet, dass er "Fremde " gemacht habe. Wahrscheinlich war er im Bernerbiet; denn man findet unter seinen Erzeugnissen, ausser den üblichen Stitzen und Glockenkannen auch hübsche Kannen in Bernerformen, oft sogar mit Steg und langer Ausgussröhre. Die gravirten Stücke sind oft gekennzeichnet durch sehr geschickt angebrachte "Tremolirstich 》-Zeichnungen. Eine weitere, für ihn charakteristische Eigenart an den Kannen sind die breiten, bandförmigen Rillen, welche sich am Kannenleib und auf dem Deckel der Bernerformen finden. Auch bei den Stitzen ist in der Mitte des Deckels ein gleichgebildetes Nabelstück.

Das Todesdatum Hans Josef Etli's ist unbekannt. Er führte sechs verschiedene Meistermarken, Nr. 11-11e (Bd. II). Die älteste Marke mit den Initialen H. I. E. findet sich auf Kannen in Bernerform und ist als Nr. 605 unter die Solothurner Marken geraten, Nr. 11 (Bd. II) Eine andere ebenfalls auf Kannen in Bernerform befindliche Marke ist als Nr. 543 unter den Bernergiessern angeführt. Ausserdem führte der Meister noch vier verschiedene Engelmarken (Nr. 11 und 11 b), von welchen zwei den voll ausgeschriebenen Namen Josef Etli und zwei die Initialen I E tragen.

' Bruderklausen-Kalender für das Jahr 1923. S. 58. Josef v. Flüe : Einbeimische Zinngiesser in Unterwalden.

2 Stammbaum der Familien Ettlin im Gemeindearchiv Kerns. 


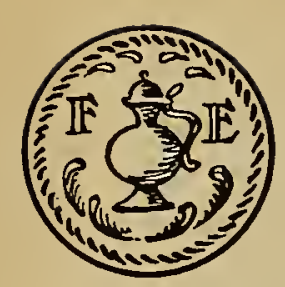

10



11

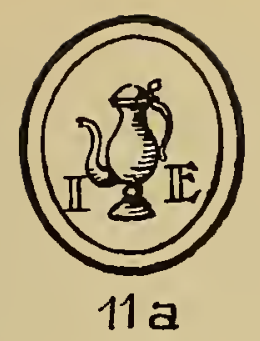

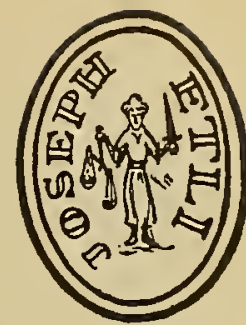

$11 \mathrm{~b}$
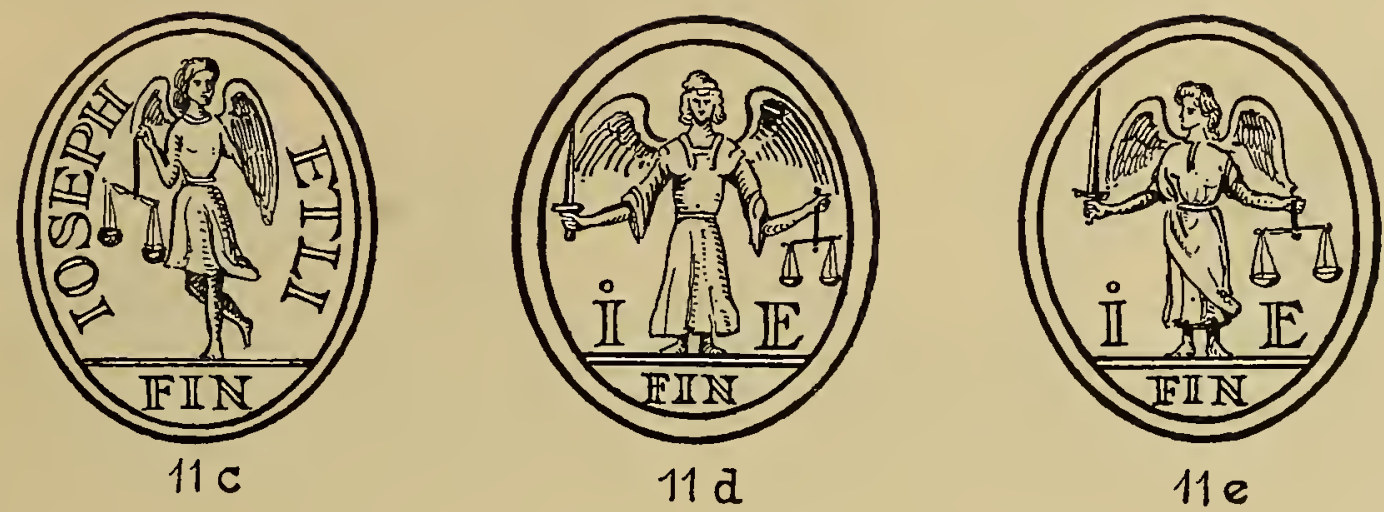

Gegenstände: Stitze ohne Schnabel von 1 Maass Inhalt. An der Spitze des Deckels das Meisterzeichen Nr. 11. Am Korpus circuläre Rillen, ferner die Initialen DV.AV. 1745. Im Boden fünfteilige Rosette. Höhe 31,5 cm; Durchmesser des Fusses 13,6 cm. (Tafel XXXIII, 11.) - Kannen in Bernerform ohne Steg von 1, 1/2 und 1/4 Maass Inhalt mit Tremolirstich-Gravur, ebenfalls mit der Marke Nr. 11. (Tafel XXXIII, 2,15.) - Giessfass im Gasthaus zum "Rössli " in Kerns und Lavaboschüssel mit der Jahrzahl ${ }_{1767}$ im Museum von Sarnen, ebenfalls Marke Nr. 11.

Gegenstände mit der Marke I E Nr. 543 (Bd. I), Nr. 11 a (Bd. II) : 1 Maass-Kanne in der Form der Berner Stegkanne. Als Deckelknopf eine Eichel. Meisterzeichen auf dem Deckelchen der Ausgussröhre. Als Steg ein Mannsarm im Puffärmerl. Höhe $33,5 \mathrm{~cm}$. (Tafel XXXIII, 13.) - 1/2 Maasskanne ohne Steg in Bernerform; Höhe 22,5 cm. Glockenka nne von 2 Maass Inhalt. (Sammlung J. v. Flüe, Kerns.) - Stitze von $1 / 2$ Maass Inhalt. - Ovale geschlagene Messkännchen-Platte. - Runde schmalrandige Platten und Teller, welche oft sehr stark bleihaltig sind.

Die Engelmarken findet man auf Tellern und Platten aus gutem oder ganz feinem Zinn, indem der Engel auch als Qualitätszeichen gilt.

Etli, Franz Xaver, wahrscheinlich der Sohn des vorigen Hans Josef Etli, der viele Kinder hatte. Ein Sohn hiess Franz Xaver und war im Jahre ${ }_{17} 56$ geboren. Er starb 1825. Sein im Stammbuch angeführter Beruf lautet nicht auf Zinngiesser, sondern auf Glaser. Allein infolge der vielen bleiverglasten Fenster, "Butzenfenster ", grenzten die beiden Berufe nahe aneinander, besonders auf dem Lande, wo die verschiedenen Berufe sich oft mit einander vermischen.

Er führte die Meistermarke Nr. 10 (Bd. I und II).

Gegenstände: Glockenkannen mit Bajonetverschluss von 2 und 1 Maass Inhalt. Sie haben weder Schild noch Bodenrosetten. (Tafel XXXIII, 10, 12.) Die Stitzen ohne Schnabel von $1 / 2$ Maass Inhalt haben ebenso wie die Glockenkannen am Fusse einen kräftigen, halbrunden Stab. (Tafel XXXIII, 9.) Ferner findet man tiefe runde Gemüseschüsseln und Teller aller Art. 
Die Obwaldner Zinngegenstände sind ziemlich häufig und zwar von beiden Etli. Auch habe ich den Eindruck, dass beide Giesser selbstständig gearbeitet haben und nur auf selbstgegossene Arbeiten ihre Meistermarken aufgeschlagen haben, im Gegensatz zu den beiden Waser von Stans. Die Zinnkannen haben als Eigentümlichkeit den Profilstab am Fusse, eine Eigenschaft, welche wir bei den gleichen Kannen der umgebenden Orte nicht finden. Tadelnswert ist der hohe Bleigehalt vieler Zinngegenstände, besonders der Teller. Hier macht sich das Fehlen einer amtlichen Controlle deutlich bemerkbar.

Ausser den ortsansässigen Zinngiessern kamen häufig die fahrenden Zinngiesser ins Land und konnten umso freier schalten, da die Obrigkeit keine Verordnungen erliess. Die meisten kamen aus italienischen Gegenden (Tessin oder Italien).

\section{GLARUS}

Glarner Zinngegenstände gehören zu den Seltenheiten sowohl in den öffentlichen wie in den privaten Sammlungen. In vielen Fällen wurden dieselben nicht als solche erkannt, weil es verschiedene Zinnstempel mit einer kleinen Mannsfigur gibt, welche als St. Fridolin gedeutet werden könnte. Als weiterer erschwerender Umstand kommt noch hinzu, dass die Stempelschneider oft nicht das Spiegelbild des Wappens ins Eisen schnitten, sondern das richtige positive Wappen. Infolgedessen ist natürlich der Abruck auf dem Zinngegenstand spiegelverkehrt. Nur die Uebereinstimmung des Landeswappens mit dem Familienwappen des Giessers gibt einwandfreie Resultate.

Das Zinngiesserhandwerk gelangte im Lande Glarus niemals zu einer grössern Blüte. Einmal war das Absatzgebiet ein kleines und dann fehlte dem Gewerbe der mächtige Schutz des Zunftwesens. Infolgedessen war dem Import aus den umliegenden Zinngiesser-Centren Zürich, St. Gallen und Chur Tür und Tor offen. Den regen commerziellen Beziehungen mit diesen Städten entsprach ein grosser persönlicher Verkehr. Die heimkehrenden Kaufleute brachten schöne Giessfässer, Kannen und Platten als Geschenke nach Hause. Daraus erklärt sich ohne weiteres das überwiegende Vorkommen fremden Zinnes im Lande Glarus, besonders zürcherischer und ostschweizerischer Zinnsachen. Die glarnerischen Zinngiesser betrieben darum ihr Handwerk oft als Nebenberuf, gerade wie auch an andern kleinen Orten, z. B. in Zug, Zofingen, u.s.w.

\section{Die Zinngiesser ${ }^{1}$}

Ruch, Balthasar, ist 1563 in Basel in der Lehre bei Asimus Barthander.

Weiss, Hans, Kannengiessermeister in Glarus, genannt Fähnrich Caspar's Sohn. Er wurde am 17. Februar 1643 geboren und starb am 15. Oktober 1693. Sein Meisterzeichen ist Nr. $53 a$ und $h$. (Bd. II).

Gegenstand: Breitrandteller von $25 \mathrm{~cm}$ Durchmesser und 6,7 cm Randbreite. Am Rande fein gravirtes Dinnerwappen mit den Initialen HH. D. (Tafel XXVI, 9.)

Breitrandteller mit dem gleichen Meisterzeichen, aber in ovaler Einfassung, Nr. $53 b$ (Variante von Nr. 53 a).

Spälti, I Hans Jakob, Kannengiesser, von Netstal, dann Bürger von Glarus. Er wurde am 15. November 1664 geboren, kaufte sich in Glarus 1687 als Bürger ein und starb am 17. August 1690 . Er führte das Meisterzeichen Nr. 49 a. (Bd. II).

'Glarner Genealogien von J. J. Kubly-Müller.

Die Kunst im Glarnerland von Dr. Ernst Buss. 1920. S. $12,15$.

Mitteilungen van Herrn Pfarrer Paul Thürer, Kantonsarchivar J. Frey und Dr. Gottfried Heer in Hätzingeo. 

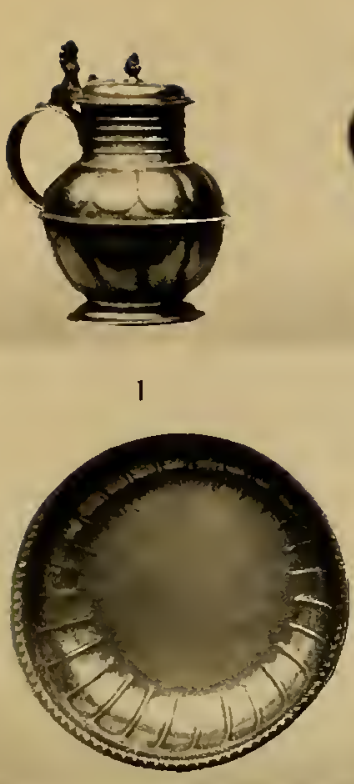

6

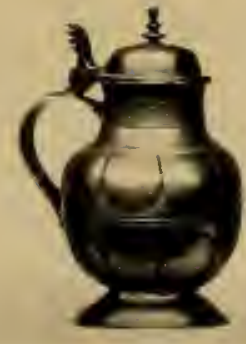

2

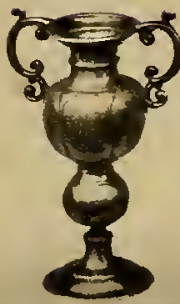

7

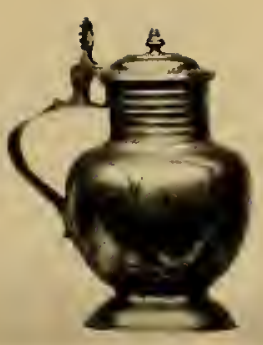

3

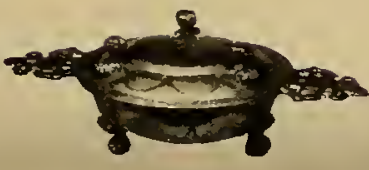

10


4

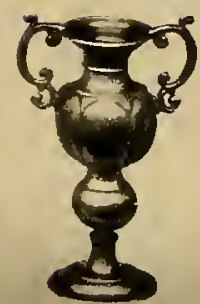

8

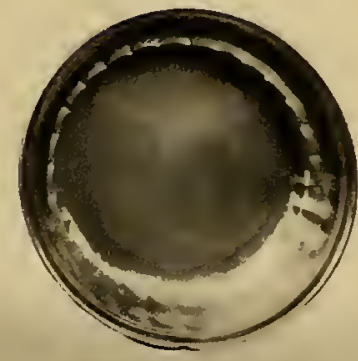

9
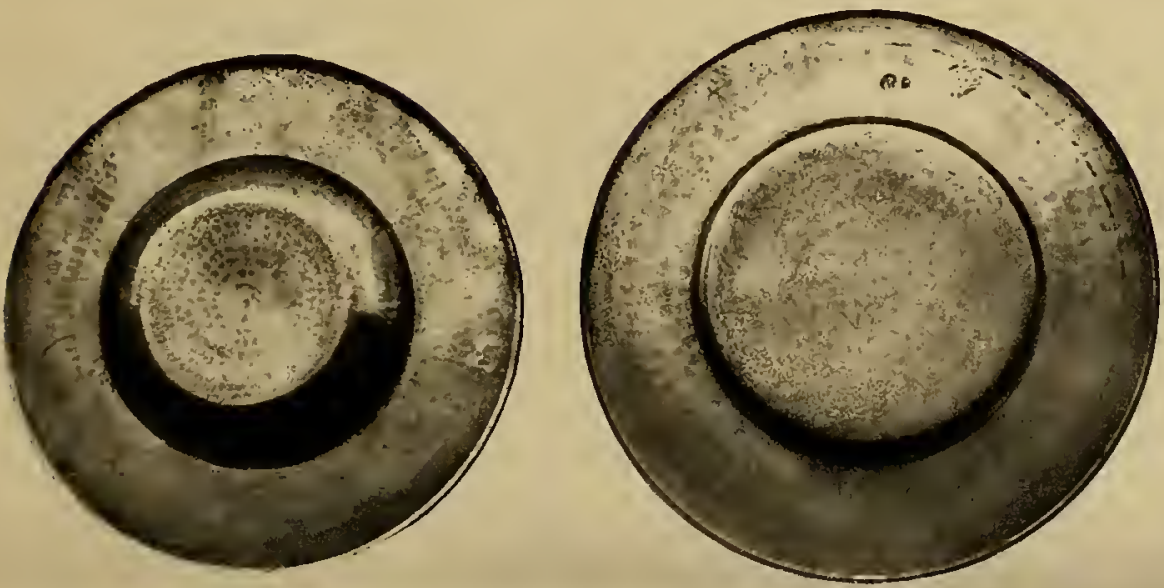

12

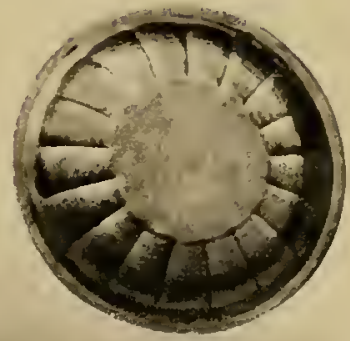

11

13



15



16

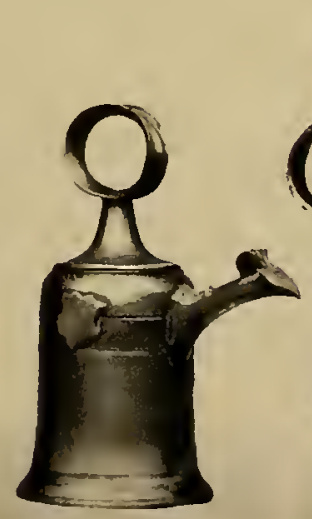

17

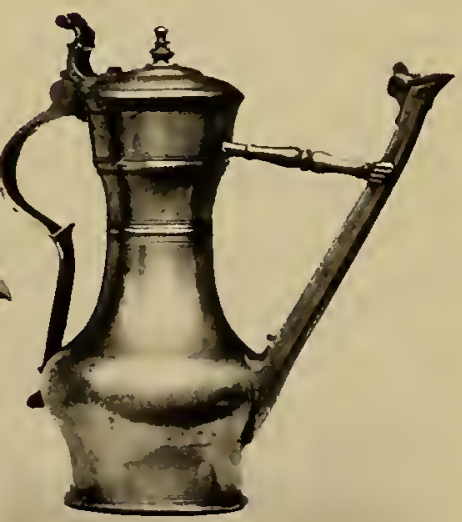

18

1-5. Kugelkrüge von Basel, Brugg, Zolingen und St. Gallen. 6-10. Getriebenes Zinngeschirr (étain bosselé oder repoussé). 11-13. Geschlagenes Zinogeschirr (étain forgé). 14-17. Glarner Gebrauchs-Zinnkannen, 18. Sehr seltene Zürcher Stegkanne in Ulmer Form. Meisterwerk des Zürcher Zinngiessers Hans Jakob Steiner (1671 zünftig). 


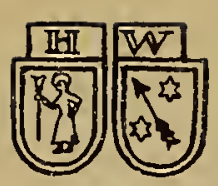

53 a

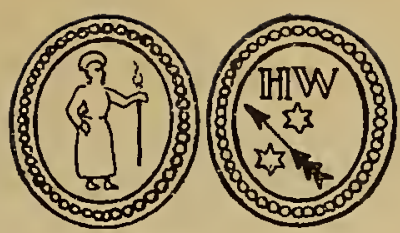

$53 \mathrm{~b}$

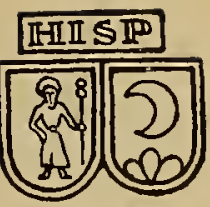

49 a

Gegenstände: Glockenkannen von 1 und 1/2 Maass Inhalt. Bajonetverschluss. Mit Schild. Bodenrosette Nr. 66 (Bd. I).

Spälti, II Hans Jakob, der Sohn des Vorigen, von Netstal und Glarus. Er wurde am 11. Februar 1690 geboren und starb am 11. Januar 1766. Er führte das gleiche Meisterzeichen wie sein Vater, also Nr. 49 a (Bd. II).

Gegenstände: Glockenkannen von 1 und $1 / 2$ Maass Inhalt. Bajonetverschluss. Mit Schild. Bodenrosette Nr. 66 (Bd. I).

Spälti, Heinrich, Zinngiessermeister, der Sohn des Vorigen. Er wurde am I. September 1729 geboren und starb ohne Nachkommen am 10. Oktober 1794. Er führte das Meisterzeichen Nr. 496 (Bd. I).

Gegenstände: Glockenkannen von 1 Maass Inhalt, mit Bajonetverschluss.

Dinner, Tinner, Issak, Zinn- und Kantengiesser, von Glarus, wurde am 5. August 1683 geboren und starb am 4. November 1734 als Wachtmeister zu Alessandria in königlich sardinischem Diensten.

Er führte die Meistermarke Nr. 48. Bodenrosette Nr. 65.

Gegenstand: Glockenkanne mit Bajonetverschluss im historischen Museum vonBasel.

Streiff, Hans Heinrich, Zinngiessermeister von Glarus. Er wurde am 13. Juli i 67 1 geboren, wurde im Jahre 1696 bevogtigt und starb am 28 . Januar 1730.

Meisterzeichen und Gegenstände von ihm sind nicht bekannt.

Streiff, Fridolin, Zinngiesser, später Tuchschärer, der Sohn des Vorigen. Er wurde im Jahre 1717 geboren und starb am 9. Juni 1751 .

Er führte das Meisterzeichen Nr. 50 .

Gegenstand: Glockenkanne mit Schraubenverschluss von 1 Maass Inhalt. Marke Nr. 5o auf dem Ausgussdeckelchen. Bodenrosette Nr. 66. Auf dem Schild die gravirten Initialen C. W. Höhe $32 \mathrm{~cm}$. (Tafel XVIII, 15.)

Streiff, Herkules, der Sohn des Vorigen, war vielleicht auch Zinngiesser. Er wurde am 12. Juni 1726 geboren und starb am 1. Dezember 1781 .

Marti, Johannes, Zinngiessermeister von Glarus, war am 7. Januar 1739 geboren. Laut Zunftbuch 1750 , Chur, war er im Jahre ${ }_{1754}$ bei Josef Ulrich Bauer in Chur in der Lehre. Er starb am 11. Juni 1801 .

Er führte das Meisterzeichen Nr. 52. Bodenrosette Nr. 68.

Gegenstände: Glockenkanne mit Bajonetverschluss von I Maass Inhalt. Marke Nr. 52 auf dem Ausgussdeckelchen. Rosette Nr. 68. Auf dem Schild die gravirten Initialen H. I. Höhe $30 \mathrm{~cm}$. (Tafel XVIII, 16.)

Gleiche Glockenkanne von $1 / 2$ Maass Inhalt. (Tafel XVIII, 17.) - Schmalrandteller.

Zweifel David, Zinngiessermeister und Wirt in Glarus, wurde am 9. Juli ${ }_{17} 67$ geboren und starb am 2o. Oktober 1818 .

Er führte das Meisterzeichen Nr. 51. Bodenrosette Nr. 67 .

Gegenstände : Kleine Stitze ohne Schnabel von $1 / 4$ Maass Inhalt. Meisterzeichen vorn am herzförmigen Deckel. Am Korpus und auf dem Deckel circuläre Rillen. Auf dem Deckel Etagenknopf. Höhe $16 \mathrm{~cm}$. (Tafel XVIII, 14.)

Gupfteller von 26,8 cm Durchmesser, Randbreite $6 \mathrm{~cm}$; Tiefe $4 \mathrm{~cm}$. Marker Nr. 51 oben am Rande. Gravirte Initialen H. I. H. und C.S. (Tafel XXVI, 6.) 
Die bekannt gewordenen Zinngegenstände bestehen also aus Stitzen, Glockenkannen, Breitrandtellern, Gupfplatten und gewöhnlichen schmalrandigen Tellern. Dieselben haben keine für Glarus besondere Form. Sie lehnen sich an die Typen der Umgebung an. Nur das Meisterzeichen mit dem Landeswappen zusammen bestimmt die Herkunft des Gegenstandes. Bis heute sind nur von acht Zinngiessern Gegenstände bekannt. Dabei erwähne ich noch speziell ein Giessfass. Die Glockenkannen haben als Grundform den zürcherischen Typus, während der Aufbau des Tragringes St. Galler Merkmale aufweist. Die technische Ausführung und die Qualität des Zinnes ist ziemlich gut; es sind fachgemäss hergestellte Erzeugnisse eines bodenständigen Handwerks.

\section{GRAUBÜNDEN}

\section{CHUR}

Als Giesserort kommt einzig Chur in Betracht. Die Zinn- und Kantengiesser gehörten zur Zunft der Schmiede. Die Zunftordnung entspricht ziemlich genau derjenigen Zürichs und wurde sehr genau eingehalten. Es gab nur fünf Zünfte. Leider enthalten die Zunftrodel keine Geburtsdaten; auch das Todesjahr ist nur selten angegeben und oft fehlt sogar die Angabe des ausgeübten Handwerks. Wir sind somit für die Zinngiesser nur auf die "Auf- und Abdingbücher " angewiesen, welche bei der Schmiedenzunft bis zum Jahre 1625 zurückreichen.

Die Zünfte ${ }^{\prime}$ bestehen in Chur seit dem Jahre 1464 , gemäss einem Diplom Kaiser Friedrichs III vom 24. April 1464. Bürgermeister, Rat und Bürger stellten am 17. Januar 1465 die erste Zunftverfassung auf. Lehr- und Wanderzeit waren genau bestimmt, ebenso die Erwerbung der Meisterschaft. Der Lehrling wurde als Glied der Familie betrachtet. Diese Bestimmungen galten bis zur Helvetik. Am 19. Oktober $179^{8}$ erliess die helvetische Regierung die Verordnung : "In Erwägung, dass der Zunft- und Innungszwang der Handels- und Gewerbefreiheit entgegen sei, sollen alle Gewerbe und Zweige der Industrie in Helvetien frei und aller bisheriger Zunftzwang gegen dieselben aufgehoben sein ". In Anbetracht des ausserordentlich conservativen und zähen Charakters der Bündner, muss man sich nicht verwundern, wenn es volle fünfzig Jahre gedauert hat, bis diese Verfügung volle Geltung erreichte. Das Ziel wurde nicht blos durch Verhandlungen sondern durch Gewaltanwendung erstrebt.

Die bei den einzelnen Zinngiessern angegebenen Daten stammen aus den Auf- und Abdingbüchern der Schmiedenzunft?

\section{$\mathrm{D}_{\text {ie }} Z_{\text {inngiesser }}$}

Castelmur, G., arbeitete in Chur vor 1625 und ist in den Auf- und Abdingbüchern nicht enthalten. Er führte das Meisterzeichen Nr. 340, welches sich auf einem Breitrandteller befindet. (Ehemalige Sammlung Manfred Dürr in Burgdorf.)

Im historischen Museum von Basel befindet sich eine stitzenförmige Kanne mit langer Ausgussröhre. Darauf das Meisterzeichen G. C. in ovaler Fassung mit dem dreitürmigen Torbogen der Castelmur.

Hempel, I Ghristoffel, Zunftbuch Jahr ?

Lehrknaben : 1625, nicht leserlicher Namen; 1627, Christ Andreas; 1634, Mengotti Peter von Poschiavo; 1643, Cadenat de, Hertli.

\footnotetext{
1 Der Kampf der Churer um die Gewerbefreibeit, ron Dr. Fritz ron Jecklin, Stadtarchivar. Chur 1917.

2 a Auf- und Abdingbücher $>$ der Churer Sehmiedenzunft, Mitteilungen ron Herrn Dr. Fritz von Jecklin, Stadtarehivar in Chur.
} 
Hempel, II Christoph, ${ }^{\sigma}$ führte das Meisterzeichen Nr. 3 fo a (Bd. II); Zunftbuch, Jahr ${ }_{16} 65$ als Eintritt in die Zunft. Lehrknabe: 1684, Mengotti Anton von

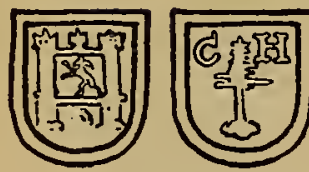

340 a Poschiavo.

Gegenstand: Sechsseitige, prismatische Quartkanne im historischen Museum zu Chur. Auf dem Schild die Jahrzahl 1682. Höhe $38,5 \mathrm{~cm}$. Auf dem Deckelchen der Ausgussröhre das Meisterzeichen : C. H. mit einer Tanne, Nr. $340 a$.

Schmid von Grüneck, Vincenz; Zunftbuch, Jahr $16_{70}$, als Eintritt in die Zunft. Lehrknabe : 1681, Kubli, Luzi, de Friederich.

Harnist, Johannes oder Hans, wurde am 18. November 1623 geboren und war verheiratet mit Ursula Christ; er starb am 18. Dezember 1693.

Er führte das Meisterzeichen Nr. 341 .

Gegenstand: Breitrandplatte von $31 \mathrm{~cm}$ Durchmesser und $6,5 \mathrm{~cm}$ Randbreite.

Harnist, Otto, Sohn des vorigen Johannes, wurde im April 1658 geboren und starb am 2. Juli 1703. Er war als Lehrling in Basel bei Jakob Christoffel Beck während der Jahre 1672${ }_{1675}$ (vgl. Verzeichnis der Hausgenossenzunft in Basel). Er war mit Elsbeth Polet 1 verheiratet. Neben seinem Kantengiesserberufe war er auch noch Baumeister. Zunftbuch, Jahr 1684 als Eintrittsjahr.

Lehrknaben : 1687, Hemmi, Johannes, de Samuel; 1697, Walser, Johannes, de Christian. Er führte das Meisterzeichen Nr. 342 .

Gegenstand: Breitrandteller von $25 \mathrm{~cm}$ Durchmesser und 6,2 cm Randbreite. Marke an der Unterseite des gehämmerten Tellers. An der Oberseite des Randes eingravirtes Wappen mit einem Adler als Helmzier. In der obern Hälfte des Wappens befindet sich eine schräg gestellte zweizipflige Fahne; in der untern Hälfte drei Schrägbalken. (Tafel XXVI, 8.)

Walser, Johannes, Kantengiesser, lernte 1697 bei Otto Harnist in Chur. Zunftbuch, Jahr 1702. Lehrknabe : 1724, Heim, Martin, de Zunftmeister Daniel Heim.

Er führte das Meisterzeichen Nr. 343. In den Kannen (Stitzen) findet sich die Bodenrosette Nr. 365.

Gegenstände : 1 Maass-Stitze ohne Schnabel. Deckelmitte kegelförmig zugespitzt. Vorn am Deckel das Meisterzeichen Nr. 343. Daneben eingeschlagen R 5o. Vorn am Kannenleib ein gravirter Kranz, darin die Jahrzahl 1704 und die Initialen B G. Bodenrosette Nr. 365. Höhe $28 \mathrm{~cm}$. (Tafel XXXIV, 3.)

Glockenkanne von $1 / 2$ Maass Inhalt mit Schraubenverschluss. Marke 343 und F auf dem Schraubdeckel. Auf dem Schild die Initialen I. G. und Hauszeichen. Bodenrosette undeutlich. Höhe 27,5 cm.

Sechsseitig prismatische Kanne mit "Cadenatschild " und Jahrzahl 1725, ist abgebildet bei Naef, Tafel XXI, Nr. 3.

Oehri, Paul, lernte 1723 bei Herkules de Cadenat (Zunftbuch 1723). Im Zunftbuch, Jahr 1728, ist er zitirt im Jahre 1754 bei einer Ledigsprechung und ${ }_{17} 5_{7}$ bei einer Aufdingung. Bei ihm lernte bis 1743 Martin Heyd. Er führte das Meisterzeichen Nr. 344; auf Breitrandplatte. (Sammlung Hirsbrunner in Luzern.)

Ludwig, Mathaens, tritt 1736 in die Schmiedenzunft. Lehrknabe : ${ }^{1739}$, Heyd, Martin, de Balthasar sel. von Ulm; lernt aber bei Paul Oehri aus 1743 (siehe beim Vorgehenden). Er führte das Meisterzeichen Nr. 345.

de Cadenath, Hertli, 1643 erwähnt als Lehrling von Christoffel I Hempel. Er ist wahrschein lich der Schöpfer der Ratskannen von Davos. (Tafel VI, 3.) Meisterzeichen Nr. 347 (Bd. I).

de Gadenat, I Hans Luzi. Zunftbuch Jahr 1684. Starb ca. 1720. Er führte die Meisterzeichen Nr. 349 und 350 .

Gegenstände : Breitrandteller von $27 \mathrm{~cm}$ Durchmesser und 6,7 cm Randbreite. Marke

' Kirchenbücher der Pfarrei Chur. F. v. Jecklin. 
Nr. 349 an der Unterseite des Randes. An der Oberseite gravirtes Wappen : Turm mit crenelirter Mauer. In der Mitte unten am Boden Marke Nr. 364. Rand unten verstärkt. Breitrandplatte von $37,7 \mathrm{~cm}$ Durchmesser und $8,5 \mathrm{~cm}$ Randbreite. Rand unten verstärkt. An der Unterseite des Randes das Meisterzeichen Nr. 35o; ferner die gravirten Initialen G B F und gekreuzte Doppellinien.

de Cadenat, II Hans Luzi, Sohn des Vorigen. Zunftbuch Jahr 1720. Er führte ebenfalls die Meisterzeichen Nr. 349 und 35o. Bodenrosette Nr. 366.

Gegenstände: Mächtige prismatische, sechsseitige Kanne mit Schraubenverschluss. Marke Nr. 35o auf dem Ausgussdeckelchen. Traubenschild ohne Gravuren. Den Kanten parallel gravirte Linien. Die zwei Vorderseiten mit Rankendekor. Hinten unten, gegenüber dem Ausguss, ein beweglicher Ring zum Heben beim Einschenken. Höhe $40,5 \mathrm{~cm}$. $1 / 4$ Maass Schnabelstitze mit Etagenknopf. Bodenrosette Nr. 366 . Höhe $18 \mathrm{~cm}$. Marke Nr. 35o am Henkel. In der Mitte des Korpus ein flacher circulärer Wulst.

Schnabelstitzchen von 14,7 cm Höhe. Marke Nr. 35o in der Deckelmitte. Unter dem Schnabel die Initialen M. S. Am Korpus circuläre Rillen. Bodenrosette Nr. 366. (Tafel XXXIV, 9.)

Schnabelstitze von $19,5 \mathrm{~cm}$ Höhe. Marke Nr. 35o; Bodenrosette Nr. 366 . Gravirte Initialen B. P. (Tafel XXXIV, 8.)

de Cadenat, I Herkules. Zunftbuch Jahr 1723. Zunftmeister von 1733-1758.

Lehrknaben: 1723, Oehri, Paulus; 1743, de Cadenat, III Hans Luzi (sein Sohn); 1744 , Bauer, Johann Ulrich, de Pfleger Matheus Bauer.

Er führte die. Meisterzeichen Nr. $3_{46}$ und 347. Die Bodenrosette Nr. 366 trägt die Jahrzahl 1733 und wird auch von seinem Sohne III Hans Luzi geführt.

Gegenstände : Sechsseitig prismatische Kanne mit Schraubdeckel. Auf dem Ausgussdeckelchen die Marke Nr. 347. Auf dem Traubenschild das gravirte Plantawappen. Oberhalb des Schildes A. 1734 M. P. Am untern Rande der Kanne ein aufgelöteter reliefirter Akanthusfries. Die beiden Vorderflächen der Kanne sind mit CampanulaRanken gravirt. Keine Bodenplakette. Höhe $36 \mathrm{~cm}$. (Tafel XXXIV, 5.)

Prismatische, sechsseitige Kanne mit Schraubverschluss. Auf dem Traubenschild die Initialen M R und U. Längs den Seitenkanten parallele Linien. Die beiden Vorderflächen gravirt mit je einer Hexe und darüber eine fünfstrahlige Blume. Bodenplakette Nr. 366 . Höhe $38 \mathrm{~cm}$. (Tafel XXXV, 4.)

$1 / 4$ Maass Stitze ohne Schnabel. Rosette mit links springendem Steinbock. Mitte des Deckels kegelförmig hochgetrieben. Initialen C AM und BWCS. Höhe 18,2 cm. (Tafel XXXIV, 2.)

de Cadenat, III Hans oder Johann Luzi, der Sohn des Vorigen, lernt 1743 bei seinem Vater

I Herkules. Zunftbuch Jahr 1753.

Lehrknaben : 1767 , de Cadenat, II Herkules und Matheus, seine Söhne ledig gesprochen; ${ }_{1789}$, Bawier, Johann Baptista, de Johannes; 1801 , Lorez, Jeremias de Andreas.

Er führte die gleichen Meisterzeichen wie I Hans Luzi de Cadenat, Nr. 349 und 350.

de Cadenat, II Herkules, Sohn des III Hans Luzi, wvird ${ }_{1} 6_{7}$ ledig gesprochen.

Er führte das Meisterzeichen Nr. 348.

Bauer, Johann Ulrich, lernte 1744 bei I Herkules de Cadenat; trat 1750 in die Schmiedenzunft

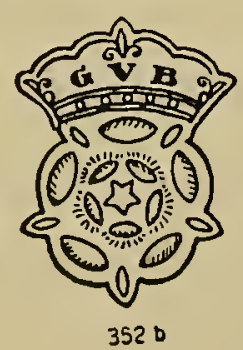
und starb 1781 .

Er führte die Meisterzeichen Nr. $352 b$ und $c$. Gegenstände : Breitrandplatte von $32 \mathrm{~cm}$ Durchmesser und $7 \mathrm{~cm}$ Randbreite. An der Unterseite des Randes sind die Marken $352 b$ und $c$ je drei Mal eingeschlagen. Oben am Rande ein gravirtes Doppelwappen (Kopf und kammartiges Gebilde).

Prismatische, sechsseitige Kanne mit Schraubdeckel. Inhalt $1 \frac{1 / 2}{2}$ Maass.

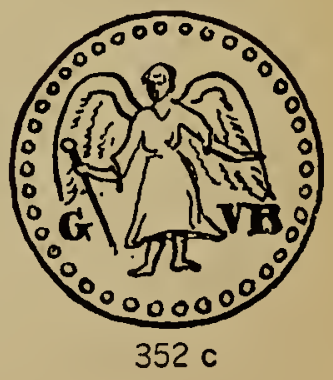





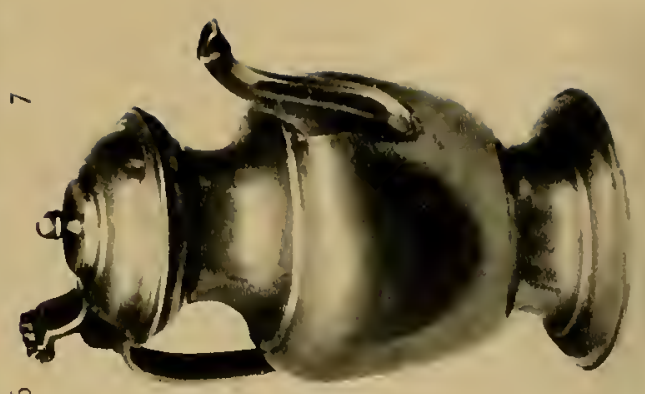

$\simeq$

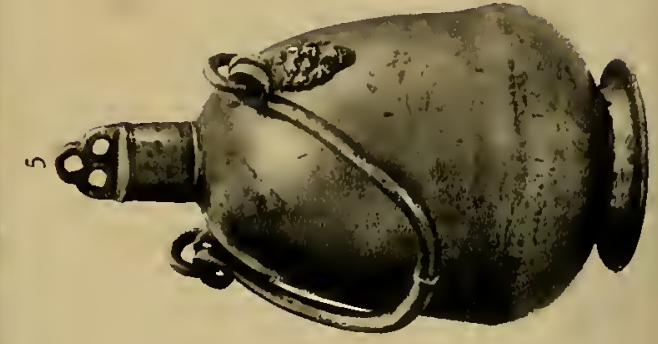

$=$
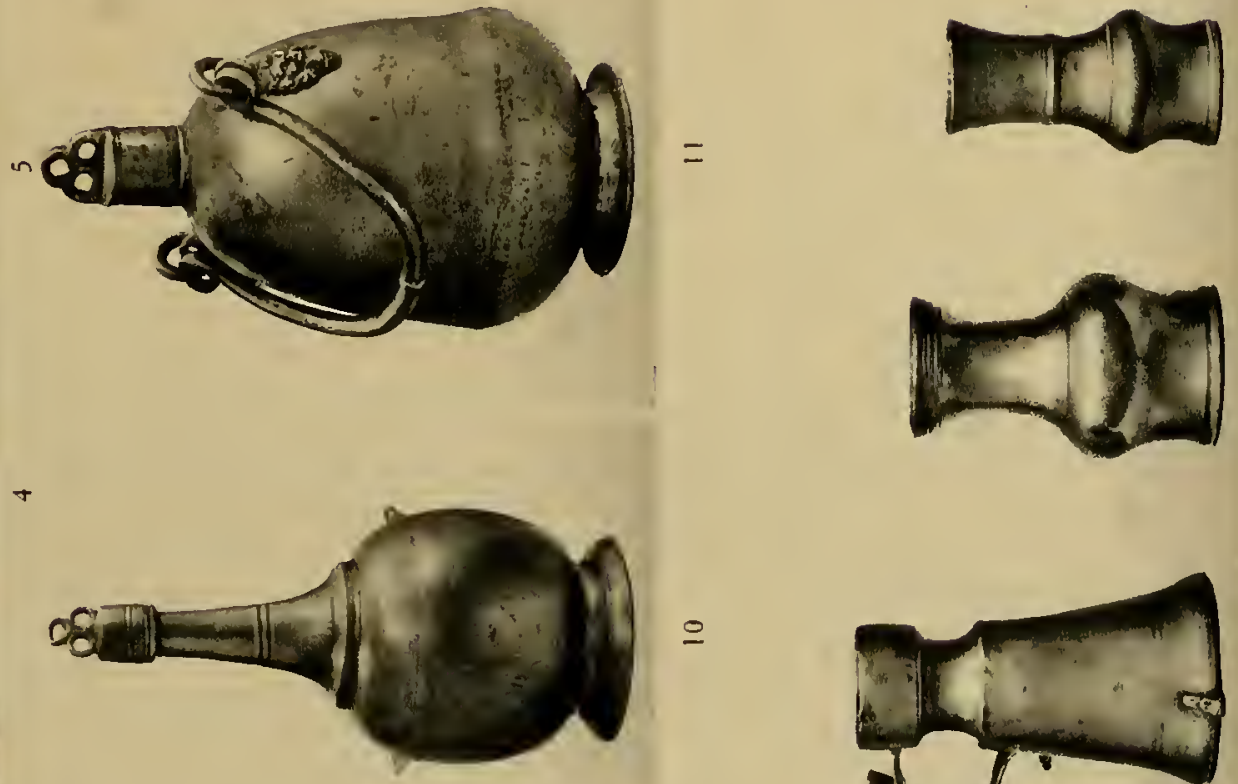

웅
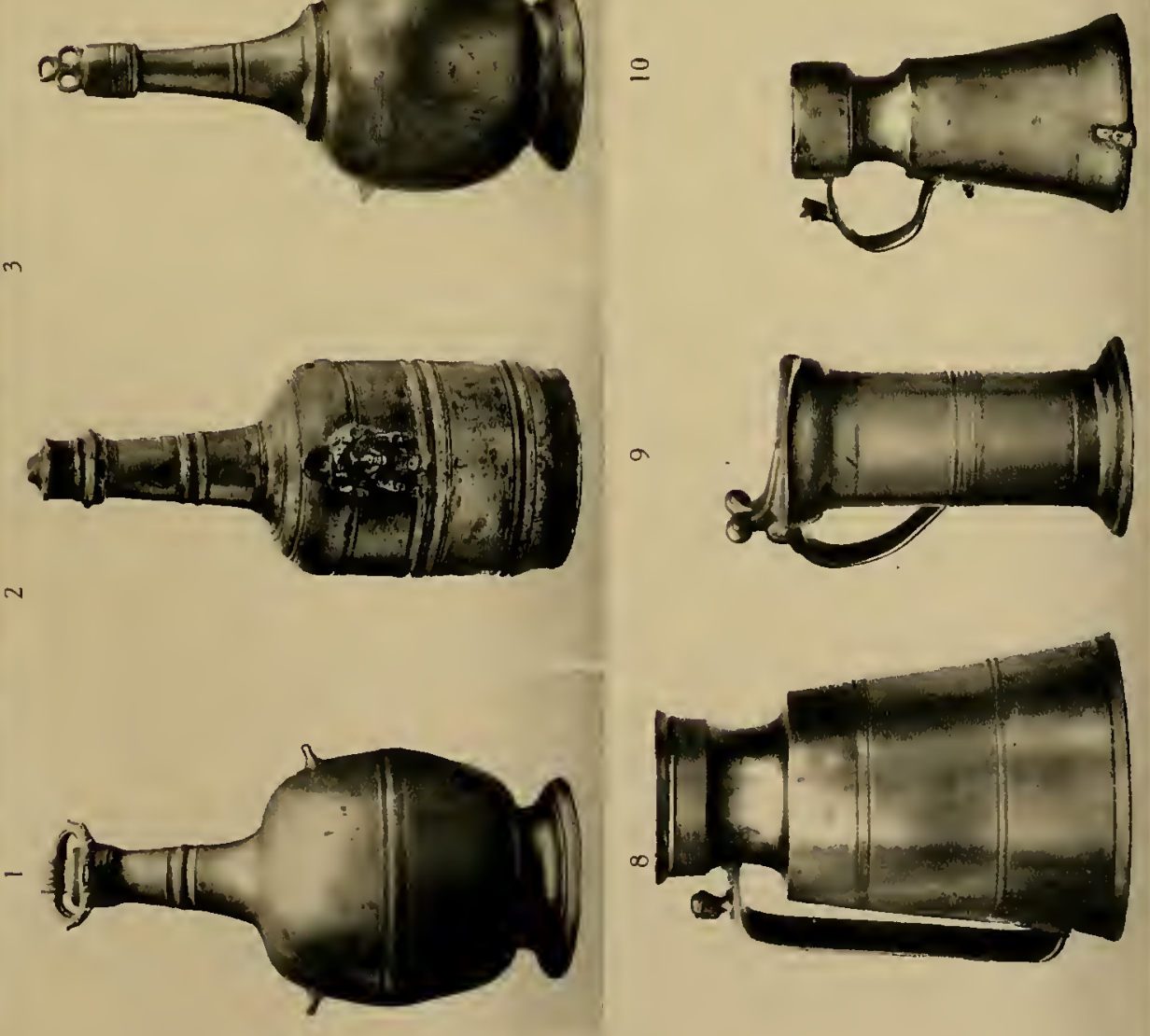

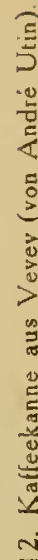

$=$

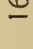

$\underline{-}$

$-$

$\pm$

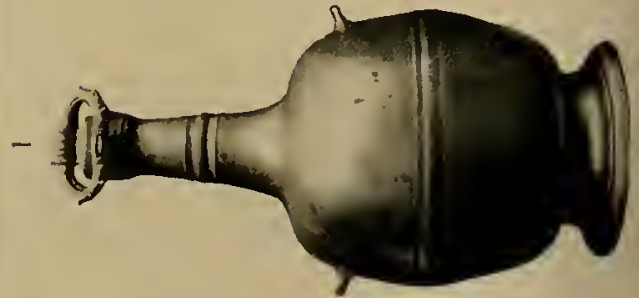



Bauer, Josef Ulrich. Zunftbuch Jahr 1750.

Lehrknaben : 1754, Marti(n) Johannes de David, Glarus; 1757, Bauer, I Matheus und Johannes, seine zwei Söhne ledig gesprochen.

Er führte das Meisterzeichen $352 a$ und Nr. 36o.

Gegenstand: Prismatische, sechsseitige Kanne mit Schraubverschluss. Auf dem Ausgussdeckelchen die Marke Nr. 352 a. Auf dem Traubenschild die Initialen C P ${ }_{1} 820$ (spätere Gravur).

Bauer, I Matheus, der Sohn des Vorigen, wurde ${ }_{17} 57$ ledig gesprochen, trat $177_{1}$ in die Schmiedenzunft und war 1783 Zunftmeister. Zunftbuch Jahr 1774 .

Lehrknaben : 1783, Bauer, Johann Jakob Ulrich und II Matheus, seine zwei Söhne ledig gesprochen; 1803 , Hitz, Daniel de Bernhard.

Er führte das Meisterzeichen Nr. 354. Bodenplaketten Nr. 367, 368 und 373. Bei Nr. 368 findet sich die Jahrzahl 1708 statt 178 o. Die Inschrift lautet: Matheus de Johann Ulrich Bauer (!).

Gegenstände: Prismatische, sechsseitige Schraubkanne mit Traubenschild. Initialen und Jahrzahl auf demselben E L 1798. Meisterzeichen Nr. 354 auf dem Ausgussdeckelchen. Bodenplakette Nr. 368. Die Kanne ist vollständig mit gravirten Blumen- und Blattranken überzogen. Höhe $36,5 \mathrm{~cm}$. Inhalt a Maass. (Tafel XXXV, 3.)

Stitze ohne Schnabel. Deckelmitte kegelförmig nach oben getrieben. Vorn am Deckel das Meisterzeichen Nr. 354. Gravirte Initialen C VW und Hauszeichen. Am Korpus circuläre Rillen. Rosette Nr. 373 . Höhe $15,5 \mathrm{~cm}$.

Schnabelstitze, Marke 354; Rosette Nr. 372 . Höhe $18,7 \mathrm{~cm}$. Initialen A H. Am Korpus flacher circulärer Wulst.

Bauer, Johann Jakob Ulrich, der Sohn des Vorigen, wurde im Jahre 1783 von seinem Vater ledig gesprochen. Zunftbuch Jahr 1797 als Eintrittsjahr in die Schmiedenzunft. Zitirt bis $\mathbf{1}_{\mathbf{2}} 6$. 1824, Werli, Rudolf, von Kütigen, Kt. Aargau, Geselle (war vorher 10 Jahre lang bei Wilhelm Gottschalk in Aarau).

Er führte die Meisterzeichen Nr. $352 a, b$ und $c$ (Bd. II), 351 und 355. Bodenrosetten Nr. 369, 370 und 372 .

Gegenstände : prismatische, sechsseitige Kanne mit massigem Fuss (sog. Bodenkanne) und Traubenschild; darauf die Initialen E R und I B. An den beiden Vorderflächen prachtvolle Blumenranken. Keine Bodenplakette. Höhe $37,5 \mathrm{~cm}$. Meisterzeichen Nr. $352 a$ auf dem Ausgussdeckelchen. (Tafel XXXIV, 15.)

Gleiches Stück mit Campanularanken. Meisterzeichen noch dreimal innen am Boden der Kanne. Auf dem Traubenschild die Initialen C G . E A.

$Z_{w}$ i Schnabelstitzchen mit dem Meisterzeichen Nr. 352 a in der Mitte des Deckels. Unterhalb des Schnabels die Initialen E B M resp. I. B. Höhe 11,5 und $12 \mathrm{~cm}$. Neunteilige Bodenrosette. Das eine hat am Korpus circuläre Rillen.

Prismatische, sechsseitige Kanne mit gebogenem Ausgussrohr, welches in einem Kopf endigt. Bodenplakette Nr. 369. Traubenschild mit den Initialen A D 1847 . Höhe $36 \mathrm{~cm}$. (Tafel XXXIV, 14.)

Kleine "Bodenkanne". Marke 352 a. Plakette 367. Höhe $29 \mathrm{~cm}$. Gravirte Initialen A P L. Parallele Linien längs den Seitenkanten. (Tafel XXXIV, 6.)

Sechsseitige Schraubkanne, Marke 352 a. Kein Schild. Vorn zwei gravirte Blumentöpfe mit Blumen. Bodenplakette Nr. 367 mit nach links springendem Steinbock und der Jahrzahl 1780 . Höhe $29 \mathrm{~cm}$.

Gleiches Exemplar mit Bodenplakette Nr. 370. Höhe $27 \mathrm{~cm}$. Hochgetriebener Boden.

Bauer, II Matheus, Sohn des I Matheus Bauer, Bruder des Vorigen, wurde von seinem Vater im Jahre 1783 ledig gesprochen. Er arbeitete gemeinsam mit seinem Bruder.

Bauer, Johann Jakob Ulrich und Matheus, als gemeinsames Geschäft. Beide wurden im Jahre 1783 von ihrem Vater ledig gesprochen. Sie führten ein Meisterzeichen Nr. 353; oder auch B-B 1804 . 
Gegenstände : Zwei achtseitig prismatische Schraubkannen mit der Marke Nr. 353 auf dem Ausgussdeckelchen. Bodenplakette Nr. 366. Alte Formen werden also wieder verwendet. Höhe $29,5 \mathrm{~cm}$ resp. $27,5 \mathrm{~cm}$. Die eine ist ungravirt, die andere weist an den zwei Vorderseiten Rankenwerk auf.

Schnabelstitze von 1 Maass Inhalt. Das Meisterzeichen Nr. 353 befindet sich auf der Mitte des Deckels. In der Mitte der Leibung flacher circulärer Wulst. Unterhalb des Schnabels die Initialen A F. Bodenrosette Nr. 371. Höhe $26,5 \mathrm{~cm}$. (Tafel XXXIV, 7.) Schnabelstitze mit dem Meisterzeichen Nr. 353. Am Korpus circuläre Rillen und die Initialen - 18 J C - S. 04. Bodenrosette Nr. 366. Höhe 14,2 cm.

Stitze ohne Schnabel mit Meisterzeichen Nr. 353. Bodenrosette Nr. 366 . Unterhalb des Ausgusses die Initialen H B. Höhe 14,6 cm. Am Korpus circulärer Wulst und Rillen. (Tafel XXXIV, 1.)

Hitz, Daniel, de Bernhard. Zunftbuch 1774. Daniel Hitz 1803 Lehrling bei I Matheus Bauer. Hitz wurde im Jahre 1809 in die Schmiedenzunft aufgenommen '. Im Jahre ${ }_{182} 5$ wird seine Frau als Wittwe erwähnt.

Er führte die Meisterzeichen Nr. 356, 357 und 358. Bodenrosette Nr. 371 .

Gegenstände: Prismatische achtseitige Kanne; auf dem Ausgussdeckelchen die Marke Nr. 357. Traubenschild mit den Initialen D. B. 1820 . Bodenrosette Nr. 371. An den zwei Vorderflächen gravirte Ranken. Höhe $34 \mathrm{~cm}$. (Tafel XXXIV, 13.)

Prismatische, achtseitige Kanne mit Schraubenverschluss. Auf dem Augussdeckel chen das Meisterzeichen Nr. 357. Bodenrosette Nr. 371. Höhe $27 \mathrm{~cm}$. Kein Schild.

Lange, Heinrich Wilhelm, Zinngiesser aus Camburg in Sachsen-Altenburg, reformirt, heiratet nach langwierigen, amtlichen Verhandlungen " im Anfang des Jahres 1826 die von ihm geschwängerte Wittfrau des Zinngiessers Daniel Hitz, bei welcher er Geselle war. Am 22. Februar 1826 wird er als Beisäss aufgenommen. Lange arbeitete noch über 2o Jahre lang in Chur und stellte z. B. 1846 anlässlich der Industrie-Austellung im Stadtschul-Saale von Chur viele $Z$ inngegenstände aus. Bei ihm arbeitete auch der Zuger Zinngiesser Beat Jakob Keiser. In der Fremdenkontrolle findet sich folgender Passus : "Keiser Beat Jakob, 21 Jahre alt, Heimat Zug, Wanderbuch vom 10. VI. (18)42: Anmeldung: 16. VI. 42 bei Lange, Zinngiesser. Ab, 8. Juni 44. Weil Keiser nun das Geschäft kannte, übernahm nach dem Tode Lange's der Vater Joachim Michael Keiser ca. 1850 daselbe und führte es einige Zeit als Filiale der zugerischen Werkstatt weiter.

Lange ist der Verfertiger der berühmten Churer "Kranzkannen ".

Er führte die Meisterzeichen Nr. 359, 361, 362 und 363.

Gegenstände: Grosse Kranzkanne. Auf dem Ausgussdeckelchen die Marke Nr. 362. (Tafel XXXIV, 1o.) Unten am Boden zwei Mal die Marke Nr. 361. (Tafel XXXV, 2.) Der Kannenboden ist stark nach einwärts gewölbt $\left(2 \frac{1 / 2}{\mathrm{~cm}}\right.$ hoch). Keine Bodenplakette. Auf dem prachtvollen Schild die gravirten Initialen A C und A R. Der in Reliefguss hergestellte Schild ist von Weintrauben und Blattwerk umgeben. Höhe $35 \mathrm{~cm}$.

Kleine Kranzkanne, ohne Schild. Auf dem Ausgussdeckelchen die Marke Nr. 362. Boden 3,7 nach innen hochgetrieben. Höhe 3o cm. (Tafel XXXIV, 4.) - Gleiches Stück mit den Initialen I. F. AS.

Grosse und kleine Kannen mit Akanthusblättern nur an der Ausgussröhre, nicht aber am Kannenfuss. (Tafel XXXIV, 11, 12.) (Sammlung L. Gally, Basel.)

\footnotetext{
1 Schmiedezunft Rodel 1804 .

2 Eingabe des Ratsherr Albert v. Salis, als Curator der Witwe des Zinngiessers Daniel Hitz sel. an den Rath und Gericht, datiert $1_{2} 6$ 1. 27. Ratsprotokoll $1825 / 26$. S. 323. Protokoll der Beisäss-Commission 1825-34. S. 32.
} 


\section{Die Clurer Zinngegenstände}

Die ältesten noch erhaltenen Zinnobjekte im Bündnerlande sind die Breitrand-Teller und-Platten. Das Exemplar des Meisters Castelmur stammt aus der Zeit vor 1625. Auf Tellern und Platten sind die Giesserzeichen meist gut erhalten und vollständig ausgeprägt, weil eben die Matritze auf eine relativ grosse ebene Fläche aufgesetzt verden konnte. Auf dem breiten Rande prangen die prachtvoll gravirten Familienwappen mit den Initialen und oft auch die Jahrzahlen. In Poschiavo und im Bergell trifft man auch recht häufig Wappen italienischer Adelsgeschlechter, z. B. der Sforza. Die breitrandigen Teller und Platten sind an der Unterseite des Randes durch einen Wulst verstärkt. Die obere Seite ist ganz glatt, ohne Rillen, Karnisse oder profilirte Stäbe.

Die Glockenkannen fehlen fast vollständig. Ich habe ein einziges Exemplar des Zinngiessers Walser gefunden, ein niedriges, massiges Stück.

Die Stitzen kommen in beiden Formen vor, mit und ohne Schnabel. Die üblichen Grössen entsprechen einem Inhalt von 1, 1/2 und 1/4 Maass. Die Deckel sind flach und tragen fast niemals einen Knopf (Ausnahme : 1/4 Maass Schnabelstitze von II Hans Luzi de Cadenat). Die kleinen Stitzen sind am Boden sehr breit und ruhen behäbig auf der Unterlage, ohne plump zu wirken. Die Dekoration und Gliederung des Korpus besteht in circulären Wülsten oder eingedrehten Rillen. Unterhalb des Ausgusses befinden sich die gravirten Initialen, Hauszeichen und Jahrzahlen. Ranken - und Blumendekorationen kommen nur ausnahmsweise vor. An der Innenseite des Bodens sind die schönen Bodenplaketten (v. Band I, Tafel XVIII). Die sogenannten "Engadiner Stitzen " sind nicht bündnerischen Ursprungs. Sie stammen von Augsburg und weisen auch diesbezügliche Stadt - und Meisterzeichen auf (Pinienzapfen und die Initialen A. V., Augusta Vindelicorum). Die mächtige Handelsstadt Augsburg exportirte viele Waren ïber Chur nach Italien und brachte auch diese Zinnkannen, die bald sehr beliebt wurden. Bis ca. 1910 konnte man im Bündner Lande alle Grössen finden.

Die prismatischen Kannen sind die häufigsten Bündnerkannen und kommen in sechsund achtseitiger Form vor. Die Kannen von 1 Maass Inhalt nannte man "Quartkannen ". Diese tragen als die für Chur typische Dekoration den reich ornamentirten Schild, welcher immer an der rechten Kannenseite angelötet wurde. Die Giesserfamilie der de Cadenat besitzt zwei Modelle verschiedener Grösse. Der grosse Schild misst bei $10 \mathrm{~cm}$ Länge 5,7 cm in der Breite; der kleine ist $8,5 \mathrm{~cm}$ lang und $4,5 \mathrm{~cm}$ breit. Der Schild ist oben rund und läuft unten in eine spitze Traube aus. Die Familie Bauer hat nur ein Modell für den Schild, 10,5 cm lang und $5 \mathrm{~cm}$ breit. Der Schild ist oben nicht rund, sondern trägt einen spitzen Aufsatz, welcher oft weiter hinaufreicht als die ebene Seitenwand der Kanne und mithin die Biegung mitmacht. Auf dem Schild befinden sich die Initialen, Wappen und Jahrzahlen. Der Zinngiesser Hitz hat einfach den Bauer'schen Schild copirt. Ebenso machten es die beiden Peter in Elgg (Zürich). Die Ausladung und Profilirung des Fussteiles bildet einen Hauptmoment für die elegante Form des Aufbaues. Wir finden alle möglichen Formen und Profilstärken. Während die Modelle der Familie Bauer besonders schön sind, steht bei Hitz die Kanne kahl, profillos und ohne Ausladung auf der Unterlage.

Die ebenen Seitenflächen eigneten sich besonders gut für die Dekoration durch den Grabstichel, eine Arbeit, welche meistens der Goldschmied besorgte. Oft findet man nur zu den Seitenkanten parallele Linien, um die Fläche etwas zu verkleinern; in andern Fällen sind die beiden Vorderflächen mit reichem Blatt- und Rankenornament verziert. In seltenen Fällen überziehen die Gravuren die ganze Kanne in geradezu kunstvoller Weise. (Tafel XXXV, 3.)

Die prismatische Ausgussröhre legt sich breitbasig an den Kannenleib und ist oben mit einem Deckelchen verschlossen. Der Schraubenverschluss der Ausgussröhre kommt nicht vor. Dagegen gibt es späte Kannen mit gebogener cylindrischer Ausgussröhre, welche in einen Tierkopf ausläuft. Dieselben sind unschön und passen nicht zum Stil der Kanne. Sie leiten zur Biedermeierzeit hinüber. 
Eine besondere Art für sich bilden die sogenannten Churer Kranzkannen. Schon in der ersten Hälfte des XVIII. Jahrhunderts hatte Herkules I de Cadenat Kannen gegossen, welchen er am untern Rand entlang einen Akanthusblätterfries auflötete. Hiedurch erzielte er eine eigenartige dekorative Wirkung und ist als Erfinder dieser Idee zu betrachten. Heinrich Wilhelm Lange benutzte nun dieselbe in der Art und Weise, dass er den Akanthusfries am Fuss der Kanne direkt mit dem Modell des Fusses verband. Damit fiel das Auflöten des Frieses weg. Um die Basis der Ausgussröhre herum componirte er eine ähnliche breite Einfassung mit stilisirten Akanthusblättern. Die Ausladung des Fusses ist eine bedeutende und verleiht der Kanne ein elegantes Aussehen. Bei den grossen Kranzkannen ist an der rechten Seite ein prächtiger ovaler Schild aufgelötet; dieser weist im Innern einen kleien Empireschild auf, welcher von Weinlaub und Trauben eingefasst ist. - Neben den vollständig ausgebildeten Kranzkannen gibt es grosse und kleine Exemplare, welchen der Akanthusfries und die Ausladung des Fusses fehlt. Die Dekoration umfasst nur die Basis der Ausgussröhre. Auch fehlt diesen Stücken meist auch der reiche Schild. (Tafel XXXIV, 11, 12.)

Der Zuger Zinngiesser Joachim Michael Keiser, welcher das Geschäft Langes ca. 1850 übernahm, goss auch einige grosse Kranzkannen nach dem Modell von Lange. Er versah dieselben mit seinem eigenen Meisterzeichen I. M. K. Während bei Lange der Boden kuppelförmig in die Kanne hineinragt, ist derselbe bei Keiser ganz flach und eben. Bei einem Exemplar hat Keiser auch Abänderungen angebracht, indem er unterhalb des Akanthusfrieses noch einen glatten Fries ansetzte. Dadurch wird die Ausladung des Fusses und die Höhe der Kanne noch bedeutender; allein sie verliert die schönen Proportionen. Bei diesem einzigen bekannten Stück besitzt die Ausgussröhre einen Schraubenverschluss.

(Tafel XXXV, 1.)

Die schmalrandigen Teller und Platten weisen keine Eigentümlichkeiten auf und sind nur an der Meistermarke erkennbar. Das Gleiche gilt für die Giessfässer und die übrigen Zinngegenstände.

Die Ratskannen in Davos sind wahrscheinlich die im alten Davoser Landbuche erwähnten " des Punds und Lands Schenkhkanten»". Sie tragen die Jahrzahl 1647 und stammen wahrscheinlich von Hertli de Cadenath, welcher im Jahre 1643 bei Christoffel I Hempel in Chur in der Lehre war. An der Vorderseite ist ein grosser Barokschild aufgelötet mit dem Wappen des Zehngerichtenbundes und der Jahrzahl 1647. Höhe $49 \mathrm{~cm}$; Durchmesser des Fusses $16,5 \mathrm{~cm}$. (Tafel VI, 3.) Meisterzeichen Nr. 347.

\section{SCHAFFHAUSEN}

Die Zinn- oder Kantengiesser bildeten in Schaffhausen eine besondere HandwerksInnung. Ihre Mitglieder gehörten aber verschiedenen $\mathrm{Z}$ ünften an. In allen weinbauenden Landen spielte der Zinngiesser eine bedeutende Rolle. Schon im Jahre ${ }_{1}{ }_{7} 6$ befasste sich der Rat von Schaffhausen mit den Kantengiessern und stellte die erste Kantengiesser-Ordnung " auf. Sie lautet :

"Kantengiesser.

"Vmb antwerk lüt, die zinin kanten vnd giessuasse vnd schüsselan vnd solich geschirre vnd ding machent in vnser Statt, ist gesetzet, das man enhain werk also hie machen sol, der maister der es machet oder würket, swere denne zu den hailigen vor hin ainen gelerten ait, das

\footnotetext{
1 Das Rathaus in Davos. S. Fümm. 1915. S. ,5.

2 Schaffhauser * Stadtbuch» Blall 74 II, Abgedruckt in der . Alemannia», Zeitschrift für Sprache, Literatur und Volkskunde, Jahrgang 1878 , Band VI, S. 276. Das "Stadtbuch * ist eine Sammlung von Gesetzen und Verordnungen aus dem 14.-16. Jahrhundert. Mitteilung von Herrn Dr. H. Werner, Staatsarehivar, Sehaff hausen.
} 
TAFEL XX
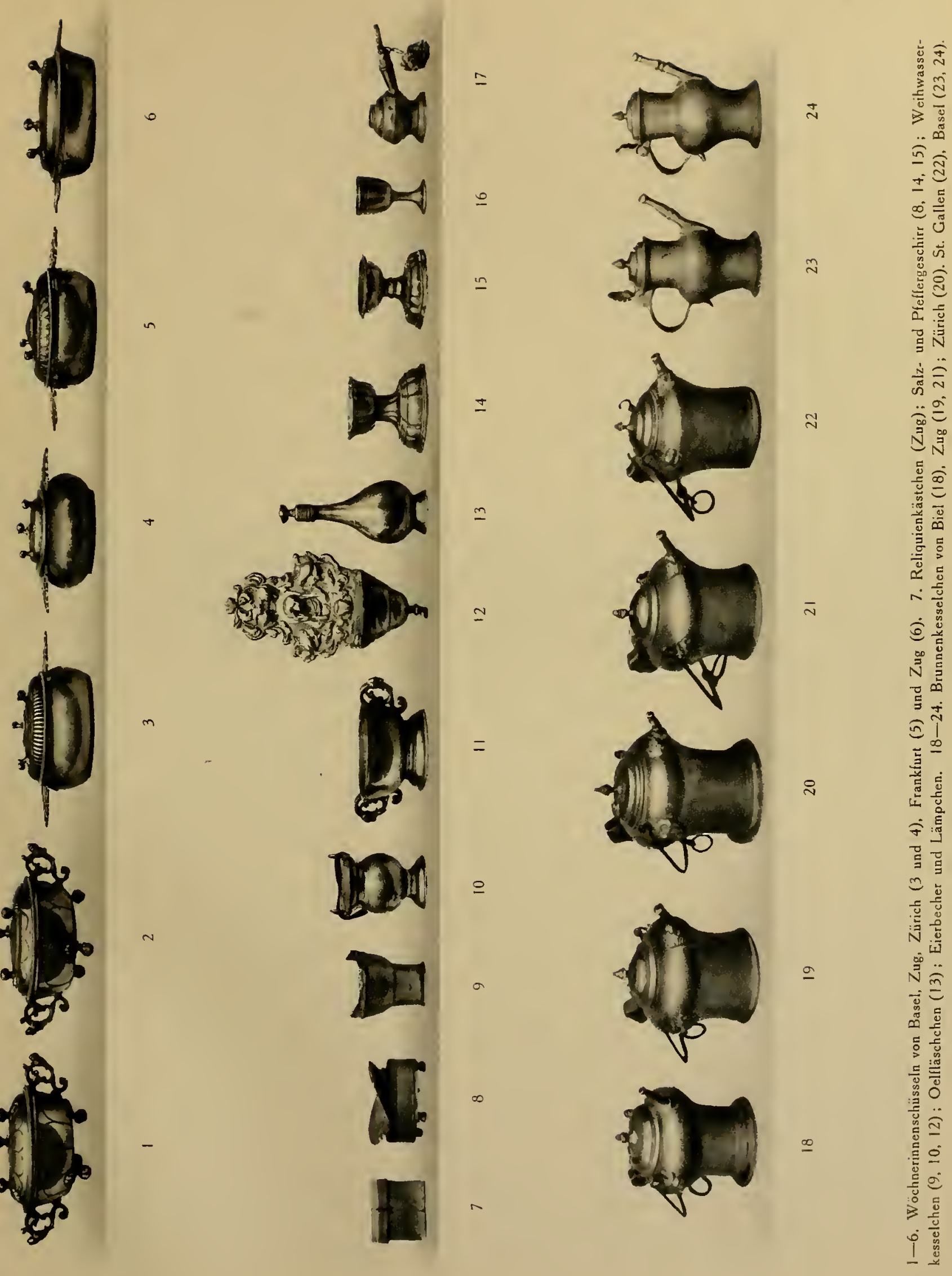

er nit me blyes darzu denne den fünften tail neme, er mache es von nüwem gezug ald von altem geschierre, vnd was er alsö machet es si ainer oder me, der sol das selbe das er ie machet zaichennen mit vnser Statt zaichen, das ex dar zu gewinnen vnd nemen sol von den, die es von vnser Statt wegen geben sont, als dik es ze schulden kunt.

"Datum anno dm. Mo ccc lxxvj."

Aus dem Jahre 1502 stammen verschiedene Verordnungen ${ }^{1}$ und Erlasse des Rates, welche sich hauptsächlich gegen minderwertige und gesundheitsschädliche Waren richten. Auch beziehen sie sich auf das Ein- und Umschmelzen älterer Zinnwaren. Wir zitiren folgende Stelle :

" Es sollen haffengiesser vnd kantengiesser sweren ain aid zu gott vnnd den hailgen, was Inen altzugs zukome zukoffen, die sy argwenig bedunck, gas nit zu schmeltzen, sonnder ainem Burgermaister zu antwurten. Dessglichen was zugs sy koffen, der sy nit argkwenig bedunckt denn edenmals vnd sy den schmeltzen, viertzechen tag offennlich lassen vff irm laden stänn. Dessglichen sö sollen die vailträgeren ouch sweren was Inen argkwenigs zukomme, zuuerkoffen, das ouch ainem Burgermaister zu offnen vnd zu ertzogen.

"Actum menntag nach barnabe Anno Mo XVc secundo."

Auf diese Verordnung von 1502 bezieht sich ferner folgende Eintragung im "Ordnungenbuch " vom Jahre 1480, Seite 153 (1053):

"Es sollen ouch der hafengiesser Kantengiesser und Kessler wiber und dienst dies obgeschrieben ordnungen halten und mit namen all ir Knecht, die ouch sweren wie die maister, so manigen si hand.

"Item diss ordnung hand geschworen al Kantengiesser haffengiesser und Kessler, geschworen uff fritag vor pabtiste im 1506 jahr.

Diss ordnung haben geschworen : Fridrich Sachs, Patt Schalch und Michel Oechsly uff fritag post Oswaldi anno 1528 .

"Die obgemelt ordnung hand geschworen: Batt Schalch, Marti Stamma, Gangwolf Offenburg und Zacharias Bumann. Actum mitwuchs post oculi 1543 .

"Die obgemelt ordnung hatt Cunrat Schalch geschworen Samstag vor Simonis und jude in 1548 jar.

"Die obgemelt ordnung hand geschworen Mölcher Schalttenbrandt und Hans Bäschli mittwuchen Mariae himmelfart im 1554 jar.

"Die ordnung hand geschworen Veith Pflum, Hanss Schalch, Hanss Werni ab Egg und Hanss Ziegler am Ryn, uff Mittwuchen nach Johannis Evangelisten im ${ }_{1} 567$ jar.

Durch diese Zitate werden uns die Namen der dreizehn ersten Schaffhauser Kantengiesser bekannt gegeben.

Aus dem Jahre ${ }_{1} 631$ stammt die zweite Kantengiesser-Ordnung, " welche folgenden Text hat:

\section{Kandtengiesder Ordnung.}

"Ihr werden schweren unsern gnädigen Herren und derogemeinen Statt trewe und warheit zehalten, üwr arbeit nach hiessiger statt prob zegiessen und zemachen, namblich das die glatte arbeit vier pfund zinn und ein pfund pley halten solle; also so offt üwere arbeit beschowt und probirt werden soll, seind uss vier lot zinn und ein lot pley zwo gleiche Kuglen, so man die nit andrest zuvor im vorrath hat, zegiessen, die dann der statt prob seind, hernach sollen durch ein unpartheyischen meister oder des Handtwerkhs kundiger von jedes Kandtengiessers glatten arbeit, die der diener under dem gschier seines gefallens usslessen mag, stuckh abgeschrotten, jedes besonderbar geschmeltzt, und ebenmässig zwo Kuglen gegossen werden, die hernach zewegen, und ie nachdem sie an gewicht und halt gefunden werden. Hat der meister mehr pley eingesetzt dan diese ordnung und der statt prob zugibt und vermag, darumb

1 Schaff thauser \& Stadtbuch * Blatt 74 II. Abgedruckt in der \& Alemannia •, Zeitschrift für Sprache, Literatur und Volkskunde, Jahrgang 1878 , Band VI, S. 276. Das \& Stadtbuch » ist eine Sammlung von Gesetzen und Verordoungen aus dem 14. 16. Jahrhundert. Mitteilang von Herrn Dr. H. Werner, Staatsarchivat, Schaffhansen.

Ordnungenbuch 1592-1642, S. $5_{71}$. Mitteilungen von Herrn Staatsarchivar Dr. H. Werner. 
er dan für jedes lot so er fehlbar 5 schilling zur buoss zubezahlen schuldig sein soll. Was aber die mit der Cron und hammer geschlagene arbeit betrifft, sol selbige ohn einigen zusatz von lautter zinn gemacht, und die es nit thun, getrafft werden.

"Und behaltend unssere gn. H. ihnne disse ordnung ze-enderen und zeverbesseren bevor.

"Diese ordnung habend zu halten geschworen den 23. (Juli ?) 1631:

Hanss Felix Abegg,

Melcher Beschlin,

Allexander Abegg.

Habend geschworen: $\left.\begin{array}{l}\text { Hanss Felix } \\ \text { Allexander } \\ \text { Allexander Beschlin } \\ \text { Adam Wüscher }\end{array}\right\}$ den 22. Augusti

Am 28. Julii 1664 haben die Kantengiesser geschworen, nämlich :

Adam Wüscher,

Heinrich Bäschlin,

Alexander Abek,

Alexander Abeken W hat angelobt. ")

Unter obigen Unterschriften finden sich wiederum die Namen und Daten von weitern sechs Kantengiessern. Von Adam I Wüscher und Alexander II Abegg stammen die ältesten erhaltenen Schaffhauser Weinkannen.

Im Ordnungsbuch 1592-1642, Seite 66o, findet sich auch ein Kopie (1854 erstellt) der sogenannten Taxierordnung der Stadt Schaffhausen vom 5. September 1655 .

Sie lautet :

"Kantengiessertax.

"Item von einem Pfund zu arbeiten zu schüsslen, tellern und anderer dergleichen Arbeit : 2 Schilling 6 Heller.

"Item von ainem Pfund des holen geschiers als Kanten, steitzen, Eichelen, brunnen Kessin und anderem : 3 Schilling.

"Und ist zu merkchen dass altem Brauch nach an 10 Pfund 1 Pfund für den abgang nach zu lassen.

"Item für a Pfund an Kanten stitzen brunnen Kessin Giessvasen flaschen eichelen und dergleichen: 10 Schilling.

" Und soll so wol der Kupfferschmiedn und Kantengiesser als anderen Handwerksleuten arbeit und wahren durch die verordnete besichtiget probirt und nach befindenden Dingen, gegen des straffbahren verfahren werden."

Das Zinngiesserhandwerk blühte und gedieh auch im XVIII. Jahrhundert. Stets waren 3-6 Meister tätig. Im XIX. Jahrhundert war meist nur ein einziger nachweisbar und auch heute noch ist dieses alte Handwerk nicht erloschen, wie anderweitig, indem Herr Alfons Wiedemann das Geschäft seines Vaters Franz Josef weiterführt.

\section{Die Kannen- und $Z_{\text {inngiesser }}$}

Sachs, Friedrich, erwähnt im Jahre ${ }_{1} 528$ bei der Beschwörung der ersten Kantengiesserordnung mit dem Nachtrag aus dem Jahre ${ }_{1502}$ '.

Schalch, Beat, (Patt), erwähnt wie der Vorige, ${ }_{1} 5_{2} 8$ und 1543 !.

Oechsly, Michel, erwähnt wie der Vorige, 1528 '.

Stamma, Marti, erwähnt bei seiner Beschwörung der Kannengiesserordnung im Jahre ${ }_{154} 3^{\prime}$. Offenburg, Gangwolf, erwähnt wie der Vorige, 1543 !.

' Ordnungeobach von 1480 , Seite $153(1063)$. 
Bumann, Zacharias, erwähnt wie der Vorige, $1543{ }^{\prime}$.

Schalch, Cunrat, erwähnt bei der Beschwörung der Kannengiesserordnung im Jahre $1548^{\prime}$.

Schaltenbrand, Melchior, erwähnt bei seiner Beschwörung der Kannengiesserordnung im Jahre $1554^{1}$.

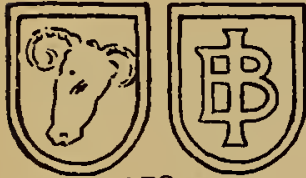

178 a

Bäschli, Hans, erwähnt wie der Vorige im Jahre $1554^{\prime}$. Auf einer $35,5 \mathrm{~cm}$ hohen Stitze im historischen Museum von Schaffhausen befindet sich neben dem Stadtzeichen ein Meister zeichen Nr. 178 a mit den Initialen I. B.

Pflum, Veith, erwähnt bei seiner Beschwörung der Kannengiesserordnung im Jahre $1567{ }^{\prime}$.

Schalch, Hans, erwähnt wie der Vorige im Jahre $1567^{1}$.

ab Egg, Hans Werni, erwähnt mit dem Vorigen im Jahre 1567 !.

Ziegler, Hans, erwähnt mit dem Vorigen im Jahre ${ }_{1} 567^{\prime}$.

Städinger, Niklaus, Kantengiesser, zitirt Ende 1573 , in einer Urkunde im Stadtarchiv von Wyl (Mitteilung von Herrn Stadtarchivar K. J. Ehrat).

Abegg, Hans Felix, erwähnt bei seiner Beschwörung der Kannengiesserordnung im Jahre ${ }_{1631}$ und 1643 , am 22. August ${ }^{1}$. Er wurde 1579 geboren und heiratete 1603 .

Gegenstand: Siehe I Alexander Abegg.

Beschlin, Melchior, beschwört die Kannengiesserordnung von ${ }_{1631}$ im gleichen Jahre ${ }^{1}$ Er wurde im Jahre 1587 geboren und heiratete 1627 .

Abegg, I Alexander, beschwört die Kannengiesserordnung von $1_{163}$ im gleichen Jahre

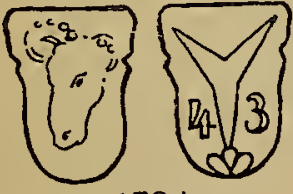

$178 \mathrm{~b}$ und wiederum 1643 am 22. August $\cong$. Geboren 1607; heiratete 1631 .

Gegenstand: Grosse Stitze im historischen Museum in Schaffhausen. Höhe 35,5 cm.Meisterzeichen : Neben dem Stempel mit demWidderkopf eine gleich grosse Marke mit dem Wappen Abegg und der Jahrzahl (16) 43 . Keine Initialen. Meisterzeichen Nr. 1786 .

Bäschlir, Alexander, erwähnt anlässlich seiner Beschwörung der Kannengiesserordnung im



Wüscher, Adam, wurde im Jahre 1618 geboren. Er wird erwähnt anlässlich seiner Beschwörung der Kannengiesserordnung im Jahre 1643 und $1664 \%$. Das Todesdatum ist nicht bekannt.

Er führte die Meistermarke Nr. 179. Unterhalb den Initialen befindet sich die Zahl (16)43, also die Jahrzahl seiner Beschwörung der Kannengiesserordnung.

Gegenstände: Mächtige Glockenkanne mit Bajonetverschluss von 3 Maass Inhalt. Auf dem Deckelchen der Ausgussröhre das Meisterzeichen Nr. 179. Bodenrosette Nr. 212. Auf dem grossen Barokschilde die Initialen H G H M und B B. Am obern Teile des Korpus drei flache circuläre Wülste, am Unterteile nur eine. Leichte Ausladung am Fusse. Höhe $40,5 \mathrm{~cm}$. Durchmesser des Fusses $20 \mathrm{~cm}$. Der ziemlich flache Deckel, welcher durch Scharnirverschluss am Drehen verhindert wird, hat zwei tiefe circuläre eingedrehte Rillen. Mächtiger Tragring.

Grosse, stark konische Stitze mit Schnabel und kräftigem Deckelknopf. Am Deckelgriff Blattornament in Reliefguss. Der kuppelförmige Deckel hat am Rande ein kräftiges Profil, welches besonders über dem Schnabel fast überstark wird. Am Traghenkel befindet sich die Meistermarke Nr. 179. Bodenrosette Nr. 21 2. Die Höhe beträgt $37,5 \mathrm{~cm}$; der Durchmesser des Fusses $19 \mathrm{~cm}$. An der Vorderseite unterhalb des Schnabels sind prächtig gravirte Wappen mit den Initialen $H$ W und M G. Unterhalb der Alliancewappen ist die Jahrzahl 1644. (Tafel XXXVI, 4.) Die Kanne ist also ein Jahr nach der Ablegung des Kannengiessereides von Adam Wüscher angefertigt worden. Das Alliance-Wappen geht

1 Ordnungsbuch von 1480 , Seite 153 (1053).

2 Alt Ordnungenbuch von $159^{2}-1642$. S. 571 . Mitteilungen von Herrn Staatsarchivar Dr. H. Werner. 
auf Hans Wüscher-Gossweiler. Hans Wüscher zum Maulbeerbaum wurde am 24. Mai 1605 geboren, heiratete am 8. November 1624 Margaretha Gossweiler. Er war der Oheim unseres Kannengiessers, Adam Wüscher, ${ }_{1647}$ Urteilssprecher, ${ }_{1648}$ des grossen Rats, 1649 Spitalmeister, 1665 Vogtrichter und 1667 Zunftmeister. Er starb am 19. August 1669 .

Zwei gleiche Stitzen, jedoch ohne Gravuren, befinden sich in Basler Privatbesitz.

Bäschlin, Heinrich, erwähnt bei seiner Beschwörung der Kannengiesser-Ordnung im Jahre 1664. Er wurde am 11. Mai ${ }_{162} 6$ geboren und wurde ${ }_{1654}$ Meister. Sein Meisterzeichen mit den Initialen H H B findet sich bei Hintze, Bd. VII, Nr. 2263.

Abegg, II Alexander, wurde im Jahre ${ }_{1637}$ geboren. Er leistete im Jahre ${ }_{1664}$ den Kannengiesser-Eid und starb 1685 .



$178 \mathrm{c}$ Sein Meisterzeichen befindet sich auf einer mächtigen Glockenkanne. Ueber dem Schaffhauser Widderkopf und dem Familienwappen Abegg sind die Initialen A A E. Dieses Zeichen befindet sich auf dem Deckelchen des Ausgussrohres und entspricht $\mathrm{Nr} .178 \mathrm{c}$. Unterhalb ist noch ein interessantes Besitzerzeichen eingeschlagen, welches das Alliancewappen Peyer-Seiler trägt und darüber die Initialen L P. V S. Hans Ludwig Peyer wurde am 1 o. Juli ${ }_{1} 645$ geboren; er war Urteilssprecher, Mitglied des grossen Rates, Vogtrichter, Obherr, Schützenmeister im Baumgarten (Bogenschützen) und Oberjägermeister. $\mathrm{Er}$ verehelichte sich im Jahre 1666 mit Ursula Seiler von der Laterne. Er starb im 96. Lebensjahre am 12. März 1741 . (Mitteilung von Herr Dr. K. Henking, Schaffhausen.)

Die prachtvoll erhaltene Glockenkanne mit Bajonetverschluss hat einen Inhalt von ca. 3 Maass bei einer Höhe von $41 \mathrm{~cm}$. Durchmesser am Fuss 20,2 cm. An der rechten Seite des Kannenleibes ist ein grosser Barokschild angelötet, welcher leer ist. Um die Basis der Ausgussröhre ist eine kleine Einfassung im sogen. Tremolirstich. In der Höhe des Basis des Ausgussröhre vier flache circuläre Wülste. Am Fuss nur gravirte Rillen. Die Bodenrosette entspricht der Nr. 214 (Bd. I). Weitere Zinngegenstände sind vorläufig nicht bekannt gevorden.

Wüscher I Hans Adam, der Sohn des Adam Wüscher, geboren 1653 '. Lebte 1707 noch. Er führte wahrscheinlich das Meisterzeichen $\mathrm{Nr}, 178$.

Wüscher, II Hans Adam, der Sohn des I Hans Adam, geboren 1681, gestorben $1743^{1}$. Er führte wahrscheinlich die Meistermarke Nr. 18 o.

Wüscher, III Hans Adam, der Sohn des Vorigen; geboren 1711, gestorben $17_{2} 1$. Er führte vielleicht die Marke Nr. 181.

Wüscher, Laurenz, wurde im Jahre 1753 geboren und starb $1804{ }^{1}$.

Er führte das Meisterzeichen Nr. 182.

Gegenstände: Schnabelstitze mit Deckeltraube von $1 / 2$ Maass Inhalt. Meisterzeichen Nr. 182 auf dem Deckel vor der Traube. Keine Bodenrosette. Am Korpus vier doppelte circuläre Rillen, welche die glatte Wand unterteilen. An der linken Seite der Kanne die Initialen M G B und die Jahrzahl 1809 (wurde also erst später angebracht). Höhe $24,8 \mathrm{~cm}$. Durchmesser des Fusses 11,5 cm. (Tafel XXXVI, 7.)

Glockenkanne mit Bajonetverschluss von 1 Maass Inhalt. Auf dem Ausgussdeckelchen das Meisterzeichen Nr. 182. Auf dem Schild die Initialen H S (S im H) und die Jahrzahl 1789. Bodenrosette Nr. 213. Höhe $33 \mathrm{~cm}$.

Brunnenkesselchen von $14 \mathrm{~cm}$ Höhe.

Wïscher, Benedikt, der Sohn des Laurenz, wurde geboren 1780 , heiratete 1804 .

Gegenstand: Mächtige Glockenkanne mit Bajonetverschluss von ca. 3 Maass Inhalt. Oben auf dem Tragring die Meistermarke Nr. 183. Am Deckelrand ein Alliancewappen (Ringkh von Wildenberg und Im Thurm). Bodenrosette Nr. 214. Die Vorderseite der Kanne ist mit plumpen, eckigen Ornamenten überzogen. Auf dem später gravirten Schilde das

1 Daten nach den Mitteilungen von Herrn J. H. B̈̈schlin, Genealog, Schafbausen. 

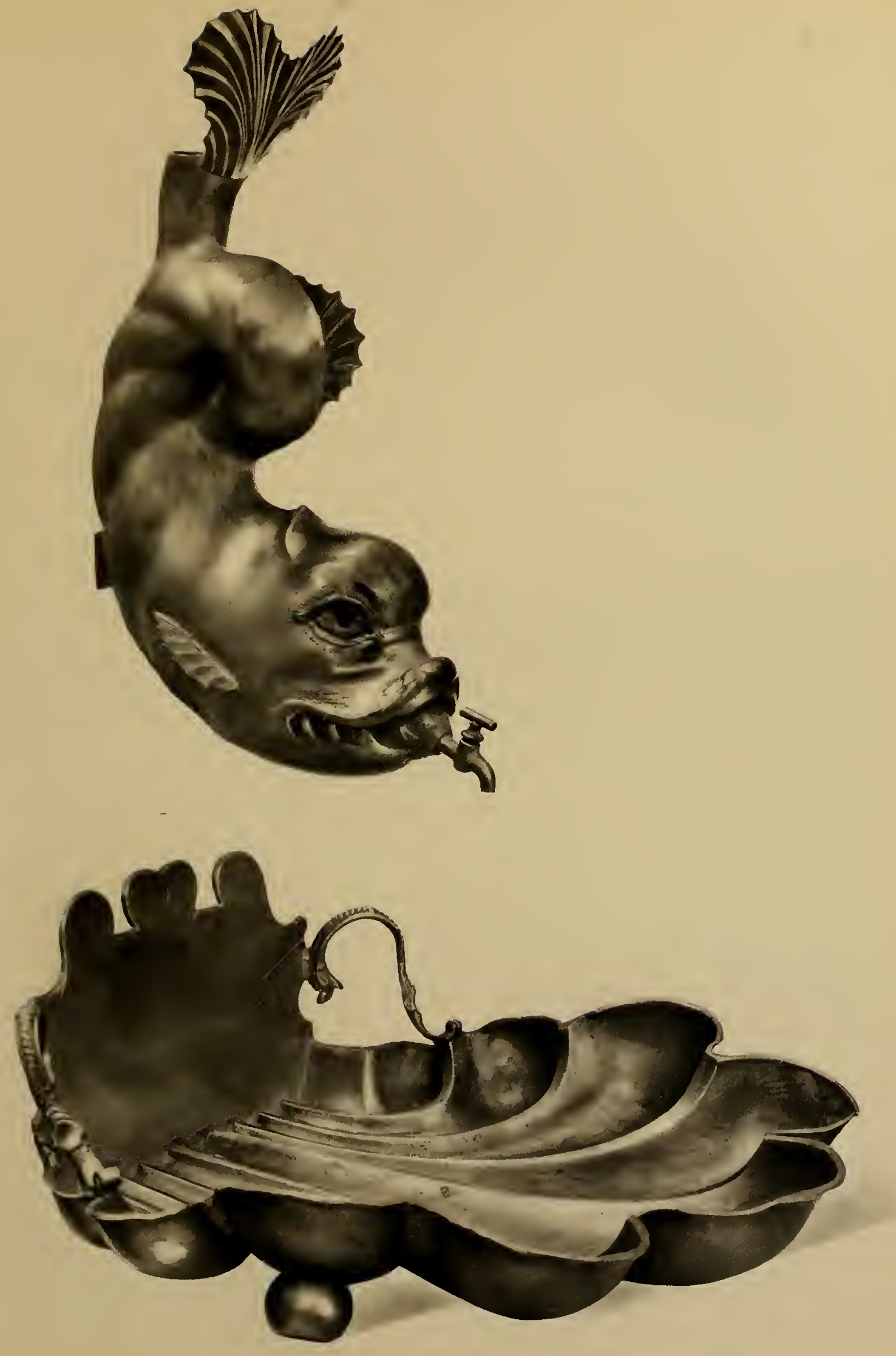

Delphin der Sammlung Hirsbrunner, Luzern (Zuger-Modell). 

Müllerwappen mit den Initialen I. R. M. und F C H 1807 . Höhe $42 \mathrm{~cm}$. Durchmesser des Fusses $20 \mathrm{~cm}$. Am obern Teile des Korpus drei flache, circuläre Wülste, am Unterteile zwei. Kolmar, P. mit ähnlichem Meisterzeichen wie Nr. 189, aber im Oval mit den Initialen P. K. Stitze von 1 Maass Inhalt in der Sammlung F. Pappe, Bern.

Kolmar, Johann Jakob, geboren 1664; gestorben $1738^{1}$.

Er führte das Meisterzeichen Nr. 189 oder 188.

Gegenstand: Glockenkanne mit dem Meisterzeichen Nr. 188. Auf dem Schild die Jahrzahl 1715 .

Kolmar, Johannes, der Sohn des Vorigen, geboren 1696; gestorben $1764^{\prime}$.

Er führte wahrscheinlich die Meisterzeichen des Vaters, Nr. 188 und 189.

In einer Glockenkanne eine Bodenrosette mit einer Blumenvase und Blumen, ähnlich der Bielerrosette $\mathrm{Nr}$. 58o.



189 a

Pfänder, I Johannes, Zinngiesser, geboren am 9. Mai 1656; verheiratet ${ }_{1682}$ mit Helene Schneblin (Schnewlin) von Stein. Er starb 1694.

Im historischen Museum von Schaffhausen ist auf einer grossen Glockenkanne sein Meisterzeichen, das Pfänderwappen mit der Jahrzahl (16)79 oder $77, \mathrm{Nr} .189 a$.

Pfänder, II Johannes, Zinngiesser, Sohn des Vorigen, geboren am 9. September 1683, verheiratet 1712 mit Anna Margaretha Peyer, gestorben im Spital am 6. März 1754.

Hurter, Hans Conrad, Zinngiesser, wurde am 3. September $16_{71}$ geboren, heiratete am 1o. Mai 1694 Dorothea Grübel und starb am 3o. Oktober $1744^{\prime \prime}$.

Er führte das Meisterzeichen Nr. 190.

Gegenstand: Glockenkännchen mit Bajonetverschluss von 1/4 Maass Inhalt. Das Meisterzeichen Nr. 190 auf dem Deckelchen der Ausgussröhre. Keine Bodenrosette. Auf dem Schild die Initialen M X D und E. Am Korpus vier Doppelrillen, circulär um den Leib. Höhe $22 \mathrm{~cm}$. Durchmesser des kräftig ausladenden Fusses 10,3 cm.

Hurter, Hans Jakob, Zinngiesser, der Sohn des Vorigen, wurde am 27. Juli 1696 geboren, heiratete am 18. November 1720 Anna Meyer und starb am 12. Juli 1752.

Er führte wahrscheinlich das Meisterzeichen seines Vaters, Nr. 190.

Schalch, I Hans Gonrad, wurde im Jahre 1590 geboren und starb ca. 1660.

Sein Meisterzeichen ist Nr. 191.

Gegenstände: Im historischen Museum von Schaffhausen sind zwei grosse Stitzen (Abendmahlkannen) von 35,5 cm Höhe mit dem Meisterzeichen $\mathrm{Nr} .191$.

Schalch, Hans Caspar, wurde geboren im Jahre $167^{2}$ und starb ca. 1740.

Weil dieser Giesser die gleichen Initialen hat wie der Vorige, so ist vielleicht Nr. 191 das Meisterzeichen.

Schalch, I Johann Conrad, der Sohn des Vorigen, wurde im Jahre 1702 geboren und starb 1767. Er führte das Meisterzeichen Nr. 192. Ferner eine Variante CS, darunter 3o (1730)".

Glockenkanne, Marke CS. 3o, Variante zu Nr. 192, datirt 1752. Bodenrosette Nr. 214. Es gibt noch eine kleine Variante dieses Stempels; allein auf allen bisher untersuchten Gegenständen war nur die obere Hälfte der Marke erhalten. Bei einer Schnabelstitze von $1 / 2$ Maass Inhalt mit Deckeltraube ist der Widderkopf der Meistermarke deutlich in einem quadratischen Feld. Bodenrosette Nr. 213 . Unter dem Schnabel die Initialen HVG. Höhe 19,8 cm. Durchmesser des Fusses 10,5 cm. (Tafel XXXVI, 1.)

Schalch, Hans Heinrich, der Sohn des Vorigen, wurde im Jahre 1709 geboren und starb in London im Hause "zum Zinngiesserwappen ". Er scheint in der Schweiz nicht gearbeitet zu haben.

1 Daten nach den Mitteilungen vnn Ilerrn J. H. Bächlin, Genealng, Sehafthausen.

2 Mitteilung von Herrn Wolfgang Pagenstecker, Prof. an der Kunstakademie in Düsseldorf, einem Descendenten einer vnn Hurter von Schafbausen.

3 Mitteilung von Herrn Dr. Hans Leemann, Bottmingermühle bei Basel. 
Schalch, II Hans Conrad, wurde im Jahre 1730 geboren und starb 1794. Er führte das Meisterzeichen Nr. 193 und vielleicht auch $\mathrm{Nr}$. 194 . Gegenstand: Mächtige Glockenkanne mit Schraubverschluss. Auf dem Deckelchen der Ausgussröhre das Meisterzeichen Nr. 193. Keine Bodenrosette, nur concentrische Kreise. Barokschild leer. Am Oberteil des Korpus drei flache circuläre Wülste und zwei am Unterteil. Höhe $42,5 \mathrm{~cm}$. Durchmesser des Fusses $20,5 \mathrm{~cm}$. Um die Basis der

Ausgussröhre herum ornamentale Einfassung im Tremolirstich. Der Deckelaufbau mit dem Tragring gleicht demjenigen der St. Galler Kannen. An der Unterseite des Bodens viele concentrische Kreise.

Schalch, Salomon, Sohn des I Johann Conrad Schalch, wurde im Jahre 1733 geboren und starb



$196 \mathrm{~b}$ in Fayence in der Provence im Jahre 1769. Er führte das Meisterzeichen Nr. 195.

Gegenstände: Glockenkanne mit Schraubverschluss von 1 Maass Inhalt.

Wöchnerinnenschüsselchen mit drei Knöpfen auf dem Deckel.

Schalch, II Johann Conrad, wurde im Jahre 1764 geboren und starb 1826 .

Er führte die Meisterzeichen Nr. $196 a$ und $b$.

Gegenstand: Rundes Plateau von $30 \mathrm{~cm}$ Durchmesser, mit reliefirtem Rande. Der Rand besteht aus einem Perlstab, einem Fries von stilisirten Blättern und einem profilirten Stab. An der Unterseite der Platte ist das Meisterzeichen Nr. $196 a$.

Schalch, III Johann Conrad, der Sohn des Johann Conrad II, wurde im Jahre 1801 geboren und starb 1849 .

Er führte die Meisterzeichen Nr. 197, 198 und 199.

Gegenstände: Glockenkanne mit Schraubverschluss von ca. 1 1/2 Maass Inhalt. Auf dem Deckelchen der Ausgussröhre das Meisterzeichen Nr. 199. Keine Bodenrosette. Um die Basis der Ausgussröhre spärliche Gravur im Tremolirstich. Am Korpus oben vier flache circuläre schmale Wülste, unten zwei. Auf dem Schild die Initialen TA. Der Fuss weist unterhalb der Ausladung noch einen $3 \mathrm{~cm}$ hohen senkrechten Untersatz auf. Höhe $36,5 \mathrm{~cm}$; Durchmesser des Fusses 15,5 cm. Am obern Rand des Deckels ein Perlstab.

Sechsseitig prismatische Kanne von $1 / 2$ Maass Inhalt mit Schraubverschluss. Meisterzeichen Nr. 199 auf dem Ausgussdeckelchen. Die Vorderseite der Kanne ist gravirt mit Ornamenten, den Initialen CST (St) und MD und der Jahrzahl ${ }_{1} 838$. Der Fuss hat keine Ausladung. Der obere Rand des Deckels weist einen Perlstab auf. Die Höhe beträgt $30,5 \mathrm{~cm}$; der Durchmesser des Fusses 11,7 cm.

Schmalrandiger Teller von 23,7 cm Durchmesser. An der Unterseite zweimal die Meistermarke Nr. 197, dazwischen ein gebogenes Schriftband mit den Worten Fein Zinn. Gemüseschüsseln.

Die Bestimmung und $Z$ uteilung der $M$ eisterzeichen der acht verschiedenen $Z$ inngiesser-Meister Schalch ist eine sehr schwierige, weil die Initialen fast alle die gleichen sind. Auch haben zu gleicher Zeit mehrere Giesser der gleichen Initialen gearbeitet. Darum haben wir einzelne Marken nur mit Vorbehalt dem Meister zugewiesen. Ausserdem kommt es öfters vor, dass die Meisterzeichen des Vaters vom Sohne weiter gebraucht wurden und deshalb geben auch datirte Zinngegenstände nicht eine absolut einwandfreie Auskunft oder Lösung des Ursprunges.

Moser, Andreas, von Schaffhausen, Zinngiesser, wurde am 29. Januar 1768 geboren und starb am 24. Dezember 1812 .

Er führte die Meisterzeichen Nr. 203, 204 und 205, oft mit der Jahrzahl 1792.

Gegenstände: Schlanke Glockenkanne mit Bajonetverschluss und Arretirung von $1 \frac{1}{2}$ Maass Inhalt. Auf dem Ausgussdeckelchen die Marke Nr. 204. An der Leibung der 
Kanne oben vier circuläre Wülste und unten zwei. Unterhalb des Ausgusses prächtige, gravirte Blumenornamente. Auf dem Schild die Initialen CL. W und MM. F 1825 . Höhe $36 \mathrm{~cm}$. Durchmesser des schön ausladenden Fusses 16,5 cm. Bodenrosette Nr. 215. (Tafel XXXVI, 3.)

Glockenkanne mit Bajonetverschluss von $1 / 2$ Maass Inhalt. Gleiches Meisterzeichen. Auf dem Schild die Initialen H. E und H. BM. 1825. Gravirte Blattranken. Höhe $26 \mathrm{~cm}$. Durchmesser des ausladenden Fusses $13 \mathrm{~cm}$. Bodenrosette Nr. 215. (Tafel XXXVI, 6.) Glockenkanne mit Schraubverschluss. Auf dem Ausgussdeckelchen die Meistermarke Nr. 203. Auf dem Schild die Initialen K ST 1848. Spärliche Gravirung um die Basis des Ausgusses herum. Höhe $37 \mathrm{~cm}$. Durchmesser des Fusses 16,8 cm. Bodenrosette Nr. 2 I 5 . Kleinste Glockenkanne mit Schraubverschluss. Auf dem Ausgussdeckelchen die Meistermarke Nr. 203. Auf dem Schild die Initialen H R M. An der Vorderseite zwei Blumen-Blattranken. An der Leibung oben fünf und unten drei circuläre Wülste. Höhe $23,5 \mathrm{~cm}$. Durchmesser des Fusses $11,3 \mathrm{~cm}$. Bodenrosette Nr. 215. (Tafel XXXVI, 2.) Sechsseitig prismatische Kanne mit Schraubverschluss von 1 1/2 Maass Inhalt. Auf dem Ausgussdeckelchen das Meisterzeichen Nr. 204. Auf dem Schild die Initialen A.H.A. An den zwei Vorderflächen je ein gravirter Tulpenzweig. Ausladung des Fusses leicht profilirt. Höhe $36,5 \mathrm{~cm}$. Durchmesser des Fusses 15,3 cm. Bodenrosette Nr. 215. (Tafel XXXVI, 5.)

Schnabelstitze von $1 / 2$ Maass Inhalt. Am Traghenkel Meisterzeichen Nr. 204. Um den Schnabel spärliche Gravuren im Tremolirstich, darunter die Initialen H ST. Bodenrosette Nr. 215 . Deckeltraube. Höhe $22 \mathrm{~cm}$. Durchmesser des Fusses 12,5 cm. Am Korpus drei doppelte circuläre Rillen.

Kleine Schnabelstitze. Am Traghenkel das Meisterzeichen Nr. 2o3. Keine Bodenrosette. Höhe $14,7 \mathrm{~cm}$. (Acanthusblattgriff.) Durchmesser des Fusses $8,3 \mathrm{~cm}$. Am Korpus circuläre Doppellinien. Um den Schnabel herum spärliche Gravur im Tremolirstich. Schnabel klein.

Meyer, Jakob, Zinngiesser aus Hallau', wurde am 26. November 1783 geboren und starb am
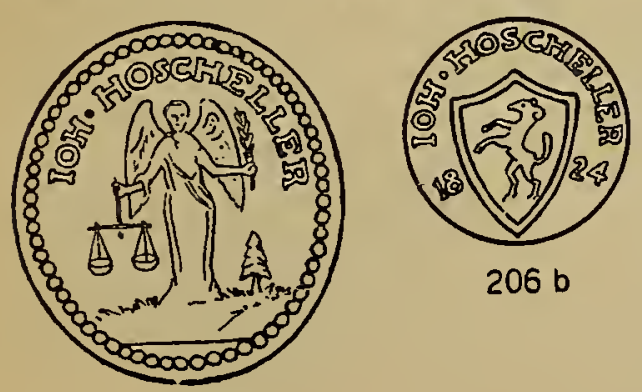

206 b 10. November 1831. Meisterzeichen Nr. 206.

Meyer, Jakob, aus Hallau, der Sohn des Vorigen, wurde geboren am 4. Oktober 1812 und starb am 1. März 1879 . Er schloss sein Zinngiessergeschäft im Jahre 1875 . Seine Meistermarke ist ebenfalls Nr. 206.

Hoscheller, Johannes, Zinngiesser, wurde am 14. Juni $179^{2}$ geboren, heiratete 1825 und starb am 29. Mai 1840 . Er führte die Meisterzeichen Nr. $206 a$ und $b$. Gegenstand: Glockenkanne von $28,5 \mathrm{~cm}$ Höhe im historischen Museum von Schaffhausen.

Oechslin, Johann Alexander, wurde im Jahre 1823 geboren, heiratete 1850 und starb 1870. Er führte als Meisterzeichen Nr. 200, 201 und 202.

Gegenstände: Glockenkanne mit Schraubverschluss. Auf dem Ausgussdeckelchen die Meistermarke Nr. 202. Auf dem Schild die Initialen B H. J J. Am obern Teil des Korpus vier, am untern Teil zwei flache circuläre Rillen. Innen in der Mitte des Bodens die Marke Nr. 201. Am obern Rand des Deckels ein Perlstab. Höhe 28,6 cm; Durchmesser des gut ausladenden Fusses $13,8 \mathrm{~cm}$.

Glockenkanne mit Schraubverschluss und beweglichem Tragring. Keine Ausgussröhre. Auf dem Deckel eine breite profilirte Oese, in welcher der Tragring läuft. Die W $\mathrm{Wülste}$ am Kannenleib sind fast völlig verstrichen. An der Unterseite des Bodens die Meistermarke Nr. 201. An der Seitenwand: G. Heer, und darunter die Initialen B. G. Höhe $22 \mathrm{~cm}$. Durchmesser des Fusses $14 \mathrm{~cm}$. (Tafel XXXII, 10.)

\footnotetext{
I Mitteilung vun Herru Jakob Pfund, Archivar in Hallan.
} 
Runde, flache Gemüseschüssel mit Henkeln; senkrechte Seitenwände. Meisterzeichen Nr. 200.

Runde Platten verschiedener Grösse.

Wiedemann, Franz Josef, wurde geboren am 4. Oktober 1846 und starb am 25. Juni 1919. Er führte als Meisterzeichen Nr. 208, 209, 210.

Wiedemann, Alfons, der Sohn des Vorigen, Zinngiesser, wurde am 17. März j 885 geboren und ist heute noch tätig.

\section{Die Zinngegenstände}

Die Qualität ist im Allgemeinen eine recht gute und der Zinnprobe entsprechend, in dem Sinne, dass die Probe immerhin dem billigsten Geschirr entspricht. Wie an andern Orten, bestellten die Kunden oft Gegenstände in besserer Legierung und so ist es nicht vertvunderlich, wenn auf einem Teller sich der Stempel befindet mit der Inschrift: "Wie das Gelt so die Waar" (Nr. 211, Bd. I).

\section{Die Kannen}

Die Glockenkannen : Die ältesten Exemplare haben stets den Bajonetverschluss. Auffallend häufig finden sich ganz grosse Stücke von 3 Maass Inhalt. Die Form der Schaffhauser Glockenkannen ist im Vergleich zu den zürcherischen viel schlanker; mithin ist sie bei gleichem Inhalt stets erheblich höher. Ferner haben dieselben immer oben und unten am Korpus je 1-5 circuläre flache Wülste. Dieselben entsprechen den Weidenreifen der Holzgefässe, welche die Dauben zusammenhalten. Bei den zürcherischen Glockenkannen steht der Tragring vermittelst eines kurzen, gedrungenen Fusses auf dem Deckel. Bei den Schaffhauser Exemplaren ist dieser Fuss schlank und hoch. Bei den Schaffhauser Glockenkannen mit Schraubverschluss ist der Deckel sehr klein, so dass das Innere der Kanne fast nicht gereinigt werden kann. Die Ausgussröhre ist stets mit einem Deckelchen verschlossen, niemals durch einen Gewindeverschluss. Sehr häufig findet man prachtvoll gravirte Stücke. Auf dem massiven gotischen Schild einer 3-mässigen Glockenkanne ist ein Familienwappen eingepunzt und daneben die Jahrzahl 1582 ; darüber die Initialen E R.V M. Leider ist das Ausgussdeckelchen, welches die Meistermarke trägt, abgebrochen. Im Kannenboden ist die Bodenrosette Nr. 212 eingesetzt.

Es gibt auch Glockenkannen ohne Ausgussröhre; der Schraubdeckel trägt eine schwere Oese, in welcher ein beweglicher Tragring läuft. Aehnliche Exemplare finden sich in Elgg, Zofingen und St. Gallen.

Die prismatischen sechsseitigen Kannen haben keine besondern Eigenschaften, welche dieselben von den zürcherischen und thurgauischen unterscheiden. Der Träger des Tragringes ist allerdings höher und schlanker; doch kann nur die Meistermarke allein für die Ortsbestimmung ausschlaggebend sein.

Recht häufig sind kleine, sechsseitige prismatische Gefässe ohne Ausgussröhre. Auf dem Schraubdeckel befindet sich in einer Oese ein beweglicher Tragring. Diese Gefässe dienten wahrscheinlich als Wärmfläschchen, indem dieselben mit heissem Wasser gefüllt wurden; vielleicht wurden auch Geviüze, Thee u. dgl. darin aufbewahrt. Wir erwähnen dieselben noch besonders aus dem Grunde, weil in den letzten Jahren im Altertumshandel oft kleine prismatische Kännchen auftauchten, welche aus diesen Gefässen hergestellt wurden. Durch das Einsetzen einer Ausgussröhre und das Auflöten eines Tragringes ist die ganze Verwandlung eine Leichtigkeit. So werden Raritäten fabrizirt, weil eben so kleine Kännchen aus der Zeit ausserordentlich selten sind. Falls man daran denkt, sind diese Objekte bald entlarvt. Ich habe sechs- und achtseitig prismatische Stücke gefunden. 


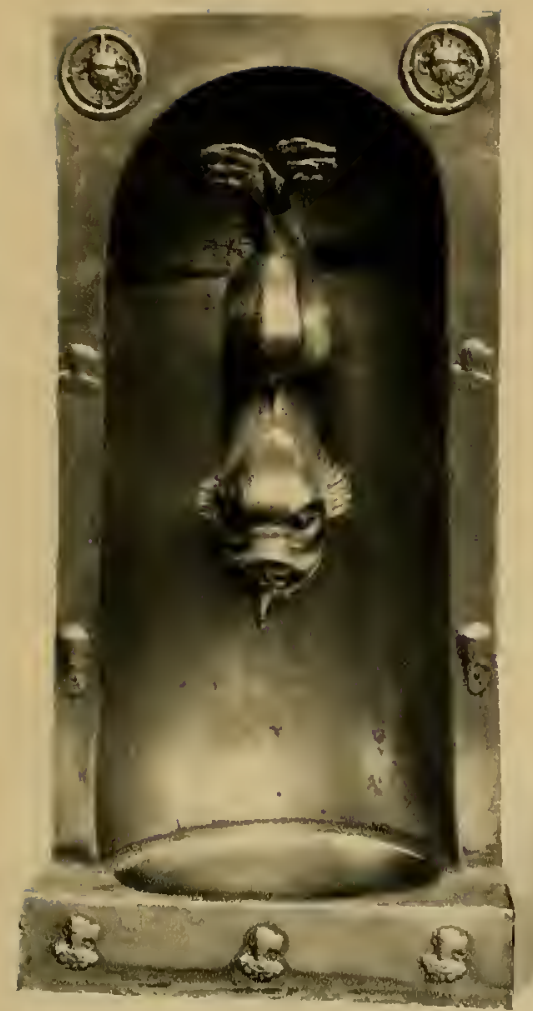

1

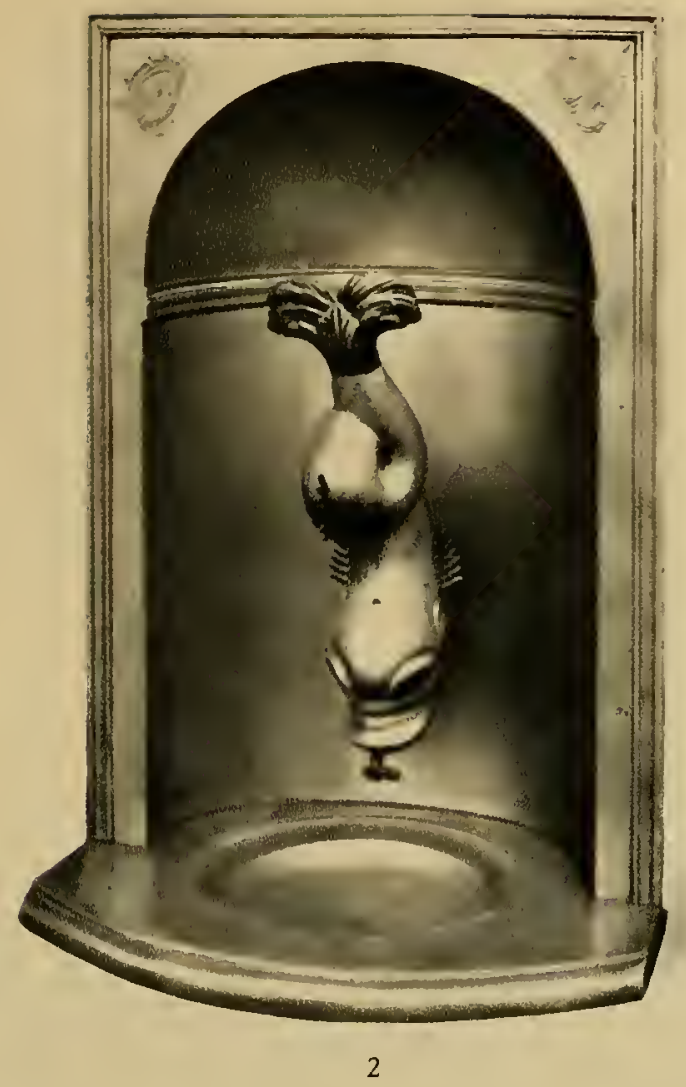

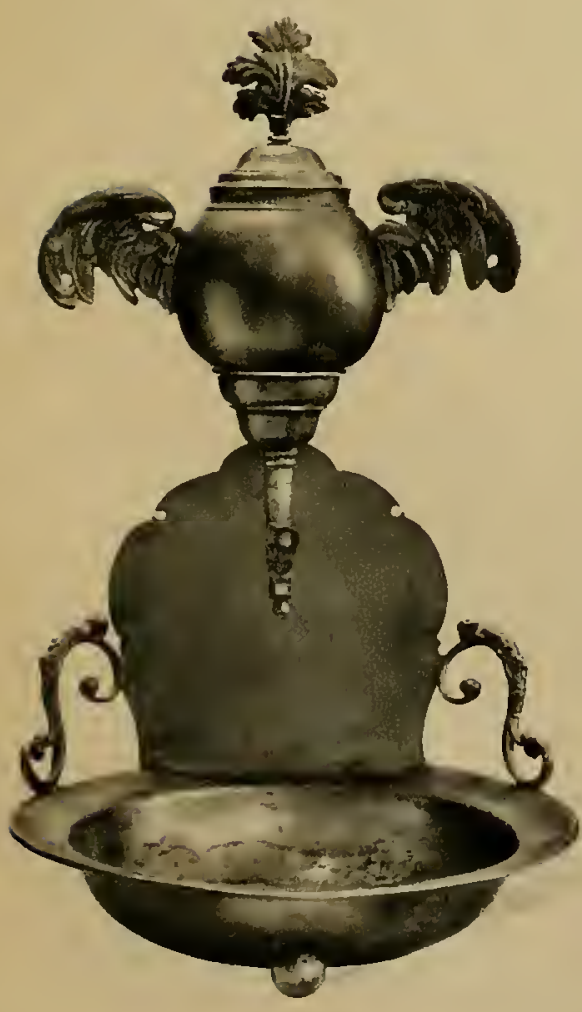

3

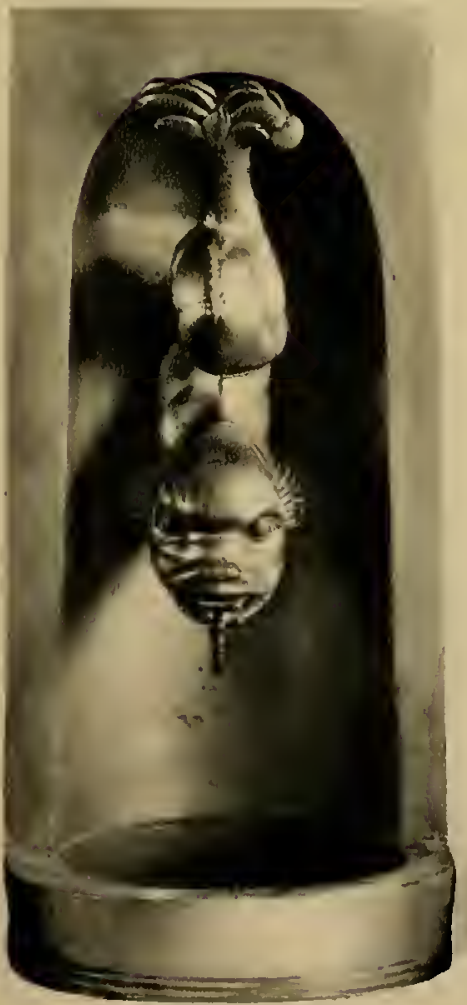

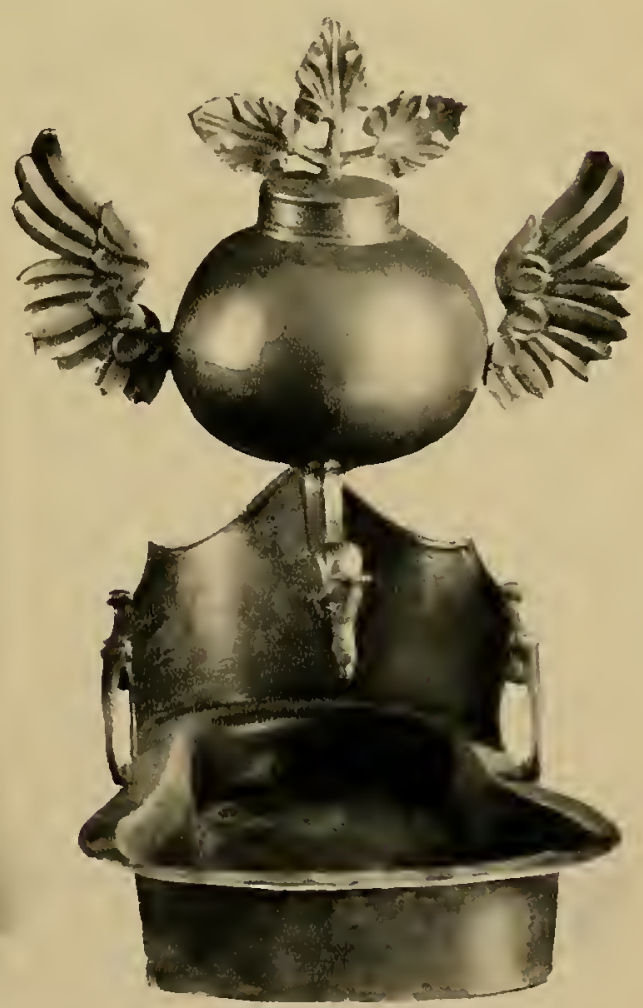

4

1. Delphin mit Nische im Renaissancestil, Sammlung F. Pappe, Bern. 2. Delphin mit Nische und grossen gravierten Wappen von Frz. Xaver Schallbretter, Luzern (1725 49 nachweisbar). 5. Delphin mit Nische, früher Sammlung C. Hirsbrunner, Luzern. 3. 4. Gellügelte Kugelgiessfässer mit zinnernen Handbecken von Chur, bei C. Hirsbrunner, Luzern. 

Die Stitzen: Sie haben stets den schnabelförmigen Ausguss und sind im Vergleich zu den andern Schaffhauser Kannen selten. Es kommen vier Grössen vor, von $14,5 \mathrm{~cm}$ bis $37,5 \mathrm{~cm}$ Höhe. Im Gegensatz zu den zürcherischen Exemplaren sind dieselben viel massiger und plumper. Die Zuteilung ist ebenfalls nur durch das Meisterzeichen möglich. Weitere Einzelheiten findet man bei den Zinngiessern Hans Bäschli, I Alexander Abegg, Adam Wüscher Laurenz Wüscher, I Hans Conrad Schalch, I Johann Conrad Schalch und A. Meier. Eine besondere Erwähnung verdienen die mächtigen Stitzen, meist Abendmahlkannen, von Hans Bäschli und I Alexander Abegg im historischen Museum in Schaffhausen, weil dieselben gleichzeitig die ältesten, erhaltenen Zinnkannen dieser Stadt sind. Aehnliche Stücke tragen die Meisterzeichen von I Hans Conrad Schalch und Adam Wüscher.

Die übrigen Gegenstände, Teller und Platten, Salzgefässe, Schüsseln, u.s.w., haben keine für Schaffhausen eingentümliche Formen und sind mithin nur durch die Meistermarke zu erkennen.

Gefälschte Meistermarken sind auffallend häufig zu treffen und zwar besonders bei den Gegenständen der verschiedenen Schalch (meistens H. C. S. und C. S.).

\section{THURGAU}

\section{FRAUENFELD}

In der Constaffelgesellschaft zu Frauenfeld waren ursprünglich nur Adelige, hohe Beamte, Geistliche oder zu Reichtum und Ansehen gelangte Bürger. Nach dem Jahre 1640 konnten auch Handwerker eintreten und mit diesen auch die Kannengiesser. Von 1746-1799 wurden aber keine einheimische Zinngiesser mehr aufgenommen; nach dem Tode oder Wegzuge des Meisters Heinrich Teucher waren es Fremde, welche das Niederlassungsrecht zur Ausübung des Zinngiesserberufes erhielten. Die Auszüge aus den Stubenbüchern der Frauenfelder Constaffelgesellschaft verdanke ich Herrn K. Frei-Kundert, zur Zeit Vicedirektor des schweiz. Landesmuseums in Zürich; ebenso die archivalischen Angaben über die Meister.

Das Wappen von Frauenfeld: in Silber ein steigender roter Löwe an goldener Kette, gehalten von einer rot gekleideten Frau, befindet sich auch auf den Meisterzeichen. Der etwas complizirte Stempel leidet bei der Verkleinerung und besonders bei der natürlichen Abnutzung der Zinngegenstände.

\section{Die $Z$ inngiesser von $F_{\text {rauenfeld }}$}

Sulzberger, Hans Caspar, Zinngiesser. Es ist nur das Todesdatum bekannt: 23. Oktober 1635 (Evang. Kirchenbuch von Frauenfeld, Sterberegister).

Müller, Melchior, Zinngiesser; er wird im Jahre 1642 in der Liste der anno 1642 lebenden Herren und Stubengesellen der Konstaffelgesellschaft aufgeführt. Er war ${ }_{1637}$ Lehrling bei Heinrich Wirz in Zürich (Staatsarchiv E II 213 fol 284).

Sulzberger, Adam, Zinngiesser, tritt 1660 als Meister in die Konstaffelgesellschaft; starb 1693. Mörigkoffer, Hans Jakob, I, Zinngiesser, trat 1670 als Meister in die Constaffelgesellschaft zu Frauenfeld; er starb am 24. November 1729 (Evang. Kirchenbuch).

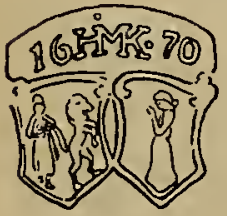

217 a

Kapeller, Hans Ulrich, Zinngiesser, führte das Meisterzeichen Nr. 217 a mit der Jahrzahl 1670. Er lernte von 1664-1668 bei Samuel Burkhart in Basel. Er trat ${ }_{1681}$ in die Constaffelgesellschaft und starb im Jahre 1712. Er war in Frauenfeld Bürger.

Gegenstand: Glockenkanne mit Bajonetverschluss; Höhe $26 \mathrm{~cm}$; Durchmesser des Fusses $12 \mathrm{~cm}$. Inhalt 1/2 Maass. Das Meisterzeichen Nr. $217 a$ ist auf dem Deckelchen der Ausgussröhre. Oben am Korpus 
ein breiter circulärer Wulst. Auf dem Schild die Initialen T H K und A M E. 1714. HB . E B S. Innen am Boden eine sechsteilige Rosette. (Tafel XXXVI, 13.)

Teucher, Hans Melchior, Zinngiesser, führte die Meisterzeichen Nr. 216, 217 (Bd. I). Im Jahre 1703 trat er als Meister in die Constaffelgesellschaft zu Frauenfeld. Er war auch Stadtwachtmeister. Laut Sterberegister des evang. Pfarrarchivs von Frauenfeld starb er am 17. Dezember 1742 .

Gegenstände: Prismatische, sechsseitige Kannen mit dem Meisterzeichen Nr. 216. Höhe ca. $40 \mathrm{~cm}$. (Landesmuseum Zürich.)

$\mathrm{Z}$ innische im Buffet des Schlosses Turbental mit dem Meisterzeichen Nr. 217.

Mörigkoffer, Hans Jakob II, Zinngiesser, trat 1705 als Meister in die Constaffelgesellschaft.

Er starb 1729.

Fehr, Adam, genannt Brunner, Zinngiesser, trat 1720 als Meister in die Constaffelgesellschaft.

Er war Stadtfähnrich. Er starb am 2. August 1763 (Constaffelbuch $\mathrm{H}_{1}$ ).

Teucher, Heinrich, Zinngiesser, trat 1746 als Meister in die Constaffelgesellschaft (M.LC.G Frauenfeld). Er starb in Bern.

Jenetti, Josef Mauritius, Zinngiesser in Frauenfeld, wird als Ansässe angeführt im Steuerbuch (C 6 fol 185) von 1775-1793.

Sessiani, Anton, Zinngiesser in Frauenfeld, Nachfolger des vorigen Josef Mauritius Jenetti. Er wird als Ansässe im Steuerregister (C 6 fol 185, Bürgerarchiv Frauenfeld) von 1794 bis 1798 angeführt.

\section{Die Zinngegenstände}

Kannen kommen in Glockenform und als prismatische sechsseitige Krüge vor. Sie haben keine charakteristische lokale Eigenschaften und sind nur durch das Meisterzeichen zu bestimmen.

Die berühmten und technisch wundervoll ausgeführten $S t a d t k a n n e n$ von Frauenfeld sind nicht mehr vorhanden (Tafel IV, 2). Sie sollen an Pierpont Morgan in New-York verkauft worden sein und zwar um 1890 herum. Vor ihrer Abreise wurden dieselben in Luzern einigen Reparaturen unterworfen; bei dieser Gelegenheit wurde auch eine gut gelungene Kopie angefertigt, welche sich zur Zeit in Luzern befindet. Auf derselben fehlt aber das Meisterzeichen des Frauenfelder Meisters.

Quellenmaterial für Frauenfeld: Stubenbuch der Constaffelgesellschaft in Frauenfeld. Im Bürgerarchiv :

$\mathrm{H}_{1}$ : in demselben befindet sich : $a$ ) die Liste der anno ${ }_{1} 64_{2}$ lebenden Herren und Stubengenossen; b) die Liste der nach 1643 eingetretenen Mitglieder.

$\mathrm{H}_{2}$ : Die Liste der von 1750 an neueintretenden Gesellschaftsmitglieder und das Verzeichnis der anno 1750 lebenden Mitglieder.

In beiden Bänden finden sich auch Lehrjungenlisten. Zürich.)

(Mitteilung von Herr Vicedirektor K. Frei-Kundert, am schweiz. Landesmuseum in

\section{BISCHOFSZELL}

Die archivalischen Mitteilungen verdanke ich dem Herrn Lehrer Th. Bridler in Bischofszell und Herrn Vicedirektor K. Frei-Kundert, Landesmuseum in Zürich. In Betracht kommen folgende Quellen :

"Memorabilia Episcopicellana oder Merkwürdigkeiten der Stadt Bischofszell ... zusammengetragen von Johann Caspar Diethelm, M. Dr. und Stadtschreiber 1749 ", Tome II im Bürgerarchiv Bischofszell. 
"Ehebuch der evangelischen Verbürgertenzu Bischofszell, auffgesetzt und angefangen von Herrn Wartmann-Vogel VDM und Vicario der Pfarrey allhier vom Jahr 1700 bis und mit dem 29. 7 bris 1743 , von da aber continuiret von Johann Caspar Diethelm med. doct. und evangel. Stadtschreiber zu Bischofszell " (Stadtbibliothek Bischofszell).

"Totenbuch vom 8 ber 1728 bis und mit 16 . August 1743 , continuiret wie beim vorigen Buch " (Stadtbibliothek Bischofszell).

\section{Die $Z_{\text {inngiesser von }} B_{i s c h o f} f_{s z e l l}$}

I. M. Meister I M führte das Meisterzeichen Nr. $242 a$, welches sich auf einer halbmässigen Glockenkanne befindet. Am Korpus der Kanne sind rautenförmige Facetten eingetrieben und geben derselben ein eigentümlich gotisirendes Aussehen. Der Besitzer wünscht Nichtbekanntgabe des Namens.

Schlatter, Heinrich, Zinngiesser, zitirt am 26 . Weinmonat 1680 , anlässlich der Heirat seiner Tochter mit Balthasar Keller, Bürger und Weber in Frauenfeld (Evangel. Pfarrbuch Frauenfeld, 1622 bis ${ }_{1} 671$, im Pfarr-Archiv).

Riedtmann, Bartholome, Zinngiesser, führte das Meisterzeichen Nr. 240 (Bd. I). Er wird als Mitglied des Gerichts 1686 zitirt. Er starb im Jahre 1727 (DM pag 547 II, Diethelm, Memmorabilia). Wird auch Rietmann geschrieben.

Gegenstände: Breitrandiger Gupfteller; Durchmesser 29,7 cm; Randbreite $6 \mathrm{~cm}$; Tiefe $4 \mathrm{~cm}$. Rand vorn und hinten verstärkt. Vorn am Rand das Meisterzeichen Nr. 240 ; daneben die Initialen I. N. und darüber in schlechter Gravierung H C N. Fundus in der Mitte hochgetrieben. An der Rückseite ein gravirtes Hauszeichen und H. I. (Tafel XXVI, 10.)

Grosse tiefe Gemüseschüssel mit dem Meisterzeichen Nr. 240 oben am schmalen Rand. (Kunsthandel, Zürich.)

Die Ratskannen von Bischofszell, zwölf Stücke, tragen ebenfalls das Meisterzeichen Nr. 240 . Die Kannen scheinen aber älter zu sein; Fuss und Korpus haben frühen Charakter. Der Bischofszeller-Schild, die zum alten Stil nicht gut passende Ausgussröhre und ein Teil des Deckels scheint aber von B. Rietmann zu stammen. Als Vorbild zur Ausgussröhre diente wohl die Berner Stegkanne. Die Ratskannen befanden sich, nebst anderem schönem Zinngeschirr, im Archiv der Bürgergemeinde und wurden sorgsam gehütet. Die Besichtigung erforderte die Gegenwart mehrerer Ratsmitglieder. Nun sind die schönen Kannen im neuen städtischen Museum ausgestellt. Höhe $53 \mathrm{~cm}$; Durchmesser des Fusses 17,7 cm. Meisterzeichen Nr. 240 auf dem Deckelchen der Ausgussröhre. Durchmesser des Korpus $17,3 \mathrm{~cm}$; Länge der Ausgussröhre $24,5 \mathrm{~cm}$. (Tafel VI, 4.)

Daller, Hans Jakob, Zinngiesser, führte als Meisterzeichen Nr. 241 c. Sein Name wird bald Daller, bald Thaler geschrieben. Er war ab 3o. Mai $169_{2}$ Lehrling bei Andreas I



$241 \mathrm{c}$ Wüger in Steckborn (Handwerksbuch der Stadt Steckborn, fol. 5o a); auch Kronenwirt und ist von 1711-1720 als Ziegler erwähnt (Diethelm, Mem. II, 5o3). Im Ehebuch wird er am 14. April 1733 zitirt. Im Totenbuch 1750.

Gegenstand: Schmalrandiger Teller von $23,8 \mathrm{~cm}$ Durchmesser. Meisterzeichen Nr. $241 c$ an der Vorderseite des Randes. An der Unterseite des Bodens die gravirten Initialen I C L.

Zwinger, Hans Caspar, Zinngiesser, wurde im Jahre ${ }_{17} 36$ geboren; wird im Ehebuch am 12. September $1_{7} 6_{2}$ erwähnt als Meister Caspar $Z$ winger, der Zinngiesser. Das Totenbuch von Bischofszell meldet am 26. März 1775: Hans Caspar Zwinger, Zinngiesser, starb zu Novarra, in Piemont, im Spital als Soldat unter Reg. Tscharner, Comp. Graf, aet. 39.

Bridler, Johann Baptist, Zinngiesser, führte die Meisterzeichen Nr. 241 und 2416 (Bd. I). Er wurde am 23. Januar $175_{1}$ geboren, war 1781 Mitglied des Gerichts (Diethelm, Mem. II, 
501). Er starb am 21. Juni 1805. Am Ende seines Lebens muss er sich in Bern aufgehalten haben, da er $1798 \mathrm{im}$ Verzeichnis der mehrjährigen Anwohner angeführt ist.

Gegenstände : Glockenkanne mit Bajonetverschluss; Höhe $26 \mathrm{~cm}$; Durchmesser des Fusses 12,4 cm. Inhalt 1/2 Maass. Auf dem Deckelchen der Ausgussröhre das Meisterzeichen Nr. 241. Am Korpus oben drei und unten zwei flache circuläre Wülste. Auf dem Schild die Initialen I. B. I. 1803 . Keine Bodenrosette. (Tafel XXXVI, 8.)

Prismatische, sechsseitige Kanne von $36 \mathrm{~cm}$ Höhe, mit dem Meisterzeichen Nr. 241 auf dem Deckelchen der Ausgussröhre. (Sammlung L. Gally in Basel.)

Schmalrandige Teller von 28 und 3o cm Durchmesser, mit dem Meisterzeichen Nr. 2416 . (Herr Lehrer Th. Bridler in Bischofszell.)

\section{ERMATINGEN}

Das Wappen von Ermatingen, am Bodensee-Untersee, in Schwarz ein stehender weisser Hund.

Ammann, Sebastian, Zinngiesser, war Lehrling bei Hans Joachim Keller in Weinfelden. Am 22. Januar 1747 wurde er für fünf Jahre bei der Schmiedezunft in Konstanz eingeschrieben (Einschreibebuch II der Schmiedezunft in Konstanz, S. 15o) (siehe auch Hintze, Bd. VII, Nr. $202 x$ ).

Ammann, Bernhard, Zinngiesser, führte das Meisterzeichen Nr. 296 (Bd. I) und 296 a (Bd. II). Er wird am 11. August 1744 im Ratsprotokoll von Steckborn

BA

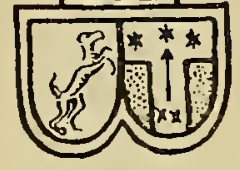

296 erwähnt und zwar anlässlich des Einzugs seiner Tochter Verena als Gemahlin des Hans Conrad Gräflin, Jung Müller in Steckborn (Ratsprotokoll im Bürgerarchiv von Steckborn).

Gegenstände : prismatische, sechsseitige Kanne; Höhe $34,2 \mathrm{~cm}$; an den Seitenwänden schön gravirte Blumenranken, Wappen und Vögel. Schraubverschluss (Historisches Museum

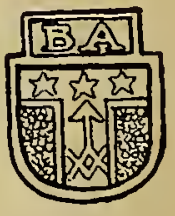

296 a von St. Gallen). Meisterzeichen Nr. 286 (Bd. I).

Glockenkanne von 1 Maass Inhalt mit Bajonetverschluss. Auf dem Deckelchen der Ausgussröhre das Meisterzeichen Nr. 296. (Sammlung C. Hirsbrunner, Luzern.)

\section{STECKBORN}

Das Wappen der Stadt Steckborn: in Blau ein goldener Ring, durch welchen zwei goldene Stäbe kreuzweise gelegt sind.

Als archivalische Grundlage stellte Herr K. Frei-Kundert, Vicedirektor am schweizerischen Landesmuseum, seine Auszüge aus den folgenden Quellen zur Verfügung: Pfarramtliche Civilstands-Register ; Tauf-, Ehe- und Sterberegister. Die Auszüge von Dr. Friedrich Horner, Zürich.

In Steckborn gibt es eigentliche Zinngiesser-Dynastien. Sechs Andreas und drei Johannes Wüger sind bekannt, ferner drei Hans Jakob Basler. Es ist unmöglich, nach der Meistermarke mit den gleichen Initialen jedem die seinige zuzuteilen. Bekanntlich sind ja auch die eingravirten Daten nicht massgebend. Auch die Zuteilung bei Hintze (Bd. VII, S. 38o-382) ist rein willkürlich und entbehrt jeder beweisenden Unterlage ; er teilt die Wappen nach der Form des Schildes zu. Eine einwandfreie Zuteilung ist einfach unmöglich.

Die Steckborner Zinngegenstände sind im Thurgau sehr verbreitet, besonders Glocken- und prismatische Kannen, häufig auch Teller und Platten. Ausser den im Band I, Tafel XI, Nr. 2 20-225, angegebenen Marken gibt es noch viele Varianten, mit den gleichen Initialen, auf deren Reproduktion verzichtet wurde. An Stelle des Steckborner Wappens findet man auf den Meisterzeichen oft einen steigenden Löwen. Damit wird die Zuteilung noch mehr erschwert. 

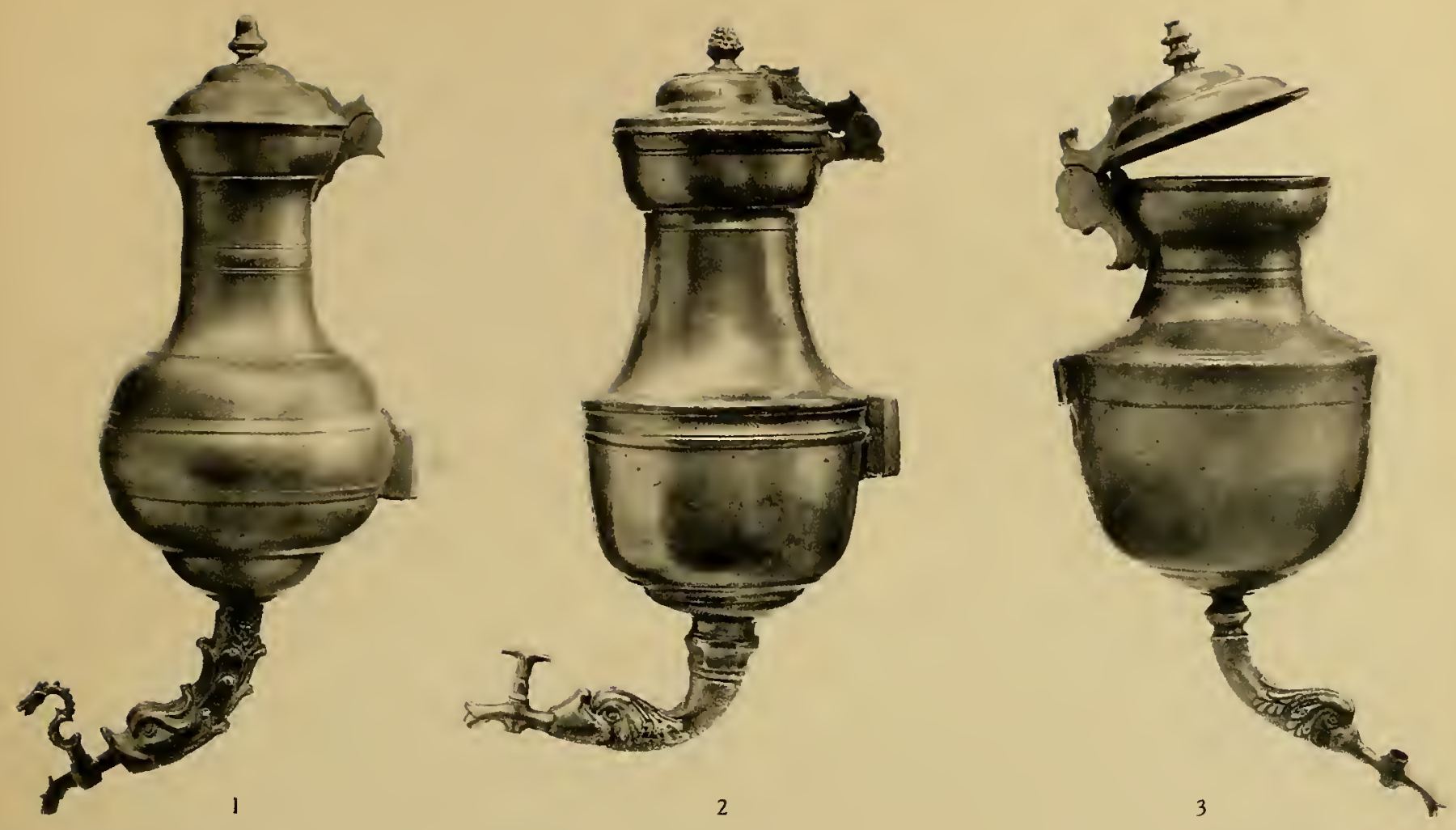

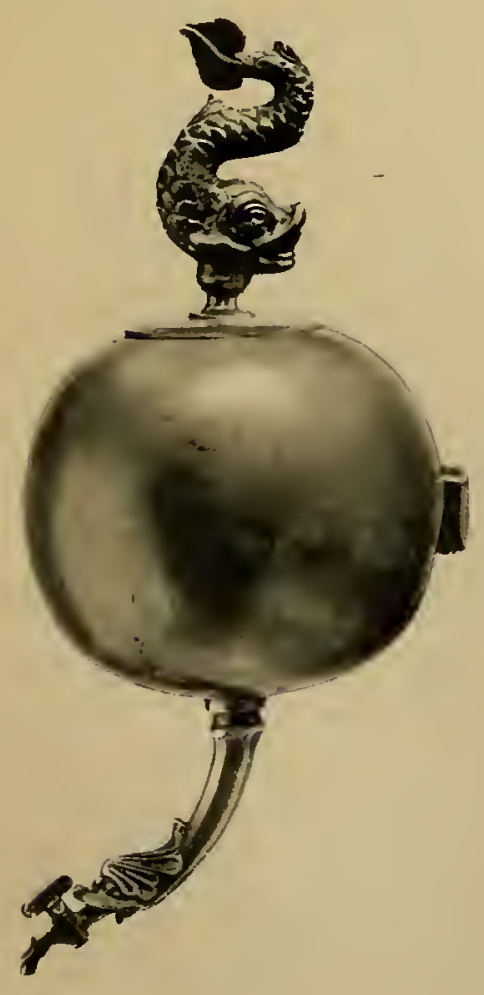

4

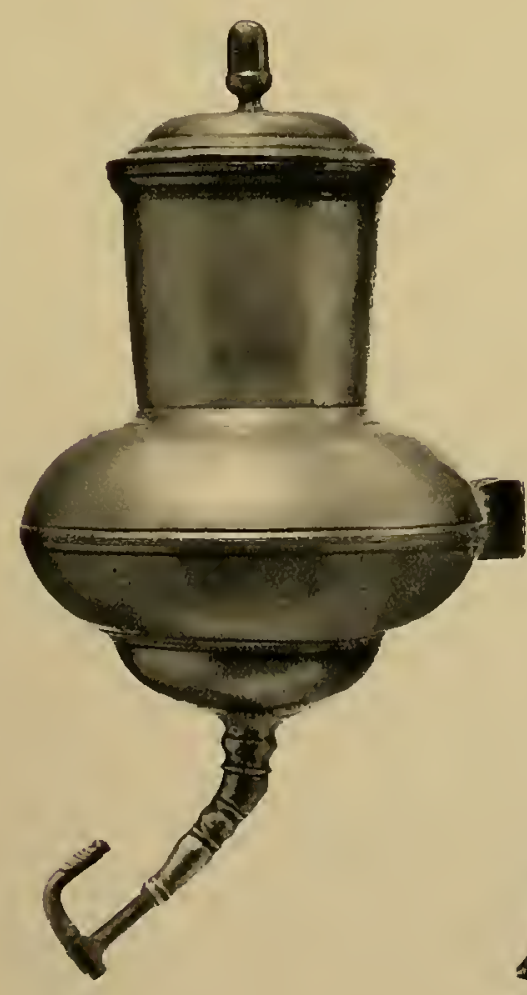

5

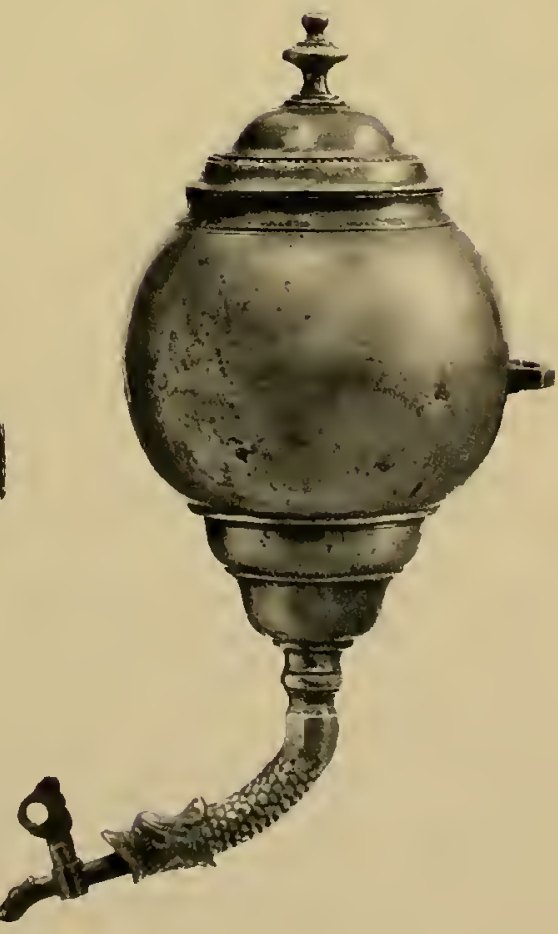

6

1-3. Giessfässer in Eichelform (Zürich und Ostschweiz). 4, 6. Kugelgiesslässer, aus Chur und Ragaz. 5. Eichelförmiges Giessfass (mit Nische) von Schwyz, von Leonhard J. Städelin in Schwyz, 1618-89. 



\section{Die Zinngiesser}

Wüger, I Johannes, Kannengiesser (Wügerlin), heiratete am 7. November 1686 Anna Magdalena Füllemann. Er war Altpfleger und des mehrern Rats. Seine Wittwe starb 1743.

Wüger, Andreas I, Kannengiesser, heiratete am 28. Januar ${ }_{1} 689$ Elisabetha Hausmann. Er hatte folgende Lehrlinge:

Benedikt Schneebeli von Stein am Rhein, vom 24. März 1679-? 1682. Beim Aufdingen sind vier ehrliche Meister des Zinngiesserhandwerks von Stein am Rhein und Diessenhofen dabei (Handwerksbuch der Stadt Steckborn, Bd. I, fol. 15 a).

Jakob Küchlin von Diessenhofen, vom 21. März 1685-? (a. a. O, fol. 24 a).

Peter Stein von Rorschach, vom 8. März 1688-12. November 169o (a. a. O, fol. $40 a$ ). Hans Jakob Thaler von Bischofszell vom 3o. Mai 1692-? (a. a. O, fol. 5o a).

Wüger, Andreas II, Kannengiesser, verheiratet mit Anna Bühl; erwähnt im Taufregister am 9. Januar 1694. Er starb 1697.

Wüger, Andreas III, Kannengiesser, der Sohn des Johannes I Wüger. Er wurde am 16. Dezember 1689 geboren und heiratete im Jahre 1724 Anna Basler.

Würger, Johannes II, Zinngiesser, war ebenfalls ein Sohn des Johannes I. Er wurde im Jahre 1697 geboren, heiratete ${ }_{1}{ }_{3} 3$ Katharina Meyer, die Tochter des Hafners Daniel Meyer-Götsch.

Würger, Johannes III, Zinngiesser, war der Sohn des Andreas III Wüger; er wurde 1724 geboren und heiratete 1749 Barbara Baldin.

Würger, Andreas IV, Zinngiesser, Sohn des Johannes III Wüger; er wurde am 29. April 1750 getauft und heiratete am 23. September 1779 Anna Maria Basler.

Wüger, Andreas V, Zinngiesser, Sohn des Andreas IV Wüger; er wurde em 14. März 1788 geboren und heiratete Magdalena Labhardt.

Wüger, Andreas VI, Zinngiesser, Sohn des Andreas V Wüger; er wurde im Jahre 1818 geboren, heiratete Anna Katharina Böni und starb 1859.

\section{Die Meisterzeichen und Gegenstände der Wüger}

Die Johannes Wüger führten die Stempel Nr. 224, 225 (Bd. I). Ausserdem gibt es noch zwei weitere Stempelvarianten mit den Initialen I. W. Die einwandfreie Zuweisung an die einzelnen Johannes ist wohl nicht möglich.

Gegenstände : Wandplatte mit zackigem Rand, Durchmesser $27,8 \mathrm{~cm}$. Meisterzeichen und Stadtzeichen von Steckborn getrennt; sonst wie Nr. 225 (Bd. I) (Hintze, Bd. VII, Steckborn Nr. 2364). (Rosgarten-Museum Konstanz.) Gehört voraussichtlich dem Johannes I Wüger.

Glockenkanne, Höhe $27 \mathrm{~cm}$, mit dem Meisterzeichen Nr. 224. Bajonetverschluss. (Antiquitätenhandel in Frauenfeld.)

Prismatische, sechsseitige Kanne, Höhe $31 \mathrm{~cm}$, Durchmesser des Fusses 15,5 cm. Schraubverschluss. Meisterzeichen Nr. 225, auf dem Deckel. (Sammlung C. Hirsbrunner, Luzern.)

Die sechs Andreas Wüger führten die Meisterzeichen Nr. 220, 221, 222 und 223; es gibt ebenfalls noch weitere Stempelvariante. Die Zuteilung an die verschiedenen Andreas ist kaum möglich.

Gegenstände: Prismatische, sechsseitige Kanne; Höhe 41,5 cm; Durchmesser des Fusses, 17,5 cm. Auf dem Deckelchen der Ausgussröhre das Meisterzeichen Nr. 220 . Um den Ansatz der Ausgussröhre gravirte Trauben. An der rechten Seite die Initialen E.A.M. 1797. Fuss mit geringer Ausladung.

Glockenkanne, Höhe $33 \mathrm{~cm}$; Durchmesser des Fusses $16 \mathrm{~cm}$. Schraubverschluss. Auf dem Deckelchen der Ausgussröhre das Meisterzeichen Nr. 220. Am Korpus oben drei und unten zwei circuläre Wülste. Um den Ansatz der Ausgussröhre gravirte Trauben. Schildchen leer. 
Glockenkanne, Höhe $26 \mathrm{~cm}$, Durchmesser des Fusses $13,6 \mathrm{~cm}$. Bajonetverschluss. Auf dem Deckelchen der Ausgussröhre das Meisterzeichen Nr. 221. Am Korpus oben drei, unten zwei schmale Wülste. Fuss stark ausgeladen. Auf dem Schild die Initialen H. B 17 ... Keine Bodenrosette. (Tafel XXXVI, 9.)

Glockenkanne, Höhe $23 \mathrm{~cm}$. Durchmesser des Fusses $11 \mathrm{~cm}$. Bajonetverschluss. Auf dem Deckelchen der Ausgussröhre das Meisterzeichen Nr. 220. Am Korpus oben drei, unten zwei Wülste. Auf dem Schild die Initialen B HH. Bodenrosette Nr. 252 .

Labhardt, Hans Heinrich, Zinngiesser, heiratete am 6. November 1727 Katharina Hausmann. Meisterzeichen und Gegenstände sind nicht bekannt.

Basler, Hans Jakob I, Zinngiesser, Mitglied des Rats, wurde am 2. März ${ }_{7} 3_{2}$ getauft, heiratete am 18. Mai ${ }_{17} 57$ Susanna Füllemann und starb im Jahre 1803.

Basler, Hans Jakob II, Zinngiesser, der Sohn des Vorigen, wurde am 28. Januar 1759 geboren, heiratete Sabine Rickenbach und starb im Jahre 1826.

Basler, Hans Jakob III, Zinngiesser, Sohn des vorigen Hans Jakob II, wurde am 27. Januar $180 x$ in Steckborn geboren, heiratete am 6. Juni 1833 Verena Düringer und starb im Jahre 1867 .

\section{Meisterzeichen und Gegenstände der drei Hans Jakob Basler}

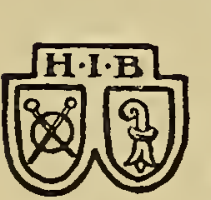

$219 \mathrm{~b}$

Das Zeichen Nr. 379 (Bd. I) findet sich irtümlicherweise unter Basel; es ist gleich dem Meisterzeichen Nr. $219 b$ (Bd. II). Daneben gibt es noch den Engelstempel Nr. $219^{c}$ mit der Inschrift H. Jacob Basler, Fin Englisch Zin. Eine exakte Zuteilung der Marke ist nicht möglich. Nr. $219^{b}$ und $c$ sind im Band II. Gegenstände: Prismatische, sechsseitige Kanne, Höhe $34,5 \mathrm{~cm}$; Durchmesser des Fusses $15 \mathrm{~cm}$. Schraubverschluss. Im Sockel des Tragringes eine weit hervorragende, circuläre, profilirte Rippe. Auf dem Deckelchen der Ausgussröhre das Meisterzeichen Nr. $379 \quad(219$ b). Die zwei Vorderflächen mit gut gezeichneten Blumen- und Früchtenranken überzogen. An der



219 c. linken Kannenseite die Initialen F M, dazwischen ein halbes Mühlerad; darunter die Jahrzahl 1791. Keine Bodenrosette. (Tafel XXXVI, 12.)

Glocken kanne, Höhe $31 \mathrm{~cm}$, Durchmesser des Fusses 16,5 cm. Bajonetverschluss. Auf dem Deckelchen der Ausgussröhre das Meisterzeichen Nr. 379 (Bd. I) : 219 b. Am Korpus oben drei, unten zwei schmale circuläre Wülste. Auf dem Schild die Initialen M R B 1802. Unterhalb der Ausgussröhre eine gravirte, kühn geschwungene Blumenranke. Innen am Boden die Rosette Nr. 435 (irrtümlicherweise unter Basel). Fuss mit schöner Ausladung. Glockenkanne, Höhe $25 \mathrm{~cm}$; Durchmesser des Fusses $13,5 \mathrm{~cm}$. Bajonetverschluss. Auf dem Deckelchen der Ausgussröhre das Meisterzeichen wie bei der vorigen Kanne. Schild leer. Vorn Blumenranke wie bei der vorigen Kanne. Bodenrosette Nr. 435 (v. bei Basel, Tafel Nr. XXI, Bd. I). (Tafel XXXVI, 14.)

Rokkoko-Terrine im Museum in Innsbruck mit dem Meisterzeichen Nr. $219 c$ (Engelmarke).

\section{WEINFELDEN}

Quellen : Auszüge aus dem Weinfelder Haushaltungs-Rodel von Pfarrer Johann Ulrich Nötzli, Civilstandsamt Weinfelden. Mitteilungen von Herr K. Frei-Kundert, Vicedirektor am schweizerischen Landesmuseum in Zürich. 


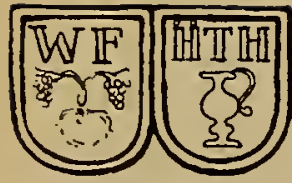

230

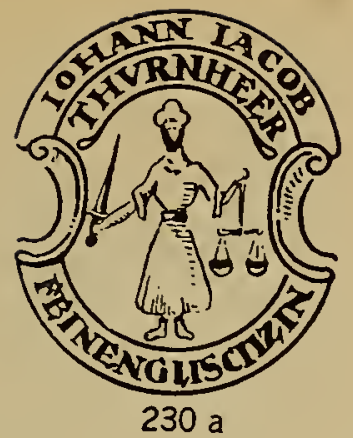

230 a

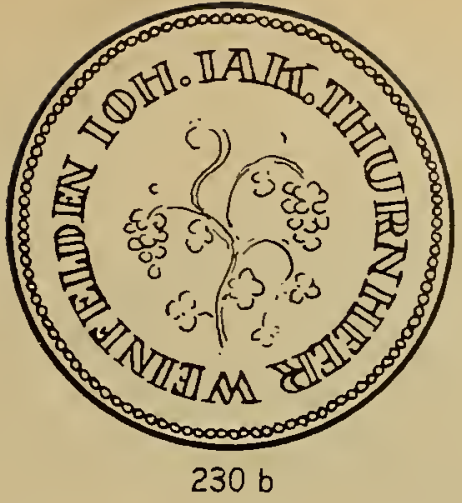

231

Gegenstände : Glocken- und prismatische Kannen in allen Grössen; Teller und Platten Giessfässer.

Keller, Hans Joachim, Zinngiesser, Hauptmann, wurde am 20. Dezember 1708 geboren, heiratete am 27. September ${ }_{1734}$ Katherina Edelmann aus Sitterdorf (Weinfelder Haushaltungs-Rodel, S. 43). Er liess sich am 6. März ${ }_{17} 35$ in die Schmiedenzunft von Konstanz als auswärtiger Meister aufnehmen und wird noch 1765 erwähnt. (Hintze, Bd. VII, S. 389.)

Er führte das Meisterzeichen Nr. 231 (Bd. I).

Gegenstand : Glockenkanne, Höhe $32 \mathrm{~cm}$. Mit Schraubenverschluss.

Thurnheer, Johann Jakob, Zinngiesser, Hauptmann, führte die Meisterzeichen Nr. 23o, 23o a, 23o $b$. Er wurde am 4. November 1736 geboren, heiratete am 10. Januar 1765 Susanna Rennhart, von welcher er 1769 das dritte Kind erhielt (Haushaltungs-Rodel 1754-1771). Er lernte bei Hans Joachim Keller von Weinfelden.

Gegenstände: Prismatisch-sechsseitige Kanne; Höhe 34,5 cm; Durchmesser des Fusses 14,5 cm. Schraubverschluss. Auf dem Deckelchen der Ausgussröhre das Meisterzeichen Nr. 23o. Kannenfuss mit sehr schwacher Ausladung. An der rechten Seite die gravirten Initialen HV HS A C W G M. Spärliche Gravirung um die Basis der Ausgussröhre. Am Sockel des Tragringes knopfförmige Verdickung. Deckel relativ sehr gross.

Runde Schüsseln, Teller und Platten mit dem Meisterzeichen Nr. 23o $a$ und $b$. (Sammlung Schwager in Frauenfeld.)

Thurnheer, Jakob, Sohn des Vorigen, lernt bei Joh. Nepomuk Vogler in Konstanz bis 1 8. Januar 1789. (Hintze, Bd. VII, S. 389.)

Keller, Johann Conrad, von Weinfelden, lernte daselbst bei Hans Joachim Keller; wurde ${ }_{1762}$ in Konstanz eingeschrieben und 1771 auswärtiger Meister (Konstanz. Einschreibebuch der Schmiedenzunft, Bd. II, S. 152).

\section{DIESSENHOFEN}

Quellen: Mitteilungen von Herrn Apotheker Dr. G. E. Brunner in Diessenhofen. Ferner die Auszüge von Herrn K. Frei-Kundert, Vicedirektor, aus Haushaltungs-Rodel von 1660, 1684, 1709 (Evangel. Pfarrarchiv in Diessenhofen: Evangel. Kirchenbuch im Pfarrarchiv). Ausgabenbuch des Klosters S. Katharinental (Thurgauisches Kantonsarchiv in Frauenfeld, S. 75 u. 76 ).

Gegenstände und Meisterzeichen: Es sind nur einige Glockenkannen und Teller bekannt, mit drei verschiedenen Meisterzeichen.

Das Wappen von Diessenhofen: Zwei schreitende, durch Schrägbalken getrennte Löwen (wie Kyburg). 
Benker, Erhart, Kantengiesser, führte das Meisterzeichen Nr. 218 (Bd. I). Er wird im Jahre 1660 im Haushaltungsrodel erwähnt. Er wurde am 3. Juli 1638 geboren und starb am 25. August 1711 .

Gegenstände : Glockenkanne, Höhe $36,5 \mathrm{~cm}$; Durchmesser des Fusses $18,6 \mathrm{~cm}$. Inhalt 2 Maass. Bajonetverschluss. Auf dem Deckelchen der Ausgussröhre das Meisterzeichen Nr. 218. Am Korpus oben vier und unten ein circulärer schmaler Wulst, welche kaum vorsteht. Auf dem Schild ein Metzgerbeil mit einem Kreuz; daneben die Initialen H. I. G. 1662. Auf dem Rand des Deckels HV. Im Boden die Rosette Nr. 212 (wie bei den A. Wüscher, Schaffhausen). (Tafel XXXVI, 11.)

Breitrandteller, Durchmesser $22,2 \mathrm{~cm}$; Randbreite $5,5 \mathrm{~cm}$. Rand unten verstärkt. An der Oberseite des Randes das Meisterzeichen Nr. 218 und die Initialen F. M.


$218 \mathrm{~b}$

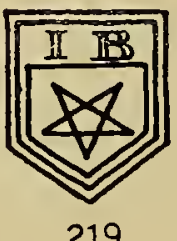

219

218 a

Benker, Hans Rudolf, Kantengiesser, führte das Meisterzeichen Nr. 218 b. Er wird im Haushaltungsrodel vom Jahre 1684 zitirt. Wurde 1650 geboren und starb 1723 .

Gegenstand: Glockenkanne von 1 Maass Inhalt, mit Bajonetverschluss. Auf dem Deckelchen der Ausgussröhre das Meisterzeichen Nr. 218 b. (Sammlung Wesner, St. Gallen.)

Küchlin, Hans Jakob, Kantengiesser, wurde am 20. November ${ }_{1667}$ geboren (HaushaltungsRodel von 1709 des evangel. Pfarrarchivs von Diessenhofen). Vom 26. März 1685 ab war er Lehrling bei Andreas I Wäger in Steckborn (Handwerksbuch der Stadt Steckborn, Bd. I, fol. 24a). Er starb am 26. Oktober 1712 (Totenregister der evang. Pfarrgemeinde).

Benker, Jonas, Kantengiesser, führte das Meisterzeichen Nr. 219 (Bd. I). Er wurde am 25. Juni 1682 geboren und starb am 19. November 1735. Im Ausgabenbuch $1710-23$ des Klosters S. Katharinental findet sich im März 1721 folgende Stelle: "Meister Kantengiesser Benker aus der Stadt (Diessenhofen) an seiner Arbeit geben $6 \mathrm{fl}-6 \mathrm{~d}$. ".

Gegenstand: Glockenkanne mit Bajonetverschluss von I Maass Inhalt. (Im Antiquitätenhandel bei Messikommer, Zürich.)

Wägele, ..., Zinngiesser, in Diessenhofen, wird im August 1743 erwähnt. "Dem Zinngiesser Wägele für Rohr und Zinn Schrauffen zum Brunnen auff dem Hoff $6 \mathrm{fl} .7 \mathrm{bz} .6 \mathrm{~d}$. " (Ausgabenbuch des Klosters S. Katharinental 1723-1749, im Thurg. Kantonsarchiv, S. 76.)

Der grosse Stadtstempel von Diessenhofen befindet sich auf einer Schaffhauser Glockenkanne mit Schraubverschluss. Auf dem Deckelchen der Ausgussröhre ist das Schaffhauser Meisterzeichen mit dem Beschauzeichen von Diessenhofen, Nr. $218 a$, überstempelt. Auf dem Schild in Empireform sind die gravirten Initialen H. D. Um den Ansatzteil der Ausgussröhre herum schön gravirte Margeritenranken. Am Korpus oben fünf und unten zwei schmale flache circuläre Wülste. Fuss mit starker Ausladung. Am Rand des Deckels ein feiner Perlstab. Höhe der Kanne $36 \mathrm{~cm}$; Durchmesser des Fusses $17 \mathrm{~cm}$. Typische Schaffhauserkanne. 

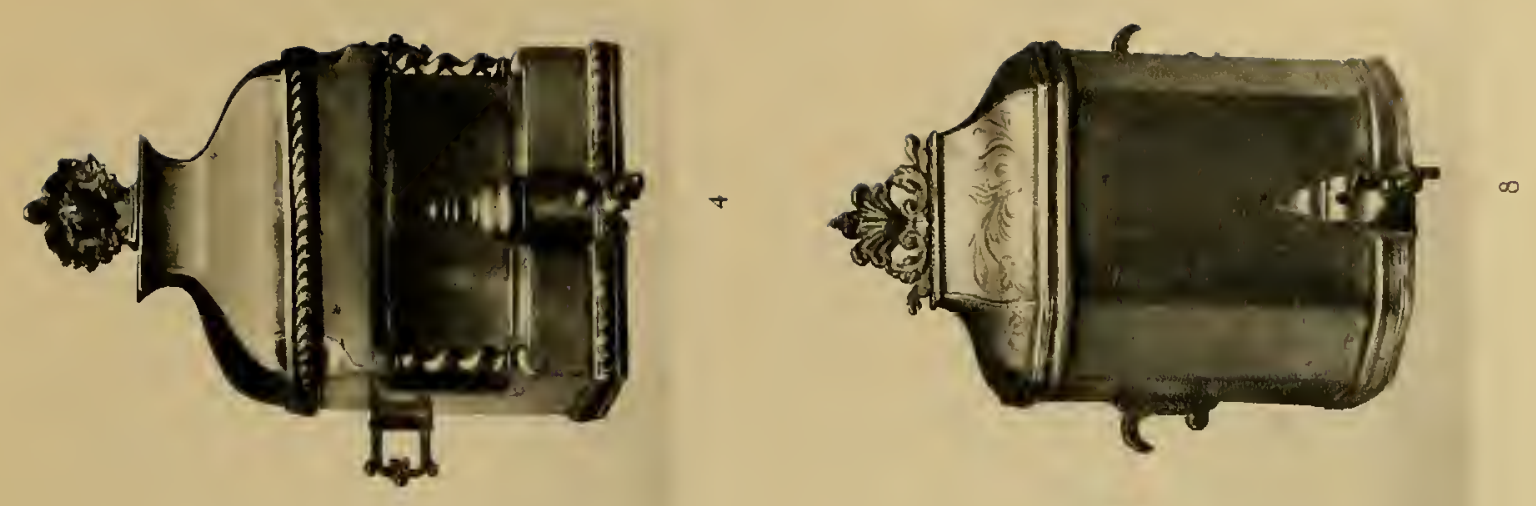

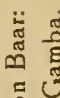

5

कू

동

解
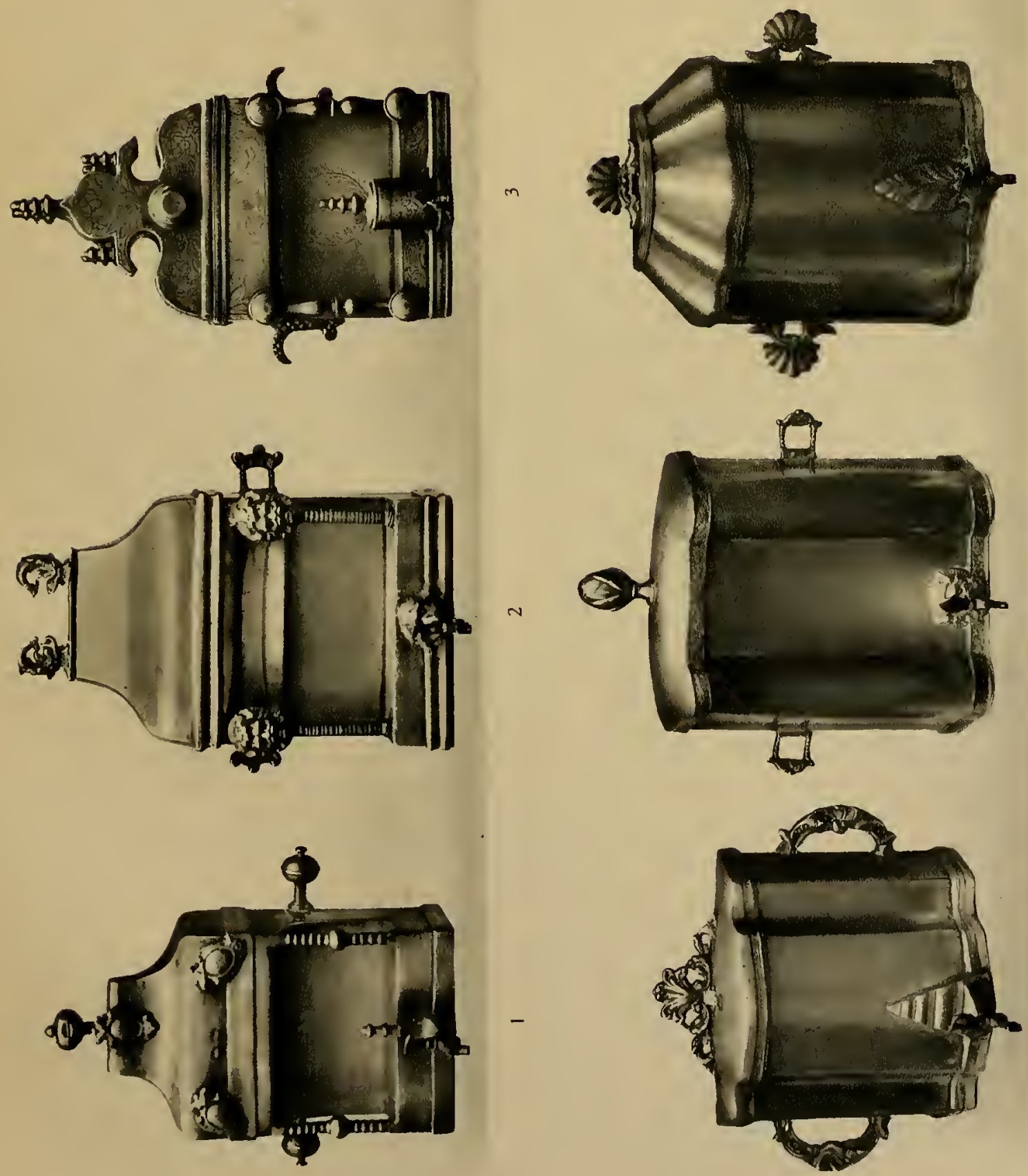

+ .

它

政

ร.

i

要

尊

放 동

m



옹

s.

趁竞量

$\exists$

总离离

呟

뎡

กิ

胥

$\frac{9}{60} \infty$



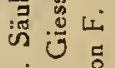

نे

Iิ

络

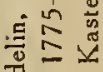

语容

ปึ่

둥

5

制

है

향

总

.

政 


\section{Ittingen}

Die Meisterzeichen Nr. 243,244 und 245 konnten nicht bestimmt werden. Sie finden sich auf Tellern und Nr. 244 auf einer Glockenkanne von 1 Maass Inhalt. Vielleicht arbeiteten diese Meister in der Karthause Ittingen und für dieselbe.

\section{ST. GALLEN}

In St. Gallen gehörten die Kanten- oder Zinngiesser zur Schmiedezunft. Die erste Kannengiesserordnung stammt aus dem Jahre 1511 und ist im Kannengiesser-Eid' enthalten. Er lautet:

"Item ain ieder Kantengiesser sol sweren alles zinngschirr ze machen uff die prob, Ime deshalb gestellt, das ist namlich under vier pfund zinn ain pfund plii, und nit mer und sunst dhain gemischt gschirr news noch altz ze machen, In kain wise noch weg ze buess an ains Rats erkanntnuss, und was er von gschirr also macht, daruff mag er sin zaichen uffschlahen.

" Ob er aber gschirr uff nürmberger gschirr und prob machti, daruff will man Im der statt zaichen zu sinem Zaichen schlahen.

"Und ist nemlich nuremberger prob under $9 \&$ zinn ain \& by (bly). "

Die letzte Zeile ist ein späterer Zusatz: "Item er sol die lut mit löten und sinem lon zimlich hallten und bi den satzungen Im gemainen Zunftbuoch begriffen pliben."

Die St. Galler Probe ist also identisch mit derjenigen Zürichs. Wie in allen Städten mit zahlreichen Meistern, gab es auch in St. Gallen beeidigte Meister zur Controlle der Zinn-BleiLegierung. Sie hiessen Probirer und mussten seit dem Jahre 1657 folgenden Eid " schwören :

"Item die Probierer der Kantengiesser sollend schweren, des Jahres viermahlen, oder so dies not ist, unversehenlich umbgegohn und bey allen Kantengiessern allerley Arbeit ze probieren nach der prob, ihnen in ihren satzungen und Eyden begriffen, und darinnen niemandts ze schonen noch anzesehen, was sich auch Unrechts und falsches befindet, einem Rath anzezeigen, damit dieselben nach Ihrem verdienen gestrafft werdindt. "

Im Jahre 1740 lautete der gleiche Eid $^{3}$ folgendermassen:

"Eyd der Probierer der Kantengiesser.

"Item die Probierer der Kantengiesser Arbeit sollend schwehren, des Jahres vier mahlen oder so dies es not ist, unversehenlich umbzegohn und bey allen Kantengiessern allerley Arbeit zu probieren nach der Prob, Ihnen in ihren Satzungen und Eyden begriffen, und darinnen niemandts ze schonen noch anzusehen, was sich auch unrechts und falsches befindet, einem Rath anzuzeigen, damit dieselben nach Ihrem Verdienen gestrafft werden. ")

Auch hier haben wir also ähnliche Bestimmungen wie in Zürich. Wir finden sehr häufig Gegenstände aus bessern Legirungen als die offizielle "Prob » vorschreibt. Dieselben haben als besonderes Kennzeichen neben dem Meister zeichen noch eine Krone ; einzelne Zinngiesser, z. B. II Heinrich Hiller, hatten alle Zeichen auf einer Matrize vereinigt. Als Qualitäts zeichen ist auch der merkwürdige, trompetenspielende Engel aufzufassen, welcher sich auf feinen Zinngegenständen von II Heinrich Hiller befindet. Das officielle Beschauzeichen der Stadt St. Gallen war in frühen Zeiten der schreitende Bär, später aber

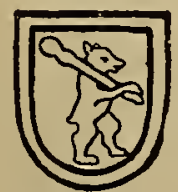

Kloster St. Gallen 262 b stets der Buchstabe $G$ in eigentümlicher Form. Darum wird derselbe oft mit einem $S$ verwechselt. Der Stadtbär von St. Gallen trägt seit dem Jahre $147^{5}$ das Halsband. Auf den Meisterzeichen ist aber dasselbe infolge der Kleinheit nicht sichtbar oder sogleich abgeschliffen. Bei dem Besitzerzeichen des Klosters St. Gallen, ein aufrecht schreitender Bär mit geschulterter Keule, verdeckt die Keule den ganzen Hals (Nr. 2626 ).

1 Aidt Buoch Nr. 1511 . S. 40. Mitteilung von Herr Dr. J. Egli. Aus dem Stadtarchiv van St. Gallen.

2 Aidt Buoch 1657. S. 55. Mitteilung von Herr Dr. J. Egli. Aus dem Stadtarchiv von St. Gallen.

3 Eyd Buch 1740. S. 85. Mitteilung von Herr Dr. J. Egli. Aus dem Stadtarchiv von St. Gallen. 
Eine wichtige Rolle spielt bei den Kannen und Maassen ausser dem Stadt- und Meisterzeichen die Bodenrosette. In der Mitte derselben befindet sich in Reliefguss das Bild eines aufrecht auf den Hinterbeinen schreitenden Bären mit deutlichem Halsband. Es ist also ausgeschlossen, dass Bodenrosetten mit dem Bären ohne Halsband st. gallischen Ursprungs sind. Für diese Stücke kommt Appenzell oder Wyl in Betracht. Zu beiden Seiten des Bären befinden sich die Initialen des Meisters, ebenfalls schon in der Gussform, nicht etrva kalt eingeschlagen. Nur in seltenen Fällen wurden die gewöhnlichen Rosetten verwendet, z. B. von J. Gmünder oder Jakob Glinz (Nr. 336, Bd. I). Die verschiedenen Bodenplaketten mit dem Bär finden sich auf Tafel XVI (Bd. I).

Eine besondere Spezialität von St. Gallen sind die Wappenteller in Reliefguss. Sie schliessen sich würdig an die prächtigen Reliefteller von Nürnberg an und ähnliche Arbeiten finden sich sonst nirgends in der Schweiz, ausser den Walliser Blumentellern. Sehr wahrscheinlich haben die Zinngiesser die Form nicht selbst hergestellt; beim Wyler Teller kommt vielleicht ein Goldschmied in Betracht. Wir verweisen auf die Beschreibung bei den Gegenständen.

\section{Die Zinngiesser von $S_{\text {t. Gallen }}$}

Die Archivalia über die St. Galler Zinngiesser verdanke ich dem grossen Entgegenkommen von Herrn Dr. J. Egli, dem verstorbenen Direktor des historischen Museums in St. Gallen. Von demselben stammt auch das Zinngiesser-Probiererverzeichnis, welches Prof. Hintze (Breslau) ohne mein Wissen benutzte und es als das meinige auffasste. Seiner Aufforderung, aus meiner Liste einige Namen zu streichen, kann ich also nicht Folge leisten, da ich erst heute eine Zinngiesserliste aufstelle. Selbstverständlich waren nicht alle Probirer gleichzeitig Zinngiesser; aber sowohl in St. Gallen als z. B. in Zug und Schrvyz kam es vor, dass auch Goldschmiede sich mit dem Zinnguss befassten, besonders beim Ornamentguss, rvie z.B. bei den prächtigen St. Galler Relieftellern. Das Monogramm des Goldschmiedes Zacharias Täschler ist nicht umsonst auf dem Wappenteller der 13 Orte; vielleicht hat er sogar die Herstellung der Gussform veranlasst, indem ja die St. Galler Goldschmiede in stetigem Verkehr mit Augsburg und Nürnberg waren. Eine andere Ansicht entspringt nicht zuletzt der Unkenntnis der schweizerischen Verhältnisse.

Von den ältesten Meistern sind nur die Probirer bekannt, wobei es vorkommen kann, dass ein Nicht-Zinngiesser dabei ist. In der Stemmatologie von St. Gallen fand Herr Dr. Egli dieselben nicht.

Frenk, Conrad, Probirer von 1561-1562.

Preisig, Jakob, Probirer von 1561-1569.

Fechter, Wolf, Probirer von 1561-1568.

Girtanner, Hieronimus, Probirer von 1563-1572.

Guldin, Melchior, Probirer von 1568-1594.

Wiedenhuber, Hans, Probirer von 1573-1582.

Kapfmann, Jakob, Probirer von 1583-1609.

M. R. führte das Meisterzeichen Nr. ${ }_{262} a$. Die Initialen sind oft sehr stark deformirt, weshalb

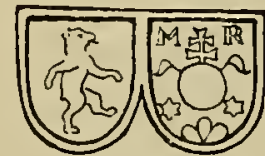

262 a dieselben früher als S. A. (Nr. 262, Bd. I) gelesen wurden. Das Meisterzeichen befindet sich auf den Stadtkannen von St. Gallen und von Wyl. Gegenstände : Stadtkannen von Wyl. Datirt 1581 . Ursprünglich waren wenigstens sechs Stück vorhanden. Nun sind dieselben zerstreut, im Museum St. Gallen, im Landesmuseum in Zürich; in Brüssel und in Frankreich. Sie gehören zu den prächtigsten Zinngegenständen der Schweiz,

Sie haben eine Höhe von $47,2 \mathrm{~cm}$. Auf hohem Fusse befindet sich ein sphäroidaler Korpus. Der schlanke Hals erweitert sich oben halbkugelförmig. Auf dem Halse sind 
zwei Schilde aufgelötet; auf dem einen befindet sich das W des Wappens der Stadt Wyl. Die schwanenhalsartige Ausgussröhre endigt in einem Tierkopfe. Der Traghenkel ist aus Eisen und läuft in einem Scharnir, welches durch senkrechte profilirte Säulen auf den Korpus abgestützt ist. Auf dem Korpus befindet sich die Jahrzahl ${ }_{1581}$. (Tafel VI, 1.)

Finsterling, Zirill, Probirer von $1595-1625$.

Bönger, I Zacharias, Probirer von 1609-1618; heiratete 1595 Anna Scherlin von Arbon.

War 1614 auch Goldschmied-Probirer (BRun, Schweiz. Künstler-Lexikon). Starb 1618.

Hiller, Othmar, Probirer von 1612-1634.

Kunz oder Cunz, David, Probirer von 1620-1664; geboren 1592, heiratete 1613 Ursula Vonwiller; starb 1664 .

Hiller, Gallus, Probirer von 1626 1639. Führte vielleicht das Meisterzeichen Nr. 272.

Spengler, Caspar, Probirer von 1636-167o. Bodenrosette Nr. $33_{2}$ in einer Glockenkanne (Hist. Museum von St. Gallen).

Bönger, II Zacharias, Probirer von 1640-1666; geboren 1602. Von 1639-44 war er Zunftmeister der Schmiedenzunft, ebenso von $166_{2}$ bis zu seinem Tode, 1666 (Künstler-Lexikon, I, 237 ).

Mittelholzer, Caspar, Probirer von 1665-168o (gestorben 1680).

Moos, Joachim, Probirer von 1667-1667 (gestorben 1667).

Kunz oder Cunz, Caspar I, Probirer von 1671-1682 (gestorben 1682).

Spengler, Barthlime, Probirer von 1678-1683 (gestorben 1683).

Friederich, Jakob, Probirer von 1680-1682 (gestorben 1682).

Schirmer, I Joachim, führte die Meisterzeichen Nr. 266, 267, 268, 288 (Bd. I) und noch einige Varianten. Als Bodenrosette benutzte er Nr. 329. Er wurde als Sohn Hermann Schirmers am 4. Januar 1613 geboren. Er war drei Mal verheiratet, 1639 mit Elisabeth Hochreutiner, 165o mit Barbara Scherer, und 1676 mit Barbara Schlumpf. Er war Probirer von $168_{2}$ bis zu seinem Tode 1697. Er war wohl der bedeutendste und productivste Meister St. Gallens.

Gegenstände: Maass des Klosters St. Gallen, Höhe 16,3 cm, Durchmesser des Fusses $9 \mathrm{~cm}$; obere Oeffnung 7,5 cm. Am obern Rande das Meisterzeichen $\mathrm{Nr} .267$ und zwei Mal das Eigentumszeichen des Klosters St. Gallen : ein Bär mit geschulterter Keule. Es ist das einzige bekannte Stück. (Tafel XIX, 16.)

Gelappter Wappenteller, mit den Wappen der 13 alten Orte am Rande. Im Fundus ist entweder das Bild der drei Eidgenossen oder das Reichswappen und darunter zwei gegeneinander gekehrte Wappen der Stadt St. Gallen. Die Meistermarken Joachim Schirmers und Zacharias Täschlers sind nicht eingeschlagen, sondern gegossen; ebenso das Stadtzeichen. Durchmesser 21,5-21,7 cm.

Demiani ${ }^{1}$ nennt in seinem prächtigen Werke über das Edelzinn als Giesser dieses Lappentellers Hans Jakob Schirmer, welcher allerdings fast gleichzeitig wirkte. Nach unsern Untersuchungen entspricht aber die Meistermarke I S Joachim Schirmer.

Siehe auch unter " die Gegenstände " von St. Gallen.

Im historischen Museum von St. Gallen befinden sich Glockenkannen, Schüsseln und Teller von Joachim I Schirmer.

Locher, Jakob, Probirer von 1683-1688 (gestorben 1688).

Fels, Conrad, Probirer von 1684-1698. Bodenrosette Nr. 333 in einer Glockenkanne im historischen Museum St. Gallen. Meisterzeichen unbekannt.

Scherer, Diethelm, Probirer von 1688-1699 (gestorben 1699).

Reutiner, Johannes, Kantengiesser, wurde im Jahre 1636 geboren, heiratete im Jahre 1660 Judith Zollikofer; er war Mitglied der Schmiedenzunft, auch Stadtrichter; Zinngiesser-

I François Briot, Caspar Enderlein und das Edelzion von Hans Demiani. Leipzig 1897 bei Karl W. Hiersemaan Leipzig. 
probirer von 1697 bis zu seinem Tode im Jahre 1699 . Er führte als Meisterzeichen, neben andern Varianten, die Nr. 263, 264, 265, 287. Die Bodenrosette Nr. 328 findet sich in einer Glockenkanne des historischen Museums von St. Gallen.

Reutiner war ein productiver Meister und in der ehemaligen Sammlung Wessner (St. Gallen) befanden sich prachtvolle Breitrandplatten von allen Grössen.

Glockenkanne in der Sammlung F. Pappe in Bern.

Reutiner, Hektor, Zinngiesser, der Sohn des Vorigen, wurde in St. Gallen am 28. Februar 1661 geboren, heiratete 1686 und starb 1740 . Sein Meisterzeichen ist genau gleich in der Zeichnung wie Nr. 265 (Bd. I), aber mit den Initialen HR. Im historischen Museum von Schaff hausen befindet sich eine breitrandige Schüssel von $36 \mathrm{~cm}$ Durchmesser bei $8,3 \mathrm{~cm}$ Randbreite.

Hiller, Josua, Kantengiesser und Bader, wurde im Jahre 1649 geboren, verheiratete sich $16_{71}$. Er war Mitglied der Schmiedezunft, Stadtrichter von $16_{77^{-1}} 68$ o ; Elfer $167_{8}$. Im Jahre 1684 wurde er $Z$ unftmeister; 1688 Ratsherr, 1692 Zeugmeister; 1698 wurde er noch Probirer und starb im gleichen Jahre.

Er führte das Meisterzeichen Nr. 273. Die Bodenrosette Nr. 334 befindet sich in einer Glockenkanne.

Bönger, III Zacharias, Probirer von 1698-1709.

Schirmer, Hans Jakob, Zinngiesser, führte das Meisterzeichen Nr. 269; in Glockenkannen findet sich die Bodenrosette Nr. 33o. Er war ein Sohn des Joachim I Schirmer und wurde am 10. Februar 1657 geboren. Er heiratete 1679 Elisabeth Specker; 1699 wurde er Zinngiesser-Probirer und starb am 20. Juni 1727.

Gegenstand: Glockenkanne mit Bajonetverschluss. Keine Meistermarke, aber Bodenrosette Nr. 33o mit den gegossenen Initialen H. I. S. Am Korpus oben drei, unten zwei breite Wülste. Deckel mit Arretirung. Auf dem Schild die Initialen H C G und D S. Höhe $32 \mathrm{~cm}$. Durchmesser des Fusses $18 \mathrm{~cm}$. Um die Basis der Ausgussröhre herum spärliche Gravirung im Tremolirstich. (Tafel XXXVII, 6.)

Deckelhumpen mit Etagenknopf. Am Traghenkel das Meisterzeichen Nr. 269. Keine Bodenrosette. Vorn die gravirten Initialen C H E. Höhe 14,7 cm. Durchmesser des Fusses mit guter Ausladung 10,8 cm. Am Deckelgriff ein Engelkopf. (Tafel XIX, 7.)

Schirmer, II Joachim, Sohn des I Joachim, führte ein achteckiges Meisterzeichen (Nr. 3o8, Bd. I) mit den Initialen I. S., dazwischen ein Henkelkrug. Bodenrosette Nr. 329.

Gegenstand: Glockenkanne mit Bajonetverschluss, Höhe $22 \mathrm{~cm}$; Durchmesser des Fusses $11 \mathrm{~cm}$. Auf dem Schild die gravirten Initialen H. S. Am Korpus oben drei, unten zwei breite Wülste.

Zollikofer, Jakob Laurenz, Probirer von 1699-1700 (gestorben 1700).

Halder, Jakob, Probirer von 1700-1720 (gestorben 1720).

Täschler, Zacharias, wurde im Jahre 1657 geboren und war von 1709-1713 Probirer. Er starb im Jahre 1717. Er war Mitbesitzer (mit Joachim Schirmer) der Gussform des St. Galler Wappentellers. Sein Monogramm findet sich in derselben und entspricht der Nr. 270 (Bd. I). Von einem eigentlichen Meisterzeichen kann nicht gesprochen werden, weil keine eingeschlagene Marke bekannt ist. Ebensowenig ist eine Bodenrosette nachweisbar. Er war von Beruf Goldschmied; allein auch solche betätigten sich oft mit Zinnguss, besonders bei kunstvollen Gegenständen, wie die St. Galler Wappenteller.

Gegenstand: Lappenteller mit den Wappen der 13 alten Orte. Vgl. unter Meister Joachim Schirmer.

Fehr, Daniel, Probirer von $1720-$ ?

Kunz, Caspar II (Cunz), Probirer von 1721 1726.

Hiller, Silverster, Probirer von 1713-1721. War auch Chirurg.

Stäheli, David, Probirer von $1722-1725$.

Wetter, Georg, Probirer von $1725-1733 \uparrow$.

Reiner, Sebastian, Probirer von $1726-173_{4} \dagger$. 

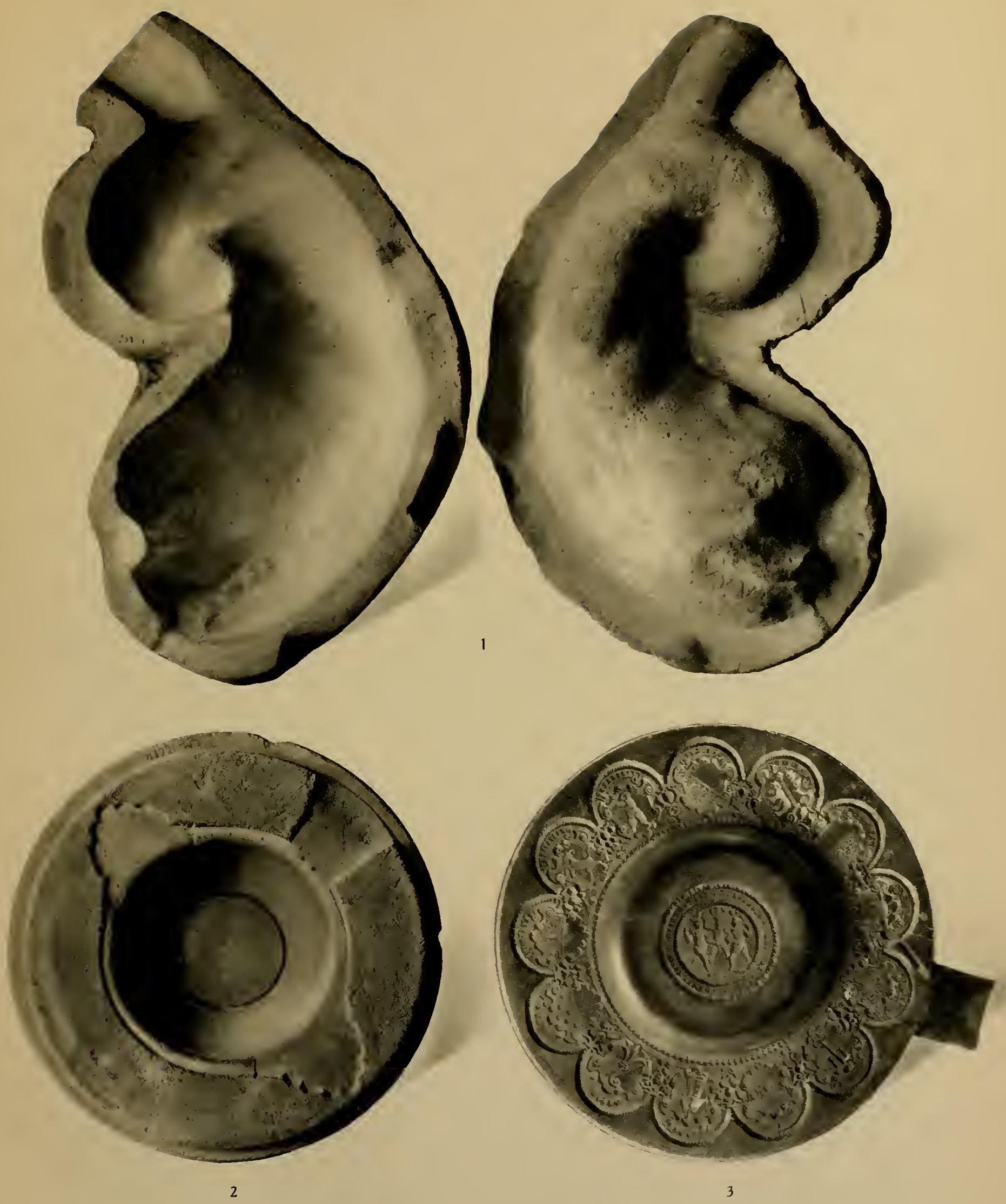

1. Ton-Modell zu einem Delphin, Landes-Museum, Zürich (L.-M. Zch.). 2. Sandstein-Mcdell zu einer Ohrenschüssel, L.-M. Zürich. 3. Bronze-Modell zum St. Galler Relieftellor, historisches Museum St. Gallen. 


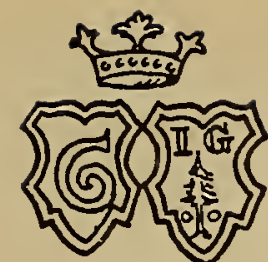

280

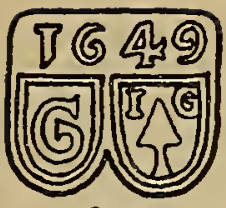

280 a



$280 \mathrm{~b}$

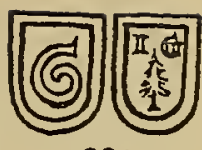

281

Girtanner, I Joachim, Zinngiesser, führte als Meisterzeichen Nr. 280 a (Bd. II), darüber im Stempel enthalten die Jahrzahl 1649. Er wurde am 3. April 1625 geboren und starb 1690. Gegenstand: Cylindrischer Humpen von $20 \mathrm{~cm}$ Höhe im historischen Museum St. Gallen. Auf dem Deckel ein Knopf in drei Etagen. Gepunzte und gravirte Blatt- und Blumenornamente. Einziges bekanntes Stück dieses Meisters.

Girtanner, II Joachim, Sohn des Vorigen, führte des Meisterzeichen Nr. 280 (Bd. I u. II), bei Feinzinn darüber eine eingeschlagene Krone. Er wurde 1650 geboren, heiratete 1675 und starb 1695 .

Gegenstand: Breitrandteller von $23 \mathrm{~cm}$ Durchmesser bei 5,5 cm Randbreite. Oben am Rande das Meisterzeichen Nr. 280 mit Krone. Daneben ein kreisrundes Eigentumszeichen mit Hauszeichen und den Initialen C. S. Darüber in gravirten Initialen E X S H. Tellerrand unten verstärkt.

Breitrandteller von 24,5 cm Durchmesser bei $6 \mathrm{~cm}$ Randbreite im historischen Museum von St. Gallen.

Girtanner, III Joachim, Sohn des Vorigen, führte das Meisterzeichen des Vaters ohne die Sternchen im Wappen, Nr. 280 (Bd. I) resp. 281 (Bd. II). Er wurde 1676 geboren, heiratete 1700 und starb 1745 .

Kanne im Nationalmuseum in München (Hintze, Bd. VII, S. 357).

Girtanner, Friedrich, Sohn des Vorigen, wurde 1709 geboren, heiratete 1746 und starb 1757 . Meisterzeichen und Gegenstände sind nicht bekannt.

Girtanner, Johannes, Zinngiesser, wurde 1747 geboren, heiratete 1779 und starb 1818 . Hintze (Bd. II, S. 361) weist demselben das Meisterzeichen $\mathrm{Nr} .282$ (Bd. I) zu und zwar ohne irgendwelche Anhaltspunkte.
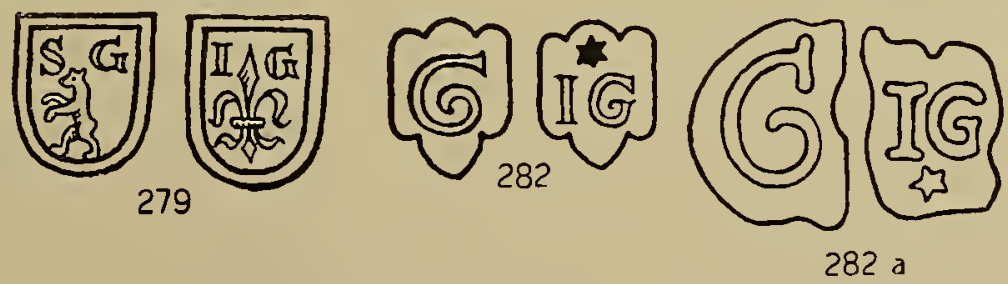

Glinz, Jakob, Kannengiesser, wurde im Jahre 1694 geboren, wurde 1733 Probirer und starb 1747. Die Meisterzeichen des Glinz und der Gmünder sind nicht mit Sicherheit auseinander zu trennen. Wahrscheinlich gehören Nr. 279 und ${ }_{2} 8_{2}$ (Bd. I) resp. Nr. 279, 282 und $282 a$ (Bd. II) dem Jakob Glinz. Ferner gehören Nr. 283 (Bd. I) resp. Nr. $283,283 a-\partial$ vielleicht den drei J. Gmünder.

Gmünder, I Jakob, Kannengiesser, wurde 1606 geboren, heiratete ${ }_{162} 8$ und 1660 und starb 1680. Gmünder, Johannes, Sohn des Vorigen, wurde 1630 geboren, heiratete 1651 und starb 1678 .

Gmünder, II Jakob, Sohn des Vorigen, wurde 1654 geboren, heiratete 1664 und starb 1689 im Kriege.

Ein Gmünder oder Glinz war Mitbesitzer des Modells des St. Galler Wappentellers und zwar ist die Meistermarke in der Gussform enthalten, also nicht eingeschlagen. In der Gussform des Wappentellers mit dem Apfelschuss Tells in der Mitte ("Wyler Teller ») 


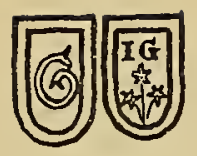

283



283 a

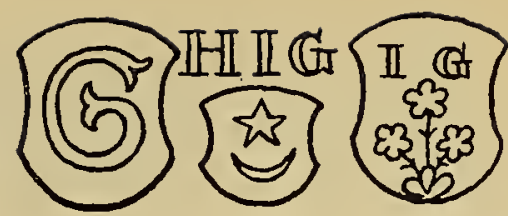

$283 b$

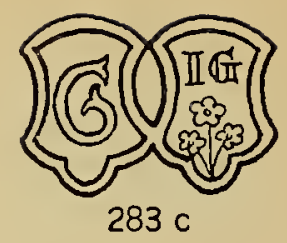

$283 \mathrm{c}$

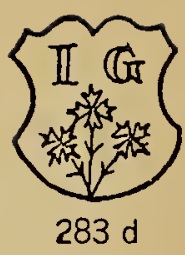

befindet sich an der Stelle des Wyler Wappens der Schild mit dem G von St. Gallen; ferner an der Stelle des Meisterzeichens Hans Melchior Müllers von Wyl das Zeichen Gmünders oder von Glinz, ähnlich Nr. 283 (Bd. I); d. h. über drei gestielten Blumen die Initialen I. G. Auf beiden Arten des Wappentellers findet man zwischen dem untern Ende des Zürcher- und Berner-Wappenschildes ein kleines Wappenschildchen mit den Initialen H I G darüber, welches wahrscheinlich dem Hersteller der Tellerform angehört (Nr. 313, Bd. I). Im Zürcher Wappenschild befindet sich noch das Meisterzeichen von Joachim oder Jakob Schirmer, I. S. eingeschlagen.

Die Gegenstände der Gmünder und von Glinz mit den Meisterzeichen Nr. 279, 282, 283, 284 und den Bodenrosetten Nr. 331, 336.

Grosse Glockenkanne mit Bajonetverschluss. Auf dem Deckelchen der Ausgussröhre das Meisterzeichen Nr. 279. Bodenrosette Nr. 331. Arretirung am Deckel. Gotisirender Schild mit gravirter Bretzel und den Initialen I. S. Am Korpus oben vier und unten drei breite, flache Wülste. Basis der Ausgussröhre von schönen Gravuren umgeben. Höhe $40,5 \mathrm{~cm}$. Durchmesser des Fusses 19,5 cm. (Tafel XXXVII, 5.)

Breitrandplatte von 33,7 cm Durchmesser und 7,7 cm Randbreite. Oben am Rande Meistermarke Nr. 279 mit grosser Krone. Gegenüber ein prächtig gravirtes Alliancewappen. Unten am Boden die Initialen F. I. M.

Kleine Glockenkanne. Auf dem Deckelchen der Ausgussröhre das Meisterzeichen Nr. 283. Bodenrosette Nr. 336. Oben am Korpus zwei, unten ein Wulst. Auf dem Schild die gepunzten Initialen V R 165o H M. Höhe 21,3 cm. (Tafel XXXVII, 1.)

Kugelkrug mit Henkel und Deckel. Am Henkel das Meisterzeichen Nr. 279. Am Korpus sechs herausgetriebene Buckel. Der ganze Krug ist mit prachtvoll gravirten Blumenranken überzogen. Der Deckelgriff wird durch ein Akanthusblatt gebildet. Höhe $17,2 \mathrm{~cm}$. Durchmesser des Fusses $8,3 \mathrm{~cm}$. (Tafel XVIII, 5.)

Blumenvasen mit zierlichen Henkeln. Oberhalb des Fusses zwei kugelförmige Leibungen. Der obere Teil weist sechs herausgeklopfte Buckel auf, welche mit Tremolirstich eingefasst sind. Höhe 19,5 cm. Durchmesser des Fusses $7,8 \mathrm{~cm}$. Ein gleiches Paar in solothurnischem Privatbesitz trägt am Fuss das Meisterzeichen Nr. 279. (Tafel XVIII, $7,8$.

Schlumpf, Hans Joachim, Probirer von 1734-1741 (gestorben 1741).

Dürler, Anthoni (Dörler), führte das Meisterzeichen Nr. 285 (Bd. I). Er wurde 1697 geboren, heiratete 1722 Anna Stähelin, war von 1728 bis zu seinem Tode ${ }_{17} 37$ Probirer.

Gegenstand: Stitze und Glockenkanne bei C. Hirsbrunner, Antiquar, Luzern.

Stäheli, Georg, Zinngiesser, wurde im Jahre 1706 geboren, verheiratete sich 1729 mit Kunigunde Schirmer. Er war Probirer von 1737 bis zu seinem Tode 1749.

Er führte die Meisterzeichen Nr. 286 und 292. Bodenrosette Nr. 329.

Gegenstände: Glockenkanne mit Bajonetverschluss. Auf dem Barokschild die Initialen V.S. Auf dem Deckelchen der Ausgussröhre das Meisterzeichen Nr. 286 . Bodenrosette Nr. 329. Am Korpus oben vier, unten zwei flache Wülste. Höhe $3_{1}, 5 \mathrm{~cm}$. Durchmesser des Fusses 15,7 cm.

Glockenkanne mit Schraubverschluss von $34 \mathrm{~cm}$. Höhe. Meisterzeichen Nr. 286 auf dem Kannendeckel. Keine Bodenrosette. Schild leer. Vorne gravirte Blumenranken. Am Korpus oben sechs, unten zwei Wülste. (Tafel XXXVII, 2.)

Glockenkanne mit Bajonetverschluss. Meisterzeichen Nr. 286 auf dem Deckelchen der 
Ausgussröhre. Bodenrosette Nr. 329. Auf dem Schild die Initialen V. S. Am Korpus oben drei, unten zwei circuläre Wülste, aber ganz schmale. Höhe $25,8 \mathrm{~cm}$; Durchmesser des Fusses $13 \mathrm{~cm}$.

Vonwiller, U1rich, war Probirer von 1741-1748 (gestorben 1748).

Zollikofer, Hans Josef, war Probirer von 1748-1758 (gestorben 1768).

Zingg, Hans Gabriel, Zinngiesser, wurde 1635 geboren, heiratete 1658 und starb 1689 .

Zingg, Jakob, Sohn des Vorigen, wurde 1671 geboren, heiratete 1699 und 1711 . Er wurde wegen falschen Eides 1731 hingerichtet.

Zingg, Hans Jakob, Sohn des Vorigen, Zinngiesser, führte das Meisterzeichen Nr. 271 (Bd. I). Er wurde 1702 geboren, heiratete 1728 und 1737 . Er starb im Jahre 1756; seine zweite Frau 1767 .

Gegenstand: Glockenkanne von 1 Maass Inhalt im Antiquitätenhandel in Zürich (Brunner, 1906).

Hiller, I Heinrich, Zinngiesser, führte das Meisterzeichen Nr. 275. Er wurde 168o geboren, war Mitglied der Schmiedenzunft. Er heiratete 1705 Magdalena Schirmer. Er wurde 1727 Probirer und starb 1728 .

Gegenstände: Glockenkanne von $25,5 \mathrm{~cm}$ Höhe im historischen Museum von St. Gallen.

Hiller, II Heinrich, Sohn des Vorigen, Zinngiesser, führte die Meisterzeichen Nr. 276, 290 und $292 b$ zusammen. Er wurde im Jahre 1702 geboren, heiratete 1732 . In der Schmiedenzunft wird er von 1744-1789 aufgeführt. Von 1749 ab war er Probirer. Er starb 1797.

Gegenstände: Maass mit dem Meisterzeichen Nr. 276. Höhe 14,3 cm. Durchmesser des Fusses $7 \mathrm{~cm}$. Am obern Rand gepunzt: V R ${ }_{18} 5 \mathrm{~T}$.

Glockenkanne mit dem Meisterzeichen Nr. 276 und $292 b$.

Teller mit den Meisterzeichen Nr. 290 und 2926 im historischen Museum von St. Gallen.

Hiller, Abraham, Zinngiesser, Sohn des Heinrich I, wurde 1719 geboren, lernte in Weinfelden bei Johann-Joachim Keller ab 1735. Er heiratete 1750 und 1791 und war Mitglied der Schmiedenzunft, von 1775-1786 Elfter. Starb 1798. Sein Meisterzeichen und dasjenige des folgenden Adrian Hiller sind nicht auseinander zu halten, Nr. 278 und 291 (Bd. I).

Hiller, I Adrian, Sohn des Zinngiessers Heinrich II Hiller, wurde 1735 geboren, heiratete 1760 und starb 1818. Meisterzeichen wie Abraham Hiller, Nr. 278 und 291.

Gegenstand: Prismatische, sechsseitige Kanne mit Schraubdeckel. Auf dem Deckelchen der Ausgussröhre das Meisterzeichen Nr. 278. Kein Schild. Ausladung des Fusses gering. Die beiden Vorderseiten sind mit Blatt- und Blumenranken gut gravirt. Die Höhe beträgt $38 \mathrm{~cm}$. Der Sockel des Tragringes hat einen dreifachen Wulst. (Tafel XXXVII, 3.)

Gleiche Kanne von $32 \mathrm{~cm}$. Höhe. An der linken Seite gravirt mit B. Roh.

Stitze mit sehr kleinem Ausgusschnabel. Am Henkel die Meistermarke Nr. 291. Am Deckelgriff ein Engelkopf. Bodenrosette : Bär mit Halsband und den Initialen S. G. Auf dem Deckel die gravirten Initialen H C.A B. 1808. Höhe 19,5 cm. Durchmesser des Fusses 10,3 cm.

Brunnenkesselchen. Höhe $16 \mathrm{~cm}$. Durchmesser des Fusses 9,5 cm. Auf dem Deckel gerillter Knopf und davor das Meisterzeichen Nr. 291. Im Boden eine Rosette mit Bär (mit Halsband) und dem Buchstaben H. Eiserner Traghenkel. (Tafel XX, 22.)

Hiller, III Heinrich, Sohn des Abraham Hiller, führte das Meisterzeichen Nr. 277 (Bd. I). Er wurde 1756 geboren, heiratete 1782 und starb 1811 .

Gegenstand: Glockenkanne mit Bajonetverschluss. Höhe $44 \mathrm{~cm}$. Durchmesser des Fusses $22 \mathrm{~cm}$. Auf dem Deckelchen der Ausgussröhre das Meisterzeichen Nr. 277. Keine Bodenrosette. Am Korpus oben sieben breite circuläre Wülste, unten zwei. Schild leer. Arretirung des Deckels fehlt.

Hiller, IV Heinrich, Zinngiesser, Sohn des Adrian I Hiller, wurde 1768 geboren, heiratete 1792 und starb 1841 . 
Hiller, II Adrian, Zinngiesser, Sohn vorigen Heinrich IV Hiller, wurde 1797 geboren, heiratete 1829 und starb 1872 .

Hiller, Sebastian, Zinngiesser, führte das Meisterzeichen Nr. 274 (Bd. I). Als Sohn des Heinrich II Hiller wurde er 1738 geboren und starb 1821 .

Gegenstand: Glockenkanne von I Maass Inhalt in historischen Museum St. Gallen. Bodenrosette Nr. 335.

Haussknecht, Heinrich, Zinngiesser, führte das Meisterzeichen Nr. 293 (Bd. I). Er wurde 1726 geboren, heiratete $17^{52}$ und starb 1792 .

Gegenstand: Prismatische, sechsseitige Kanne, Höhe ${ }_{27}, 5 \mathrm{~cm}$. Gravirte Jahrzahl 1741. Historisches Museum St. Gallen.

Merz, Joachim, Zinngiesser, führte das Meisterzeichen Nr. 295 (Bd. I). Er wurde ${ }_{17} 37$ geboren, heiratete $17^{61}$ und starb 1771 .

Gegenstand: Prismatische, sechsseitige Kanne mit dem Meisterzeichen Nr. 295. Höhe der Kanne $33 \mathrm{~cm}$. Historisches Museum von St. Gallen.

Zollikofer, Rupprecht, Zinngiesser, wurde ${ }_{17} 3_{7}$ geboren, heiratete ${ }_{17} 6_{2}$ und starb ${ }_{1} 8_{1} 3$.

Halder, Friedrich, Zinngiesser, wurde 1769 geboren, heiratete 1801 und starb 1823 .

Halder, David, Zinngiesser, Sohn des Vorigen, wurde 1803 geboren und heiratete $1832 . \operatorname{Er}$ starb 1871 .

Steinli, Hector, Zinngiesser, wurde 1785 geboren, heiratete 1810 und starb 1861 .

\section{Die Gegenstände}

St. Gallen besass ein sehr entwickeltes Zinngiesserhandwerk und mehrere ausgezeichnete Meister. Das historische Museum besitzt eine der wenigen gut geordneten Zinnsammlungen der Schweiz und zwar ist darin St. Gallen in einzig vollständiger Art vertreten. Darunter befinden sich einige Unica.

Weitaus der grösste Teil der Kannen sind Glockenkannen. Dieselben zeichnen sich von allen andern schweizerischen Glockenkannen durch ihre Massigkeit aus, indem der Durchmesser im Verhältnis zur Höhe erheblich grösser ist als bei den andern. Trotzdem machen sie keinen plumpen Eindruck, weil der Kannenleib durch circuläre Wülste gut gegliedert ist. Je älter eine Glockenkanne ist, umso flacher und breiter sind diese Wülste. Sie stellen die Weidenreifen dar, welche die entsprechenden primitiven Holzgefässe zusammenhielten. Ebenso findet man bei den frühen Exemplaren stets den Bajonetverschluss. Der Schraubenverschluss finden wir erst bei den Meistern Georg Stäheli und A. Hiller. Die Bodenplaketten und Bodenrosetten (siehe Band I, Tafel XVI) fehlen ebenfalls niemals bei den alten Stücken und sind oft kleine dekorative Kunstwerke. Wie im weinbauenden Schaffhausen findet man auch in St. Gallen oft sehr grosse Glockenkannen bis zu $44 \mathrm{~cm}$ Höhe. Auf dem Lande war der Most von Birnen und Aepfeln das Nationalgetränk, besonders auch im benachbarten Thurgau. Der Tragring der Kanne ist ebenfalls gross und massig, besonders im Vergleich zu den Schaffhauser und Zürcher Exemplaren. Der Sockel des Tragringes ist relativ niedrig und weist oft circuläre Rillen und Wülste auf, welche letztere Eigenschaft sich nur bei den St. Galler und Appenzeller Glockenkannen findet.

Die prismatischen, sechsseitigen Kannen treten erst spät auf und zwar mit dem Zinngiesser A. Hiller. Sie haben keine für St. Gallen besonderen Eigenschaften und sind nur durch die Meistermarke zu erkennen. Auf denselben befinden sich oft prächtige Blumen- und Rankengravuren, welche die Hand des kundigen Goldschmiedes verraten.

Stitzen sind sehr selten. Es sind mir nur zwei Exemplare unter die Augen gekommen, unter welchen sich allerdings ein frühes Exemplar von Antoni Dürler befindet.

Breitrandplatten kommen noch häufig, auch im Handel, vor und weisen die Zeichen der ältesten Meister auf. Platten und Teller sind nur an der Meistermarke, als von St. Gallen stammend, erkennbar. 


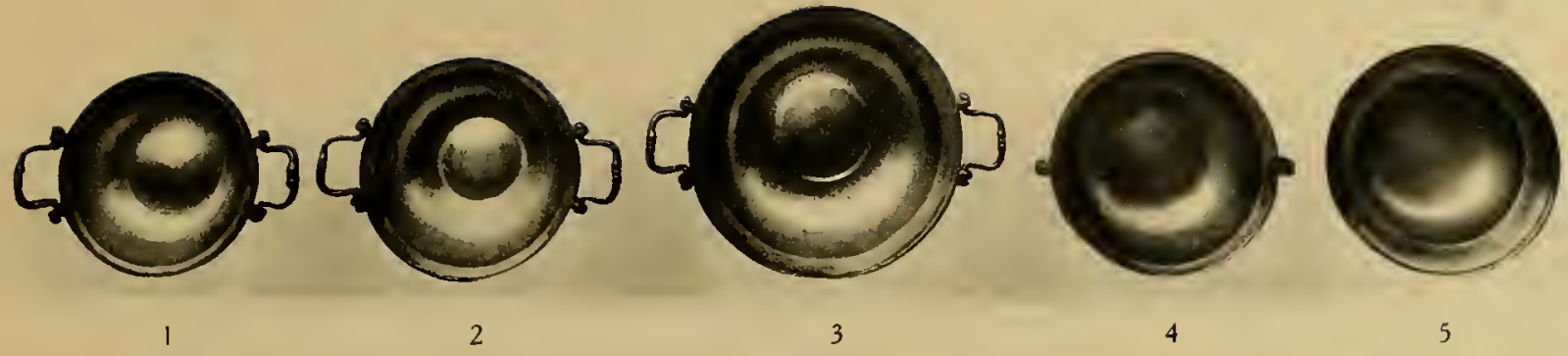

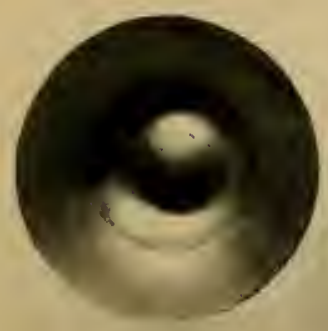

6



7

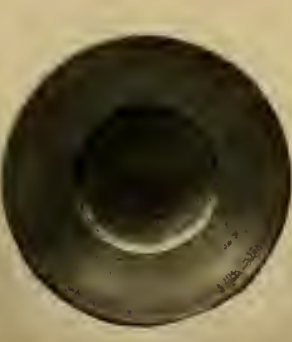

8

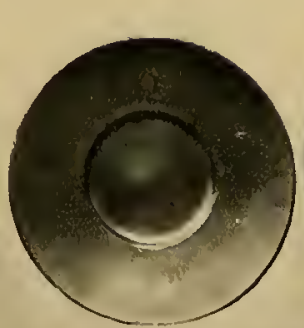

9

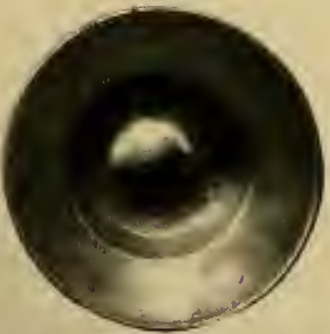

10
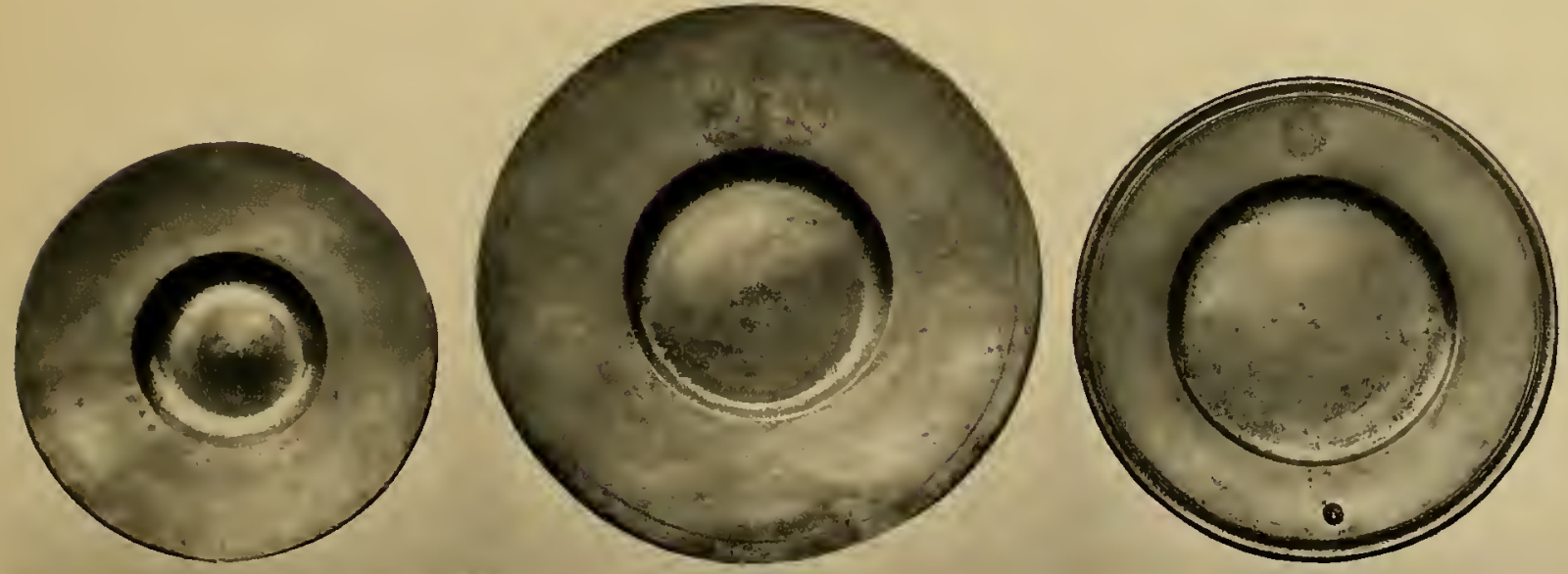

11

12

13


14

15

16

17

1-3. Henkelschüsseln von Zug, von Joachim Leonz Keiser in Zug, 1728-1809. 4. Schüssel von Sargans, von HIE oder B 5. Schüssel von HK, mit dem Beschauzeichen von Uri. 6-10 Breitraodteller von Zug, Chur und Glarus; Guplteller von Glarus und Bischolszell (6 und 10). 11--13. Breitrandplatten von Zürich, Tirano und Genl. 14. Guplplatte von Zug; 15. Guplplatte von Zürich; 16. Guplteller von Luzern; 17. Von Zug. 

Die Reliefteller. Wir finden vier verschiedene Teller vor, welche sich stilistisch an die Nürnberger Teller anschliessen. Allerdings sind die St. Galler Teller viel spätern Datums. Die drei gelappten Teller tragen je drei verschiedene Marken. Zwischen dem Wappen von Appenzell und Zürich befindet sich das Zeichen St. Gallens, ein Buchstabe G in etwas merkwürdiger Form; zwischen dem Wappen von Zürich und Bern der Schild mit dem Monogramm Joachim Schirmers und zwischen den Wappen von Bern und Luzern dasjenige Zacharias Täschlers. Joachim Schirmer war von 1682-1697 Probirer und Zacharias Täschler lebte von 1657-1717. Die Teller stammen also aus der Zeit um 1700 herum, obwohl der Stil der Schilder und Ornamente ein viel früherer ist. Alle Marken sind gegossen, also schon in der Gussform enthalten. Diejenige des historischen Museums St. Gallen besteht aus Messingbronze und ist sehr gut erhalten. Meiner Ansicht nach hat keiner der beiden Zinngiesser und noch weniger beide zusammen an der Herstellung der Gussform gearbeitet. Das Modell stammt vielmehr von einem routinirten Formenschneider, welcher dasselbe für die beiden Zinngiesser anfertigte.

Erste Variante: Gelappter Rand; in jedem Lappen das Wappen eines der i3 alten Orte. Im Fundus das Reichswappen und darunter zweimal das Wappen der Stadt St. Gallen gegeneinander gekehrt. Bei den scharf gegossenen Exemplaren ist das Halsband bei beidenBären deutlich erkennbar; es ist mithin keines ein Appenzellerwappen. Durchmesser des Tellers 21,7 cm. An der Rückseite des Tellers deutliche Abdrehspuren. (Tafel XXXVIII, 2.)

$Z$ weite Variante: Gleiche Ausführung wie die Vorige; nur ist der Teller kreisförmig, indem die Zwickel zwischen den Lappen ausgefüllt sind. Durchmesser 21,8 cm.

Dritte Variante: Im gelappten Rande sind die Wappen der 13 alten Orte wie bei der ersten Variante. Im Fundus befindet sich in einem doppelten runden Friese das Bild der drei ersten Eidgenossen, welche die rechte Hand zum Schwur erheben. Zivischen den beiden Friesen steht der Spruch: "Dieser.Pundt.ward.von.Gott.erwelt.Do.man.13o8 zelt ». Durchmesser des Tellers $21,6 \mathrm{~cm}$. (Tafel XXXVIII, 1.)

Es gibt auch Abgüsse in Bronze und sogar in Gusseisen (v. Goertzke, Bibliothekar des "Herold ", Berlin).

Der St. Galler Reliefteller nach dem sogenannten Wyler Modell. Das einzige, prachtvoll erhaltene Exemplar befindet sich in zugerischem Privatbesitz. Es handelt sich um den runden Wyler Teller mit den Wappen der 13 alten Orte am Rande; im Fundus ist die Darstellung von Tells Apfelschuss. Am Rande zwischen der Inschrift Appenzell und Zürich befindet sich ein Wappenschild mit dem $G$ von St. Gallen und zwischen derjenigen von Zürich und Bern das Meisterzeichen des Jakob Glinz oder des J. Gmünder (vergl. Nr. 283, Bd. I). Diese beiden Schilder sind relativ sehr gross unf befinden sich schon in der Gussform und sind nicht etwa eingeschlagen. Am Innenborde des Randes ist wie beim Wyler Teller ein kleiner Wappenschild und darüber die Initialen H. I. G. Ebenso wenig wie Schirmer und Täschler hat Jakob Glinz das Modell und die Gussform gemacht. Der Künstler ist der H. I. G., welcher bei diesem Teller sein Wappen und seine Initialen angebracht hat. In die linke Seite des Zürcherschildes hat Joachim Schirmer sein Meisterzeichen eingeschlagen und man weiss nicht, soll man es als Spott oder Protest gegen Jakob Glinz auffassen. Durchmesser des Tellers $19,8 \mathrm{~cm}$. (Tafel XXXVIII, 3.)

Von allen vier Abarten gibt es im Kunsthandel gute und schlechte Nachahmungen. Man achte hauptsächlich auf die Schärfe des Gusses in den Wappenbildern von Uri, Glarus, Schaffhausen, auch des Damastes und berücksichtige die Abnutzung des scharfen Gusses durch das Alter und das Abputzen. Das Gewicht des Tellers, die Drehzüge auf der Rückseite sollen ebenfalls berücksichtigt werden. Die grösste Sicherheit bietet aber der Vergleich mit einwandfreien Exemplaren.

Vom XVI. bis zum XIX. Jahrhundert gab es keinen Schutz für geistiges Eigentum. Die schönsten Originale der Goldschmiede wurden vom Zinngiesser, Kupferschmied, Messingschläger, vom Hafner und Krugbäcker ohne Bedenken verwendet. Ich erinnere an die Ver- 
wendung der Modelle von Briot durch Caspar Enderlin, an die Copien der bronzenen spanischen Suppenschüsseln durch die Strassburger Zinngiesser, an die Verwendung der kunstvollen Bleiplaketten durch die Hafner der Familie Vest in Augsburg, von Palissy in Frankreich, u.s.w. Ferner finden wir z. B. ähnliche Wappenserien der 13 alten Orte auf den blaugrauen Steinzeugkrügen in den Sammlungen Oppler und Oppenheim (Katalog der Sammlung Oppler anlässlich der Auction bei Lepke, Berlin, im Jahre 1913, 25. Februar). Nach solchen Originalen wurden auch die Formen der St. Galler Reliefteller hergestellt und eben darum fehlt denselben der bodenständige Zug und der Geist der Zeit, welchem sie ein Jahrhundert nachhinken. Immerhin sind es prächtige, sehr gesuchte Objekte und die einzigen Repräsentanten des Relieftellers im Schweizerlande, ausser den sogenannten Walliser Blumentellern.

Ausser der Stadt St. Gallen gab es in den Landstädtchen Rheineck, Wyl, Rapperswyl und Sargans Zinngiesser, ebenso im Marktflecken Lichtensteig im Toggenburg; auch in Uznach (im Wappen eine gestielte Rose).

\section{RHEINECK}

Es war stets nur ein Meister in Rheineck als Zinngiesser tätig. Jedenfalls gab es zeitweise auch fahrende Giesser, besonders wenn kein ansässiger Kantengiesser vorhanden war.

Pfeifer, Johannes, führte das Meisterzeichen Nr. 30o. Ausser Pfeiffer gibt es in Rheineck kein anderes Geschlecht mit der Initiale P. Geboren 1741 ; gestorben 1779.

Gegenstände: Glockenkanne, Höhe 27,8 cm (historisches Museum St. Gallen).

Prismatische, sechsseitige $\mathrm{K}$ anne, Höhe $33,5 \mathrm{~cm}$ (historisches Museum St. Gallen). Beide mit dem Meisterzeichen Nr. 3oo.

Berlocher, Hans Jakob, Zinngiesser, geboren ?, heiratete ${ }_{1670}$ Barbara Messmer. Machte schlechte Geschäfte und fallirte; er ging 1689 unter Zurücklassung der Familie nach Flandern, woselbst er schon 1690 starb.

Er führte das Meisterzeichen Nr. 3o4.

Gegenstände: Glockenkanne mit Bajonetverschluss von 1/2 Maass Inhalt.

Stitze von $1 / 2$ Maass Inhalt mit schnabelförmigem Ausguss. Die Form der Stitze veist nach Süddeutschland. Der seltene Krug befindet sich im historischen Museum von St. Gallen.

Bösch, Johann oder Hans Heinrich, Zinngiesser. Er war auch Kronenrvirt und Stadtammann, 1718-1769; er war verheiratet, zuerst mit Dorothea In der Maur und nachher mit Regina Messmer.

Er führte das Meisterzeichen Nr. 3o3. Bodenrosette Nr. 337.

Gegenstand: Glockenkanne mit Bajonetverschluss. Auf dem Ausgussdeckelchen das Meisterzeichen Nr. 3o3. Bodenrosette Nr. 337. Auf dem Schild die gepunzten Initialen H. C. B. Höhe $27 \mathrm{~cm}$. Durchmesser des Fusses $12,4 \mathrm{~cm}$.

Bösch, Johannes, der Sohn des Vorigen, wurde am 25. April 1755 geboren und heiratete Anna Katharina Niederer von Herisau.

Er führte das Meisterzeichen des Vaters, Nr. 3o3.

Höchner, Johannes, Zinngiesser, Seckelmeister und Municipalrat, lebte von 1751-1801. Er war mit Anna Barbara Höchner verheiratet.

Er führte das Meisterzeichen Nr. 3o1, das sich auf einem zierlichen Spital- oder Wöchnerinnenschüsselchen befindet. (Historisches Museum St. Gallen.)

Alle genealogischen Angaben verdanke ich Herrn Heinrich A. Custer, Apotheker in Rheineck. Von Gegenständen sind uns nur Glocken- und prismatische sechsseitige Kannen und schmalrandige Teller bekannt; ferner ein Wöchnerinnen-Schüsselchen. 


\section{RORSCHACH}

Stein, Peter, Kannengiesser, von Rorschach, war Lehrling bei Andreas I Wüger in Steckborn vom 8. Mai 1688-12. November 169o (Handwerksbuch der Stadt Steckborn, Bd. I, fol. $40 a)$.

A. H. Meister A. H. führte die Meistermarke Nr. $3{ }_{2} 6$ (Bd. I).

Gegenstand: Glockenkanne, Höhe $27 \mathrm{~cm}$. Meisterzeichen Nr. 326; Bodenrosette Nr. 327 (Bd. I).



326 a

Runde Schüssel von 28,5 cm Durchmesser und $4 \mathrm{~cm}$ breitem Rand. Beide Gegenstände sind im historischen Museum von St. Gallen.

I. H. Meister I. H. hatte das Zeichen Nr. $3{ }_{2} 6 a$ (Bd. II), aber mit den Initialen I. H.

Gegenstand: Glockenkanne; Höhe $26,5 \mathrm{~cm}$ (historisches Museum St. Gallen).

\section{WYL}

In der Stadt Wyl lassen sich die Kantengiesser schon sehr früh nachweisen. Die erste

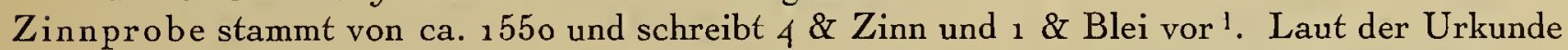
XIII. 32 des Stadtarchives Wyl empfiehlt am 3o. Januar 1562 "der Statthalter und Rath der Statt Stein am Ryn " den Adam Koch und dessen Sohn Crispinus als Kanntengiesser zur Aufnahme als Bürger, indem sie (zu Stein) vernommen hätten, in Wyl sei kein Kannengiesser. In Stein haben sie deren genug. Montag nach Lätare 1565 wird im Rats- und Gerichtsbuch $367 / 24$ ohne Namensangabe "der Kannengiesser sagt ... " zitirt.

Laut Ratsprotokoll 414-41, Mitte August 1545, hält der Rat einem Kantengiesser Spitzli vor "wie er allerlei Krämereien feil habe, dazu in Lichtensteig einen eigenen Laden und darin feil habe. Beschlossen : solle kein Laden mehr in Lichtensteig haben, wohl dahin zu Markt fahren, solle dort Burgerrecht aufgeben. Zudem möge er sein Handwerk mit dem Kannengiessen desgleichen den Eisengewerb, Kernengewerb in Wil brauchen ».

Im Rats- und Gerichtsbuch 421, Samstag nach Katharinentag 1586, wird von der Kundschaft gegen Bernardi Spitzli geklagt. Bernardi sagt, wenn er ihn einen faulen Kannengiesser schelte, könne er nichts sagen, denn er stünde morgens ungern auf.

Aus dem Jahre 1571 stammt die zweite Kannengiesser-Ordnung ?. Sie lautet:

"Wie die Kannttengiesser allhie das Zinygeschirr machenn söllen. Namlich. Söllen sy under vier pfund louter Zynn ain pfund bly thun unnd nit mer. Daruff mögen sy dann die brob schlachen unnd sunst was darunder ist nit. Was aber über die Brob, daruff mögen sy auch der Statt Zeichen schlachen.

"Item alles das mann Innen aus guter Werschaft zemachen gibt, Das sällenn sy bim trüwlichsten machen unnd werchen, und dasselbig inn selbiger werschaft wider überantworten unnd so das nüt werschaft wäry, dem soll es werschaft thun ze synem Lasten.

"Ist immer der Eyd vorzelesenn.

"Unnd als sach weere, dass Innen etwas argwänisch geschirr fürkäme, das söllenn sy einen Schultheyssen malden unnd annzeygen trüwlich unngefarlich.

-Was aber nit prob daruff möge Er sein Zeichen nur einfach und nid doplet schlagen.

"Den 8. Augsten 1671 hat M. Barthlime Marx von Fischingen Kanntengiesser allhir mit aufgehabt fingern auf obige punkte ein aid geschworn."

Der Teil nach 2 , also die letzten 9 Zeilen, sind von späterer Hand ( ${ }_{1} 6_{71}$ l).

Im Ratsprotokoll 429-51 vom Jahre 1602 wird ein Kannengiesser S toffel Wick zitirt.

1 Notizen aus den Rats- und Gerichtsprotokollen ron K. J. Ehrat, Archivar in Wyl.

2 Nüw Stattbuch ainer Statt Wyl im Thurgöw. 1571. Blatt 10. 
Laut Ratsprotokoll $434-54$ vom Montag nach St. Martinstag 1612 "ist Mein rad Weldtin aus der Reichenau seines Handwerks ein Kannengiesser auf sein Wohlhalten hin zu einem Hintersassen auf und angenommen worden, doch dass er $100 \mathrm{fl}$. wie bräuchlich vertröste ". Im Ratsprotokoll Nr. 436 wird er als Meinrad Welti nochmals im Jahre 1614 erwähnt. Er starb 1638 .

Laut Ratsprotokoll 440-57 vom 8. November 1636 hält Peter Hindenlang von Basel an "dass man ihm das Kannengiessen erlaube, sei Willens, Meinrad Welti's frauen das Werkzeug abzukaufen. ") Peter Hindenlang von Liestal' ${ }^{\prime}$ war von 1617 ab Lehrling bei Conrad Biermann in Basel.

Wie überall wurden auch in Wyl die fahrenden Giesser eine Plage für die ansässigen Meister und laut obigem Ratsprotokoll wurde am 25. April ${ }_{1} 637$ der Rat schlüssig, die " welschen Kantengiesser abzuschaffen ». Doch wurde der Beschluss nicht ausgeführt; denn laut Ratsprotokoll 441-58 vom 4. Februar 1645 wird folgender Beschluss gefasst : "Die welschen Kantengiesser sind abermals zitiert, Ihnen wiederum der Eid vorgelesen, darauf Vater und Sohn den Eid getan, fürhin Prob zu machen und das Stadtzeichen darauf zu schlagen, was aber ein Burger Ihnen $Z$ inn zu verändern und zu verarbeiten geben, sollen sie den Burgern dasselbig. in seinem Preis wiederum zustellen und was sie für gemachtes Geschirr haben, soll visitiert werden, dass sie solches wohl mögen verkaufen und hinweg geben, wie es diesmals ist aber wie gesagt, fürhin kein Geschirr mehr machen und verkaufen, das die Prob nicht hat und der Stadt Zeichen. "Am 6. Oktober ${ }_{1} 66_{1}$ sind Cahar der welsche Kannengiesser und Johannes Ambrosi und sein Bruder alle welsche Kannengiesser bestraft worden wegen begangenen Frevels und Schwörens.

Ich habe bis zu diesem Zeitpunkte die Archivalia in extenso angeführt, weil sie ein interessantes Bild des Handwerks in einer kleinen Stadt geben. Auch sind an kleinen Orten selten die Protokolle und Urkunden in solcher Vollständigkeit erhalten.

\section{Die Zinngiesser}

Spitzli, zitirt 1545 (Ratsprotokoll $414-41$ ).

Spitzli, Bernardi, zitirt 1586 (Rats- und Gerichtsbuch 421 ).

Wick, Stoffel, zitirt 1602 (Ratsprotokoll 429-51).

Welti, Meinrad, wird Hintersässe am 11. November 1612. Stirbt ${ }_{1635}$ (Ratsprotokoll $434-54$ und 436$)$.

Hindenlang, Peter, von Basel (Liestal), zitirt am 8. November 1636 (Ratsprotokoll 440/57). Lehrling von 1617 ab bei Conrad Biermann in Basel.

Galinger, Wilhelm, Kannengiesser, zitirt am 27. Oktober 1638 (Ratsprotokoll 440, B. 57). Er hält unter obigem Datum nur den Hindersitz an, dass er sein Kannengiesser Handwerk treiben könne - wird bewilligt, müss Abscheid von Bischofzell bringen, sich tragen und halten, wie es einem ehrlichen Meister zusteht, die Leute nicht überfordern, im rechten Preis sich halten, die Prob darauf schlagen, das Stadtzeichen - hat sich anerboten, was in benachbarten Städten zu Lohn nehmen, er auch nehmen wolle s- von Giessfass und Glater Arbeit 3 B, von Kannen 2 B, von Blatten 1 B $6 \partial$.

Trutz, Albrecht, und sein Bruder Johannes, zitirt am 14. Januar 1645 (Ratsprotokoll 441, B.58). Stammten aus dem Mailänder Gebiet. "So ein Bürger oder Bauer Ihnen altes zinnernes Geschirr brächte zu erneuern, sollen sie es machen so gut man es ihnen gibt, so es Probe nicht ist, sollen sie die Prob nicht darauf schlagen — ist eingestellt, soll man Nachfrag. halten gen St. Gallen und Konstanz schreiben." "

Ehrhart, Franz, der Kannengiesser, den Eid getan am 29. April 1656 (Ratsprotokoll 442-59). Er starb am 3. April 1666.

'Auszüge aus den Akten der Hausgenossenzunft in Basel, von J. Vogl-Ammannn, Architekt, Basel. 


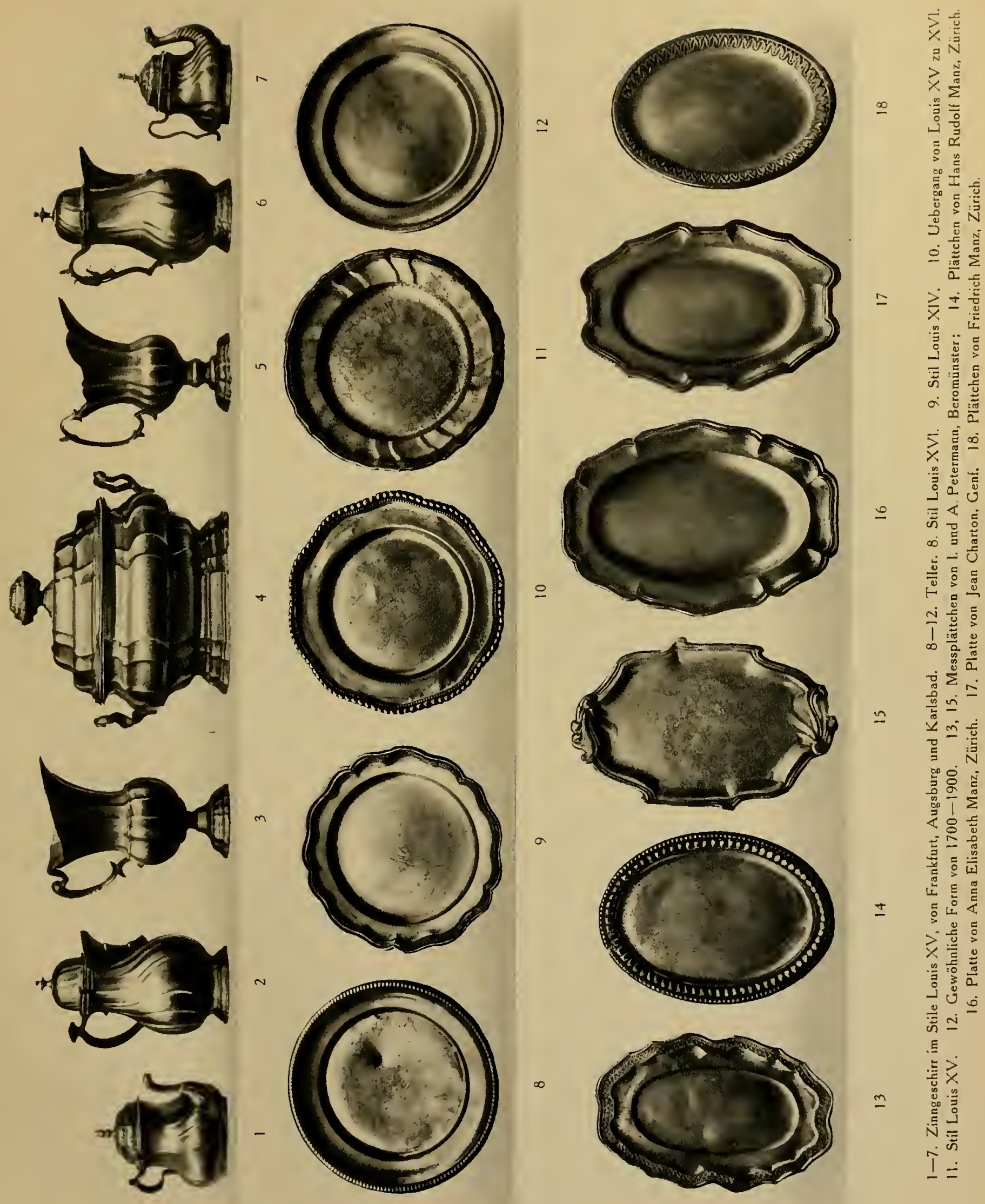



Müller, Hans Melchior, Zinngiesser ${ }^{1}$ wurde am 8. April 1660 geboren als Sohn des Apothekers und Stadtschreibers Joh. Ludwig Müller (1626-92). Er heiratete am 16. August ${ }_{1682}$ Elisabeth Schnider von Baltenswil und wohnte bis 1687 in Wyl, 1691-96 in Dussnang, 1697 im Neuhaus bei Wuppenau und nachher wieder in Wyl. Im Ratsprotokoll der Sitzung vom 13. Januar 1685 findet sich folgender Passus: "Kleger: Joachim Scherer, Apoteckher Isenring, Joannes Müller, Huotmacher, Hans Balthas Müller, Apotekher, Hans Melchior Müller Zingiesser, Hans Georg Kienberger der Nagler und Isengewerbe, Hans Georg Randli, Sekhler und Christof Wickh, alle Burger. Tragt vor Joachim Scherer im Namen aller gegenwertigen und abwesenden Burger, die Handtwerkher oder Gewerbsleuth sind, das sie in villen Stuckhen beschwerdt (sigen) wegen Landkrämern, die ihnen ihr Stuckh Brot vor der Mund abschneiden. Bitten umb obrigkeitliche Hilf, u.s.w. "

Das Wappen auf dem sogen. Wyler Teller ist dasjenige des Zinngiessers Hans Melchior Müller. Im Jahre 1722, am 2o. Juli verheiratete er sich zum zweiten Male und zwar mit Katharina Habisrütiner. Er starb am 13. März 1733.

Gegenstand: Der Wyler Reliefteller mit dem Wappen der 13 alten Orte und der Apfelschusscene Tells im Fundus (siehe unter den Gegenständen). Die Meisterzeichen sind gegossen, nicht geschlagen, also in der Gussform enthalten. (Tafel XXXVIII, 3.)

Scher, ....., Kannengiesser, zitirt am 1. September 1668 (Ratsprotokoll 445-61).

Marx, Bartholomä, Kannengiesser von Fischingen, zitirt am 28. Juni $167^{\circ}$ (Ratsprotokoll 445 , B. 61) "welcher sich bei 12 Jahr zu Appenzell ehrlich und redlich aufgehalten laut Attestation zum Hindersassen angenommen, auf sein Wohlhalten und nicht länger, als lang ein Burger das Kannengiesser-Handwerk allhier nicht treibt ». Laut Zusatz zur zweiten Kannengiesserordnung wurde er am 6. August ${ }_{16} 6_{1}$ in den Eid genommen und war mithin Meister.

Langenhart, Michel, Kannengiesser, zitirt 15. April ${ }_{1679}$ (Ratsprotokoll 447-62 und 449-64). Am 16. November 1698 bringt Seckelmeister vor, dass er auf das Rathaus sieben silberne Löffel, eine viermässige und zwei Quartkannen, acht Voressenplatten und 36 Teller angenommen und gut erkannt, dass man dem Zinngiesser Langenhardt für das Pfund Zinn $7 \mathrm{~s}$ geben wolle. Er kommt auch in der Seckelamtsrechnung von 1709-10 vor.

Seyller, Josef, Kanntengiesser, zieht aus der Stadt Wyl aus am 15. Mai 1703 als (Ratsprotokoll 449-64) Gefreiter (Auszugsrodel vom 15. Mai 1703). Ferner kommt er als Zinngiesser in den Seckelamtsrechnungen von 1704-1714 vor.

Isenring, Michel, Zinngiesser, wird im Jahre 1765 erwähnt (Ratsprotokoll 457-72).

\section{Gegenstände}

Der Wyler Reliefteller ist ein seltenes und künstlerisch sehr gutes Object. Derselbe ist rund und hat einen Durchmesser von 19,8 cm bei $4,7 \mathrm{~cm}$ Randbreite. Der Rand ist innen und aussen von einem schmalen Blattfries eingefasst; zwischen denselben sind, in Frucht- und Blumenornamente eingebettet, die Wappen der dreizehn alten Orte. Ueber jedem Wappen ist ein kleines Schriftband mit dem betreffenden Namen. Zwischen dem Namen Appenzell und Zürich ist das Stadtwappen von Wyl und zwischen Zürich und Bern die Meistermarke mit den Initialen H. M. M. Z wischen den gleichen Wappen, aber am Fusse derselben, ist ein kleinerer Schild mit einem querstehenden Halbmond und darüber einem Stern. Oberhalb des Schildchens sind die Initialen H. I. G. Im Fundus des Tellers befindet sich die Darstellung der Apfelschussscene Wilhelm Tells, ebenfalls von einem Blätterkranz eingefasst. Der Teller vurde meiner Ansicht nach von Hans Melchior Müller gegossen. Der Künstler aber, welcher das Modell und die Gussform schuf, war der Meister mit dem kleinen Wappenschild, ein querliegender Viertelmond, darüber ein Stern und die Initialen H. I. G.

1 Die genealogischen Angaben und Daten stammen von Herrn Paul Zuber in Wyl, ebenso der Anszug aus dem Ratsprotokoll. Band 63. Fol. 143 . 
Nur in diesem Falle ist es möglich, dass auch Jakob Glinz oder J. Gmünder in St. Gallen den gleichen Teller giessen konnte mit dem Stadtzeichen von St. Gallen und seiner eigenen Meistermarke, unter Beibehaltung des kleinen Wappens mit den Initialen H. I. G. Glinz oder J. Gmünder liess einfach in der Wyler Gussform das Wappen von Wyl und des Wyler Zinngiessers Hans Melchior Müllers durch dasjenige von St. Gallen und das seinige ersetzen. (Man siehe auch die Angaben bei Jakob Glinz, St. Gallen, und J. Gmünder.)

Auf einer dünnen Gussprobe des Wyler Tellers befindet sich überhaupt nur das kleine Schildchen mit den Initialen H. I. G. und das Wappen der Stadt Wyl. Darüber ist, ebenfalls gegossen, die Jahrzahl 169o. Die Stelle des Zinngiesserwappens (H M M oder I. G.) ist leer.

\section{RAPPERSWIL}

Der älteste erwähnte Kantengiesser ist $\mathrm{H}$ ans Rainsperg. Am 29. April 1492 entscheidet der Rat von St. Gallen einen Rechtsstreit zwischen dem Schultheiss und Rat der Stadt Rapperswil und Hans Rainsperg dem Kantengiesser über eine Geldforderung '. Voraussichtlich hat daraufhin Rainsperg nicht in Rapperswil Wohnsitz genommen, obwohl er Rudi Brenys Tochtermann war. Nach andern Angaben wurde er schon 1485 Bürger. - Das Gerichtsbuch 363-21 von Wyl nennt am Dienstag nach Lätare ${ }_{153}$ unter den Personen in Rapperswil den Kleinhans Breny, der Kannengiesser. - Ein Conrad Schmidt, Kannengiesser, bürgerte sich 1538 ein und wird 1541 verwarnt " sol andre werschafft sins handtwerchs machen $" 2$.

Eine Kannengiesserordnung ist nicht aufgefunden worden; doch sagt das Ratsprotokoll von $1569^{3}$ " die Kantengiesser ouch die ordnung und eid sch(wören) ). Wahrscheinlich handelte es sich um die gleiche Prob wie in St. Gallen. Weitere Kannengiesser werden erwähnt: $157^{2}$ ein Rickenmann; 1596 bürgerte sich ein Fridolin Fridinger von Sirnach ein. Von allen diesen Meistern kennt man weder Gegenstände noch das Meisterzeichen.

Im XVII. Jahrhundert erwähnt das Regimentsbuch den Hans Wetzstein ", Kannengiesser, als Mitglied des grossen Rats von 1669-1674. Im Ratsprotokoll von 1697-1713 wird mehrfach Johann Heinrich Breny", der Kantengiesser, zitirt. Der am 3o. Juni 1696 ebenfalls genannte Johann Hermann Weichel" hat das Bürgerrecht nicht erhalten.

Die Kantengiesser gehörten zur Erhardi- $Z$ unft bis zum Jahre ${ }_{17} 3_{1}$, nebst den Kaufleuten, den Bauhandwerkern, Kesslern, Hafengiessern, Kupferschmieden, Degenmachern, Wagnern Drehern, Hafnern, Goldschmieden, Malern, Bildhauern, Glasern, Sattlern, Badern, Müllern, Küfern, Säcklern, Zieglern und Kartenmachern. Um das Zinngiesser- und Kupferschmiedehandwerk zu fördern, wurden diese beiden durch Ratsbeschluss der Zunft "der geschenkten Handtierungen" zugeteilt. Die Angehörigen dieser Zunft konnten von der "Dingung und Ledigsprechung bei der Meistermachung " dispensirt werden. Auch sollte das Geld nicht an die fahrenden Galangger und Fecker verwendet werden (damit "viele Kösten, so sonsten an die frömbde expendiert worden, erspart würden ", Ratsprotokoll 739). Das Zunfthaus hatten die Kantengiesser mit der Erhardizunft auf der sogenannten Schmiedstube gemeinsam; doch mussten ihre Angehörigen 1 fl. weniger zum "Einstand " geben. Am 12. und 21. Februar ${ }^{17} 39$ wurde der frühere Ratsentscheid bestätigt und zugleich erkannt, dass der Kupferhammerschmied Baptist Helbling und der Zinngiesser Jakob Anton Zimmermann der neuen Zunft beizutreten haben. Die weitern Kannengiesser werden im Zinngiesserverzeichnis behandelt, welches ebenfalls die bekannten Daten enthält.

Das Beschauzeichen der Kannengiesser war das Stadtwappen mit den zwei Rosen.

1 Urkunde im Stadtarchiv van Rapperswil A 17 I. 1, Mitteilung von C. Helbling, Ratsschreiber.

2 Mitteilungen von Dr. M. Schnellmann, Stadtarchivar von Rapperswil ${ }^{3}$ Ratsprotokoll Band II. S. 199.

${ }^{3}$ Auszüge aus den Ratsprotokollen der Stadt Rapperswil, van C. Helbling, Ratsschreiber. 


\section{Die Zinngiesser}

Rainsperg, Hans, Kantengiesser, wurde 1485 Bürger; erwähnt $149^{2}$ (siehe oben).

Breny, Kleinhans, Kannengiesser, erwähnt ${ }_{1532}$ (siehe oben).

Schmidt, Conrad, Kannengiesser, wurde 1538 Bürger; erwähnt 1541 (siehe oben).

Rickenman, ...., Kannengiesser, erwähnt 1572 (siehe oben).

Fridinger, Fridolin, von Sirnach, wurde 1596 Bürger.

Wetzstein, Hans, Kannengiesser, wird im Regimentsbuch erwähnt als Mitglied des grossen Rats von 1669 bis 1674 . Er wanderte später aus und starb am 27. März ${ }^{16} 79$ in Alessandria bei Turin.

Breny, Johann Heinrich, Zinngiesser, wurde am 21. September 1668 geboren. Er wird im Ratsprotokoll von 1697-1713 oft erwähnt und war Mitglied des grossen Rates von 1713 bis 1715. Er beschäftigte sich auch mit der Fischerei. Sein Todestag ist der 7. März 1716. Gegenstände: stark bleihaltige Teller (Mitteilung von Dr. M. Schnellmann, Stadtarchivar in Rapperswil).



299 a

Weichel, Johann Herrmann, zitirt 1696, wird nicht Bürger (siehe Einleitung). Rothenfluh, Jakob, Zinngiesser, führte das Meisterzeichen Nr. 299 a.

Gegenstand: Kanne, mit dem Besitzerwappen Reifli und der Jahrzahl 1696. Meisterzeichen und Stadtmarke auf dem Deckelchen der Ausgussröhre. Meisterwappen Rothenfluh und darüber die Buchstaben M R F, Nr. 299 a. (Privatbesitz in Rapperswil.)

Reiman, Franz, wurde geboren am 25. August ${ }_{1684}$ : kam 1699 in Konstanz zu H. Jakob Raiffel in die Lehre und wurde am 6. Januar 1700 bei der Schmiedezunft für 3 Jahre eingeschrieben (Einschreibebuch I, 1688-1732) (Hintze, VII, S. 349). Er wurde am 12. Juli 1717 in den grossen Rat und am 13 . Juli 1733 in den kleinen Rat der Stadt gewählt, in welchem er das angesehene Amt des Spitalpflegers bekleidete. Er starb am 7. August 1744.

Er führte das Meisterzeichen Nr. 299.

Gegenstände: Prismatische sechsseitige Kanne mit Schraubverschluss, im historischen Museum von St. Gallen. Die reich gravirte Kanne hat die Jahrzahl ${ }_{171} 3$. Meisterzeichen Nr. 299.

Tintenfass der Ortšgemeinde Rapperswyl. Schüssel in dortigem Privatbesitz.

Zimmermann, Jakob Anton, Zinngiesser, wurde am 19. Mai 1716 geboren. Im Jahre 1739 wurde er in die Zunft "der geschenkten Handtierungen " aufgenommen und wird ziemlich oft in den Ratsprotokollen angeführt. Er wurde Spitalpfleger, ${ }_{17} 57$ Mitglied des grossen Rats und ${ }_{1769}$ Beisitzer des Stadtgerichts, in welchen beiden Aemtern er bis 1798 verblieb. Er starb am 13. November 1802.

Er führte die Meisterzeichen Nr. 297 und 298.

Gegenstände: Giessfass im Rathaus von Rapperswyl mit dem Meisterzeichen Nr. 297 (aus der Sammlung von Dr. Nägeli).

Prismatische, sechsseitige Kanne mit Schraubverschluss. Ausgussröhre mit Kettchen und Schraubverschluss. Stadt- und Meisterzeichen Nr. 298 auf dem Deckel. Auf der rechten Seite gravirte Wappen mit den Initialen B. B. und K. H. 1746. Höhe der Kanne $41 \mathrm{~cm}$. Durchmesser des ziemlich ausladenden Fusses 18,6 cm (über die Ecke gemessen). (Tafel XXXVII, 4.)

Die Ratskannen von Rapperswil (Tafel VI, 2) sind im Antiquitätenhandel verschwunden. Das letzte Exemplar sah ich 1909 im Kunsthandel in Luzern und es gelang mir, noch wenigstens ein gutes Photo zu bekommen. Die Höhe der Kanne beträgt $45 \mathrm{~cm}$. Auf dem Deckel steht ein Adler; auf dem aufgelöteten Schild befinden sich die zwei Rosen des Rapperswiler Wappens. Das Meisterzeichen war so verschliffen, dass die Initialen nicht entziffert werden konnten. 


\section{LICHTENSTEIG}

So klein dieser Ort ist, besass er doch lange Zeit hindurch ortsansässige Zinngiesser. Ueber 200 Jahre lang hatte sich in ein- und derselben Familie das Handwerk vererbt in sechs aufeinander folgenden Generationen. Es bestand also eine eigentliche Zinngiesser-Dynastie mit dem Namen Steiger'. Die erhaltenen Zinngegenstände sind ziemlich selten und bestehen in Tellern, Platten und Glockenkannen ohne spezielle Formen. Zur Erkennung dient einzig das Ortszeichen und die Meistermarke. In einer Glockenkanne fanden wir sogar eine Bodenplakette mit dem Bär ohne Halsband und den gegossenen Initialen I. ST. Auch Giessfässer kommen vor und sechsseitige prismatische Kannen.

Das Ortswappen besteht in einem Schild mit dem Buchstaben L.

\section{Die Zinngiesser}

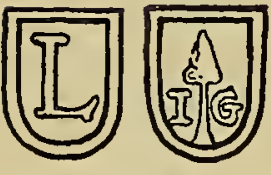

309 a

Giezendanner, Georg, Zinn- und Kannengiesser, wurde am 22. Februar 1655 geboren, heiratete am 19. November $16_{79}$ Ursula Brächer und starb am 4. Juni 173 o.

Girtanner, J., führte das Meisterzeichen Nr. 3og a (Bd. II), ähnlich Nr. 281 (Bd. I). Davor das Beschauzeichen, das $\mathrm{L}$ von Lichtensteig. Gegenstand: Glockenkanne von 31,5 cm Höhe im historischen Museum von St.Gallen.

Steiger, I Jakob, von Lichtensteig, Kannengiesser, wurde im Jahre 1622 geboren, heiratete 1645

Barbara Schweizer, hatte 13 Kinder und starb am 5. Mai 1679.

Steiger, II Jakob, Zinngiesser und Schützenhauswirt, das neunte Kind des Vorigen, wurde am 26. März 166o geboren, heiratete am 5. April 168^ Barbara Reich aus Mogelsberg und am 20. Februar 1707 Barbara Wälli aus Cappel. Er starb am 2. November 1728 .

Steiger, III Jakob, Zinngiesser ${ }^{2}$; seine Tochter Barbara heiratete im Jahre 1718 den Bösch

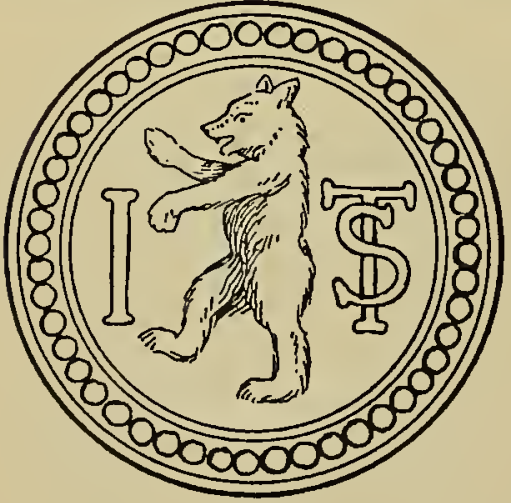

$338 \mathrm{~b}$ Josef, Schneider in Lederbach.

Einer oder mehrere dieser Jakob Steiger führten das Meisterzeichen Nr. 307 und 308. Alle haben die gleichen Initialen; doch ist $\mathrm{Nr} .307$ das ältere Zeichen.

Gegenstand: Glockenkanne mit Bajonetverschluss. Auf dem Ausgussdeckelchen befindet sich das Meisterzeichen Nr. 3o8; im Kannenboden die Eingangs erwähnte Bodenplakette mit den Initialen I. ST., Nr. 338 b. Am Kannenleib oben drei und unten zwei circuläre flache Wülste. Auf dem Schildchen die Initialen H. S. Höhe 21,7 cm. Durchmesser des Fusses $11 \mathrm{~cm}$.

Breitrand-Teller mit dem Meisterzeichen $\mathrm{Nr}$. 307 ist jedenfalls dem Meister Jakob I oder II Steiger zuzuweisen.

Steiger, Hans Heinrich, Zinngiesser, war auch Messner, Schützenhauswirt, Stadtweibel. Er war das fünfte Kind erster Ehe von II Jakob Steiger und wurde am 2. Oktober 1695 geboren. Er heiratete am 28. Juli 1722 Rosina Giezendanner aus Lichtensteig und am 7. Juli 1733 Margarete Hell. Sein Todestag fällt auf den 7. Juli 1763.

Steiger, Johann Conrad, Zinngiesser (Stannaius) und Messner, wurde als fünftes Kind erster Ehe des Hans Heinrich Steiger am 1. März 1724 geboren. Er heiratete am 23. April 1754

I Auszug aus den Kirchenbüchern von evang. Lichtensteig von 1647-1842. Von J. J. Kubly-Müller, Genealog in Glarus.

${ }^{2}$ Kirchenbuch von Oberhelfenswil. Mitteilung von J. J. Kubly-Müller, Glarus. 


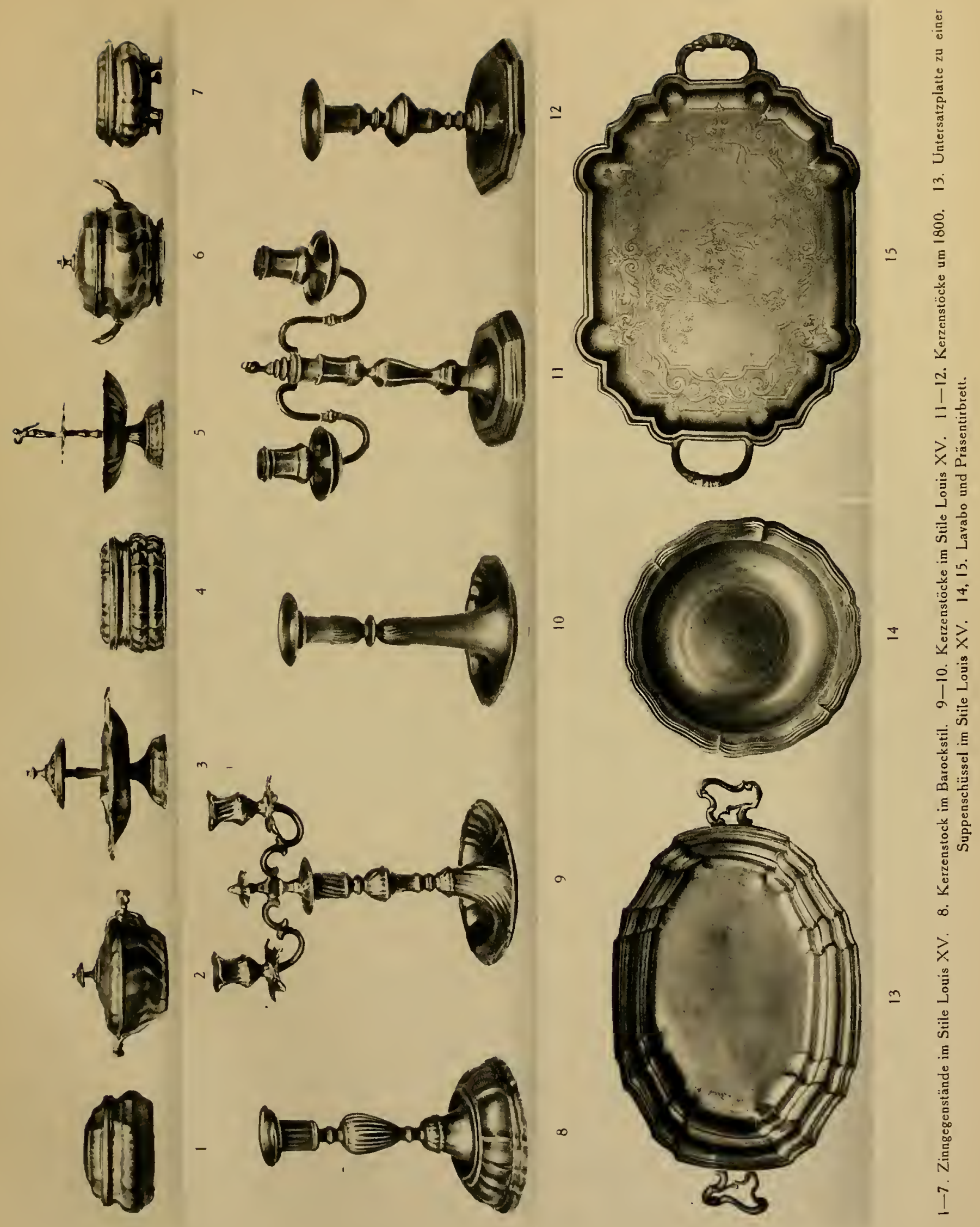



Verena Giezendanner von Lichtensteig, von welcher er 10 Kinder hatte, und starb am 22. Mai 1792 .

Er führte das Meisterzeichen Nr. 306 .

Gegenstand: Glockenkanne mit Bajonetverschluss. Auf dem Deckelchen der Ausgussröhre das Meisterzeichen Nr. 3o6. Keine Bodenrosette, nur eine Spirallinie. Keine circulären Wülste, nur Rillen. Auf dem Schildchen die Initialen F B und M O. Höhe $22,5 \mathrm{~cm}$. A ehnliches Exemplar mit Bär im Kannenboden.

Steiger, Johann Jakob, Zinngiesser, das vierte Kind des Johann Conrad Steiger, wurde am 29. Januar ${ }_{7} 758$ geboren. Er war drei Mal verheiratet, war Stadtweibel, Agent, Gemeinderat, Schützenhauswirt und Stadtrichter. Sein Todesdatum ist der 9. August 1833. Er hatte nur aus der dritten Ehe Kinàer und zwar zwölf.

Steiger, IV Jakob, Zinngiesser, der älteste Sohn des Vorigen, wurde am 31. August 1800 geboren, heiratete am 23. November ${ }_{1824}$ Sara Steiger von Lichtensteig. Das Todesdatum ist nicht bekannt, aber $184^{2}$ lebte er noch.

\section{SARGANS}

H. I. E. oder B. Meister H. I. E. oder B. führte das Meisterzeichen Nr. 314 (Bd. I) und lebte im Anfang oder in der Mitte des XVIII. Jahrhunderts.

Gegenstände: Glockenkanne von 1/2 Maass Inhalt. Auf dem Deckelchen der Ausgussröhre das Meisterzeichen Nr. 314 .

Runde Gemüseschüssel, Durchmesser 19,1 cm. An der Seite zwei kurze geriffelte, unbewegliche Henkel. Tiefe der Schüssel $6,5 \mathrm{~cm}$; schmaler profilirter Rand. An der Unterseite des Bodens das Meisterzeichen Nr. 314. (Tafel XXVI, 4.)

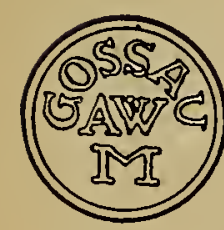

$313 \mathrm{~b}$

\section{GOSSAU}

Der Vollständigkeit wegen erwähnen wir eine $1 / 2$-mässige sechsseitigprismatische Schraubkanne der historischen Museums von St. Gallen. Dieselbe trägt eine kreisrunde Giessermarke, am Rande die Inschrift Gossau, in der Mitte die Initialen $\mathrm{A}$ W.

\section{APPENZELL}

Die Nähe der Stadt St. Gallen und die Kleinheit der Ortschaften im Lande Appenzell waren der Entwicklung eines bodenständigen Zinngiesserhandwerks nicht günstig. Immerhin muss es $a b$ und $\mathrm{zu}$ einen ortsausässigen Meister gegeben haben, wenn auch der archivalische Nachweis bis jetzt nicht erbracht werden konnte.

In der schönen Zinnsammlung des historischen Museums von St. Gallen und auch in einigen Privatsammlungen finden sich Glockenkannen mit Bodenplaketten, welche den Bären ohne Halsband enthalten. Man findet deren Abbildungen unter Nr. 338 und 339 (Bd. I) mit den Initialen A. I. B. und I. C. E. In einer gut erhaltenen Glockenkanne mit dem MeggeliWappen auf dem Schilde und der Jahrzahl 1608, findet man ebenfalls den Bären ohne Hals- 


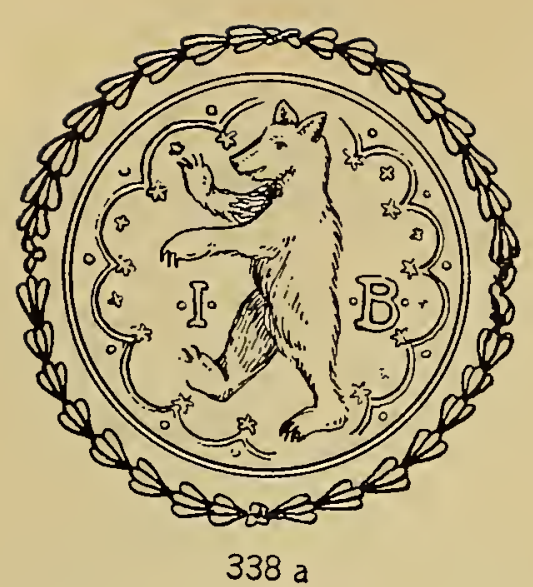

band und die Initialen I. B. Weil auch in Wyl und sogar in Lichtensteig die Kannengiesser diesen Bären ohne Halsband führen, ist eine einwandfreie Zuweisung der obigen Initialen unmöglich.

I. B. Glockenkanne mit Bajonetverschluss. Kein Ortsoder Meisterzeichen. Im Kannenboden eine Rundplakette Nr. 338 a mit dem Bären ohne Halsband und den gegossenen Initialen I. B. Auf dem Schild das alte Appenzeller Wappen der Meggeli. Am Korpus oben fünf und unten zwei flache circuläre Wülste. Neben und unter halb der Basis der Ausgussröhre die gravirten Initialen M. M. 1608 . Höhe $31 \mathrm{~cm}$. Durchmesser des Fusses ${ }_{18,2} \mathrm{~cm}$. Am Sockel des Tragringes ebenfalls zwei circuläre flache Wülste. (Tafel XXXVII, 8.)

A. I. B. Ebenfalls in Glockenkanne, Nr. 338 (Bd. I).

I. G. E. In Glockenkanne des historischen Museums in St. Gallen, Nr. 339 (Bd. I).

H. I. E. Herisau ? Siehe Nr. 315 (Bd. I).

Um die Wende des Jahres 1800 bis ca. 1840 ist eine fahrende Zinngiesserfamilie nachweisbar, von welcher fast sämmtliche im Appenzellerlande befindlichen "Appenzeller Kannen "stammen. Sie heissen P. Cane, G. Cane, Fratelli M. F. P. Cane. Alle lieferten bei sehr guter Qualität eine einwandfreie technische Arbeit. Ich fand nur prismatische sechsseitige Kannen in allen Dimensionen. Sie sind ziemlich klotzig und haben einen relativ engen Schraubverschluss. Um den Fuss der Kanne zieht sich ein breites, mit zwei Rillen versehenes, aufgelötetes Zinnband, welches dem Krug ein eigenartiges Aussehen gibt. Ausserdem findet man Suppenteller, Bettwärmflaschen und runde Platten.

Cane, F. Gegenstände mit dem Meisterzeichen Nr. 324: Prismatische sechsseitige Kanne mit Schraubverschluss. Auf dem Ausgussdeckelchen die Meistermarke Nr. 324. Die zwei Vorderflächen der Kanne sind mit gravirten Tulpenranken überzogen, welche von einem Herz ausgehen. An der rechten Seitenfläche die Initialen H ST M und $M M E$ 1829. Höhe 29,5 cm. Durchmesser des Fusses $12 \mathrm{~cm}$ (über die Ecken gemessen). (Tafel XXXVII, 12.)

Gleiches Exemplar mit gleichen Blumengravuren, aber mit den Initialen L L und A M R 1829. Höhe $34 \mathrm{~cm}$. Durchmesser des Fusses $15 \mathrm{~cm}$. (Tafel XXXVII, 11.)

Cane, G., führte das Meisterzeichen Nr. 324 .

Gegenstände: Prismatische sechsseitige Schraubkanne. Auf dem Ausgussdeckelchen das Meisterzeichen $\mathrm{Nr}$. 324. An der rechten Seitenfläche die Initialen H. K. Z. W. 1826. Mächtiger Tragring von 11,3 cm Durchmesser. Höhe $37 \mathrm{~cm}$. Durchmesser des Fusses $18 \mathrm{~cm}$ (über die Ecken gemessen). (Tafel XXXVII, 9.)

Gleiches Exemplar mit den Initialen H. I. A. 1826. Höhe $39 \mathrm{~cm}$. Durchmesser des Fusses $18 \mathrm{~cm}$.

Fratelli M. F. P. Cane. Meistermarke in Oval, Nr. $32_{2} 5$ und $32_{2} 5$ a.

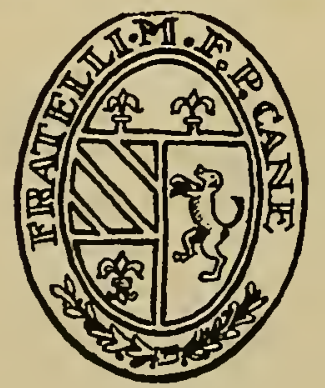

Gegenstände : Kuppelförmige, tiefe Suppenteller ohne flachen Rand von $21 \mathrm{~cm}$ Durchmesser. Meisterzeichen an der Unterseite des Bodens. - Bett-Wärmeflasche, oval und flach. - Prismatische sechsseitige Kanne von $30 \mathrm{~cm}$ Höhe. (Privatbesitz in Baar.)

Prachtvolle gravirte Abendmahlkanne, datirt 1743, ohne Meistermarken. Die Kanne ist siebenkantig. Unterhalb der Ausgussröhre die Initialen G G und 1743. (Tafel XXXVII, 10.)

325 a 


\section{B. DIE NORDWESTSCHWEIZ}

$\begin{array}{ll}\text { Basel : } & \begin{array}{l}\text { Basel. } \\ \text { Liestal. }\end{array} \\ \text { Solothurn. } & \text { Freiburg. } \\ \text { Freiburg : } & \text { Bulle. } \\ & \text { Estavayer. } \\ & \text { Murten. }\end{array}$

\section{BASEL}

In dieser grossen Handelstadt spielte auch das Zinngiesserhandwerk eine ganz bedeutende Rolle und erreichte eine hohe Blüte. Infolge der lebhaften Handelsbeziehungen zum Gotthardpass finden wir Basler Zinngegenstände nicht nur häufig im Lande Uri, sondern auch im Tessin, im Misox bis ins Calancatal hinauf, im Veltlin und sogar im Mailändischen. Alle Handwerke stunden unter dem machtvollen Schutze der Zünfte. Die Kannengiesser gehörten zur Zunft der Hausgenossen, Familia episcopi, oft auch nach dem Zunfthause Bärenzunft genannt. Zu derselben gehörten ebenfalls die Goldschmiede, Goldschläger, Edelsteinarbeiter, Steinschneider, Wechsler, Münzmeister, Buchdrucker, Gelbgiesser, Glockengiesser, Buchstaben- und Erzgiesser, die Stuckgiesser, die Hafengiesser und Rentner ("Müssiggänger " genannt). Innerhalb der Hausgenossenzunft bildeten die Kannengiesser eine besondere Innung mit eigenen Satzungen und Rechten. Die Zunftbücher dieser Zunft beginnen mit dem Jahre 1520 und sind bis ins Jahr 1777 fortgeführt.

$Z \mathbf{u}$ den ältesten Zinngegenständen in Basel gehören drei Kannen und ein Oelgefäss aus dem bischöflichen Haushalt des XIV. Jahrhunderts. Prof. Heyne, Göttingen, beschreibt sie folgendermassen : " es sind gewöhnliche Hausgeräte, aber hier in den heiligen Dienst gestellt, insofern man in ihnen, wie die Inschriften lehren, das Chrisma, das oleum puerorum und

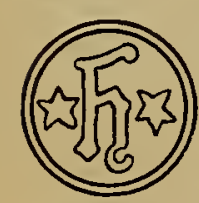

374 a das oleum infirmorum aufbewahrte. Ein Zinnstempel tritt an diesen $\mathrm{Ge-}$ fässen schon auf $\left({ }^{\circ} b^{*}\right), N r .374 a$ (Bd. II). Der walzenförmige Behälter, auf seinem Deckel in einem Wappenschild die bischöfliche Hausmarke tragend, aus der sich später das Wappen der Stadt, der Baselstab, entwickelte, ebenfalls für das oleum puerorum dienend, hat ganz die Form der Büchsen, in denen man noch Jahrhunderte nachher die Latwergen aufhob. "Diese Gefässe sind kaum baslerischer Herkunft.

Sehr guten Aufschluss über das frühe Vorkommen von Zinngegenständen geben uns die alten Inventare.

Laut Basler Zeughausinventar vom Jahre 14151 befanden sich im Richthaus " 2 zinnen Kannen ». - Im gleichen Inventar vom Jahre 1445: " 3 zinnen Kannen, 4 zinen platten ".

Inventar der auf dem Schloss zu Pfeffingen ${ }^{2}$ durch die Basler aufgefundenen Gegenstände am 27. September 1445: "Item 3o kannen lalein und gros - item 1 gross 4 messig fleschen - it' 12 zynen teller — it' 8 blatten - it' 66 Zynenschüsslen. " — Ein etwas späteres Inventar aus dem gleichen Jahre erwähnt : "Zynen geschir : Item des ersten 46 zinen schüslen klein und gross (3 hin). Item 5 blatten. It' 12 Zinin teller. It' 3o kannen klein und gross. Item a fiermessig flesch. "

I Ein Basler Zeughausinventar von 1415. Dr. E. A. Gessler. Anzeiger für schweizerische Altertumskunde 1910. S. 230.

${ }^{2}$ Miseellen. Dr. Ernst Weydmann. Anzeiger für schweizerische Altertumskunde. $1902 / 1903$. S. 198 und ff. 
Das Inventar des gleichen Schlosses aus dem Jahre 1515, März 19, meldet: "In dem Kemerli im früwen Zimer : 11 geschlagen platten klein und gross, 5 platten ungschlagen klein und gross, 9 zinni ess schüsslen, 6 zini Senfschüssli, 12 zin teller, 3 zini Sallzpfeffer, 7 Kannen gross und klein, 1 gstrubti zini flesch, 13 Becher 10 nüw und 3 allt. »)

Leider lassen sich keine Zinngegenstände aus dieser Zeit mehr nachweisen, weil dieselben stets umgegossen wurden.

Das offizielle Basler Meisterzeichen besteht nur aus einer Marke. Dieselbe setzt sich zusammen aus der Krone, dem Wappen der Hausgenossenzunft, aus dem Baselstab und den Initialen des Meisters zu beiden Seiten des Baslerwappens. Bei ganz feinem Zinn tritt an die Stelle des Baselstabes eine fünf bis sechsteilige Rose oder dann befindet sich ein ganz kleiner Baselstab in der Mitte der Rose. Einzelne Giesser haben auch eine Extramarke bestehend aus einer Krone mit dem darunter sich befindlichen Wort FIN. Nach dem Jahre 1700 wird die Engelmarke mit dem vollen Meisternamen beliebt und häufig.

\section{$\mathrm{Die}_{\text {ie }}$ inngiesser von $\mathrm{B}_{\text {asel }}{ }^{1}$}

Werlin, Lienhart, von Augsburg, kauft die Zunft 1490. Vater des Werlin Jerg, Kantengiesser.

Dub, Claus, kauft die Zunft 149 .

Suochdentrunk, Andreas, kommt zum ersten Mal 1500 vor.

Zhann, ...., kommt 1502 zum ersten Mal vor.

Werlin, Jerg, kauft die Zunft 1511 , Sohn von Werlin, Lienhart. Seine angebliche Meistermarke ist kein einwandfreies Kannengiesserzeichen.

Stetter, Alexius, kauft die Zunft 1512.

...., Jakob, von Trier, kauft die Zunft 1512 .

Zschan, Martin, kauft die Zunft 1520 .

...., Sigmund von Toll, kauft die Zunft 1521 .

Schlep, Hans, von Pforzheim, wird ${ }_{1} 527$ zünftig (eventuell erst 1542 , neues Zunftbuch).

Meier, Kilian, kommt im alten Zunftbuch schon 1535 vor; nach dem neuen wird er erst 1542 zünftig.

Barthander, Asimus, wohnte ${ }^{1567}$ im Hause Appenzell am Kornmarkt. Bei ihm lernen : ${ }_{1557}$, Jakob Friedrich, sein Stiefsohn; 1557 , Hans Gucker von Solothurn ; 1563 , Baltzer Ruch; 1570 , Ludwig Brombacher; 1554 , Hans von Milbardt.

Fridrich, Diebold, kauft die Zunft am 13. Juni 1542.

Banwald, Asimus, kauft die Zunft am 13 . Juni 1540.

Klein. Jakob, kauft die Zunft am 28. Juni 1536.

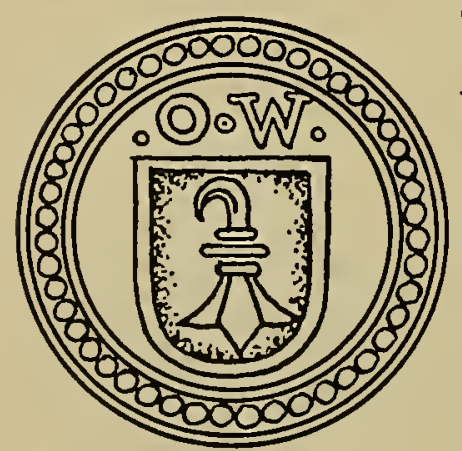

$374 \mathrm{~b}$

Grineus, Philipp, kauft die Zunft 1547 . Bei ihm lernen : 1558, Lux Wetzel von Kolmar; 155 , Lorenz ( ?) von Kolmar.

Werlin, Onophrion, führte als Meisterzeichen Nr. $374 b$ (Bd. II); erneuert die Zunft 1547. Bei ihm haben ausgelernt: 1559, Augustin Heckel, Michel Golb (Kolb), Stoffel Schuldess; 1562 , Karis Bumart; 1564 , Batt Huober; $157 x$, Hans Bieller von Stouffen, Hartmann Debong aus Delsperg.

Gegenstand: Humpen. Höhe 12,6 cm, nach oben verjüngt. Auf dem Deckel die kreisrunde, gegossene Meistermarke, Wappen mit Baselstab und darüber die Initialen O. W. (Historisches Museum von Basel.)

\footnotetext{
1 Auszng aus den Akten des historischen Museums in Basel: Hausgenossenzunft. Die Zunftbüeher der Hausgenossenzunft geben von $1520-1777$.

- Stammbaum der Bürgergeschlechter von Liestal, von Arnold Seiler-Rosenmund. 1908. Gebrüder Lüdin in Liestal.
} 


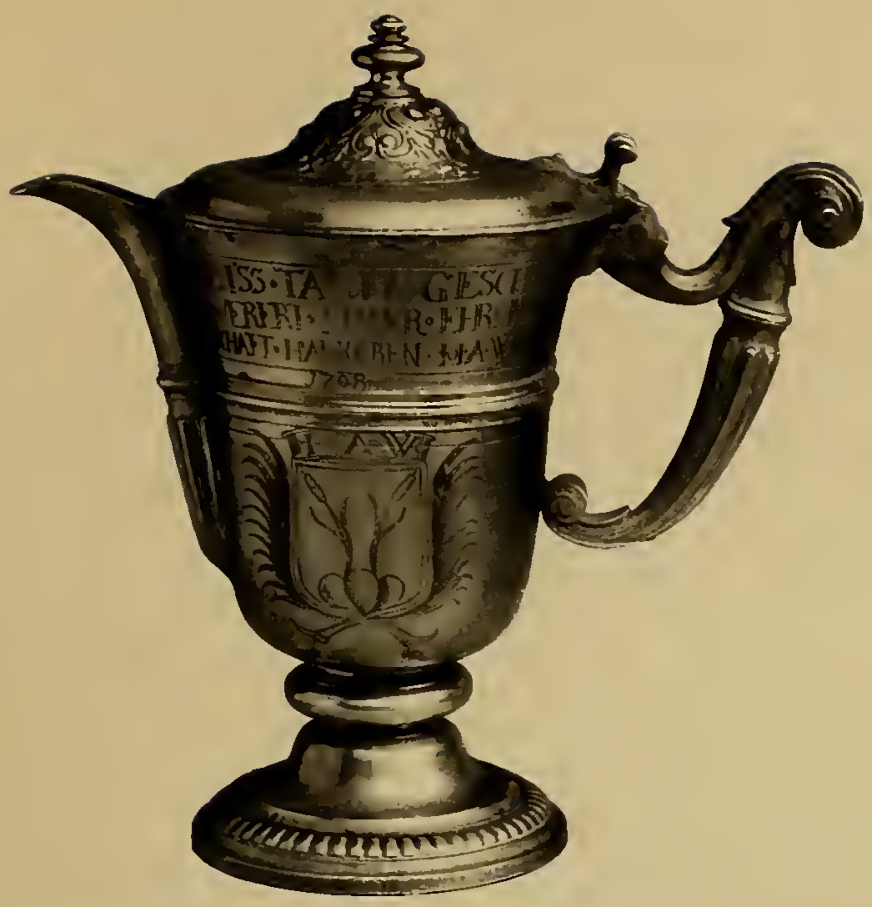

1

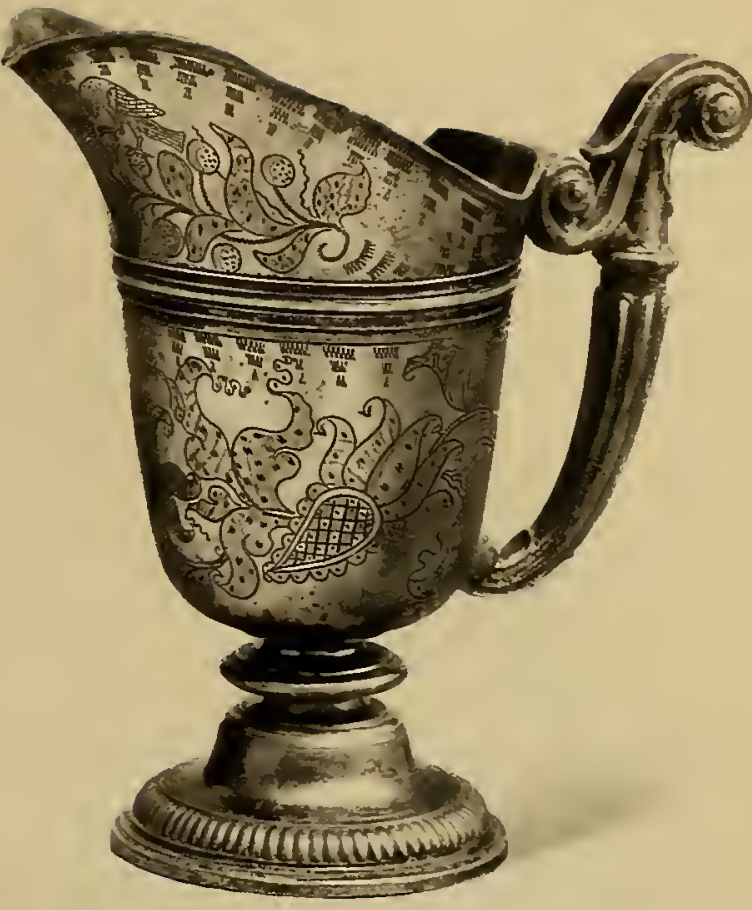

2

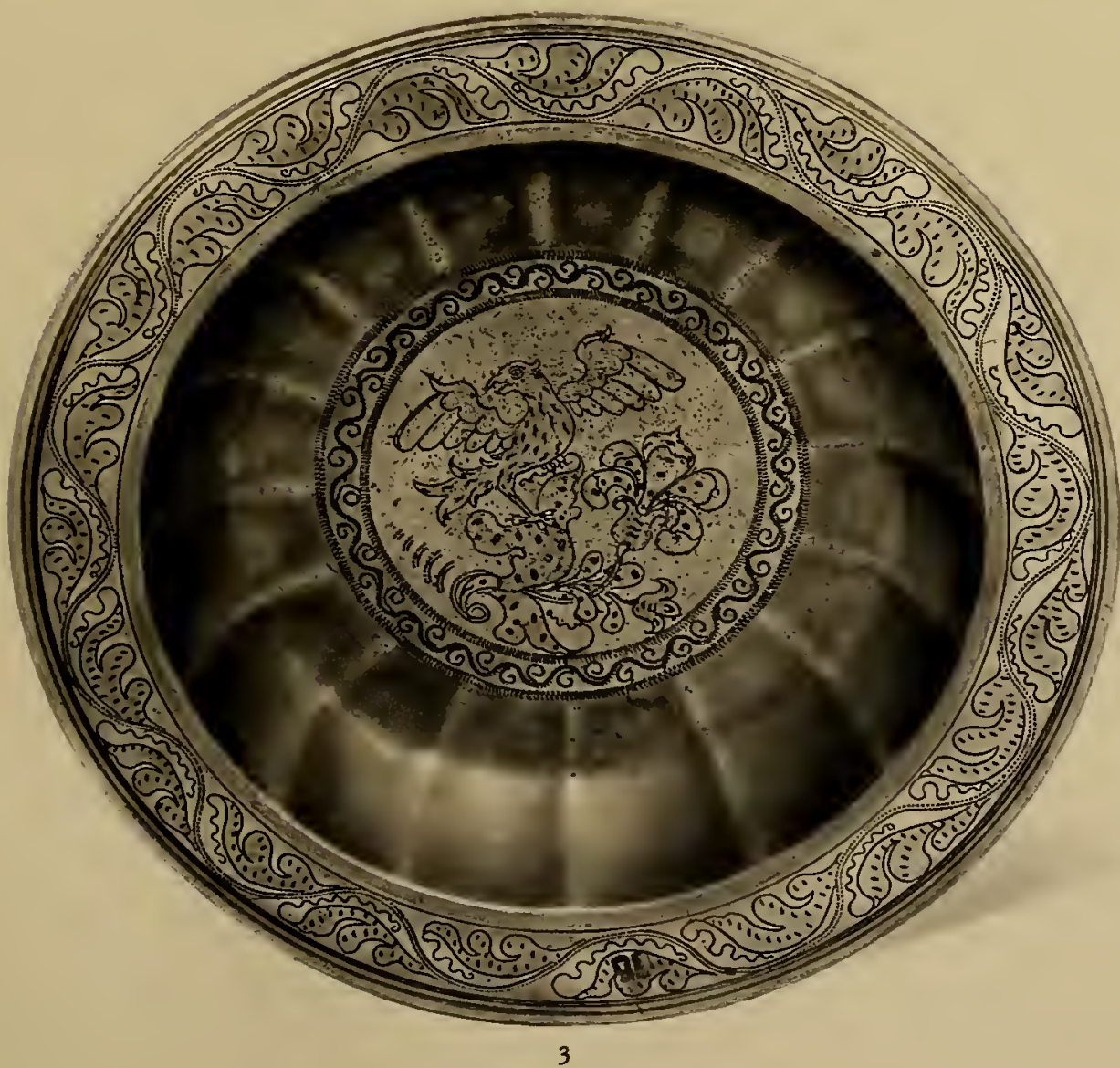

1. Taufkanne der Talschalt Habkeren, datirt 1708, mit den gravirten Wappen von Habkern und Wyss (Kolben). Französischen Ursprungs 2, 3. Taufkanne und Schale, von Josef Gloggner, Luzern, erwähnt 1765-71. Aul beiden Stücken das Wappen der Falk, Luzern. 
Lochmann, Apollinarius, (Paulus), kauft die Zunft am 31. Januar 1552. Bei ihm haben ausgelernt: 1558, Hans Gerster von Bern und Ludwig Berger von Altkirch; 1560, Hans Friderich und Jakob Meder, 1561. In seinem Hause wohnt 1572 Batt Huober, der der Hausgenossenzunft zinst.

Schor, Herrmann, kauft die Zunft am 21. November 1557.

Stadler, Peter, kauft die Zunft am 1. Oktober 1562.

Maeder, Jakob, kauft die Zunft am 5. März 1564. Lernte 1561 bei Apoll. Lochmann.

Fridenrich, Jakob, erneuert die Zunft am 28. Juni 1565 und starb, 71 Jahre alt, am 25. Mai 1613. Er lernte 1557 bei seinem Stiefgrossvater Asimus Barthander. Bei Jakob Fridenrich oder Fridrich lernen : 1566, Gebhart ,Jeronimus; 1571 , Hans Goling und Jerg Lebart; 158 , Michael Hummel, sein Stiefsohn; 1558, Zacharias von Eusten; 1597, Hans Krittli von Pruntrut; 1574 , Jakob Lepart; 1573 , Rudolf Marty von Biel; 1578 , Jakob Wyss von Bern und Jakob Barrezin von Hannigen.

Hotinger, Gotthard, von Zürich, kauft die Zunft am 6. Juni 1566. Bei ihm lernen : 1568, Jeronimus Andlawer; 1571, Anton Bell, der Sohn von Konstanz Bell, des Becken beim Aeschentor; 1578 , Hans Urech von Rhynfelden; 1588, ..... sin Vetter.

Er führte das Meisterzeichen Nr. 374 .

Gegenstand: flaches Plättchen, scheibenförmig, rund, $21 \mathrm{~cm}$ Durchmesser. Im historischen Museum von Basel. Auf demselben sind verschiedene Wappen ausser der Meistermarke Nr. 374, so das Wappen des Hieronimus Froben (1501-1563), ferner das Alliancewappen des Conrad Meyer z. Pfeil und der Judith Schönauer.

Huober, Beat, erneuert die Zunft am 3. Dezember 1568 und weist gleichzeitig sein Meisterstück vor. Er lernt 1564 bei Onophrion Werlin. Seine Lehrlinge : 1574 oder 1575 , Hans Scherb, sein Verwandter; 1574 oder 1575, Steffan Biego aus Mümpelgart; 1582, Jan I Trautz, von Schwarzach, Stiefsohn von Martin Hoffmann ; 1587, Eusebius Engelhart; 1598, Christian Wolleb; 1601, Abraham Klinglin von Kolmar; 1608, Tobias Freschesser von Kolmar; 1611, Hans Heinrich Grineus von Mülhausen; wohnt im Haus von Pauli Lochmann.

Lochmann, Hans, erneuert die Zunft am 23. Juni 1572 und weist gleichzeitig das Meisterstück vor.

Fridenrich, Hans, erneuert die Zunft am .. Juni 1572. Bei ihm lernt 1574 Caspar Enderli. Kaspar Enderlin, der nachherige berühmte Nürnberger Zinngiesser, wurde in Basel geboren und getauft-im Juni 1564, trat am 25. Februar 1574 bei Hans Fridenrich in die Lehre. Er verliess Basel im Jahre 1583 und hatte 1584 das Bürgerrecht in Nürnberg. Er starb am 17. Februar 1614 in Nürnberg.

Griner, (Grineus), Jakob, erneuert die Zunft 1579 .

Gebhardt, Geronimus, kauft die Zunft 1583 und legt gleichzeitig das Meisterstück vor; er lernte bei Jakob Fridenrich. Es lernten bei ihm : 1583, Heinrich Brachner von Bern; 1608, Caspar Sichler von Rheinfelden; 1609 , Han Geronimus.

Hummel, Michael, kauft die Zunft 1588 und weist gleichzeitig sein Meisterstück vor. Er war der Stiefsohn des Jakob Fridenrich, bei welchem er vom 12. Januar 1582 ab lernte.

Lichtenhan, Matheus, von Schnehberg, kauft die Zunft 1589 und weist gleichzeitig sein Meisterstück vor. Bei ihm lernt 1590 Isaac von Brun.

Fridenrich, Hans Jakob, der Jüngere, erneuert die Zunft 1590. War voraussichtlich der Sohn von Jakob Fridenrich.

Pfyster, Lorentz, kauft die Zunft am 7. Januar 1581.

Biermann, Hans Conrad, Bei ihm lernten : 1617, Peter Hindenlang; 1619, 1. Mai, Marx Huber; 1624-28, Christian Keller und Josef Strübin.

Huber, Marx; Bei ihm lernt: $1_{27}$, Niklaus Burckhart.

Strübin, Josef, von Bubendorf; wurde 1608 geboren und starb ${ }^{1674}$ oder 1675 . Er lernte ab 1621 drei Jahre bei Conrad Biermann, lernt aber wegen "Gespan " bei J. Brandmüller aus. Er heiratet Judith Brombach. Bei ihm lernen: 1631-34, Christoph Brombach und 
Christianus Strübin; 1645 , Johann Buer. Strübin wurde 1647 Sechser. Er war Bürger von Liestal und Basel.

Er führte das Meisterzeichen Nr. 376,377 (424 und 425 bei Baselland). Bodenrosette Nr. $430,436,437$.

Gegenstände: Schnabelstitze von $1 / 2$ Maass Inhalt. Höhe $23,2 \mathrm{~cm}$. Auf dem Traghenkel das Meisterzeichen Nr. 377. Bodenrosette Nr. 437. Unter dem Schnabel die Initialen M. S. - Schnabelstitze (Tafel XXXIX, 5) von I Maass Inhalt. Auf dem Traghenkel die Marke Nr. 377 und das Wappen von Baselland. Höhe $30,2 \mathrm{~cm}$. Bodenrosette Nr. 436. Unter dem Schnabel die Initialen H S P 1769 zwischen zwei Zweigen. - Schnabelstitze von a Maass Inhalt. Am Henkel das Meisterzeichen Nr. 376. Bodenrotsete Nr. 43o. Vorn die Initialen G. D. C. Höhe 3o,6 cm. Prismatische, sechsseitige Kanne mit beweglichem Tragring. Am Ende der Ausgussröhre ein Tierkopf. Meisterzeichen Nr. 376 . Höhe $28 \mathrm{~cm}$. (Im historischen Museum von Basel.)

Brandmüller, Hans Heinrich, wurde im September 1594 getauft und starb 1662. Nov. 29. Bei ihm lernen : 1623-24, Josef Strübin; 1626, Hans Linder ; 1629-31, Christian Stöcklin ; 1633-37, Jakob Frey von Lindau. Wurde 1646 Zunftmeister.

Linder, I Johannes oder Hans Lukas, Sohn des Ratsherrn Hieronimus Linder, wurde im Jahre 1611 geboren; war 1668 Sechser; starb am 10. März 1678. Er lernte vom 28. August 1626 an bei Joh. Heinrich Brandmüller. Bei ihm lernen : $1637-40$, Samuel Hugnott; 1647-5o, Jakob Beck; $1651, \ldots$ Satler ; 1659-62, Ernst Biermann; 1663-66, Hieronimus Linder.

Er führte das Meisterzeichen Nr. 378 und vielleicht auch Nr. 41 1 (?).

Die zwölf Kannen des kleinen Rats von Basel sind wahrscheinlich seine Arbeit (Demiani, S. 34). Höhe $42 \mathrm{~cm}$. Korpus flach linsenförmig. Zur Dekoration Ketten. Es sollen ursprünglich 24 Stück gewesen sein. Laut Abrechnung von 1638 erhält Linder für 24 Kannen (Modell und Guss) 62 Pfund und 10 Schilling. (Tafel VII, 1.)

Brombach, Ghristoph, lernte vom 31. März 1631 bis 1634 bei Josef Strübin. Bei ihm lernen : 1647-5o, Reinhard Dussmann. Er war der Vater des Jakob Brombach, welchen er 1677 dem Nikolaus I Uebelin in die Lehre gab.

Beck, Johann Jakob, Sohn des Albert Valentin Beck, lernte vom 14. Juli 1647 ab bei Johann Linder. Bei ihm lernt 1662-65 Oswald Steinbrunner.

Iselin, Lux, Hans, wurde 1622 geboren, 1651 zünftig; heiratete 1652 Magdalene Burckhardt. Bei ihm lernen: vom 18. November 1657 ab drei Jahre Peter Engelhardt; 1662-65, Christoffel Beck, des Clingenthal Schaffner Jakob Becks Sohn. Lux Iselin war am 17. August 1683 Schaumeister bei Hans Rudolf Burger. Sein Geselle Griser wird 1686 Vogt der Kinder des Goldschmieds Sebastian Fechter.

Er führte das Meisterzeichen Nr. 38o.

Gegenstände: Basler "Rundele " von $1 / 2$ Maass Inhalt. Am Fuss, am Deckel und am obern Kannenrand ein breiter Blattfries, auch am Schnabel. Am Traghenkel das Meisterzeichen Nr. 38o. Höhe $22 \mathrm{~cm}$. (Tafel XXXIX, 6.) - Gleiches Stück von 1 Maass Inhalt. Höhe $28 \mathrm{~cm}$. - Gleiches Stück im historischen Museum Basel von $31 \mathrm{~cm}$ Höhe. - Schnabelstitze von $1 / 2$ Maass Inhalt in zürcherischem Privatbesitz. Scholer, I Emanuel, erneuert die Zunft Ende August 1683. Bei ihm lernen : 1651, Jakob Bischoff; 1659-62, Hans Jakob Böler; 1674-?, Theodor Chaliet; 1688-91, Lux Hagenbach; 1695-98, Hans Jakob Wetzel. 1685 ist er Schaumeister von Hs. Rudolf Burkhardt. Er starb im Jahre 1741.

Er führte das Meisterzeichen Nr. 381 und wahrscheinlich auch Nr. 398.

Gegenstände: Mächtige Schnabelstitze mit Traubenknopf. Auf dem Traghenkel die etwas verschobene Meistermarke Nr. 381. Keine Bodenrosette. Unterhalb des Schnabels die Initialen G A P in cinem Rankenkranz. Um den Kannenleib ein reich profilirter Wulst. Fuss weit ausladend. Höhe $35,5 \mathrm{~cm}$. Durchmesser des Fusses 
$18,5 \mathrm{~cm}$. - Prismatisches sechsseitiges Gefäss mit Schraubdeckel und beweglichem Traghenkel. Meisterzeichen Nr. 381. Höhe $20,5 \mathrm{~cm}$. (Historisches Museum Basel.)

Biermann, Johann Ernst, wurde am 3o. Juli 1644 getauft. Bei ihm lernt: 1762-76, Rudolf Hertenbrot von Mülhausen.

Beck, Christoffel Jakob, des Clingental Schaffners Sohn, wurde am 31. Oktober 1647 getauft. Bei ihm lernt: $16_{72-75}$, Otto Harnisch von Chur.

Ebneter, Hans Jakob, Sohn des Messerschmieds Frantz Ebneter, lernte vom 4. August $166_{2}$ an 3 Jahre lang bei Gustav Heinrich Fäsch. Bei ihm lernen : 1678-82, Jak. Meier; $1682-85$, Simon Batier; 1677 spricht er seinen Lehrling Rudolf Burkhardt ledig. 1686 hat er als Gesellen Georg Adam aus Bamberg. 1686 wird er von Rudolf Burkhardt wegen schlechten Zinnes verklagt. Er starb am 22. Januar 1687.

Er führte das Meisterzeichen Nr. 382 und 383.

Gegenstand: Prismatisches, sechsseitiges Gefäss mit Schraubverschluss. Auf dem Deckel ein runder beweglicher Tragring. Daselbst am Rande das Meisterzeichen Nr. 382. Höhe $23 \mathrm{~cm}$. Durchmesser 9,5 cm. Wahrscheinlich ein Oelgefäss; weil auch noch der Knopf mit dem Ring wiederum aus dem Deckel herausgeschraubt werden kann(Tafel XXXII, i3.)

Im historischen Museum Basel ist ein ähnliches Gefäss mit ausladendem Fuss. Meister. zeichen Nr. 382. Höhe mit dem Deckel $25,5 \mathrm{~cm}$.

Faesch, Gustav Heinrich, Bei ihm lernt 1662-65 Hans Jakob Ebneter.

Burkhardt, Samuel, wurde 1613 oder 1614 geboren. Bei ihm lernt $1664-68$ der Lehrjung Hans Ulrich Kappeler von Frauenfeld. Ferner Joseph Wick vom 13. November 1669 ab. Er starb am 24. Juni 1689 .

Er führte das Meisterzeichen Nr. 384.

Gegenstände: Basler "Rundele » von 1 $1 / 2$ Maass Inhalt mit Traubenknopf auf dem Deckel. Auf dem Traghenkel die stark deformirte Marke Nr. 384. Höhe 31,5 cm. Durchmesser des Fusses $15 \mathrm{~cm}$. - Basler "Rundele " von 1 Maass Inhalt. Unterhalb des Schnabels zwei Blattzweige, darin ein Wappen mit Metzgerbeil und den Initialen N G B. Höhe $28,8 \mathrm{~cm}$.

Im historischen Museum von Basel: Schnabelstitze mit Traubenknopf. Höhe ohne Deckel $25 \mathrm{~cm}$. Meisterzeichen Nr. 384. - Schnabelstitze von $9 \mathrm{~cm}$ Höhe (ohne Deckel), mit gleichem Meisterzeichen.

Wick, Joseph, wurde 1654 geboren und lernte vom 13. November 1669 an bei Samuel Burkhardt. Bei ihm lernt vom 3o. Januar 1686 an Jakob Burkhardt. Am 17 . August 1683 ist er Schaumeister bei Hans Rudolf Burger. Im Jahre ${ }_{1} 687$ hat er als Gesellen Peter Saurwald aus Berlin. Er starb am 31. Oktober 1721.

Er führte das Meisterzeichen Nr. 385 und vielleicht auch Nr. 391.

Gegenstände: Mächtige Basler "Rundele " von 2 Maass Inhalt in feinster Arbeit. Am Traghenkel das Meisterzeichen Nr. 385. Höhe 36,5 cm. Durchmesser des Fusses ${ }_{17,2} \mathrm{~cm}$. Unterhalb des Ausgusschnabels die Initialen H. G., dazwischen eine Bretzel. (Tafel XXXIX, 4.)

Im historischen Museum von Basel: prismatische sechsseitige Zinnflasche mit dem Meisterzeichen Nr. 385. Ferner ein runder Krug, kleine Krüglein mit der Jahrzah] 1721 ; eine grosse Schüssel mit der Jahrzahl 1735. Kugelkrug von $11 \mathrm{~cm} \mathrm{Höhe.-}$ Breitrandplatte von 3o cm Durchmesser, Meistermarke Nr. 385.

Da Josef Wick und Jakob Wetzel die gleichen Initialen haben und auch zu gleicher Zeit lebten, ist es unmöglich, die Gegenstände der beiden Zinngiesser auseinander zu halten.

Uebelin, I Niklaus, wurde 1648 geboren; kaufte die Zunft im Jahre ${ }_{1674}$. Er starb 1722. Bei ihm lernen : 1677-8o, Jakob Brombach; 1682-85, Hans Jakob Altenburger ; 1687-9o, Niklaus Linder. Als Gesellen hat er : 1687 , Soffren Andres von Laibach und Grevel 
Christoph von Wildau. 1686 ist er Zeuge bei der Klage Rudolf Burkhardt's gegen Hs. Jakob Ebneter wegen schlechten Zinnes. 1687 hat er als Gesellen Hs. Rudolf Lohner von Thun.

Er führte als Meisterzeichen Nr. 386, 387, 388. Bodenrosette Nr. 431 .

Gegenstände: Basler "Rundele " von 1/4 Maass Inhalt. Auf dem Traghenkel das Meisterzeichen Nr. 387. Höhe $26,6 \mathrm{~cm}$. Keine Initialen oder Zeichen. - Schnabelstitze von 1 Maass Inhalt mit Deckeltraube. Am Traghenkel das Meisterzeichen Nr.387. Bodenrosette Nr. 431. Unterhalb des Schnabels die Initialen B. M. Höhe 29,3 cm. Gleiches Stück von 23,5 cm Höhe im historischen Museum Basel. - Kugelkrug mit zwei Reihen herausgetriebener Buckel. Meisterzeichen Nr. 388. (Basler Privatbesitz.) Krug in Form eines hohen Brunnenkesselchens mit runder Ausgussröhre. Anstatt des eisernen Traghenkels ein zinnerner Handgriff. (Historisches Museum Basel.) (Tafel XX, 23, 24.)

1selin, Andreas, Sohn des Hans Lux Iselin, wurde im Jahre 1654 geboren und 1678 zu Hausgenossen zünftig. Bei ihm lernte ab 1684 Abraham Leonhardt von Bern. Er starb 1732. Sein Meisterzeichen besteht in den Initialen A I, dazwischen der Baselstab. (Hintze, Bd. VII, Nr. 1852.)

Linder, I Niklaus, Sohn des Johann Linder, lernte vom 6. September ${ }_{1} 687$ an drei Jahre bei Niklaus Uebelin und wurde 1694 zünftig. Er wurde am 2. Oktober 1740 beerdigt.

Er führte das Meisterzeichen Nr. 389.

Wetzel, Hans Jakob, wurde ca. 168 o geboren, lernte vom 22. August 1695 ab drei Jahre lang bei I Emanuel Scholer. Er wurde im Jahre 1710 zünftig und wurde am 9. März 1738 beerdigt.

Er führte die Meisterzeichen Nr. 390, 392, 393 (event. auch 391).

Gegenstand: Im historischen Museum von Basel : flache Schüssel von 3o cm Durchmesser, darauf das Wappen der Universität Basel und dasjenige des Bonifacius Fäsch (Feschius). Meistermarke Nr. 391.

Grynaeus, Simon, wurde 1664 geboren und im Jahre 1691 zünftig. Bei ihm lernte 1711-1714 Johann Gysin von Liestal. Die vier grossen Kannen der Universität Basel tragen die Jahrzahl 1704. Er starb 1726.

Er führte als Meisterzeichen die Nr. 395 und 396. Bodenrosette Nr. $43_{2}$.

Gegenstände: Die vier grossen Kannen der Universität Basel. Höhe $52 \mathrm{~cm}$. (Tafel VIII, 1.)

Kugelkrug mit zwei Reihen herausgetriebener Buckel. Auf dem Deckel eine vollrund gegossene Traube; als Deckelgriff ein Akanthusblatt. Unten am Boden die Meistermarke Nr. 395. Höhe $17 \mathrm{~cm}$. Durchmesser des Fusses 8,5 cm. (Tafel XVIII, 1.)

Schnabelstitze von $1 \frac{1}{2}$ Maass Inhalt. Auf dem Traghenkel das Meisterzeichen Nr. 395. Bodenrosette Nr. 432. Höhe 32,3 cm. Deckeltraube.

Kugelkrug mit zwei Reihen herausgetriebener Buckel. Meistermarke Nr. 396. Die Höhe beträgt 15,5 cm. (Historisches Museum Basel.)

Burkhart, Rudolf, wird am 1. Januar 1677 von seinem Lehrmeister Jakob Ebneter ledig gesprochen. Am 21. April 1685 erhält er den Auftrag, sein Meisterstück in Hans Georg Meiers Laden zu machen. Am 7. Mai 1685 weist er sein Meisterstück vor. Schaumeister sind Niklaus Uebelin und Emanuel Scholer. Im Jahre 1686 wird er bestraft wegen Misshandlung seines Gresellen Kronberger, sowie wegen Verläumdung seines Lehrmeisters Hans Jakob Ebneter.

Burger, Hans Rudolf, will am 17. August 1683 sein Meisterstück machen. Schaumeister sind Hans Lux Iselin und Joseph Wick. Ende August 1683 weist er sein Meisterstück vor und kauft die Zunft. Im Jahre 1686 figurirt er als Zeuge in der Klage Rudolf Burkharts gegen Hans Jakob Ebneter wegen schlechten Zinns. Im Jahre 1686 hat er als Gesellen Joseph Wanger von Freisingen und Theobold Bachmann von Thun. 
TAFEL XXX
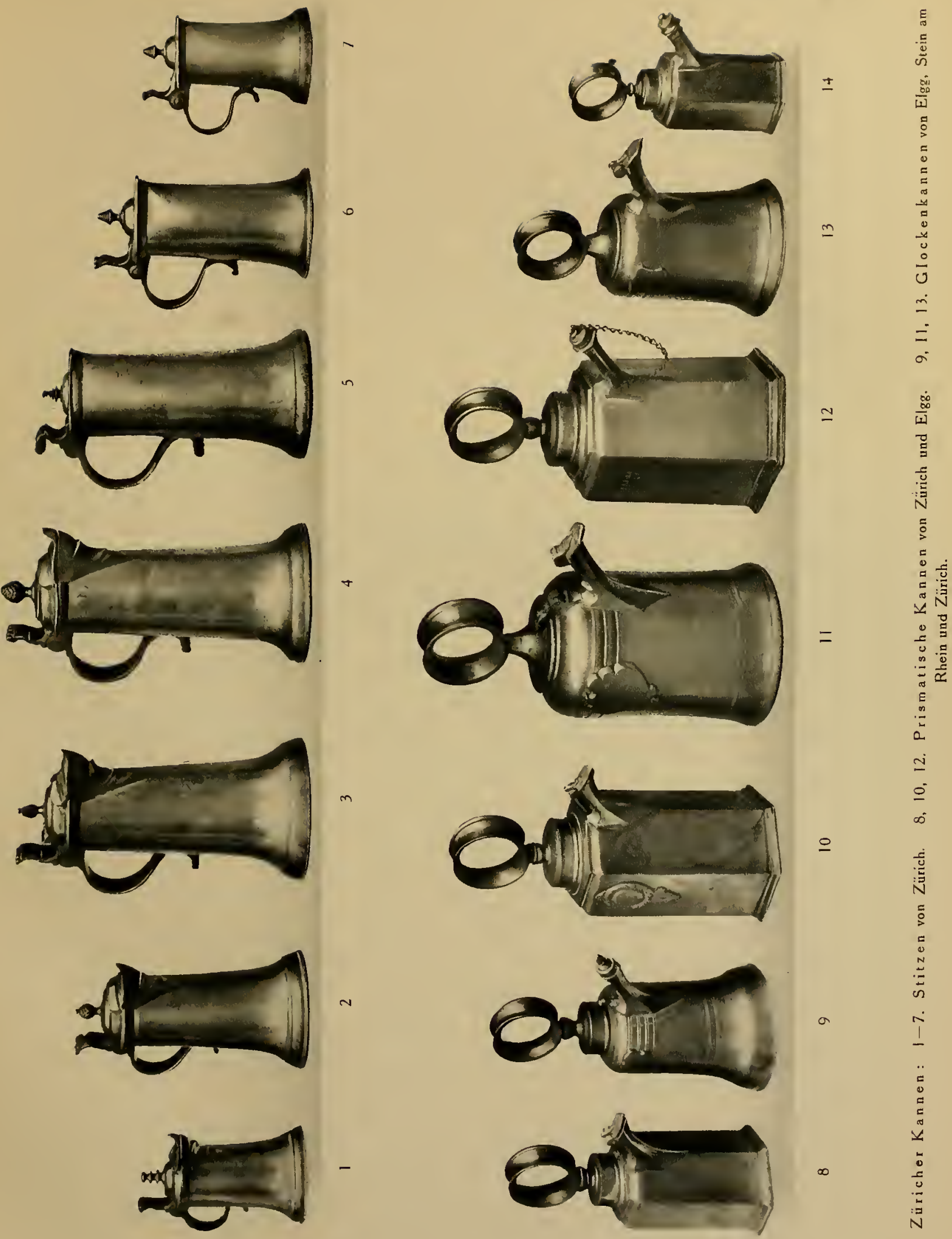

${ }^{1}$ Strübin, Peter, von und in Liestal, Kannengiesser. Lebte von 1628-1689; heiratete 1648 Barbara Imhof. Im Jahre 1684 klagen die gesammten Zinngiesser von Basel gegen ihn. Auch sein Sohn Peter war Zinngiesser. Er lebte von 1653 bis 1720.

'Strübin, Niklaus, Sohn des Kannengiessers Strübin Josef. Niklaus lebte von 1643-1695. Das Meisterzeichen Nr. 426 ist kaum die Marke N. Strübins. Ebenso die Bodenrosette Nr. 438 .

Gegenstand: Schnabelstitze von 2 Maass Inhalt. Höhe $35,2 \mathrm{~cm}$.

${ }^{1}$ Strübin, Johann, der Bruder des Vorigen, übte seinen Beruf als Kannengiesser vom Jahre 1649 bis zu seinem Tode 1674 .

Sein Meisterzeichen ist vielleicht gleich dem des Josef Stübin, Nr. 424, 425. Bodenrosetten Nr. 436,347 .

Burkhardt, Hans Rudolf, weist sein Meisterstück vor und kauft die Zunft am 7. Mai 1685 . Schaumeister sind Niklaus Uebelin und Emanuel Scholer.

Meier, Hans Georg. Am 21. April 1685 soll Rudolf Burkhardt sein Meisterstück in Meier's Laden machen. Im Jahre 1686 war Meier Zeuge bei der Klage Burkhardts gegen Ebneter wegen schlechten Zinnes.

Linder, II Niklaus, der Jüngere, wurde geboren im Jahre 1728; er erneuerte die Zunft 1765 . Er wurde beerdigt am 5. Juli 1785 .

Er führte das Meisterzeichen Nr. 394.

Scholer, II Emanuel, der Sohn des I Emanuel Scholer, wurde 1737 zünftig. Er starb im Jahre 1788 .

Er führte die Meisterzeichen Nr. 397, 398, 399, 40o, mit 401 (398 gehört wahrscheinlich zu Scholer, I Emanuel). Bodenrosette Nr. 433 .

Gegenstände: Schnabelstitze von $1 / 4$ Maass Inhalt mit Deckeltraube. Am Handgriff die Marke Nr. 401. Keine Bodenrosette. Höhe $18,4 \mathrm{~cm}$. Unter dem Schnabel die Initialen L. M. D. (Tafel XXXIX, 1.)

Stitze ohne Schnabel von 1 Maass Inhalt. Flacher Deckel, im Centrum kegelförmig nach oben getrieben. Am Traghenkel das Meisterzeichen Nr. 401. Einfache sechsteilige Bodenrosette. Höhe $28,8 \mathrm{~cm}$. (Tafel XXXIX, 3.)

Runde Schale mit Randfries im Stile Louis XIII. An der Seitenwand 26 radiäre Rippen, welche in den flachen Boden auslaufen. An der Unterseite des Bodens zwei Mal das Meisterzeichen ${ }^{-N r}$. 397 und dazwischen das Zeichen Nr. 398. Darüber zwei hebräische Worte. Durchmesser der Schüssel ${ }_{2} 3,3 \mathrm{~cm}$. (Tafel XVIII, 6.) - Stitze ohne Schnabel von 1/2 Maass Inhalt. Am- Traghenkel das Meisterzeichen Nr. 401. Höhe 22,5 cm. Unterhalb des Ausgusses die Initialen I. K. Einfache sechsteilige Bodenrosette.

Grynaeus, Hans Jakob, kaufte am 4. Juli 1723 die Zunftgenosseschaft; er starb 1753 .

Er führte das Meisterzeichen Nr. 402 .

Gegenstände: Basler "Rundele " von $1 / 2$ Maass Inhalt. Deckel ganz flach. Auf dem Traghenkel das Meisterzeichen Nr. 402. Höhe ${ }_{23,2} \mathrm{~cm}$. (Tafel XXXIX, 2.) Schnabelstitze von $1 / 2$ Maass Inhalt mit Deckeltraube. Am Traghenkel die Marke Nr. 402. Höhe 22,5 cm. Bodenrosette glatt.

Scholer, Jakob Christoph, wurde im Jahre ${ }_{1694}$ getauft und im Jahre ${ }_{1723}$ Mitglied der Hausgenossenzunft. Wurde am 10. Juli 1761 beerdigt.

Er führte das Meisterzeichen Nr. 403.

Gegenstand: Prächtiges Giessfass mit schraubenförmig gedrehten Säulen. Höhe $25 \mathrm{~cm}$. Meisterzeichen Nr. 403 hinten am Deckel. (Kunsthandel in Basel.)

Wick, Bernhard, wurde im Jahre 1684 geboren und ca. 1720 Meister. Er starb 1747 . Er führte die Meisterzeichen Nr. 404 und 405 . Bodenrosette Nr. 434 .

1. Stammbaum der Bürgergeschlechter roo Liestal » von Arnold Seiler-Rosenmund. 1908. Gebrüder Lüdin in Liestal. 
Gegenstand: Stitze ohne Schnabel von ca. 1/, Maass Inhalt. Deckel in der Mitte $k$ elförmig in die Höhe getrieben. Auf dem Traghenkel die Meistermarke Nr. 405. Bodenrosette Nr. 434. Unter dem Ausguss die Initialen H S V T. Höhe 18,7 cm. Am Traggriff befindet sich noch ein eigentümliches Eigentumszeichen mit den Initialen DP. (Tafel XXXIX, 7.)

Im historischen Museum von Basel : Teller von 22,5 cm Durchmesser. Meisterzeichen $\mathrm{Nr} .405$.

Uebelin, II Niklaus; er wurde im Jahre 1705 Mitglied der Hausgenossenzunft. Er wurde am 21. April 1756 beerdigt.

Er führte die Meisterzeichen $\mathrm{Nr} .406,407,408$.

Gegenstände: Runde Gemüseschüssel von $24,8 \mathrm{~cm}$ Durchmesser und $6,7 \mathrm{~cm}$ Tiefe. Oben am Rand das Beschauzeichen von Uri Nr. 4 mit der Jahrzahl 1762 und an der Unterseite des Bodens drei Mal das Meisterzeichen Nr. 4o8. - Wöchnerinnenschüsselchen mit je drei Klauenfüssen am Boden und auf dem Deckel. An der Unterseite des Bodens drei Mal das Meisterzeichen Nr. 407. Durchmesser mit den Traggriffen $22,3 \mathrm{~cm}$. Höhe $10 \mathrm{~cm}$. (Tafel XX, 2.)

Wick, Lukas, geboren im Jahre 1700. Er wurde am 4. März 1733 zünftig und am 3o. April 1765 beerdigt.

Er führte die Meisterzeichen Nr. 409 und 410.

Gegenstände: Basler "Rundele " von 1/2 Maass Inhalt. Auf dem Traghenkel das Meisterzeichen $\mathrm{Nr}$. 409. Höhe $22,7 \mathrm{~cm}$. Vorn unter dem Schnabel die Initialen H B; dazwischen ein Metzgerbeil. (Tafel VIII, 3.)

Im historischen Museum Basel : Stitze mit der Jahrzahl 1740. Ferner ein Becher mit Fuss und Deckel; Höhe $10 \mathrm{~cm}$; Meistermarke Nr. 409. - Teller von 22,5 cm Durchmesser mit der Meistermarke Nr. 410.

Linder, II Johannes, Zinngiesser und Sensal, wurde 1698 geboren und im Jahre 1723 zünftig und am 29. April 1769 beerdigt.

Er führte das Meisterzeichen Nr. 411 und 413.

Gegenstände: Zinnflasche im historischen Museum von Basel, mit der Inschrift "Das Ersame Handwerck der Beckenknechte \%. Meisterzeichen Nr. 411.

Ebendaselbst eine Basler "Rundele " von 31,5 cm, mit der Meistermarke Nr. 411. Kleine Schnabelstitze von 10,5 cm Höhe (ohne Deckel). - Ferner ein flaches prismatisches Gefäss auf vier Kugelfüssen. Alle mit dem Meisterzeichen Nr. 411.

Cylindrisches Gefäss von $17 \mathrm{~cm}$ Höhe mit Schraubdeckel und beweglichem Tragring. Meisterzeichen Nr. 411. Alle Gegenstände im historischen Museum von Basel.

Linder, III Johannes, geboren im Jahre 1732, gestorben 1777. Es ist fraglich, ob derselbe überhaupt ein Zinngiesser war.

Scholer, Johann Jakob, wurde im Jahre 1739 getauft. Er starb im Jahre 1815.

Er führte das Meisterzeichen Nr. 412 ; ferner eine Marke wie Nr. 401, nur befindet sich im untern Rand der Krone noch der Buchstabe I.

Streckeisen, I Emanuel. Er wurde 1765 zünftig und starb im Jahre 1818.

Er führte das Meisterzeichen Nr. 414 .

Schnabelstitze von $1 / 2$ Maass Inhalt mit Deckeltraube. Höhe $24 \frac{1}{2} \mathrm{~cm}$ (ohne Deckel). Auf dem Traghenkel die Meistermarke Nr. 414.

Streckeisen, II Emanuel, wurde im Jahre ${ }_{1781}$ geboren und starb im Spital 1859 .

Er führte die Meisterzeichen Nr. 415,416,417; vielleicht mit seinem Vater zusammen. Gegenstände: Runde Gemüseschüssel von $23 \mathrm{~cm}$ Durchmesser und $5,5 \mathrm{~cm}$ Tiefe. An der Unterseite des Bodens die Marken Nr. 415 und 416 . Oben am Rande das Beschauzeichen von Uri Nr. 4 und die Jahrzahl 1782. - Wöchnerinnenschüsselchen mit je drei Klauenfüssen auf dem Deckel und am Boden. Auf dem Deckel die Initialen I. W.; ebenfalls unten am Boden. Am Boden zwei Mal die Meistermarke Nr. 415. Breite mit den Handgriffen $23 \mathrm{~cm}$. Höhe $10 \mathrm{~cm}$. 
Schneck, Johann Jakob, auch Schnegg geschrieben, wurde im Jahre 1797 geboren; er war auch Glockengiesser (S. BRUn, Schweiz. Künstlerlexikon, Bd. IV, S. 391) und starb 1858. Er führte die Meisterzeichen Nr. 418,419, 420, 421 und 422.

Gegenstände: Schmalrandiger Teller von $20 \mathrm{~cm}$ Durchmesser. Meisterzeichen Nr. 421. - Ferner ein Maass mit Ausguss von $28 \mathrm{~cm}$ Höhe, mit der Meistermarke Nr. 419. - Cylindrisches Gefäss mit Schraubdeckel und beweglichem Ring, von $16 \mathrm{~cm}$ Höhe. Meisterzeichen Nr. 422. - Grosse Suppenschüssel von $15 \mathrm{~cm}$ Höhe (ohne Deckel) mit der Meistermarke Nr. 420. - Trinkbecher von 10,5 cm Höhe mit dem Meisterzeichen Nr. 418. - Flache runde Schüssel von 27,5 cm Durchmesser mit der Meistermarke Nr. 420 (Variante mit den Initialen I. I. S. unter dem Engel). Letztere fünf Gegenstände im historischen Museum von Basel.

Klein, Herrmann, Zinngiesser, lebte von 1882 bis 1913 .

Er führte das Meisterzeichen Nr. 423.

Seiler, Leonhard, von und in Liestal, Zinngiesser; er lebte vom Jahre 1812 bis 1882 .

Er führte die Meisterzeichen Nr. 427, 428, 429 .

Gegenstand: Prismatisches, sechsseitiges Gefäss mit Schraubdeckel und beweglichem Tragring. Höhe 20,5 cm (ohne Deckel). Meisterzeichen Nr. 427, unten am Boden.

\section{Die Basler Zinngegenstände}

Die ältesten erhaltenen Gegenstände sind der Humpen des Onophrion Werlin und das flache, scheibenförmige, runde Plättchen des Meisters Gotthard Hotinger aus der zweiten Hälfte des XVI. Jahrhunderts. Sie befinden sich im historischen Museum von Basel. Das Plättchen trägt ausser der Meistermarke Nr. 374 noch das Wappen des Hieronimus Froben (1501-1563) und das Alliancewappen des Conrad Meyer zum Pfeil und der Judith Schönauer.

$\mathrm{Zu}$ den besten Arbeiten des Basler Zinngiesserhandwerlks gehören die zwölf stattlichen Kannen des kleinen Rats von Basel. (Tafel VII, 1.) Dieselben fanden wahrscheinlich bei festlichen Anlässen ihre Verwendung als Weinkannen. Die prächtigen, $42 \mathrm{~cm}$ hohen Stücke stammen von Meister I Johannes Linder und tragen vorn am Fusse die zwei Meisterzeichen Nr. 378. Das erste ist das offzielle Meisterzeichen. Der Wichtigkeit des Auftrags entsprechend und vielleicht auch aus Freude über das gute Gelingen der Arbeit, fügte der Meister noch seinen Privatstempel dazu. In einem Achteck befindet sich das Familienwappen der Linder : schräg gekreuzte Doppelhacken mit darauf liegendem dicken, senkrecht nach oben gerichtetem Pfeil; dazu noch die Initialen I. L. Der Aufbau der Kannen ist sehr elegant. Auf einem vierseitigen, nach oben sich verjüngendem Fuss steht der runde, linsenförmige Korpus, welcher in seiner Mitte ein Medaillon trägt. Dasselbe besteht aus einem von zwei Basilisken gehaltenen Basel-Wappen, umgeben von einem Blattkranze. Der schlanke Hals des Ausgusses wird durch einen $Z$ inndeckel verschlossen, welcher in einem Scharnir läuft. $Z u$ beiden Seiten des Ausgusses ist je eine Oese, welche vom Halse eines vollrund gegossenen Basilisken gebildet wird. Diese Oesen dienen zur Befestigung der massiven zinnernen Tragoder Zierkette. Die Kannen sind ebenfalls im historischen Museum von Basel.

Weitere Prachtstücke sind ebenfalls die vier schönen, $52 \mathrm{~cm}$ hohen Weinkannen der Universität Basel (Tafel VIII, 1), welche für die vier Fakultäten bestimmt waren. Sie stammen von Meister Simon Grynæus und tragen das Meisterzeichen Nr. 395. Der Fuss der Kanne ist rechteckig und verjüngt sich in schönem Aufbau nach oben. Darauf liegt der grosse, runde, scheibenförmige Korpus. In der Mitte der Vorderseite befindet sich eine runde Messingplakette. Auf derselben ist der Baselstab und darüber das Wappen der Universität. Ein aufgeschlagenes Buch wird von einer Hand gehalten, welche einer Wolke entragt. Rechts und links vom Baslerwappen ist je eine Hälfte der Jahrzahl 1704. Unterhalb der Messingplakette ist vermittelst einer Oese ein beweglicher Ring angebracht. Dadurch wird das Neigen der Kanne beim Einschenken erleichtert, was bei dem grossen Gewicht der 
gefüllten Kanne notwendig ist. Die Rückseite des Korpus ist ganz glatt. Der aufgesetzte, nach oben sich leicht erweiternde Hals wird durch einen grossen Holzpfropfen verschlossen. Ein eiserner, in Oesen laufender, beweglicher Henkel dient zum Tragen der gewichtigen Stücke, welche ebenfalls im historischen Museum von Basel deponirt sind.

Die typische und häufigste Baslerkanne ist die Stitze. Dieselbe kommt in verschiedenen Grössen vor, von 9 bis $36 \mathrm{~cm}$ Höhe. Es gibt solche mit und ohne schnabelförmigem Ausguss. Die grössten Exemplare haben stets den schnabelförmigen Ausguss. Die Ausführung dieser Stücke ist stets bis in die kleinsten Einzelheiten gut und sorgfältig. Die Basler Stitzen sind schlanker als die Zürcher. Auch ist der Bau des Fusses niedriger und weniger ausladend. Detaillirte Beschreibungen einzelner Stücke finden sich bei den entsprechenden Zinngiessern.

Eine für Basel eigentümliche und besondere Kannenart ist die sogenannte "Rundele". Sie gleichen Kaffeekannen, haben einen schnabelförmigen Ausguss wie die Stitzen und ebenfalls einen ähnlichen, flachen Deckel. Derselbe trägt nur ausnahmsweise die vollrund gegossene Deckeltraube. Meist ist die ganze Oberfläche glatt. In seltenen Fällen befindet sich am Fuss, am obern Rand der Kanne und des Deckels ein reliefirter Blattfries. Die Höhe der Kannen variirt von 18 bis $37 \mathrm{~cm}$. Diese Kannenform findet man im Zeitraum von 1650 bis 1750 . Sie kommt auch in Solothurn vor.

Basler Glockenkannen habe ich niemals finden können. Es gibt wohl Glocken mit dem Baselstab in der Giessermarke; allein es handelt sich hiebei um das Zinngiessergeschlecht der Basler (Familienname) von Steckborn, welche daselbst ihren Beruf in ausgedehnter Weise ausübten.

Die prismatischen Kannen sind ausserordentlich selten und ich kenne nur zwei bis drei Stücke vom Giessermeister Josef Strübin (siehe daselbst). Häufiger dagegen sind sechsseitig prismatische Gefässe ohne Ausgussröhre mit einfachem oder doppeltem Schraubverschluss. Sie dienten zur Aufbewahrung von dickflüssigen Substanzen, Oelen, Honig, Latwergen u. dgl. Ich habe solche Gefässe beschrieben beim Zinngiessermeister Hans Jakob Ebneter.

Schalen, Platten und Teller haben keine Besonderheiten; nur die Meistermarke weist auf den Ursprung. Auffallend häufig findet man die Basler Gemüseschüsseln im Lande Uri, woselbst denselben noch das Urner Beschauzeichen aufgeschlagen wurde.

Giessfässer, Kerzenstöcke, u.s.w. sind ebenfalls nur am Meisterzeichen erkenntlich.

Wöchnerinnen-Schüsselchen in hübscher Ausführung wurden besonders von II Emanuel Streckeisen und II Niklaus Uebelin angefertigt. Dieselben gleichen auffallend den zugerischen Exemplaren, sind aber bedeutend leichter und dünner gearbeitet. Auch hat der Deckelrand einen Perlstab. Die Handgriffe sind zierlich und endigen in einem Engelkopf.

\section{LIESTAL}

Das Wappen: Roter Bischofstab mit links gerundeter Krümmung, darum 7 Punkte. Urech, Hans, von Rheinfelden, lernte ab 1578 bei Gotthard Hotinger in Basel. Er kam ca. 1587 von Schaffhausen nach Liestal.

Strübin, Josef, wurde 1608 geboren und starb 1674 oder 1675 . Er war auch Stadtbürger von Basel. Weitere Einzelheiten sind bei den Basler Meistern zu finden. Die Meisterzeichen des Josef und Johann Strübin haben die gleichen Initialen und sind nicht auseinander zu halten. Meisterzeichen Nr. 376,377 .

Strübin, Peter, Zinngiesser von und in Liestal, wurde 1628 geboren, heiratete ${ }_{164} 8$ und starb 1689 (Schweiz. Künsller-Lexikon, Bd. IV, S. 422, Klage der Basler Zinngiesser). Meisterzeichen und Gegenstände sind nicht bekannt.

1 - Stammbaum der Bürgergeschlechter von Liestal • von Arnold Seiler-Rosenmund. 19o8. Gebrüder Lüdin in Liestal. 

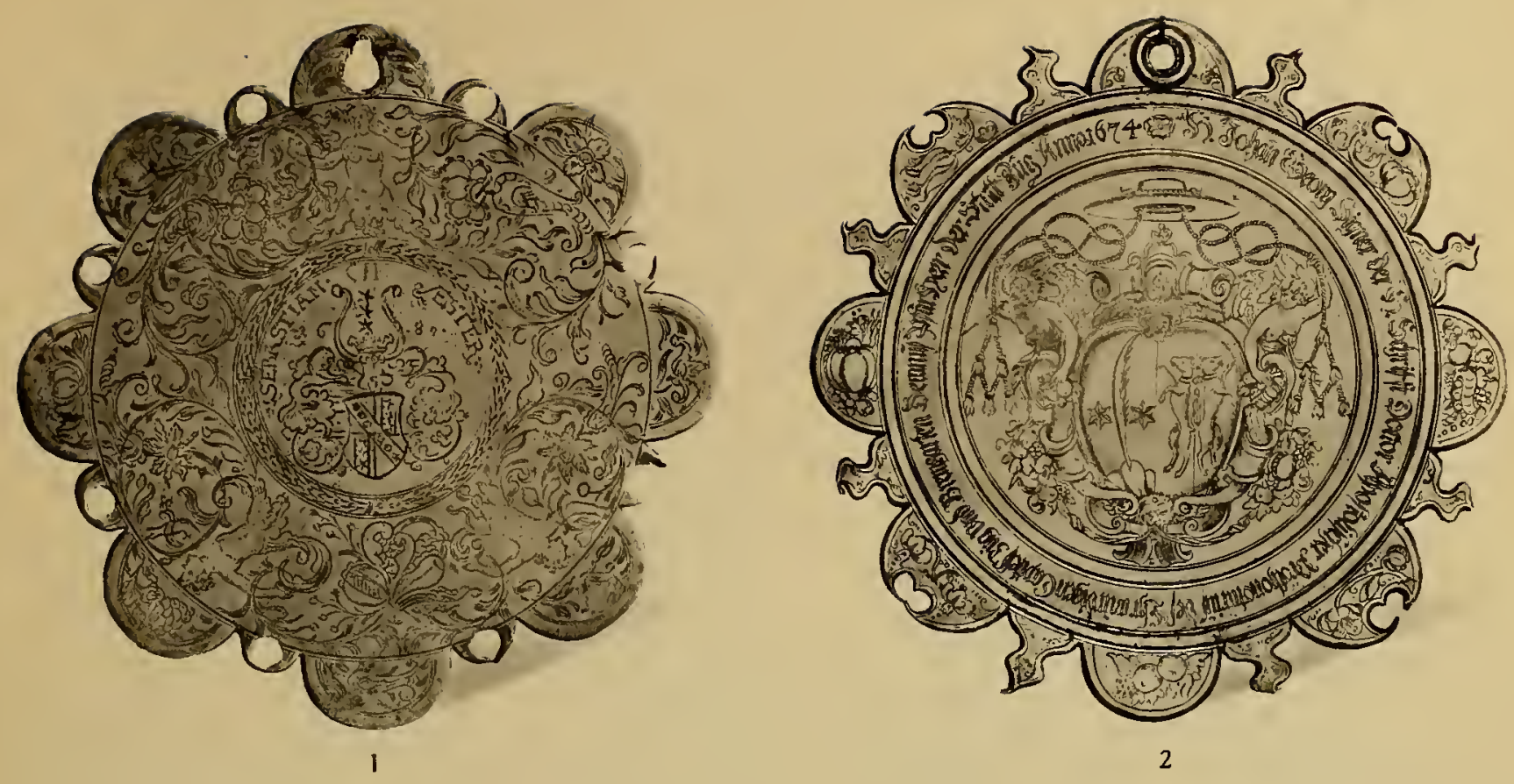

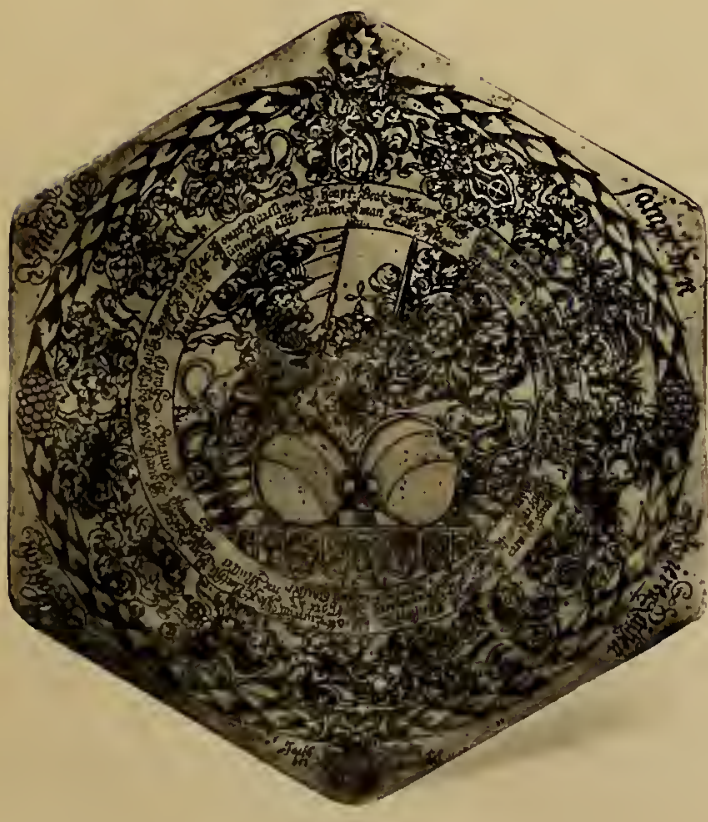

3



4

1. Wandplatte, geschenkt dem Sebastian Eister, 1683. 2. Wandplatte, geschenkt dem Joh. Georg Signer von seinen Eltern (Signer-Blunschi) 1674. 3. Wandplatte, Geschenk der Stadt Zug an eine Nachbarstadt, 1641. 4. Schützenteller von Zürich, von Hans Georg Thumysen, Zürich, datirt 1650. 

Senn, Johannes, Zinngiesser, wurde 1720 geboren, heiratete 1745 und starb 1788 . Er hat ebenfalls die gleichen Initialen wie Josef und Johann Strübin. Siehe Meisterzeichen Nr. 424 .

Senn, Ursus, Sohn des Vorigen, wurde 1751 geboren, heiratete im Jahre 1777 und starb 1812. Gegenstände und Meisterzeichen sind nicht bekannt.

Seiler, Leonhard, Zinngiesser, führte die Meisterzeichen Nr. 427, 428, 429. Er wurde 1812 geboren, heiratete 1838 und starb am 25. Mai 1882. Er war von und in Liestal.

Gegenstand: Prismatisches, sechsseitiges Gefäss mit Schraubdeckel und beweglichem Tragring. Höhe ohne Deckel 20,5 cm. Das Meisterzeichen Nr. 427 befindet sich unten am Boden.

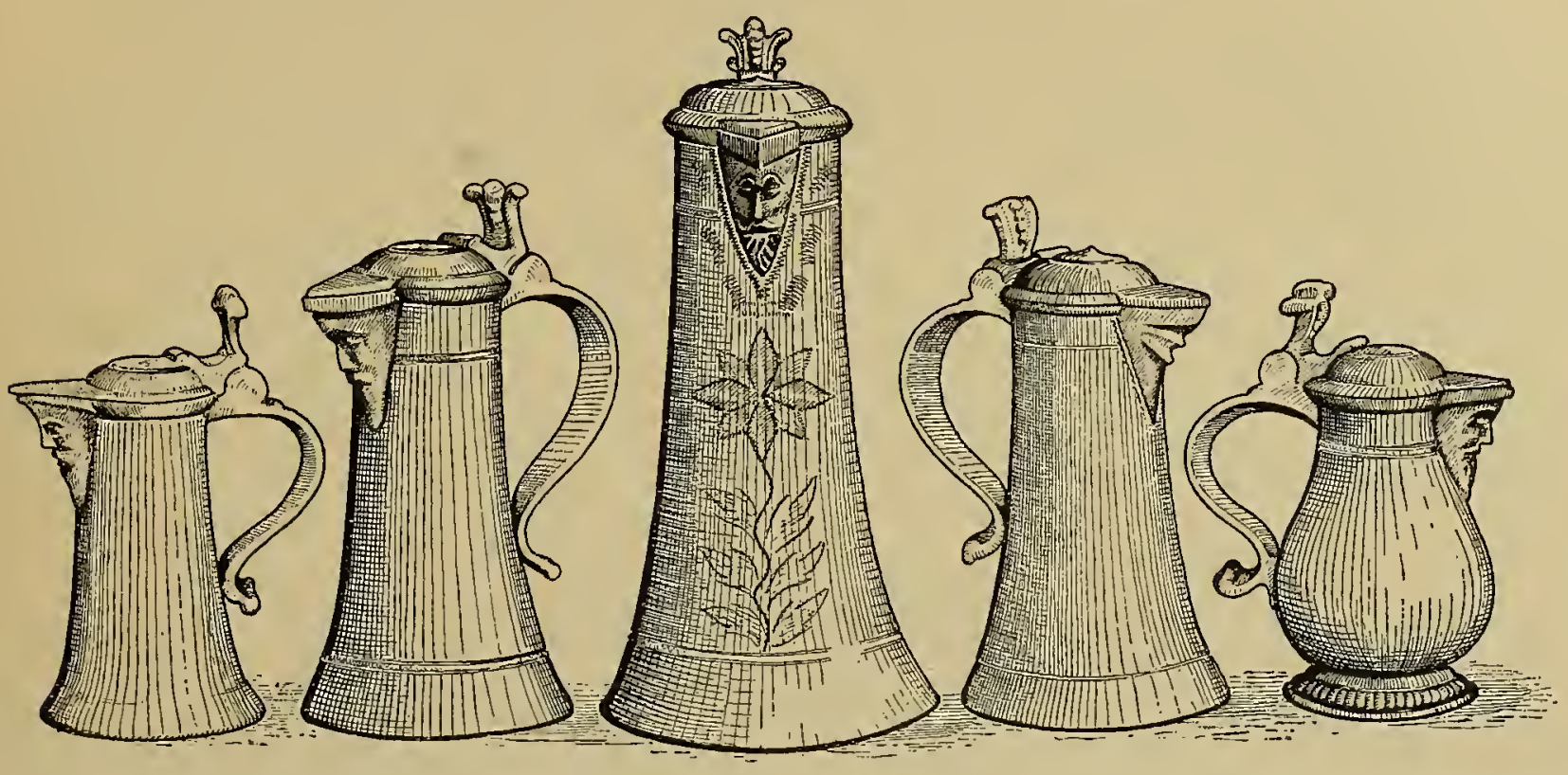

SOLOTHURN

Die Beschauzeichen auf den Zinngegenständen von Solothurn und von Ulm sind zum Verwechseln ähnlich; nicht aber kommt Freiburg in Frage, weil die Freiburger Zinngiesser niemals das Standeswappen, sondern das Stadtwappen von Freiburg (drei gezinnte Türme mit darüber schwebendem Adler) anbrachten, und zudem nur in seltenen Fällen. Die von Naef (S. 14) als Freiburger Kanne abgebildete Kanne stammt ebenfalls aus Ulm; die unrichtige Zuteilung Naefs findet die Nachfolge bei Browns Abhandlung über "das Zinngiesserhandwerk in der Schweiz " (S. 17).

Im Band I sind also die Meisterzeichen Nr. 593, $594 a$ und $b$ der Tafel XXX, Solothurn, zu eliminiren, weil dieselben Ulmer Meistern (Georg Wilhelm Werlin und Georg Christoph Weber) angehören. Weil ferner seit dem Jahre 1920 durch die archivalischen Arbeiten von Herrn Staatsarchivar Dr. Kälin und durch die Studien von Herrn J. Simmen in Solothurn viele bisher unbekannte Meister und Meisterzeichen gefunden wurden, habe ich die Tafel Solothurn neu zeichnen lassen. Die Zahl der Meisterzeichen ist damit ebenfalls bedeutend grösser geworden. Das Meisterzeichen Nr. 605 fällt für Solothurn nicht in Betracht; es gehört dem Obwaldner Zinngiesser Josef Etli. - Ferner fällt auch die Ulmer Bodenrosette Nr. 611 (Bd. I) weg.

Die ältesten Nachrichten über das Zinngiessergewerbe reichen in den Anfang des XV. Jahrhunderts zurück. Die archivalischen Arbeiten basiren auf folgenden Quellen: 
Ratsprotokolle und Seckelmeisterrechnungen der Stadt Solothurn (Auszüge von Herrn Dr. Kälin); das Protokoll der Schmiedenzunft; ferner Protasius Wirz O. C. "Die Bürgergeschlechter der Stadt Solothurn ". Viele Meisterzeichen wurden von Herrn J. Simmen direkt von den Zinngegenständen abgezeichnet.

Die frühesten Bestimmungen über die Zinngiesser findet man im Kannengiesser-Eid, welcher im Jahre 1469 von Meister Conrad Ruchti geleistet wurde. Er schwört « $\mathrm{dz}$ er das zinnen geschirr sol zeichnen mit dem gilgen und darumb werschafft tun und mischel geschirr für mischel als $\mathrm{dz}$ gewonlichen ist und keinen geverd nitt triben noch suchen in keynen weg, sunder uffrecht und redlich sin andwure triben erberlich und ungevarlich. Er mag ouch allerley geschirr kouffen, und was im bedunkt argwenig sin und froembd zeichen hat, sol er by sinem vorgeschribnen eyd sagen eynem rat und das leyden." (Ratsprotokoll I, S. 40.)

Neben dem $\mathrm{Feinzinn} \mathrm{wurde} \mathrm{auch} \mathrm{das} \mathrm{gewöhnliche} Z$ inn verarbeitet. Unter gewöhnlichem $Z$ inn verstand man die Legirung von vier Teilen Zinn mit einem Teil Blei. Diese Legirung wurde gekennzeichnet durch Einschlagen des Stadt- und des MeisterzeichensAuf Letzterm findet man häufig eine französische Lilie - der Gilgen (in der Inner. schweiz, die Ilge - Lilie). Für die Bezeichnung des Feinzinns findet man ab und zu auch die bekrönte Rose oder das Wort FIN. Sehr häufig findet man im Meisterzeichen nur den Zinngiesser-Hammer und die Initialen des Meisters.

Auch in Solothurn musste sich der Rat ab und zu mit fahrenden Zinngiessern befassen, welche dem ansässigen Meister ins Handwerk pfuschten. Dieselben wurden stets ausgewiesen, oft gebüsst und die Ware beschlagnahmt.

\section{Die Zinngegenstände}

Die Kannen kommen in drei verschiedenen Formen vor: die Stitze, die bauchige Rundele und die Stegkanne. Glockenkannen und prismatische Formen fehlen vollständig. Die Stitze hat eine für Solothurn charakteristische, einzigartige Form. Der Korpus ist kegelförmig, ohne Fussausladung. Vom Kannenboden bis zum obern Rand nimmt der Durchmesser stetig $a b$; die Seitenwand ist also nirgends vertikal; meist ist die Oberfläche ganz glatt; ab und $\mathrm{zu}$ werden einige circuläre Linien oder Rillen zur Gliederung angebracht. Die Stitze lrommt in drei Grössen vor, entsprechend einem. Inhalt von 1, 1/2 und 1/4 Maass. Je nach der Form des Ausgusses unterscheidet man Schnabelstitzen und Bartmannstitzen. Stitzen ohne Schnabel kommen nicht vor.

1. Die Schnabelstitze. Der Schnabel ist im Verhältnis zu demjenigen der Zürcherund Baslerstitzen eher klein und einfach in der Modellirung. Als Deckeldrücker findet man oft das Akanthusblatt. In der Mitte des Deckels ist oft einekleine kreisförmig'e Scheibe, oft eine lkleine, kegelförmige Erhöhung. Die Kannenoberfläche ist ganz glatt; als Verzierung sind Wappen, Besitzerinitialen oder Jahrzahlen eingravirt.

2. Die Bartmannstitze. An Stelle des Ausgusschnabels ist ein bärtiges Mannsgesicht, ein Maskaron, auch Fratze genannt; daher der im Handel häufige Ausdruck " Solothurner Fratzenkanne ". Vielleicht stammt die Idee von den deutschen resp. rheinischen Bartmannkrügen in Steinzeug. Diese kommen schon seit ca. 1570 (siehe Falke, Rheinischeo Steinzeug, Bd. II, S. 16) vor und sind sicherlich im Handel auch in der Schweiz gekommen. Vielleicht aber ist es eigene Erfindung; denn im Profil gleicht der Schnabelausguss oft so sehr einem Kopf, dass man nur die Augen hinzu denken muss, um das Gesicht vollständig zu machen. Die älteste, mir bekannte Bartmann-Stitze von Solothurn trägt die Jahrzahl 1679 und das Meisterzeichen Nr. 599 (Bd. I) resp. Nr. 593 a des neuen Blattes. Ein Mannsgesicht befindet sich schon an einem kleinen Zinnlrrug vom Homberg, aus dem XIII. oder XIV. Jahrhundert (siehe Tafel I, Bd. II). 
Bei Vergleichung vieler Bartmannstitzen kann man drei verschiedene Gesichtsmodelle unterscheiden und zwar bei den grossen 1 Mass-Kannen: 1) der grosse Mannskopf des Meisters W. G., 1679; 2 a) das Kopfmodell von Joseph Graff; 2 b) das Kopfmodell seines Sohnes Urs Graff, in gleicher Grösse wie $2 a$, aber in verbesserter Modellirung der Gesichtszüge ; 3) das Kopfmodell von Franz Jaus, weist eine ganz andere Physiognomie auf; es ist auch schmaler, aber sehr kräftig im Ausdruck.

Die mittelgrossen Bartmannstitzen haben einen kleinern Bartmannkopf als die Maasskannen. Dieser besitzt wiederum ein eigenes Modell, mit einem von der Mitte nach auswärts frisirten Bart.

Die kleinsten Bartmannstitzen haben ein entsprechend kleines Modell des Kopfes, welcher aber die gleiche Bartfrisur aufweist wie bei den Maasstitzen des Joseph und Urs Graff.

Die Rundele ist ein bauchiger Krug auf breitem Fuss mit einem schnabelförmigen Ausguss wie die Schnabelstitze. Die Oberfläche ist ganz glatt ; seltener durch circuläre Perlstäbe gegliedert. Diese Kannenform ist relativ selten. Sie kommt ebenfalls in drei Grössen vor. Als Unikum ist in meiner Sammlung eine kleine Rundele mit Bartmannkopf als Ausguss. (Tafel XXXIX, 8.)

Die Stegkanne. Diese seltenste Solothurner Form ist nur in zwei Exemplaren bekannt. Die eine befindet sich in der Sammlung H. Kirsch in München (v. Hintze, Bd. VII, Nr. ${ }_{2331}$ ) und trägt die Meistermarke Nr. 599 (Bd. I) resp. Nr. 593 a des neuen Blattes; das zweite Exemplar ist in meiner Sammlung und trägt das Meisterzeichen Nr. $59_{2}$ (Bd. I) resp. Nr. 592 a des neuen Blattes (siehe Kannengiesser Wilhelm Byss). In der Mitte des Deckels befindet sich, wie bei einigen Stitzen, ein kreisrundes Plättchen, welches man nur bei einigen Solothurner Kannen findet.

\section{Die Maasse}

Der kegelförmige Korpus hat einen tiefeingezogenen $\mathrm{Hals}$ und einen cylindrischen Ausgussteil. Der Henkel trägt oft ein Akanthusblatt. Viele Maasse stehen auf drei kleinen Füssen. Am Henkel und am Ausguss sind die Aichzeichen und die Jahrzahl, z. B. Maass auf drei Füssen; Höhe 18,7 cm, Durchmesser des Fusses 11,3 cm. Am Henkel die Jahrzahl 1812; am obern Rand des Korpus das Aichzeichen Nr. 604 (Bd. I) resp. Nr. 6ogb des neuen Blattes.

\section{Die Zinngiesser von Solothurn}

Hans von Sitten, Kannengiesser, kauft das Bürgerrecht 1442 um einen Gulden; wird auch Gutermut genannt. (Hans Morgenthaler, Anzeiger für Schweizerische Altertumskunde, Bd. XXVI, 1924 , S. 234 .)

Hug, Kannengiesser, zitirt 1456, macht das Testament. (Morgenthaler, Anzeiger für Schweiz. Altertumskunde, 1924 , S. 234 .)

Ruchti, Conrad, Kannengiesser, zitirt im Ratsmanual, S. 4o, beim Ablegen des Kannengiesser-Eides, im Jahre 1469 . Im Jahre 1471 wird er Bürger; er figurirt bis 1497 in den Stadtrechnungen.

Hüpschlin, Dietrich, Kannenmacher, reparirt 1462 die Turmknöpfe. (Ratsprotokoll.)

Meister Niklaus, zitirt 1553.

Meister Martin, zitirt 1560.

Fassnacht, Antoni, wird 1569 Bürger. (Brun, Schweiz. Künstler-Lexikon, I, S. 442.)

Adam von Biel, Kannengiesser, zitirt in Biel ${ }_{1} 557$ und 1558 ; wird in Solothurn im Jahre 1562 erwähnt.

Bernhard, Adam, von Niuvenstat, wird ${ }_{1} 5_{7} 5$ Stubengesell. (Protokoll der Schmiedenzunft.) 
Bapst, Melchior, Kannengiesser aus dem "Mailändischen », erhält ${ }_{1576}$ die Erlaubnis, in Solothurn als Kannengiesser zu arbeiten; nach 3 Jahren, 1579, "muss er wieder dem alten Zinngiesser Platz machen " und Solothurn verlassen. (Ratsmanual.)

Wyss, Antoni, von Solothurn, arbeitet 1580 bei Adam Lienhart in Bern (Brown, S. 54).

Gugger, Johannis, Kannengiesser (auch Guckher geschrieben). Er war ${ }_{1} 557$ Lehrling bei Asimus Barthander in Basel.

Wiell, ...., Stadt-Kannengiesser, erwähnt 1615, er solle die fremden Verkäufer, welche nicht-probehaltige Ware feilhalten, vertreiben (s. Brown, S. 64; Ratsmanual von Solothurn, Bd. 119, S. 101).

A. W. Ob die Meistermarken mit den Initialen $\mathrm{A} W \operatorname{dem} W$ iell angehören, ist nicht entschieden (siehe Bd. II, Nr. $59^{2} c$ ).

Gegenstände: Teller im Museum Solothurn. Durchmesser $18 \mathrm{~cm}$. Trägt das Meisterzeichen Nr. $59_{2} \partial$. Aussen ein eingeschlagener Doppelstempel mit den Familienwappen Schwaller und Gugger.

Ein würfelförmiges Reliquienkästchen $(3,5 \times 3,5$ und $5,6 \mathrm{~cm}$ Höhe mit Deckel, ebenfalls im Museum von Solothurn, trägt ebenfalls das A W im Meisterzeichen. Letzteres hat die Form von Nr. $59_{2} b$ mit den Initialen A W (in einander gestellte Buchstaben).

Eine Schüssel von $27 \mathrm{~cm}$ Durchmesser in der Sammlung von Jules Simmen in Solothurn, hat das Meisterzeichen Nr. $59^{2} \partial$.



$592 \mathrm{c}$

TAFEL XXXII
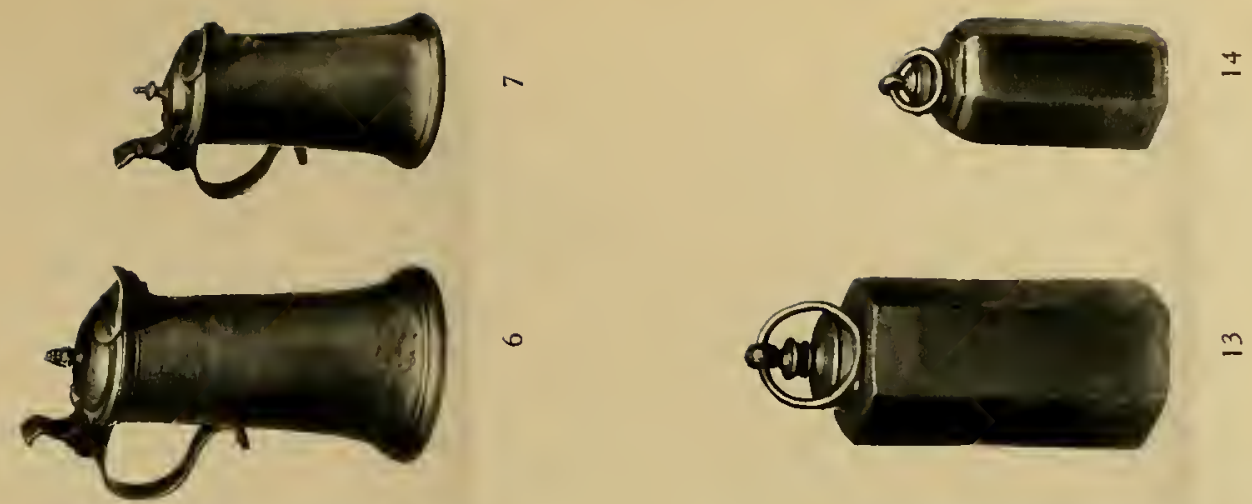

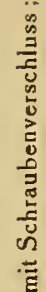
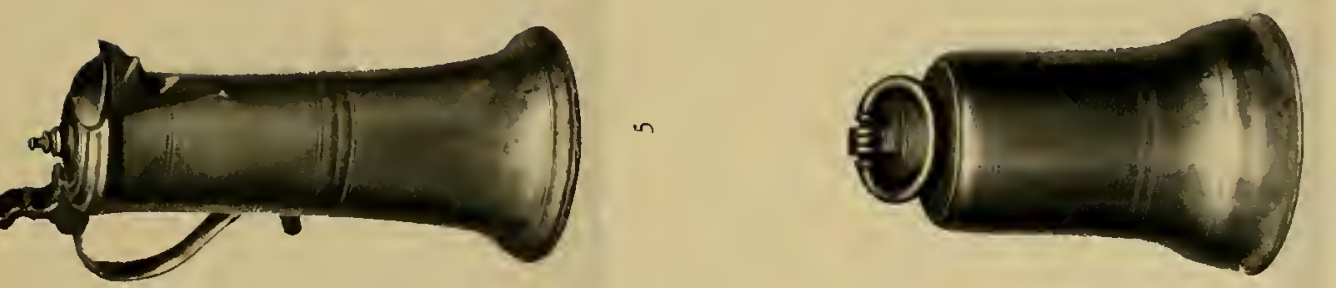

$\simeq$
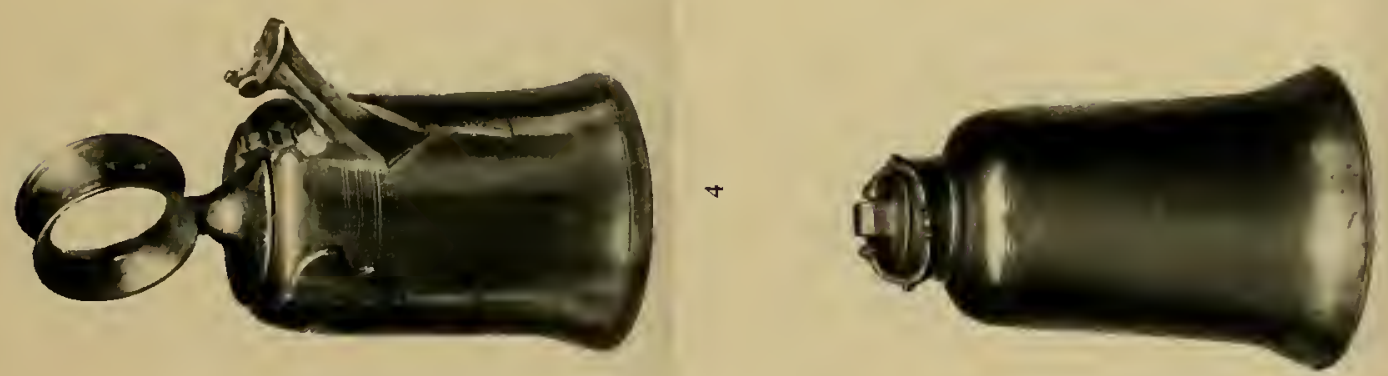

$\underline{-}$

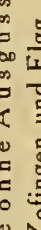

:

跑

N

I

要

๕ั

政

:

ن=

$\sum_{i}^{\infty}$

$+\frac{\infty}{+\infty}$

要要

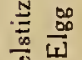

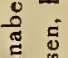

起
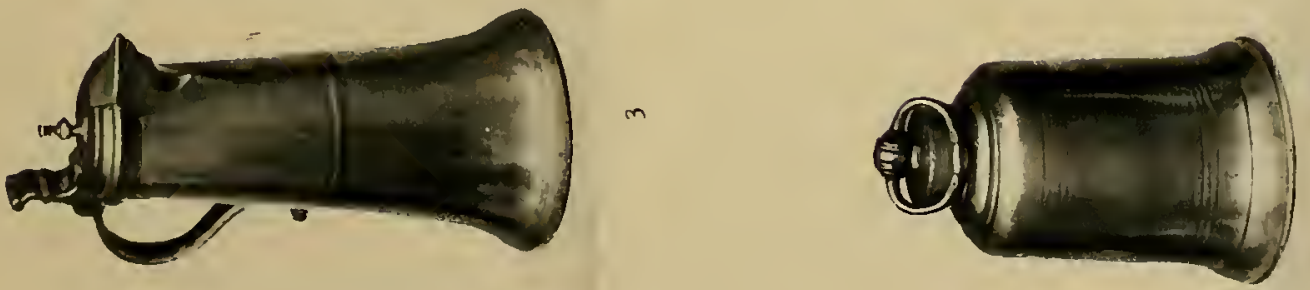

음
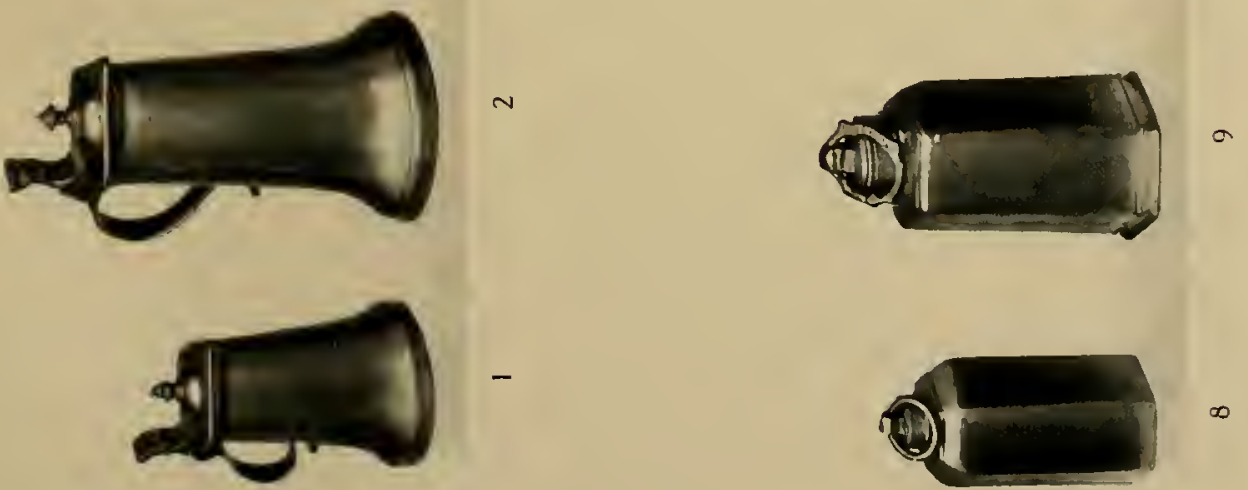

o.

in

$\because \overline{0}$

苞

พั้

要

ㅁ

竞少

io

$=\infty$

: 


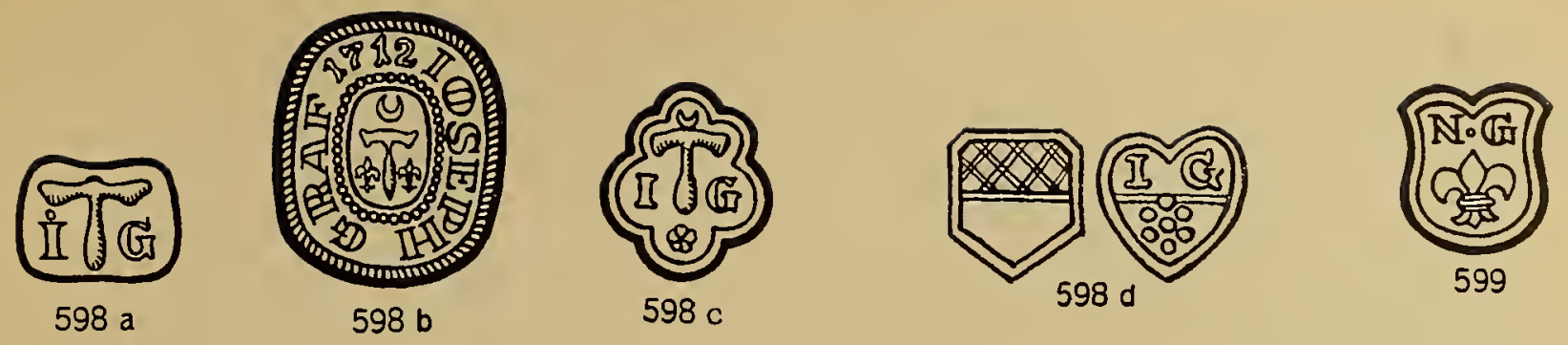

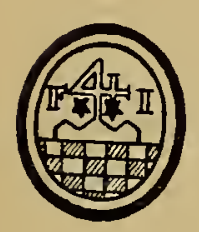

600

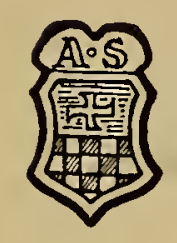

601
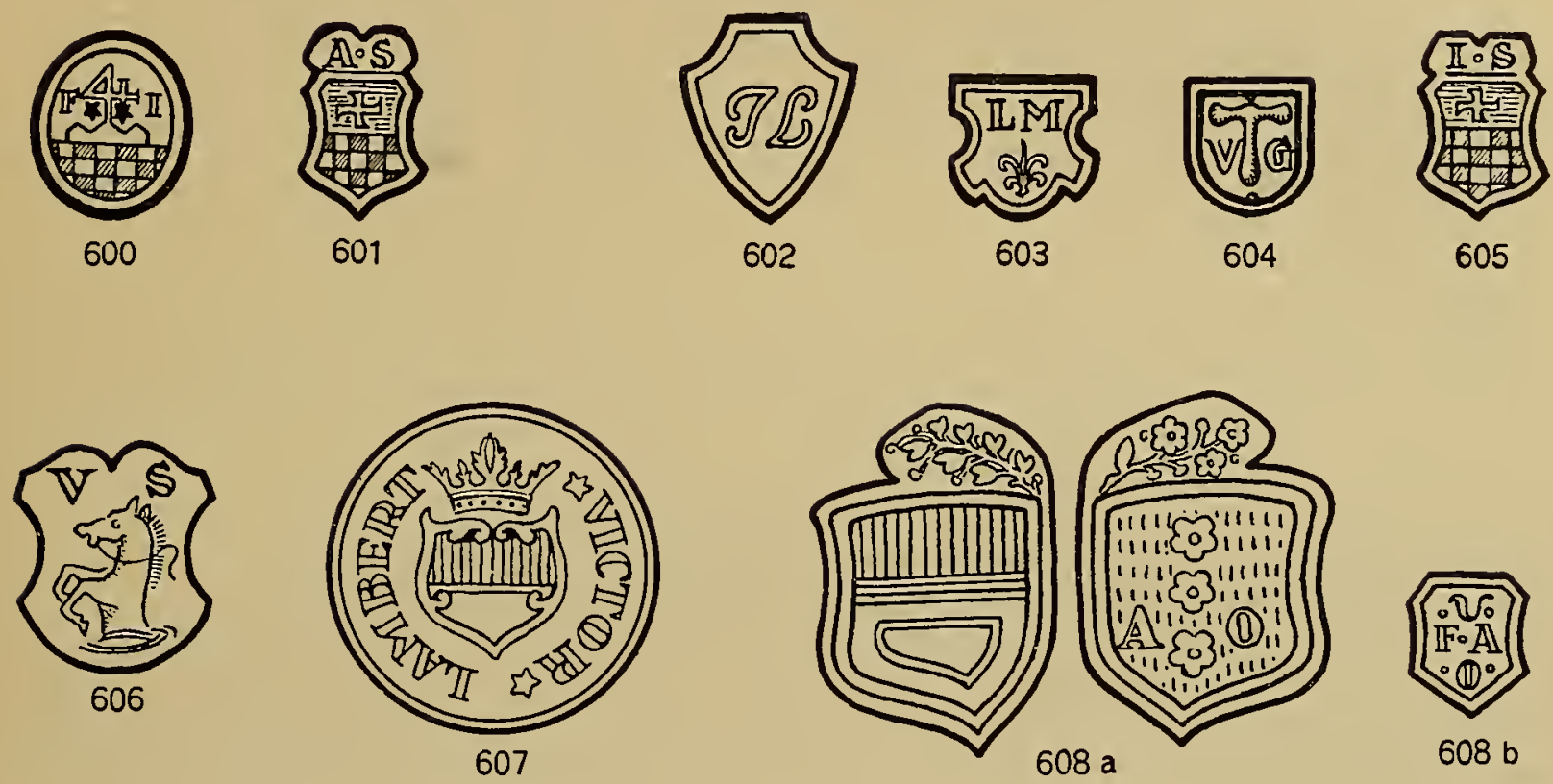



609 a

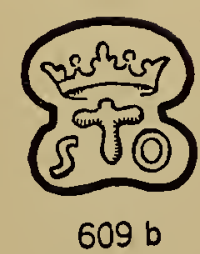

$609 \mathrm{~b}$
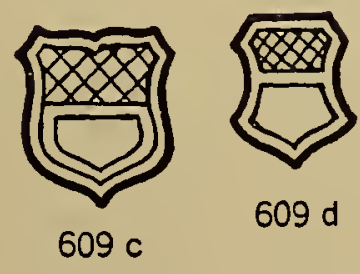

$609 d$
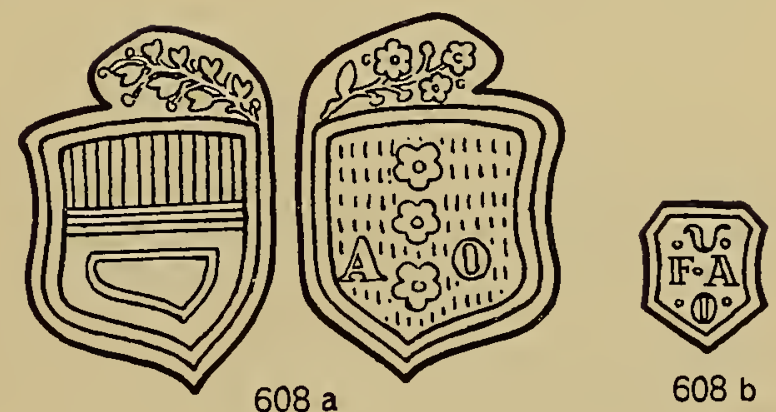

$608 \mathrm{~b}$



609 e

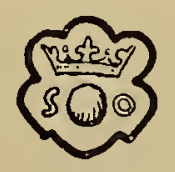

$609 \mathrm{f}$
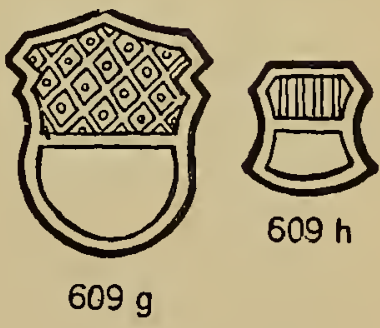

Nr. 609 a-h sind Beschau- und Aichzeichen.

Byss, J. Wilhelm, der Kannengiesser ist uff Johanni ${ }^{1639}$ zum Zunftbruder angenommen worden (Protokoll der Schmiedenzunft). Er führte das Meisterzeichen Nr. 592 a (neues Blatt) oder 592 (Bd. I). Geboren 1611, Bürger 1639, gestorben 1696 (BRuN, Schweiz. Künstlerlexikon, I, S. 250 ).

Gegenstand: Stegkanne mit reliefirtem Henkel. Höhe 3o cm. Durchmesser des Fusses $13 \mathrm{~cm}$. Auf dem Deckelrücken Ueberreste eines reliefirten Ornamentes. Deckel kuppelförmig; in der Mitte ein prominirendes, kreisrundes Plättchen (wie z. B. auch bei Urs und Franz Jaus). Steg mit zwei auseinander laufenden, reliefirten Akanthusblättern; keine Hand. Ausgussteil, Hals und Korpus glatt, ohne Wellen, nut mit circulären Rillenpaaren; Fuss konisch, nicht abgesetzt (reparirt). Oben am Henkel in einem Schildchen 
das Meisterzeichen Nr. 592 (Bd. I) oder Nr. 592 a des neuen Blattes. Der Henkel ist mit eigentümlich verschlungenen reliefirten Bändern und Zacken überzogen. Innen am Boden die Bodenrosette Nr. 610 (Bd. I). Unikum. (Tafel XXXIX, 11.)

Graff, Ghristoph, führte als Meisterzeichen den Lilienstempel Nr. 598 (Bd. II) mit den Initialen C. G. Zitirt als Zeuge 1679 beim Einschreiben des Lehrjungen Conrad Albisser zu Benedict Tscharandi in Solothurn.

Gegenstand: Grosse Breitrandplatte (im Antiquitätenhandel in St. Gallen).

I. B. führte das Meisterzeichen Nr. $59_{2} b$ des neuen Blattes (fehlt in Band I). Ob es sich um Hans Jakob Byss, zünftig 1595, handelt, oder um obigen J. Wilhelm Byss, ist nicht zu entscheiden.

Gegenstand: Teller im Museum von Solothurn. Durchmesser 21,5 cm. Auf einem Eigentumsstempel die Jahrzahl 1640.

Tscharandi, Benedict, Kannengiesser; geboren 1618; gestorben 1687. War auch Vogt zu Gilgenberg (Protokoll der Schmiedenzunft). Lehrlinge : ${ }_{16} 6{ }_{2}$ Wilhelm Jaus und ${ }_{16} 69$ Conrad Albisser.

W. G. führte die Meisterzeichen Nr. 599 (Bd. I) und $593 a$ und $b$ des neuen Blattes. Auf datirter Kanne die Jahrzahl 1679. Vielleicht ein Giesser Namens Graff.

Gegenstand: Stitze von $1 / 2$ Maass mit Bartmann-Maske, in der Sammlung Senn, Zofingen. Als Deckelgriff ein Akanthusblatt. In der Mitte des Deckels ein kreisrundes, prominirendes Plättchen. Der Deckel des Ausgusschnabels hat Herzform. Der Bartmannkopf ist verhältnismässig sehr gross. Vorn am Korpus die gravirten Initialen :

\begin{tabular}{l|l} 
H. I G & V V A
\end{tabular}

$16 \quad 79$

Gravirte Wappen mit Wappen mit quergestelltem stehendem Löwen

Meisterzeichen Nr. 599 (Bd. I), 593 a des neuen Blattes

Ovales Plättchen für Messkännchen im Museum von Solothurn, trägt das Meisterzeichen Nr. $593 b$ des neuen Blattes. Länge $27 \mathrm{~cm}$, Breite $21 \mathrm{~cm}$. Reich gravirt mit Blattund Blumenranken.

Gritz, Heinrich, Zinngiesser, wird Zunftbruder 1679 (Protokoll der Schmiedenzunft) " auf dem Neujahrsbott 17. Christmonat 1679 für ein Zunftbruder angenommen, soll gäben $18 \mathrm{Kr}$. $2 \mathrm{lb}$. wachs ".

Jaus, Urs, Zinngiesser, führte als Meisterzeichen Nr. 595, 596 (Bd. I) resp. Nr. $594 a, b, c$ und $\partial$ des neuen Blattes. Er wurde im Jahre 1688 Vierer, d. h. er wurde in den engern Rat einer löblichen Meisterschaft der Zinngiesser gewählt. Als solcher amtirte er auch 1707, 1711, 1712, 1726. Als Lehrlinge hatte er: Franz Josef Jaus, sein Sohn, 1710, ledig und los gesprochen; Franz Josef Graff von Baden, 1712; Abraham Löw, 1707-1711, später Meister in Burgdorf; Franz Antoni Jaus, seinen Sohn, 1711 ledig gesprochen; Germond Peruly aus Freiburg, Lehrling 1718-1720 (s. Freiburg); Samuel Josef Broije von Stäffis, 1727. Der Meister Urs Jaus starb ca. 1731.

Zusammen mit der Meistermarke Nr. $594 a$ und $b$ findet man das Stadtzeichen $609 c$. Mit der Meistermarke Nr. $594 c$ und $\partial$ zusammen findet man das Stadtzeichen $609 f$. - Als Bodenrosette hatte er Nr. 612 (Bd. I).

Gegenstände: Schnabelstitze. Höhe $28,3 \mathrm{~cm}$, Durchmesser des Fusses 14,7 cm. Als Deckeldrücker ein Akanthusblatt. In der Mitte des Deckels prominirendes, kreisförmiges Scheibchen. Am Henkel das Meisterzeichen Nr. 594 a resp. 595 (Bd. I). Korpus glatt, mit einigen circulären Linien. (Sammlung C. Hirsbrunner, Luzern, und L. Gally, Basel.) Schnabelstitze. Höhe $28,5 \mathrm{~cm}$, Durchmesser des Fusses 14,5 cm. Deckeldrücker ein Akanthusblatt. Oben am Henkel das Meisterzeichen Nr. 596 (Bd. I) resp. Nr. $594 b$ des neuen Blattes. Am Korpus zwei Linienpaare; dazwischen ein feingravirtes vierteiliges Wappen. Im Kannenboden die Rosette Nr. 612 (Bd. I). (Tafel XXXIX, 10.) 
Runde Schale. Durchmesser $24 \mathrm{~cm}$, mit dem Meisterzeichen Nr. $594 c$ (neues Blatt), befindet sich in der Sammlung von J. Simmen in Solothurn.

Runder Teller. Durchmesser 21,5 cm, mit dem Meisterzeichen Nr. $594 \partial$ (neues Blatt), befindet sich in der Sammlung von J. Simmen in Solothurn. - Eine runde Schüssel, Durchmesser 28,5 cm und ein schmalrandiger Teller, Durchmesser 23,5 cm, ebenfalls mit dem Meisterzeichen Nr. $594 \partial$, im Museum in Solothurn.

Bauchige Kanne, mit circulären Perlstäben am Fuss, am obern Drittel des Korpus und am untern Rand des Deckels.

(Tafel XL, 1.)

Meyer, Wolfgang, Zinngiesser, führte das Meisterzeichen $\mathrm{Nr}$. 600 (Bd. I) resp. Nr. 595 des neuen Blattes. Er wurde 1665 geboren, wurde 1693 Vierer, amtirte als solcher 1707, 1711 und 1712. Starb 1720. Als Bodenrosette verwendet er Nr. 615 (Bd. I).

Gegenstände: Schnabelstitze. Höhe $27,8 \mathrm{~cm}$; Durchmesser des Fusses $15 \mathrm{~cm}$. Als Deckeldrücker ein Akanthusblatt; in der Mitte des Deckels eine flache, kegelförmige Erhöhung. Flacher, dreieckiger Schnabeldeckel; darauf das Meisterzeichen Nr. 600 (Bd. I) resp. 595 des neuen Blattes. Schnabel mit Tremolirstich eingefasst. Oben und unten am Korpus je ein feines Linienpaar. Vorne die gravirten Initialen I. W. Innen am Boden die Rosette Nr. 615 (Bd. I).

Schnabelstitze. Höhe 22,5 cm; Durchmesser des Fusses 11,6 cm. Als Deckeldrücker Akanthusblatt. Deckel wie bei der Vorigen. Auf dem flachen Schnabeldeckel das Meisterzeichen $\mathrm{Nr}$. 6 oo (Bd. I) resp. Nr. 595 des neuen Blattes. Oben und unten am Korpus je ein tiefes Rillenpaar. Vorn die gravirten Initialen H A und HV A. Bodenrosette Nr. 615 (Bd. I).

Schnabelstitze. Höhe 20,6 cm; Durchmesser des Fusses 11,6 cm. Als Deckeldrücker ein Akanthusblatt. Auf dem Schnabeldeckel das Meisterzeichen Nr. 600 (Bd. I) resp. Nr. 595 des neuen Blattes. Oben und unten an der Kanne je ein circuläres Rillenpaar. Vorn gravirte Initialen L L, dazwischen eine Sanduhr und darunter die Jahrzahl 1709. Innen am Boden die Rosette Nr. 615. (Tafel XXXIX, 9.)

Stitze mit Bartmannmaske im historischen Museum von Bern, mit der Jahrzahl 1706. Stitze mit Bartmannmaske. Höhe $16,6 \mathrm{~cm}$; Durchmesser des Fusses 9,7 cm. Als Deckeldrücker ein Akanthusblatt. Auf dem Schnabeldeckel das Meisterzeichen Nr. 6oo (Bd. I). Bartmannmaske stark abgenutzt. Oben und unten am Korpus ein Linienpaar. Bodenrosette Nr. 615 (Bd. I).

Arnold-Obrist, Franz, Zinngiesser, führte das Meisterzeichen Nr. 596 des neuen Blattes von Solothurn; auf demselben ist der volle Namen ausgeschrieben. Er wurde 1696 zünftig.

Gegenstand: Messkännchenplatte mit dem Meisterzeichen Nr. 596 des neuen Blattes. Sammlung J. Simmen, Solothurn.

B. S. B. S. führte als Meisterzeichen Nr. $597 a$ und $b$ des neuen Blattes von Solothurn. Fehlt in Band I.

Gegenstände: Breitrandteller von 22,8 cm Durchmesser; Rand hinten verstärkt. Unterseite gehämmert. Trägt das Meisterzeichen Nr. 597 a. Im Museum von Solothurn. Giessfass in Eichelform, trägt das Meisterzeichen Nr. 597 . Sammlung J. Simmen in Solothurn.

Graff, Joseph, Zinngiesser, führte die Meisterzeichen Nr. 597 (Bd. I) resp. Nr. $598 a, b$ und $c$ des neuen Blattes von Solothurn (Bd. II). Laut Protokoll der Schmiedenzunft trat er im Jahre 1703 in dieselbe ein; 1704 wurde er Vierer und amtirte als solcher 1707, 1711, 1712, 1724, 1737, das letzte Mal als " Hauswirth ". Er wurde im Jahre 1685 geboren und starb 175o. Er hatte folgende Lehrlinge: Jost Frey von Münster, 1729-1732; Josef Rue von Steffis, 1734-?; Franz Josef Krutter, von Solothurn, 1740-1743.

Als Bodenrosette in den Kannen verwendete er Nr. 613. Das Meisterzeichen Nr. $598 c$ in Verbindung mit $\mathrm{Nr} .609 e$.

(Tafel XL, 2.) 
Gegenstände: Bartmann-Stitze. Höhe $26,8 \mathrm{~cm}$. Durchmesser des Fusses 14,8 cm. Als Deckeldrücker ein Akanthusblatt; in der Mitte des Deckels flache kegelförmige Erhöhung. Auf dem dreieckigen Schnabeldeckel das Meisterzeichen Nr. 597 (Bd. I) resp. 598 a des neuen Blattes. Als Schnabel ein Bartmannkopf. Oben und unten am Korpus je ein Rillenpaar; unterhalb des Schnabels die Initialen H AE. V. S. Keine Bodenrosette. (Tafel XXXIX, 12.)

Bartmann-Stitze. Höhe $21 \mathrm{~cm}$. Durchmesser des Fusses $12 \mathrm{~cm}$. Als Deckeldrücker ein Akanthusblatt. In der Mitte des Deckels flache, kegelförmige Erhöhung; darum herum ein Rillenpaar. Auf dem dreieckigen Deckel des Schnabels das Meisterzeichen Nr. 597 (Bd. I). Am Korpus einige circuläre Linien. Unterhalb des Bartmannkopfes die Initialen V B K. Keine Bodenrosette.

Bartmann-Stitze. Höhe 21,8 cm. Durchmesser des Fusses 11,8 cm. Als Deckeldrücker ein Akanthusblatt. In der Mitte des Deckels eine flache, kegelförmige Erhöhung; darum herum eine feine kreisförmige Linie. Am Deckelsteg und am Ansatz des Schnabeldeckels Verzierungen im Tremolirstich. Auf dem Schnabeldeckel das Meisterzeichen Nr. 597 (Bd. I). Sehr gut erhaltener Bartmannkopf als Ausguss. Oben und unten am Korpus je ein Rillenpaar. Innen am Boden die Rosette Nr. 613. (Tafel XXXIX, 13.)

Schnabelstitze. Höhe $16 \mathrm{~cm}$. Durchmesser des Fusses $9 \mathrm{~cm}$. Als Deckeldrücker ein Akanthusblatt. Deckel flach, kuppelförmig. Auf dem Schnabeldeckel das Meisterzeichen Nr. 597 (Bd. I). Oben und unten am Korpus ein circuläres Linienpaar. Keine Bodenrosette. (Tafel XXXIX, 15.)

Bartmann-Stitze. Höhe 16,6 cm. Durchmesser des Fusses 9,7 cm. Als Deckeldrücker ein Akanthusblatt ; in der Mitte des Deckels flache kegelförmige Erhöhung. Keine Meisterzeichen, aber das gleiche Bartmann-Modell wie die drei vorigen Bartmannstitzen. Keine Bodenrosette. Oben am Korpus zwei tiefe Rillenpaare, unterhalb der Mitte und zu unterst je ein tiefes Rillenpaar. Unterhalb des Bartmannkopfes die Initialen I. I. N. K. (Tafel XXXIX, 14.)

Runde Schüssel mit profilirtem Rand. Durchmesser $32 \mathrm{~cm}$. Am Rande fein gravirtes Doppelwappen. Meisterzeichen Nr. $598 c$ des neuen Blattes von Solothurn. Sammlung J. Simmen, Solothurn.

Ovales Plättchen. Maasse $29 \times 21 \mathrm{~cm}$. Trägt das Meisterzeichen Nr. $598 b$ des neuen Blattes. Sammlung J. Simmen, Solothurn.

Runder, schmalrandiger Teller. Durchmesser ${ }_{2} 3,5 \mathrm{~cm}$. Rand profilirt, mit einem gravirten Wappen. Museum Solothurn.

Auf einem gewöhnlichen Teller von $23,5 \mathrm{~cm}$ Durchmesser, mit profilirtem Rand, befindet sich eine weitere Stempel-Variante : in einem herzförmigen Schilde befinden sich in der obern Hälfte die Initialen I. G., in der untern Hälfte sieben Punkte in sternförmiger Anordnung. Nr. 598 d (Bd. II).

Gritz, Niklaus, Zinngiesser, führte das Meisterzeichen Nr. 599 des neuen Blattes. Geboren 1685, wurde er 1710 Meister. Er starb im Jahre 1755. Er war auch Vierer und amtirte als solcher 1712 und 1737 (Protokoll der Schmiedenzunft).

Gegenstand: Schüssel mit Handgriffen, Durchmesser mit den Griffen $17,5 \mathrm{~cm}$. Die Schüssel trägt das Meisterzeichen Nr. 599 des neuen Blattes. Sammlung J. Simmen in Solothurn.

Schwaller, J. Anton, Zinngiesser, führte das Meisterzeichen Nr. 607 (Bd. I) resp. Nr. 601 des neuen Blattes. Sein Vater war der Goldschmied Antoni Schwaller in Solothurn. Der Zinngiesser war im Jahre 1685 geboren und wurde ungefähr 1708 oder 1709 Meister. Fehlt bei Protasius.

Meisterzeichen Nr. 601 des neuen Blattes in Begleitung mit Nr. $609 c$ und $\partial$. Gegenstand: Giessfass mit aufstülpbarem Deckel, der mit zwei Knöpfen bekrönt ist. An der Rückwand des Deckels das Meisterzeichen Nr. 607 (Bd. I) resp. Nr. 6o1 des neuen Blattes. Am untern Rand des Deckels und des Unterteils ein $11 / 2 \mathrm{~cm}$ breites 
TAFEL XXXIII
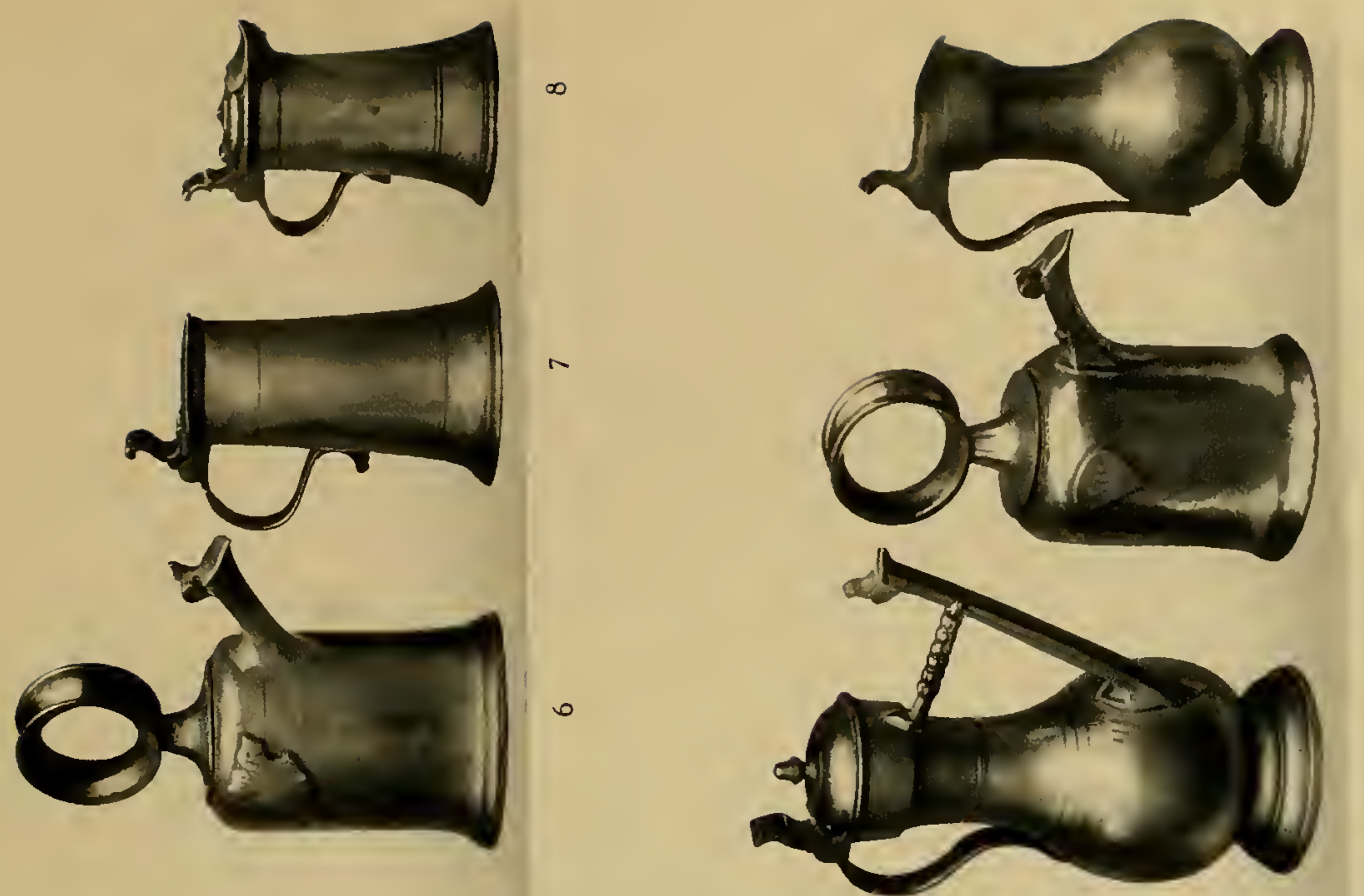

号

$\stackrel{-7}{5}$
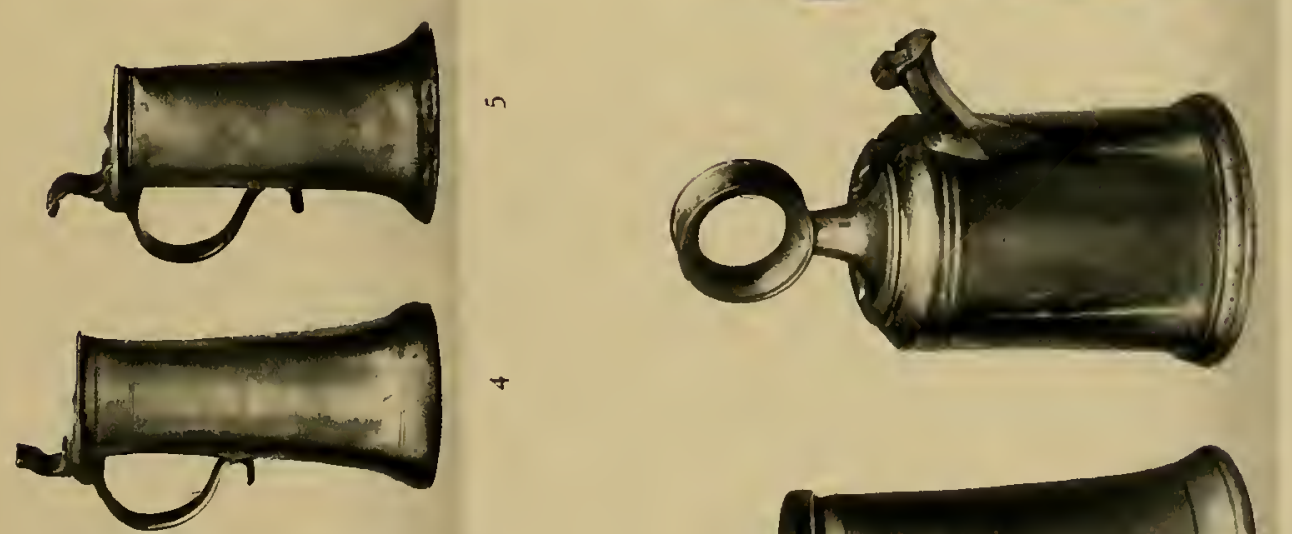

ㄴ

E

a. $\frac{20}{3}$

$\pm$

ป ․ㅡㄹ

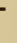

๓ं

咅

촐

$\underline{2}$

또

ㅇํำ

a

至

응

(

$\simeq$

$\begin{array}{ll}0 & \\ 0 & 0 \\ 0 & x \\ 3 & \infty\end{array}$

0 :

$=$ in

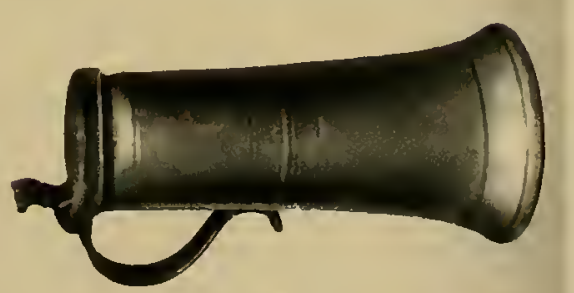

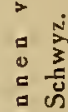

$=$
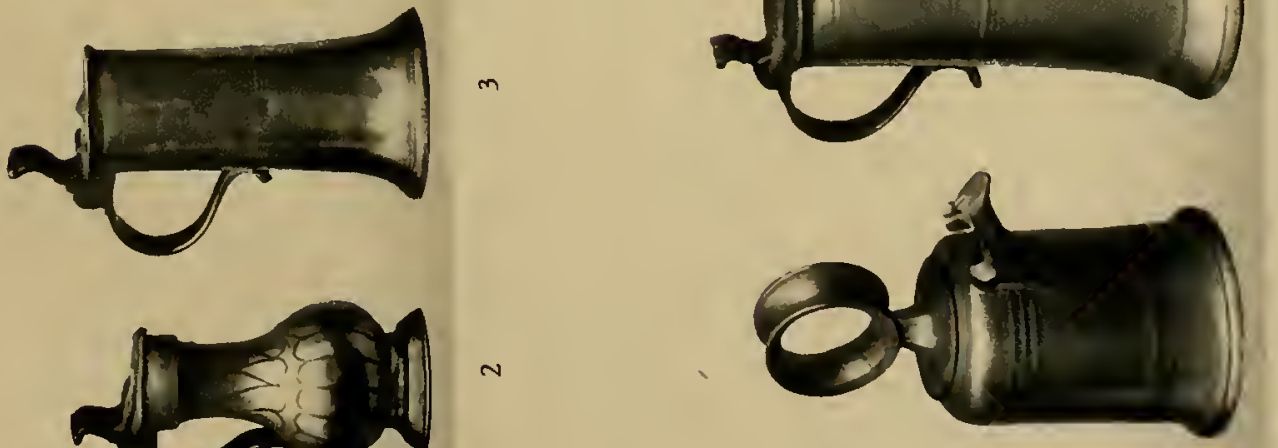

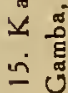

mi

$=$ :

i

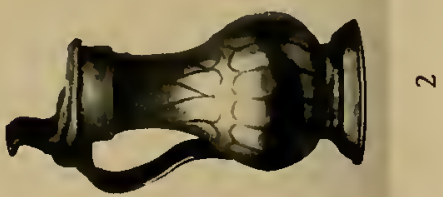

오

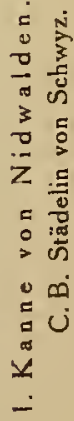
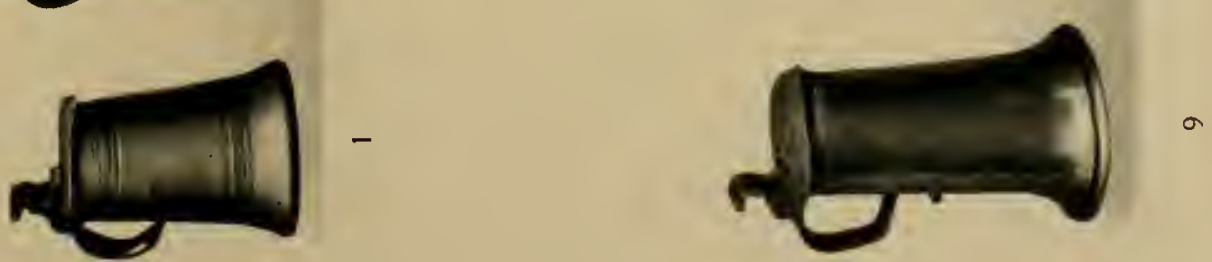

reliefirtes Band mit Kreisen und Strichen. In der Mitte der vordern Seite des Deckels, im Reliefbande ein Wappen und die Initialen D G. In der Sammlung von J. Simmen in Solothurn.

Jaus, Franz-Josef, Zinngiesser, führte als Meisterzeichen Nr. 6o2, 603 (Bd. I) resp. Nr. 600 des neuen Blattes. Er war der Sohn des Urs Jaus, lernte bei seinem Vater und wurde 1710 ledig- und losgesprochen. Sein Meisterzeichen, Nr. 600 des neuen Blattes, findet sich in Begleitung der Stempel Nr. $609 c$ und $609 f$. Als Lehrlinge hatte er: Peter Miller (Molitor) von Freiburg, 1727 ; Josef Schwaller von Solothurn, der Stiefsohn des Franz Jaus, ab $173_{2}$ und arbeitete bei ihm bis 1737 .

Gegenstände: Bartmann-Stitze. Höhe $28,3 \mathrm{~cm}$; Durchmesser des Fusses $14,3 \mathrm{~cm}$. Als Deckeldrücker ein breites Akanthusblatt. In der Mitte des Deckels eine kreisrunde, prominirende Platte. Schnabeldeckel herzförmig, gewölbt. Eigener, von den frühern Bartmannköpfen stark verschiedener Maskaron. Am Henkel das Meisterzeichen Nr. 6o2 (Bd.I) resp. Nr. 600 (neues Blatt), in Verbindung mit dem Solothurnerwappen Nr. 6o9 $c$ (neues Blatt). Korpus durch zwei circuläre Linienbänder in drei gleiche Teile gegliedert. Bartmannkopf mit Tremolirstich eingefasst. Keine Bodenrosette. Kabinetstück.

Runde Schale, Durchmesser 24,2 cm. Am Rand ein breiter Perlstab; Seitenwand der Schale gross-gebuckelt; Tiefe 2,8 cm. Am Boden innen ein feingravirtes, vierteiliges Wappen mit Krone und Bändern. Rückseite der Schale gehämmert. Am Boden das Meisterzeichen Nr. 603 (Bd. I) resp. Nr. 600 in Verbindung mit Nr. $609 f$ des neuen Blattes von Solothurn. (Tafel XVIII, 13.)

Jaus, Josef Antoni, Sohn des Kannengiessers Urs Jaus, lernte beim Vater, wurde 1711 ledigund losgesprochen. Am 27. Dezember 1719 wurde er zünftig, amtirte als Vierer 1734 . Er starb 1736.

Gritz, Philipp, Kannengiesser, geboren 1696, verehelichte sich mit Magdalena Reinhard.

Lambert, Joseph, führte das Meisterzeichen Nr. 602 des neuen Blattes, tätig zwischen $1710-30$;

Meyer, Ludwig, Zinngiesser, führte das Meisterzeichen Nr. 603 (neues Blatt), wurde ${ }_{17} 3_{1}$ zünftig, amtirte als Vierer $17^{3-1737}$. Er wurde im Jahre 1700 geboren und starb 1780. Gegenstand: Runde Schüssel mit schmalem, profilirtem Rand. Durchmesser 32,5 cm. Gravirung: Halbmond, Blattzweige und Besitzerinitialen. Sammlung J. Simmen in Solothurn.

Schwaller, Joseph, Zinngiesser, führte als Meisterzeichen Nr. 606 (Bd. I) resp. Nr. 605 (neues Blatt). Er wurde 1722 geboren als Sohn des Zinngiessers Joseph Anton Schwaller; lernte bei seinem Stiefvater Franz Josef Jaus von 1732-1737. Er war mit der Tochter Helena, des Zinngiessers Joseph Antoni Jaus verheiratet. Er starb 1783. Das Meisterzeichen Nr. 605 oft in Verbindung mit Nr. $609 c, \partial$ oder $f$.

Gegenstände: Runde Schale von 23,5 cm Durchmesser. Am Boden Ornamente im Tremolirstich. Seitenwand radiär gerippt. Sammlung von J. Simmen in Solothurn. Meisterzeichen Nr. 605 (Bd. I).

Messkännchenplättchen in der Sammlung J. Simmen, Solothurn.

Giessfass. Höhe $35 \mathrm{~cm}$; Breite (ohne Henkel) $25 \mathrm{~cm}$, mit Henkel $33 \mathrm{~cm}$. Der untere Rand des aufstülpbaren Deckels und der untere Rand des Giessfasses ist mit einem 1,5 cm breiten reliefurten Band eingefasst, das mit Blumen- und Blattranken ausgefüllt ist. Auf dem Deckel ein Pinienzapfen als Griff. An der Hinterwand des Deckels zwei Mal das Meisterzeichen Nr. 606 (Bd. I) resp. Nr. 605 des neuen Blattes. Der Ausguss steckt im Rachen eines Löwenkopfes; der Hahnen hat die Form einer französischen Lilie. (Tafel XXIV, 6.)

Schwaller, Victor Joseph, Zinngiesser, führte das Meisterzeichen Nr. $6 \circ 9$ (Bd. I) resp. Nr. 606 des neuen Blattes. Zitirt 1757 als Lehrmeister des Hans Jakob Bengg von Zug.

Gegenstand: Zinnernes Handbecken, zu obigem Giessfass (s. Joseph Schwaller). Länge oder Tiefe 22,8 cm; Breite 29,4 cm; Höhe der Rückwand 19,4 cm. Die Rückwand 
und der Vorderteil sind oben und unten mit einem 1,5 cm breiten Reliefband eingefasst, welches mit Blumen- und Blattranken ausgefüllt ist. An der Vorderseite der Rückwand zwei Mal das Meisterzeichen Nr. 609 (Bd. I) resp. Nr. 606 des neuen Blattes. An jeder Seite ein geschwungenes breites Zinnband als Traghenkel.

Graff, Urs Victor, Zinngiesser, führte das Meisterzeichen Nr. 598 (Bd. I) resp. Nr. 604 des neuen Blattes. Er ist der Sohn des Meisters Joseph Graff, und wurde im Jahre 1713 geboren und starb 1791. Er war auch Zeugwart. Er verkaufte meist ungestempelte Kannen, welche aber an dem meisterhaft modellirten Bartmannkopfe doch erkennbar sind. Gegenstände: Bartmann-Stitze. Höhe 29,5 cm; Durchmesser des Fusses $14,5 \mathrm{~cm}$. Als Deckeldrücker ein Akanthusblatt. In der Mitte des Deckels eine kleine kegelförmige Erhöhung. Auf dem dreieckigen Schnabeldeckel das Meisterzeichen Nr. 598 (Bd. I) resp. Nr. 604 des neuen Blattes. Grosse Bartmannmaske "mit Hut ». Korpus glatt; 2 cm oberhalb des Fusses eine circuläre Rille. Vorn am Korpus die Besitzer-Initialen I. GI. Keine Bodenrosette.

Bartmann-Stitze. Höhe 28,4 cm; Durchmesser des Fusses 14,3 cm. Als Deckeldrücker ein Akanthusblatt. In der Mitte des Deckels kleine kegelförnige Erhöhung und darum herum vier circuläre Linien. Keine Meistermarke. Grosse Bartmannmaske mit "Hut ", eingefasst in Tremolirstich. Darunter eine fein gravirte achtzackige Blume mit sechs Blättern. Oben und unten am Korpus circuläre Rillenpaare. Keine Bodenrosette. (Tafel XXXIX, 12.)

Lambert, Victor, Zinngiesser, führte das Meisterzeichen Nr. $60_{7}$ des neuen Blattes (fehlt in Band I) und war in der zweiten Hälfte des XVIII. Jahrhunderts tätig. Datirte Gegenstände von 1760 .

Gegenstände: Suppenschüssel mit dem Meisterzeichen Nr. 607 und eine Platte in der Sammlung von J. Simmen in Solothurn.

Arnold-Obrist, Urs Friedrich, führte die Meisterzeichen Nr. 608 and $b$ des neuen Blattes; ausserdem einen Engelstempel mit der Inschrift: Englisch Block Zin. F. Arnold Obrist. Er wurde im Jahre 1739 geboren; seine Haupttätigkeit fällt in die Jahre 1672-180o. Er wurde im Jahre 1773 Grossweibel und starb 1810 als Zunftwirt zu Schützen (BRUn, Schweiz. Künstler-Liexikon, I, S. 52).

Gegenstände: Runde Schüssel. Durchmesser 3o, $1 \mathrm{~cm}$; mit profilirtem Rand. Meisterzeichen Nr. 608 a des neuen Blattes von Solothurn. Sammlung von J. Simmen, Solothurn. Ein zweites Exemplar im Museum von Solothurn.

Giessfass, kastenförmig mit senkrechter Gliederung. Auf dem Deckel zwei aufgelötete Delphine. Meisterzeichen Nr. 6086 des neuen Blattes. Museum von Solothurn.

Ovales Plateau, Maasse : 29,3 cm Länge zu 20,5 cm Breite. Rand mit RokkokoOrnamentik. Meisterzeichen : Engelmarke mit dem Meisternamen. Sammlung J. Simmen in Solothurn.

Schwaller, Niklaus Joseph, Zinngiesser; wurde im Jahre 1769 geboren; er wanderte aus und liess sich in Lyon nieder. Er ist der Legatär der Schwaller-Stiftung.

Gegenstand: Stitze ohne Schnabel. Höhe $30,3 \mathrm{~cm}$; Durchmesser des Fusses $14,5 \mathrm{~cm}$. Auf dem Deckel zwei Mal das Zeichen Nr. 601 (Bd. I) resp. $609 b$ des neuen Blattes. Am Henkel der Aichstempel Nr. 604 (Bd. I) resp. 609 des neuen Blattes und die Jahrzahl 1810 . In der Bodenrosette Nr. 614 (Bd. I) finden sich die Initialen N S, welche vielleicht auf Niklaus Schwaller deuten. Sammlung J. Simmen, Solothurn.

Lambert, Urs Victor, Zinngiesser; er wurde im Jahre 1778 geboren, heiratete 1803 und starb in Bern 1843 .

Schaffner, Joseph Fidel, Zinngiesser, "Eingeteilter " (war also vorher heimatlos); verheiratete sich 1814 mit Marie Anna Kiefer. Nach Simmen hat er vier Meisterzeichen.

Lambert, Franz Felix, Zinngiesser, wurde 1797 geboren und siedelte ca. 1835 nach Bern

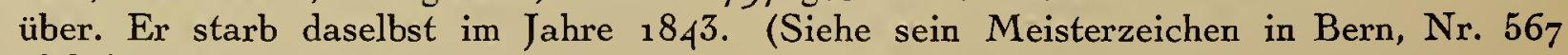
(Bd. I). 


\section{FREIBURG}

Viele archivalische Auszüge verdanke ich dem verstorbenen Freiburger Historiker Max von Techtermann und neuerdings Fräulein Dr. J. Niquille ', Archivarin am Staatsarchiv in Freiburg. Schon aus dem XV. Jahrhundert gibt es vier Ordonnancen, welche sich aber mehr mit Handel, Umgiessen und Proben befassen. Laut der ersten Verordnung vom Jahre 1436 sind die Zinngiesser verpflichtet, alle ihre Arbeiten zu stempeln; 1441 wird weiter bestimmt, dass ausserdem die Probirer ein Gegenzeichen aufschlagen sollen. Die Ordonnance von 1463 dagegen bestimmt, dass nur die Arbeiten in Feinzinn gestempelt werden müssen, nicht aber das übrige Zinn, d. h. die Legirungen. Diese mehr negative Bestimmung hat sich dann bis im XVIII. Jahrhundert forterhalten und dürfte eine der Hauptursachen sein, weshalb man so viele ungestempelte Freiburger Zinngegenstände, besonders auch Kannen findet. Aus dem Jahre 1441 datirt der erste Kannengiesser-Eid.

Die Ordonnance von 1604 (Brown, J. A., Das Zinngiesserbandwerk Jer Schweiz, 1930, S. 66) befasst sich mit dem Verkaufe neuer Zinngegenstände und dem Ankaufe alten Zinnes, in dem Sinne, dass der ganze Handel nur den ortsansässigen Meistern zukomme. Allein auch diesen Bestimmungen wurde nicht nachgelebt, weil die Handhabung der Kontrolle nicht durchgeführt wurde. Dadurch wurde den fahrenden Zinngiessern Tür und Tor geöffnet.

Die Abstempelung der Zinngegenstände erfolgte weitaus in den meisten Fällen nur durch das Meisterzeichen. Die Anbringung des Freiburger Stadtzeichens ist so selten, dass man unter fünfzig Gegenständen kaum einmal diese Marke findet. Das früheste Zeichen dieser Art ist Nr. 645 neben dem Meisterzeichen F F (Meister Franz Fracheboud, zitirt 1725). Etwas häufiger fand ich $\mathrm{Nr}$. 642 neben dem Meisterzeichen des Antoine Klein und Joseph Perret. Das Zeichen Nr.641, V F, Ville de Fribourg, war auf einem gewöhnlichen, schmalrandigen Teller, ohne Meisterzeichen. Der Stempel Nr. 634 fand sich oft auf in Freiburg importirten Zinngegenständen; es ist das Meisterzeichen von Jacques Taudin (siehe Cotterell, Nr. 4651, Taudin, tätig und zitirt von 1680-17oo). Die Marke Nr. 640 ist wahrscheinlich französischen Ursprungs.

Niemals wurde das Standeswappen (quergeteilter, schwarz-weisser Schild) als Beschauzeichen aufgeschlagen. Die bei Naef (S. 14) abgebildete Stegkanne ist keine Freiburger Kanne (im historischen Museum von Bern), sondern eine Ulmer Kanne des Meisters Georg Wilhelm Werlin (zitirt 1652, Hintze, Bd. VII, Nr. 136).

\section{Die Gegenstände}

Die plumpe Form der Freiburger Kannen steht einzig da. Auf einem Korpus in der Form eines Kegelstumpfes sitzt der fast vollkommen cylindrische Hals. Der Ausguss entsteht entweder durch einfaches seitliches Zusammendrücken der obern runden Oeffnung zu einer Herzform oder aber durch Anlöten eines schnabelförmigen Ausgussteiles. Im ersten Falle ist der Deckel herzförmig und flach; im zweiten ist der Deckel kuppelförmig mit dreieckigem Ansatz zum Verschluss des Schnabels. Bei den ältern Kannen ohne Ausgusschnabel ist der obere Rand nicht horizontal, sondern nach vorn ansteigend.

Die Qualität der Legirung ist oft eine bedenkliche. Dadurch leidet auch die Druckfestigkeit der Gegenstände; dieselben geben auf Fingerdruck nach, z. B. besonders bei den Kannen von I. B., Jean Bon. Allerdings war der Letztere wahrscheinlich ein fahrender Zinngiesser, ein richtiger Stümpler oder Magnin.

Teller und Platten von Freiburg weisen keine Besonderheiten auf.

1 Freiburger Staatsarchiv. Première collectioa lois $\mathrm{N}^{\circ} 467$ f. ${ }_{13} 3_{2}\left(1436\right.$ uod $\left.{ }_{1440}\right) ; N^{\circ} 63_{7}$ f. 175 (1463). 


\section{Die $Z$ inngiesser von Freiburg}

Nach den Auszügen des Herrn Max von Techtermann und

Fräulein Dr. J. Niquille, Archivarin am Staatsarchiv in Freiburg.

Heid, Hanns, zitirt 1450 als Kannengiesser sel. (Inventaire des armes vendues à l'arsenal en 1450). (Nach v. Techtermann.)

v. Tirez, Hans, zitirt 1450 (ebendaselbst). (Max v. Techtermann.)

Ysenbart, Hans, zitirt von 1453 bis 1500 .

Crissier, Hanns, zitirt 1497,1500 (Schmiedenzunft). Von Murten gebürtig.

Challandat, Pierre, zitirt 1497 beim Eintritt in die Schmiedenzunft.

Gyr, Hanns, zitirt 1503 beim Eintritt in die Zunft der Kaufleute.

Herbst, Thomas, zitirt 1504; 1508 Bürger; erwähnt bis 1531 (Schweiz. Künstler-Lexikon).

Herd, Hans, der Kantengiesser, tritt in die Zunft (ohne Datum, Abbaye des Maréchaux Nr. 2, f. 318 ).

Bachmann, Hans, Bürger und Mitglied der Schmiedenzunft 1530 .

Steinbrecher, Hensly, der Kantengiesser, tritt als Meister in die Abbaye des Maréchaux (ohne Datum, Abbaye des Maréchaux Nr. 2, f. 322 ).

Reysberger, Veltin, zitirt $1533,1535$.

oder Ertzberger, Välty, wird ${ }_{1537}$ in die Zunft aufgenommen (Abbaye des Maréchaux Nr. 2, f. 388).

Frantz, Philippe, zitirt 1537,1547 (Stadtrechnungen).

Herbst, Ulli, zitirt von 1538-1548 (besonders in den Stadtrechnungen).

Burde, Burdi, Jacques, zitirt 1543-1557 (Schweiz. Künstler-Lexikon).

Jörg von Bern, der Kantengiesser, wird Mitglied der Abbaye des Maréchaux ${ }_{15} 55$ (Abbaye des Maréchaux Nr. 2, f. 274.)

Tschiepo, Hanns Ulrich, 1546 in der Schmiedenzunft; erscheint bis 1567 in den Stadtrechnungen.

Boden, Niklaus, der Kantengiesser, wird als Meister aufgenommen (ohne Datum, Abbaye des Maréchaux Nr. 2, f. 325).

Buschi, Hans, zitirt 1564 als Mitglied der Schmiedenzunft; zitirt als Kantengiesser (Abbaye des Maréchaux Nr. 2, f. 413 ).

Tschiepo, Niklaus, zitirt 1566 als Mitglied der Schmiedenzunft.

Schönhand, Hanns, zitirt 1568 als Mitglied der Schmiedenzunft.

Graillex, Jakob, fondeur d'étain; 1573 Bürger (AEF. RN 158, f. 135).

Tschiepo, Peter, zitirt $1575-1591$ in den Stadtrechnungen.

Wuilleret, Adam, 1576, Mitglied der Schmiedenzunft; zitirt in den Stadtrechnungen bis 1613.

Stadtkantengiesser.

Von Viffis, Peter, zitirt 1602 als Mitglied der Schmiedenzunft.

Wuilleret, Anthoni, zitirt von 1604 bis 1630 . Stadtkantengiesser.

Boine, Olivier, zitirt 1667,1670 .

Villeneufe, Pierre, war bis 1674 in Faoug bei Avenches. Siehe bei Neuenburg.

Morat, potier d'étain, zitirt 1666, 20. Dezember (AEF Manual Nr. 217, p. 489).

F. B. Vergleiche die Meisterzeichen Nr. 619, 631, 636. Ob Franz Blasi, aus Freiburg, ist fraglich (Siehe bei Obwalden).

Gegenstand: Sechskantige, pyramidenförmige Schnabelstitze. Höhe $35 \mathrm{~cm}$; Durchmesser des Fusses 19,5 cm. Abgekröpfter Deckeldrücker. Der sechsseitige Deckel ist kuppelförmig und endigt in der Mitte in einem Knopf mit zwei Etagen. Auf dem Deckel die eingeschlagenen Initialen NVG. Der dreieckige, nach oben steigende Schnabel hat einen herzförmigen Deckel. Am kräftigen Traghenkel befindet sich das Meisterzeichen Nr. 619. Korpus sechsseitig-pyramidenförmig. Fussplatte etwas vorstehend. (Tafel XLI, 4.) 

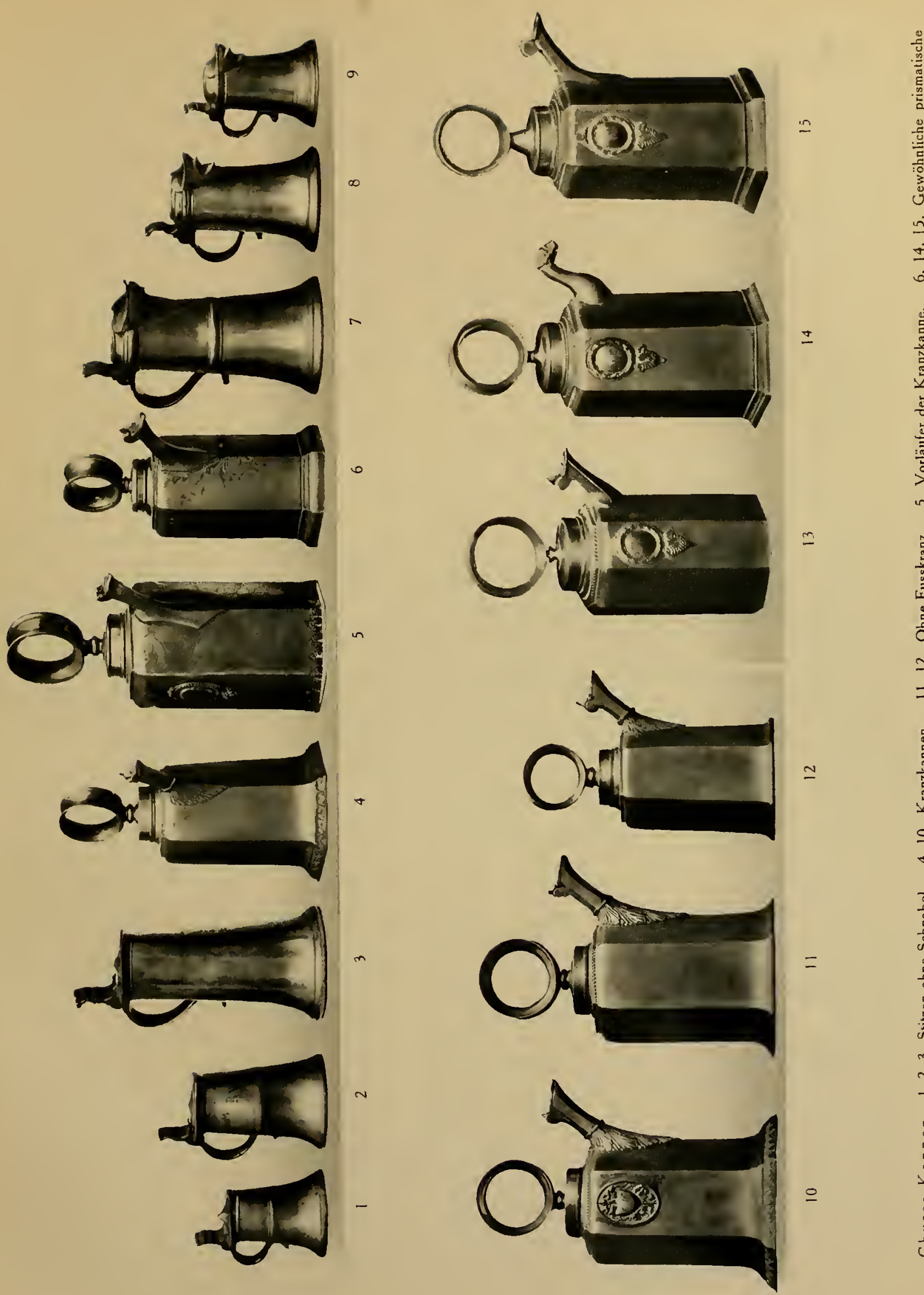

Kerzenstock mit dem Meisterzeichen Nr. 636 im Antiquitätenhandel.

Weihwassergefäss mit dem Meisterzeichen Nr. 631, bei Herrn Max von Techtermann.

Frachebond, Frantz, führte das Meisterzeichen Nr. 645 ; daneben befindet sich das grosse Stadtzeichen von Freiburg, Nr. 645. Erwähnt ${ }^{6} 694$ in der Rechnung der Schmiedenzunft (Abbaye des Maréchaux, Nr. 7, I). Am 31. August ${ }_{1} 695$ wird er zitirt anlässlich der Beerdigung eines Kindes. Im Jahre 1725 liefert er " 12 zinnige thäller zum bruch der coralissen in der Cantnerey " (Kirchmeier-Rechnung). Ferner 1 70o. III.4 : Frantz Fracheboud, der Kantengiesser, mit der Meisterschaft spänig (AEF, Manual Nr. 251, p. 123).

Bernard, Guérrin, (Garrig und Garing), führte die Meisterzeichen Nr. 617,618. Stammt aus Savoyen und wurde $168 \mathrm{o}$ Bürger, nachdem er schon einige Jahre in Freiburg ansässig war (Max v. Techtermann). Als Zeuge erwähnt 1720.III.16, 1721.I.13 (AEF, RN 425). Er wird als " Kantegiesser » zitirt 1735.I. 19 (AEF, Manual Nr. 286, p. 16). Am 1. August 1735 wird er nochmals erwähnt (AEF, Manual Nr. 286, p. 293).

Gegenstände : Stitze ohne Schnabel. Höhe $3_{2}, 8 \mathrm{~cm}$. Durchmesser des Fusses $17,7 \mathrm{~cm}$. Am Deckelgriff zwei Eicheln; Deckel flach, herzförmig; darauf das Meisterzeichen Nr. 618 und die gravirten Initialen E F. Z $Z_{\text {wischen }} \mathrm{Hals}$ und Korpus ein breiter, flacher Wulst. Am Hals und am Korpus circuläre, feine Linien. (Tafel XLI, 3.)

Runde Breitrandplatte mit dem Meisterzeichen Nr. 618.

Schnabelstitze. Höhe $28 \mathrm{~cm}$. Durchmesser des Fusses $14 \mathrm{~cm}$. Als Deckelgriff ein Akanthusblatt. Auf dem kuppelförmigen Deckel ein gerillter Knopf. Der Schnabel reicht bis in den Korpus hinab. Der Deckel des Schnabels ist herzförmig, vorne aufgebogen. Am Traghenkel befindef sich die tief eingeschlagene Meistermarke Nr. 617. Zwischen Hals und Korpus ein flacher Wulst und circuläre Linien. Vorn am Korpus in einem Blattkranz die Initialen I M und $M H_{1713}$. Unten am Korpus circuläre Rillen. Tafel XLI, 6.)

Klein, Anthoine, führte das Meisterzeichen Nr. 625, ferner noch eine Variante mit A K und zwischen den beiden Initialen ein Zinnkrug. Im Livre des Bourgeois wird er als potier d'étain zitirt; "son fils s'appelle Nicolas, inscrit comme bourgeois, le 5 février 1721, peu de temps après la mort de son père " (Max de Techtermann).

Gegenstände: Stitze ohne Schnabel. Höhe $25,7 \mathrm{~cm}$. Durchmesser des Fusses $14,5 \mathrm{~cm}$. Abgekröpfter Deckeldrücker mit gewelltem Steg. Deckel herzförmig. In der Mitte ein prominirender Umbo und circuläre Rillen. Davor das Meisterzeichen Nr. 625 . Der obere Kannenrand steigt nach vorne an und hat einen circulären Wulst. Z Zwischen Hals und Korpus ein breiter Wulst und zwei tiefe Rillen. Korpus glatt. Am Fussteil ein breites, profilirtes Band. Innen im Boden die Bodenrosette Nr. 644 .

Kanne in Walliserform Typ. I. Höhe $27,8 \mathrm{~cm}$; Durchmesser des Fusses $12 \mathrm{~cm}$. Am Deckelgriff zwei Granatäpfel. Ueber dem Deckelsteg die Variante des Meisterzeichens Nr. 625, also A K mit Krug dazwischen. Auf der andern Seite des Deckels ein breiter Aichstempel F 1676. An der Spitze des Deckels die gravirten Initialen I. W. An der Seite des Ausgussteiles das Wappen des Zehnden Conches im Wallis. Hals und Korpus glatt, mit feinen circulären Linien. In der Mitte des Halses ein flacher, fast verlaufender Wulst. Peroulla, Germain, (Peruli, Perolla), führte die Meisterzeichen Nr. 622 and b. "Germond



$622 b$ Peruly von Freiburg im Uechtland " lernt vom 25 . Juli 1718 bis 28 . Juni 1720 bei Urs Jaus in Solothurn (Protokollbuch der Schmiedenzunft in Solothurn). Im Jahre 1726 erscheint er als Zeuge (Notariatsreg. 420, Bl 21 2, 213). Ferner 1730. VIII. 1 als Bürger zitirt (AEF, RN, 396).

Gegenstände: Schnabelstitze. Höhe $30,7 \mathrm{~cm}$. Durchmesser des Fusses $14,1 \mathrm{~cm}$. Als Deckeldrücker ein Akanthusblatt. Auf dem kuppelförmigen Deckel ein kleiner, aufgelöteter Delphin. Der Schnabel reicht bis in den Korpus hinab. Schnabeldeckel herzförmig. Zwischen Hals und Korpus ein kräftiger, circulärer Wulst und viele Rillen. Vorn am Korpus der eingravirte Name I. PON; darunter die Jahrzahl 1742. Korpus glatt, am untern Rand drei circuläre Rillen. Auf dem Traghenkel das Meisterzeichen Nr. 622 b. (Tafel XLI, 2.) 
(Kleine) Schnabelstitze, in gleicher Ausführung. Höhe 13,2 cm; Durchmesser des Fusses $7,8 \mathrm{~cm}$. Als Deckeldrücker ein Akanthusblatt. Auf dem kuppelförmigen Deckel ein spitzer, gerillter Knopf. Zwischen Hals und Korpus ein kräftiger Wulst. Am Korpus die Initialen P N Z (N!). Am Henkel ein Ueberrest des Meisterzeichens.

Suppenschüssel, mit der Jahrzahl 1744 und dem Meisterzeichen 622 a (Couvent de Montorge). - Dreifüssige Schüssel bei den Ursulinerinnen (Max v. Techtermann).

Müller Peter (Molitor, Miller), "Kantengisser », führte das Meisterzeichen Nr. 624. Er tritt am 11. Mai 1727 bei Franz Josef Jaus in Solothurn in die Lehre (Protokoll der Schmiedenzunft in Solothurn). Seit 1738 wird er als Meister erwähnt. In den Stadtrechnungen kommt er bis ${ }_{1784}$ vor (Compte d'Etat Nr. 64b). Tritt ${ }_{17} 3_{2}$ in die Schmiedenzunft (Recettes de l'Abbaye des Maréchaux).

Gegenstand: Stitze ohne Schnabel. Höhe $26,8 \mathrm{~cm}$; Durchmesser des Fusses $14,3 \mathrm{~cm}$. Glatter, abgekröpfter Deckeldrücker. Deckelsteg gewellt (wie bei den Lausanner Kannen). Deckel flach, herzförmig. In der Mitte zwei concentrische Rillenpaare. Davor der Stempel Nr. 624. Zwischen Hals und Korpus ein flacher Wulst. Vorn am Korpus die gravirten Initialen N. ST.

Teller.

Müller, Peter Roman (Pierre Romain), führte ein gleich gezeichnetes Meisterzeichen wie Peter Müller, aber mit den Initialen R M und den Hammer dazwischen. Im Jahre ${ }_{17} 6_{2}$ erneuert er sein Bürgerrecht für sich und seine vier Söhne (AEF. RB, VII, f. 142). Im Jahre 1800 wird er als 6o-jähriger erwähnt, ist also ca. 1740 geboren.

Gegenstand: Platte bei Herrn Max von Techtermann.

Cantin, ...., zitirt 1753-54 : "von dem Zinngiesser Cantin gekaufft 10 blätlein von Englisch zinn für die messkändlein, das stück zu 22 b. 2 s. (AEF, Kirchmeyerrechnung $\mathrm{Nr} .68$ b).

Hayoz, Joseph, Kantengiesser, Sohn des Löwenwirten Peter Hayoz, wird ${ }_{17} 52$ oder 1753 zünftig bei den Schmieden (Abbaye des Maréchaux, Nr. 7, I). 1755 als abwesend zitirt in einer Klage des Meisters Wattel von Neuenburg (AEF, Manual Nr. 3o6, p. 425).

Perret, Joseph führte die Meisterzeichen Nr. 623 $a$ und $b$. Er wird 168o zitirt als Reysmeister der Zunft zu den Schmieden (Abbaye des Maréchaux, Nr. 7, I). Ferner



$623 \mathrm{~b}$ 1693.IX.3o erwähnt als " maître potier d'estaing de Fribourg " (AEF. RN 307, p. 183).

Gegenstände: Grosse Stitze ohne Schnabel. Höhe 34,5 cm. Durchmesser des Fusses $17,8 \mathrm{~cm}$. Abgekröpfter Deckelgriff mit gewelltem Steg. Deckel herzförmig, flach. In der Mitte zwei concentrische Rillen. Darum herum elegant gravirte Blumen- und Blattranken. Auf dem Henkel das Meisterzeichen Nr. $6{ }_{2} 3$ a. Zwischen Hals und Korpus ein dreifach profilirter breiter Wulst. Vorn am Korpus zwischen gravirten $Z$ weigen ein Herz und die Initialen C. ST. Z. 1758. Am untern Teil des Korpus drei feine Linienpaare.

(Tafel XLI, 5.)

Platte, gehämmert, mit dem Freiburger Stadtstempel Nr. $64_{2}$ und dem Meisterzeichen Nr. $623 b$ (Mitteilung von Herrn M. Merian in Malans).

Breitrandplatte. Durchmesser $36 \mathrm{~cm}$ bei $7,3 \mathrm{~cm}$ Randbreite. Rand aussen $1,7 \mathrm{~cm}$ breit profilirt. Rand unten verstärkt. An der Unterseite des Randes die Initialen M. B.S. und das Meisterzeichen Nr. $623 b$.

Burkart, Johann Albrecht, führte das Meisterzeichen ?

Zitirt am 10. January 1774 : "die Ehefrau des Johann Albrecht Burkhart, tollerirten Zinngiesser allhier » (AEF, Manual Nr. 325, p. 2, 117,145 ). Er ist also nur tollerirt (geduldet) und bezahlt dafür 21 baz.; ebenfalls für 1775, 76, 77 (AEF, Abbaye des Maréchaux, Nr. 7, II, Tolleranzen). Michel, Martin, führte das Meisterzeichen Nr. 621 .

Gegenstand: Stitze ohne Schnabel von $1 / 2$ Maass Inhalt. Antiquitätenhandel bei C. Hirsbrunner, Luzern.

P. A. I., führte das Meisterzeichen Nr. 629. 
Gegenstand: Stitze ohne Schnabel. Höhe 20,5 cm. Durchmesser des Fusses 11,3 cm. Abgekröpfter Deckelgriff mit gewelltem Steg. Auf dem Deckel gravirte Rillenpaars, exentrisch angebracht. An der Spitze des flachen, herzförmigen Deckels die Meistermarke Nr. 629 (ohne Engel). Zwischen Hals und Korpus ein kräftiger Wulst und circuläre Rillen. Drei Rillen am obern Kannenrand und vier Rillen unten am Korpus. (Tafel XLI, 7.)

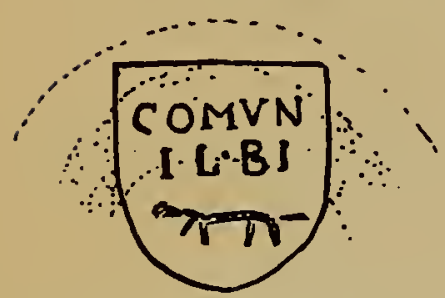

I. L. Meisterzeichen Nr. 626 . Gegenstand: Platte bei Herrn Max von Techtermann. Stitze ohne Schnabel. Höhe $27,2 \mathrm{~cm}$. Durchmesser des Fusses $15 \mathrm{~cm}$. Deckelgriff glatt, abgekröpft; Deckelsteg gewellt. Davor das Meisterzeichen Nr. 626. Am Korpus zwei Linienpaare. Am Fuss breites, profilirtes Band. Eine weitere Stempelvariante ist Nr. 626 a. Auf $1 / 2$ Mass-Stitze (Privat-Besitz in Yverdon).

I. M. Meisterzeichen Nr. 628 und Hintze, Bd. VII, S. 335.

Gegenstand: Teller bei Herrn Max von Techtermann.

C. M. Müller, Christoffel führte das Meisterzeichen $\mathrm{Nr}$. 63o. Er wird als Zinngiesser erwähnt 1759-6o bei den Aufnahmen in die Schmiedenzunft (AEF, Abbaye des Maréchaux, Nr. 7, I). Am 4. Juni 1771 als tot gemeldet (AEF, Manual Nr. 122, p. 23o).

Gegenstand: Teller bei Herrn Max von Techtermann.

M. V. Meisterzeichen Nr. 627 .

Gegenstand: Teller bei Herrn Max von Techtermann.

I. R. F. Meisterzeichen Nr. 635.

Gegenstand: Zinnernes Zifferblatt einer Uhr (bei Herrn Max von Techtermann).

Bigiuli, Sebastien, potier d'étain, zitirt 1800 , von Casale bei Verbano (Langensee), starb alt im Spital zu Freiburg am 6. September 1800.

Alavache, Jean, maistre pottier d'estaint de d'Ouveide, Ittalien (AEF, RN 3o64 f. 15). Albeuve 1. II. 1710 .

Morêt, François, potier d'étain, bourgeois de Bulle, zitirt bei einem Verkauf eines Grundstückes am 28. Februar 1771. (AEF, Manual Nr. 322, p. 97).

George, Jaques, natif d'Avry, fils de Pierre. George, originaire d'Italie, prie de lui octroyer la permission de demeurer dans ce canton et d'y excercer la profession de potier d'étain (melde er sich an einem Orth, wo man ihn wird annehmen wollen, alsdann wird er sich vor M. G. H. H. wieder stellen, um daselbst sich niederlassen und sein Handwerk treiben zu können (1773 I. 13). AEF, Manual Nr. 324, p. 10.

\section{Kannen ohne Meisterzeichen}

Stitze ohne Schnabel. Höhe 27,4 cm. Durchmesser des Fusses 14,5 cm.

Stitze ohne Schnabel. Kannenrand nach vorn in die Höhe steigend. Höhe $20,5 \mathrm{~cm}$. Durchmesser des Fusses 11,3 cm. Innen am Boden die Bodenrosette Nr. 643. Deckelgriff und Steg, sowie die Bodenrosette weisen auf Joseph Perret (Meistermarke Nr. 623 a). (Tafel XLI, 1.)

Stitze ohne Schnabel. Höhe $16,2 \mathrm{~cm}$. Fussdurchmesser $8,8 \mathrm{~cm}$. Zwischen Hals und Korpus ein flacher Wulst und zwei Rillenpaare. Am untern Rand des Korpus ein breiter profilirter Wulst wie bei den Kannen von Anthoine Klein.

Stitze ohne Schnabel. Höhe 14,7 cm. Durchmesser des Fusses 8,6 cm. Zwischen Hals und Korpus nur zwei circuläre Rillenpaare. In der Mitte des Deckels eine circuläre breite Rille.

Stitze ohne Schnabel. Höhe 27,8 cm. Durchmesser des Fusses 14,8 cm. Am Deckelgriff zwei Granatäpfel. In der Mitte des Deckels eine prominirende runde Scheibe. Viele Aichstempel auf dem Deckel, von 70-79. Am Hals und Korpus nur circuläre Rillen. 


\section{BULLE}

Bon, Jean, führte das Meisterzeichen Nr.632; er war voraussichtlich ein fahrender Zinngiesser. Er fabrizirte Kannen in Walliser Form und plumpe Stitzen, meist ohne Schnabel. Das verwendete Material ist aussergewöhnlich bleihaltig und zwar in solchem Grade, dass die Kannenwand mit dem Finger eingedrückt werden kann. Den Jahrzahlen auf den Gegenständen entsprechend, arbeitete er zwischen 1750 und 1800 .

Gegenstand: Kanne in Walliserform, Typ. I. Höhe 31,2 cm; Durchmesser des Fusses 13,5 cm. Am Deckeldrücker zwei Eicheln. Auf dem flachen Deckel das Meisterzeichen Nr. 632. In der Mitte des Halses ein Wulst und zwei Rillenpaare ; ebenso in der Mitte des Korpus.

I. B. Jean Bon, führte das Meisterzeichen Nr. 633.

Gegenstände: Kanne in der Form der Berner Stegkanne. Höhe 31,3 cm; Durchmesser des Fusses 11,6 cm. Als Deckelgriff ein Akanthusblatt. Auf dem kuppelförmigen Deckel ein dünner Etagenknopf mit Spitze. Am Henkel das Meisterzeichen Nr. 633. Ausgussteil bauchig. In der Mitte des Halses ein circulärer profilirter Wulst. Zwischen Hals und Korpus vier breite circuläre Rillen. Am Aequator des Korpus zwei Linienpaare. Lange sechskantige Ausgussröhre mit Deckelchen. Der Steg wird durch einen Arm mit Puffärmel gebildet; ist aber schlecht modellirt.

Stitze ohne Schnabiel. Höhe 3o,7 cm. Durchmesser des Fusses 14,2 cm. Deckeldrücker abgekröpft. In der Mitte des flachen Deckels ein kleiner Kegel und darum herum zwei circuläre Rillen. An der Spitze des herzförmigen Deckels befindet sich das Meisterzeichen Nr. 633. Am cylindrischen Korpus zwei feine circuläre Linienpaare. Fussteil mit starker Ausladung.

Stitze ohne Schnabel. Höhe $22,8 \mathrm{~cm}$. Durchmesser des Fusses $12 \mathrm{~cm}$. Gleiche Ausführung und gleiches Meisterzeichen wie die vorhergehende Kanne.

\section{EST AVAYER (Stäffis, Steffis)}

Weder Gegenstände noch Meisterzeichen von Estavayer sind nachweisbar. Die Rose von Estavayer als Wappen findet sich auf der Zinnmarke Nr. 637; die Zuweisung dieses Stempels ist sehr problematisch.

Reutter (S. 12) zitirt aus den Comptes de la Bourserie, ohne Angabe eines Namens, "le potier d'Estavayer ", 1498 und 1500.

Unter den Lehrlingen in Solothurn finden sich :

Samuel Josef Broije von Stäffis, Lehrling bei Urs Jaus ab 1727 ; Josef Rue von Steffis, Lehrling bei Josef Graff ab 1734 .

Auf Kannen findet man ab und zu eine eingeschlagene Rose. In Estavayer gibt es auch runde Platten mit der "grossen oder kleinen Rose von Estavayer ». Bei den Kannen scheint dieselbe als Aichstempel zu dienen; sonst ist es wohl das Stadtzeichen, z. B. auf Schützenplatten (siehe Nr. $637 a$ und $b$, Bd. II).

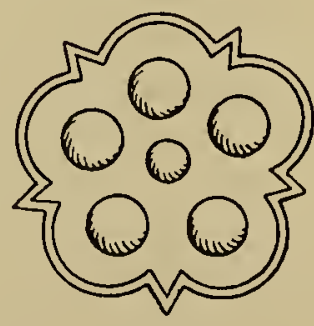

637 a

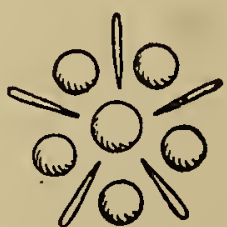

$637 \mathrm{~b}$ 



1. Zuger Kranzkanne von Joachim Michael Keiser in Zug, 1775-1853. 2. Churer Kranzkanne von Heinrich Wilhelm Lange in Chur, tätig 1826- ca. 1850. 3. Churer "Quartkanne" von Mathaeus I. Bauer in Chur, tälig 17j7- ca. 1803. 4. Churer "Quartkanne" von Herkules I. de Cadenat in Chur, tätig 1723-1744 oder noch später? 



\section{MURTEN (Morat)}

Aus Murten stammte Crissier, Hans, welcher im Jahre 1497 Bürger von Freiburg wurde und daselbst sein Handwerk als Kantengiesser ausübte (Freiburg, Bürgerbuch II, Bl. 108 b). Jakob Chattoney, wvird im Jahre 1660 als Zinngiesser in Murten erwähnt und ihm eine Art Rechtsbrief ausgestellt, damit er sich gegen die fahrenden Zinngiesser wehren konnte (J. A. Brown, Das Zinngiesserbandwerk der Schweiz, S. 70).

Die prächtigen Stadtsannen von Murten (Tafel V, 3) tragen das Meisterzeichen von Pierre Villeneufve (vor 1674 einige Jahre in Faoug bei Avenches, ab 1674 in Neuenburg und $a b{ }_{1} 696$ in Bern tätig). Die Kannen befinden sich im Museum von Murten; sie haben die Form der Berner Stegkanne, aber mit eigentümlichen Abänderungen. An der Seite befindet sich in Reliefguss das Wappen von Murten, ein steigender bekrönter Löwe; der Steg läuft vorn in eine abnorm grosse Hand aus, welche die Ausgussröhre umfasst. Der Deckelgriff wird von einem mächtigen Knopf gebildet. Neben dem gewöhnlichen Henkel ist noch ein grosser beweglicher Traghenkel vorhanden. Die Höhe der Kannen beträgt $41,2 \mathrm{~cm}$.

Fizaula, David. Die datirten Kannen und Platten tragen die Jahrzahlen 1740-60.

Stadtwappen von Murten (steigender bekrönter Löwe) auf einer Freiburger Stitze ohne Schnabel. Höhe $27 \mathrm{~cm}$; Durchmesser des Fusses $14,8 \mathrm{~cm}$. Deckeldrücker schwach abgekröpft; Deckelsteg gewellt. Auf dem flachen Deckel concentrische, kreisförmige Rillen. Davor das eingeschlagene Wappen von Murten Nr. 62o. Zwischen Hals und Korpus ein kräftiger circulärer Wulst und zwei Mal drei circuläre Rillen. In der Mitte des Korpus drei tiefe Rillen. Gravirte Initialen H F. Oberhalb des Fusses ein breites, profilirtes Band.

Das Meisterzeichen Nr. 640, C.P. ist wahrscheinlich eine französische Marke (ob Pletti von Yverdon ?). Kanne in Bernerform, Typ. II. Am Deckeldrücker zwei Eicheln. Auf dem Deckel die Marke Nr. 640. Höhe der Kanne 1917 cm. Durchmesser des Fusses $8 \mathrm{~cm}$.

1604 III. 4 (AEF, RN 3395).

Jean-Baptiste de La Tour, bourgeois et postier destin de Moratt. 


\title{
C. BERN UND DER AARGAU
}

\author{
Bern: Bern. \\ Thun. \\ Burgdorf. \\ Biel. \\ Neuenstadt. \\ Münster. \\ Pruntrut. \\ Delsberg. \\ Aargau : Aarau. \\ Brugg. \\ Bremgarten. \\ Wettingen. \\ Lenzburg. \\ Zofingen. \\ Baden.
}

\section{BERN}

Die archivalische Grundlage verdanke ich in erster Linie den Auszügen des verstorbenen Dr. A. Zesiger in Bern. Derselbe brachte Auszüge aus dem Burgerrechtsrodel KR Archiv (Kriegsrats Archiv); ferner Gruner Mss hist. Helv. XVII 61; Bucher, Regb. I, 840 ; Fluri, Kulturgeschichtliche Mitteilungen I, 19; Stadtrechnung; Seckelmeister-Rechnung, S. 28; Thunstätter-Rodel, II. Viertel, S. 56. Ferner Alt Polizei, Eid- und Spruchbuch und Auszüge aus dem Ratsmanual. Auch Herr Staatsarchivar G. Kurz in Bern lieferte wertvolles Material, und die sehr gute Arbeit von John A. Brown, "Das Zinngiesserhandwerk der Schweiz ", 193o, enthält sehr wichtige Aufschlüsse.

Die ersten Nachrichten über Berner Zinngiesser stammen aus dem Ende des XIV. Jahrhunderts. Im Jahre 1407 erschien eine Ordnung über die "goltschmit und Kannengiesser ", weil erstere auch mit Kupfer, Zinn und Blei arbeiteten. Wichtiger sind die Bestimmungen vom 3 1. März 1413 (Alt Polizey, Eyd- und Spruchbuch, Stadtarchiv Bern) : "Die Kannengiesser. Ordneten der schultheis und die ret der stet Berne über die Kannengiesser in unsre stet: Des ersten, was si geheissen werden fin machen oder inen selber machend, das söllend si ouch fin machen und luter ane zusatz, und söllend ouch kein ding zeichennen, so si denne fin. Denne so söllent si ouch keinen zusatz anders machen denne ze IX \& zins 1 \& blis und nit me nach ma(r)chzalnuss." Dieses ist also die erste bernische Kannengiesser-Ordnung.

In der Ordnung von 1470 wird für gewöhnliches Zinngeschirr eine Mischung von 1 Pfund Blei auf vier Pfund Zinn erlaubt. Aber " eggechtes geschirr soll alles fin zin sin" (Polizeybuch I, 28).

Zur Kontrolle der Zinn-Bleilegirung wurde im Jahre ${ }_{1521}$ ein Zinnprobirer bestimmt (Brown, S. 41 u. 44) und 1547 eine eigentliche Kontrollbehörde. Seit ${ }_{1614}$ gab es einen obrigkeitlichen Stadt-Kannengiesser (Brown, S. 42).

Von der zweiten Hälfte des XVI. Jahrhunderts ab finden wir die meisten Zinngiesser bei der Gesellschaft zu Schmieden.

Von ca. $1500 \mathrm{ab}$, mussten die Kannengiesser einen Eid ablegen, ihre Ordnung zu halten.

Im Jahre ${ }_{1} 646$ wurde bestimmt, dass nicht Probehaltiges Zinngeschirr nicht mit dem Stadtwappen gestempelt werden darf. 
Die ältesten Berner Zinngiesser führen in ihren Meisterzeichen die Lilie (nach französischem Gebrauche), so z. B. Jakob I und II Wyss, Samuel Kuhn, Peter Küpfer (Meisterzeichen Nr. 506,507,510,512). Am 3. Juli 1609 (Ratsmanual 18, 7) erhalten die Kannengiesser die Erlaubnis, am Meisterzeichen den Bären anzubringen (Nr. 513, 523, 53o und viele andere). Dies war aber kein Gebot, sondern nur eine Erlaubnis; deshalb findet man noch oft die Lilie. Eine halbe Lilie soll schlechteres Zinn bedeuten (?).

Für einen Berner völlig unverständlich sind die Klagen einiger Berner Zinngiesser im Anfang des XVIII. Jahrhunderts. Damals kamen die Engelstempel auf und die Zinngiesser behaupteten, derart gestempelte Zinnwaren hätten grössern Absatz. Auf ihr Verlangen gestattete der Rat von Bern, an die Stelle des Bären einen Engel zu setzen (Brown, S. 84). Die Meister Hans Küpfer, Jakob und Abraham Gauting, Johann Grütter und David Nötiger, brachten diese "Neuerung " an, auch Franz Ludwig Naffzger in Thun. Dass aber auch diese Meister Gewissensbisse hatten, beweist der Umstand, dass sie neben dem Engelstempel doch auch den Bärenstempel führten. Man beachte die Meisterzeichen Nr. 515, 516, $535,537,541,572$ und daneben Nr. 513,514,536, 540 und 570-71 (Band I, Tafel XXVIXXVIII). Die vorgenannten Meister erzeugten die schönsten existirenden Bernerkannen und benutzten auch das feinste Material.

Die Schützenfestgaben wurden ebenfalls besonders gezeichnet und zwar wurde in Bern das Zeichen eines kleinen Gewehres ein- oder zweimal eingeschlagen, über oder neben dem Meisterzeichen.

Gegen Ende des XVIII. Jahrhunderts ging das Zinngiesserhandwerk in Bern stark zurück. Im Jahre 1770 sind in der Stadt Bern nur noch zwei Zinngiesser : "Ganting (Bürger) und Petersohn (Aeusserer)". Auf der "Walz" ist als Geselle Ludwig Roder (Mss. h. h. X 23 , Nr. 10) 1822 . In Bern sind zwei Zinngiesser : Friedrich Melley, Metzgergasse 75 ; J. Samuel Roder, Kramgasse 214 (Adressbuch von Messerli, S. 58). Die englischen Compositionen (Sheffield, Christoffel, etc.), die Fayence- und Porzellanindustrie vernichteten das Zinngiessergewverbe (Berner Haustöpferei in Langnau, Heimberg, etc.). Immerhin gab es im XIX. Jahrhundert noch mehrere Meister, so Peter Weisbrod, Caspar Michael Stadlin von Zug, Franz Lambert, Sessiani und Peter Borocho, welcher erst im Jahre 1914 sein Geschäft schloss.

\section{Die Gegenstände}

Die Kannen. Umm bei den Zinngiessern und ihren Arbeiten die Wiederholungen zu vermeiden, unterscheiden wir auch bei den Berner Kannen zwei Typen : Typus I, die Stegkanne und Typus II, die Berner Kanne ohne die lange Ausgussröhre.

Die Stegkanne, der Typus I. Diese unhandliche, schwer zu reinigende Kanne weist eine Form auf, welche sonst nur in der Steinzeugfabrikation vorkommt. In Siegburg am Unterrhein gab es schon um das Jahr 1500 derartig geformte Steinzeugkrüge, Siegburger Schnabelkannen, und ich verweise auf das Prachtwerk "Das rheinische Steinzeug " von Otto von Falke, 1908 , Band I, S. 110 und folgende und Band II, S. 16. Allerdings gibt es auch noch frühere Zinnkannen mit der langen Ausgussröhre, doch fehlt dabei der Steg; ich erinnere an die Kannen des XIV. Jahrhunderts aus dem Basler Münster. Genau die gleiche Kannenform findet man bei den holländischen Zinnkannen. - Die Grundform der Stegkanne ist bedeutend schlanker als bei den Genfer- oder Walliserkannen. Der Kannenleib, der Korpus ist mehr birnförmig als kugelig; ex steht auf einem breiten Fusse und läuft oben in den langen Halsteil aus. Derselbe ist rach oben leicht konisch und hat einen kreisrunden Querschnitt, welcher aber kleiner ist als derjenige des Korpus. An der Uebergangsstelle vom Korpus in den Hals sind meistens 3-5 circuläre, wellenförmige Rillen und in der Mitte des Halses ein flacher circulärer Wulst. Eigenartig ist die Ausgussröhre. Dieselbe ist sechsseitig prismatisch und sitzt mit dem untern Ende der Mitte des Kannenleibes an. Sie steigt, allmälig etwas dünner werdend, schräg aufwärts bis zur Höhe des Kannenrandes und ist oben durch ein zierliches Deckelchen verschlossen. Das obere Ende steht also weit von der Kanne ab und würde bei jeder Gelegen- 
heit beschädigt oder verbogen, wenn die Ausgussröhre nicht durch einen Querbalken mit dem obern Teil der Kanne verbunden wäre. Dieses Verbindungsstück ist der Steg, welcher meist gegen die Kanne zu etwas ansteigt. Die Form des Steges ist sehr manigfaltig und dient auch (Tafel XLIII) zur Dekoration der Bernerkanne. Bald stellt er einen ausgestreckten Mannsarm im Puffärmel dar, bald einen schlanken Damenarm im eng anliegenden Aermel verschiedenster Zeichnung. Hiebei umfasst die geöffnete Hand die kantige Ausgussröhre. Sie wurden geradezu als " Herren» und "Damen " bezeichnet und waren beliebte Hochzeitsgeschenke. Der Henkel hat eine eigentümlich geschweifte Form und trägt oben das Scharnir für den Deckel. Derselbe ist kuppelförmig, bei den frühen Exemplaren sehr flach, und passt genau in einen Falz des Kannenrandes. Infolgedessen ist der Verschluss ein viel genauerer und vollkommener als bei den Genfer- und Walliserkannen, bei welchen der Deckel dem Rande nur aufliegt. Auf der Mitte des Deckels sitzt ein knopfförmiges Gebilde, bald eine Eichel, eine Traube oder ein kleiner Mohrenkopf. Die Stegkanne kommt in drei Grössen vor: die Doppel-Maasskanne, die Masskanne und die halbe Maasskanne. Die Doppel-Maasslianne findet sich fast nur als Abendmahlkanne in den Kirchen; sehr selten findet man dieselbe in Privathaushalt.

Das Meisterzeichen befindet sich bei den Stegkannen entweder auf dem Deckel, auf dem Henkel oder seltener auf dem Deckelchen der Ausgussröhre. Die Schützengabenstempel sind stets auf dem Deckel angebracht, neben oder über der Meistermarke.

Die Bernerkanne ohne Steg und ohne Ausgussröhre, der Typus II. Die Grundform der Kanne ist die gleiche, nur fehlt der Steg und die Ausgussröhre. Die ursprünglich kreisförmige obere Kannenöffnung ist vorn seitlich zusammengedrüclkt und wird dadurch herzförmig. Dadurch ist der Ausguss gleich wie bei den Walliser- und Genferkannen. Ebenso liegt bei diesem Typus II der Deckel flach auf, ebenso wie bei den erwähnten Kannen. Die Meistermarke ist meist auf dem flachen Deckel, seltener am Henkel.

Bei dieser Kannenform gibt es vier Grössen, also Kannen von 2, 1, 1/2, 1/4 Maass Inhalt. Ein Miniaturkännchen von $1 / 8$ Maass Inhalt ist ein Unikum.

Die Zinntaschen oder Zinnbulgen. Im historischen Museum von Bern sind sechs Stück, zum Teil mit prachtvoll gravirten Wappen (zum Teil in Vergoldung). (Tafel IX, 1, 2, 3.) Die Teller und Platten haben keine speziellen Eigentümlichkeiten.

\section{Die Zinngiesser der $S_{\text {tadt }}$ Bern}

Hentz (oder Entz), Kannengiesser, zitirt in den Stadtrechnungen von 1379-1383 (Friedrich WeLti, Die Stadtrechnungen von Bern aus den Jabren 1375-1384, Bern 1896).

Hug, Kannengiesser, zitirt 1383 (WeLtı, S. 283).

von Miltenberg, Hans, Kannengiesser, zitirt in den Stadtrechnungen von 1435-45 (BRUN, Scbweiz. Künstler-Lexikon II, S. 410).

Dittlinger, Heinrich, Sohn des Peter, zitirt als Kannengiesser 1466, als Rat 1470 , zuletzt 1476 (Mss. H. H., XVII 10, S. 25).

Gasser, Johann, Kannengiesser, zitirt $149^{2}$ in der Stadtrechnung, liefert Feuerpfeile und Büchsensteine.

Hüpschi, (Hübsch), Dietrich, liefert 1462 nach Solothurn (Hans Morgenthaler, Anzeiger für schweiz. Altertumskunde, 1923, S. 31; 1924, S. 234).

Gasser, Jakob, Kannengiesser, zitirt 1505-1508 (Stadtrechnung Orig. und FLURY I, 19), Büchsenmeister.

Hübsch, Nicolas, liefert im Jahre 1509 nach Neuenburg (Reutter, Extrait Ju Musée Neuchatelois, 1919 , S. 12).

Baumgarter, Peter I, getauft ca. 1504 , zitirt 1553, 1558. Sein Sohn Niklaus I, Kannengiesser, geboren 1556 (Mss. H. H. XVII, 5). Seit 1551 Mitglied der Gesellschaft zu Schmieden. Von 1556-1563 ist er städtischer obrigkeitlicher Kannengiesser.

Baumgarter, Niklaus I, getauft 1556, VII.24, Kannengiesser; zitirt 1585 als Kannengiesser. Gestorben 1604 durch Selbstmord. Söhne: Adrian und Niklaus II (Mss. H. H. XVII, 
TAFEL XXXVI
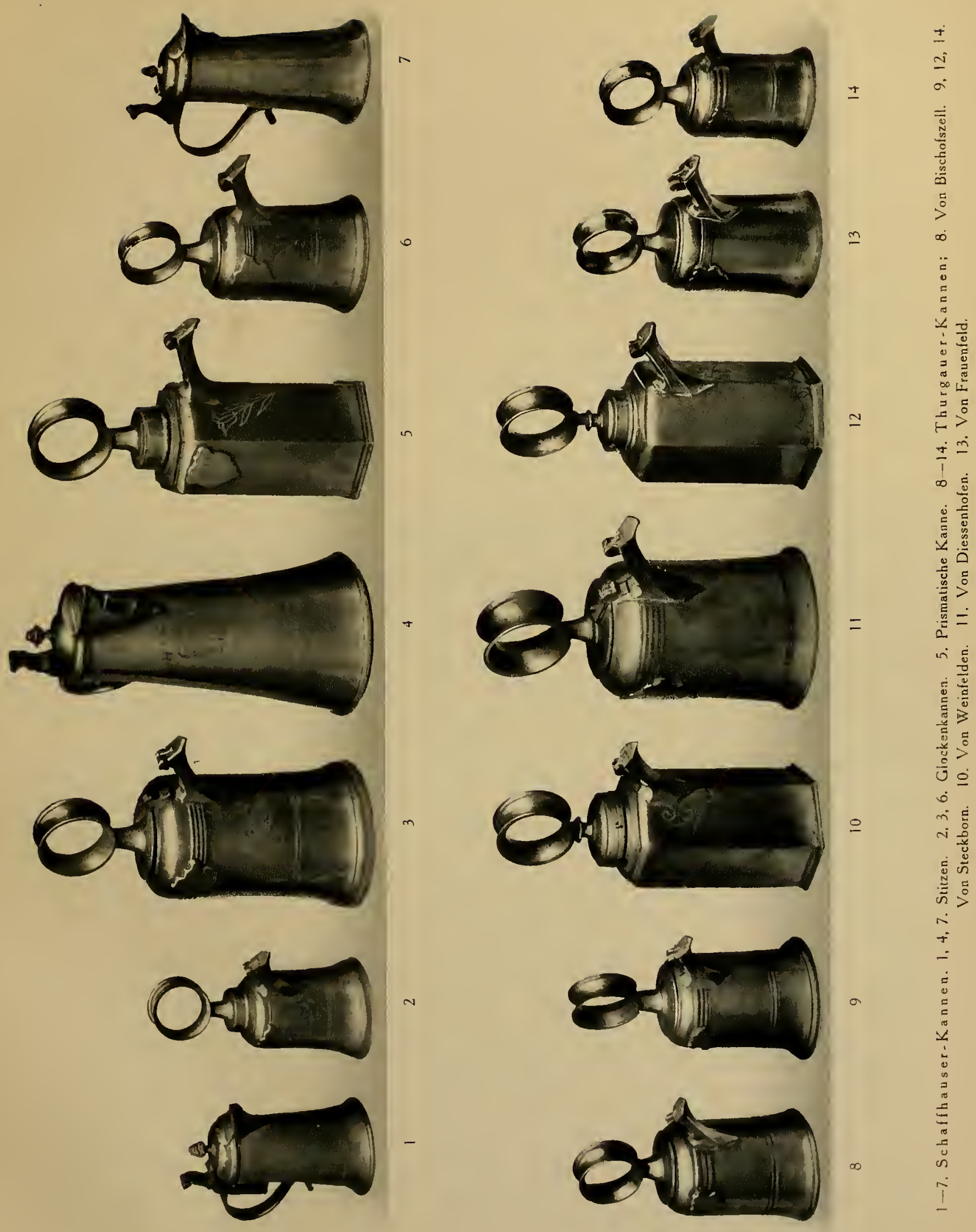
5, S. 35). Seit $1578 \mathrm{Mitglied}$ der Gesellschaft zu Schmieden. Ist 1581-1593 obrigkeitlicher Kannengiesser.

Baumgarter, Adrian, Kannengiesser, führte das Meisterzeichen Nr. 5o1 ; getauft 1593; ca. 1629 als Kannengiesser tätig; zitirt als Mitglied der Gesellschaft zu Schmieden seit 1614; weiterhin bei den Schmieden zitirt 1650,1659 und 1667. Starb 1669. Sein Sohn : Niklaus (Mss. H. H. XVII, 5, S. 41).

Gegenstand: Abendmahlkanne im Berner Münster mit dem Meisterzeichen Nr. 501 .

Baumgarter, Niklaus II, Bruder des Adrian und ebenfalls Sohn des Niklaus I; getauft 1595 , III. 23 ; ca. 1629 Kannengiesser. Zitirt 1645 bei der Gesellschaft zu Schmieden ; starb 1652 (Mss. H. H. XVII, 5, S. 43).

Baumgarter, Peter II, Kannengiesser, führte das Meisterzeichen Nr. 501 a (Bd. II); getauft 1550 . Zitirt von 1570 bis 1581 (Mss. H. H. XVII, 5, S. 38). Nr. 501 a Meisterzeichen. Zitirt 1571 (Thunstätter-Rodel, II. Viertel, S. 56).

Gegenstände : Zwei Abendmahlkannen in der Stadtkirche von Biel. Zrvei grosse Meisterzeichen : 1) Im Tartschenschild das Baumgarter-Wappen und die Initialen P B; 2) Ein Zinn-

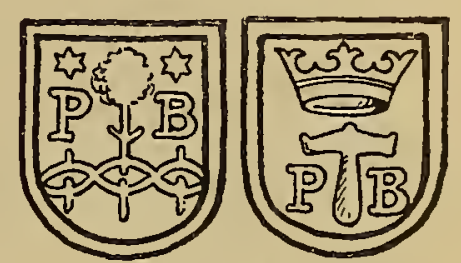

501 a giesserhammer mit den Initialen P B, darüber eine Krone mit drei Blättern. (Tafel XI, 6.) Seiler, Lienhard, Kannengiesser. Zitirt im Februar ${ }_{1505}$ (Stadtrechnung betreffend den Nideckturm).

Schaltenbrand, der jüngere; zitirt 1512 " dem Kannengiesser zu gantzer zalung $5 \& 18 \beta 8 \partial$ » (Stadtrechnung).

Gerster, Hans, von Bern, ist Lehrling bei Apollinarius Lochmann, Kannengiesser in Basel, ab 1558 (Akten der Hausgenossenzunft in Basel).

Har, Antoni, zitirt ab 1533 als Mitglied der Gesellschaft zu Schmieden.

Koler, Rudolf, zitirt als obrigkeitlicher Kannengiesser von 1536-1544.

Galdi, Oswald, zitirt als Mitglied der Gesellschaft zu Schmieden 1546. Von ${ }_{1556-1563}$ ist er obrigkeitlicher Kannengiesser.

Wyss, Antoni (im Wappen Typha-Kolben), Kannengiesser, getauft ${ }_{1531}$; er war fünf Mal verheiratet. Starb 1588 (Gruner, Mss. H. H. XVII, 61, und Brun, Schweiz. KünstlerLexikon III, S. 537). Seit 1553 ist er bei der Gesellschaft zu Schmieden.

Wyss, Jakob I, Sohn des Vorigen, Kannengiesser und Burger; getauft 1561.X.13. Im Jahre 1578 war er Lehrling bei Jakob Fridenrich in Basel. Am 25. Dezember 1585 ist er Stubengesell bei der Gesellschaft zu Schmieden. Stirbt 1603 (Gruner, Mss. H. H. XVII, 61). Gegenstände: Auf den $48 \mathrm{~cm}$ hohen, grossen Schenkkannen von Aeschi befindet sich das Meisterzeichen Nr. 5o6, also ohne Initialen. Vielleicht weist es auf Jakob I Wyss. (Tafel IV, 1.)

Wyss, Jakob II, Kannengiesser und Burger, Sohn des vorigen Jakob I, getauft 1597.VII.31. Im Jahre 16. . war er Lehrling bei Jakob Lienhart in Heidelberg; 1621 Stubengesell zu Schmieden. Er starb 1665 (Gruner, Mss. H. H. XVII, 61).

Gegenstand: Auf einer grossen Abendmahlkanne im Berner Münster befindet sich das Meisterzeichen Nr. 507, welches ich dem Jakob II Wyss zuveisen möchte (aus dem Aussehen und Stil der Kanne). Auch auf Berner Kanne Typ II. - Glatter Humpen, Höhe 16,5 cm, Durchmesser des Fusses 11,3 cm. Am Deckelgriff ein Akanthusblatt. Auf dem kuppelförmigen Deckel ein aufgelöteter Delphin, darunter zwei kreisförmige Rillenpaare und das Meisterzeichen Nr. 507. Korpus glatt, mit zwei circulären Rillenpaaren. (Tafel XIX, 1.)

Wyss, Jakob III, Kannengiesser und Burger, Sohn des vorigen Jakob II; getauft 1622.X.2; 1651 Mitglied bei der Gesellschaft zu Schmieden; 1674-1681 Stubenmeister. Starb 1683 ohne männliche Nachkommen (Mss. H. H. XVII, 61).

Gegenstand: Stegkanne von 1 Maass Inhalt, mit der Meistermarke Nr. 508, welche ich Jakob III Wyss zuweise (vergleiche die gleichzeitige Marke Nr. 509 von Samuel Kuhn, 
welcher gleichzeitig lebte und tätig war). Der Stempel Nr. 508 findet sich ebenfalls auf einer Abendmahlkanne des Berner Münsters. Ferner auf einer $52 \mathrm{~cm}$ hohen Bulge, ${ }_{1666 \text {, }}$ der Kirchgemeinde Lenk (historisches Museum Bern). (Tafel IX, 1.)

Wyss, Samuel I, der Aeltere, Sohn des Antoni Wyss (s. oben), Kannengiesser und Burger; getauft ${ }_{1557}$. Zitirt ${ }_{1} 601$. VIII. 23 bei der Gesellschaft zu Schmieden (Mss. H. H. III, 75 , Nr. 3, S. 18 ; V. v. Stürler, Genealogien).

Wyss, Samuel II, Sohn des Samuel I Wyss, Kannengiesser und Burger; zitirt bei der Gesellschaft zu Schmieden (...?).

Wyss, Samuel III (im Wappen: Lilie), Kannengiesser; getauft 1658.VII.18. Hat 1685 Stubenrecht bei den Webern; zitirt 1699 als Siechenmeister. Starb 1716.II.17 (Mss. H. H. 61, Wyss mit den Lilien).

Fuchs, Lienhard, Kannengiesser. Zitirt ${ }_{1} 550$ bis 1565 ; hat sechs Kinder (Mss. H. H. 66; Fuchs, S. 3).

Glaner, Caspar, Kannengiesser, wird 1551 Mitglied der Gesellschaft zu Schmieden 'und ist 1564-1580 obrigkeitlicher Kannengiesser. Von $155_{2-15} 5$ hat er ${ }_{1} 5$ Kinder. Im Jahre 1565 reparirt er vier Schenkkannen. Im Jahre 1571, um den "grossen Knopf uff dem Nydeck Thurn, wigt 1 q $3_{1} \&$ lutter Zin, von jedem \& samt dem Giesserlon bezalt 5 betzem, macht $87 \& 6$ B $8 \partial$ (Fluri, Kulturgesch. Milteil. I, 19). Stirbt 158o (Mss. H. H. XVII, 64, S. 275).

von Rütte, Samuel, Kannengiesser, getauft 1572 .IX.26, Sohn des David; heiratet 1595 Elisabeth Gering (4 Kinder). 1610 Stubengeselle bei der Gesellschaft zu Schmieden; heiratet zum zweiten Mal 1613 Elisabeth Dürs, von welcher er 1614-16348 Kinder hat. Von 1609 bis 1614 ist er obrigkeitlicher Kannengiesser. Todesdatum unbekannt (Mss. H. H. XVII, 45 ; Bucher, Regb. 840).

H. R. Meisterzeichen Nr. 502. Initialen nicht aufgeklärt.

Gegenstand: Grosse Stegkanne, Höhe 33,2 cm, Durchmesser des Fusses $13,3 \mathrm{~cm}$. Als Deckeldrücker ein Akanthusblatt. Auf der Mitte des kuppelförmigen Deckels ein Knopf mit drei Etagen. Auf dem Deckel circuläre Rillen und Linien. Nahe dem obern Kannenrand ein circulärer schmaler Wulst. Am Hals und Korpus nur circuläre Linienpaare. Als Steg ein Mannsarm im Puffärmel. Am obern Teil des Henkels das grosse, tief eingeschlagene Meisterzeichen Nr. 5o2. Am breiten Fuss zwei circuläre Linienpaare.

F. R. Meisterzeichen Nr. 5o3. Initialen nicht aufgeklärt.

Gegenstand: Grosse Stegkanne, Höhe 32 cm; Durchmesser des Fusses 13,1 cm. Als Deckeldrücker ein Akanthusblatt. In der Mitte des kuppelförmigen Deckels ein profilirter Knopf mit zwei Etagen; davor das Meisterzeichen Nr. 5o3. Als Steg, verzierter Aermel ohne Hand. Am Hals und Korpus tiefe breite circuläre Rillen und Linien. Am breiten Fuss zwei Linienpaare.

B. R. und A. F. Meisterzeichen Nr. 504 und 505 (Bd. I), gehören den Strassburger Meistern Balthasar Rosenbach (zitirt 1606-1631) und Antoine II Fuessle (zitirt 1648-1700) (A. Riff, Les Etains Strassbourgeois, 1925).

Weyermann, Hans, Kannengiesser, zitirt $1574.1 X .8$ als Stubengesell bei der Gesellschaft zu Schmieden (Mss. H. H. III, $75, \mathrm{Nr} .3$ ).

Lienhart, Adam, Kannengiesser, ab 1578 in Bern als Meister tätig; heiratet 1580 . Von 1582-90 hat er vier Kinder (dabei den Sohn David). Im Jahre 1578 wird er Mitglied der Gesellschaft zu Schmieden. Er war in spätern Jahren oft in finanziellen Schwierigkeiten; so war schon 1588 Geldstag. Zuletzt wird er 1593 zitirt (Brown, S. 54). Weitere Quelle : Mss. H. H. XVII, 33. Adam Lienhart verfasste das kulturhistorisch einzigartig wertvolle Rechnungs - und Hausbuch, welchem J. Brown ein eigenes Kapitel widmet und auf welches ich ganz besonders aufmerksam mache (John A. Brown, Das Zinngiesserhandwerk der Schweiz, 1930, S. 47-55).

Lienhart, David, Kantengiesser, Sohn des Vorigen; zitirt 1610 als Stubengesell der Gesellschaft zu Schmieden (Bucher, Regb. I, 840). Er wurde 1583.XII.28 getauft. Starb vor 1624 (Mss. H. H. XVII, 23 u. XII, 10). 
Dittlinger, Jakob I, Kannengiesser; getauft 1580; heiratet im Jahre 1600 Anna Keller. Im Jahre 1601 wird er Mitglied der Gesellschaft zu Schmieden; 1606 wird sein Sohn Jakob II, der nachmalige Kannengiesser, geboren (Mss. H. H. XVII 10, S. 76).

Dittlinger, Jakob II, Sohn des Vorigen, Kannengiesser; getauft 1606.X.17; Todesdatum unbekannt (Mss. H. H. XVII 10, S. 77). Zuletzt zitirt 1610 (Bucher, Regb. I, 840).

Brachner, Heinrich (Bracher) von Bern, tritt am 16. August 1603 für drei Jahre bei Jeronimus Gebhart in Basel in die Lehre (Hausgenossenzunft in Basel; Akten des historischen Museums).

Huber, Hans, Kannengiesser, zitirt 1584 (Gruner, Mss. H. H. XVII 74). War in der Gesellschaft z. Mittelleuen (Zesiger, S. 145).

Lienhart, Sebastian, zitirt als Mitglied der Gesellschaft zu Schmieden von 1610 ab.

Glaner, Samuel, Kannengiesser, zitirt als Stubengesell zu Schmieden 1624 .

Engelhart, Peter I, Kannengiesser, verheiratet mit Anna Witz im Jahre 1631. Der Sohn Peter II ist im Jahre 1639 geboren (Mss. H. H. XVII, 8).

Engelhart, Peter II, Kannengiesser, getauft 1639. XI.10. Er war Lehrling bei Hans Lux Iselin in Basel vom 18. November 1657 bis ${ }_{1} 660$ (Akten der Hausgenossenzunft in Basel im historischen Museum). Zum zweiten Mal verheiratet 1665 und zum dritten Mal 1666. Todesdatum unbekannt (Mss. H. H. XVII, 8).

Kuhn, Samuel, Kannengiesser, führte die Meisterzeichen Nr. 509, 510 und 511 ; Sohn des Moritz, getauft $1634 . \mathrm{V} \cdot 7$. Verheiratet mit Margarethe Weyermann. Bei der Gesellschaft zu Schmieden seit 1672 , zitirt 1688 als Stubengesell (Mss. H. H. XVII, 32).

Gegenstand: Kleine Kanne, Typ. II, Höhe 19,8 cm; Durchmesser des Fusses 8,5 cm. Deckeldrücker abgekröpft. Auf dem Deckel eine circuläre Rille und ein Linienpaar; davor das Meisterzeichen Nr. 51 o. Am Uebergang des Halses zum Ausgussteil und zum Korpus breite, flache Rillen und ober- und unterhalb derselben je ein Linienpaar. Breiter, kräftig profilirter, sehr schwerer Fussteil.

Grosse Stegkanne mit dem Meisterzeichen Nr. 509 im historischen Museum in Bern. Kleine Bulge mit dem Meisterzeichen Nr. 510 auf dem Deckel. An der Vorderseite ein schön gravirtes Wappen der v. Steiger (historisches Museum von Bern). (Tafel IX, 2.)

von Rütte, Christof, Kannengiesser, hat 1640 Stubenrecht bei der Gesellschaft zu Schmieden (Mss. H. H. III, 75, Nr. 3).

Küpfer, Peter, Kannengiesser, führte das Meisterzeichen Nr. 512. Getauft 1652.V.29. Verheiratet mit Margarethe Klingler im Jahre 1679 , hat bis 1682 zwei Kinder. Im Jahre 1688 ist er Stubengesell bei den Webern. Er starb 1691. IX.2 (Mss. H. H. XVII, 19).

Gegenstände: Grosse Stegkanne, Höhe 32,8 cm; Durchmesser des Fusses $12,5 \mathrm{~cm}$. Auf dem abgekröpften Deckeldrücker ein reliefirter, geflügelter Engelkopf. In der Mitte des flach-kuppelförmigen Deckels ein Knopf in Eichelform; darum eine circuläre Rille; davor das Meisterzeichen Nr. 512. Der Deckel liegt ohne Falz glatt auf der Kanne. Am Uebergang zwischen Hals und Ausgussteil und dem Korpus je drei flache circuläre, breite Vertiefungen. Den Steg bildet ein fünfseitig prismatischer Stab mit Wülsten, der vorne an der Ausgussröhre aufgerollt ist. Hals sehr hoch und schlank. Breit auslaufender Fussteil. (Tafel XLI, 11.)

Kleine Stegkanne, Höhe $27,7 \mathrm{~cm}$; Durchmesser des Fusses 10,8 cm. Deckeldrücker abgekröpft. Steg wie bei der vorigen Kanne. Deckelknopf kegelförmig, gerillt. Am Ansatz der Ausgussröhre gravirte Blätter und Blumen.

Küpfer, Hans oder Johann, Zinngiesser, führte die Meisterzeichen Nr. 513, 514, 515, 516. Getauft: ${ }_{1672}$.XI. 1 o. Als Meister ab ${ }_{1} 695$ tätig. Er war Seckelmeister zu Schuhmachern. Todesdatum unbekannt (Mss. H. H. XVII, 19).

Gegenstände: Mittlere Kanne, Typ. II, Höhe $25,2 \mathrm{~cm}$; Durchmesser des Fusses $10,5 \mathrm{~cm}$. Deckelgriff abgekröpft. Auf dem flachen, herzförmigen Deckel tiefe circuläre Rillen und Linien; davor das Meisterzeichen Nr. 513. In der Mitte des Halses ein schmaler 
circulärer Wulst und zwei feine Linienpaare. Beim Uebergang vom Hals zum Ausgussteil und zum Korpus breite, flache Wellen. Breiter Fuss mit abgesetzter Kante.

Grosse Stegkanne, mit dem Meisterzeichen Nr. 515 (Sammlung L. Gally, Basel).

Bulge mit dem Wappen: Baum, Sonne und Halbmond, Initialen H. R - C. W. ${ }_{1725}$ (Tafel IX, 4.) (Sammlung L. Gally, Basel.)

Gemüseschüssel mit dem Engelstempel und den Initialen H. K. Darauf das Beschauzeichen von Uri. (Tafel XXVI, 5.)

Wagner, Daniel, Kannengiesser; getauft 1659, Januar ... Sein Vater war der Pfarrer Vincenz Wagner. Zitirt 1688 als Stubengesell der Gesellschaft zu Schmieden. Er war ab 23. August ${ }_{1676}$ Lehrling bei Léonard Bourrelier in Genf (NAEF, S. 135). Er starb im August 1738 (Grunner, Mss. H. H. XVII, 58 und Burgerrechtsrodel des KriegsratArchives).

Boyve, Josue, von Neuenburg, Sohn des David, führte die Meisterzeichen Nr. 518, 519, 520. Er lernte beim Vater. Er arbeitete als Meister in Bern von 1663-1682 (Reutter, S. 16 und Schweiz. Künstler-Lexikon von BRUN, IV, 482). Später etablirte er sich in Neuenburg, war 1691 Mitglied der F M C.

Gegenstand: Kanne, Typ. II, mit dem Meisterzeichen Nr. 520 (Sammlung Manfred Dürr in Burgdorf).

Kanne, Typ. II, Höhe 19,8 cm; Durchmesser des Fusses 8,3 cm. Deckeldrücker abgekröpft. Deckelsteg bis zur Mitte des herzförmigen Deckels. Davor das Meisterzeichen Nr. 52o. In der Mitte des Halses ein schmaler, stark prominirender Wulst; zwischen Hals und Korpus drei schmale, wenig ausgeprägte circuläre Wellen. Korpus glatt. Breiter, abgesetzter Fuss. (Tafel XLI, 8.)

Lienhart, Abraham, Zinngiesser, getauft 1668.V.1. Von 1701 ab wird er als Zinngiesser zitirt und zwar als Mitglied zu Schuhmachern; 1726 war er Salzdirektor von Bern. Er starb im Jahre 1729 (Mss. H. H. XVII, 33).

Flügel, Salomon, Kannengiesser, führte das Meisterzeichen Nr. 521 . Zitirt ${ }_{1674}$ als Mitglied der Gesellschaft zu Schmieden; 1668 Stubengesell zu Schmieden. Starb kinderlos. Todesdatum unbekannt (Burgerrechts-Rodel des Kriegsrat-Archives).

Gegenstand: Stegkanne von 1 Maass Inhalt (Sammlung C. Hirsbrunner, Luzern).

Nötiger, David, Zinngiesser, führte die Meisterzeichen Nr. 523, 524. Getauft 168o; sein Vater hiess auch David. Der Zinngiesser starb kinderlos im Oktober 1742 (Mss. H. H. XVII, 44, S. 61).

Gegenstand: Kanne, Typ. II, 1/2 Maass. Höhe 25,6 cm; Durchmesser des Fusses $10,8 \mathrm{~cm}$. Deckeldrücker glatt, abgekröpft. Auf dem flachen, herzförmigen Deckel zwei tiefe, parallele, kreisförmige Rillen; davor das Meisterzeichen $\mathrm{Nr}$. 523; daneben die gravirten Initialen A H. In der Mitte des Halses ein flaches profilirtes circuläres Band. Am Uebergang von Hals zum Korpus und zum Ausgussteil je drei bis vier breite flache Rillen. Fuss breit mit abgesetzter Kante.

Bodmer, Samuel, Kannengiesser, führte das Meisterzeichen Nr. 527. Getauft 12. Juni 1682. Zitirt 1724 . Macht 1748 Konkurs. Stirbt im Jahre 1752 (Mss. H. H. XVII 8, S. 9).

Gegenstand: Stegkanne. Höhe $32 \mathrm{~cm}$; Durchmesser des Fusses $13,3 \mathrm{~cm}$. Deckelgriff in Form eines Akanthusblattes. Auf dem kuppelförmigen Deckel ein eichelförmiger Knopf, darum herum eine circuläre Rippe. Unten am Traghenkel das Meisterzeichen Nr. 527. Als Steg ein cylindrischer, von zwei Knoten unterbrochener Stab, welcher vorne in die Höhe gerollt ist. In der Mitte des Halses ein kräftiger circulärer Wulst und zwei Linienpaare. Nur am Uebergang vom Hals zum Korpus drei breite circuläre Rillen. Vorn am Korpus die gravirten Initialen B. L. Breiter Fuss mit scharf abgesetzter Kante. (Tafel XLIII, 1.)

Kanne Typ. II. Höhe $20 \mathrm{~cm}$. Durchmesser des Fusses 8,7 cm. Deckeldrücker glatt, abgekröpft. In der Mitte des flachen herzförmigen Deckels zwei tiefe circuläre Rillen; davor das Meisterzeichen Nr. 527 und die gravirten Initialen C. S. In der Mitte des Halses 

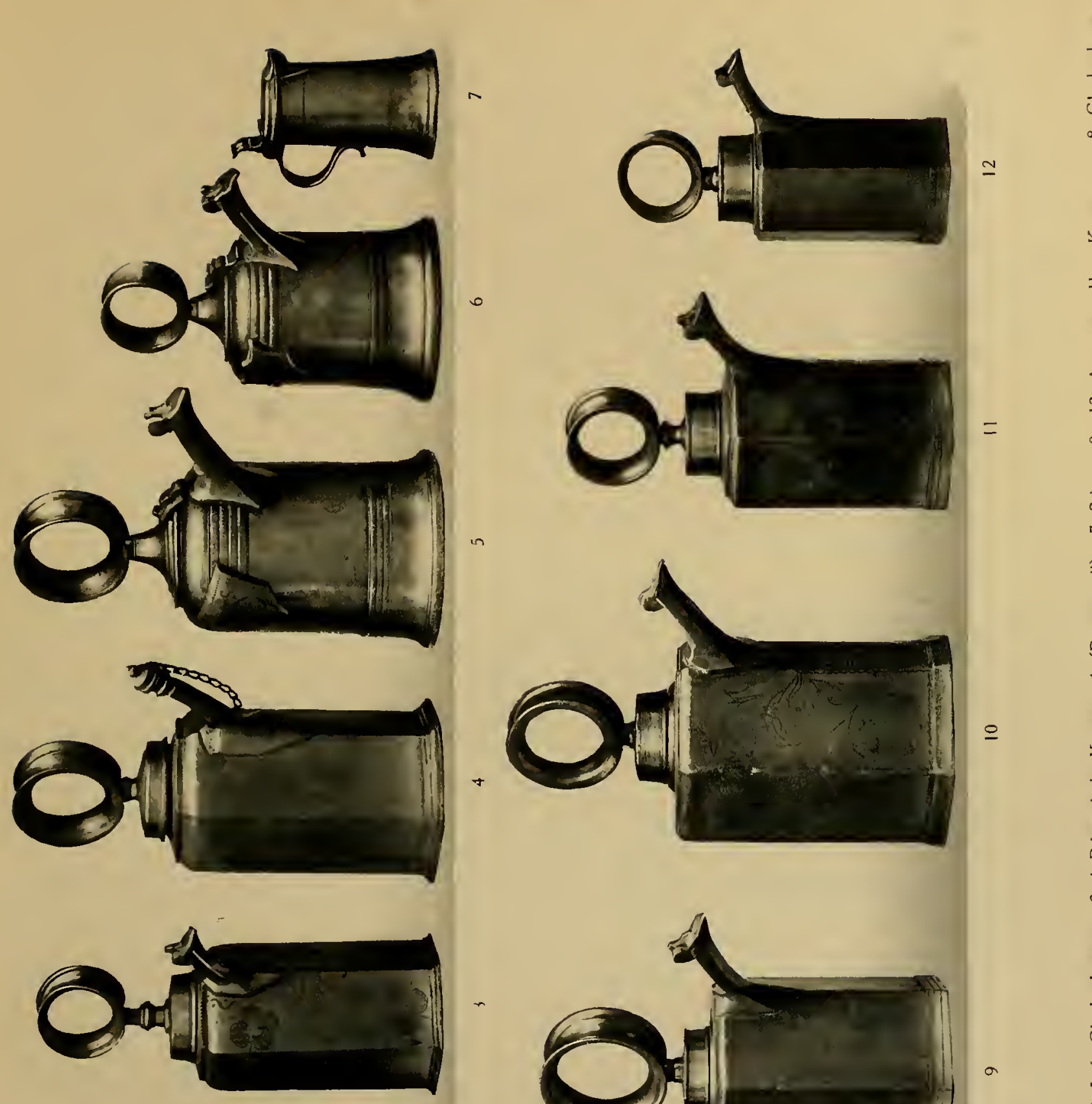

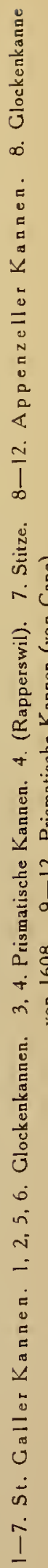
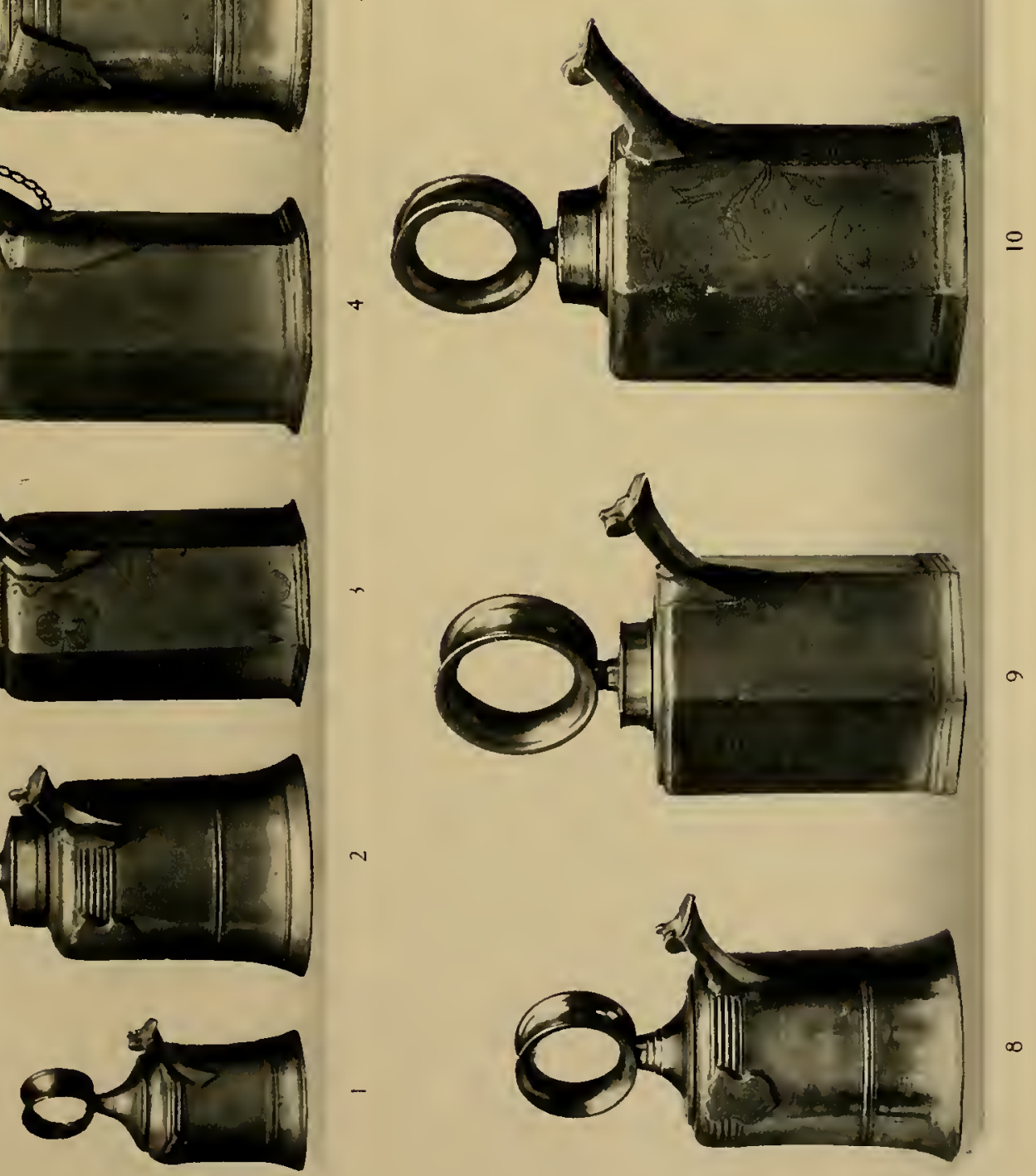
kräftiger breiter Wulst und zwei Linienpaare. Nur am Uebergang vom Hals zum Korpus drei breite flache Rillen. (Tafel XLI, 14.)

Schärer, Adam (Scherer), führte das Meisterzeichen Nr. 586. Zitirt 1687 in der Seckelmeisterrechnung, Abteilung Handwerksleute, als Lieferant von zwei Paar Zinnflaschen, auf welche der "Petschiergraber " Hans Jakob Huber das Standeswappen gravirte. Wahrscheinlich war er auch in Burgdorf tätig.

Gegenstand (vide bei Burgdorf): Grosse Zinnbulge im historischen Museum von Bern. Auf dem Rande des Halses das Meisterzeichen Nr. 586. An der Vorderwand der Bulge das Wappen von Diesbach. (Tafel IX, 3.)

Stooss, Albrecht Emmanuel, Zinngiesser, führte vielleicht das Meisterzeichen Nr. 529 mit der Jahrzahl 1700 und 1706. Er war der Sohn des Schreibers Jakob Christof. Der Zinngiesser heiratete 1708 Lisabeth Lombard, von welcher er 1709 bis 1732 zehn Kinder hatte (Mss. H. H. XVII, 53).

Gegenstand: Das Meisterzeichen Nr. 529 findet sich auf einer grossen Stegkanne im historischen Museum von Aarau. Im Bau gleicht die Kanne denjenigen von J. Zehender.

I. S. Unbekannter Meister mit der Meistermarke Nr. 53o, welche sich auf einer Bernerkanne Typ. II mit der Jahrzahl 1713 befindet.

von Rütte, David, Kannengiesser, getauft 1692. Er starb kinderlos im Jahre 1758, im Februar. Sein Vater war Hans Rudolf von Rütte, welcher 1721 starb (Mss. H. H. XVII, 45).

Tressel, Daniel, Zinngiesser von Walperswil bei Bern, zitirt 25. Mai 1694 anlässlich der Verlobung mit Jeanne Duc, Flüchtling aus Frankreich (NAEF, S. 201).

Villeneufve, Pierre, Zinngiesser, führt das Meisterzeichen Nr. 532. Er stammte aus Frankreich, arbeitet von 1674-1695 in Neuenburg, woselbst er seit 1677 bei den F M C zünftig ist. 1696.XI.14: "J. G. habend dem Zinngiesser Villeneufve bewilligt, sich umb die Statt zu setzen, sein Handwerk zu Dienst der Burgerschaft und Gewinnung seiner Nahrung (von) maniglich ohngehindert zu treiben " (Burgerkammer-Manual V, 37).

Gegenstände: Ratskannen von Murten.

Grosse Kanne im Landesmuseum in Zürich. (Tafel XIV, 3.)

Dietzi, Lienhart (oder Diezi), Zinngiesser, führte das Meisterzeichen Nr. 522. Geboren 1699 VII. 25 ; um 1725 Meister. Er starb im Oktober 1759 (Mss. H. H. XVII, 11, S. 10).

Gegenstand: Kanne Typ. II. Höhe $32 \mathrm{~cm}$. Durchmesser des Fusses $12,8 \mathrm{~cm}$. Deckelgriff flach, abgekröpft. In der Mitte des flachen, herzförmigen Deckels zwei feine circuläre Linienpaare; davor das Meisterzeichen Nr. 522. In der Mitte des Halses ein kräftiger Wulst und zwei Linienpaare ; oben am Korpus sieben schmale circuläre Wellen als Eigenart des Dietzi. Fuss breit mit senkrecht abgesetzter Kante. (Tafel XLI, 12.)

Kanne, Typ. II. Höhe 20,2 cm; Durchmesser des Fusses $8,2 \mathrm{~cm}$. Deckeldrücker flach, abgekröpft. Auf dem flachen herzförmigen Deckel ein circuläres Linienpaar und das Meisterzeichen Nr. 522. In der Mitte des Halses ein starker Wulst und zwei Linienpaare Oben am Korpus die sieben schmalen circulären Wellen. Fuss wie vorige Kanne.

Grütter, Johann Rudolf, Zinngiesser, führte die Meisterzeichen Nr. 533, 534 und 538. Zitirt in den Jahren $1705,1735,1745$ und ${ }_{17} 50$ (Mss. H. H. XVII, 78 ; im Schuhmacherrodel am Ende des Bandes, S. 23o, 271 u. 407). Die übrigen Nummern der Meisterzeichen mit den Initialen I. G. gehören nach meiner Ansicht dem Jakob Ganting.

Gegenstände: Sechs Kannen in der Mauritiuskirche in Saanen.

Stegkanne, Höhe 32,7 cm; Durchmesser des Fusses 13,2 cm. In der Mitte des flachen, kuppelförmigen Deckels ein Knopf mit zwei Etagen; darum herum flache circuläre Rillen; davor das Meisterzeichen Nr. 534. Deckeldrücker flach, abgekröpft. Als Steg ein Mannsarm mit Puffärmel und dahinter noch ein $3 \mathrm{~cm}$ langes glattes Stück. Hals lang und schlank. Am Deckelrand, am obern Rand des Ausgussteiles und unten am Hals je ein feines Linienpaar. Oben am Korpus drei flache circuläre Wellen. Fuss breit, mit abgesetzter Kante. Breitrandplatte, Durchmesser $33,8 \mathrm{~cm}$, Randbreite 7,5 cm. Rand an der Rückseite verstärkt; die Rückseite der Platte ist gehämmert. Am Rand das Meisterzeichen Nr. 538, 
aber mit fünfteiliger Rose ohne den Bären in der Mitte. Daneben ein ovales Qualitätszeichen F mit Krone. - Auch auf Stegkanne; Meisterzeichen Nr. 538. (Sammlung Manfred Dürr, Burgdorf.)

Thyss, Adam Lienhart, Zinngiesser, heiratet 1708 Jeanne Marie Nicod von Vevey, von welcher er in den Jahren 1709-1716 drei Kinder hat (Mss. H. H. XVII, 56).

Ganting, Jakob, führte die Meisterzeichen Nr. 535, 536,537. Da er die gleichen Initialen hat wie Johann Rudolf Grütter, so ist die Ausscheidung der Stempel nur durch den Untersuch der Arbeiten möglich. In der Tat sind die Arbeiten klar von einander zu trennen, zum Teil infolge der verschiedenen Technik und besonders infolge kleiner, construktiver Unterschiede. Auch hat Abraham Ganting die Stempel des Jakob Ganting direkt übernommen unter blosser Aenderung des I G in A. G. Jakob Ganting arbeitete von ca. 1710 ab (datirte Zinngegenstände).

Gegenstände: Kanne Typ. II; Höhe 33,2 cm. Durchmesser des Fusses $13,3 \mathrm{~cm}$. Deckelgriff flach, abgekröpft. In der Mitte des flachen, herzförmigen Deckels zwei circuläre Linienpaare. Dazwischen das Berner Schützengabenzeichen, ein kleines, eingeschlagenes Gewehrchen; davor das Meisterzeichen Nr. 537. In der Mitte des Halses ein circulärer Wulst und zwei Linienpaare. Am Uebergang vom Hals zum Korpus drei flache, circuläre Wellen. Vorn am Korpus drei schön gravirte Blumen mit Blättern und die Initialen H-B. (Tafel XLI, 10.)

Kanne Typ. II; Höhe 25,7 cm; Durchmesser des Fusses 10,7 cm. Deckeldrücker flach, abgekröpft. Auf dem flachen, herzförmigen Deckel zwei concentrische, circuläre Linienpaare. Davor das Meisterzeichen Nr. 536, aber als Variante ein Tartschenschild. Daneben die gravirten Initialen PS. In der Mitte des Halses ein circulärer Wulst. Zwischen Hals und Korpus vier flache circuläre Wellen und zwei Linienpaare. Vorn am Korpus die gravirten Initialen H. B. Breiter Fuss mit abgesetzter Kante.

Teller mit schmalem, fein ausgezacktem Rande; Durchmesser 21,5 cm. Vorn auf dem Rande das Meisterzeichen Nr. 536. Gegenüber am Rand zwei Familienwappen mit den Initialen M M W und mit einem unleserlichen Buchstaben, ebenfalls eingeschlagen.

Ganting, Abraham, führte die Meistermarken Nr. 540,541. Im Jahre 1745 war er im Bürgervorschlag. Datirte Kannen von 1743,1753 . Im Jahre $177^{\circ}$ war er der einzige bürgerliche Zinngiesser in Bern neben H. Peterson, der ein Aeusserer war (Mss. H. H. X, 33, Nr. 10; Mss. XVII, 78 , S. 273 ).

Gegenstände: Stegkanne; Höhe $32,4 \mathrm{~cm}$. Durchmesser des Fusses 13,5 cm. Am Deckeldrücker ein Akanthusblatt. Auf dem kuppelförmigen Deckel ein Knopf in Form einer Eichel. Daneben je ein eingeschlagenes Gewehrchen. Davor das Meisterzeichen Nr. 541 und zwei Mal das Qualitätszeichen F mit Krone. Als Steg ein kräftiger Mannsarm im Puffärmel. In der Mitte des Halses ein breiter flacher Wulst. Zwischen Hals und Korpus drei breite circuläre Wellen. An der rechten Seite des Korpus, zwischen zwei Palmzweigen, das Wappen Im Obersteg und darüber die Initialen M. IO. Auf der andern Seite das Wappen des Simmentales, ein halber Bär zwischen Palmzweigen. Um den Ansatz der Ausgussröhre eine Einfassung im Tremolirstich.

Stegkanne, Höhe 31,5 cm; Durchmesser des Fusses 13,5 cm. Als Deckelgriff ein Akanthusblatt. Auf dem Deckel als Knopf eine Eichel auf einer Etage. Abstempelung gleich der vorigen Kanne. Steg und Hals ebenfalls wie bei der Vorigen. Zwischen Hals und Korpus fünf schmale circuläre Wellen. Die ganze rechte Seite des Korpus ist von einer grossen Blume mit Blättern eingenommen. Auf der andern Seite zwischen Palmwedeln das bekrönte Wappen Matti mit den Initialen I. M. (Wappen : Auf Dreiberg steigender Löwe mit einem Schwert in der rechten Pranke). Daneben eine grosse Tulpe. (Tafel XLIV, 3.) Stegkanne, mit gleichen Maassen, gleichem Deckeldrücker, Deckelknopf, Steg, Hals und Korpus. Auf dem Deckel das Meisterzeichen Nr.5 fo. Zu jeder Seite des Korpus eine grosse prächtige Blume am Blattzweig. An der rechten Seite die Initialen A-Z-S-A. Kleine Stegkanne, Höhe $26 \mathrm{~cm}$. Durchmesser des Fusses 1 o,8 cm. Deckeldrücker flach, 
abgekröpft. Deckel sehr flach-kuppelförmig. Als Deckelknopf eine Eichel auf einer Etage. Davor das Meisterzeichen Nr. 541 mit zwei F mit Krone. Als Steg ein kräftiger Mannsarm im Puffärmel. In der Mitte des Halses ein breiter circulärer Wulst und zwei Linienpaare. Zwischen Hals und Korpus vier breite flache Wellen. Der Ansatz der Ausgussröhre ist im Tremolirstich ornamentirt. Auf dem Korpus die gross gravirte Inschrift: VEREHRT HR PETER BVILER VND STAFFAN ZWALEN.

Kleine Stegkanne von gleichen Dimensionen. Als Deckeldrücker ein Akanthusblatt; als Deckelknopf eine grosse Eichel; Deckel kuppelförmig mit breitem horizontalem Rande. Auf der Kuppel zwei eingeschlagene Gewehrchen und das Meisterzeichen Nr. 540. Steg, Korpus und Hals gleich wie bei der vorigen Kanne, Um den Ansatz der Ausgussröhre Ornament im Tremolirstich. Am Korpus die gravirten Initialen H LD. (Tafel XLI, 13.) Zehnder, J., führte das Meisterzeichen Nr. 544. Er war Lehrling des Basler Kantengiessers Niklaus II Uebelin. Am 19. Oktober 1745 zahlt die Gesellschaft z. Mittelleuen für die Ledigsprechung die Summe (1744, Seckelmeisterrechnung, S. 28 u. 24: 1747).

Gegenstände : Kanne Typ. II; Höhe 31,2 cm; Durchmesser des Fusses $13 \mathrm{~cm}$. Deckelgriff flach, abgekröpft. In der Mitte des Deckels tiefe circuläre Wellen. An der Spitze des flachen, herzförmigen Deckels das Meisterzeichen Nr. 544. In der Mitte des Halses ein schmaler Wulst und circuläres Linienpaar; letzteres auch am Ausgussteil. Zrvischen Hals und Korpus sechs schmale circuläre Wellen. Fuss breit, fast rechtwinklig abgesetzt, mit circulären Linienpaaren.

Stegkanne, Höhe 31,3 cm; Durchmesser des Fusses $13 \mathrm{~cm}$. Gleiche Arbeit und gleiche circuläre enge Wellen wie die vorhergehende Kanne. Als Deckelknopf kleine Eichel. Als Steg Mannsarm im siebenmal unterbrochenem Puffärmel. Keine Meistermarke. Am Korpus neben der Ausgussröhre eine Blume, auf der andern Seite ein gravirter Becher und ein komischer Bär; dazu die Initialen M. S. 1806.

Kanne, Typ. II, Höhe 25,7 cm; Durchmesser des Fusses 10,5 cm. Form, Deckel, Wellen in genau gleicher Ausführung wie die obige Zehnder-Kanne. Meisterzeichen Nr.544 vorn am Deckel. An der Unterseite des Bodens die gravirten Initialen $M Z$, umgeben von einer Schleife.

Hemmann, Daniel, führte das Meisterzeichen Nr. 542. Tätig nach 1730 ; starb kinderlos im September 1750 (Mss H. H. XVII, 28 ).

Gegenstände: Kanne Typ. II Höhe $25,4 \mathrm{~cm}$; Durchmesser des Fusses $10,8 \mathrm{~cm}$. Deckeldrücker glatt, abgekröpft. In der Mitte des herzförmigen Deckels vier circuläre Linien; davor das Meisterzeichen Nr. 542. In der Mitte des Halses ein Irräftiger Wulst und circuläre feine Linien. Zwischen Hals und Korpus drei flache mittelbreite circuläre Wellen. Am Ausgussteil und am Fuss circuläre, feine Linienpaare.

Kanne Typ. II, Höhe 19,7 cm; Durchmesser des Fusses 8,7 cm. Gleiche Ausführung des Deckels, des Griffes und des Korpus, wie bei der vorhergehenden Kanne. Meisterzeichen Nr. 542 auf dem Deckel. (Tafel XLII, 1.)

Petersohn, Johann Heinrich, Zinngiesser, führte als Meisterzeichen Nr. 554, 555, 556. Datirte Kannen 1780, 1786. Ca. 1780 einziger " äusserer " Meister in Bern (Mss. H. H. X, 33, Nr. 10). Auch Peterson geschrieben.

Gegenstände: Stegkanne, Höhe $32,3 \mathrm{~cm}$; Durchmesser des Fusses $13 \mathrm{~cm}$. Als Deckeldrücker ein Akanthusblatt (Stil Louis XVI). Auf dem kuppelförmigen Deckel eine grosse Eichel und zwei concentrische Linienpaare. Dazwischen das Meisterzeichen Nr.555. Der Steg ist ein Mannsarm, mit flüchtig modellirter Hand, in primitivem Puffärmel, der für Petersohn charakteristisch ist. In der Mitte des Halses ein Wulst und zwischen Hals und Korpus vier flache Wellen. Ansatz der Ausgussröhre mit gravirten Ornamenten eingefasst. An der Ausgussröhre die Initialen S. K. (Tafel XLIII, 5.)

Stegkanne, Höhe 25,6 cm; Durchmesser des Fusses 10,1 cm. Gleicher Deckel und Drücker wie bei der vorigen Kanne. Gleiche Meistermarke. Korpus schön gravirt mit Blumen und Blattranken. Steg gleich wie bei der vorigen Kanne. 
Stegkanne, Höhe $26,3 \mathrm{~cm}$. Durchmesser des Fusses 10,5 cm. Gleiche Ausführung wie die vorige Kanne. Steg dchlecht modellirt. Auf dem Korpus die Initialen N. B. V. E. B O I ST.

Kanne, Typ. II, Höhe $25,8 \mathrm{~cm}$; Durchmesser des Fusses 10,5 cm. Deckeldrücker flach, abgekröpft. Auf dem herzförmigen Deckel circuläre Wellen und in der Mitte das Meisterzeichen Nr. 555. Hals, Korpus und Fuss in gleicher Ausführung wie die vorigen Kannen.

Roder, Ludwig, Zinngiesser, führte als Meisterzeichen Nr. 545,546,547, 548. Zitirt als Geselle auf der Wanderschaft 1780 (Mss. H. H. X, 33, Nr. 10).

Gegenstände: Stegkanne, Höhe $32 \mathrm{~cm}$; Durchmesser des Fusses $13,3 \mathrm{~cm}$. Als Deckeldrücker ein Akanthusblatt. In der Mitte des kuppelförmigen Deckels ein vollrundgegossener Mohrenkopf. Am Henkel das Meisterzeichen Nr. 546. Als Steg ein schlanker, fein modellirter Damenarm. In der Mitte des Halses ein flacher breiter Wulst und zwei feine Linienpaare. Zwischen Hals und Korpus sieben circuläre Wellen. Am Korpus gravirte Blätter und Blumen in roher Ausführung und die Initialen C G. A L. (Tafel XLIII, 6.)

Stegkanne, Höhe $31 \mathrm{~cm}$; Durchmesser des Fusses $13,4 \mathrm{~cm}$. Als Deckeldrücker ein Akanthusblatt. Auf dem flach-kuppelförmigen Deckel ein flacher Knopf. Am Henkel das Meisterzeichen Nr. 545. Als Steg ein schlanker Damenarm mit einem Aermel aus Akanthusblättern. In der Mitte des Halses ein breiter profilirter Wulst. Zwischen Hals und Korpus drei circuläre Wellen und zwei Linienpaare. Korpus glatt. Ausgussröhre mit Ansatzplatte.

Stegkanne, Höhe $26 \mathrm{~cm}$; Durchmesser des Fusses 10,3 cm. Als Deckeldrücker ein Akanthusblatt. In der Mitte des Deckels ein vollrund gegossener Mohrenkopf. Meisterzeichen Nr. 546 am Henkel. Als Steg ein feiner Damenarm in geriffeltem Aermel. In der Mitte des Halses breiter flacher Wulst. Zwischen Hals und Korpus sechs circuläre Wellen. Neben der Ausgussröhre am Korpus zwei gravirte Tulpen. (Tafel XLIII, 7.) Stegkanne, Höhe $25,5 \mathrm{~cm}$; Durchmesser des Fusses 10,3 cm. Als Deckeldrücker ein Akanthusblatt. Auf dem flach-kuppelförmigen Deckel ein flacher Knopf. Als Steg ein Damenarm im Aermel in Akanthusblatt-Ornamenten. In der Mitte des Halses ein dreifach profilirter Wulst. Zwischen Hals und Korpus fünf schmale Wellen. Am Korpus zwei grosse gravirte Blumen, ferner die Initialen C. W. 1793. Ausgussröhre nit Tremolirstich verziert.

Kanne, Typ. II, Höhe 19,8 cm; Durchmesser des Fusses 8,5 cm. Flacher, abgekröpfter Deckelgriff. Auf dem flachen, herzförmigen Deckel circuläre Rillen und Linien. Am Henkel das Meisterzeichen Nr. 545. Zwischen Hals und Korpus vier circuläre Wellen. In der Mitte des Halses circulärer Wulst.

Roder, Johann Samuel, Zinngiesser, führte als Meisterzeichen Nr. 549, 55o, 551, $552,553$. Wohnt 181 o im Rotquartier; 1822 an der Kramgasse ; 1836 ist er Münstersigrist und auch Spielwarenhändler; 1839 als gestorben zitirt. War Stubengeselle zu Metzgern (Burgerbuch 1843 , S. 95 ; Adressbuch von Messerli, S. 58 ; von Sommerlet's Adressbuch I, S. 132). Gegenstände : Alle Arten Kannen, Teller, Platten.

Teller. 23,2 cm Durchmesser. In der Mitte der Rückseite interessante Stempelvariante. Grosse, runde Meistermarke, in der Mitte ein frei stehender Bär; darüber am Rand die Schrift: Bern" Zinn; unter dem Bär die Meisterbezeichnung I. S. RODER.

Stegkanne, mit dem Meisterzeichen Nr. 551 (im Antiquitätenhandel).

Eiselin, Jakob, Zinngiesser, führte als Meisterzeichen Nr. 557 (auch Iselin). Wohnt schon 1810 in Bern in der Metzgergasse. Im Jahre 1822 wohnt daselbst Friedrich Meley; Eiselin ist nicht mehr erwähnt (Berner Adressbuch von J. J. Burgdorfer, S. 40). Er stammt von Schaffhausen und wurde 1744 geboren. Erwähnt 1798 im Verzeichnis der mehrjährigen Einwohner von Bern.

Gegenstand: Kanne, Typ. II, Höhe $34,7 \mathrm{~cm}$; Durchmesser des Fusses 12,7 cm. Deckeldrücker flach, S-förmig gebogen. In der Mitte des flachen, herzförmigen Deckels 

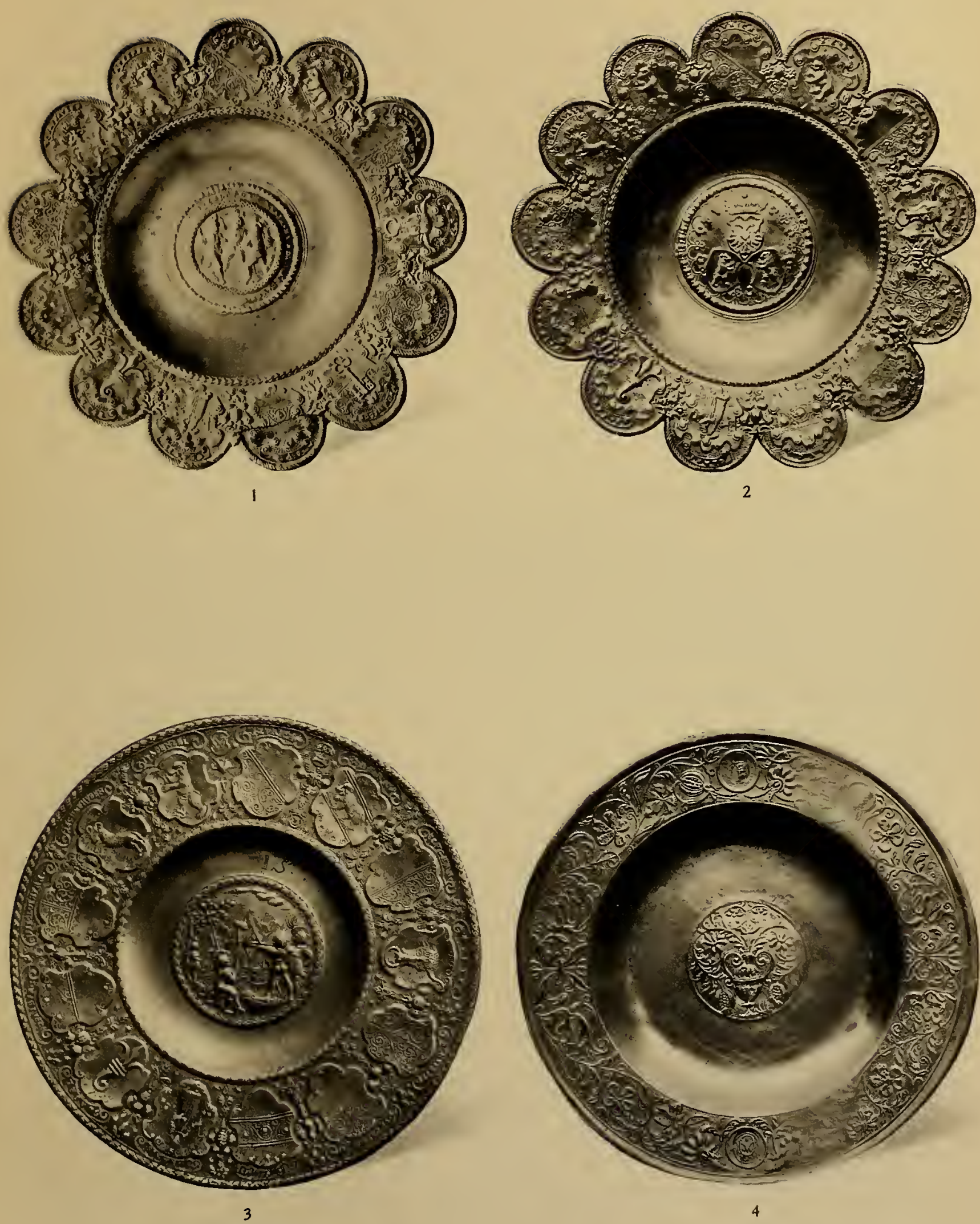

1. Lappenteller von St. Gallen, mit den drei Eidgenossen im Umbo. 2. Lappenteller von St. Gallen, mit dem Reichswappen und dem St. Galler Stadtwappen im Umbo. 3. Der Wyler Reliefteller, von Hans Melchior Müller in Wyl, 1660-1733. 4. Walliser Blumenteller, von Joannes Surd, datirt 1651. (Gallerie Fischer, Luzern) 

eine circuläre Welle und zwei tiefe Rillen. Zu beiden Seiten je ein Meisterzeichen Nr. 557 . In der Mitte des Halses ein breites, profilirtes Band. Z $Z_{\text {wischen }}$ Hals und Korpus vier breite circuläre Wellen. Der breite Fuss ist schräg abgesetzt. (Tafel XLII, 3.)

Meley, Jakob Friedrich, Zinngiesser, Burger zu Bern, führte als Meisterzeichen Nr. 558 und einen grossen Engelstempel mit der Inschrift : Fein Engels Zinn. F. Meley in Bern. (Auch

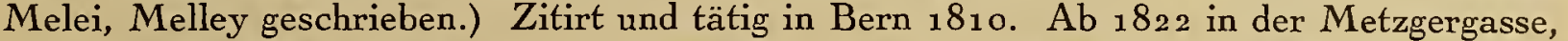
im Hause Eiselins (Adressbuch von Messerli). War Stubengesell zu Pfistern. Starb ${ }_{1822}$ (Burgerbuch 1848 , S. 80).

Gegenstand: Stegkanne (Tafel XLI, 9), Höhe $26,3 \mathrm{~cm}$; Durchmesser des Fusses $10,3 \mathrm{~cm}$. Als Deckeldrücker ein Akanthusblatt. Auf dem flachen, kuppelförmigen Deckel ein vollrund gegossener Mohrenkopf, fast ohne Hals. Am Henkel ein Rudiment des Meisterzeichens Nr. 558 (nur MEL sichtbar). Als Steg der gleiche dünne Frauenarm (Tafel XLIII, 7) wie bei Ludwig Roder. In der Mitte des Halses ein flacher Wulst und zwei Linienpaare. Zwischen Hals und Korpus drei flache circuläre Wellen. Um den Ansatz der Ausgussröhre gravirte Palmenzweige.

Grosse Stegkanne, bei Hirsbrunner, Luzern, im Antiquitätenhandel.

Weissbrod, Peter, Zinngiesser, führte das Meisterzeichen Nr. 559, 56o. Wohnt 1826 im Gelbquartier, Marktgasse. War weder Bürger noch Hausbesitzer. Unter Jahr 1848 ist er nicht mehr im Berner Adressbuch von C. v. Sommerlett; aber noch im Jahre 1836 . Im Jahre 1843 zieht er nach Heidelberg und führt das gleiche Meisterzeichen weiter (Hintze, Bd. V, Nr. 1134 ).

Gegenstände: Teller und Platten mit dem Meisterzeichen Nr. 559 und 56o. (Im Antiquitätenhandel häufig.)

Stadlin, Caspar Michael, Zinngiesser, führte die Meisterzeichen Nr. 561, 562, 563, 564, 565, 566. Er führte aus irgend einem Spleen eine Marke (Nr. 565) mit dem Bernwappen und zwei Ypsilon; auch einen Namenstempel (Nr. 566) mit diesen zwei Buchstaben. Bei Nr.561 ist die vordere Hälfte das Stadlinwappen. Er wurde in Zug geboren, im Jahre 1796. Seit 1836 wohnt er in der Spitalgasse in Bern Nr. 174; wird in diesem Haus auch 1848 und 1859 zitirt (Einsassen-Verzeichnis von 1848, S. 152 ; Adressbuch von Sommerlett, S. 132). Am 7. Oktober 1881 starb Stadlin in Zug durch Suicidium, weil die Verwandten dem 84 jährigen Manne die Ehe verwehrten.

Gegenstände: Stegkanne, Höhe $31 \mathrm{~cm}$; Durchmesser des Fusses $12,8 \mathrm{~cm}$. In der Mitte des Deckels ein massiver Knopf; auf dem flachen, kuppelförmigen Deckel befindet sich die paradoxe Meistermarke Nr. 565 mit den zwei Y. Als Deckeldrücker ein Akanthusblatt. Der Steg ist gleich wie bei den Thuner Kannen, also zwei auf einem Rundstab auseinanderlaufende, gerollte Blätter. In der Mitte des Halses ein breiter bandförmiger Wulst. Zwischen Hals und Korpus drei flache, circuläre Wellen. Um den Ansatz der Ausgussröhre eine wellenförmig gravirte Einfassung und die Initialen E F. Grosse Stegkanne mit Meisterzeichen Nr. 561. (Sammlung F. Pappe, Bern.)

Teller, schmalrandig. Durchmesser $22,7 \mathrm{~cm}$. An der Unterseite das Meisterzeichen Nr. 561.

Berner Maass, Höhe $27 \mathrm{~cm}$; Durchmesser des Fusses $18 \mathrm{~cm}$. Oben am breiten Traghenkel ein vollrund gegossener Mohrenkopf, wie auf den Stegkannen. Korpus kegelförmig; darauf ein tief eingezogener $\mathrm{Hals}$ und ein niedriger cylindrischer Ausgussteil. $\mathrm{Zu}$ beiden Seiten des obern Randes eine eingefeilte Kerbe, von der Aichung herrührend, darunter der Berner Stempel. Am Korpus zwei circuläre Rillenpaare und eines am Aus gussteil. Unten am Boden das Meisterzeichen Nr. 561. (Tafel XIX, 13.)

Runde Platte mit dem Meisterzeichen Nr. 563 und 563. (Sammlung F. Pappe in Bern.)

Lambert, Franz, führte als Meisterzeichen Nr. 567. Der Zinngiesser wohnte 1839 in der Kesslergasse, Sonnseite Nr. 6 (Ergänzungsheft zum Berner Adressbuch von Sommerlatt, S. 49, 81). Er stammt von Solothurn, wurde 1797 geboren und starb 1843 . 
Diaceri, E., Zinngiesser, zitirt 1860 im "Adresskalender für die Stadt Bern ", S. 68 u. 164 . Bomonti, A., Zinngiesser, erwähnt 1860 im "Adresskalender für die Stadt Bern », S. 164. Sesiani, ...., führte einen Engelstempel mit der Inschrift: Fein Englisch Zinn, und einen kleinen Namenstempel: S]ES][ATST] in Bern ca. 1870 . Borocho, Peter, Zinngiesser, führte als Meister[D] C 568 a Schopfheim (Baden). Novara geboren. Er war in Bern von 1874 bis 1914 tätig. Sein Vater war Zinngiesser in

\section{THUN}

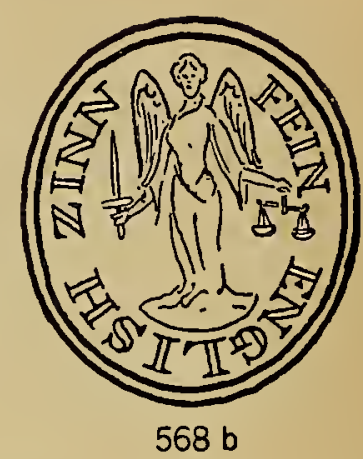

Die Nähe Berns verhinderte eine grössere Entwicklung der Zinngiesserei, da die Berner Zinngiesser mit Ross und Wagen die Jahrmärkte zu befahren pflegten, so z. B. Adam Lienhart (s. John Brown, S. 47 u. ff.). Von ältern Meistern sind keine Gegenstände und Zinnmarken bekannt.

Im Jahre 1686 arbeitete ein Theobald Bachmann von Thun als Geselle bei Hans Rudolf Bürger in Basel und 1687 ein Rudolf Lohner von Thun bei Niklaus I Uebelin in Basel (Akten der Hausgenossenzunft in Basel). Ob die Beiden je Meister wurden, ist nicht bekannt.

\section{Die Thuner Kannen}

Die Thuner Kannen zeichnen sich durch ihren schlanken Bau aus. Die Stegkannen besitzen einen ganz besonders geformten Steg, und zwar in zwei Abarten. Der häufigste Thunersteg besteht aus einem cylindrischen Stab, auf welchem zwei auseinander laufende Akanthusblätter modellirt sind, je nach der Grösse der Ausgussröhre wird der Steg entweder gerade oder leicht gebogen, angebracht. Die zweite, seltenere Form besteht in einem geraden, cylindrischen Mannsarm mit Hand. Der flache Puffärmel ist 9-8 Mal abgeteilt und hat nur ein flaches Relief. Die Naffzger verwenden beide Stegformen; der Zinngiesser R B und M R B nur die zweite Form. (Tafel XLIII, 2.)

Die Thuner Zinngiesser, besonders aber die Naffzger, waren sehr produktiv und lieferten erstklassige Ware. Ausser Thun versorgten sie besonders das Berner-Oberland, das Kanderund Simmental und deren Seitentäler.

Die Stegkannen kommen in zwei Grössen vor und die Kannen Typ. II, also ohne Steg, sogar in vier Grössen (1, 1/2, 1/4 und sehr selten $1 / 8$ Maass).

\section{Die Zinngiesser}

Naffzger, Franz Ludwig, Vater und Sohn, auch Näffzger geschrieben, führten die Meisterzeichen Nr. 569-574. Dabei findet sich auch der Engelstempel, welchen die Berner Zinngiesser bei ihrer Anfrage an den Rat erwähnten (Brown, S. 84); ferner ein eigener Schützengabenstempel (Nr. 574 und 862). Die beiden Naffzger sind ${ }_{1764}$ zitirt und zwar auf zwei zinnernen Kirchturmspitzen (im Besitz von Antiquar Th. Fischer, Luzern). Auch gibt es einwandfrei datirte Kannen von $1765,1779,1792$.

Gegenstände: Stegkannc, Höhe 35,7 cm; Durchmesser des Fusses $13 \mathrm{~cm}$. Glatter S-förmig gebogener Deckeldrücker. Hoher, dreiteiliger Deckelknopf. Davor das Meisterzeichen Nr. 57o. Steg mit den zwei Akanthusblättern, ohne Hand. In der Mitte des Halses ein schmales profilirtes Band. Zwischen Hals und Korpus vier circuläre Wellen. Zu beiden 
Seiten des Ansatzes der Ausgussröhre die Initialen C. W. Der Fuss ist fast senkrecht abgesetzt.

Stegkanne, Höhe $35,2 \mathrm{~cm}$; Durchmesser des Fusses 12,9 cm. Deckelgriff S-förmig gebogen. Deckelknopf dreiteilig, massig und niedrig. Auf dem Deckel das Meisterzeichen Nr. 570. Der Steg und das Band in der Mitte des Halses ist wie bei der vorhergehenden Kanne. Zwischen Hals und Korpus vier circuläre Wellen. Um den Ansatz der Ausgussröhre die Initialen MR-MF. 17-79, zwischen zwei Palmzweigen. (Tafel XLII, 4.)

Stegkanne, Höhe 34,5 cm; Durchmesser des Fusses 12,7 cm. Als Deckeldrücker ein Akanthusblatt. Massiver eichelförmiger Deckelknopf; davor das Meisterzeichen Nr. 570. In der Mitte des Halses ein breites, glattes Band. Steg wie bei der vorigen Kanne. Zwischen Hals und Korpus drei breite circuläre Wellen. Die Ausgussröhre sitzt mit einer breiten Platte auf dem Korpus, mit Tremolirstich eingefasst. Inschrift : ANNA SPHIER 1792.

Stegkanne, Höhe $27 \mathrm{~cm}$; Durchmesser des Fusses 10,8 cm. Als Deckeldrücker ein Akanthusblatt. Massiver, eichelförmiger Deckelknopf. Davor das Meisterzeichen Nr. 573. Steg wie bei der Vorigen. In der Mitte des Halses ein breites, flaches Band. Zwischen Hals und Korpus drei circuläre Wellen. Um den breiten Ansatz der Ausgussröhre spärliche Gravur. (Tafel XLII, 2.)

Stegkanne, Höhe 36,9 cm; Durchmesser des Fusses 13,3 cm. Glatter, S-förmige gebogener Deckeldrücker. Hoher, dreiteiliger Deckelknopf. Davor das Meisterzeichen Nr. 57 o. In der Mitte des Halses ein schmales profilirtes Band. Als Steg ein cylindrischer Mannsarm mit Hand und neunteiligem Puffärmel; ganz gerade. Ansatz der Ausgussröhre schmal. Zwischen Hals und Korpus drei schmale circuläre Wellen.

Stegkanne, gleiches Prachtexemplar, aber ohne Meisterzeichen.

Kanne Typ. II, also ohne Steg, Höhe 33,6 cm; Durchmesser des Fusses 1 2,6 cm. Deckeldrücker S-förmig gebogen. In der Mitte des flachen, herzförmigen Deckels zwei circuläre Rillenpaare und dazwischen ein circulärer Wulst. Zu beiden Seiten je die Hälfte des Meisterzeichens Nr. 573. An der Spitze des Deckels die gravirten Initialen S. M. In der Mitte des Halses ein breites profilirtes Band. Zrvischen Hals und Korpus drei breite Wellen und zwei Linienpaare. (Tafel XLII, 5.)

Kanne Typ. II, Höhe $27 \mathrm{~cm}$; Durchmesser des Fusses 10,8 cm. Deckel wie bei der Vorigen. Meisterzeichen Nr. 573. An der Deckelspitze die Initialen H. Z. In der Mitte des Halses ein schmales, profilirtes Band. Zwischen Hals und Korpus drei schmale circuläre Wellen und zwei Linienpaare.

Kanne Typ. II, Höhe $20,8 \mathrm{~cm}$; Durchmesser des Fusses $8,5 \mathrm{~cm}$. Auf dem Deckel zwei Mal das Meisterzeichen Nr. 570. (Sammlung F. Pappe, Bern.)

Kanne Typ. II, Höhe 16,2 cm; Durchmesser des Fusses 5,9 cm. Auf dem Deckel das Meisterzeichen Nr. 57 o. (Unikum.)

R. B., 1733. Führte das Meisterzeichen Nr. 531 (Bd. I) mit der Jahrzahl 1733.

Gegenstand: Stegkanne, Höhe 27,5 cm; Durchmesser des Fusses 10,8 cm. Glatter, S-förmiger Deckeldrücker. Als Deckelknopf eine kleine Eichel. Auf dem Deckelchen der Ausgussröhre das Meisterzeichen Nr. 531. Als Steg : cylindrischer, gerader Mannsarm mit Hand und achtteiligem Puffärmel. In der Mitte des Halses sehr schmales, profilirtes Band. Zwischen Hals und Korpus drei schmale, circuläre Wellen. Ansatz der Ausgussröhre schmal. (Tafel XLII, 6.)

Kanne Typ. II, Höhe 21,6 cm; Durchmesser des Fusses 8,2 cm. Schwach abgekröpfter Deckeldrücker. An der Spitze des Deckels das Meisterzeichen Nr. 531. In der Mitte des Halses ein dreiteiliges, profilirtes Band. Zwvischen Hals und Korpus vier flache schmale Wellen zwischen zwei tiefgeritzten Linienpaaren. (Tafel XLII, 7.)

H. R. B. Auf dem Stempel in Bandform nur diese Buchstaben; keine weitere Embleme. Meisterzeichen Nr. 531 a (Bd. II).

Gegenstand: Kanne Typ. II, Höhe $20,5 \mathrm{~cm}$; Durchmesser des Fusses $8,2 \mathrm{~cm}$. 
Kleinste Thuner Stegkanne, Höhe $25,3 \mathrm{~cm}$; Durchmesser des Fusses $10,5 \mathrm{~cm}$. Als Deckeldrücker ein Akanthusblatt. In der Mitte des Deckels an Stelle eines Knopfes eine kleine Flasche. Steg am Ansatz fünfkantig, wird dann cylindrisch und ist vorn in eine Spitze aufgebogen. In der Mitte des Halses ein schmaler Wulst. Zwischen Hals und Korpus drei schmale Wellen. Der Deckel, Hals, Korpus und Ausgussröhre sind mit feinen Gravuren vollständig überzogen; auch Brustbilder von Mann und Frau. Oberhalb des Korpus die Inschrift: PETER GRVNE WALD. Siehe die Abbildung dieser $\mathrm{K}$ anne in Band I, Textseite 8.

\section{BURGDORF}

Schärer, Adam, Kannengiesser, führte das Meisterzeichen Nr. 586. Er wird ${ }_{168} 6{ }_{7}$ in Bern zitirt als Lieferant von Zinngeschirr. Viele seiner Kannen und Platten tragen das Burgdorfer Schützengabenzeichen und er hat vielleicht auch in Burgdorf gearbeitet.

Löw, Abraham, führte als Meisterzeichen Nr. 587, 588. Er war von 1707-1711 Lehrling be Urs Jaus in Solothurn und wurde 1711 "lediggesprochen und abgedingt".

Gegenstände: Kanne Typ. II, Höhe $26 \mathrm{~cm}$; Durchmesser des Fusses 10,7 cm. Glatter, abgekröpfter Deckeldrücker. Auf dem herzförmigen, glatten Deckel ein kreisförmiges Linienpaar und aussen herum eine einfache circuläre Linie. An der Spitze des Deckels das Meisterzeichen Nr. 587. In der Mitte des Halses ein flacher Wulst und zwei circuläre Linienpaare, ebenso am Ausgussteil. Zwischen Hals und Korpus zwei circuläre Wellenpaare. Korpus glatt. Fuss stumpfwinklig abgesetzt.

Schmalrandige Platte mit profilirtem Rand. Durchmesser 34,7 cm. Am Rand das schöne Schützengabenzeichen von Burgdorf (Nr. 852). An der Unterseite des Bodens das Meisterzeichen Nr. 588 und zwei Mal das Qualitätszeichen F mit Krone und den Meisterinitialen A L.

Lang, Johann Friedrich, Zinngiesser von Zofingen, führte in Burgdorf die Meisterzeichen Nr. 589, 59o. Er hatte in Burgdorf ebenfalls eine eigene Werkstatt: 1738.XII.5: "Friedrich Lang bittet um Heimatschein und Leumundzeugnis, um sich in Burgdorf niederlassen zu können ". (Ratsmanual 17, 257; Granicher, Anz. f. schw. Altertemskunde, 1917, S. 108.)

Gegenstände: Schnabelstitze, Höhe 29,8 cm; Durchmesser des Fusses $14 \mathrm{~cm}$. Deckeldrücker abgekröpft. Deckel kuppelförmig, mit flachem Rand. In der Mitte der Kuppel eine gerillte Halbkugel. Davor das Meisterzeichen Nr. 59o. Die Kuppel wird durch einen breiten Perlstab eingefasst. Der Schnabel wird durch ein Maskar on gebildet, einem bärtigen, gegossenen Mannskopf (nach dem Modell des Franz Jaus in Solothurn copirt). Der Ausguss ist mit fein gravirtem Blattwerk eingefasst. Um die Mitte des Kannenleibes geht ein breites Reliefband, welches ein gitterartiges Muster mit Vierecken und Punkten aufweist. In diesem Ornamentband sind vorne und zu beiden Seiten Medaillons ausgespart. In den seitlichen befinden sich gut gezeichnete Krieger mit dem Schwert in der Manier Behams; in den zwei vordern Blumenvasen mit Blumen. Unter. halb des Reliefbandes die Initialen A O B. Der breit ausladende Fuss trägt ein breites, geripptes Band.

Cylindrischer Humpen. Höhe $16,5 \mathrm{~cm}$; Durchmesser des Fusses 10,7 cm. Als Deckeldrücker ein Akanthusblatt. Auf dem zwei Etagen aufweisenden, kuppelförmigen Deckel ein dreifach gerillter Knopf. Der Rand des Deckels und des Fusses sind gekerbt. Auf dem Deckel das Meisterzeichen Nr. 589. Der ganze Humpen ist mit zwei breiten Bändern von gravirten Blumen- und Blattranken überzogen. (Tafel XIX, 2.) 

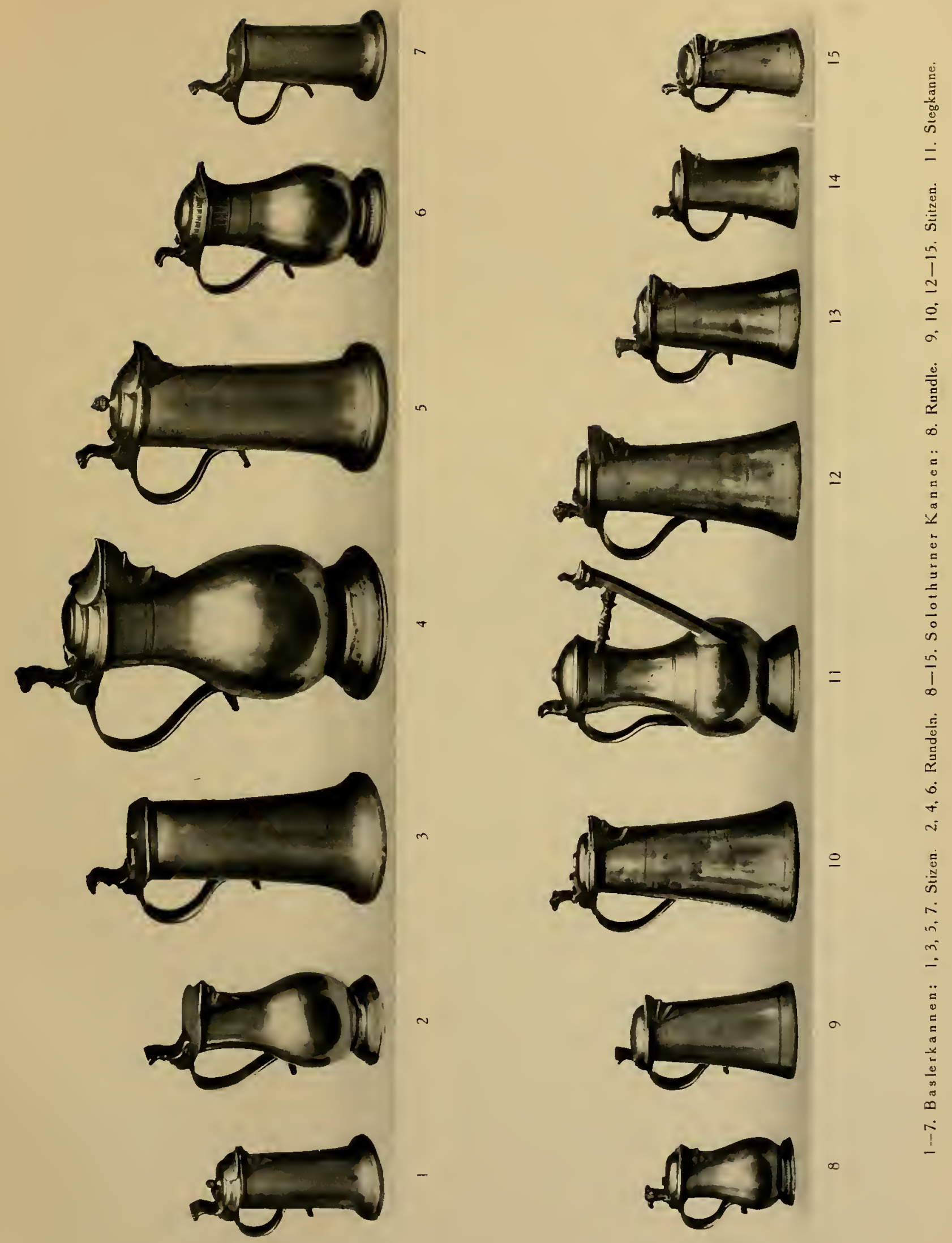


\section{BIEL}

Als Musterbeispiel für das Zinngiesserhandwerk in der Ostschweiz habe ich Wyl im Toggenburg gewählt; für die Westschweiz eignet sich Biel ganz besonders gut als Grenzort zwischen der deutschen und französischen Schweiz. Auch hat mir Herr Werner Bourquin in zuvorkommender Weise das gesammte archivalische Material zur Verfügung gestellt, welches er aus den Ratsprotokollen, den Seckelmeisterrechnungen, den Taufrodeln, den Zinsbüchern der Gesellschaft der Waldleute, u.s.w. gesammelt hatte.

Die Zinngiesser in Biel gehörten zur Gesellschaft zum Wald (zu den Waldleuten) nebst den Schmieden, Goldschmieden, Klein-Uhrenmachern, Hafnern, Bauhandwerkern, Degen-, Messer- und Nagelschmieden. Die ältesten amtlichen Verfügungen über das Zinngiessergewerbe stammen aus dem Jahre 1535 (Ratsprotokoll VII, 522). Es wurde den fremden Kesslern und Spenglern verboten, in der Stadt an andern Tagen als Donnerstags und den Markttagen Kessel und Zinngeschirr zu flicken, da dieses von den Kannengiessern zu verrichten sei. Die Zunft der Waldleute wurde ermächtigt, die Fehlbaren mit einer Busse von fünf Schilling zu bestrafen.

Am 7. Februar 1545 (Ratsprotokoll VIII, 149) beschloss der Rat, in Bern nachzuforschen, welche Verordnungen für die Goldschmiede und Kannengiesser bestehen. Das Resultat dieser Nachforschungen bildete wahrscheinlich die Grundlage zum nachfolgenden Kannengiesser-Eid, welcher die Bestimmungen über das Gewerbe enthält und vom Zinngiesser zu leisten war. Im Urkundenbuch des Boys CCXL.VII.5 lautet:

"Des Kannengiessers Eyd: Der Kannengiesser schwert einem Meyer, Rhat und der Statt Byell gehorsam zu sin, ir nutz eher zu fürdern und schaden zu wenden. Was im auch von biderben lüten zu machen gegeben, wurdt an zynn und anders, trüwlich zu verwerchen und das iren widerumb zu verantwurtten, gewicht, gross und klein recht zu halten und in allen kein geverd zu bruchen, sondern das zu thun, so in Gott und sin conciens underwaist, alles getrüwlich und ungeferlich.

"Volgt, wie er werchen soll, auch sin belonung:

" Erstlich soll er den züg und zyn zum vierden werchen und mit ringer. Wer aber bloss züg haben will, last man das zu;

"Item, was sich treyget, als Kannen, platten und dergleichen, soll man für den macherlon umbs Pfund geben zwey Schilling, nit witter. ")

"Item, welcher altzüg git zu verwerchen, soll allweg von zehen pfundt eins abgon und

Es gab also Feinzinn und die Zinn-Bleilegirung: 4 \& Zinn und 1 \& Blei.

Auswärtige, fahrende Zinngiesser durften in Biel und Umgebung nicht ständig arbeiten; so wurde im Jahre ${ }_{1601}$ ein fremder Kannengiesser, Namens Lorenz Simon, "aus der Lombardei ", auf Betreiben des ortsansässigen Zinngiessers Hans Müntschi vom Rate ausgewiesen.

Im Jahre 1634 wurde einem herreisenden Händler das Zinngeschirr confiscirt, " weil sie an der Prob nit währschafft, sondern wider den Inhalt der Kandtengiesser ordnung gar zu schlecht sich befunden " (Ratsprotokoll XVII, 126).

Meist besass Biel nur einen einzigen Zinngiesser, ab und zu gar lreinen. Darum kamen oft Berner und Neuenburger Kannengiesser mit Ross und Wagen nach Biel, so z. B. Adam Lienhart von Bern; Louis Perrin von Neuenburg (1783) hatte sogar einen Verkaufsladen, eine Art Niederlage bei einem Herrn Laubscher in Biel (S. Reutter, S. 46 ; am Schlusse des Inventars des Kannengiessers Louis Perrin).

Werner Bourquin, Biel. Die Bieler Zinngiesser ; Blätter für Bernische Geschichte, Kunst und Altertumskunde (Jahrgang XVII , 1921 , Dezember, S. $277-92$ ).

Werner Bourquin, Biel. Ein Führer für Geschichts- und Altertnmsfreunde. 1922. Verlag von Andres \& Co., Biel.

Werner Bourquin, Beiträge znr Geschichte Bicls, S. 1-9; 1922. Verlag von Andres \& Co., Biel. 


\section{Die Bieler Zinngiesser}

Niklaus, Kannengiesser, im Jahrzeitenbuch der Benediktuskirche in den ersten Jahren nach 1400 erwähnt. (Bourquin, S. 278.)

Ryf, Hans, der Kannengiesser; zitirt seit 1450, zuletzt 1468. Er stammt von Bibrach und starb ca. 1458 . (BourQuin, S. 278 81.)

Kölner, Jakob, lieferte 1459 an die Stadt; 1473 bezahlte die Stadt einen Beitrag zur Herstellung des Beschauzeichens oder der Meisterstempels. (Bourquin, S. 278.)

Madstetter, Bendicht, zitirt 1480. (Bourquin, S. 281.)

Jeger, Bendicht, Kannengiesser; tätig ca. 1500 (BourQuin, S. 281). Kauft Zinngeschirr bei Adam Lienhart in Bern! (BRown, S. 49).

Jeger, Heinrich, Kannengiesser; zitirt 1550 anlässlich der Herstellung des Kirchturmdaches. (Bourquin, S. 281).

Adam, Kannengiesser, zitirt in den Stadtrechnungen von ${ }_{1557}$ und 1558 . Zog dann nach Solothurn, wo er unter dem Namen Adam von Biel zitirt wird. (BourQuin, S. 281.)

Marty, Rudolf, von Biel, war ab 1573 Lehrling bei Jakob Fridenrich in Basel; 1578 arbeitet er als Gehilfe oder Geselle bei Adam Lienhart in Bern. Er zog dann nach Biel und wurde dort selbstständig ; seine Gussformen bezog er zum Teil von Adam Lienhart. (Brown, S. 53.)e

Jörg von Ulm, arbeitete als Geselle von 1579-1580 bei Adam Lienhart in Bern. Er zog dann später nach Biel und wurde selbstständig. (BRown, S. 53).

Müntschi, Hans, Kannengiesser, aus altem Bieler-Geschlecht; lieferte ${ }_{1598}$ Kannen auf das Rathaus. War 1599 Stubenmeister, 1609 Siechenvogt. Starb am 21. Juli 1610. Als Lehrling hatte er Philipp Finsler. (Bourquin, S. 282, 292.)

Bäschlin, Alexander, Kannengiesser, von Schaffhausen, führte als Meisterzeichen Nr. 575 (Bd. I) und Nr. $575 a, b, c$ auf dem neuerstellten Blatt (Band II). Als Bodenrosette findet man Nr. 58o und 581 (Band. I). Bäschlin wurde im Oktober ${ }_{1615}$ als "Hintersäss" aufgenommen. In den Seckelmeisterrechnungen kommt er bis 1635 vor. Er lieferte auch Schützengaben, Zinnplatten und Salzbüchslein.

Gegenstände: Kanne Typ. II, Höhe 31,2 cm; Durchmesser des Fusses 12,7 cm. Deckeldrücker abgekröpft, mit geflügeltem Engelkopf in Reliefguss; Deckelsteg lang, vorn spitz auslaufend. In der Mitte des herzförmigen, flachen Deckels concentrische Kreise; davor das Meisterzeichen Nr. 575; darunter das Fragment eines kleinen eingeschlagenen Gewehrchens (Schützengabenzeichen). Zwischen Hals und Ausgussteil und Korpus 2-3 flache circuläre Wellen. An der Hinterseite des Traghenkels reliefirte Blatt- und Blumenranken. Inwendig am Kannenboden die Bodenrosette Nr. 581 (Bd. I).

Brunnenkesselchen (Wassergiesser), Höhe 15,5 cm; Durchmesser des Fusses 10,5 cm, mit gewundenem, eisernem Traghenkel, der frei beweglich ist. $\mathrm{Zu}$ beiden Seiten je ein reliefirter Frauenkopf, welcher oben in die Oese des Henkels ausläuft. In der Mitte des Deckels ein Knopf mit zwei Etagen. Aufdem Deckel concentrische eingeritzte Linienpaare. Dazwischen das Meisterzeichen Nr. 575 (Bd. I) und ein Eigentumsstempel (zwei gelkreuzte Bäckerschaufeln über einem Dreiberg, drei Sterne und ein Halbmond; ferner die Initialen A TS.), ferner die gravirten Initialen C. S. Oben am Korpus zwei breite circuläre Wellen. Aus einem Frauenkopf steigt die runde Ausgussröhre steil empor. Fuss mit starker Ausladung. Innen am Boden die Rosette Nr. 58o (Bd. I). (Tafel XX, 18.)

Die drei Abendmahlkannen in der Kirche von Ligerz, mit der Bodenrosette $\mathrm{Nr}$. 58o. Auf dem Deckel eine Musquete! Gravirt von H. Zührer, 1661; eine andere, 1638 Pierre Clenin. (Tafel XI, 1-3.)

Borlier, Heinrich, Kannengiesser, führte vielleicht das Meisterzeichen Nr. ${ }_{2} 6$ (Bd. I) oder besser gezeichnet auf dem neuen Blatt Biel Nr. 577. Er wurde am 15 . Dezember 1638 als Hintersäss aufgenommen. Er kam von Montbéliard und ist nur zrvei Jahre (bis November 


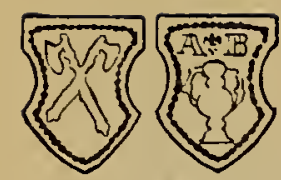

575 a

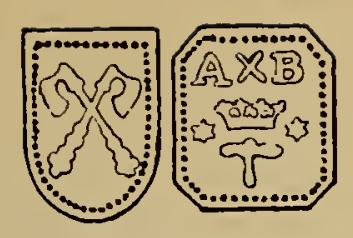

575 b

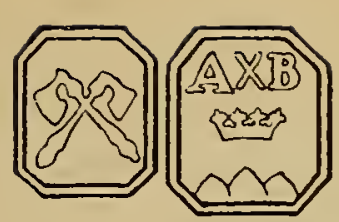

$575 \mathrm{c}$

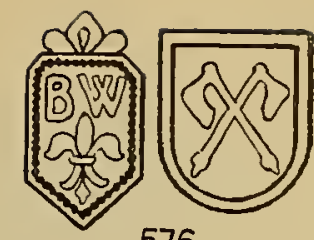

576


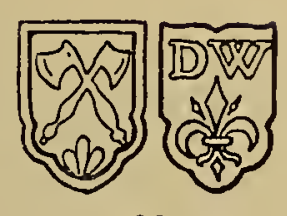

582 b



583



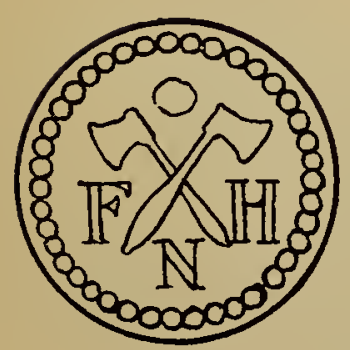

584 a

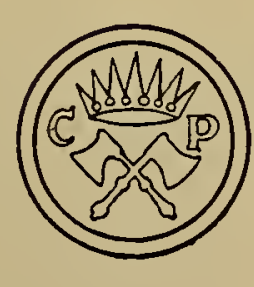

585
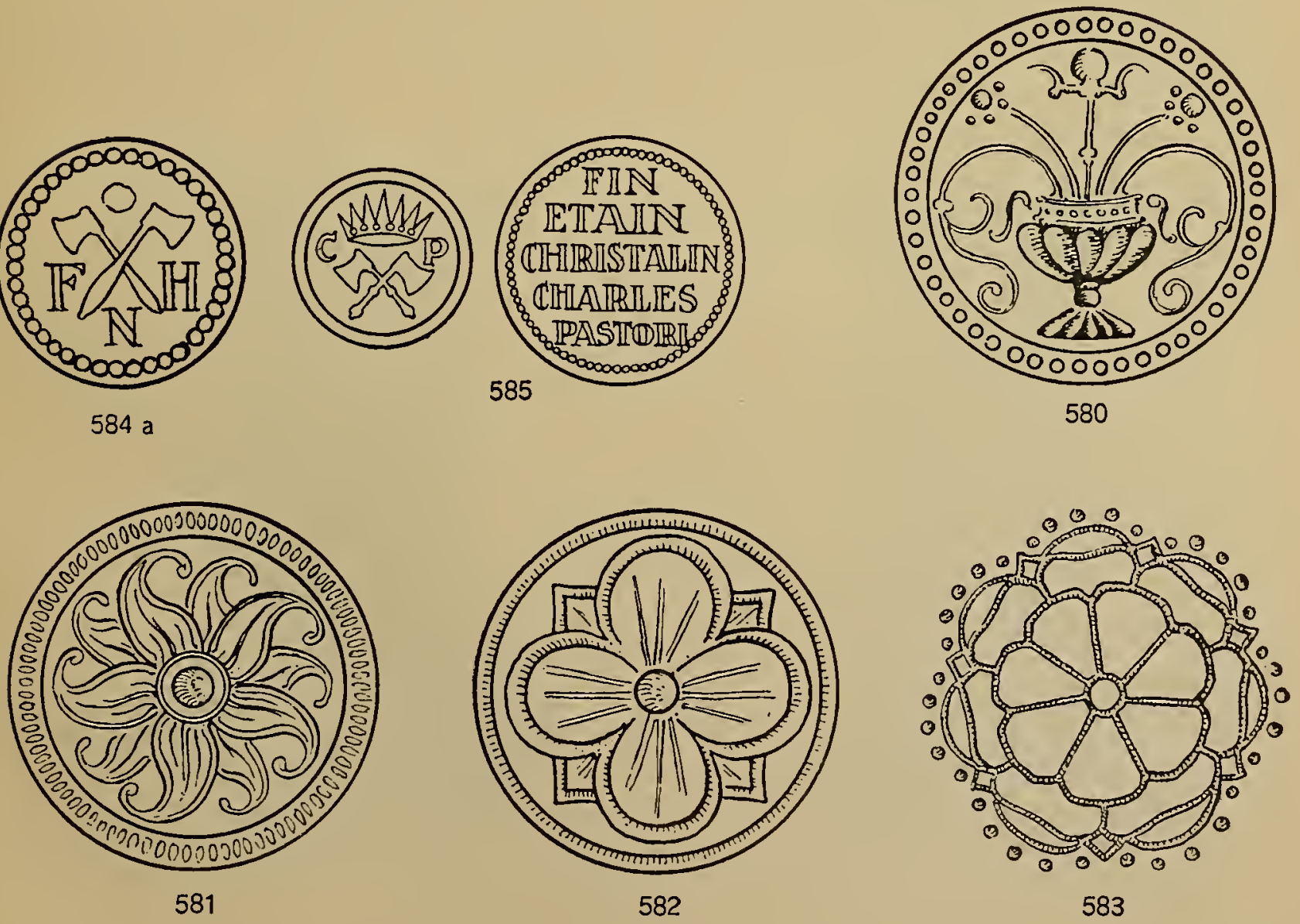
1640) in Biel nachweisbar. Da auf der Meistermarke $\mathrm{Nr} .525$ resp. 577 das grosse Bieler Siegelwappen figurirt, so bezieht sich vielleicht die vom Rate ausgesprochene Busse auf diesen Meister, welcher "uff ein stämpfel hinderrucks und unbegrüsst das Bielerwapen stechen und als die Prob schlachen " liess (Bourquin, S. 286).

Gegenstand: Kanne Typ. II, Höhe $30,5 \mathrm{~cm}$; Durchmesser des Fusses $13 \mathrm{~cm}$. Deckeldrücker abgekröpft; darauf ein reliefirter, geflügelter Engelkopf. Deckelsteg vorn spitz auslaufend. Deckelmitte etwas erhöht, mit concentrischen Kreisen. An der Spitze des herzförmigen Deckels das Meisterzeichen Nr. 526 resp. 577 Bd II. Zwischen dem hohen Hals und dem Korpus vier schmale circuläre Wellen und zwei Linienpaare. Traghenkel ohne Reliefband. Keine Bodenrosette. Die Kanne ist aus sehr stark bleihaltigem Zinn verfertigt.

Eberhart, Hans Friedrich, Kannengiesser, führte als Meisterzeichen Nr. 576 (Bd. I) oder Nr. 578 des neuen Blattes; es gibt noch eine Stempelvariante, bei welcher im Schildfiuss ein Dreiberg enthalten ist. Eberhart wird erstmals zitirt anlässlich der Taufe einer Tochter im Jahre 1646. Laut Stadtrechnung lieferte er 1647 ein Dutzend Schützenplatten für die Knaben. Zuletzt ist er im Jahre 166 o erwähnt. (BourQuin, S. 286.) Als Bodenrosette benutzt er Nr. 581 .

Gegenstand: Kanne Typ. II, Höhe $31 \mathrm{~cm}$; Durchmesser des Fusses 11,3 cm. Deckeldrücker abgekröpft, mit reliefirtem, geflügeltem Engelkopf. Deckelsteg lang, vorn spitz auslaufend. An der Spitze des flachen, herzförmigen Deckels das Zeichen der Schützen, zwei gekreuzte Musketen in einem Schilde (Nr. 853, Bd. I). Ausgussteil, Hals und Korpus ganz glatt, keine einzige Rille oder Linie. Oben am glatten Traghenkel die Meistermarke Nr. 576 (Bd. I) resp. Nr. 578 (Bd. II). Innen am Boden die Rosette Nr. 581 (Bd. I).

Zwei Abendmahlkannen in Kappeln tragen das gleiche Meisterzeichen; nur steht der Eber auf einem Dreiberg.

Breitrandplatte; Durchmesser $31 \mathrm{~cm}$; Randbreite $5,8 \mathrm{~cm}$. Rand hinten verstärkt. Vorn am Rand das Meisterzeichen Nr. 576 resp. Nr. 578 . Der Grund der Platte ist in der Mitte in die Höhe getrieben. Tiefe der Platte 3,5 cm.

Wagner, Bendicht, Kannengiesser, führte das Meisterzeichen Nr. 576; es ist im Band I nicht vorhanden. Wagner, der Sohn des Ratsherrn Martin Wagner, war 1664 des grossen Rats, 1677 auch des kleinen Rats. Er starb am 12. Januar 1687.

Gegenstände: Zwei grosse Abendmahlkannen in der Stadtkirche von Biel; beide tragen die Meistermarke Nr. 576. (Tafel XI, 5.)

Witz, Hans Caspar, Kannengiesser, führte das Meisterzeichen Nr. 577 (Bd. I) resp. Nr. 579 des neuen Blattes. Als Bodenrosette benutzt er Nr. 582 (Bd. I). Seine Tätigkeit ist von $1667-1677$ in Biel nachweisbar. (BourQuin, S. 287.)

Gegenstand: Kanne Typ. II, Höhe $33 \mathrm{~cm}$; Durchmesser des Fusses $12,7 \mathrm{~cm}$. Deckeldrücker abgekröpft, oben kein Engelkopf; nur Tremolirstich-Ornament. Deckelsteg sehr kurz. In der Mitte des herzförmigen Deckels zwei concentrische Kreise; an der Spitze das Meisterzeichen Nr. 577 resp. 579 des neuen Blattes. Hals hoch und schlank, mit einigen circulären feinen Linien. In der Mitte des Bauches ein aecquatoriales breites aufgelötetes Zinnband. An der äussern Seite des Henkels ein reliefirtes Blatt- und Blumenrankenband. Innen am Kannenboden die Rosette Nr. $58_{2}$ (Bd. I). (Tafel XLII, 1о.)

Witz, David I, Kannengiesser, führte das Meisterzeichen Nr. 58o des neuen Blattes; es fehlt im Band I. David I Witz wurde in Vinelz bei Erlach geboren und war als Kannengiesser zuerst in Neuenstadt tätig. Am 26. Januar ${ }_{1} 678$ wurde er mit seinen Söhnen in Biel als Bürger aufgenommen. Er wird oft in den Stadtrechnungen ervähnt und starb am 21. November 1703 .

Gegenstände: Abendmahlkanne in Twann in Form einer Berner Kanne mit Steg. Sie wurde 1679 vom Schultheiss Samuel Frisching von Bern gestiftet. Das Meisterzeichen befindet sich auf dem Henkel. (Bourquin, S. 288.) 

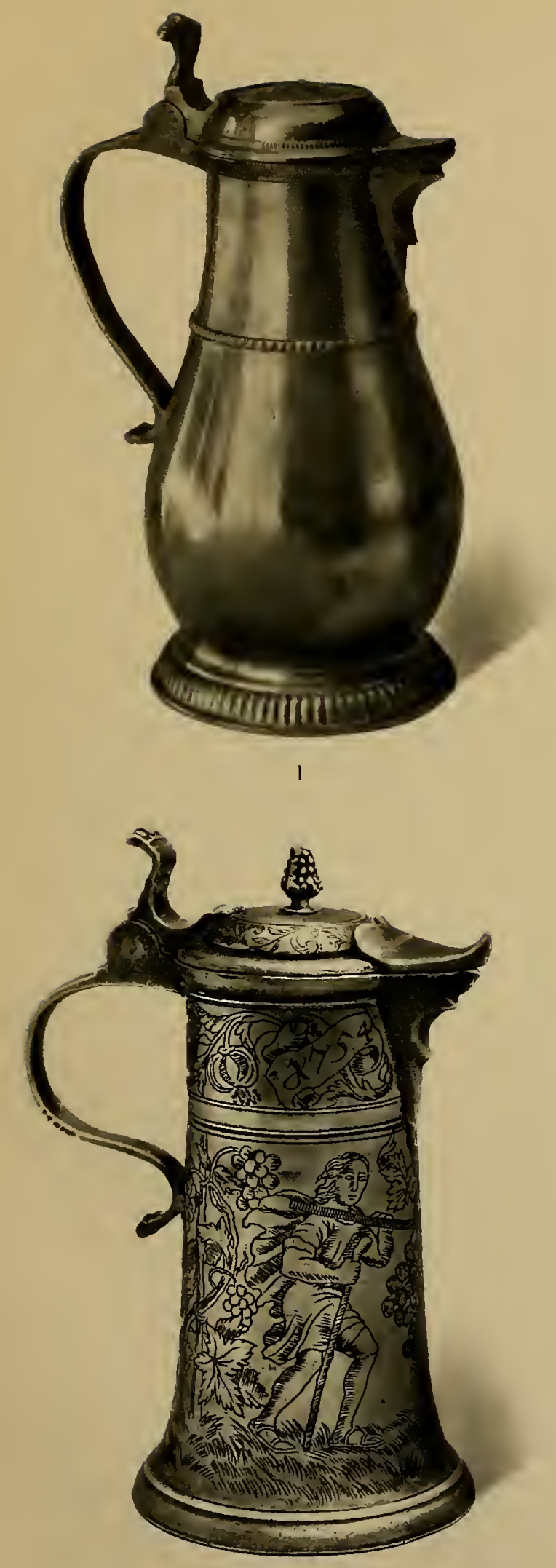

3
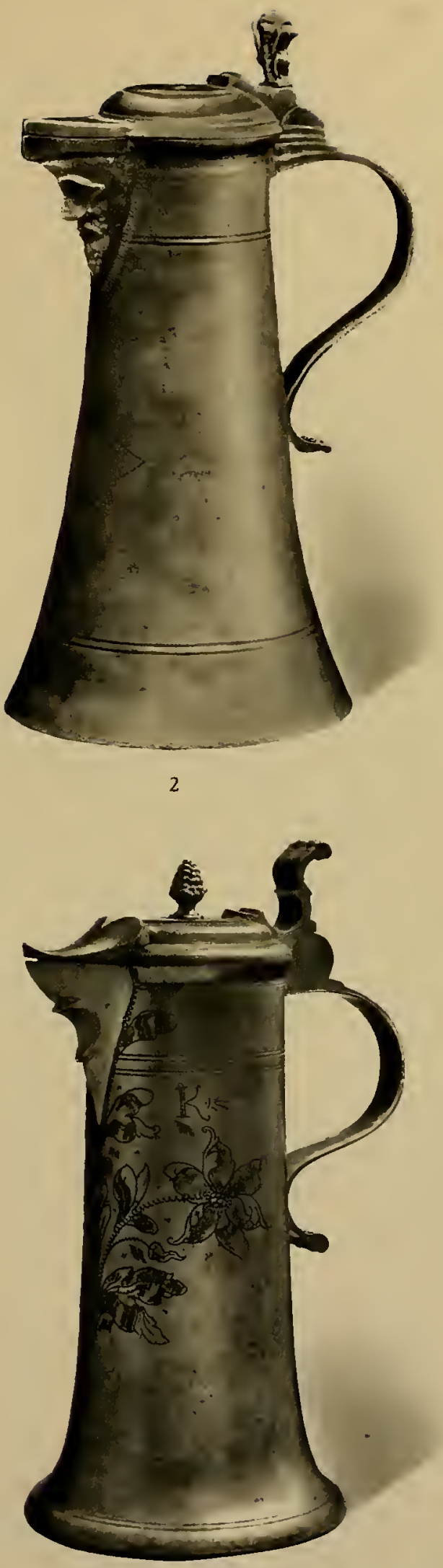

4

Solothurner Kannen: I. Rundele von I Masss. 2. Stitze mit Bartmannmaske von I Maass. Schnabelstitze von $1 / 2$ Maass. 4. Baslerstitze: Schnabelstitze von I Maass. 
Abendmahlkanne in Twann. Sechsseitig prismatischer Korpus, der in einen cylindrischen Hals übergeht. Berveglicher eiserner Traghenkel. Vom gleichen Donator ${ }_{1679}$ geschenkt. Oben am Korpus ein Spruchband. (BourquiB, S. 288.)

Teller in der Kirche von Trwann, ebenfalls mit dem Meisterzeichen Nr. 58o.

Witz, David II, Kannengiesser, führte das Meisterzeichen Nr. 581 des neuen Blattes (fehlt in Band I). Ausserdem findet sich sehr selten das Meisterzeichen Nr. 582 a des neuen Blattes, wobei aber an Stelle der französischen Lilie sich eine sechsteilige Rose befindet. David II arbeitete vor 1703 in der Werkstatt des Vaters, David I. Nach dessen Tode betrieb er die Zinngiesserei als Meister bis 1743 , in welchem Jahre er selbst das Zeitliche segnete.

Gegenstände: Stegkanne, in der Kirche von Gottstatt. Steg ähnlich der Thuner-Form ; auf dem flachen kuppelförmigen Deckel ein aufgelöteter Delphin. $Z$ wischen Hals und Ausgussteil und dem Korpus je zwei circuläre Wellen. Meistermarke Nr. 581.

Abendmahlkanne der Kirche von Gottstatt bei Biel. Höhe $40 \mathrm{~cm}$. Sechsseitig prismatischer Korpus; cylindrischer Hals und schnabelförmiger Ausguss. Auf dem Deckel ein kegelförmiger Knopf. Meisterzeichen Nr. 581. Eiserner, beweglicher Traghenkel. Inschrift: Kirchen Gottstatt 1706. (Bourquin, S. 289.) (Tafel XII, 1.)

Humpen. Höhe $18,6 \mathrm{~cm}$; Durchmesser des Fusses $13 \mathrm{~cm}$. Auf dem Deckeldrücker ein Blattornament. In der Mitte des Deckels ein Knopf mit drei Etagen. Davor das seltene Meisterzeichen Nr. 582 a, aber an Stelle der Lilie eine sechsteilige Rose. Am Henkel eine schönes Reliefband. Deckel, Korpus und Fuss sind mit feinen Gravuren überzogen, als Blätter, Blumen, Früchte, ornamentale Bänder; vorn am Korpus die Initialen E H. Fuss mit mächtiger Ausladung. Innen am Boden eine zehnteilige Bodenrosette. (Tafel XIX, 5.)

Witz, David III, Kannengiesser, Sohn des David II ; führte als Meisterzeichen Nr. 578 (Bd. I) resp. Nr. $582 a$ und $b$ des neuen Blattes. Er wurde im Jahre 1690 geboren, ging 17 o8 auf die Wanderschaft. In den Stadtrechnungen kommt er bis 1771 vor, in welchem Jahre er starb. In den Kannen findet man die Bodenrosette Nr. 583 (Bd. I) und im Humpen die zehnteilige Rosette wie bei seinem Vater David II.

Gegenstände: Kanne Typ. II; Höhe 3o,8 cm; Durchmesser des Fusses 12,8 cm. Am Deckeldrücker ein reliefirter, geflügelter Engelkopf; langer zugespitzter Deckelsteg. In der Mitte des herzförmigen, flachen Deckels zwei concentrische Kreise. Davor das Meisterzeichen Nr. 578 (Bd. I) resp. 582 a des neuen Blattes. Zweischen Ausgussteil und Hals und am Fusse je ein circuläres Linienpaar, sonst ist die Oberfläche der ganzen Kanne vollständig glatt. Am Henkel ein Reliefband. Im Kannenboden die zehnteilige Bodenrosette. Auf dem Deckel die Initialen H. G. (Tafel XLII, 12.)

Kanne Typ. II; Höhe 20,5 cm; Durchmesser des Fusses $8 \mathrm{~cm}$. Deckeldrücker flach, abgekröpft; Deckelsteg kurz, zugespitzt. Auf dem flachen, herzförmigen Deckel zwei circuläre Wellen. Davor das Meisterzeichen Nr. 578 (Bd. I) resp. 582 a des neuen Blattes. Ferner die gravirten Initialen SM-R. Das Kännchen ist völlig glatt, mit drei circulären feinen Linien, davon zwei am Fusse. Henkel glatt, ohne Reliefband. Innen am Boden die Rosette Nr. 583 (Bd. I). (Tafel XLII, 9).

Humpen. Höhe $18,5 \mathrm{~cm}$. Durchmesser des Fusses 12,8 cm. Deckeldrücker mit reliefirtem Blattornament. In der Mitte des Deckels hoher Knopf mit drei Etagen. Vor demselben das Meisterzeichen Nr. 578 (Bd. I) resp. 582 a des neuen Blattes. Am Korpus zwei circuläre Wülste, welche den Mittelteil begrenzen. Auf dem Deckel und am Korpus zwischen den zwei Wülsten, grosse Blatt- und Blumenornamente. Vorn am Korpus die Initialen H. R. F. und darunter H. R. R. Am Henkel feines Reliefband. Fuss mit mächtiger Ausladung. Innen am Boden eine zehnteilige Rosette.

Kanne Typ. II, im Museum Biel (1 Maass-Kanne).

Zinnteller in der Kirche von Täuffelen. (BourQuin, S. 289.)

Witz, Hans Peter, Kannengiesser, wahrscheinlich der Sohn des ${ }_{1667-1677}$ in Biel tätigen Hans Caspar Witz. Er wurde 1678 getauft, ging 1694 auf die Wanderschaft nach Holland. 
Im Jahre 1710 heiratete er Margret Tschaggeney. Sein Todesjahr ist 1757 . Von ihm sind weder Arbeiten noch Meistermarken bekannt. (Brourquin, S. 290.)

Witzig, Hans Heinrich, Kannengiesser, führte das Meisterzeichen Nr. 583 des neuen Blattes (fehlt im Band I). Er ist nur einmal in der Stadtrechnung von 1713 zitirt, sonst fehlen weitere Angaben über ihn vollständig. (Bourquin, S. 29o.)

Gegenstand: Runde Platte mit schmalem Rand; Durchmesser 29, $4 \mathrm{~cm}$. Rand profilirt. An der Oberseite des Randes das Meisterzeichen Nr. 583 (den neuen Blattes). Einziges bekanntes Stück.

Hemmet, Friedrich Niklaus, Zinngiesser, führte das Meisterzeichen Nr. $5{ }_{2} 5$ und 579 (Bd. I) resp. Nr. 584 und 584 a des neuen Blattes. Er wurde im Jahre 1775 als Bürger aufgenommen weil er " eine Profession hat, welche dermahlen an hiesigem Ort abgangen ". Er war nicht lange in Biel und wurde zahlungsunfähig. (BourQuin, S. 290.)

Gegenstände: Kanne Typ. II. Höhe $26 \mathrm{~cm}$; Durchmesser des Fusses 11,2 cm. Auf dem Deckeldrücker ein grosser, reliefirter Engelkopf. Deckelsteg nach vorn zugespitzt. In der Mitte des flachen, herzförmigen Deckels ein circulärer Wulst und zwei tiefe Rillen. Davor das Meisterzeichen Nr. 579 (Bd. I) resp. Nr. 584 des neuen Blattes; ferner die gravirten Initialen A K. Zwischen Hals und Ausgussteil und Korpus je zwei breite circuläre Wellen und je zwei Linienpaare. Am Traghenkel reliefirtes Blumenrankenband. Innen am Boden die Rosette Nr. 58o (Bd. I) wie bei Alexander Bäschlin; also copirt. (Tafel XLII, 13.)

Kanne Typ. II. Höhe $40,5 \mathrm{~cm}$; Durchmesser des Fusses 17,3 cm. Am abgekröpften Deckeldrücker reliefirter, geflügelter Engelkopf. Deckelsteg profilirt, vorne zugespitzt. In der Mitte des herzförmigen Deckels zwei concentrische Kreise. In der Mitte des hohen Halses ein breiter circulärer Wulst und zwei Linienpaare; ebenso zwei Linienpaare oben und unten am Hals und unten am Ausgussteil. Zwischen Hals und Korpus vier breite circuläre Wellen. Fuss stark ausladend. Henkel flach ohne Reliefband. Keine Bodenrosette. Kein Meisterzeichen. In Bau, Proportionen und Wellen als eine Arbeit von Niklaus Hemmet zu betrachten. (Tafel XLII, 11.) Teller mit dem Meisterzeichen Nr. 584 a.

Pastori, Charles Joseph, Zinngiesser, führte das Meisterzeichen Nr. 585 des neuen Blattes (fehlt in Band I). Er stammte aus Gozzano im Piemont. Er starb in Biel im Alter von 551/2 Jahren am 27. Mai 1858. Sein Vater Johann Baptista war Spengler. (Mitteilung von Herrn W. Bourquin in Biel.)

Gegenstand: Teller in der Bielstube zu Biel mit dem ersten Teil des Meisterzeichens Nr. 585.

Teller und Schüsseln in Ligerz, mit dem zweiten Teil, dem ausgeschriebenen Namen des Zeichens Nr. 585.

\section{Die Bieler Zinngegenstände}

Die Kannen. - Die Stegkannen sind relativ selten; ich fand dieselben nur bei den Meistern David I und II Witz.

Der Berner Typ. II ist die übliche Kannenform, welche in vier Grössen vorkommt : 2 Maass, 1 Maass, $1 / 2$ und sehr selten $1 / 4$ Maass. Der Ausguss ist wenig betont, ein Schnabel kommt nicht vor. Die kreisförmige Oeffnung der Kanne wird durch seitliches Eindrücken der vordern Hälfte herzförmig und damit zugespitzt, wodurch das Ausgiessen erleichtert wird. Der Deckeldrücker trägt sehr häufig einen in Reliefguss ausgeführten geflügelten Engelkopf. Der Deckelsteg ist vorn zugespitzt und reicht oft über die Mitte des Deckels hinaus. Diese Art ist für Biel eigentümlich. An der Hinterseite des Henkels findet man sehr häufig ein reliefirtes Ornamentband mit Blumen-, Früchte- und Blattranken. (Diese Eigenart findet sich auch in Zofingen, Neuenstadt und sehr selten im Wallis beim Meister I. B.) Die Grundform der Kanne gleicht der Berner Kanne Typ. II, wird aber immer mehr vereinfacht. Die circulären Wellen 
und Rillen werden spärlicher und verschwinden oft ganz. Dadurch bilden die Bieler Kannen den Uebergang zum Neuenburger Typus. Dieser wird noch besonders erreicht durch das Längerwerden des Kannenhalses.

Eine Ausnahmestellung nehmen die Abendmahlkannen von Twann und Gottstatt ein. Sie gehören zu den seltenen Vertretern in der Westschweiz, welche einen sechsseitig prismatischen Korpus aufweisen. Sie wurden von David I und II Witz hergestellt.

Zum Schlusse erwähne ich die prachtvollen Kirchenkannen von Ligerz, von Alexander Bäschlin gegossen. Ihre Form erinnert unwillkürlich an die prächtigen, rheinischen Steinzeugkannen eines Jan Emans oder Baldem Mennickens. In der Technik schliessen sie sich an die seltenen zinnernen Kugelkrüge von Simon Grynæus in Basel oder Jakob Glinz von St. Gallen.

Die Humpen sind Raritäten und haben als Eigentümlichkeit den mächtigen, breit ausladenden Fuss. Der Deckeldrücker ist gleich wie bei den Kannen, der geflügelte Engelkopf in Reliefguss. Sie sind mit kunstvollen Gravuren überzogen. Sie haben auch Bodenrosetten und zwar die gleichen wie die Kannen, meist die zehnteilige Rosette.

Teller und Platten haben keine für Biel eigenen Besonderheiten.

\section{NEUENSTADT}

Die frühesten Nachrichten über Zinngiesser stammen aus dem XVI. Jahrhundert. Es scheinen wenig leistungsfähige Meister gewesen zu sein, welche sogar Zinnwaren von auswärts bezogen. So lieferte 1579 der Berner Kannengiesser Adam Lienhart an den Neuenstadter Zinngiesser Burguner, allerdings nur Zinn; aber 1581 an den Zinngiesser Bapst auch Geschirr (Brown, S. 5o) und auch die Ausrüstung der Werkstatt.

$\mathrm{D}$ as Neuenstadter Wappen gleicht ausserordentlich demjenigen von Regensburg in Bayern. Zur Verhütung von Verwechslungen verweise ich auf Hintze, Bd. VI, S. 190 u. ffff.

\section{Die Zinngiesser}

Burguner ...., tätig in Neuenstadt ca. 1500.

Bapst, ...., tätig am Ende des XVI. Jahrhunderts.

Bernhard, Adam, Kannengiesser von Niuvenstadt, ist 1575 Stubengesell in Solothurn (FamilienRegister von Protasius Wirz).

Schnider, Hans, ist 1581 Lehrling bei Adam Lienhart in Bern (Brown, S. 54). Arbeiten und Meistermarke sind nicht bekannt.

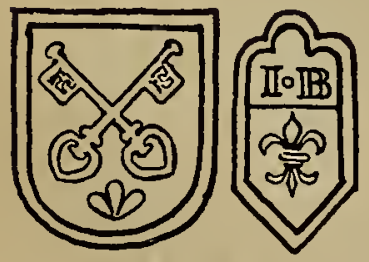

591 a

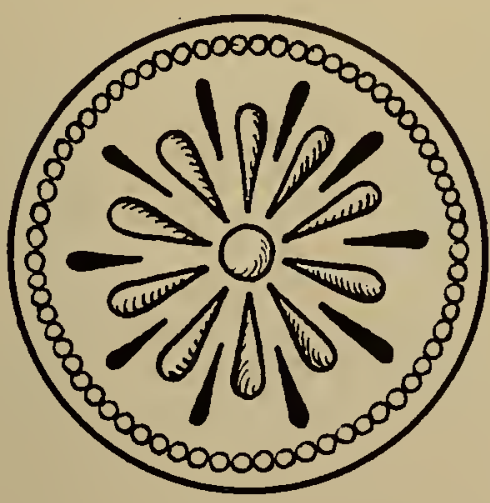

$591 \mathrm{~b}$

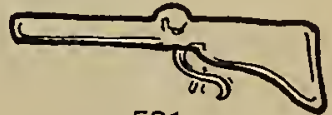

591 c 
I. B. Meister I. B. hat als Meisterzeichen Nr. $591 a, b, c$ des Bandes II, die gleiche Wappenform wie Bendicht Wagner von Biel (Nr. 591 a des neuen Blattes), aber mit den Initialen I. B. über der Lilie; im Wappenaufsatz ebenfalls eine kleine Lilie. Die beiden Marken stammen zweifellos vom gleichen Stempelschneider. Infolgedessen ist das ungefähre Datum auf das Jahr 1660 zu setzen.

Gegenstand: Kanne Typ. II, Höhe 31,4 cm; Durchmesser des Fusses $1_{2,8} \mathrm{~cm}$. Deckeldrücker und Deckelsteg neu ergänzt. In der Mitte des herzförmigen Deckels ein concentrisches Rillenpaar. Daneben zwei ganz abgeschiffene Marken D... (David Witz) und ein kleines, eingeschlagenes Gewehrchen als Schützengabenzeichen. Hals und Korpus glatt, mit einigen wenigen circulären Linien. Am obern Ende des Henkels das Meisterzeichen I E über einer Lilie; daneben das Beschauzeichen von Neuenstadt, zwei gekreuzte Schlüssel im Tartschenschild. Die Rückseite des Henkels ist mit reliefirten Blatt- und Blumenranken überzogen. Im Boden eine zehnteilige Rosette (wie bei David Witz u. a.). (Tafel XLVI,5.)

Humpen in Privatbesitz in Neuenstadt. Auf dem Deckel das Stadtwappen und das gleiche Meisterzeichen : Lilie und die Initialen I. B.

Witz, David, Kannengiesser, von Vinelz bei Erlach, führte das Meisterzeichen Nr. 591 (Bd. I). Zitirt 1663-1677. In der Neuenstadter Stadtrechnung von 1663: A David Witz, potier d'étain, pour les fleurs des jeunes arbalétriers à cause de la plainte des enfants que les coupes étaient trop petites. Les ai fait faire de $7 \frac{1}{2} \mathrm{batz}$, au lieu de $5 \mathrm{batz}$ - - 1673. A David Witz, potier d'étain pour les fleurs des jeunes gens: $4 \frac{1}{2}$ écus. Im Januar 1678 wird er in Biel als Bürger aufgenommen. (Mitteilung von Herrn Werner Bourquin.)

Variante des Meisterzeichens Nr. $5_{91}$ (Bd. I). Bei den Bieler Kirchenkannen steht die Lilie über einem Dreiberg.

Zinngegenstände von David Witz in Neuenstadt:

Kanne Typ. II, Inhalt 1/2 Maass, mit dem Meisterzeichen Nr. 591 (Bd. I). Im Antiquitätenhandel bei C. Hirsbrunner in Luzern.

Zwei Kirchenkannen in der Stadtkirche von Biel. Als Meisterzeichen Nr. 591; aber die Lilie steht über einem Dreiberg. (Tafel XI, 4.)

Im Museum von Neuenstadt befindet sich eine Platte mit dem Stadtwappen und der Jahrzahl 1675, welche vielleicht auch von David Witz stammt. Das Meisterzeichen aber fehlt.

Auch in Neuenstadter Privatbesitz befinden sich zwei Kannen mit dem Stadtzeichen allein. (Mitteilung von Dr. Florian Imer.)

Baillif, Charles Francois, von La Neuveville, war Lehrling bei Jacques Gallot in Neuenburg, ca. 1720.

\section{MÜNSTER IM BERNER JURA (MOUTIER)}

Frey, Jost, von Münster, zitirt 1729-1732 als Lehrling bei Joseph Graff in Solothurn (siehe unter Solothurn).

\section{PRUNTRUT}

Krittli, Hans, von Pruntrut, lernt 1597 bei Jakob Fridenrich in Basel.

\section{DELSBERG, DELÉMONT}

(Gehörte zum Bistum und bischöflichen Besitz des Bischofs von Basel.)

Debong, Hartmann, von Delsperg, lernt ${ }_{15} 5_{1}$ bei Onophrius Werlin in Basel.

Nr. 59 i $f$ (Bd. II), Beschauzeichen von Delément: Ovaler Stempel. Ueber doppel- 



m

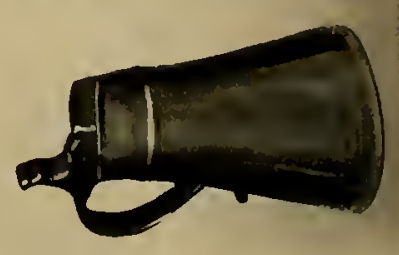



tem Dreiberg ein grosser Baselstab zwischen den Buchstaben D und $M$ (Delémont). Daneben ein zweiter Stempel: Bekrönter Zinngiesserhammer ohne Initialen (vergleiche Meisterzeichen Nr. 376, Basel, Band I, Tafel XIX).

Auf schmalrandigem Teller, Durchmesser 22,4 cm. Meisterzeichen in der Mitte der Rückseite. Vorn am Rand ein Eigentumsstempel, Doppelwappen; im ersten Wappen ein grosses Herz, darüber I. R G.; im zweiten Wappen drei Sterne und die Initialen C. H. (das Doppelwappen samt den Initialen in einem Queroval).

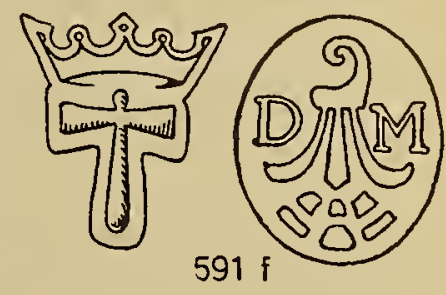

\section{AARAU}

Die Stadt Aarau hatte niemals eigentliche $Z$ ünfte, weshalb auch die diesbezüglichen Rödel (in Aarau Rötel genannt) fehlen. Von einigen Handwerksverbänden sind "Ordnungen " vorhanden, nicht aber von den Kannengiessern. Dagegen findet man schon frühzeitig in den Seckelmeisterrechnungen ${ }^{1}$ der Stadt Aarau Angaben über Kannen- und Zinngiesser. Ein Cunrat Harlapp liefert ${ }_{1575}$ und ${ }_{1579}$ Schenkkannen, Salzbüchslein, Platten, Ohrenschüsseln und Teller. Melchior Harlapp oder Harlepp liefert $1585,1587,1589$ und 1595 Platten auf das Rathaus. Im Jahre ${ }_{1602}$ und 1605 ist er erwähnt wegen Reparaturen, so z. B des Kirchenturmknopfes und des Stadtbrunnenknopfes, ferner von Schenkkannen. Ein M. Jakob Keller, Kannengiesser, ist wahrscheinlich identisch mit J. Keller, Ehegemahl der Magdalena Pfander, von welcher er von 1592-1619 neun Kinder hat. Laut Seckelmeisterrechnung vom Jahre 1613 liefert er Zinngeschirr aufs Rathaus.

Das Wappen und Beschauzeichen von Aarau besteht in einem nach links (heraldisch rechts) schauenden Adler; allein die Stempelschneider gaben darauf wenig acht und oft findet man auch nach der andern Seite schauende Adler (z. B. bei dem Meisterzeichen von Daniel Wasmer und Georg Fisch).

\section{Die Zinngiesser}

Schmid, ...., Zinngiesser in Aarau 1528 (MErz, Aarauer Wappenbuch, S. 239).

Harlapp, Cunrat, Kannengiesser, wird in den Seckelmeisterrechnungen von 1575 und 1579 erwähnt.

Harlapp, Melchior, Kannengiesser, wurde am 29. April 1565 getauft, in den Seckelmeisterrechnungen von $1585-1605$ oft erwähnt, und starb am 8. Dezember 1617 .

Hunziker, Hans Heinrich, Kannengiesser, wurde am 1. November 1590 getauft, und wird im Ratsmanual 37 unter dem 7 . Mai 1626 erwähnt.

Keller, M. Jakob, Kannengiesser, wird in den Jahren 1592-1619 (Taufregister) als Gemahl der Magdalena Pfander öfters genannt. Im Jahre ${ }_{1613}$ liefert er laut Seckelmeisterrechnung auch aufs Rathaus ${ }^{\text {. }}$

Wasmer, Brandolf, Kannengiesser, wurde am 8. Mai 1642 geboren. Er wird im Seckelmeisterrotel vom Jahre 1677 erwähnt, "dem Zinngiesser ist bezahlt worden 4 \& 18 B 8 Haller ". Er war Tavernenwirt zum Adler und starb am 3. Juni 1705.

Er führte das Meisterzeichen Nr. 441 .

Gegenstand: Stegkanne in Bernerform von 1 Maass Inhalt. Meisterzeichen Nr. $44^{2}$ auf dem Deckel. Höhe 29,5 cm. Durchmesser des Fusses 12,5 cm.

Stegkanne von 2 Mass Inhalt in Luzerner Privatbesitz. Meisterzeichen Nr. $44^{1}$ auf dem Traghenkel.

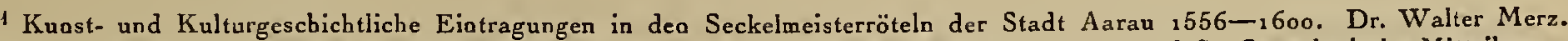
Anzeiger für schweiz. Altertumskunde vom Jahre 1905/06. Seite 161. - Seckelmeisterrötel von 1602 und ft. Geoealogische Mitteilungeo von Herrn Dr. Walter Merz-Diebold an den Verfasser. 
Wasmer, Daniel, der Sohn des Vorigen, Zinngiesser, wurde am 18. Juni 1660 getauft, heiratete am 13. November ${ }_{1682}$ Katharina Schmid. Am 28. Dezember 1702 sagt er vor dem Rat aus, er habe von einem aus dem Spital $1 \frac{1}{2} \&$ Bley und später wieder 4 \& verschmelzt Bley gekauft und verdacht geschöpft, etc. Dieses ist der einzige archivalische Anhaltspunkt für seinen Beruf als Zinngiesser. Er starb am 6. April 1727.

Er führte das Meisterzeichen Nr. 442. Bodenrosette Nr. 455 .

Gegenstand: Stegkanne in Bernerform von 1 Maass Inhalt. Das Meisterzeichen Nr. 442 auf dem Deckel. Bodenrosette Nr. 455. Der Traghenkel hat in der Mitte einen Absatz zum Einsetzen eines Fingers beim Einschenken. Höhe 29,5 cm. Durchmesser des Fusses 12,5 cm. Der Steg besteht aus einem dünnen Arm mit Puffärmel und kleiner Hand, welche die Ausgussröhre anfasst. Das Modell dieser Kanne ist in allen Teilen das gleiche wie dasjenige seines Vaters und wurde also direkt übernommen. (Tafel XLV, 4.)

Beck, Johann Arnold, Zinngiesser, führte die Meisterzeichen Nr. 439 und 440 in Band I. Als Bodenrosette in den Kannen findet man Nr. 454 (Bd. I). Als Sohn des Goldschmieds Hans

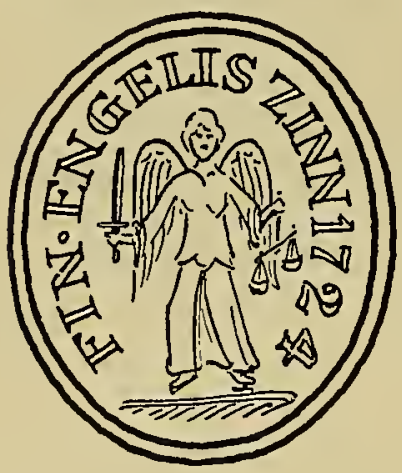

440 a



$440 \mathrm{~b}$ Georg Beck wurde er am 14. August 1698 getauft. Im Jahre 173 o heiratete er Veronika Schmid und starb am 27. Dezember 1766. Eine Stempelvariante findet sich in Band II, Nr. $440 a$ und $b$.

Gegenstände : Stitze ohne Schnabel von $1 / 2$ Maass Inhalt. Am Henkel das Meisterzeichen Nr. 440; doch kein Stadtzeichen. Bodenrosette Nr. 454. Fuss mit guter Ausladung. Am Korpus in der Mitte vier circuläre Rillen. Höhe 22,8 cm. Durchmesser des Fusses $11 \mathrm{~cm}$. (Tafel XLV, 1.)

Im Museum in Burgdorf befindet sich eine seltene Bulg e mit dem Meisterzeichen Nr. 439. In Brugger Privatbesitz befindet sich eine Stitze ohne Schnabel von gleicher Beschaffenheit wie die oben erwähnte. Am Korpus die Initialen M B und auf dem Deckel die Zahl 26 eingravirt. Höhe $19 \mathrm{~cm}$.

Runde Platte. Durchmesser 33,2 cm bei 4,5 cm Randbreite. Aussenrand profilirt. An der Unterseite ein eigenartiger Stempel. In einer füfteiligen Rose der Adler von Aarau; darüber eine Krone. Im Kreise die Inschrift : Joh. Arnold Beck, Arau. Daneben ein Engelstempel mit der Inschrift: Fin Englis Zin 1724. (Aeltester datirter Engelstempel).

Meister H. I. W. und H. W. in einem Aarauer Stadtwappen, Nr. 443 und 444 , auf Breitrandplatten konnten nicht bestimmt werden. Wahrscheinlich deutsche Meistermarken.

Fisch, Johann Georg, Zinngiesser, wurde am 23. Dezember 1703 geboren und war mit Anna Barbara Gysi verheiratet, im Jahre 1741 Mitglied des Grossen Rats und starb am 16. August 1780 .

Er führte das Meisterzeichen Nr. 445. Bodenrosetten Nr. 456 und 457. Seine Arbeiten sind sehr gut und die untersuchten Gegenstände bestehen meist aus Feinzinn.

Gegenstände: Prachtvolle Schnabelstizte von einer Maass Inhalt mit lrugelförmigem Deckelknopf. Meistermarke Nr. 445 zwei Mal auf dem Traghenkel. Kein Stadtzeichen. Bodenrosette Nr. 456. Am Korpus oben, in der Mitte und unten je ein circuläres Rillenpaar. An der Vorderseite fein gravirte Blattranken um den Schnabel und unterhalb desselben ein geschlossenes Blumenornament in einer Raute ; darunter ein Bänderknoten. Rechts und links des Ausgusschnabels die gravirten Initialen $H G$ und AB. (Tafel XLV, 3.)

Stitze ohne Schnabel von 1/2 Maas Inhalt mit flachem Deckel. Am Traghenkel das Meisterzeichen Nr. 445. Kein Stadtzeichen. Bodenrosette Nr. 457. Am Korpus oben, in der Mitte und am Fusse circuläre Rillen. Höhe $23 \mathrm{~cm}$. Durchmesser des Fusses 11,5 cm. als Deckelgriff ein einfaches Akanthusblatt (wie bei vielen Solothurner Stitzen). (Tafel XLV, 2.) 
Fisch, Johann Heinrich, Zinngiesser, wurde am 29. November 1744 geboren, heiratete am 15. Oktober 1772 Elisabeth Dürr, war im Jahre 1779 Mitglied des mittleren Rats und starb am 22. April 1789. Am 27. August 1777 siegelt er mit seinem Wappen : Meerjungfer mit Doppelschweif. $1 / 2$ mässige Stitze ohne Schnabel, in Zuger Privatbesitz.

Beck, Martin, Zinngiesser, lebte von 1729-1805. Seine Tochter Marie (geboren 1766 , gestorben 1827) heiratet 181 o den Zinngiesser Johann Wilhelm Gottschalk aus Tilsit oder Königsberg. Beck führte das Meisterzeichen Nr. 446. Bodenrosette Nr. 458.

Gegenstand: Schnabelstitze mit Deckelknopf von einer Maass Inhalt. Auf dem Traghenkel zwei Mal das Meisterzeichen Nr. 446. Kein Stadtzeichen. Bodenrosette Nr. 458. Korpus fast cylindrisch, mit wenigen circulären Rillen. Vorn neben und unterhalb des Schnabels die gravirten Initialen I ST und I. L. 1784. Kräftige Ausladung des Fusses. Höhe $28,8 \mathrm{~cm}$. Durchmesser des Fusses 13,8 cm. (Tafel XLV, 5.)

Gottschalk, Johann Wilhelm, Zinngiesser, aus Tilsit oder Königsberg, wurde im Jahre 1768 geboren, heiratete 1810 die Tochter Marie des Zinngiessermeisters Martin Beck, bei welchem er seit ca. 1795 als Geselle gearbeitet hatte. Mit der Heirat wurde er selbstständiger Meister und ist der Schöpfer der Aarauer Zinnfiguren-Industrie ${ }^{1}$. Man nannte ihn " den Bayern ", weil er unzweifelhaft in Nürnberg gelernt oder längere Zeit gearbeitet hatte. Von Nürnberg und Fürth stammt die Zinnfiguren-Industrie und wurde von Gottschalk nach Aarau verpflanzt. Viele Soldaten- und besonders Reiterfiguren gleichen stark denjenigen Hilperts von Nürnberg und vielleicht hat Gottschalk bei demselben gearbeitet. In Aarau arbeitete er mit Gesellen und Lehrlingen, unter welchen sich auch Ru'dolf Wehrli von Küttigen befand. Gottschalk starb im Jahre 1843 .

Er führte die Meisterzeichen Nr. 447, 448, 449. Bodenrosette Nr. 459.

Gegenstände : Stitzen, Teller, Platten, Zinnsoldaten und Batterien, eine schöne Hirschjagd, Lustgärten und Promenaden mit Figuren, Weiden mit Kühen, Schafen und Fohlen. Grosse Gemüseschüssel von 42,5 cm Durchmesser und $7 \mathrm{~cm}$ Tiefe. An der Unterseite des Bodens das Meisterzeichen Nr. 449 und das Aarauer Stadtwappen. Das Meisterzeichen ist eine Variante der Nr. 449, indem es die Initialen I. W. G. trägt.

Wehrli, Johann Rudolf, von Küttigen, Zinngiesser, wurde im Jahre 1801 geboren und trat 1814 bei Johann Wilhelm Gottschalk in die Lehre. Nach langer Lehrzeit ging er acht Jahre auf die Wanderschaft durch die Westschweiz, Deutschland (auch Nürnberg) und Oesterreich. Im Jahre 1824 finden wir ihn als Gesellen bei Jakob Ulrich Bauer in Chur. In Aarau eröffnete er erst Eñde der 2oer Jahre ein eigenes Geschäft. Auch er fabrizirte neben den üblichen Zinngegenständen Zinnfiguren. Auf seiner Verpackung nannte er sie "Zinnkompositionsfiguren ". Er hielt sich an die Modelle seines Meisters; doch machte er auch selbstständige Arbeiten. Er starb im Jahre ${ }_{1} 876$.

Er führte die Meisterzeichen Nr. 460 und 461 .

Gegenstände: Teller, Platten, Zinnfiguren aller Art. Eine besondere Spezialität waren



Wehrli, Friedrich, der Sohn des Vorigen, Zinngiesser, wurde im Jahre 1847 geboren. Im Jahre 1863 trat er bei seinem Vater für 3 Jahre in die Lehre. Nach dem Tode des Vaters führte er das Geschäft weiter, ohne etwas Neues zu schaffen. Der Betrieb ging immer mehr zurück und hörte im Jahre 1887 gänzlich auf. Damit erlosch in Aarau das alt-ehrwürdige Zinngiesserhandwerk.

\footnotetext{
${ }^{1}$ Wegleitungen des Kunstgewerbemuseums der Stadt Zürich. 1916. Nr. 12. Die Schweizer Zinnfiguren-Industrie von L. MeyerZschokke, Aarau.
} 


\section{Die Gegenstände}

Im historischen Museum von Aarau befinden sich einige mittelalterliche Zinngegenstände, welche anlässlich Ausgrabungen der 1356 zerstörten Burg Homberg gefunden wurden, zwei achtseitige Zinnkännchen, ein achteckiger Deckel, eine flache Zinnschüssel von $35 \mathrm{~cm}$ Durchmesser und ein Tellerchen (Tafel I).

Im Zeitalter des Zinnes, also vom XV. Jahrhundert bis 1798, war Aarau bernische Municipalstadt. Der Einfuss Berns ist auch deutlich bei den Kannenformen bemerkbar, indem es Aarauerkannen in Bernerform mit und ohne Steg gibt. Glockenkannen sind recht selten; dagegen gibt es prächtige, massige Stitzen, welche aber nur durch die Meisterzeichen zugewiesen werden können. Die Qualität des verwendeten Zinnes ist fast ausnahmslos eine sehr gute, und zwar sowohl bei den Kannen als auch bei den übrigen Zinngegenständen. Bei der Abstempelung fehlt ab und zu das Stadtwappen, dafür ist aber das Meisterzeichen oft zweimal eingeschlagen. Sogenannte Ratskannen sind nicht vorhanden. Prismatische Kannen mit dem Stadtzeichen von Aarau habe ich nicht finden können.

Die Zinnfiguren ${ }^{1}$. Wir finden dieselben nur in Aarau bei den drei Zinngiesseru Johann Wilhelm Gottschalk, Johann Rudolf und Friedrich Wehrli. Diese drei Meister verfertigten dieselben neben den übrigen Zinngegenständen. Den Impuls brachte Johann Wilhelm Gottschalk, welcher in Nürnberg diese Fabrikation kennen gelernt hatte. Die frühesten Modelle tragen den deutlichen Stempel der Frederizianischen und Napoleonischen Zeit. Die Uniformen sind bis in alle Details korrekt. Neben den kriegerischen Gestalten finden wir aber auch alle möglichen Typen aus dem bürgerlichen Leben. Der Einfluss der Maler Reinhard und König ist ein prägnanter bei der Darstellung von Bauern, Biedermeier-Herren und Damen. Ausser den Menschen wurden aber auch Tiere aller Art reproducirt, Jagden, Menagerien, Promenaden und Theater, u.s.w. Von eigenem Reiz ist die Darstellung des Paradises, voll komischer Bilder die Soldaten-Fassnacht.

Die Modelle zu den Figuren stammen kaum von den Zinngiessern selbst. Der Einfluss des in Aarau wohnenden Kunstmalers J. Reinhard ist deutlich. Auch ist die Mitarbeit des Zeichners und Plastikers F. Eggiman bei Gottschalk nachgewiesen. In Wehrlis Werkstatt hat Gottlieb Käser, J. Stirnimann und zeitweise ein Bruder Wehrlis die künstlerische Arbeit ausgeübt.

Die Gussform war bei den flachen Figuren zweiteilig in sächsischen Schiefer gravirt; bei den grossen Stücken, z. B. Räder, Geschützrohre, bestand die Form aus Messing. Das Material, die Zinn-Bleilegirung musste einerseits gut fliessen, um alle Einzelheiten im Relief zu geben, andererseits eine ziemliche Festigkeit besitzen, um nicht leicht zu verbiegen. Man nahm also ca. 2 Teile Zinn und 1 Teil Blei für die feinen Gegenstände, für die gröbern Teile beide Metalle zu gleichen Teilen. Nach dem Gusse mussten die Figuren von allen Gussansätzen der Guss- und Luftröhren mit Messerchen und kleinen Kneipzangen gereinigt werden, was eine mühevolle und unlohnende Arbeit war.

Die Bemalung war die letzte Etappe, welche bei Wehrli von der ganzen Familie betrieben wurde. Später kam die Heimarbeit zuhilfe, indem Frauen und Töchter des obern Fricktales damit beschäftigt wurden. Bei dem niedrigen Preise der fertigen Zinnfiguren war der Malerlohn auch ein entsprechend kleiner.

Die Zinnfiguren-Industrie hörte im Jahre 1887 gänzlich auf, indem der letzte Zinngiesser Friedrich Wehrli seine Werkstatt schloss. Die Matrizen zu vielen Aarauer Zinnfiguren befinden sich heute im schweizerischen Landesmuseum in Zürich.

Die chirurgischen Zinninstrumente, Kanülen, Bettpfannen, Spritzen aller Dimensionen, Katheter u. dgl. stammen aus der Werkstatt von Johann Rudolf Wehrli. Die Ansprüche der Asepsis, der Hartgummi und Kautschuk, entzogen der Zinn-Industrie rasch den Boden.

1 Wegleitungen des Kunstgewerbemuseums der Stadt Zïricb. 1916. Nr. 12. Die Schweizer Zinnfiguren-Industrie von L. MeyerZschokke, Aarau. 
TAFEL XLII







\section{BRUGG}

Aus dem alten Brugger Geschlechte der Jäger ${ }^{1}$ stammen die frühesten Kannengiesser von Brugg. Weil Vater und Sohn den gleichen Vornamen hatten und der Beruf in den Tauf- und Sterberegistern nicht angegeben ist, kann der Entscheid nur durch die Altersbestimmung der rvenigen erhaltenen Gegenstände gefällt werden, besonders durch die Jahrzahlen und den Stil. Vielleicht führten beide auch noch den gleichen Stempel zur Anbringung des Meisterzeichens. Das Stadtzeichen von Brugg besteht in einem Brückenkopf (siehe Nr. 452, Bd. I).

Jäger, I Hans Dietrich, lebte von 1630-1682.

Jäger, II Hans Dietrich, der Sohn, lebte von 1673-1734; er war Mitglied des Rates der Zwölf.

Seine Frau war Johanna Stäbli von Brugg (1674-1738).

Es ist nur das Meisterzeichen Nr. 452 bekannt.

Gegenstände: Stitzen ohne Schnabel von 1 und $1 / 2$ Maass Inhalt.

Kugelkrug mit aequatorialem Wulst; oberhalb und unterhalb desselben je neun herausgetriebene Buckel, welche mit Tremolirstichlinien eingefasst sind. Der Deckel trägt einen, Etagenknopf, der Deckelgriff wird durch ein Akanthusblatt gebildet. Der Traghenkel weist verticale Rillen auf. An der Unterseite des Bodens befindet sich das Stadtzeichen von Brugg und das Meisterzeichen Nr. 452. Höhe $19 \mathrm{~cm}$; Durchmesser des Fusses $10 \mathrm{~cm}$. (Tafel XVIII, 2.)

Jäger, Johann, Kannengiesser, der Sohn des Vorigen, lebte vom Jahre 1699 bis 1740. Seine Frau war Verena Vogt. Seine Tochter Johanna heiratete den Zinngiesser Johann Rudolf Frölich.

Gegenstände und Meisterzeichen habe ich nicht aufgefunden, vielleicht führte er ebenfalls dasjenige seines Vaters.

Frölich, Hans Rudolf, Zinngiesser, lebte von 1663-1722; seine Frau war Anna Marie Stäbli (gestorben 1737 ).

Frölich, I Johann Rudolf, Zinngiesser, der Neffe von Hans Rudolf I, lebte von 1696-1773. Ratsherr. Seine Frau war Anna Elisabethe Nägeli (1710-1761).

Frölich, II Johann Rudolf, Zinngiesser, lebte von $1726-1798$.

Er war mit Johanna Jäger, der Tochter des Zinngiessers Johann Jäger, verheiratet, welche von 1730-180o lebte- Er war Ratsherr auf der Schmittenbrugg.

Alle drei führten das Meisterzeichen Nr. 453. Bodenrosette Nr. 460.

Gegenstände: Stitze ohne Schnabel von 1 Maass Inhalt. Meisterzeichen Nr. 453 auf der Spitze des Deckels. Deckelmitte kegelförmig hochgetrieben. Am obern Teil des Korpus mehrere circuläre Linienpaare. Vorn die gravirten Initialen H. S. W. und die Jahrzahl 1763. Bodenrosette Nr. 46o. Höhe 28,5 cm; Durchmesser des Fusses 14,4 cm. (Tafel XLV, 6.)

Stitze ohne Schnabel von $1 / 2$ Maass Inhalt. Aeusseres der Kanne wie bei der vorigen Stitze. Meisterzeichen Nr. 453 auf der Spitze des Deckels. Bodenrosette Nr. 46o. Vorn unterhalb des Ausgusses die gravirten Initialen M. M. und die Jahrzahl 1779. Höhe 23,8 cm. Durchmesser des Fusses 11,2 cm. Am Oberteil des Korpus ein flacher circulärer Wulst und Rillen. (Tafel XLV, 7.)

Teller und Giessfass bei Herrn a. Bezirkslehrer Frölich in Brugg.

Die Brugger Zinngiesser verkauften ihre Erzeugnisse auch in Zurzach anlässlich der Frühjahrs- und Herbstmesse (Verena Messe). Laut den Aufzeichnungen des Stadtpfarrers Joh. Emanuel Feer-Frölich (1754-1833) soll das Zinngiesser-Gewerbe in Brugg anno $177^{\circ}$ "bereits eingegangen "sein.

\footnotetext{
' Die genealogischen Angaben verdanke Herrn a. Bezirkslehrer C. W. Frölich in Brugg.
} 


\section{BREMGARTEN}

Unter den "Kunstgeschichtlichen Notizen aus Bremgarten " von Walter Merz ${ }^{1}$ im Anzeiger für schweizerische Altertumskunde, finden sich folgende Kantengiesser :

"Hans Kolb, von Ruswyl, der Kantengiesser, ist zuo einem hindersessen uf und angenommen worden und hat uf dato synen inzug erleit. Den $19 t$. Januarii anno 1617 .

"Dem Martin Brakh, Kantengiesser, us dem Meilander Gepiet, wird die Ausübung des Handwerks in Bremgarten bewilligt. 1682. XI.3o. "

Gegenstände und Meistermarken sind keine bekannt. Doch findet man ab und zu Teller mit Züricher Meistermarken (I Andreas Wirz), welche das Beschauzeichen von Bremgarten (steigender Löwe mit dem Buchstaben B) und die Jahrzahl ${ }_{17} 57$ tragen. Demnach besass damals die Stadt keinen ansässigen Zinngiesser.

\section{MELLINGEN}

Gegenstände und Meistermarken sind nicht bekannt. Urkundlich ist zwei Mal ein Kantengiesser erwähnt, aber ohne Namensangabe.

\section{WETTINGEN}

Aus dem Kloster Wettingen stammt eine mächtige Glockenkanne, welche nur das eingeschlagene Klosterwappen (zweischwänzige Meerjungfer) aber kein Meisterzeichen trägt. Es ist also wohl möglich, dass das Zinngiesserhandwerk von einem Klosterinsassen ausgeübt wurde. Vielleicht ist aber das Klosterwappen nur das Besitzerzeichen, wie wir es auch in Einsiedeln und Engelberg finden.

\section{LENZBURG}

Im Buche Lehmanns "Die Burg Wildegg " findet sich folgende Stelle: Salome von Effinger-Mey, geboren 1677, dem Kannengiesser zu Lenzburg — Auftrag für 3 Dutzend Teller, 2 Dutzend Platten, 2 Suppenteller, kosteten 12 Gulden 2 Batzen. Eine Namensangabe fehlt.

\section{ZOFINGEN}

Herr Architekt Th. G. Gränicher hat 1917 eine ausführliche, auf archivalischen Studien und der Untersuchung des vorhandenen Zinnmateriales basirende Abhandlung herausgegeben. Die Arbeit erschien unter dem Titel "Das Zinngiesserhandwerk in Zofingen " im Anzeiger für schweizerische Altertumskunde, 1917, S. 26-42 und S. 99-121. Gränicher hat die Zinngegenstände von Zofingen, in den umgebenden Kirchgemeinden, in vielen Museen und Privatsammlungen untersucht. Das gesammte Notizenmaterial stellte er mir freundlichst zur Verfügung.

Zofingen liegt an wichtigen Durchgangsstrassen und hatte früher bedeutende Märkte. Das Zinngiesserhandwerk ist schon sehr früh nachweisbar und spielte eine erhebliche Rolle in der Belieferung bis weit in die Umgebung hinaus. Im Oberaargau, im angrenzenden Teil von Luzern und Solothurn findet man heute noch Zofinger Zinngeschirr.

\footnotetext{
${ }^{1}$ Anzeiger für schweizerische Altertumskunde, Jahrgang 1906. S. 318.
} 
Im "Tobinium politicum " Frikhardts wird unter den Ratsherren ein Zinngiesser Heinrich Bakenmejer im Jahre 1258 erwähnt, vielleicht das älteste diesbezügliche Zitat der Schweiz. Ohne Namenangabe, blos als "Kannengiesser ", berichtet die Stadtrechnung von 1448 und 1498; auch unter dem Namen "Kannenmacher ". Im XVI. Jahrhundert gab es fast immer einen Kannengiesser in Zofingen und ich verweise auf das Verzeichnis der Zinngiesser; am Ende des Jahrhunderts, 1577-79, vergab der Rat Arbeiten an den "Kannengiesser von Aarau ". Wahrscheinlich fehlte also in diesen Jahren eine einheimische Kraft. (GräNICHER, S. 35 u. ff.)

Die Zinngiesser gehörten neben den Rotgiessern, Schlossern, Schmieden, zur Gesellschaft der Ackerleute. Die Lehrzeit betrug vier Jahre; dann folgte eine zwei bis dreijährige Wanderschaft zur Ausbildung. Sehr interessant sind in Gränichers Arbeit die ausführliche Beschreibung des "Gruss und Handwerks-Gebrauch der Zinngiesser " des "Gruss beim versammelten Bott der Gesellen " und "die grosse Umfrage " (Gränicher, S. 31-33). — Für die Kontrolle der Zinn-Bleilegirung galt die Berner Probe. Doch wurde 1620 sogar die Legirung 2:1 gestempelt; dies geschah eben auch in den umliegenden Orten, besonders in Luzern und Solothurn.

Auch in Zofingen gab es Familien, in welchen das Zinngiesserhandwerk durch viele Generationen weiterlebte, so die Rudolf, deren erster 1598 von Schaffhausen nach Zofingen kam und deren Letzter 1722 starb. Bei den Müller findet sich dieser Beruf durch vier Generationen hindurch.

In Zofingen finden sich einige Meister, welche die üble Gewohnheit hatten, ab und zu fremden Zinngegenständen über das ursprüngliche Meisterzeichen das eigene aufzuschlagen. Diese Unsitte ist bei Moritz I Rudolf (GränICHER, S. 10o), besonders aber bei Johann Friedrich Lang und einmal bei Johann Rudolf Müller nachgewiesen (Gränıcher, S. 110). Die Verhältnisse von Friedrich Lang finden sich bei der Rubrik "Zinngiesser von Zofingen " genauer erörtert.

Auch in Zofingen wurde Zinngeschirr als Ehrengaben abgegeben, so 1484 bei einem Fest der Schneiderzunft; 1596 bei den Armbrust-Schützen, 1598 den Bogenschützen und 1599 sogar als Schulprämien, eine fast einzig dastehende Tatsache (GRÄNICHER, S. 27).

Die Zofinger Zinngiesser waren zum grössten Teil gute Fachleute und sehr produktiv. Das Zinngiesserhandwerk in Zofingen nimmt im Aargau weitaus die erste Stelle ein.

\section{Die Zinngegenstände von Zofingen}

Wohl nur wegen der geographischen Lage zwischen Nordost- und Westschweiz erklärt sich die Tatsache, dass in Zofingen Kannen fast sämmtlicher schweizerischen Formen hergestellt wurden. So finden wir die Glocken- und prismatischen Kannen, wie in der Nordostschweiz, ferner die Stitze in der Uebergangsform zum Solothurner Modell; ausserdem die Bernerform sowohl als Stegkanne wie als Typus II, also ohne Steg.

Sie Stitze ist die häufigste Kanne ; stets hat dieselbe einen schnabelförmigen Ausguss, oft mit Bartmannkopf. Am Deckeldrücker ist häufig ein reliefirtes Ornament oder ein geflügelter Engelkopf. In der Mitte der Leibung ist ein für Zofingen eigentümlicher breiter circulärer Wulst. Im Innern des Kannenbodens befindet sich eine schöne Bodenrosette; besonders interessant ist diejenige mit dem Froburger Wappen. Die Stitze kommt in vier Grössen vor, je nach dem Inhalt von 2, 1, $1 / 2$ und $1 / 4$ Maass.

Die Berner Kannenform hat in Zofingen ebenfalls ihre Eigentümlichkeiten. Am Deckeldrücker findet man, wie bei den Stitzen, oft den reliefirten Engelkopf oder ein architektonisches Ornament. In der Mitte des Henkels ist ein Ansatz angelötet, welcher nicht als Verstärkung zu betrachten ist. Derselbe erleichtert das Einschenken in dem Sinne, dass infolge des Ansatzes, die Hand nicht abgleiten kann. Als Ansatz wird oft der Deckeldrücker angelötet. Auch bei der Bernerform findet man ab und zu Bodenrosetten. 
Die Stegkannen finden sich in Grössen von 2, 1 und $1 / 2$ Maass. Die Form des Typus II in 1, 1/2 und $1 / 4$ Maass. Eine doppelmässige Stegkanne befindet sich im kleinen Museum von Wietlispach. Bei der Bernerform findet man ab und zu am Henkel ein Reliefband mit Blattund Blumenranken.

Die Glocken- und prismatischen Kannen finden sich bei den betreffenden Kannengiessern. Beide Kannenformen gehören zu den Seltenheiten und befinden sich meistens in den Kirchen als Abendmahlkannen, ab und zu als Ratskannen (nur zwei bekannte Glockenkannen).

Die Kugelkr üge waren wahrscheinlich Meisterstücke. Ich konnte nur drei Exemplare auffinden. Eines befindet sich im historischen Museum von Bern (Abbildung bei Gränicher, Tafel III, Nr. 9). Ein zweites Stück ist in einer bernischen und das dritte in meiner PrivatSammlung. Als Vorbild zu dieser Form dienten wohl die rheinischen Kugelkrüge aus Steinzeug, welche auch in der Schweiz sehr verbreitet waren und von fahrenden Händlern vertrieben wurden.

Eine Kannenform, welche in der ganzen Schweiz einzig dasteht, ist die Stitze mit Bartmannskopf und Reliefband von Johann Friedrich Lang. Es sind ebenfalls drei Exemplare bekannt, eines im schweizerischen Landesmuseum und zwei in meiner Sammlung, wovon eines mit dem Stadtzeichen von Burgdorf (Beschreibung siehe unter Lang, Zofingen, und Lang, Burgdorf).

Die Z ofinger Ma asse haben die gleiche Form wie diejenigen in Bern (siehe Abbildung auf Tafel II, Nr. 1, bei Gränicher, S. 17).

Teller, Platten und Schalen bieten keine Besonderheiten. Doch gab es in Oftringen einen Zinngiesser, welcher als Schalengiesser oft erwähnt wird, mit Namen Scheibler. Das Meisterzeichen ist nicht bekannt, nicht einmal die Tatsache, ob er eines führen durfte. Eine Maria Elisabeth Scheibler war die Frau des Zinngiessers Johann Rudolf Müller von Zofingen (GR̈̈NICHER, S. 110 ).

Die Giessfässer weichen nicht von der allgemein üblichen Form ab. Besondere Erwähnung verdient nur das Säulengiessfass von Josua Täschler (Abbildung bei Gränicher, Tafel IV, Nr. 3), welches zugleich das älteste Zinnstück von Zofingen ist (Sammlung Senn in Zofingen).

Die Stadtkannen von Zofingen und Willisau finden ihre Beschreibung beim Hersteller derselben, dem Meister Hans Müller.

\section{Die $Z_{\text {ofinger }} Z_{\text {inngiesser }}$}

\section{(Die Meisterzeichen siehe Band I, Tafeln XXIV und XXV.)}

Backenmejer, Heinrich, zitirt 1258 als Zinngiesser in Frikhardt's Tobinium politicum (nach Gränicher, S. 35, eine unsichere Quelle).

Nuikom, Heini, zitirt $147^{5}$ als Kantengiesser im Umgeltrodel (persönliche Mitteilung von Herrn Th. G. Gränicher, Architekt in Zofingen).

Matschi, Hans, erwähnt im Stiftsurbar von 1534 .

Foppell, Gunrat, zitirt im Zunftbuch der Schneider, in der zweiten Hälfte des XVI. Jahrhunderts.

Täschler, Josua, Kannengiesser, führte das Meisterzeichen Nr. 461 (Bd. I). Er wurde im Jahre 1558 getauft, wurde 1580 bei den Ackerleuten und Schneidern zünftig; heiratete im gleichen Jahre Agnes Ammann von Brugg. Zum letzten Male wird er 1587 zitirt, anlässlich der Taufe des jüngsten Sohnes (Gränicher, S. 36).

Gegenstand : Säulengiessfass (abgebildet bei Gränicher, Tafel IV, Nr. 3) der Zofinger Gesellschaft zu Schneidern. Der halbrunde Deckel ist abhebbar. Er trägt die Meistermarke Nr. 461. Es befindet sich in der Sammlung F. Senn in Zofingen. 

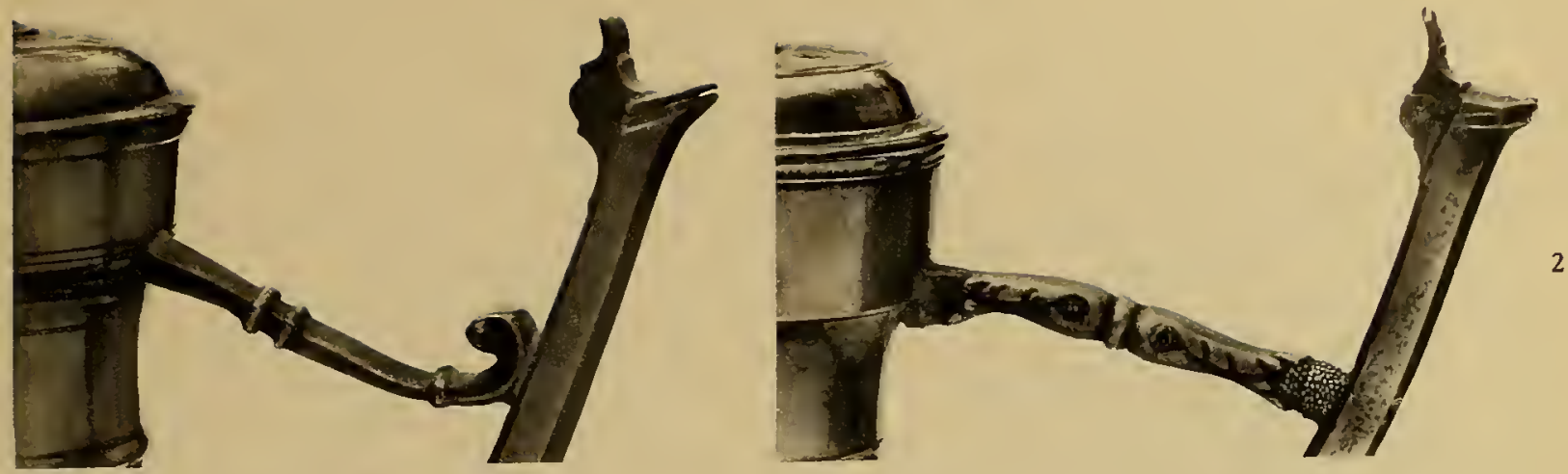

3

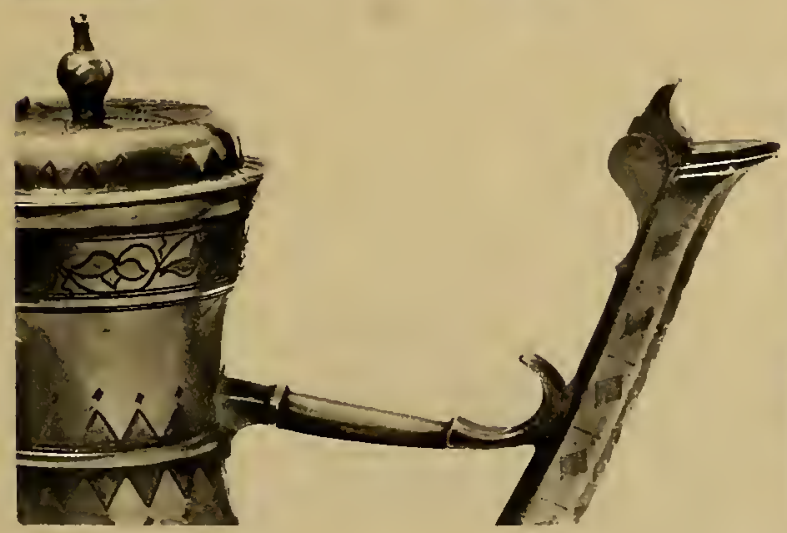

5

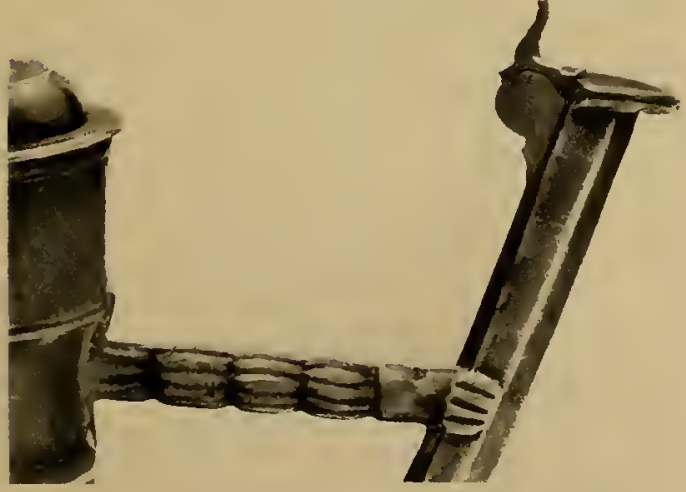

7

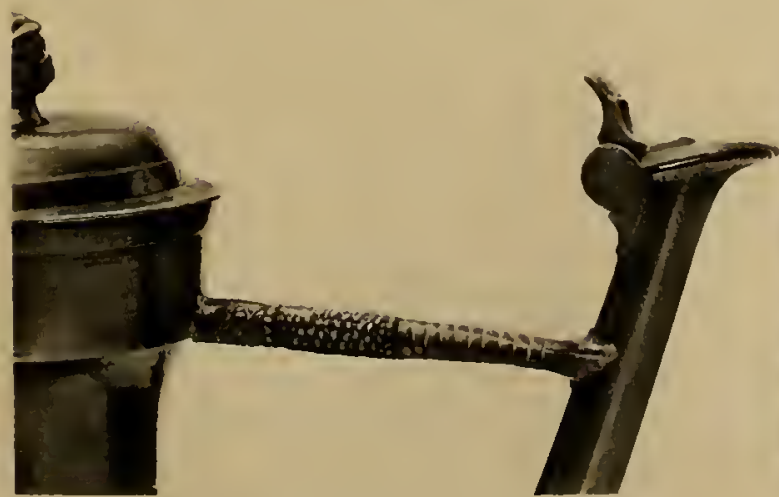

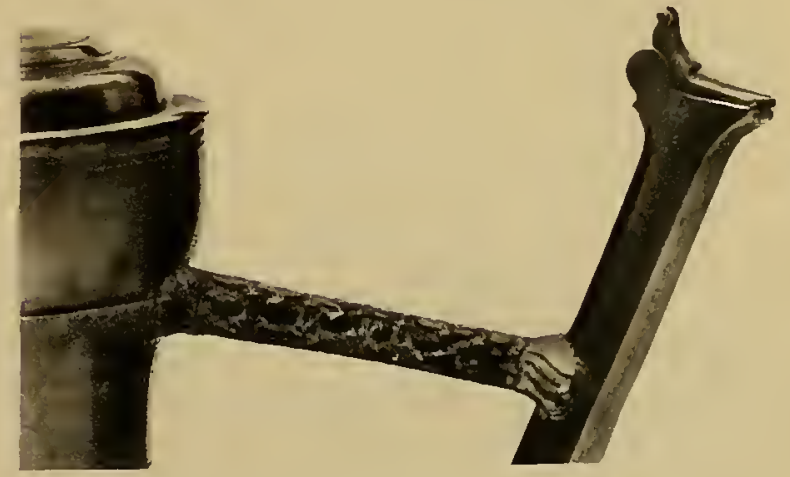


Verschiedene Formen des Stoges bei Bernerkannen: 1. Bernersteg bei den Zinngiessern S. B. Samuel Bodmer und Peter Küpfer, Bern. 2. Thunersteg der beiden Franz, Ludwig Naffzger. 3. unbezeichnet. 4. J. B. Jean Bon, Bulle. 5. Joh, Heinrich Petersohn, Bern. 6. Louis Roder, Bern. 7. Louis Roder und J. F. Meley, Bern. 8. Abraham und Jakob Ganting, Grütter etc., häufigster Bernersteg. 
Humler, Thomas, Kannengiesser, von Lindau. Laut Ratsmanual wurde er am 14. Januar 1589 als Bürger aufgenommen. Am 3. März des gleichen Jahres heiratete er Agnes Amman, die Wittwe Josua Täschlers. Er soll um 1624 gestorben sein (Gränicher, S. 37 u. 38).



462 a

Rudolf, Hans Ulrich, aus dem Schaffhauser Lande, Kantengiesser, führte das Meisterzeichen Nr. 462 a des Bandes II, wurde laut Ratsmanual I im Jahre 1598 Bürger; in erster Ehe mit Salome Mösching verheiratet; in zweiter Ehe mit Dorothea Sporn, welche den Stammbaum weiterführte. In den Rechnungen der Stiftsschaffner wird er von 1633-1647 zitirt; in den Stadtrechnungen 1638 und 1643 . Er starb 1646 oder 1647 . (Gränicher, S. 38, 39.) Gränicher kennt keinen Gegenstand.

Gegenstand : Mächtige Schnabelstitze; Höhe $35 \mathrm{~cm}$; Durchmesser des Fusses $15 \mathrm{~cm}$. Deckelknopf mit zwei runden Scheiben. Auf dem Deckel das Meisterzeichen mit den Initialen H. V. R., darum ein Z; daneben das Beschauzeichen von Zofingen. Korpus glatt, unten zwei circuläre Rillen. Innen am Boden sechsteilige Rosette (Landesmuseum in Zürich, Nr. 201). Auf dem Schnabeldeckel ein Alliancewappen als Eigentumszeichen. (Tafel XIV, 4.)

Schwarz, Hans Andreas, Kannengiesser von Lindau. Wurde laut Ratsmanual 1599 Bürger. Zitirt 1610 in der Stadtrechnung als Lieferant für die Armbrustschützen. Zuletzt erwähnt in der Stiftsschaffner-Rechnung von 1635. (Gränicher, S. 39.)

Rumpler, Elias, Kannengiesser von Nürnberg. Wurde im Jahre 1605 Bürger; erwähnt in der Stadtrechnung von 1609 für zwei Giessfässer auf das Rathaus; ferner für Kannen, Platten und Teller. Er war ein sehr guter Meister und Gränicher möchte seiner Kunst auch den Zunftbecher der Metzger zuweisen. Er hat die Form eines Schuhes und ist bei Gränicher abgebildet, Tafel III, Nr. 2. Rumpler soll 1611 an der Pest gestorben sein (persönliche Mitteilung von Herrn Architekt Th. Gränicher).

Krieg, Lienhart, Kannengiesser, Nachfolger im Geschäft Elias Rumplers. Zitirt in der Stadtrechnung von 1620 (Gränicher, S. 41).

Müller, Lienhart, Kannengiesser, von Zofingen. Sein Vater war der Schultheiss Jakob Müller. Er wurde im Jahre 1615 geboren, heiratete 1654 Elisabeth Friedrich und 1686 Magdalena Wyss. Im Jahre 1640 trat er in die Zunft oder Gesellschaft der Ackerleute. Im Jahre ${ }_{1648}$ oder 1649 lieferte er an das Stift. Er starb im Jahre 1703 (Gränicher, S. 41).

Rudolf, Moritz I, Kannengiesser, führte die Meisterzeichen Nr. 462, 463, 464; Sohn des Kannengiessers Hans Ulrich Rudolf. Moritz wurde im Jahre 1623 geboren; er heiratete Veronika Schärer. Zitirt in den Stiftsrechnungen von 1651-1653 (Gränicher, S. 41).

Gegenstände: Berner Kanne ohne Steg mit den Meisterzeichen Nr. 462 und 463 (Bd. I) und der eingravirten Jahrzahl 1668 (Gränicher, S. 41).

Zwei prismatische Kannen mit dem Meisterzeichen Nr. 463 (Bd. I). Höhe $41 \mathrm{~cm}$. Auf dem aufgelöteten Schild folgende Inschrift: "Der Kirch. 1669. und Gemein Winaw und Riken zustendig " (Gränicher, S. 41).

Stegkanne mit dem Meisterzeichen Nr. $464 \mathrm{im}$ schweiz. Landesmuseum in Zürich (Gränicher, S. 41).

Müller, Michael, Kannengiesser, führte das Meisterzeichen Nr. 477 (Bd. I). Er war der Sohn des Schultheissen Jakob Müller, wurde 1624 getauft und starb 1670 .

Gegenstand: Glockenkanne in der Kirche Uerkheim. Schild leer. Meistermarke Nr. 477 (Bd. I) (siehe Gränicher, S. 42).

Rudolf, Hans Heinrich, Kannengiesser, Sohn Hans Ulrichs, führte das Meisterzeichen Nr. 465 (Bd. I). Er wurde 1624 oder 1625 geboren. In den Stadtrechnungen wird er $16_{74}$ und 1688 erwähnt (Gränicher, S. 42).

Gegenstand: Glockenkanne mit Bajonetverschluss, im Museum von Zofingen; trägt das Meisterzeichen Nr. 465 . 
Hoffer, Moritz, Kannengiesser, erwähnt 1681 und $168_{2}$ in den Vogt-Rechnungen von Aarwangen (Gränicher, S. 99).

Rudolf, Samuel, führte das Meisterzeichen Nr. 470 (Bd. I); zitirt 1669 (Stammbaum der Rudolf, Gränicher, S. 34 und Fussnote).

Gegenstand: Bartmann-Stitze; Höhe $29,5 \mathrm{~cm}$; Durchmesser des Fusses 13,8 cm. Am Deckeldrücker ein reliefirter Engelkopf. Auf dem kuppelförmigen Deckel eine Traube als Knopf. Auf dem Schnabeldeckel das Meisterzeichen Nr. 470 (R undeutlich). Als Schnabel ein Bartmannkopf mit stark prominirenden Augen; unteres Augenlid kaum angedeutet. In der Mitte des Kannenleibes ein breiter, circulärer Wulst und Rillen. Rechts und links des Maskarons je eine grosse gravirte Tulpe. Unterhalb des Wulstes die Initialen E. L. H. Henkel glatt. Innen am Boden zwei ineinander liegende sechsteilige Rosetten. Siehe Nr. 496, Band I. (Tafel XLV, 10 Bd. II.)

Rudolf, David I, Kannengiesser, führte das Meisterzeichen Nr. 469. Er war der Sohn Hans Heinrich Rudolfs und wurde im Jahre ${ }_{1} 650$ geboren. In den Stadtrechnungen zitirt 1677. Er war auch Totengräber. (Gränicher, S. 99.)

Gegenstände: Berner Kanne ohne Steg. Höhe 26,2 cm; Durchmesser des Fusses $11 \mathrm{~cm}$. Deckeldrücker abgekröpft. Auf dem flachen, herzförmigen Deckel zwei circuläre Rillen und davor das Meisterzeichen Nr. 469. Ausgussteil hoch, mit vier circulären Rillenpaaren. In der Mitte des Halses ein starker Wulst und sechs Rillen. Glatter Korpus; breiter abgesetzter Fuss. Am Henkel ein Reliefband von Blatt- und Blumenranken. Innen am Boden Rosette Nr. 496. (Tafel XLV, 15.)

Stegkannen, erwähnt von Manfred Dürr in Burgdorf. (Gränicher, S. 99).

Rudolf, Moritz II, Kannengiesser, führte die Meisterzeichen Nr. 466,467 und 468 . Er war der Sohn des Moritz I und lebte von 1657-1729. Er heiratete in erster Ehe Esther Sprüngli und 1705 Anna Müller. (Gränicher, S. 100).

Gegenstände: Stegkanne, Höhe $31,3 \mathrm{~cm}$; Durchmesser des Fusses $13,6 \mathrm{~cm}$. Am Deckeldrücker ein reliefirtes Renaissance-Ornament. Auf dem kuppelförmigen Deckel ein gerillter Knopf. Davor zwei Mal das Meisterzeichen Nr. 467. Am Ausgussteil ein tiefes, circuläres Rillenpaar. In der Mitte des Halses ein breiter profilirter Wulst. Bauch ganz glatt. Als Steg ein Mannsarm im sechsteiligen Puffärmel. Steg samt der Hand flüchtig modellirt. Henkel mit Reliefband, fortlaufende Blattranken. An der Innenseite des Henkels, ungefähr in der Mitte, ein Ansatz zur Erleichterung beim Einschenken. Er trägt das gleiche Ornament wie der Deckeldrücker. Innen am Boden die Rosette Nr. 495 .

Stegkanne. Höhe 31,2 cm. Durchmesser des Fusses 13,5 cm. Am Deckeldrücker ein reliefirter Engelkopf. Auf dem kuppelförmigen Deckel ein hoher, zweiteiliger Knopf. Davor das Meisterzeichen Nr. 468 . Steg wie bei der vorhergehenden Kanne. In der Mitte des Halses ein feiner, schmaler Wulst und zwei Rillenpaare. Am Ausgussteil oben drei tiefe Rillen. Am Henkel ein gleiches Reliefband wie bei der Vorigen. Am Ansatz an der Innenseite das gleiche Ornament wie am Deckelgriff, ein Engelkopf. Innen am Boden die Rosette Nr. 498. (Tafel XLV, 13.)

Stegkanne, im Museum von Zofingen, mit dem Meisterzeichen Nr. 466 . Steg mit Akanthusblatt-Ornamenten.

Platte mit Meisterzeichen Nr. 468, erwähnt bei Gränicher, S. 1oo. In Solothurner Besitz.

Laufer, Daniel, Kannengiesser; erwähnt in den Stiftsrechnungen von 1703-1704. Zuletzt lebte er mit seinen Kindern als Armengenössiger im Spital und verunglückte tödlich im Jahre 1712 bei einer Geschützprobe. (Gränicher, S. 99 u. 100.)

Laufer, Jakob, Kannengiesser, führte das Meisterzeichen Nr. 476. Er lebte von 1683 bis 1746 . Im Jahre 1712 trat er in die Gesellschaft der Ackerleute; 1728 figurirte er in der Stadtrechnung für Reparaturen. Er war auch Totengräber. (Gränicher, S. 102.)

Gegenstand: Schnabelstitze. Höhe 21,5 cm. Durchmesser des Fusses 11,5 cm. Als Deckeldrücker ein Akanthusblatt (aussen aufgerollt). Auf dem kuppelförmigen Deckel 
ein Knopf mit zwei Etagen. Davor das Meisterzeichen Nr. 476; circuläre Linienpaare. Unterhalb der Mitte des Korpus ein starker circulärer Wulst und zwei Linien. Darunter ein schlecht gravirtes Metzgerwappen und die Initialen H C. B - A. A 1707. Am Henkel Reliefband mit Blattranken. Innen die Bodenrosette Nr. 498. Einziger bekannier Gegenstand.

Müller, Daniel, Kannengiesser, führte die Meisterzeichen Nr. 478, 479. Als Sohn des Kannengiessers Michael Müller wurde er 1661 getauft. Im Jahre 1683 trat er in die Gesellschaft zu Ackerleuten; 1686 wurde er Mitglied des grossen Rates und 1707 des kleinen Rates der XII. 1709 wurde er Mühleherr und 1714 Kornschaffner. Er starb hochangesehen am 5. November 1719. (Gränicher, S. 100-101.)

Gegenstände: Stegkanne, Höhe $31,3 \mathrm{~cm}$; Durchmesser des Fusses 12,9 cm. Am Deckeldrücker abgeschliffener reliefirter Engelkopf. Deckel kuppelförmig mit breitem flachem Rand. Auf der Mitte des Deckels ein hoher Knopf mit drei Etagen. Vorn am Rand das Meisterzeichen Nr. 478. Schlanker Steg mit Akanthusblatt-Ornament; vorn keine Hand. In der Mitte des Halses ein hoher aber schmaler Wulst. Korpus glatt. Henkel glatt, in der Mitte ein Ansatz. Um den Ansatz der Ausgussröhre leichte Verzierung im Tremolirstich. Bodenrosette Nr. 499. (Tafel XLIV, 4.)

Berner Kanne ohne Steg, Höhe 29,3 cm; Durchmesser des Fusses 12,9 cm. Oberer Teil des Deckeldrückers fehlt. In der Mitte des herzförmigen Deckels eine Halbkugel, darum herum drei circuläre Rillen; zwischen denselben das Meisterzeichen Nr. 478 und zwei S-förmige eingeschlagene Schnörkel. Ausgussteil hoch; in der Mitte des Halses ein kräftiger schmaler Wulst. Korpus gegen den Hals abgesetzt (auch bei der vorherigen Kanne). Korpus glatt. Henkel glatt; vorn in der Mitte der zofingerische Ansatz. Bodenrosette Nr. 499.

Platten mit dem Meisterzeichen Nr. 478 in der Kirche von Zofingen; ebenso eine doppelmässige Stitze als Abendmahlkanne (Gränicher, Tafel V, Nr. 7) mit reliefirtem Henkel.

Giessfass im Rathauskeller der Stadt Zofingen; datirt 1709 mit Meistermarke Nr. 478. (Gränicher, Tafel IV, Nr. 5 a.)

Sechsseitig prismatische Kannen im Museum von Zofingen. (Gränicher, Tafel V, Nr. 6), Mit Bajonetverschluss.

Stegkanne, in Privatbesitz in Burgdorf, mit dem Meisterzeichen Nr. 479. (Gränicher, S. 102.$)$

Rudolf, Jakob, Kannengiesser, Sohn des Moritz II, führte das Meisterzeichen Nr. $468 b$ (Bd.II),

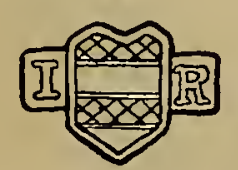

$468 \mathrm{~b}$ wurde 1687 getauft und starb 1761. Wurde städtischer Bannwart. Zwei Gegenstände und das Meisterzeichen sind bekannt. Das Meisterzeichen besteht im Zofingerschild, rechts und links davon I R.

Gegenstand: Humpen, Höhe $16 \mathrm{~cm}$; Durchmesser des Fusses 10,5 cm. Als Deckeldrücker ein Akanthusblatt. Auf dem Deckel Knopf in zwei Etagen. Der ganze Korpus ist mit fein gravirten Blumen überzogen. Am Traghenkel die Meistermarke I. R. Bodenrosette ähnlich Nr. 497. Unikum.

Grosse Stegkanne von 1 Maass, Meisterzeichen Nr. 468 b, auf dem Henkel. Unikum.

Rudolf, Daniel I, Kannengiesser, führte das Meisterzeichen Nr. 471. Er war ebenfalls ein Sohn des Moritz II. Er wurde 1690 getauft, trat 1729 in die Gesellschaft der Ackerleute; 1728 heiratete er Salome Lienhardt und starb 1763. (Gränicher, S. 102.)

Gegenstände: Schnabelstitze, Höhe $31,5 \mathrm{~cm}$; Durchmesser des Fusses 13,6 cm. Abgekröpfter Deckeldrücker. Kuppelförmiger Deckel mit kreisförmigen Scheibchen in der Mitte. Auf demselben das Meisterzeichen Nr. 471. Auf dem Schnabeldeckel Spuren der Ziehklinge. In der Mitte des Korpus ein sehr breiter, flacher, profilirter Wulst; oberhalb desselben die gravirten Initialen V. W. Der Fuss hat eine ziemlich starke Ausladung. Henkel glatt, ohne Ansatz in der Mitte. Innen im Boden die Rosette Nr. 498. (Tafel $\mathrm{XLV}, 12$. 
Schnabelstitze; Höhe 17,1 cm; Durchmesser des Fusses 9,1 cm. Als Deckeldrücker ein Akanthusblatt. Auf der Mitte des kuppelförmigen Deckels ein kreisförmiges Scheibchen mit der Meistermarke Nr. 471. In der Mitte des Korpus ein sehr breiter, flacher, profilirter Wulst. Fuss mit starker Ausladung. Henkel glatt, ohne den Ansatz in der Mitte. Bodenrosette undeutlich.

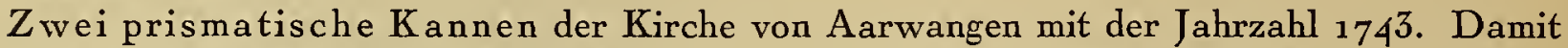
konnte die Meistermarke des Daniel I Rudolf mit Sicherheit bestimmt werden. (Gränicher, S. 102-103.)

Stegkanne von 1/2 Maass Inhalt; Höhe 24,3 cm; Durchmesser des Fusses $10 \mathrm{~cm}$. Steg-Arm mit Akanthusblättern ohne Hand. Auf der Kuppel des Deckels das Meisterzeichen Nr. 471. (Sammlung F. Pappe, Bern.)

Müller, Hans, Sohn des Kannengiessers Daniel Müller, führte die Meisterzeichen Nr. 48o, 481, 482,483 . (Bd. I.) Er wurde im Jahre 1691 getauft und starb 1765. Er war 1741 Grossweibel, 1755 des kleinen Rats und 1759 Armenverwalter. (Gränicher, S. 103-107.) Er war der produktivste und einer der besten Zinngiesser Zofingens. Seine Frau hiess Barbara Müller und starb 8 Jahre nach dem Tode ihres Mannes, also im Jahre 1773.

Gegenstände: Kugelkrug, Höhe 18,7 cm; Durchmesser des Fusses 9,6 cm. Höhe bis zum obern Rand $15,5 \mathrm{~cm}$ (also ohne Deckel); oberer innerer Durchmesser 6,2 cm. Als Deckeldrücker ein ovales, hinten hohlgegossenes Akanthusblatt, wie bei den Deckeln der rheinischen Steinzeugkrüge. Deckel kuppelförmig, in der Mitte der bei Hans Müller übliche, kegelförmige, fünffach gerillte Knopf. Davor das Meisterzeichen Nr. 480 (Bd. I). Der Rand des Deckels ist gewellt und passt in einen rechtwinklig abgesetzten Falz des Korpus. Der Kannenleib ist kugelförmig und aus demselben sind sechs herzförmige Buckel herausgetrieben, welche mit Tremolirstich eingefasst sind. In den untern dreieckigen


förmige in haarfeiner Ausführung. Oberhalb der sechs Buckel sind zwei Linienpaare und dazwischen wiederum ein wellenförmiges Band steiler, haarfeiner Zickzacklinien. Oben am Korpus schliesst der cylindrische Halsteil an, welcher aus vier breiten circulären Wellen besteht. Der breit auslandende Fuss zeigt deutliche Spuren der Vibrationen des Drehbankes. Der Henkel besteht aus einem flachen, profilirten Zinnband, welches oben die Initialen seiner Frau B. M., Barbara Müller, trägt. (Ausführliche Beschreibung, weil der Kugelkrug von David II Rudolf, im historischen Museum von Bern, ausserordentlich ähnlich ist (Abbildung Tafel III, Nr. 9, von Gränicher, S. 29).) (Tafel XVIII, 3.)

Schnabel-Stitze, Höhe 28,6 cm; Durchmesser des Fusses ${ }_{13} 3 \mathrm{~cm}$. Abgekröpfter Deckeldrücker. In der Mitte des kuppelförmigen Deckels ein kegelförmiger, fünffach gerillter Knopf. An der rechten Seite des kuppelförmigen Teils das Meisterzeichen Nr. 480. Etwas oberhalb der Mitte des Korpus ein breiter, flacher, circulärer Wulst und je sechs feine Linien. Rechts und links vom Ausgusschnabel grosse gravirte Blumenranken und starke und feine Tremolirstichzeichnungen. Korpus vom Fuss schwach abgesetzt. Henkel glatt. Innen am Boden die Rosette Nr. 499 (das Wappen der Grafen von Froburg).

Schnabelstitze, gleiche Maasse. Der Wulst in der Mitte des Korpus ist breiter als bei der vorgehenden Kanne. Fussdurchmesser $14 \mathrm{~cm}$. Unterhalb des Wulstes, vorne in der Mitte, die gravirten Initialen L B M. Gleiche Bodenrosette Nr. 499.

Schnabelstitze von $1 / 2$ Maass Inhalt. Höhe 24,2 cm. Durchmesser des Fusses 11,1 cm. Deckelgriff abgekröpft. In der Mitte des kuppelförmigen Deckels ein kreisförmiges Scheib chen mit dem Meisterzeichen Nr. 48o. In der Mitte des Korpus ein flacher, breiter, circulärer Wulst und viele feine Linien. Oberhalb desselben die gravirten Initialen $\mathrm{K}$. E. Im Kannenboden die Bodenrosette Nr. 5oo. (Tafel XLV, 9.)

Schnabelstitze von 1/4. Maass Inhalt, "Quärtli ". Höhe 17,5 cm. Durchmesser des Fusses 8,7 cm. Deckeldrücker abgekröpft. In der Mitte des kuppelförmigen Deckels der kegelförmige Rillenknopf. Davor das Meisterzeichen Nr. 48o. In der Mitte des Korpus 

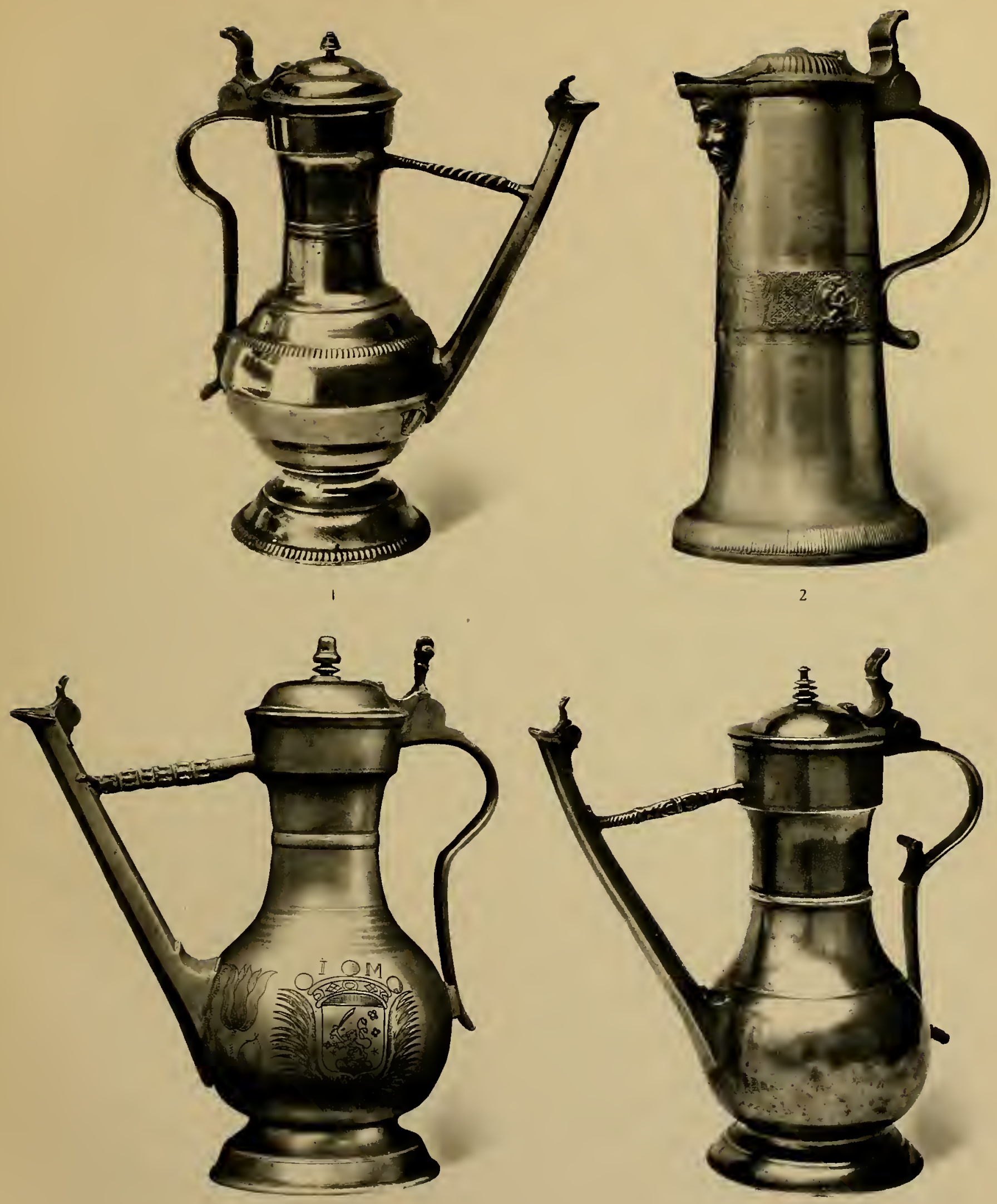

4

1, 4 Stegkannen von Zofingen. 2. Reliefirte Zofinger-Stitze mit Maskaron. 3. Stegkanne von Bern, von Abraham Ganting mit Schützengabenstempel, fein gravierte Blumen und Matti-Wappen. 

ein breiter flacher Wulst. Am Henkel ein reliefirtes Band von Blättern und Blumen. Bodenrosette Nr. 5oo. (Tafel XLV, 8.)

Berner Kanne ohne Steg, "Quärtli ", Höhe 19,5 cm; Durchmesser des Fusses 8, 5cm. Deckeldrücker abgekröpft. In der Mitte des flachen, herzförmigen Deckels eine kleine kegelförmige Erhöhung; davor das Meisterzeichen Nr. 48o. Am Ausgussteil zwei breite Rillen. Hals glatt. Am obern Teil des Korpus drei breite flache Wellen. Fuss stark abgesetzt. Henkel glatt, mit der typischen Berner Schweifung. (Tafel XLV, 16.)

Schnabelstitze von 2 Maass Inhalt in der Kirche von Wynau. Höhe $35 \mathrm{~cm}$ (Gränicher, S. 104$)$. Meisterzeichen Nr. 480.

Stegkannen im Museum Burgdorf.

Prismatische, sechsseitige Kannen im Rathaus von Zofingen.

Bulgen der Kirchgemeinde von Zofingen, von 6 Maass Inhalt; sie tragen die Meisterzeichen Nr. 481 und 482 . Höhe ohne Henkel 47,3 cm. Breite des Fusses 33,3 cm. Sie tragen als Schild das Bernerwappen im Renaissancestil. Mit Gränicher gehe ich einig, dass Hans Müller nur den Hals und den Deckel angebracht hat, während die Kannenleiber viel älter sind.

Prismatische, sechsseitige Kannen von $38 \mathrm{~cm}$ Höhe, mit dem Meisterzeichen Nr. $48 \mathrm{I}$ und 482, gehören ebenfalls der Kirchgemeinde von Zofingen (Gränicher, S. 1 o5).

Kaffeekanne im Museum von Zofingen mit der Meistermarke Nr. 481, nur der Engel allein.

Die vier Stadtkannen von Zofingen, im historischen Museum von Zofingen aufgestellt, sind von eigenartiger Form, ähnlich den Kannen des kleinen Rats von Basel oder den vier Kannen der Universität Basel. Auf einem vierseitigen, profilirten Fuss sitzt in einer klammerartigen Fassung der senkrecht gestellte linsenförmige Korpus. Im kreisrunden Mittelfeld befindet sich das rot-weiss gemalte Wappen von Zofingen. Der Hals ist wie der Fuss mit dem Korpus verbunden und darauf liegt der herzförmige Deckel mit dem kugligen Knopf. Der schmiedeiserne Henkel, originell geschweift, ist vermittelst zweier Oesen am Korpus befestigt und frei beweglich. Die Kannen tragen die Meistermarke Nr. 480. Vielleicht stammen diese Kannen vom Sohne Hans Müllers, der des Vaters Meisterzeichen oft benutzte. (Tafel VII, 3.)

Die vier Stadtkannen von Willisau tragen ebenfalls das Meisterzeichen Hans Müllers und zwar Nr. 483 in Verbindung mit dem Zofingerwappen von Nr. 481 . Auf dem kreisrunden Mittelfelde des Corpus ist das Willisauer Stadtwappen aufgemalt, ein schreitender Löwe auf einem Dreiberg. Es sind nur noch zwei Kannen in Willisau vorhanden; die andern zwei Stücke wurden leider ins Ausland verkauft. (Tafel VII, 4.)

Müller, Johann Rudolf, Zinngiesser, der Sohn des Hans Müller, benutzte meistens die Meisterzeichen seines Vaters. Johann Rudolf wurde 1725 getauft; 1749 heiratete er Marie Elisabeth Scheibler, des Schalengiessers von Oftringen; er starb am 1o. August 1789. Wahrscheinlich arbeitete er anfänglich mit seinem Vater zusammen (Gränicher, S. 110). Sein eigenes Meisterzeichen ist $\mathrm{Nr} .484$ und 485 (Bd. I).

Gegenstände mit den Meisterzeichen Nr. 484-484. Nur Teller und Platten, oft mit Barokrändern. Eine Schale im Museum von Zofingen.

Hürsch, Johann, Zinngiesser; geboren 1691; gestorben 1740. Weder Gegenstände noch Meisterzeichen sind bekannt (Gränicher, S. 107).

Genelat, Samuel, Zinngiesser; getauft 1706; gestorben 1778. Wahrscheinlich nur Schalengiesser, als Hersteller von Tellern, Platten und Schalen (Gränicher, S. 109).

Rudolf, David II, Zinngiesser, führte die Meisterzeichen Nr. 472, 473, 474 (Bd. I). Er wurde im Jahre 1712 geboren und starb 1784. Seine Frau hiess Susanna Senn (1711-1764). Er war auch Torwächter am obern Tor (Gränicher, S. 109).

Gegenstände: Stegkanne, Höhe 32,2 cm; Durchmesser des Fusses 13,4 cm. Deckelgriff abgekröpft; in der Mitte des kuppelförmigen Deckels ein Knopf mit zwei Etagen; davor das Meisterzeichen Nr. 472. Ausgussteil niedrig; Hals schlank, in der Mitte ein 
flacher, breiter Wulst und viele circuläre Linien. Schlanker Steg mit Akanthusblättern; keine Hand. Zwischen Hals und Korpus zwei breite circuläre Wellen. Am Aequator des Korpus zwei Linienpaare; an der rechten Seite die gravirten Initialen HR. M. Glatter Henkel mit Ansatz in der Mitte. Bodenrosette Nr. 497. (Tafel XLV, 11.)

Berner Kannen ohne Steg, Kirche von Aarwangen.

Stitzen im Museum Zofingen.

Kugelkrug mit herzförmigen Buckeln. Im historischen Museum von Bern (abgebildet bei Gränicher, Tafel III, Nr. 9). Er gleicht vollkommen dem vorhin beschriebenen Kugelkrug von Hans Müller, welcher von beiden der ursprüngliche ist, kann kaum entschieden werden. Beim Kruge von David II Rudolf sind die herzförmigen Buckel mit gut gravirten Blumen überzogen; die Zwickel sind gleich behandelt wie bei Hans Müller. Bei letzterm Krug ist der Hals gewellt. bei Rudolf ist er glatt.

Giessfass, im Museum von Zofingen (nach Mitteilung von Herrn Th. Gränicher), mit dem Meisterzeichen Nr. 473, in Verbindung mit dem Zofingerwappen des Stempels Nr. 472.

Rudolf, Daniel II, führte das Meisterzeichen $\mathrm{Nr}$. 475 (Bd. I). Er lebte von 1731 bis 1788 ; war der Sohn von Daniel I Rudolf und neben seinem Beruf als Zinngiesser auch Stadtbote. Wahrscheinlich hat er das Geschäft seines Vaters ab ${ }_{17} 63$ selbstständig weitergeführt. (Gränicher, S. 111.)

Gegenstände: Schnabelstitzen, ähnlich denjenigen Hans Müllers, mit dem Meisterzeichen Nr. 475. Der circuläre Wulst liegt oft unter der Mitte des Korpus und wirkt damit ungünstiger.

Lang, Johann Friedrich, Zinngiesser, führte die Meisterzeichen Nr. 486, 487, 488, 489 (Bd. I). Er lebte von 1706 bis 1787 , war aber im Alter krank und arbeitunfähig. Ab 1777 erhielt er vom Rat Unterstützung, nach der Entlassung als Nachtwächter. Er war ein unruhiger Geist, der alles probirte und dem aber fast alles finanziell misslang. Im Anfang scheint es ihm in Zofingen schlecht gegangen zu sein; denn 1738 eröffnete er auch in Burgdorf eine Werkstatt, blieb aber nur 2-3 Jahre. Wenn man viele seiner Erzeugnisse untersucht, so kommt man doch zum Schlusse, dass er ein ausgezeichneter Zinngiesser war. Er lieferte oft wundervolle Stitzen von wahrhaft künstlerischer Form und Dekoration. Allerdings war er in der Wahl der Mittel ohne Gewissensbisse. Den Bartmannkopf kopirte er von Franz Jaus von Solothurn; die reliefirten Ornamente irgend einem Goldschmied. Warum er aber Baslermarken mit der seinigen überstempelte und zwar in einer Art und Weise, dass man es auch heutzutage auf den ersten Blick sieht, ist unbegreiflich. Vielleicht hat aus Rache für dieses Gebaren ein Basler Zinngiesser ${ }^{1}$ oberhalb dem Meisterzeichen F L den Stempel PRO FL eingeschlagen, siehe Nr. 489 (Bd. I). Es ist aber auch ebenso wohl möglich, dass der arme Teufel zeitweise nur noch Handel treiben konnte und für einen Basler Zinngiesser Geschirr verkaufte.

Die Ornament-Stitzen mit Bartmannkopf von Zofingen und von Burgdorf sind Meisterwerke der schweizerischen Zinngiesserei und mit Sicherheit nur von Lang allein hergestellt worden; ebenso die prachtvoll geformte Stitze in der Sammlung L. Gally, Basel. Das Kopiren von Modellen und Ideen wurde eben früher anders beurteilt, als in unsern Zeiten. Ich erinnere nur an die Kopien, welche Kaspar Enderlin nach den Arbeiten von Briot anfertigte, wenn auch mit teilweiser Umarbeit. Der Ansicht Gränichers (S. 107), als habe Lang ungestempelte Solothurner Kannen mit Maskaron einfach mit seiner Marke versehen, kann ich nicht beipflichten. Im Gegenteil ist, nach Untersuchung der verschiedenen Maskaronmodelle, der Schluss berechtigt, Lang habe stets mit dem gleichen Modell (nach Franz Jaus) gegossen.

Gegenstände: Bartmann-Stitze, Höhe 29,7 cm; Durchmesser des Fusses $14 \mathrm{~cm}$. Deckeldrücker wenig abgekröpft. In der Mitte des kuppelförmigen Deckels befindet sich

${ }^{1}$ Emanuel Scholer. Es handelt sich um die Zusammensetzung einer Zürcher-Stitze mit einem Snlnthurner Bartmann-Ausguss, also eine richtige Parndic auf Lang. Das Stück ist einzig. 
eine radiär gerippte Halbkugel. Vor derselben ist das Meisterzeichen Nr. 488 (Bd. I). Die Wand der Deckelkuppel wird von einem breiten Perlstab gebildet. Auf dem Schnabeldeckel sind im Tremolirstich die Initialen B L eingravirt. Der Bartmannkopf ist nach dem Modell von Franz Jaus (Solothurn) gegossen. In der Mitte des Korpus läuft das Reliefband wie bei der Burgdorfer Stitze Langs, mit den Medaillons der Kriegerfiguren; die zwei vordern Vasenmedaillons sind weggelassen. Dafür gehen die feinen Gravuren, welche den Bartmannkopf einfassen, über das Band hinunter, indem sie die Initialen B C und B L einschliessen. Oberhalb des Fusses befindet sich ein breites Band von verticalen Rippen (primitiv modellirt). Henkel glatt. Keine Bodenrosette. (Tafeln XLIV, 2; XLV, 14.)

Bartmann-Stitze mit dem Beschauzeichen von Burgdorf von Friedrich Lang, siehe bei Burgdorf.

Bartmann-Stitze, wie die vorangehende, mit dem Meisterzeichen Nr. 489 (ohne Pro F. L.) von Friedrich Lang; befindet sich im Landesmuseum in Zürich. Das Reliefband ist gleich wie bei der Burgdorfer Stitze. Auf dem Deckel befindet sich aber ein ähnliches Medaillon wie im Reliefband.

Schnabel-Stitze von 1/2 Maass Inhalt. Höhe 22,7 cm; Durchmesser des Fusses 11,5 cm. Kleiner, abgekröpfter Deckeldrücker. Kuppelförmiger Deckel mit einem Kegelstumpf als Deckelknopf. Um den Ausgusschnabel herum gravirte Blattornamente. Am Korpus zwei Paare gerillter Linien. Dazwischen vorne ein gravirtes Blumenornament. Keine Bodenrosette. Am glatten Henkel das Meisterzeichen Nr. 489 (ohne Pro F L).

Humpen, Höhe $18,8 \mathrm{~cm}$. Durchmesser des Fusses 11,5 cm. Deckeldrücker abgekröpft. In der Mitte des kuppelförmigen Deckels ein schlanker Knopf. Der ganze Deckel ist überzogen mit haarfeinen, radiären Tremolirstich-Bändern. Korpus cylindrisch, durch Gravirung in fünf Ovale eingeteilt, in welchen sich fein gravirte Blumenzweige befinden. Fuss mit starker Ausladung. Am flachen Henkel das Meisterzeichen Nr. 487 (Bd. I) ohne irgendwelche Ueber- oder Unterstempelung. Keine Bodenrosette.

Humpen. Höhe 15,2 cm; Durchmesser des Fusses 11,3 cm. Auf dem Deckel eine Traube an Stelle des Knopfes. Der cylindrische Korpus zerfällt in sechs Ovale, welche buckelförmig herausgetrieben sind. Darauf befinden sich fein gravirte Blumenzweige. Fuss mit starker Ausladung. Auf dem bandförmigen Henkel befindet sich das Meisterzeichen Nr. 489 über einem Baslerstempel (Nr. 490, Bd. I). Keine Bodenrosette. (Tafel XIX, 6.)

Stegkanne mit apartem Steg, elegante Form des Korpus, circuläre Perlstäbe. (Sammlung L. Gally, Basel.) (Tafel XLIV, 1.) Form des Korpus mit deutlichem deutschem Einfluss.

Sutermeister, Johann Heinrich, Zinngiesser, führte als Meisterzeichen Nr. 491 (Bd. I). Er wurde 1757 getauft; heiratete 1786 Elisabeth Ringier und starb im Jahre 1814.

Gegenstände: Suppenschüsseln in einfachster Ausführung, im Museum von Zofingen. Mit dem Meisterzeichen Nr. 491, in Verbindung mit dem Zofinger-Wappen des Stempels Nr. 481 (siehe Gränicher, S. 111).

Frikart, Daniel, Zinngiesser, führte die Meisterzeichen Nr. 492, 493 und 494 (Bd. I). Er wurde $177^{5}$ getauft; trat $179^{2}$ für 4 Jahre bei J. H. Sutermeister in die Lehre und ging dann auf die Wanderschaft; 1802 erhielt er das helvetische Patent als Meister. Er starb 1814. (Gränicher, S. $112-113$.

Gegenstände: Stitze mit Schnabel in der Form einer Schaffhauser Stitze. Sie trägt das Meisterzeichen Nr. 492 (Bd. I). Museum von Zofingen.

Giessfass, gewöhnliche Form; auf dem Deckel zwei Engelköpfe. Trägt das Meisterzeichen Nr. 492. Sammlung Th. Gränicher.

Schüssel und Teller in Zofinger Privatbesitz mit dem Meisterzeichen Nr. 493.

Glockenförmige Kruse, Höhe 26,8 cm; Durchmesser des Fusses 17,4 cm. Auf dem Schraubdeckel ist ein beweglicher Tragring; darum herum drei circuläre Rillen. Der Korpus ist durch circuläre Rillen in fünf, ungefähr gleiche Zonen gegliedert. In der Mitte des glatten 
Bodens befindet sich das Meisterzeichen Nr. 494 (Bd. I). Innerhalb des Schraubdeckels ist noch ein zweiter, eingesetzter Deckel mit Knopf wie bei den Bettwärmeflaschen. (Tafel XXXII, 11.)

\section{BADEN}

Es ist mir bis im Mai 1934 niemals gelungen, Zinngegenstände und Zinnmarken von Baden zu finden, auch nicht in der historischen Sammlung in Baden. Dagegen finden sich im Wappenbuch der Stadt Baden von Walter Merz (Aarau, 1920) folgende Kannen- und Zinngiesser :

Falk, Johannes, Sohn des Ulrich Falk, wird 1504 im Zürcher Glückshafenrodel erwähnt; als gestorben wird er am 9. September 1549 zitirt. (Merz, S. 8o u. ff.) (Stammtafel 10.)

Falk, Caspar, ist der Meister der grossen Kannen der Stadt Baden. Die Beschreibung findet sich Seite ... Sie tragen das Meisterzeichen Nr. $500 a$ und $b$ (Bd. II). (Tafel IV, 3.)

von Aegeri, Heinrich, Sohn des Felix, wurde am 3o. Juli 1544 ge-

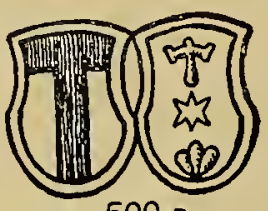

500 a


tauft, 1584 als gestorben erwähnt. (Merz, Stammtafel 1.)

Eckert, Christoffel, von Cham, wird am 12. Januar 1622 als Bürger aufgenommen. (Merz, S. 370 .)

Wegmann, Hans Heinrich, Sohn des Bernhart, wurde am 3. Juni 1620 getauft, heiratete am 24. Januar 1644 und starb am 7. September 1699. (Merz, Stammtafel 28.)

Keller, Franz, Sohn des Hans Caspar, wurde am 23. Oktober 1631 getauft, heiratete am 23. November 1653 und starb am 6. April 1721. (Merz, S. 40, 156 u. Stammtafel 8.) 


\section{DIE SÜDWESTSCHWEIZ}

$\begin{array}{ll}\text { Genf: } & \text { Genf. } \\ \text { Waadt : } & \text { Lausanne. } \\ & \text { Vevey. } \\ & \text { Yverdon. } \\ & \text { Orbe. } \\ & \text { Payerne. } \\ & \text { Moudon. } \\ & \text { Morges. } \\ & \text { Gland bei Morges. } \\ & \text { Grandson. } \\ & \text { Neuenburg. } \\ & \text { Môtiers-Travers. } \\ \text { Neuenburg : } & \text { Sitten. } \\ & \text { Visp. } \\ \text { Wallis : } & \text { Brig. } \\ & \text { Leuk. } \\ & \text { Martigny. } \\ & \text { Monthey. } \\ & \text { Tessin. }\end{array}$

\section{GENF}

Ueber das Zinngiessergewerbe in Genf hat Herr Ernest Naef ein grosses Werk herausgegeben unter dem Titel : L' Etain et le livre au potier d'étain genevois. 1920. Dasselbe enthält nicht nur alle Angaben über die Zinngiesser, ihr Leben, ihre Produkte, sondern auch alle auffindbaren Einzelheiten über das Metall, den Handel, Lehrzeit und Meisterschaft und die Beziehungen zu den umliegenden Ländern. Deshalb beschränke ich mich auf das Verzeichnis der aktiven Zinngiesser, auf ihre Wirkungszeit mit den Daten aus Naefs Werk. Für den Sammler gebe ich eine kurze Beschreibung der Genfer Zinnprodukte, welche sich in meiner Privatsammlung befinden.

Die Genfer Zinngiesser führten neben ihrem Meisterzeichen niemals ein Genferwappen oder eine diesbezügliche Beschriftung, wie in der Nordostschweiz. An Stelle des Ortszeichens findet sich die Jahrzahl der entsprechenden Giesserordnung (ordonnance). Die früheste Jahrzahl ist 1557 , die zweite 1609 ; beide sind durch die Ordonnance vorgeschrieben und fehlen niemals. Dieselbe befindet sich stets im innersten Teil der Giessermarke, unterhalb irgend eines Zinngiesser-Emblems (Mohrenkopf, Rose, Hammer, etc.). Die erste Zinngiesser-Ordnung von 1557 ist nicht mehr vorhanden; die zweite von 1609 ist eine sehr ausführliche Zusammenfassung aller Bestimmungen über das Gewerbe. Nach der Ordnung von ${ }_{1723}$ müssen alle alten Stempel vernichtet werden. An deren Stelle haben neue zu treten. Die Jahrzahlen nach 1723 bedeuten meistens das Jahr der Meisterschaft oder der Heirat und Geschäftseröffnung.

Bei der Ordnung von 1557 unterscheidet man die Bezeichnung Feinzinn für fast reines Zinn und die gewöhnliche Legierung (étain commun) mit 8-9 Pfund Blei auf 1 oo \& Zinn. Bei der zweiten Ordnung von 1609 wird das gewöhnliche Zinn (étain commun) mit einem C bezeichnet und darf auf hundert Pfund Zinn 17 Pfund Blei enthalten. Das Feinzinn wird mit F (meist mit einer Krone) gestempelt. - Etain cristallin: Englisches Zinn (Naef, S. 114 ); diese Bezeichnung findet sich in Genf erst nach 1722. 


\section{Die Zinngegenstände}

In Genf findet man die Kannentypen I und II ; letztere sind jedoch viel seltener als die erstern. Teller und Platten sind in allen Grössen und Formen gemacht worden. Besonders schön und gesucht sind die Schützengabenteller und die Ehrengaben bei den verschiedenen Festen. Die eigenartig geformten Genfermaasse finden sich bei Naef, Seite 48, im Bilde. Infolge des relativ kleinen Bleigehaltes ist die Qualität der Genfer Zinnwaren eine sehr gute und sticht, besonders gegen die Innerschweiz, auf den ersten Blick vorteilhaft ab. Die Kannen haben eine sehr schöne Form, sind aber ganz glatt; so fehlt stets der bandförmige, profilirte

Wulst am Aequator des Korpus.

\section{Die Zinngiesser}

Urkundlich sind Zinngiesser schon im XV. Jahrhundert nachgewiesen (Naef, S. 57). Viele Meister kamen aus Frankreich nach Genf, besonders in der Hugenottenzeit. Ihre $\mathrm{Zahl}$ ist gegen Ende des XVI. Jahrhunderts eine bedeutende. Von 1540 bis 1580 werden 43 Namen genannt; Naef erwähnt 111 Zinngiesser von Genf. Von 69 Meistern kennt man weder Gegenstände noch Meisterzeichen. Von den restirenden 42 Zinngiessern führen vier die Jahrzahl der frühesten Zinngiesserordnung, also 1557 ; achtzehn die Jahrzahl der zweiten Ordonnance 1609 , allein oder auch mit spätern Jahrzahlen, und zwanzig nur mit Jahrzahlen nach 1700 . längert.

Die obligatorische Lehrzeit betrug drei Jahre, wurde aber oft bis auf vier Jahre ver-

\section{Die Zinngiesser mit der Jahrzahl 1557 (Ordonnance)}

Charton, Estienne führte das Meisterzeichen Nr. 728 (Naef, S. 15o). Zitirt (Naef, S. 150) 1572 als Einwohner; starb 1606 oder 1607.

De La Fontaine, Pierre I. Seine Meistermarke findet sich bei Naef, S. 192. Der Meister wird 1541 als Einwohner erwähnt; er starb 1597.

Poncet, Jean. Seine Meistermarke findet sich bei Naef, S. 251 . Poncet wurde ca. 1573 geboren und starb 1636 .

Soenori, Noel, dessen Meisterzeichen bei Naef, S. 272 ,abgebildet ist, von 1535 bis 1595 .

\section{Die übrigen Zinngiesser in alphabetischer Reihenfolge}

Boisdechesne, Antoine, führte vier Meisterzeichen (Naef, S. 123 ) ; geboren 1665, gestorben 1737 . Bourrelier, Leonard I, führte die Meistermarken Nr. 740, 741 und 742. Naef (S. 127) hat noch weitere fünf Meisterzeichen. Leonard I wurde 1639 geboren, liess sich in Genf 1671 nieder und starb 1730 .

Gegenstände: Breitrandplatte, Durchmesser $41 \mathrm{~cm}$, Randbreite 8,5 cm. Der Rand der Platte ist profilirt. Am Rande der grosse Gabenstempel der Schützengesellschaft von Sitten Nr. 854 und gegenüber ein Eigentumsstempel mit einem Familienwappen mit den Initialen I M L. Unterseite der Platte gehämmert. Am Rand die Meister marke Nr. 742, daneben ein bekröntes F. als Qualitätszeichen für Feinzinn. (Tafel XVIII, 12.)

Breitrandplatte von gleichen Dimensionen und gleicher Arbeit. An der Oberseite des Randes zwei Mal die Marke eines Fechtklubs, zwei gekreuzte Säbel, darüber die Initialen I. B. H. An der Unterseite des Randes das Meisterzeichen Nr. 742, daneben bekröntes F. (Tafel XXVI, 13.)

Abendmahlkannen von Genf. (Tafel XIII, 1, 2.) 
TAFEL XLV
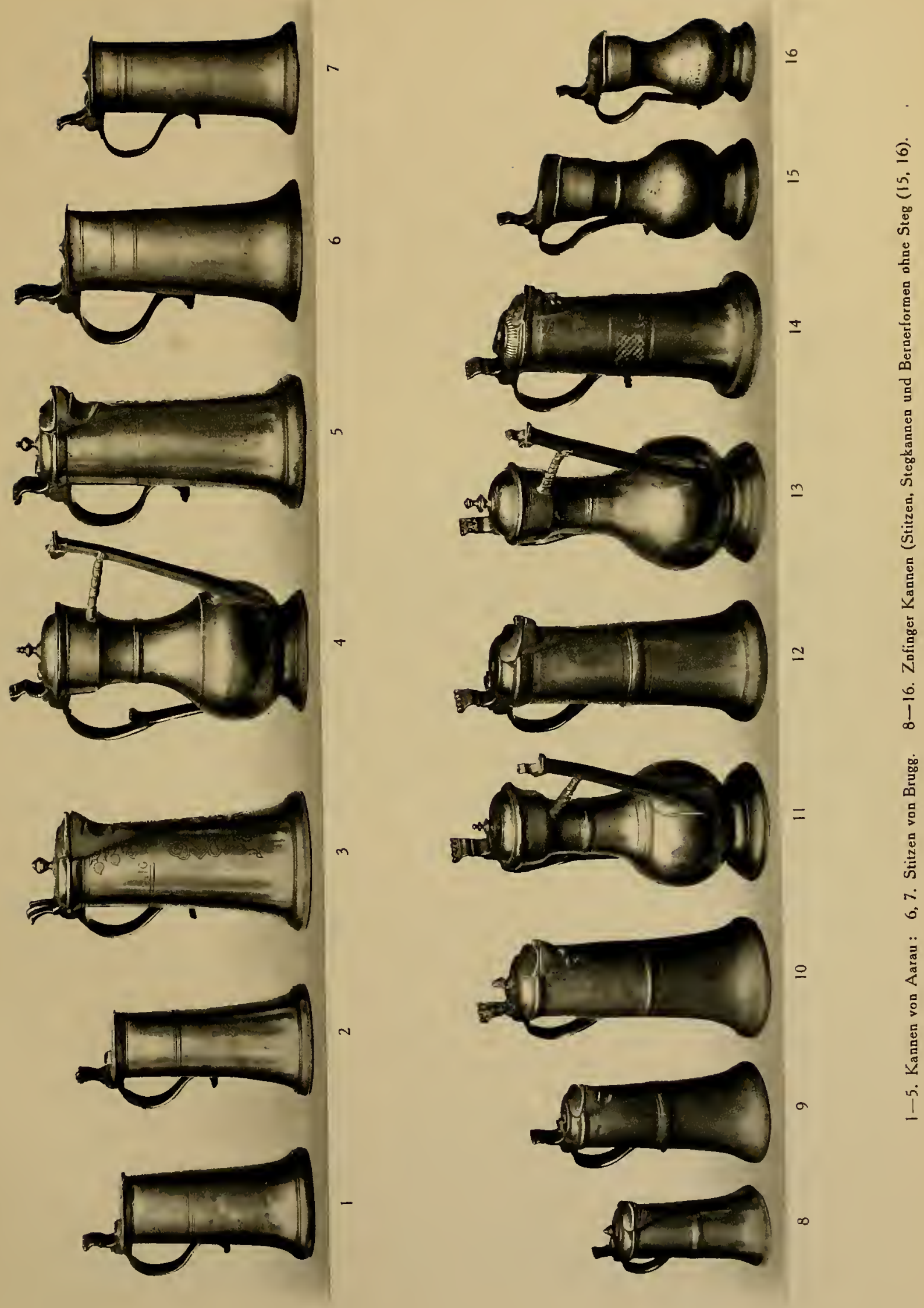

Bourrelier, Jean, Sohn des Léonard I, führte die Meisterzeichen Nr. 743, 744 und 768 . Naef (S. 138) bringt noch fünf weitere Meistermarken. Bourrelier wurde 1676 geboren, arbeitete ab 1709 mit seinem Vater und führte ab 1717 das Geschäft allein weiter. Er starb im Jahre 1755 .

Gegenstand: Kanne, Typ. II; Höhe 29,5 cm; Durchmesser des Fusses 13,6 cm. Am Deckelgriff zwei Granatäpfel. Auf dem Deckel das Meisterzeichen Nr. 743 und die eingeschlagenen Initialen F N. Am glatten Korpus zwei feine Linienpaare. In der Mitte des Halses ein profilirter Wulst. Am Ausgussteil ein Linienpaar. (Tafel XLVI, 8.)

Bourrelier, Melchisédec, führte nach $\operatorname{Naef}($ S. 140) sechs verschiedene Meisterzeichen. Er wurde 1678 geboren, wird 1723 noch erwähnt, starb...

Bourrelier, Pierre, führte nach Naef (S. 148) fünf Meisterzeichen. Er wurde 1720 geboren und starb 1679 .

Gegenstand: A bendmahlkanne in Genf. (Tafel XIII, 3.)

Brunet, Jakob, führte nach Naef (S. 149) nur eine Meistermarke, welche sich auf der einzigen, bekannten Kanne befindet. Heiratete 1638 und wird 1667 noch zitirt.

Charton, Antoine I, führte nebst der Meistermarke Nr. 729 nach Naef (S. 154) noch zwei weitere Marken. Er wurde ${ }_{1618}$ geboren und starb 1697.

Charton, Antoine II, führte vielleicht die gleichen Meisterzeichen wie Antoine I. Antoine II wurde 1644 geboren und starb im Jahre 1699 (ermordet, siehe Naef, S. 159 u. ff.).

Charton, Jean-Antoine, führte die Meisterzeichen Nr. 73o, 731, 732, 733 . Naef bringt noch weitere sechs (Naef, S. 163). Jean-Antoine wurde im Jahre 1658 geboren und starb 1739.



Gegenstände : Kanne, Typ. II. Höhe $25,5 \mathrm{~cm}$. Durchmesser des Fusses $13,8 \mathrm{~cm}$. Am Deckeldrücker zwei flache Granatäpfel. Auf dem Deckel das Meisterzeichen Nr. 731 . Korpus und Hals ganz glatt; die Gefässform hat Anklänge an die Genfer Maass formen. Kanne, Typ. I. Höhe $37,8 \mathrm{~cm}$. Durchmesser des Fusses 15,7 cm. Am Deckelgriff zwei und in der Mitte des Deckels ein grosser Widderkopf. Auf dem Deckel die Marke Nr. 732. Daneben das prächtige Gabenzeichen der Schützengesells chaft von Siders (Sirrum mit der Jahrzahl 1681). Korpus glatt, mit fast senkrechtverlaufender Seitenwand. Am Korpus vier feine circuläre Linien. In der Mitte des Halses ein flacher Wulst. Am Ausgussteil je zwei feine, circuläre Linienpaare. (Tafel XLVI, 1 2.)

Kanne, Typ. I. Höhe $33 \mathrm{~cm}$. Durchmesser des Fusses $15 \mathrm{~cm}$. Am Deckelgriff zwei und in der Mitte des Deckels ein Widderkopf. Neben Letzterem das Meisterzeichen Nr. $7_{2}$. Vor demselben das Zeichen des Seigneurie Nr. 764 und die schlecht eingepunzten Initialen M I A. Korpus glatt, mit zwei feinen circulären Linien. In der Mitte des Halses ein profilirter Wulst. Am Ausgussteile zwei feine Linienpaare. Am Henkel die schlecht gravirte Jahrzahl 1705.

Kanne, Typ. I. Höhe $29 \mathrm{~cm}$. Durchmesser des Fusses 12,2 cm. Am Deckelgriff zwei Granatäpfel. Auf dem Deckel die Meistermarke Nr. 732 ; davor die eingravirten Initialen M G P. Korpus glatt; in der Mitte des Halses ein profilirter Wulst. Am Ausgussteil zwei feine Linienpaare.

Kanne, Typ. I. Höhe ${ }_{26,2} \mathrm{~cm}$. Durchmesser des Fusses 12,4 cm. Am Deckelgriff zwei Granatäpfel. In der Mitte des Deckels das Meisterzeichen Nr. 732 und die gravirten Initialen C F. Korpus glatt, in der Mitte des Halses ein flacher Wulst. Am Ausgussteil zwei feine Linienpaare. (Tafel XLVI, 14.)

Kanne, Typ. I. Höhe $25,4 \mathrm{~cm}$. Durchmesser des Fusses $10 \mathrm{~cm}$. Am Deckeldrücker zwei Granatäpfel. Auf dem Deckel die Marke Nr. 732. Daneben ein tief eingeschlagenes dreiblättriges Kleeblatt. Korpus glatt. In der Mitte des Halses ein circulärer profilirter Wulst. (Tafel XLVI, 8.) 
Teller, mit schmalem Rand; Boden mit circulären Wellen. Durclımesser $25,7 \mathrm{~cm}$. Am Boden prominirender Umbo, darum herum circuläre Linien und eingepunzte Blätter in kreisförmi er Anordnung. An der Unterseite das Meisterzeichen Nr. $73_{2}$ und das Qualitätzseichen $\mathrm{F}$ mit Krone. Daneben die eingravirten Initialen $\mathrm{H} \mathrm{I} \mathrm{H.}$

$\mathrm{K}$ anne mit prismatischem achtseitigem Korpus. Höhe 41,5 cm. Fussdurchmesser 25,2 cm. Als Deckeldrücker zwei Granatäpfel. Am Boden das Meisterzeichen Nr. 733 . Schwerer, geschweifter Zinnhenkel, der an zwei massigen Knöpfen artikulirt ist. Auf dem Deckel sechs eingeschlagene Sterne und die Initialen L P, des Besitzers L. de Preux, in Siders. (Tafel XLVI, 11.)

Kanne, Typ. I. Höhe $37,8 \mathrm{~cm}$. Durchmesser des Fusses 15,3 cm. Am Deckelgriff zwei Widderköpfe und einer in der Mitte des Deckels. Davor das Meisterzeichen Nr. 733 und die eingeschlagenen Initialen G T. und S Z. An der Spitze des Deckels ein eingeschlagenes Kreuz. Korpus glatt; in der Mitte des Halses ein profilirter Wulst.

Kanne, Typ. I. Höhe 29,2 cm; Durchmesser des Fusses 12,3 cm. Am Deckeldrücker zwei Granatäpfel. In der Mitte des Deckels ein Widderkopf. Davor das Meisterzeichen Nr. 733 und F mit Krone. Gravirte Initialen R D-P T; dazwischen das eingravirte Wappen der von Riedmatten. Ferner zwei eingeschlagene Kreuze und die Initialen P I. K. Korpus glatt; in der Mitte des Halses ein flacher Wulst.

Charton, Gabriel I, führte die Meistermarken Nr. 734, 735, 737. Naef (S. 167) bringt fünf weitere Marken. Gabriel I wurde 1663 geboren und starb 1737 .

Gharton, Marc, führte nach Naef (S. 172) vier verschiedene Meisterzeichen. Er wurde ca. 1693 geboren und starb 1753 .

Charton, Jean I, führte nach Naef (S. 175) vier Marken. Er lebte von 1695 bis 1778 . Er heiratete 1724, welche Jahrzahl sich auch auf dem Meisterzeichen befindet.

Charton, Jean II, führte die Meistermarke Nr. 736. Nach E. Naef (S. 180) gibt es zwei Marken. Jean II lebte von 1728 bis 1799.

Classen, Frédérich-Antoine; geboren 1778; gestorben 1815 .

Classen, Abraham-Isaac, führte die Meistermarke Nr. 762; geboren 1804; gestorben 1884 .

Classen, Louis-Auguste, führte nach Naef (S. 183) zwei Meisterzeichen. Er wurde im Jahre 1841 geboren und war bis 1860 als Zinngiesser tätig.

Constançon, Jakob, führt nur ein Meisterzeichen (Naef, S. 186). Er wurde im Jahre 1635 geboren und starb 168 o.

Cougnard, Pierre, führt ebenfalls nur ein Meisterzeichen (Naef, S. 189). Er lebte von 16o5 bis 1677 .

Delafontaine, Estienne, führte das Meisterzeichen Nr. 748. Siehe auch Naef (S. 196). Er lebte vom Jahre 161 o bis 1683 . Er war ein Sohn von Pierre II Delafontaine und heiratete im Jahre 1641. Im Jahre 1665 lieferte er Zinnpreise an die Gesellschaft der Bogenschützen in Bern (Naef, S. 6o).

Gegenstand: Kanne Typ. I. Höhe $35,6 \mathrm{~cm}$. Durchmesser des Fusses $15,3 \mathrm{~cm}$. Am Deckelgriff zwei Widderköpfe und einer in der Mitte des Deckels. Daneben die Meistermarke Nr. 748. Korpus ganz glatt. In der Mitte des Halses ein glatter Wulst und eine tiefe Rille oberhalb desselben. Am Ausgussteil ein Linienpaar. (Tafel XLVI, 1o.)

Gaudy, Abraham, führte nach Naef (S. 206) nur ein Meisterzeichen. Er lebte von 1623 bis 1676 .

Gaudy, Etienne, führte nach Naef (S. 208) zwei Meisterzeichen. Er lebte von 1650 bis 1699.

Krüger, Guillaume-Werner, führte nach Naef (S. 220) drei Meistermarken. Er lebte von 1784 bis 1849 ; in Genf von 1814 an.

Lacombe, Philippe, führte nach Naef (S. 221) zehn Meisterzeichen. Er lebte von 1808 bis 1876 . Vgl. Abendmahlkanne in Genf. (Tafel XIII, 4.)

Lacombe, Jean-François-Louis I, führte die Meisterzeichen gemeinsam mit seinem Bruder Philippe. Er wurde im Jahre 1811 in Vevey geboren. In Genf war er als Meister von 1834 bis 1898 tätig. Siehe auch das Meisterzeichen Nr. 763 (Bd. I). 
Lacombe, Maurice-Louis II, Sohn des Vorigen (Naef, S. 221), führte auch dessen Meisterzeichen und arbeitete mit ihm bis ${ }_{1898}$, also bis zur Aufgabe des Geschäftes. Louis II lebte von 1839 bis 1914 .

Lacombe, Jean-Henri, Sohn des Philippe Lacombe, führte ebenfalls die Meisterzeichen desselben. Er lebte von 1843 bis 1910.

Morel, Jacques I, führte das Meisterzeichen Nr. 753 und nach Naef (S. 23o) noch drei weitere Marken. Er wurde im Jahre 1678 geboren, heiratete 1706 und starb 1752. Auf seinen Meistermarken sind die Jahrzahlen 1609, 1719.

Gegenstand: Kanne, Typ. I. Höhe $28 \mathrm{~cm}$. Im Antiquitätenhandel in Luzern (Hirsbrunner).

Morel, Jacques II, führte die Meisterzeichen Nr. 754, 755 mit der Jahrzahl 1743 . Naef bringt noch eine weitere Marke. Jacques II wurde 1714 geboren, heiratete 1743 und starb 1776. Gegenstand: Kanne Typ. II. Höhe 19,2 cm. Durchmesser des Fusses 11,8 cm. Am Deckelgriff zwei Eicheln. Vor dem Deckelsteg das Meisterzeichen Nr. 754. Davor das Zeichen der Seigneurie Nr. 765. Korpus glatt. In der Mitte des Halses ein flacher Wulst. Am Ausgussteil zwei circuläre Rillen.

Morel, Pierre, führte die Meistermarken Nr. 756, 757, 770 mit der Jahrzahl 1737 . Naef hat ebenfalls drei Marken. Morel wurde im Jahre 1710 geboren, heiratete 1758 und starb 1781. Seine Produkte sind sehr gut.

Gegenstand: Kanne, Typ. I. Höhe 34,8 cm. Durchmesser des Fusses 15,5 cm. Am Deckelgriff zwei Eicheln, deren Näpfchen hohe Buckel aufweisen. Vor dem Deckelsteg ein grosser aufgelöteter Delphin. Vor demselben das Meisterzeichen $\mathrm{Nr}$. 756 , ferner drei eingeschlagene $\mathrm{G}, \mathrm{S}$ G und in kleinen Buchstaben A G. Korpus glatt. In der Mitte des Halses ein bandförmiger, profilirter Wulst. Am Ausgussteile zwei feine circuläre Linienpaare.

Morel, Jean-François II, führte die Meistermarken Nr. $758,759,760$. Naef (S. 242 ) bringt vier weitere Meisterzeichen. Jean-François wurde im Jahre 1743 geboren, heiratete 1765 und starb 1824 .

Paul, Nicolas, führte die Meisterzeichen Nr. 750, 751, 752. Ein viertes Zeichen, nebst diesen, bringt Naef (S. 247). Er wurde im Jahre 1695 geboren, heiratete 1729 und starb 1766.

Gegenstände : Kanne, Typ. II. Höhe 3o cm. Durchmesser des Fusses, 13,8 cm. Am Deckelgriff zwei Granatäpfel. Auf dem Deckel das Meisterzeichen Nr. $7_{2}$; ferner zwei Mal je drei eingeschlagene Sterne. Korpus glatt. In der Mitte des Halses ein schmaler glatter Wulst. (Tafel XLVI, 13.)

Kanne, Typ. I. Höhe $25 \mathrm{~cm}$. Durchmesser des Fusses 10,1 cm. Vor dem Deckelsteg die Meisterzeichen Nr. 750 und 751 ; daneben ein grosses eingeschlagenes Winzerwappen (Traube mit Blatt). Korpus glatt. In der Mitte des Halses ein schmaler, glatter Wulst. Kanne, Typ. II. Höhe 24,7 cm. Durchmesser des Fusses $12 \mathrm{~cm}$. Am Deckelgriff zwei Granatäpfel. Vor dem Deckelsteg die Meisterzeichen Nr. 750 und 751 und die gravirten Initialen C A. Korpus glatt mit einem Linienpaar. In der Mitte des Halses glatter, flacher Wulst und zwei Linienpaare.

Kanne, Typ. I. Höhe $25 \mathrm{~cm}$. Durchmesser des Fusses $10 \mathrm{~cm}$. Am Deckelgriff zwei Granatäpfel. Auf dem Deckel die Meisterzeichen Nr. 750 und $7_{51}$ und die gravirten Initialen F T. Korpus glatt. In der Mitte des Halses flacher, glatter Wulst.

Rossier, André, führt nach Naef (S. 258) zwei Meisterzeichen.

Royaume, Pierre I, führte die Meistermarken Nr. 746, 747 (ebenfalls bei Naef, S. 259). Er wurde in Lyon geboren, war nach 1569 in Genf, wurde 1572 Einwohner und erst ${ }_{1598}$ Bürger.

Royaume, Pierre II, der Sohn des Vorigen, führte wahrscheinlich die gleichen Meisterzeichen wie der Vater; er wurde im Jahre ${ }_{1} 573$ geboren und starb 1646.

Royaume, Pierre III, Sohn des Pierre II, führte vielleicht ebenfalls die gleichen Marken wie die zwei Vorgänger; er wurde im Jahre 1605 geboren und starb 1676. 
Royaume, Jehan, führte nach Naef (S. 265) keine sicher bestimmbare Meistermarke. Er wurde 1659 geboren und war 1676 Lehrling bei Léonard Bourrelier.

Roze, Pierre I, von Grenoble, führte das Meisterzeichen Nr. 749. Er heiratete im Jahre 1653, wurde 1688 Bürger und starb ? Als Zinngiesser arbeitete er von 1653 bis ca. 1691 . Sein Sohn Pierre II führte das gleiche Meisterzeichen. Er heiratet 1692 und starb? Gegenstände: Kanne, Typ. I. Höhe 29,2 cm. Durchmesser des Fusses 12,5 cm. Am Deckelgriff zwei Granatäpfel. In der Mitte des Deckels ein aufgelöteter Widderkopf; ferner das Meisterzeichen Nr. 749 und das Qualitätszeichen F mit Krone. Auf der andern Seite das Wappen des Zehnden Conthey. An der Deckelspitze ein Familienwappen mit den Initialen P K M (Eigentumszeichen) und ein eingeschlagenes Kreuz. Korpus glatt In der Mitte des Halses ein flacher Wulst und eine Rille. Am Ausgussteil eine feines circuläres Linienpaar.

Kanne, Typ. I. Höhe 25,5 cm. Durchmesser des Fusses 10,2 cm. Am Deckelgriff zwei Granatäpfel. Auf dem Deckel die Marke Nr. 749, ferner ein kreisrunder Stempel mit den Initialen AT und ein herzförmiger Stempel MIZK 1702. Korpus glatt: in der Mitte des Halses ein flacher Wulst. Am Ausgussteil zwei circuläre Linienpaare.

Kanne, Typ. I. Höhe 17,5 cm. Durchmesser des Fusses $8 \mathrm{~cm}$. Am Deckelgriff zwei Granatäpfel. Auf dem Deckelsteg zwei erhabene Querstriche. Davor die Meistermarke Nr. 749 und das Qualitätszeichen F mit Krone; ferner die Initialen I N B und zwei Andreaskreuze. Korpus glatt und in der Mitte des Halses ein profilirter circulärer Wulst. Valin, Jakob, führte das Meisterzeichen Nr. 769. Er war 1635 Bürger und starb 1671 . Er war Specialist für chirurgische Instrumente in Zinn.

Gegenstände: Kannen Typ. I im Antiquitätenhandel und im Kunsthandel in Luzern (Hirsbrunner).

Zum Ende : Kleine Genferkanne Typ. II, ohne Meistermarken. Höhe 15,2 cm. Durchmesser des Fusses 6,7 cm. Am Deckelgriff zwei Eicheln. An der Seite des Ausgussteiles die eingeschlagenen Genferwappen Nr. 766 und 767. Korpus glatt, mit einem feinen Linienpaar. In der Mitte des Halses ein flacher Wulst. Am Ausgussteil ein feines Linienpaar.

\section{WAADT}

\section{LAUSANNE}

Aus dem XVI. und XVII. Jahrhundert sind keine Giessermarken und mithin auch keine Zinngegenstände von Lausanne nachweisbar. Dagegen haben in Genf mehrere Lehrlinge von Lausanne ihre Lehrzeit durchgemacht.

Lionna, Jean, von Lausanne, war Lehrling bei Pierre II Royaume ab 23. Juli 1614 (Naef, S. 261).

Eschaux, Virgil, von Lausanne, war Lehrling bei Jakob Valin ab 15 . April 1633 (Naef, S. 274).

Dappaz, Louis, von Lausanne, war Lehrling bei Leonard I Bourrelier ab 1673 (Naef, S. 135).

Die spärliche Anzahl der Zinngiesser im XVII. Jahrhundert ist auffallend. Von obigen drei Namen ist nur einer als Meister zu finden und auch keine auf dieselben hinweisende Zinngegenstände. Vielleicht liegt der Grund zum Teil darin, dass in dieser Zeit in Vevey die ausserordentlich leistungsfähige Familie der Zinngiesser Utin bestand, welche das ganze Waadtland und den untern Teil des Wallis mit ihren Erzeugnissen versorgte. Auch importirte Lausanne Zinngegenstände aus Genf; so lieferte schon im Jahre 1658 der Genfer Zinngiesser Jakob 
Constançon (Naef, S. 89). Im Jahre 1692 werden die Lausanner Meister als Lieferanten für Schützengaben zugelassen, aber nur unter der Bedingung, dass sie in gleicher Qualität liefern wie die Genfer Meister (Naef, S. 6o). Es handelt sich um die Zinngiesser Dappaz und Lombard.

\section{Die Lausanner Zinngegenstände}

Die Kannen. Ausser den Typen I und II findet man - wohl mit Rücksicht auf die Berner Oberherrschaft - die typische Bernerform mit langem Ausgussrohr, welches mit dem Hals durch einen Steg verbunden ist. Allein sowohl die Form der Kanne, als auch der Steg und der Deckel, haben die vollständige waadtländische Eigenart bewahrt. Die Form der Kanne ist genau dieselbe der übrigen Waadtländer Kannen. Der Steg kommt in zwei Formen vor, entweder vierkantig oder bandförmig; in beiden Fällen mit vielen Abkröpfungen. Bei einer einzigen Stegkanne von Vevey (von André Utin) habe ich die gleiche Form gefunden.

Beim Kannentyp I findet man oft eine geradezu künstlerische Umbildung der plumpen Walliserform. Auch beim Typus II wird der Aspekt durch stärkere Ausladung des Fusses und des Ausgussteiles für das Auge angenehmer gestaltet.

Die Maasse haben eine ganz eigentümliche Form infolge des cylindrischen Korpus, der breiten Ausladung des Fusses und des Ausgussteiles mit dem mächtig überragenden Deckel. Die Teller und Platten bieten keine Besonderheiten.

\section{Die Zinngiesser}

Dappaz, Louis, als Zinngiesser erwähnt 1692 .IV.5 (Naef, S. 6o).

Lombard, als Zinngiesser erwähnt ${ }_{1692}$. IV. 5 (Naef, S. 6o).

Reuchlin, Jean-Jacques und Frédéric, Zinngiesser, aus Strassburg stammend, kamen ca. 1750 nach Lausanne und wurden im Jahre ${ }_{1759}$ in Prilly ins Bürgerrecht aufgenommen '.

Reuchlin, Jean-Jacques, führte die Meisterzeichen Nr. 689 und 689 a.

Gegenstände: Kleine Stegkanne in Bernerform. Deckelgriff glatt, Deckel hochkuppelförmig mit Knopf in der Mitte. Steg kräftig, vierkantig, mehrmals abgekröpft. Lange Ausgussröhre wie bei den Berner Stegkannen. Am Henkel das Meisterzeichen Nr. 689. $Z$ wischen Korpus und Hals eine Gruppe von circulären Rillen, ebenso in der Mitte des Halses. Höhe 26,5 cm. Durchmesser des Fusses 10,6 cm. (Tafel XLVII, 6.)

Kleine Stegkanne mit dem gleichen Meisterzeichen am Henkel. Der Steg ist bandförmig flach, ebenfalls mit Abkröpfungen. Die Rillen am Korpus und Hals sind ziemlich verwischt. Maasse wie bei der Vorigen.

Zwei Abendmahlkannen im Museum Romainmôtier. Korpus siebenseitig prismatisch. Deckeldrücker nach hinten abgekröpft; beweglicher Traghenkel. Höhe der Kanne $35 \mathrm{~cm}$; Durchmesser des Fusses $23 \mathrm{~cm}$. Meisterzeichen Nr. 689. (Tafel XV, 2.)

Abendmahlkanne von Pailly bei Yverdon. Korpus prismatisch, siebenkantig. Iange Ausgussröhre mit Tierkopf am Ende. Deckel hochkuppelförmig. Höhe der Kanne $33 \mathrm{~cm}$. Meisterzeichen Nr. 689 a auf Schriftband.
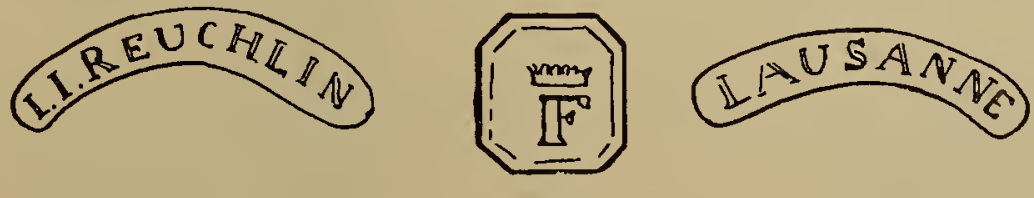

689 a

${ }^{1}$ Histor.-Biograph. Lexikon der Schweiz sub. Reuchlio. 
Reuchlin, Frédéric, führte die Meisterzeichen Nr. 690 und 691. Auf beiden Zinnmarken befindet sich die Jahrzahl 1773 .

Gegenstände: Kanne Typ. I. Höhe 29,5 cm; Durchmesser des Fusses 13,2 cm. Deckelgriff flach, der Steg reicht bis zur Mitte des Deckels und ist gewellt. Auf dem Deckel das Meisterzeichen Nr. 690 und zwei circuläre Rillen. Die Initialen H I - M T S sind nur eingekritzelt. Korpus glatt, mit zwei circulären Rillen. In der Mitte des Halses flacher Wulst und vier Rillen. (Tafel XLVII, 13.)

Kanne, Typ. I. Höhe 24,2 cm. Durchmesser des Fusses $16 \mathrm{~cm}$. Der Steg auf dem Deckel ist gewellt. Deckeldrücker glatt. Auf dem Deckel das Meisterzeichen Nr. 690. Korpus und Hals wie bei voriger Kanne.

Kanne, Typ. I. Höhe 34,5 cm; Durchmesser des Dusses $16 \mathrm{~cm}$. Ausführung wie die zwei Vorhergehenden. Auf dem Deckel die Meistermarke Nr. 690.

Abendmahlkannen in Lausanne. (Tafel XIV, 1, 2.)

Goldner, Alexandre, führte das Meisterzeichen Nr. 692 und Nr. 692 a mit der Jahrzahl 1804.

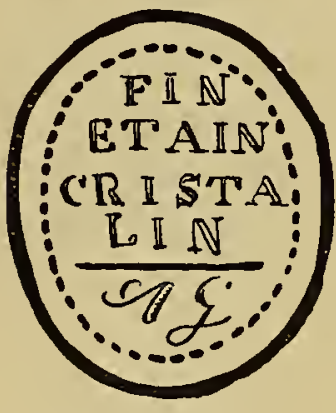

692 a Er war der Sohn von Charles-Christophe Goldner in Orbe. Er wurde am 21. Januar 1776 in Orbe getauft; heiratete 1802 und liess sich, nachdem er vorher in Bern als Zinngiesser gearbeitet hatte, ca. 1803 in Lausanne nieder. Er starb im 5o. Lebensjahr am 27. Oktober ${ }_{1826 .}$ Sein Sohn Jacques-David wurde am 7. Mai 1819 geboren.

Gegenstände: Kanne, Typ. II. Höhe $22,8 \mathrm{~cm}$; Durchmesser des Fusses $11,3 \mathrm{~cm}$. Deckeldrücker glatt. Steg auf dem Deckel ähnlich demjenigen von Frédéric Reuchlin, gewellt. Auf dem Deckel das Meisterzeichen Nr. 692, davor die eingeschlagene Zahl 27 und zu beiden Seiten das Schützengabenzeichen Nr. 864. Korpus glatt; in der Mitte des Halses ein Wulst.

Kanne, Typ. II. Höhe 22,2 cm. Durchmesser des Fusses $10 \mathrm{~cm}$. Deckeldrücker mit vier Knöllchen. Auf dem Deckel kurzer gewellter Steg und Meisterzeichen Nr. 692. Korpus glatt; in der Mitte des Halses circulärer Wulst, im Mittelband mechanisch fein gerillt (Zeichen der beginnenden Mechanisirung der Ornamente).

Mass, cylindrischer Form. Höhe $18,2 \mathrm{~cm}$; Durchmesser des Fusses 8,2 cm. Deckelgriff und Steg wie bei der erst erwähnten Kanne. Sehr grosser, den Rand weit überragender Deckel; darauf das Meisterzeichen Nr. $69^{2}$ und die eingeschlagene Zahl 87. Am Korpus drei Bänder feiner circulärer Rillen.

Plateau der Kirchgemeinde Pailly bei Yverdon mit dem Meisterzeichen Nr. 692 a.

Beneti, Georg, führte das Meisterzeichen Nr. 696. Auch er arbeitete um das Jahr 180o. Ein ähnliches Meisterzeichen weist in der Mitte eine strahlende Sonne auf.

Gegenstand: Maass von cylindrischer Form. Höhe $25,8 \mathrm{~cm}$; Durchmesser des Fusses 13,3 cm. Am Deckelgriff zwei Eicheln. Auf dem Deckel die Marke Nr. 696 und die Initialen G. L. In der Mitte des cylindrischen Korpus ein Band von fünf circulären Rillen; oben und unten je zwei Rillen. Fuss und Ausgussteil stark prominirend. Oben am Korpus die eingeschlagenen Initialen $\mathrm{M} \mathrm{C}$.

Gleiches Gefäss im Museum von Romainmôtier. Höhe ohne Deckelgriff $23,5 \mathrm{~cm}$. Durchmesser des Fusses $13,5 \mathrm{~cm}$. (Mitteilung von F. Herrmann, Yverdon.)

Lacombe, Philipp. Er führte das Meisterzeichen Nr. 693, 694 und 695. Bei Naef (S. 221) sind noch sechs andere abgebildet. Er wurde im Jahre 1808 geboren und starb 1876 . Er arbeitete zuerst bei Jean-François II Morel in Genf. Sein Geschäft in Lausanne eröffnete er im Jahre 1830 . Sein Bruder Louis trat im Jahre 1834 in sein Geschäft und betrieb es gemeinsam mit ihm bis 1857 . Philipp betrieb es wieder allein bis 1869 und schloss es damals (vide Naef, S. 222 ).

Lacombe, Louis I, wurde am 1. April 1811 in Vevey geboren. Er arbeitete von 1834 bis 1857 gemeinsam mit seinem Bruder Philipp in Lausanne. Nachher führte er sein eigenes Geschäft 


in Genf. Er starb am 23. Dezember 1897 (siehe Naef, S. 222). Er führte die Meisterzeichen Nr. 693, 694, 695 (mit Philipp Lacombe zusammen).

Gegenstände: Maass von cylindrischer Form. Höhe $23 \mathrm{~cm}$; Durchmesser des Fusses 1 1,5 cm. Am Deckeldrücker zwei Granatäpfel. Vor dem Steg das Meisterzeichen Nr. 693. In der Mitte des Korpus ein Band von fünf flachen, circulären Wülsten. Fuss und Ausgussteil stark ausladend.

Teller und Platten häufig im Antiquitätenhandel in Genf und Lausanne.

Abendmahlkanne, $37 \mathrm{~cm}$ hoch, abgebildet bei Naef, Tafel VI, Nr. 1.

Messkännchen von ganz gleicher, für Lacombe charakteristischer Form. Höhe 12, $4 \mathrm{~cm}$.

Durchmesser des Fusses 6,3 cm. Deckeldrücker zweiteilige Spiralen. Auf dem Deckel gravirt A. und V. Am Fuss und am Deckel je zwei feine Perlstäbe. Form des Kännchens gleich der grossen Abendmahlkanne (Naef, Tafel VI, Abb. 1).

\section{VEVEY}

Die ältesten bekannten Zinngegenstände gehen Kaum auf das Jahr 1600 zurück. Die ersten Zinngiesser machten wahrscheinlich ihre Lehrzeit in Genf. Am 3. April 1647 finden wir den Estienne Secrétan von Vevey als Lehrling bei Estienne Delafontaine in Genf (Naef, S. 196) und zwar für drei Jahre. Ferner trat Jean Dubourg von Vevey im Jahre 1660 für vier Jahre bei Anthoine I Charton in Genf in die Lehre (Naef, S. 155). Beide sind als Meister in Vevey nicht nachgewiesen. Der früheste, sicher nachgewiesene Meister ist Jehan Hutin oder Jehan Utin. Zwar verfertigte er nicht alle Gegenstände selbst, sondern bezog viele aus Genf von Anthoine II Charton (Naef, S. 89 u. 16o-61). Der Genfer Meister Jakob Constançon lieferte schon im Jahre 1658 Zinnwaren nach Vevey und Lausanne (Naef, S. 89).

Von Beginn des XVIII. Jahrhunderts aber nahm das Zinngiesserhandwerk in Vevey einen gewaltigen Aufschwung. Noch heute gehören die Kannen von André Utin zu den häufigsten und schönsten am ganzen Genfersee. Die Leistungsfähigkeit der Zinngiesser von Vevey beeinträchtigte sogar das Handwerk in Lausanne.

\section{Die Gegenstände}

Die Kannen sind in den Typen I und II vorhanden; ausserdem existirt wie bei Lausanne noch der Typ der Berner Stegkanne. Ebenfalls bleibt aber die Grundform der Kanne rein waadtländisch und fällt beim ersten Anblick auf. Eine Verwechselung mit einer Berner Stegkanne ist ebenso unmöglich wie bei der Lausanner Stegkanne. Die letztern allerdings sind von denjenigen von Vevey nur durch die Giesserzeichen zu unterscheiden.

\section{Die Zinngiesser von $\mathrm{V}$ evey}

\section{Die Familie der Utin}

In den Urkunden wird der Name Hutin, Utain und Utin geschrieben; auf den Giessermarken Utin und Utain. Im Livre d'or des Bourgeois de Vevey von Chatelain Perret vom 20. Juni 1749 finden sich folgende Angaben ${ }^{1}$ : François Utin und sein Sohn Etienne werden am 26. Januar ${ }_{1643}$ Bürger. Sein zweiter Sohn Pierre und dessen Knabe André bürgern sich

\footnotetext{
${ }^{1}$ Brun, Schweizerischer Künstler-Lexikon III. S. 356.
} 
im gleichen Jahre 1643 am 2. Februar ein. Ein Sohn des letztern André ist Jehan Utin, der mit Elise Dubourg verheiratet war. Vielleicht ist dieselbe eine Descendentin des oben als Lehrling erwähnten Jean Dubourg - Pierre-André Utin, verheiratet mit Marie Gauchet, wurde wahrscheinlich im Jahre 1736 Meister (Meistermarke Nr. 699). Sein Sohn war JeanJacques-Samue1, der einzige Utin mit den Initialen I. I. (Utin), weshalb ihm der Stempel Nr. 698 zugewiesen wurde. Er führt auch später seine Marke neben derjenigen seines Vaters, oft beide auf der gleichen Kanne als Schützengaben. Auch das Meisterzeichen seines Vaters allein findet man noch auf datirten Kannen der Jahre 1764,1765 und $177^{2}$.

Utin, Jehan, oder Hutin Jean, führte das Meisterzeichen Nr. 697. Urkundlich ist er nachgewiesen am 3. November 1699, anlässlich der Ermordung des Anthoine II Charton, von welchem er Zinngegenstände zu kaufen pflegte. Er starb im Jahre 1731.I.10.

Gegenstand: Kanne, Typ. I, 23,7 cm hoch; Durchmesser des Fusses $11 \mathrm{~cm}$. Am Deckeldrücker zwei merkwürdig geformte Eicheln. Der Steg am Deckel ist oben breit und verjüngt sich stark auf dem Deckel. Davor das Meisterzeichen Nr. 697 und das Qualitätsstempelchen F mit Krone. An der Spitze des Deckels die gravirten Initialen I P F. Auf der einen Seite des Ausgusses der eingeschlagene Buchstabe B, auf der andern Seite ein Wappen. Korpus der Kanne glatt, in der Mitte des Halses ein circulärer Wulst. (Tafel XLVII, 7.)

Utin, André, führte das Meisterzeichen Nr. 699 mit der Jahrzahl 1736 und später dasjenige Nr. 701. Die Jahrzahl 1736 ist vielleicht die Zeit der beginnenden Meisterschaft. Der Bernerstempel Nr. 721 a findet sich auf kleiner Kanne von André Utin (!) Da sich unter dem Bernerwappen ein V(tin) befindet, scheint eine Beeinflussung Berns nicht abzuweisen sein.

Gegenstände: Stegkanne in Bernerform, Höhe 33,2 cm; Durchmesser des Fusses $13 \mathrm{~cm}$. Oben am Deckeldrücker kleiner profilirter Rundstab. Deckel hoch, kuppelförmig mit Eichelknopf in der Mitte. Am Henkel die Meistermarke Nr. 699. Lange sechskantige Ausgussröhre, welche durch einen längs halbirten Steg mit dem obersten Teil der Kanne verbunden ist. Korpus glatt. Am Uebergang zum Hals circuläre Wülste. In der Mitte des Halses und am obern Kannenrand je zwei circuläre feine Rillen. (Tafel XVII, 4 und Tafel XLVII, 5.)

Kleine Stegkanne in Bernerform, Höhe $26,3 \mathrm{~cm}$; Durchmesser des Fusses $11 \mathrm{~cm}$. Deckelgriff wie bei der vorigen Kanne. Deckel kuppelförmig mit tiefer, circulärer Einziehung; in der Mitte des Deckels ein Knopf. Lange, sechskantige Ausgussröhre. Auf dem Deckelchen derselben das Meisterzeichen Nr. 699. Der cylindrische Steg hat knotenförmige Anschwellungen und ist am Kannenhals angelötet. Korpus glatt mit den Initialen I. V. und der eingekritzelten Jahrzahl 1753. Am Uebergang zum Hals circuläre Wülste. In der Mitte des Halses und am obern Kannenrand je zwei feine circuläre Linien. (Tafel XLVII, 2.)

Grosse Stegkanne in Bernerform. Höhe 33,5 cm; Durchmesser des Fusses 13,2 cm. Am Henkel das Meisterzeichen Nr. 701. Der Deckeldrücker ist abgekröpft. Deckel kuppelförmig mit grossem Knopf. Der Steg ist kurz und besteht in einem profilirten Rundstab; er verbindet die lange Ausgussröhre mit dem obersten Teil der Kanne. Korpus glatt, mit den eingravirten Initialen E B B W - 1764. In der Mitte des Halses ein flacher Wulst und circuläre Rillen.

Grosse Stegkanne in Bernerform, wie die Vorige. Höhe 34,5 cm; Durchmesser des Fusses 13,3 cm. Deckelknopf in drei Etagen gegliedert. Meistermarke fehlt. Korpus glatt, mit den eingravirten Initialen C. K. M. S. - 1772 und zwei grossen Blumen- und Blattranken. (Tafel XVII, 3 und Tafel XLVII, 3.)

Kleine Stegkanne in Bernerform. Höhe $26,5 \mathrm{~cm}$; Durchmesser des Fusses $10,8 \mathrm{~cm}$. Deckeldrücker abgekröpft. Deckel kuppelförmig mit grossem Knopf. Steg wie bei den zwei vorigen Kannen. Am Henkel das Meisterzeichen Nr. 701. Korpus glatt, mit den Initialen I. B. - 1765 . 
Kanne, Typ. I. Höhe 36,5 cm ; Durchmesser des Fusses $15,5 \mathrm{~cm}$. Am Deckelknopf zwei Granatäpfel; vor dem Steg des Deckels ein kleiner, aufgelöteter Delphin. Daneben das Meisterzeichen Nr. 701 und die Qualitätsmarke F mit Krone in oktogonaler Einfassung. Am Aequator des Korpus ein breiter, profilirter Wulst und viele feine Linien. In der Mitte des Halses flacher circulärer Wulst und vier Rillen. $Z \mathrm{u}$ beiden Seiten des Ausgussteiles je ein starker Knopf zur Befestigung der langen Kette.

Kanne, Typ. I. Höhe $35 \mathrm{~cm}$; Durchmesser des Fusses $16 \mathrm{~cm}$. Am Deckeldrücker zwei Granatäpfel. Vor dem Steg des Deckels ein grosser, aufgelöteter Delphin. Daneben die Meistermarke Nr. 701. Am Aequator des Korpus ein circulärer, profilirter Wulst; in der Mitte des Halses glatter Wulst und vier Rillen.

Kanne, Typ. I. Höhe 29,5 cm; Durchmesser des Fusses $12 \mathrm{~cm}$. Am Deckeldrücker zwei Granatäpfel. Auf dem Deckel die Meistermarke Nr. 701. und die Initialen 17 - I. F. - 69. Korpus glatt, mit zwei eingravirten Blatt- und Blumenranken. In der Mitte des Halses ein flacher, glatter Wulst und vier Rillen.

Kanne, Typ. I. Höhe 24,5 cm; Durchmesser des Fusses $11 \mathrm{~cm}$. In der Mitte des Deckels das Meisterzeichen $\mathrm{Nr} .701$ und die Qualitätsmarke $\mathrm{Nr} .700$ und die gravirten Initialen $\mathrm{H} \mathrm{Z}-\mathrm{M}$. Korpus glatt, in der Mitte des Halses ein flacher Wulst und Rillen.

Kanne Typ. II. Höhe $16,8 \mathrm{~cm}$; Durchmesser des Fusses 8,3 cm. Am Deckelgriff zwei grosse Granatäpfel. Vor dem Deckelsteg das Meisterzeichen Nr. 701, Qualitätsmarke Nr. 700; ausserdem der Schützengabenstempel Nr. 866, wahrscheinlich das Zeichen der Schützengesellschaft von Vevey. Korpus glatt; Fussteil wenig prominirend. In der Mitte des Halses glatter Wulst und vier Rillen.

Platte, $29 \mathrm{~cm}$ Durchmesser, ebenfalls mit dem Meisterzeichen Nr. 701 und dem Schützengabenstempel Nr. 866. Im historischen Museum von Genf.

Theekanne mit Ausgussröhre (prismatisch und gebogen). Höhe 19,6 cm; Durchmesser des Fusses $10 \mathrm{~cm}$. Korpus wie bei den Kannen; eingezogener Hals. Deckel wie bei den Stegkannen, mit Knopf und abgekröpftem Drücker. Ohne Marke. (Tafel XIX, 12.)

Utin, I. I., Utin, Jean-Jacques-Samuel, Sohn des Pierre-André Utin. Sein Meisterzeichen findet sich nur in Verbindung mit dem Schützengabenstempel, also Nr. 698. Meist befindet sich daneben noch die Meistermarke Nr. 701 .

Gegenstände: Kanne, Typ. I. Höhe $20 \mathrm{~cm}$; Durchmesser des Fusses $8 \mathrm{~cm}$. Am Deckelgriff zwei flache Granatäpfel. Auf dem Deckel die zwei Meisterzeichen Nr. 698 und 701, daneben noch Nr. 700. Korpus glatt; in der Mitte des Halses flacher Wulst und vier feine Rillen.

Kanne, Typ. II. Höhe $16,3 \mathrm{~cm}$; Durchmesser des Fusses $8,8 \mathrm{~cm}$. Am Deckeldrücker zwei flache Granatäpfel. Auf dem Deckel die Meisterzeichen Nr. 698 und 701. Auf der einen Seite des Ausgusses die eingeschlagenen Buchstaben G O und der interessante Stempel Nr. $721 a$; auf der andern Seite ein Wappen. Korpus glatt; Fuss mit guter Ausladung. In der Mitte des Halses ein circulärer Wulst und feine Linien; ebenso zwei circuläre Linien am obern Rand des Kännchens.

Utain, .... Utain, ...., führte als Meisterzeichen einen quadratischen Stempel mit dex nachstehenden Bezeichnung. Der Vorname fehlt; dagegen ist die Jahrzahl 1747 vorhanden. Zinngegenstände mit dieser Marke sind sehr selten.

ETAIN
CRISTALLIN
VTAIN
1747

Gegenstände: Mächtige Kanne, Typ. I. Höhe $35,7 \mathrm{~cm}$; Durchmesser des Fusses 15,5 cm. Am Deckelgriff zwei Widderköpfe und vorne am Steg ein kleinerer. Auf dem Deckel befindet sich obige Meistermarke. Der mächtige Corpus ist glatt, mit vielen circulären feinen Linien, ebenso am Ausgussteil. In der Mitte des Halses flacher Wulst 
und wiederum viele, fein eingeritzte Linien. Die Widderköpfe zeigen eine ganz andere Modellirung als bei den Walliser Kannen. (Tafel XLVII, 12.)

Runde Schaale. Durchmesser $23,3 \mathrm{~cm}$; Tiefe $4,3 \mathrm{~cm}$. Rand schmal, profilirt; an der Seitenwand längliche Buckel. Der Boden ist glatt und in demselben befindet sich obiges Meisterzeichen und ein Doppelwappen mit den Initialen I M - A S D (gravirt). (Tafel XVIII, 9.)

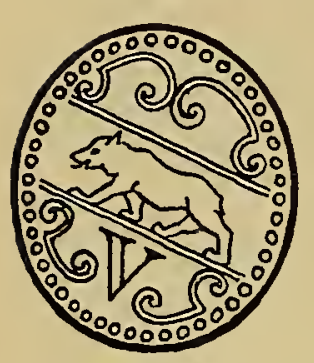

721 a

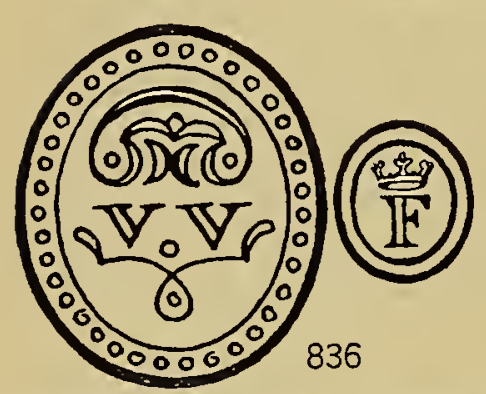

V. und V. V. Vielleicht auch den Utins zuzuweisen. Die beiden Stempel sind einander in der Zeichnung so verwandt, dass man auf ein- und denselben Stempelschneider schliessen muss. Die Marke V auf Stempel mit dem Wappen von Bern, Nr. 721 a, befindet sich auf einer kleinen Kanne, Typ. II, von André Utin, neben dem Meisterzeichen Nr. 701 und 698. Höhe 16,3 cm; Durchmesser des Fusses 8,8 cm. Der Bernische Einfluss auf den Meister ist in diesem Objekt wohl einzig in seiner Art dokumentiert.

V. V. Diese Marke, Nr. 836, befindet sich auf einer grossen Waadtländer Kanne, Typ. I, neben dem Schützengabenstempel von Sitten, Nr. 865, und dem Qualitätsstempel F mit Krone. Die Kanne befand sich im Antiquitätenhandel bei C. Hirsbrunner in Luzern. - Ferner Waadtländer Kanne, Typ. II. Höhe $20,8 \mathrm{~cm}$; Durchmesser des Fusses $11 \mathrm{~cm}$. Am Deckelgriff zwei Granatäpfel. In der Mitte des Deckels die Meistermarke Nr. 836. In der Mitte des Halses ein circulärer Wulst und zwei Linienpaare.

Kanton Bern. Berner Wappen, darunter die Inschrift KANT. BERN. Trotz der Unmenge der untersuchten Kannen fand ich das Bernerwappen nur zwei Mal, obwohl damals die Waadt unter Bern stand (Nr. 7216).

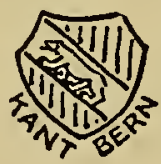

Gegenstand: Kanne, Typ. II. Höhe 22,5 cm; Durchmesser des Fusses 11,7 $\mathrm{cm}$. Form der Kanne von Utin André. Am Deckelgriff zwei Eicheln. Keine Meistermarke. Korpus glatt; am Aequator zwei Rillen. In der Mitte des $721 \mathrm{~b}$ Halses ein flacher Wulst und vier tiefe Rillen. Auf dem Henkel .zwei Mal das Wappen von Bern; darunter die Inschrift: Kant. Bern. (Nr. $7_{21}$ b). . (Tafel XLVII, 8.)

Kanne, Typ. II. Gleiche Grösse. Am Deckelgriff zwei Eicheln von eigenartiger Form. Keine Meistermarke. Am glatten Korpus, in der Mitte des Halses und am obern Kannenrand je zwei tiefe circuläre Rillen. Vorn am Korpus in fein gravirter Schrift mit schöner Wappenbekrönung (Tafel XLVII, 14):

$$
\begin{aligned}
& \text {... DEMIS ... POT ... } \\
& \ldots \text { DE .... CHALLEX .... }
\end{aligned}
$$

Magnin, Pierre und Etienne, waren ursprünglich wahrscheinlich Zinngiesser ohne festen Wohnsitz. Einige Einzelheiten bei ihren Kannen weisen ins Unterwallis und ins Waadtland. Auch findet man ihre technisch vorzüglichen Erzeugnisse bis in den Neuenburger Jura und nach Genf. Auch L. Reutter in Neuenburg schreibt in seiner Monographie ${ }^{\prime}$ über die Neuenburger Zinngiesser, dass er die beiden Magnin dem Wallis oder der Waadt zuteilen möchte. Bei Naef (S. 122) findet sich ein Guillaume Magnin, Sohn des Pierre Magnin von Macon, als Lehrling bei Jean Berger, Zinngiesser in Genf. Der Eintritt in die Lehre erfolgte im Jahre 1569. Ob unsere Magnin mit Letzterm im Zusammenhange stehen, ist nicht nachweisbar. Da Pierre Magnin im Jahre 1712 in Vevey starb und Etienne Magnin an die Schützengesellschaft Vevey lieferte, so teile ich die beiden Magnin zu den Zinngiessern von Vevey.

1 L. Reutter, Potiers d'étain neuchâtelois. Musée Neuchâtelois 1920. 


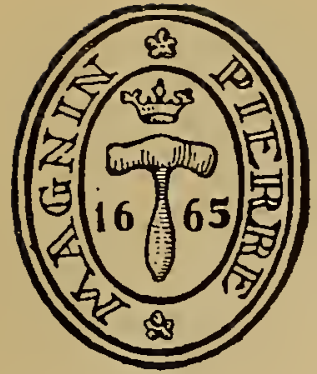

824
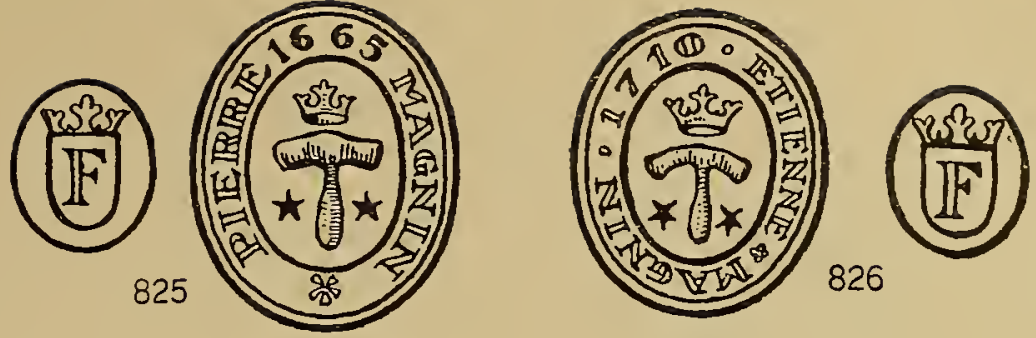

Magnin, Pierre, Zinngiesser, führte die Meisterzeichen Nr. 824 und 825 mit der Jahrzahl 1665. Laut Mitteilung des Zivilstandsamtes ${ }^{1}$ von Vevey, stirbt Pierre Magnin, fondeur d'étain, am 18. September 1712 in Vevey.

Gegenstände: Kanne, Typ. I. Höhe $3 x \mathrm{~cm}$; Durchmesser des Fusses 15,8 cm. Am Deckelgriff zwei Granatäpfel. In der Mitte des Deckels ein aufgelöteter Delphin; davor die Meistermarke Nr. 825 und ein eingeschlagener Eigentumsstempel D C. Vorn ein eingeschlagener Stern als Hauszeichen. Der Korpus ist nicht kugelförmig, sondern sphäroidal, flach von oben nach unten zusammengedrückt. Der mächtige Hals enthält einen grossen Teil des Kanneninhalts. Am Aequator des Korpus und in der Mitte des Halses befindet sich je ein circulärer, stark profilirter Wulst. Der Aspekt dieser Kanne ist ein eigenartiger und diese Kannenform findet man ausschliesslich bei den beiden Magnin.

Kanne, Typ. I. Höhe 24,7 cm; Durchmesser des Fusses 9,5 cm. Am Deckelgriff zwei Granatäpfel. Auf dem Deckel das Meisterzeichen Nr. 824, daneben Initialen, Hauszeichen, Monogramm und eine spätere Jahrzahl (1749). An der Seite des Kannenhalses befindet sich das eingeschlagene Wappen des Bezirkes Goms, Nr. 819. Der Korpus ist glatt und kugelförmig. In der Mitte des Halses ein glatter, circulärer Wulst. (Tafel XLVII, 1.)

Breitrandplatte. Durchmesser $32,5 \mathrm{~cm}$; Randbreite $6,5 \mathrm{~cm}$. Rand an der Unterseite verstärkt. An der Oberseite des Randes das Meisterzeichen Nr. 825 und die Qualitätsmarke F mit Krone; ferner ein fein gravirtes Wappen der Venetz, die Jahrzahl 1681 und die Initialen I. V R. In der Bekrönung als Wappenzier ein halber Steinbock.

Magnin, Etienne, führte das Meisterzeichen Nr. 826 mit der Jahrzahl 1710. Er war vielleicht der Sohn oder ein Verwandter des Vorigen. Bei den grossen Kannen findet man ebenfalls den eigentümlichen, flach-sphäroidalen Korpus wie bei Pierre Magnin; ebenfalls die stark profilirten Wülste und den kräftigen Delphin auf dem Deckel. Arbeitete wahrscheinlich in Vevey, wo Pierre Magnin starb.

Gegenstände: Kanne, Typ. I. $35 \mathrm{~cm}$ hoch; Durchmesser des Fusses $16 \mathrm{~cm}$. Am Deckelgriff zwei Granatäpfel; in der Mitte des Deckels ein relativ grosser aufgelöteter Delphin; daneben das Meisterzeichen Nr. 826. Auf dem Steg des Deckels die primitiv gravirten Initialen P L A. Korpus flach sphäroidal mit circulärem, stark profilirtem Wulst ; ebenso am Halse. (Tafel XLVII, 1o.)

Kanne, Typ. I. $23 \mathrm{~cm}$ hoch; Durchmesser des Fusses 10,5 cm. Am Deckelgriff zwei Granatäpfel. Auf dem Deckel die Meistermarke Nr. 826. Daneben findet sich der prachtvolle Schützengabenstempel der Mousquetaires de Vevey, Nr. 857. Korpus kugelförmig, glatt, in der Mitte des Halses ein glatter, circulärer Wulst.

Goncet, Pierre, führte das Meisterzeichen $\mathrm{Nr}$. 761 , ein sehr guter Kannengiesser, Anfang und Mitte des XVIII. Jahrhunderts tätig. Die Goncet sollen von Rougemont stammen und liessen sich in Corseaux nieder. Wahrscheinlich verlegte er seinen Wohnsitz von Zeit zu Zeit, ins Unterwallis und ins Waadtland, wie die Giesser Magnin. Seine Kannen

1 Brief von C. Moriggi fils, Vevey, 25. August 1933. 
findet man vom Wallis bis nach Genf und Neuenburg, aber er arbeitete weder am einen noch am andern Ort (vide Naef und Reutter). Er arbeitete in der ersten Hälfte des XVIII. Jahrhunderts. Seine Kannen haben eine ähnliche Form wie diejenige der beiden Magnin; doch ist die Abplattung des Korpus nicht so stark. Der profilirte, aequatoriale Wulst ist ebenfalls vorhanden und weist die Kannen ins Waadtland.

Gegenstände: Kanne, Typ I. Höhe $36 \mathrm{~cm}$; Durchmesser des Fusses 15,6 cm. Am Deckeldrücker zwei Widderköpfe; in der Mitte des Deckels vor dem Steg ebenfalls ein grosser Widderkopf. Auf dem Deckel das Meisterzeichen Nr. 761, daneben die gravirten Initialen I F. VC. Korpus kugelförmig. Am Aequator und in der Mitte des Halses ein circulärer Wulst und Rillen.

Kanne, Typ II. Höhe $26,5 \mathrm{~cm}$; Durchmesser des Fusses $14 \mathrm{~cm}$. Am Deckelgriff zwei Granatäpfel. Auf dem Deckel die Marke Nr. 671. Vorn das Walliser-Aichzeichen Nr. 820 mit 13 Sternen. Daneben die gravirten Initialen M M D und I I.D S N, ferner die eingeschlagenen Initialen $C{ }^{*} M$ und L I V. An der Seite des Halses das grosse Walliser-Wappen mit sieben Sternen (Nr. 817); daneben eine zweite Aichjahrzahl 1787. Auf einer andern Kanne der Aichstempel von 1722 (Nr. 816). Im Museum von Neuenburg befindet sich ein Gefäss mit der Jahrzahl 1746.

Doret, Philipp Benjamin, führte die Meisterzeichen Nr. 702 und 7o3. Er war in Vevey geboren am 19. Juli 1771. Als Meister arbeitete er von ca. $1795 \mathrm{ab}$. Er starb nicht in Vevey. Von 1787-179o war er Lehrling bei Louis Perrin in Neuenburg (Reutter, S. 3o).

Gegenstände: Kannen, Typ. I und II, Teller und Platten im Antiquitätenhandel in Vevey und Lausanne.

Angelin, David, führte die Meisterzeichen Nr. 704,705 und 706. Wahrscheinlich war er der Nachfolger des letzten Zinngiessers Utin. Er wurde in Vevey geboren am 13. April 1780 und starb daselbst am 15. Juni 1844. Seine Erzeugnisse sind qualitativ hochstehend, wie diejenigen der Utin, und häufig im Antiquitätenhandel anzutreffen.

Gegenstände: Kanne von mächtiger Erscheinung; der Korpus ist ein niedriges achtseitiges Prisma auf starker Bodenplatte. Darauf sitzt eine Halbkugel, welche oben in den Hals übergeht. Am Deckeldrücker zwei Granatäpfel. Vor dem Deckelsteg das Meisterzeichen Nr. 705 und die eingeschlagene $\mathrm{Zahl} \mathrm{8.} \mathrm{Zu} \mathrm{beiden} \mathrm{Seiten} \mathrm{des} \mathrm{Ausgussteiles}$ je ein starker Knopf zur Befestigung des halblkreisförmigen, beweglichen, zinnernen Traghenkels. In der Mitte des Halses ein flacher Wulst und vier feine Rillen. (Tafel XLVII, 11.) Aehnliche Kannen finden sich, ausser in meiner Sammlung, im historischen Museum von Basel und in der ehemaligen Sammlung von Dr. Niccola in Lausanne.

Kanne, Typ. II. Höhe $21 \mathrm{~cm}$; Durchmesser des Fusses $11 \mathrm{~cm}$. Am Deckelgriff zwei Granatäpfel. Vor dem Deckelsteg die Meistermarke $\mathrm{Nr} .705$ und die eingeschlagenen Initialen P. C. Korpus glatt, mit schön ausladendem Fuss. In der Mitte des Halses ein circulärer flacher Wulst und Rillen.

Kanne, Typ. I. Höhe $18,5 \mathrm{~cm}$; Durchmesser des Fusses $7,7 \mathrm{~cm}$. Am Deckelgriff zwei Granatäpfel. Vor dem Deckelsteg die Meistermarke Nr. 705 und der Qualitätsstempel F mit Krone in rechteckiger Einfassung. Korpus glatt, in der Mitte des Halses ein glatter, circulärer Wulst.

Kanne, Typ. I. Höhe $17 \mathrm{~cm}$; Durchmesser des Fusses 8,2 cm. Am Deckelgriff zwei Granatäpfel. Vor dem Deckelsteg das Meisterzeichen Nr. 7 o5 und die Qualitätsmarke F mit Krone in rechteckiger Einfassung. Korpus glatt; in der Mitte des Halses ein flacher circulärer Wulst und vier Rillen.

Trinkgefäss, in der Form einer oberhalb Korpus abgesägten Kanne von Typus I. Am Deckeldrücker zwei Granatäpfel. Vor dem Deckelsteg die Meistermarke Nr.705. Fuss nur wenig ausladend. In der Mitte des Halses ein flacher Wulst und vier Rillen.

Teller mit der Jahrzahl $\mathbf{1 8 4 2}$.

Kanne, Typ. II. Höhe 24,5 cm. Auf dem Deckel das Meisterzeichen Nr. 704. Im Antiquitätenhandel in Genf. 
Goldner, Louis, führte das Meisterzeichen Nr. 707. Arbeitete bis in die Mitte des XIX. Jahrhunderts. Datirte Gegenstände von 186o. Er war vielleicht der Sohn des Charles-Gabriel Goldner in Orbe.

Gegenstand: Kanne, Typ. I. Höhe $29 \mathrm{~cm}$; Durchmesser des Fusses $13 \mathrm{~cm}$. Am Deckelgriff zwei Granatäpfel. Vor dem Deckelsteg das Meisterzeichen Nr. 707 mit Qualitätsstempel $\mathrm{F}$ mit Krone. Davor das Schützengabenzeichen von J. J. Utin Nr. 698. Korpus glatt; in der Mitte des Halses ein flacher circulärer Wulst und vier Rillen. (Tafel XLVII, 9.)

Moriggi '. Die Familie stammt aus Brissago im Kanton Tessin. Laut Angabe von Herrn Charles Moriggi, Sohn, war schon sein Urgrossvater ein Zinngiesser. Der Grossvater Moriggi Dominico wurde in Brissago geboren im Jahre 1805 . Er arbeitete zuerst mit seinem Vater an verschiedenen Orten der Ostschweiz, dann im Berner und Neuenburger Jura. Ab 1835 arbeitete er allein in Neuenburg. Er hatte zwei Söhne: Achille und Charles. Beide wurden Zinngiesser. A chille liess sich ca. 1867 in Neuenburg nieder und wurde Bürger. Er war im Jahre 1833 geboren und starb 1871 . Seine zwei Söhne waren nicht Zinngiesser. Dominico und Achille Moriggi finden sich bei den Neuenburger Meistern.

Moriggi, Charles I, führte die Meisterzeichen Nr. 713, 714, 715, 716. Er ist im Jahre 1839 geboren und arbeitete als Zinngiesser zuerst einige Jahre in Neuenburg. Am 8. Juli 1869 etablirte er sich in Vevey und zwar im gleichen Lokal in welchem heute noch sein Sohn das Geschäft betreibt. Er starb am 17. August 1913 in Vevey.

Moriggi, Charles II, der Sohn des Vorigen, führt die Meisterzeichen Nr. 717, 721 und viele kleine Qualitäts- und Ortsstempelchen. Er wurde am 20. Januar 1877 geboren und übernahm das Geschäft seines Vaters am 1. Januar 1909. Er hat einen Sohn Namens LouisCharles, geboren 10. Juni 1913.

Gegenstände: Alle Arten Kannen, Platten in allen Stilarten. Prächtige Qualitätsarbeiten.

Gippa, Frères, in Vevey, führten das Meisterzeichen Nr. 7o9. Sie waren in Vevey tätig um das Jahr 1870 .

Gegenstände: Teller im Antiquitätenhandel in Lausanne.

Scalia et Gippa, in Vevey, führten die Meistermarke Nr. 708. Scalia Josef, ein Tessiner, führte ca. 1880 ein Geschäft in Vevey und Yverdon ${ }^{1}$. F. Herrman, Holzbildhauer in Yverdon besitzt einen Teller mit der Marke: Scaglia A YVERDON.

Gegenstand: Suppenschüssel im Antiquitätenhandel, mit der Meistermarke Nr. 708 .

\section{YVERDON}

Laut Mitteilung von Herrn F. Herrmann in Yverdon


stammen die Michod aus dieser Stadt. Archivalisch sind aber keine Zinngiesser dieses Namens nachgewiesen.

Michod, David, führte das Meisterzeichen $\mathrm{Nr} .837$ mit der Jahrzahl 1681.

Gegenstand: Breitrandplatte von $35,5 \mathrm{~cm}$ Durchmesser bei 7,5 cm Randbreite. Vorn am Rand das Meisterzeichen Nr. 837; gegenüber ein fein gravirtes Wappen mit den Initialen C. G. S. und G. M. und der Jahrzahl 1688. Rückseite der Platte gehämmert; Rand an der Rückseite verstärkt.

' Brief von C. Moriggi fils, Vevey, 25. August 1933. 
Michod, J. François, führte ein ovales Meisterzeichen : in der Mitte ein nach rechts steigender Löwe, darum herum die Inschrift : I. FRANCOIS MICHOD. Vielleicht ein Sohn des Vorigen.

Gegenstand: Waadtländer Kanne, Typ. I, mit der Jahrzahl 1716 (Mitteilung von Herrn F. Herrmann, Yverdon). Höhe $28 \mathrm{~cm}$; Durchmesser des Fusses $13,5 \mathrm{~cm}$. Am Deckelgriff zwei Eicheln.

Scaglia, von Vevey, führte 1880 auch ein Geschäft in Yverdon. Es handelt sich um Vater und Sohn.

Pletti, ...., Zinngiesser, ebenfalls ca. 1880 tätig (Mitteilung von Herrn F. Herrmann, Yverdon).

Paillard, Jean, Zinngiesser, lebte von 1822 bis 1900, war auch Friedensrichter und Präsident

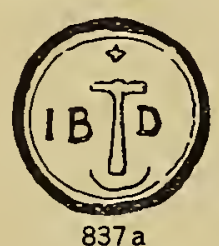
(Mitteilung von Herrn F. Hermann, Yverdon).

Auf der Abendmahlkanne von Yverdon befindet sich das Meisterzeichen : ein Zinngiesserhammer mit den Initialen I B. D. Höhe $43 \mathrm{~cm}$; Durchmesser des Fusses 23,5 cm. Kleine gebogene Ausgussröhre mit Tierkopf am Ende, an der Basis ovales Gesicht mit Strahlennimbus. Eiserner Traghenkel. Runder Knopf auf dem Deckel. Als Deckeldrücker zwei Granatäpfel. (Tafel XV, 1.)

\section{ORBE IM JURA}

Freneysy, David (?), Zinngiesser in Orbe. Er führte die Meisterzeichen Nr. 638 und 639 (Bd. I). Laut nebenstehendem Zitat war er im Jahre 1711 in Orbe tätig.

Registre du Conseil de la Généralité du 4 septembre 1711: "Il a été ordonné que le Gouverneur fera refondre les grandes semaises au pôtier Freneysy d'Orbe et en faire d'autres avec le même étain, qui contiennent 3 pots. Elles seront faites avec façon de bouteille avec des chainettes. ")

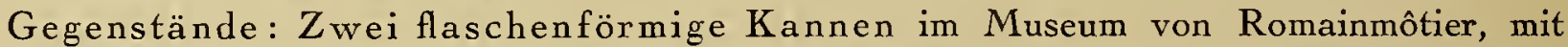
Meisterzeichen Nr.639. Am obern Rande des sechskantigen, prismatischen Korpus sind zwei Oesen zur Befestigung der Kette. Der cylindrische Hals trägt oben einen abschraubbaren Kapseldeckel. Höhe der Kanne $36 \mathrm{~cm}$; Durchmesser des Fusses $14 \mathrm{~cm}$; Höhe des Korpus $21 \mathrm{~cm}$. Auf dem Deckel das Meisterzeichen Nr. 639. (Tafel XV, 3.)

$\mathrm{K}$ anne in Bernerform. Höhe $20,8 \mathrm{~cm}$; Durchmesser des Fusses $8,2 \mathrm{~cm}$. In der Mitte des herzförmigen Deckels das Meisterzeichen Nr. 638. Am Ausgussteil zwei Rillenpaare; in der Mitte des Halses drei feine circuläre Linien. Am glatten Korpus drei Linienpaare. Breitrandplatte von 24,3 cm (Sammlung Hauptmann a. D. Geiger, Neu-Ulm, zitirt bei Hintze, Bd. VII, S. 345).

Zwei Abendmahlkannen von glockenförmigem Profil (Kannenform wie bei Reutter, Extrait du Musée Neuchatelois, 1919, Tafel II) aus einer Kirche in Vully (Kanton Waadt). Siehe Anzeiger fiir schweiz. Altertumskunde, 1904, S. 76 : Ankäufe.

Goldner, Charles-Christophe, Zinngiesser von Dresden, führte das Meisterzeichen Nr. 712 und

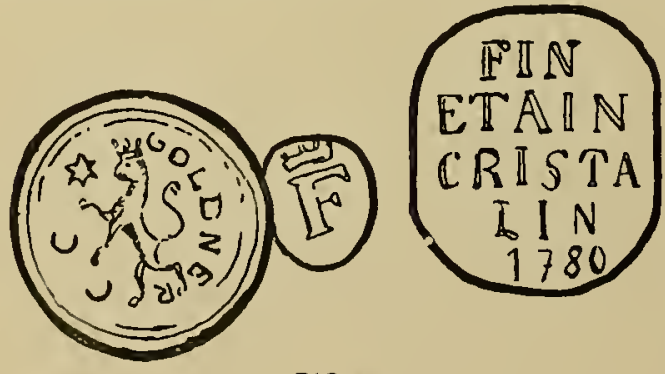

712 a 712 a. Er wurde im Jahre 1736 geboren und kam, schon verheiratet, im Jahre 1769 nach Orbe. Laut Manual des kleinen Rats von Orbe war er im Jahre 1795 weder Bürger noch Niedergelassener. Er war nur geduldet (toléré), weil er sich gut aufführte und weil es in Orbe keinen Zinngiesser gab. Er starb in Orbe am 5. September 1809 (laut Mitteilung des Staatsarchivs von Lausanne). - Sein Sohn Alexander arbeitete ab 1803 als Zinngiesser in Lausanne. 

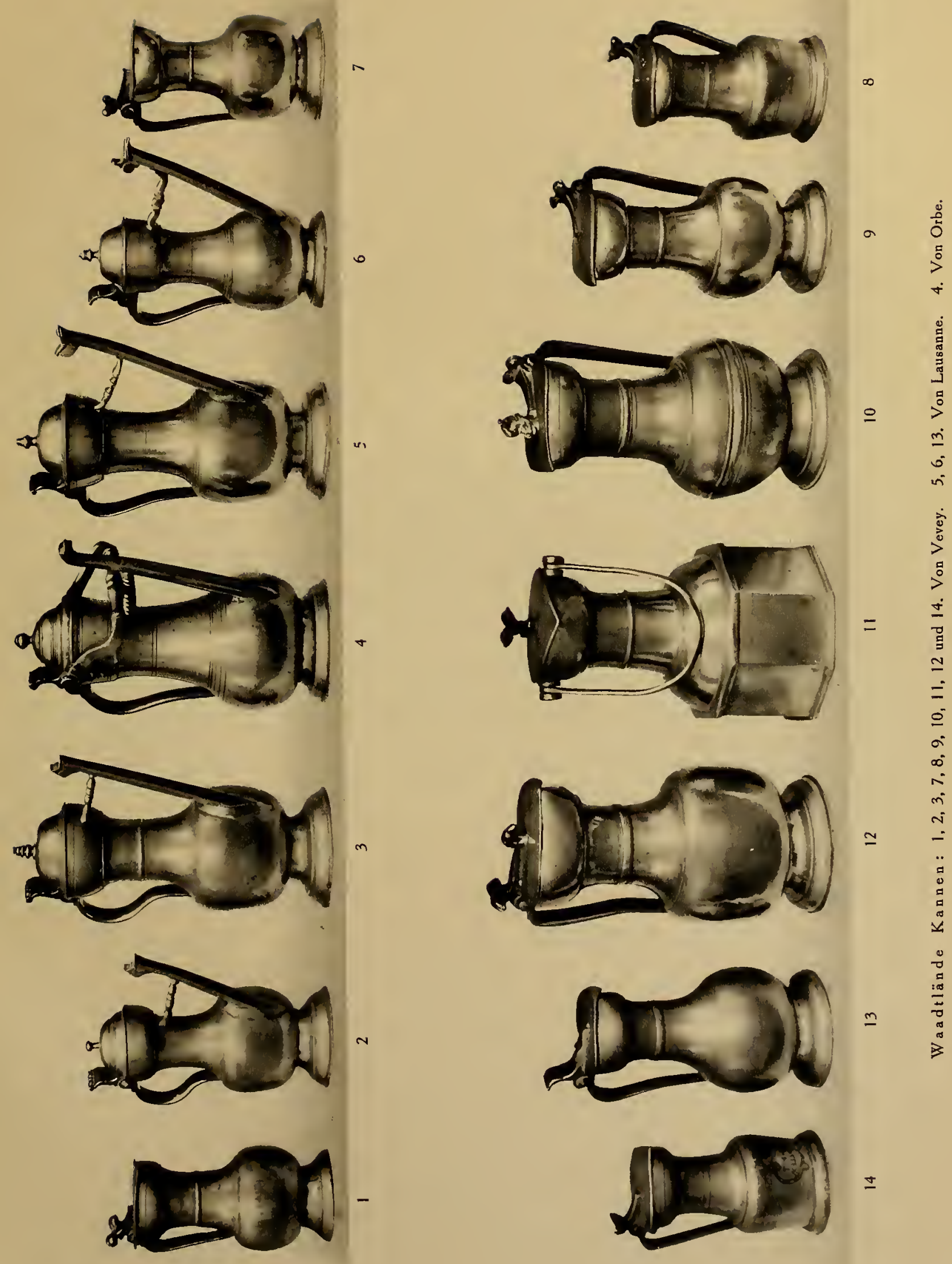
Sein Sohn Charles-Gabriel war ebenfalls Zinngiesser und führte das Meisterzeichen des Vaters; er heiratete 1812 in Belmont ob Lausanne Jeanne-Louise-Françoise Werdtmüller. Im Jahre 181 o kaufte er das Bürgerrecht von Orbe und liess sich als Zinngiesser nieder. Er konnte die Einkaufssumme nur mit Mühe bezahlen; so 1811 wieder eine Rate von $200 \mathrm{Fr}$. Das Todesjahr ist nicht bekannt. Louis Goldner, in Vevey als Zinngiesser tätig, war vielleicht sein Sohn.

Goldner, Charles-Christophe, Meistermarke Nr. 712 und 712 a.

Gegenstände: Steglkanne in Bernerform mit beweglichem, zinnernem Traghenkel. Höhe $33 \mathrm{~cm}$; Durchmesser des Fusses 13,8 cm. Deckeldrücker wie bei den Lausanner Kannen. Deckel kuppelförmig, mit Knopf in der Mitte. Die lange, sechskantige Ausgussröhre läuft in einen Vogelkopf aus und ist mit dem Kannenhals durch einen gerillten Steg verbunden. $Z_{\mathbf{u}}$ beiden Seiten des obern Kannenrandes je ein Scharnir, an welchem der schön profilirte, bewegliche Traghenkel läuft. Am Korpus, Hals und Ausgussteil circuläre Rillen. An der Unterseite des Bodens befindet sich die Meistermarke Nr. 712 mit dem Wappen von Orbe. (Tafel XLVII, 4.)

Zwei Abendmahlkannen in der Kirche von Orbe. Der Korpus ist ein vierseitiger, rechteckiger Pyramidenstumpf. Bodenfläche $22 \times 15,5 \mathrm{~cm}$. Höhe der Kannen $42 \mathrm{~cm}$. Lange Ausgussröhre mit ähnlichem Steg wie bei obiger Kanne in Bernerform. Beweglicher Traghenkel. An der Vorderseite das Wappen von Orbe und die Jahrzahl 18o3. (Tafel XV, 5.)

Abendmahlkamme von Oppens, von ähnlicher Form wie diejenigen von Orbe. Der Ausguss ist jedoch schnabelförmig. Die Kanne trägt das Meisterzeichen Nr. 712 a (Band II).

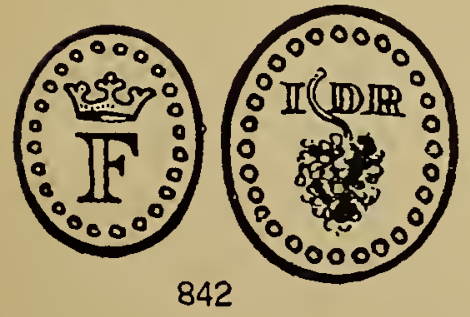

\section{PAYERNE}

Rapin, Jean-David, auch Rappin geschrieben, führte das Meisterzeichen Nr. 842 (Bd. I). Er lässt am 9. April 1711 eine Tochter, Judith-Madelaine, taufen (Kantonsarchiv von Lausanne).

Gegenstand: Platte mit dem Wappen der Familie Comte, mit der Jahrzahl 1721 (Mitteilung von Prof. Burmeister in Payerne).

Stadtkannen von Payerne: Tafel V, 4. Keine Meisterzeichen.

\section{MOUDON}

Frossard, Samuel, von Moudon, trat im Juni ${ }_{1691}$ auf vier Jahre bei Jean-Antoine Charton (1658-1739) in Genf in die Lehre (Naef, S. 164). Ueber seine Tätigkeit und seine Erzeugnisse ist nicht bekannt.

Stadtkannen von Moudon, ähnlich denjenigen von Payerne; auf dem Schild ein M.

\section{MORGES}

Rossier, André, heiratet 1663, arbeitet ${ }_{1664}$ in Genf und zieht 1665 nach Morges (Naef, S. 258). 


\section{GLAND BEI MORGES}

Decarli, ...., Zinngiesser, arbeitete noch 1875 (persönliche Mitteilung des noch in Vevey tätigen Meisters Charles Moriggi, fils), in Gland bei Morges.

Gegenstand: Kleine Suppenschüssel mit Traghenkel. Keine Meisterzeichen; nur ein eingeschlagener Stempel mit dem Worte "Gland ». (Sammlung C. Hirsbrunner, Luzern.)

\section{GRANDSON}

Das Stadtwappen zeigt in Blau eine strahlende goldene Sonne über einem querliegenden, nach oben gesichteten, goldenen Halbmond. Auf den Abendmahlkannen von Grandson, drei Stück, befindet sich dasselbe mit dem Meisterzeichen (Nr. $712 a$ und $712 b$, Bd. II).

Savioz, David oder Daniel, führte das Meisterzeichen Nr. 712 a (Bd. II) mit den Initialen DS und der Jahrzahl 1725. Die Aehnlichkeit mit dem Meisterzeichen Nr. 531 (Bd. I) ist auffallend (RB - 1733). Laut Hist. Biogr. Lexikon

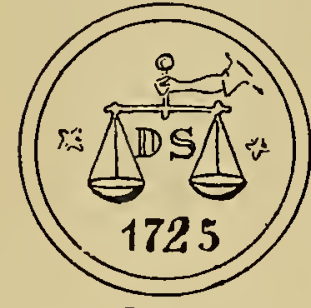

712 a ist die Familie Savioz seit dem XV. Jahrhundert in Lausanne und Moudon ansässig.

Gegenstände : Drei Abendmahlkannen in Grandson. Höhe $30,5 \mathrm{~cm}$; Durchmesser des Fusses $16 \mathrm{~cm}$. Auf dem Deckel Meisterzeichen Nr. $712 a$ und das Stadtzeichen von Grandson (Mitteilung von F. Herrmann, Holzbildhauer in Yverdon). Die Form der Kanne entspricht dem Typus II der Waadtländer Kannen. Deckeldrücker nach hinten abgebogen,

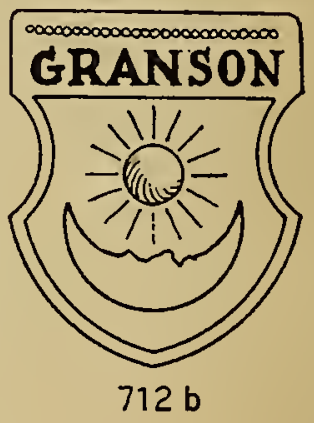

Deckelsteg in Form des Lausanner Deckelsteges. (Tafel XV, 4.)

In der Kirche von Yvonand bei Yverdon befinden sich zwei prächtige Abendmahlkannen mit dem Meisterzeichen Nr. 827 (Bd. I). Der Zinngiesser Jacques Touvenin, 1727, war wahrscheinlich in Frankreich tätig. Korpus oblong-achtkantig; Hals und Deckel genau wie bei den Lausanner Kannen, Typ. I. Starker zinnerner, abgebogener Traghenkel. Höhe der Kanne $33 \mathrm{~cm}$. Querdurchmesser $24 \mathrm{~cm}$; kleiner Durchmesser von vorn nach hinten $11 \mathrm{~cm}$. (Mitteilung von Herrn F. Herrmann, Yverdon.) (Tafel XV, 7.)

\section{FIN}
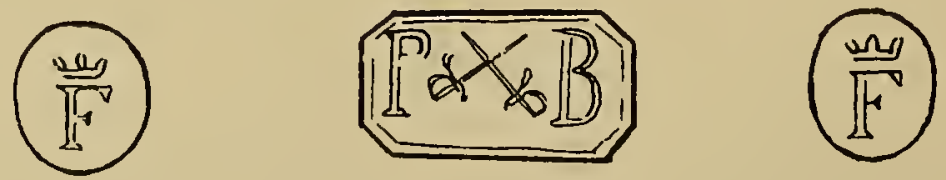

$712 \mathrm{c}$

In Rovray bei Yvonand ist ebenfalls eine ganz aparte Abendmahlkanne. Auf dem hohen bulgenförmigen Korpus erhebt sich ein kräftiger Hals, wie bei den Waadtländer Kannen. Als Deckeldrücker zwei Eicheln. Nebst dem gewöhnlichen Griffhenkel hat die Kanne noch einen halbkreisförmigen, beweglichen, zinnemen Traghenkel. Auf dem Deckel ein oblonges Meisterzeichen mit den Initialen P B neben gekreuzten "Säbeln "; dazu je zwei Mal die Qualitätsstempelchen FIN und bekröntes F. Höhe der Kanne bis zum Deckel $38 \mathrm{~cm}$; Höhe des Korpus $24 \mathrm{~cm}$; Länge und Breite am Kannenfuss 19,5 und 10,5 cm. (Tafel XV, 6.) 


\section{NEUENBURG}

Im Jahre 1919-20 erschien im Extrait Ju Musée Neuchatelois eine ausführliche Arbeit über "Potiers d'étain neuchatelois " von Herrn Architekt Louis Reutter; dieselbe enthält nebst vielen Archivalia auch das Meister- und Markenverzeichnis. Herr Reutter war mir schon bei der Herausgabe des I. Bandes, die Zinngiesser der Schweiz und ihr Werk, ein sehr guter Berater, besonders bei der Agnoscirung der Meistermarken; nun haben sich seither verschiedene Zuteilungen geändert, welche ich berücksichtigen werde.

Nach Reutter finden sich in den Archiven von Neuenburg keine Verordnungen über die Zinngiesser. Die Goldschmiede befassten sich ab und zu auch mit Zinnarbeiten. Sie gehörten, wie die Zinngiesser, zur Corporation des favres, maçons et chapuis (Schmiede, Maurer und Schreiner). Man unterscheidet bei der Qualität der Zinnware das Feinzinn (étain fin: Feinzinn; étain cristallin : englisches Feinzinn), welches mit F mit Krone, fin mit Krone oder, ausgeschrieben, mit Etain fin cristallin bezeichnet wurde. Als Etain commun, gewöhnliches $Z$ inn, bestimmte der Kannengiesser-Eid (Reutter, S. 5 u. 6) diejenige Legirung, welche in Bern vorgeschrieben war, also vor dem Jahre 1470 neun Teile Zinn und ein Teil Blei; nach $147^{\circ}$ vier Teile Zinn und ein Teil Blei. Ungestempelte Ware weist eine noch schlimmere Legirung auf, sogar bis zwei Teile Zinn auf einen Teil Blei.

Die Lehrzeit dauerte drei Jahre und Reutter zitirt mehrere Lehrlingsverträge in extenso. Die Söhne der Meister mussten keine Lehrzeit bestehen; sie mussten nur drei Jahre beim Vater oder bei einem befreundeten Meister arbeiten. Auch mussten dieselben kein Meisterstück anfertigen.

Der Zinngiesser hatte meistens zwei Meistermarken : eine grosse mit dem voll ausgeschriebenen Familien- und Vornamen, und eine kleine mit den Initialen allein. Beide Marken finden sich oft in Verbindung mit dem Wappen von Neuenburg und oft mit dem Zinngiesserhammer.

Die Zinngiesser sind in Neuenburg schon im XV. Jahrhundert nachweisbar, zum ersten Mal im Jahre 1424 (Reutter, S. 9); aus dem Jahre 1552 ist das Inventar des Hôpital de Neuchatel erhalten, das viele Zinngegenstände anführt; ebenso dasjenige vom Schloss Valangin aus dem Jahre ${ }_{1} 556$. Erhaltene Zinngegenstände mit Meistermarken stammen erst aus dem XVII. Jahrhundert.

Zinnerne Platten und Kannen als Schützenfestgaben finden wir in Neuenburg ab 1678 . Im Jahre 1733 wurden 112 Zinngegenstände als Schützengaben ausgeteilt. In meiner Sammlung befindet sich eine Kanne von Jonas Huguenaud mit der Jahrzahl 1686 und dem Schützengabenstempel Nr. $646 a$. Das Zeichen der Schützengabe bestand in einer eingeschlagenen oder zwei gekreuzten Musketen (Reutter, S. 13). - Laut Kaufvertrag vom Jahre ${ }_{1678}$ (Reutter, Musée Neuchatelois, 1920, Juli-August, S. 6-7) lieferte Pierre Villeneufve die zinnernen Schützengaben nach Grandson.

Neben den Meisterzeichen findet man oft eingeschlagene Wappen von Neuenburg und Chevrons. Reutter betrachtet dieselben nur als Controllzeichen, also zur Bezeichnung des Herstellungsortes, Neuenburg. An andern Orten (z. B. im Wallis) sind diese Wappen Aichzeichen.

\section{Die Gegenstände}

Die Kannen kommen in drei verschiedenen Formen vor. Der Typus der Freiburger Kanne ist sehr selten und findet sich nur beim Zinngiesser Jonas Huguenaud. Am häufigsten ist die bauchige Form in der Art der Bernerkanne ohne die lange Ausgussröhre. Man kann den allmäligen Uebergang von der typischen Bernerform zur Bieler und endschaftlich zur Neuenburgerform genau verfolgen. Bei der Letztern ist Hals und Korpus ganz glatt und einfach, nux mit feinen Rillen oder circulären Linien etwas gegliedert. Diese Kannenform existirt in vier Grössen. $x, 1 / 2,1 / 4$ und sehr selten $1 / 8$ Maass. 
Die dritte Art bildet die für Neuenburg eigenartigste Form. Der Korpus wird durch einen Kegelstumpf gebildet; darauf sitzt ein tief eingezogener Hals und darüber folgt der cylindrische Ausgussteil mit herzförmigem Deckel. Von dieser Form gibt es ganze Serien von fünf bis sechs verschiedenen Grössen. Sie dienten auch als Maasse.

Neben den Tellern üblicher Form gibt es eine für Neuenburg eigenartige Abart. Der Fundus dieses Tellers ist vollkommen eben, kaum $1 \mathrm{~cm}$ tiefer als der Rand, welcher seinerseits ebenfalls völlig horizontal, glatt und schmal ist. Der Teller wirkt eigenartig durch seine Einfachheit und Nüchternheit.

\section{Die Zinngiesser von Neuenburg}

(Corporation des favres, maçons et chapuis : F. M. C.)

Aus dem Verzeichnis Reutters sind die Zinngiesser Pierre und Etienne Magnin auszuschalten. Dieselben gehören zu den Meistern von Vevey; Ferner gehört Pierre Goncet ebenfalls zu den Zinngiessern des Waadtlandes.

Sanczon oder Samson, Zinngiesser, reparirt " cimarres" im Jahre 1424 (Reutter, S. 9).

Terraillon, Henry, zitirt 1488 und 1490 (Reutter, S. 12).

Hubsch, Nicolas, Bürger von Bern, macht Turmknöpfe 1509 .

Chevalier, Jean, reparirt Zinnkrüge im Schloss 1530 (Reutter, S. 12).

Bonvespre, Henry, liefert 158 4-160o Turmknöpfe (Reutter, S. 12 ).

Larget, Pasquier, Huguenotte aus Reims, zitirt 1588-94 (Reutter, S. 14).

Favarger, Jonas, liefert 1621 an die Mousquetaires (Reutter, S. 14).

Petermann, Jean, zitirt 1625 (Reutter, S. 14).

Pury, Jean, zitirt 1644 (Reutter, S. 14 ).

Henzeli, David, F.M.C. $166_{2}$ (Reutter, S. 18 ).

Henzeli, Jacques, F.M.C. 1663 (Reutter, S. 18). Sein Lehrling, Jean Larchet, 1664 (Reutter, S. 18 ).

Bonvespre, Abraham (Bonvêpre), führte das Meisterzeichen Nr. 664 (Reutter, S. 13), F.M.C. 1668. Zuletzt erwähnt ${ }_{1675}$. Seine Meistermarke wurde am Knopfe des Turmes des Chavannes gefunden.

Villeneufve, Pierre, von Marennes, Charente inférieure, führte das Meisterzeichen Nr. 532 (bei Bern angeführt, Tafel XXVI). Er arbeitete zuerst in Faoug bei Avenches. Er heiratete 1671. Im Jahre ${ }_{16} 3$ hatte er als Lehrling Henri-François Duperron von Neuenburg. Im Jahre 1674 übersiedelte er nach Neuenburg, wurde aber erst $16_{77}$ in die F.M.C. aufgenommen. In Neuenburg hatte er als Lehrlinge: Jonas Huguenaud, François de Diesse, Jacques Wattel, und nach Reutter auch Erhard Borel. Er war ein hervorragender Meister. Bei Reutter fehlt die Meistermarke. Im Jahre 1696 zog Villeneufve nach Bern und erhielt die Erlaubnis zur Niederlassung (Burgerkammermanual Bern V, 37 ).

Reutter lässt die Frage offen, ob es nicht zwei Villeneufve gab. Eigentümlicherweise wird ein Villeneufve 1680.VIII.26, Pierre Villeneufve de Maraines en Xaintonge, als Einwohner von Yverdon zitirt (Reutter, 1919, S. 40). und zwar anlässlich des Lehrvertrages von Jacques Wattel auf drei Jahre.

Grosse $\mathrm{K}$ anne im Landesmuseum in Zürich: Tafel XIV, 3.

Huguenaud, Samuel, zitirt 1637-1640. Samuel Huguenott, vom welschen Neuenburg, lernt 1637-40 bei Johannes Linder in Basel (Hausgenossenzunft in Basel, Auszug).

Huguenaud, Jonas, führte die Meisterzeichen Nr. 646 und $646 a$ (Reutter, S. 13 ). Auf Ersterem gibt Reutter die Jahrzahl 1666, was vielleicht auf einem Lesefehler beruht; denn Jonas Huguenaud war Lehrling bei Pierre Villeneufve, welcher vor $16_{74}$ nur wenige Jahre in Faoug bei Avenches war und ${ }_{16} 64$ nach Neuenburg kam. Auch wurde Jonas Huguenaud erst $16_{77}$ in die F.M.C. aufgenommen. 
Gegenstand: Kanne in Freiburger-Form. Höhe 25,3 cm; Durchmesser des Fusses $14 \mathrm{~cm}$. Abgekröpfter Deckeldrücker. Auf dem herzförmigen Deckel das Meisterzeichen Nr. 646 a (Reutter, S. 3 im Nachtrag 1920 des "Musée Neuchatelois) mit der Jahrzahl 1686; ferner zwei Mal der Stempel mit den Initialen AMT und ein herzförmiger Stempel mit den Initialen I A MT. MT vielleicht: Môtiers-Travers. Dazwischen eingeschlagen eine kleine Muskete als Schützengabenzeichen. Zwischen Hals und Korpus ein flacher Wulst und zwei Linienpaare; am Ausgussteil ein Linienpaar. Unten am Fuss der Kanne ein circulärer Wulst und drei parallele Linien. (Tafel XVII, 11.)

Ghaillet, Théodore, führte das Meisterzeichen Nr. 65o. "Chaliet Théodor, von Kartger im welschen Bernbiet, lernt vom 7. März ${ }_{16} 64$ ab bei Emmanuel Scholer (Basel) und wird am 17. März 1677 ledig gesprochen" (Akten der Hausgenossenzunft in Basel). Nach Naef (S. 135) lernt er ab 11 . September 1677 (oder arbeitet) bei Léonard Bourrelier in Genf. Chaillet wird im Jahre 1678 in die F.M.C. aufgenommen. Er starb am 26 . November 1694 (Reutter, S. 2o).

Boyve, Noë, Obmann der F.M.C., zitirt 1647,1650 (Reutter, S. 14).

Boyve, Samuel, Sohn des Vorigen, tritt 168 o in die F.M.C. und stirbt im Jahre 1715 (Reutter, S. 16 ).

Boyve, Frédéric, Sohn des Noë und Bruder des Vorigen, bei welchem er in der Lehre war. Er wird 1686 Mitglied der F.M.C. (Reutter, S. 16).

Boyve, Jeremias, zitirt 163o; starb vor 1659 (Reutter, S. 14 ).

Boyve, David, Sohn des Vorigen, zitirt 1659 , 1664. Hatte als Lehrlinge : Frédéric Gaudet (Reutter, S. 2o) und Jacques Gallot (Reutter, S. 20).

Boyve, Josue, Sohn des David und auch sein Lehrling; er führte das Meisterzeichen Nr. 666 (Reutter, S. 13). Er war von 1663 bis 1682 in Bern tätig und führte dort die Meisterzeichen Nr. $518,519,520$. In Neuenburg tritt er 1691 in die F.M.C. ein.

Gegenstand: Kanne, bauchige Form. Höhe $18,5 \mathrm{~cm}$; Durchmesser des Fusses 9,1 cm. Auf dem Deckel das Meisterzeichen Nr. 518 und ein eingeschlagene Initialen G F.

Stitze. Höhe $19 \mathrm{~cm}$; Durchmesser des Fusses $10 \mathrm{~cm}$. Auf dem flachen, herzförmigen Deckel die Meistermarke Nr. 518 und die eingeschlagenen Initialen $\mathrm{O} H$.

Boyve, Abraham (nach Alfred Godet, Neuenburg), lieferte am Ende des XVII. Jahrhunderts an Siméon Crible, Metzger in Saint-Blaise.

Boyve, Simon, wird Mitglied der F.M.C. im Jahre 1692 (Reutter, S. 16).

Boyve, Jakob, wird Mitglied der F.M.C. im Jahre 1719; sirbt 1739 (Reutter, S. 16).

Boyve, Daniel, führte das Meisterzeichen Nr. 667 (Reutter, S. 13) und Nr. 668 (Reutter, Nachtrag 1920, S. 3). Auf dem Stempel die Jahrzahl 1722. Daniel trat 1742 in die F.M.C. und starb im September 1782 (Reutter, S. 16). )

Boyve, François, wird in die F.M.C. im Jahre 1769 augenommen (Reutter, S. 16).

Duperron, Henri-François, wird 1680 Mitglied der F.M.C. und stirbt 1717. Bei ihm lernt 1684 Rodolphe Hermann. Duperron arbeitet gemeinsam mit dem folgenden $F$. de Diesse (Reutter, S. 20).

De Diesse, François, war Lehrling bei Pierre Villeneufve. Wurde Mitglied der F.M.C. im Jahre 1681 (Reutter, S. 20).

Gaudet, Frédéric, lernte bei David Boyve. Wurde im Jahre 1684 Mitglied der F.M.C. (Reutter, S. 20).

Breton, Jean, von Nîmes, führte das Meisterzeichen Nr. 665, das sich auf einem einzigen bekannten Teller befindet (Reutter, S. 15 u. 20). Im Jahre 1686 wurde er bei den F.M.C. aufgenommen.

Gallot, Jacques, führte die Meisterzeichen Nr. 647, 648, 649 (Reutter, S. 3 u. 37). Er war Lehrling bei David Boyve. Bei den F.M.C. wird er im Jahre 1686 aufgenommen. Er lieferte auch an die Schützengesellschaften (Reutter, S. 21). Er starb im März des Jahres 1728 (Reutter, S. 21). Bei ihm lernte Baillif Charles-François (Neuenstadt ?). 
Gallot, Henry, lieferte an die Société des Mousquetaires; er war auch Goldschmied. Er starb im Jahre 1719 (Reutter, S. 22).

Motta, Jean-Henri; in die F.M.C. aufgenommen im Jahre 1687 (Reutter, S. 22).

Hermann, Rodolphe, in die F.M.C. aufgenommen im Jahre 1689 (Reutter, S. 22 ).

Chàtelain, Glaude, in die F.M.C. aufgenommen im Jahre 1693 (Reutter, S. 22).

Wattel, Jacques, führte das Meisterzeichen Nr. 663 (Reutter, S. 25). Reutter bringt sechs Marken (S. 31 und II, S. 5). Er wurde 1703 bei den F.M.C. aufgenommen.

Gegenstand: Kanne, gewöhnliche Form. Höhe $20,6 \mathrm{~cm}$; Durchmesser des Fusses $8,7 \mathrm{~cm}$. Abgekröpfter Deckeldrücker. Auf dem herzförmigen Deckel das Meisterzeichen Nr. 663 mit dem chevronirten Adler. Am Ausgussteil zwei Rillenpaare; in der Mitte des Halses ein Rillenpaar; am obern Rand des Korpus drei circuläre Rillen. Auf dem Deckel eine eingeschlagene kleine Musquete als Schützengabenzeichen (Nr. 863, Bd. I, Tafel XLIII).

Wattel, David-François, oder Daniel-François, führte das Meisterzeichen Nr. 662 (Reutter, S. 25 ). Er wurde im Jahre 1725 bei den F.M.C. aufgenommen und starb im Jahre $177^{\circ}$ (Reutter, S. 3o).

Chàtelain, Jean-Jacques, führte die Meistermarken Nr.651,652, 653 mit den Jahrzahlen 17o9, 1717, 1719, 1722. Reutter bringt elf verschiedene Meisterzeichen (S. 15, 33, 36). Er wurde im Jahre 1704 bei den F.M.C. aufgenommen. Sein Todesjahr ist 1733.

Als Lehrlinge: Perrin François, Corevon Pierre-Marc und Aymann Daniel. Gegenstände: Kanne, gewöhnliche Form. Höhe $31,5 \mathrm{~cm}$; Durchmesser des Fusses 13,7 cm. Deckeldrücker abgekröpft. In der Mitte des herzförmigen Deckels zwei concentrische kreisförmige Rillen; davor das Meisterzeichen Nr. 651 mit der Jahrzahl 1717. Hals und Korpus glatt. An jedem Teil ein Rillenpaar. An der Seite des Halses ein undeutlicher Eigentumsstempel. (Tafel XLVI, 3.)

Kanne, gewöhnliche Form. Höhe $26,3 \mathrm{~cm}$; Durchmesser des Fusses 10,9 cm. Deckeldrücker abgekröpft. Auf dem herzförmigen Deckel ein kreisförmiges Rillenpaar. Davor das Meisterzeichen Nr. 651 mit der Jahrzahl 1717 und den eingeschlagenen Initialen F B. Ausgussteil, Hals und Korpus glatt; auf jedem Teil zwei feine circuläre Linienpaare.

(Tafel XLVI, 2.)

Kanne, gewöhnliche Form. Höhe 21,5 cm; Durchmesser des Fusses 8,7 cm. Deckeldrücker abgekröpft. Auf dem herzförmigen Deckel das Meisterzeichen Nr. 651. In der Mitte des Deckels drei circuläre Rillen. Am Ausgussteil zwei Rillenpaare; in der Mitte des Halses ein Rillenpaar ; zwischen Hals und Korpus zwei Linienpaare. (Tafel XLVI, 1.) Abendmahlkanne von Le Locle, datirt 1706. (Tafel XII, 2.)

Borel, Erhard, Lehrling des Pierre Villeneufve, vielleicht schon in Bern. Bei den F.M.C. wurde er im Jahre 1704 aufgenommen. Todesjahr 1740 (Reutter, S. 24).

Corevon, Pierre-Marc, Lehrling bei Jean-Jacques Châtelain. Bei der F.M.C. im Jahre 1705 aufgenommen (Reutter, S. 24).

Aymann, Daniel, bei den F.M.C. aufgenommen 1712 (Reutter, S. 24 ).

Guillebert, Jean-Henri, Zinn- und Glockengiesser, geboren 1694; bei den F.M.C. 1716; starb 1748 (Reutter, S. 24).

Claude, Pierre-Paul, bei den F.M.C. aufgenommen 1719 (Reutter, S. 26).

L'Ecuyer, Jean-Jacques, bei den F.M.C. 1728 (Reutter, S. 26).

Motheux, Mathurin, Zinnhändler von Paris, führte die Meisterzeichen Nr. 669, 670, 671, 672 673 , oft mit der Jahrzahl 1734. Bei den F.M.C. im Jahre 1734. Er lieferte schon im Jahre 1730 an die Schützengesellschaften. Er starb im Jahre 1739 (Reutter, S. 19, 21, 26).

Bonhôte, Abraham, von Peseux. Zitirt 1733-44 (Reutter, S. 26).

Bonhôte, François, lieferte die Gaben für die Schützen und die Musquetire von 1762-1770. Er war der Schwiegervater des folgenden Meisters, Louis Perrin.

Perrin, François, führte die Meisterzeichen Nr. 654, 655, 656; Reutter hat noch zwei weitere (S. 21, 23, und Nachtrag 1920, S. 2). Geboren 1706; er war Lehrling des Jean-Jacques 
Châtelain; wurde 1728 bei den F.M.C. aufgenommen. Er starb im Jahre 1748 (Reutter II, S. 3). Auf seinen Marken ist oft die Jahrzahl 1729.

Gegenstände : Krüge, Kannen, Teller, Platten.

Abendmahlkanne von Saint-Blaise, Tafel XII, 3.

Perrin, Josué, Sohn des Vorigen, führte die Meisterzeichen Nr. 657 (mit negativer Inschrift), 658. Reutter bringt vier Meistermarken (S. 24 und Nachtrag 1920, S. 3). Er war nicht Mitglied der Corporation der F.M.C. Wahrscheinlich lieferte er auch an die Schützengesellschaften bis im Jahre $17_{62}$, in welchem er starb.

Gegenstände: Kanne, gewöhnliche Form. Höhe $32,4 \mathrm{~cm}$; Durchmesser des Fusses $13,1 \mathrm{~cm}$. Deckelgriff stark nach hinten gebogen, oben profilirt. Auf dem herzförmigen Deckel ein kreisrundes Linienpaar und die Meistermarke Nr. 657. Eingeschlagene Initialen H. RH. Am Ausgussteil und in der Mitte des Halses je ein Linienpaar; beim Uebergang in den Korpus zwei Linienpaare. Am Fusse der Kanne circuläre Rillen. (Tafel XLVI, 4.) Runde Schale. Durchmesser $22 \mathrm{~cm}$; Tiefe $3,8 \mathrm{~cm}$. Innen am Boden das Meisterzeichen Nr. 657. Die Seitenwand der Schale ist gebuckelt.

Perrin, Louis, Sohn des François, führte das Meisterzeichen Nr. 659 und 66o. Reutter bringt sechs Meisterzeichen (S. 23, 31). François wurde 1746 geboren, wurde ${ }_{17} 66$ bei den F.M.C. aufgenommen und starb 1821 .

Gegenstand: Kanne, gewöhnliche Form. Höhe 19,6 cm; Durchmesser des Fusses $8,7 \mathrm{~cm}$. Deckeldrücker abgekröpft. Der flache, herzförmige Deckel trägt die Meistermarke Nr. 659. Am Ausgussteil ein Rillenpaar. Zwischen Hals und Korpus zwei Rillenpaare. Fuss profilirt. (Tafel XLVI, 7.)

Platte, datirt 1781 , im historischen Museum von Neuenburg.

Perrin, Louis, fils (Abram-Louis), führte das Meisterzeichen Nr. 661. Reutter bringt drei Meistermarken (S. 25). Er wurde im Jahre 1773 geboren; wurde 1799 bei den F.M.C. aufgenommen und starb 1860 (Reutter, S. 32 ).

Abendmahlkanne von Boudry, Tafel XII, 4.

Thonnet, Charles, führte die Meisterzeichen Nr. 674, 675; Reutter bringt fünf Meisterzeichen (S. 19, 26, 28, 31, 33, 36). Er wurde 1744 bei den F.M.C. aufgenommen. Von 176o-1770 lieferte er der Compagnie des Mousquetaires. Datirte Gegenstände von 1745 bis 1762 . Seine Arbeiten sind einwandfrei und meist aus feinstem Material. Er starb 1775 .

Gegenstände: Kanne mit kegelstumpfförmigem Korpus. Höhe 23,2 cm; Durchmesser des Fusses 11,8 cm. Deckelgriff abgekröpft. In der Mitte des herzförmigen Deckels ein kreisförmiges Rillenpaar. Darüber laufend die eingeschlagenen Namen CHARLO PICINO; davor das Meisterzeichen Nr. 674 mit der Jahrzahl 1745 . Am Ausgussteil zwei Rillenpaare und zu beiden Seiten je ein eingeschlagener chevronirter Adler. In der Mitte des tief eingezogenen Halses ein Rillenpaar. Am glatten, kegelförmigen Korpus zwei Rillenpaare. (Tafeln XVII, 12 und XLVI, 6.)

Miniaturkanne gewöhnlicher Form. Höhe 15,7 cm; Fussdurchmesser 7,2 cm. Aufdem Deckel das Meisterzeichen Nr.674. Am Ausgussteil zwei Mal drei circuläre Linien ; am Hals und oben am Korpus je ein Linienpaar. Fussteil dreimal abgesetzt. (Tafel XLII, 8.)

Borel, Jean-Jacques, führte die Meisterzeichen Nr. $676,677,678,679,680$, 681 (Reutter, S. 17 u. 37 ). Er wurde bei den F.M.C. im Jahre 1782 aufgenommen. Gegenstände: Viele Teller und Platten.

Borel-Fabry. Soll um 1800 geliefert haben. Nach Reutter ist diese "Firma " nicht nachweisbar (S. 32).

Morigi, Dominico, führte die Meisterzeichen Nr. 684, 685, 686, 687, 710,711 . Reutter bringt acht Meistermarken (S. 34, 27, 29 u. 31). Er wurde im Jahre 1805 in Brissago geboren und liess sich 1835 in Neuenburg nieder.

Morigi, Achille, Sohn des Vorigen, führte die Meisterzeichen Nr. 682 und 683 (Reutter, S. 27). Er wurde im Jahre 1833 geboren, 1858 Bürger von Neuenburg und arbeitete ab 1867 daselbst. Er starb im Jahre 1873 . (Mitteilung von Herrn Ch. Moriggi fils, in Vevey.) 
Moriggi, Charles I, führte die Meisterzeichen Nr. 688, 713, 714, 715, 716 (Reutter, S. 29, zwei). Er wurde im Jahre 1839 geboren und lebte in Neuenburg bis 1869 , wobei er einige Jahre als Zinngiesser arbeitete. Am 8. Juli 1869 eröffnete er sein Geschäft in Vevey.

\section{MOTIERS-TRAVERS}

Sandoz, Abraham, Zinngiesser in Motiers. Ihm wird am 26. Januar 1706 ein Sohn getauft (Reutter, S. 24).

\section{WALLIS}

Infolge seiner geographischen Gestaltung, seiner Bevölkerungsverteilung, seiner Sitten und Gebräuche, nimmt das Wallis eine ganz besondere Stellung ein. Das lange, mächtige Rhonetal mit seinen bis $40 \mathrm{~km}$ langen Seitentälern ist von gewaltigen Gebirgen eingeschlossen. Die meisten Passübergänge sind mehr als das halbe Jahr nicht begehbar, zumal in der Zeit vor 1800 . Fast der gesammte Handel und Verkehr kam nur vom Genfersee her. Grosse Städte gibt es keine. St. Maurice, Martigny, Sitten, Siders und Brig hatten weder Innungen noch Zünfte im üblichen Sinne. Daraus folgt obne Weiteres, dass ortsansässige Zinngiesser nur ein mageres Auskommen finden konnten, obwohl das weinreiche Land einen relativ grossen Bedarf an Zinngeschirr, besonders Weinkannen, hatte. Man darf nicht ausser Acht lassen, dass das Zinngeschirr viele Male geklopft und gelötet wurde, ehe man es zum Umschmelzen gab. Die einfachen Reparaturen wurden zudem sehr häufig von fahrenden, meist italienischen Kesselflickern und Zinngiessern (franz. magnins genannt) besorgt.

In den kleinen Ortsarchiven sind die Nachforschungen sehr umständlich und fast nur für Ortsansässige möglich und gerade über die Zinngiesser ist das Material ausserordentlich spärlich. Während mehr als 3o Jahren habe ich das ganze Land besucht und bin bei den vielen Bergturen in alle Seitentäler gelangt. In unzähligen Häusern babe ich Nachschau gehalten und bin so auf empirischem Wege in den Besitz der Giessermarken gelangt. Es war in der gleichen Zeit, als Herr Prof. Stebler von Zürich das Material für seine prächtigen Walliser-Monographien sammelte. Noch im Jahre 1900 fand man nirgends solche Mengen schöner Platten und Kannen in allen Grössen und in gutem Zustande; waren doch noch viele im täglichen Gebrauche, besonders in den Seitentälern, im Lötschen- und Eifischtal.

Die auf den Kannendeckeln und den Platten befindlichen Meistermarken bewiesen auf den ersten Blick, dass ein grosser Teil derselben aus dem Waadtlande oder aus Genf stammten. Bei plötzlichem grössern Bedarf, so anlässlich der Schützenfeste, genügte die einheimische Produktion nicht. Grosse Bestellungen wurden im XVII. und XVIII. Jahrhundert besonders in Genf und Vevey gemacht. Auf grossen Breitrandplatten vom Schützenfest in Sitten befinden sich Meisterzeichen von Leonard I Bourrelier (1639-173o); auf Platten und Kannen von dem Schützenfest des Jahres 1681 in Siders die Stempel von Jean Antoine Charton (1658-1739), beide bekannte Genfer Zinngiesser. Auf Tafel XLIII des I. Bandes findet man eine Auswahl der besten Zeichen von Sitten, Siders und Leuk, neben denjenigen anderer Städte.

Die Walliser Zinngiesser waren oft genötigt, ihren Wohnsitz zu verändern, wenn die Aufträge zu spärlich waren oder zu viele fahrende Zinngiesser das Land durchreisten. Es gab keine Zünfte, welche das einheimische Gewerbe erfolgreich schützen konnten. Zu dieser Feststellung gelangte ich nach Untersuchung von Hunderten von Kannen und Platten, deren ortsansässige Hersteller doch an einen bestimmten Bezirk (desenus) gebunden waren. So findet man im Zehnten Goms die meisten Arbeiten von Surd, Sior und Storno, auch des Meisters A S.

Nach dem Jahre 1800 findet man aber Zinngiesser von grosser Leistungsfähigkeit, so die Maciago in Brig, die Alvazzi und Castel in Sitten. Wohl zwei Drittel der heute noch vorhandenen Walliser Kannen stammen von ihnen. Die Alvazzi und Castel besassen schon eigene Schützengabenstempel mit ihren Initialen (siehe Band I, Tafel XLIII, Nr. 859 u. 86o). 
TAFEL XLVIII

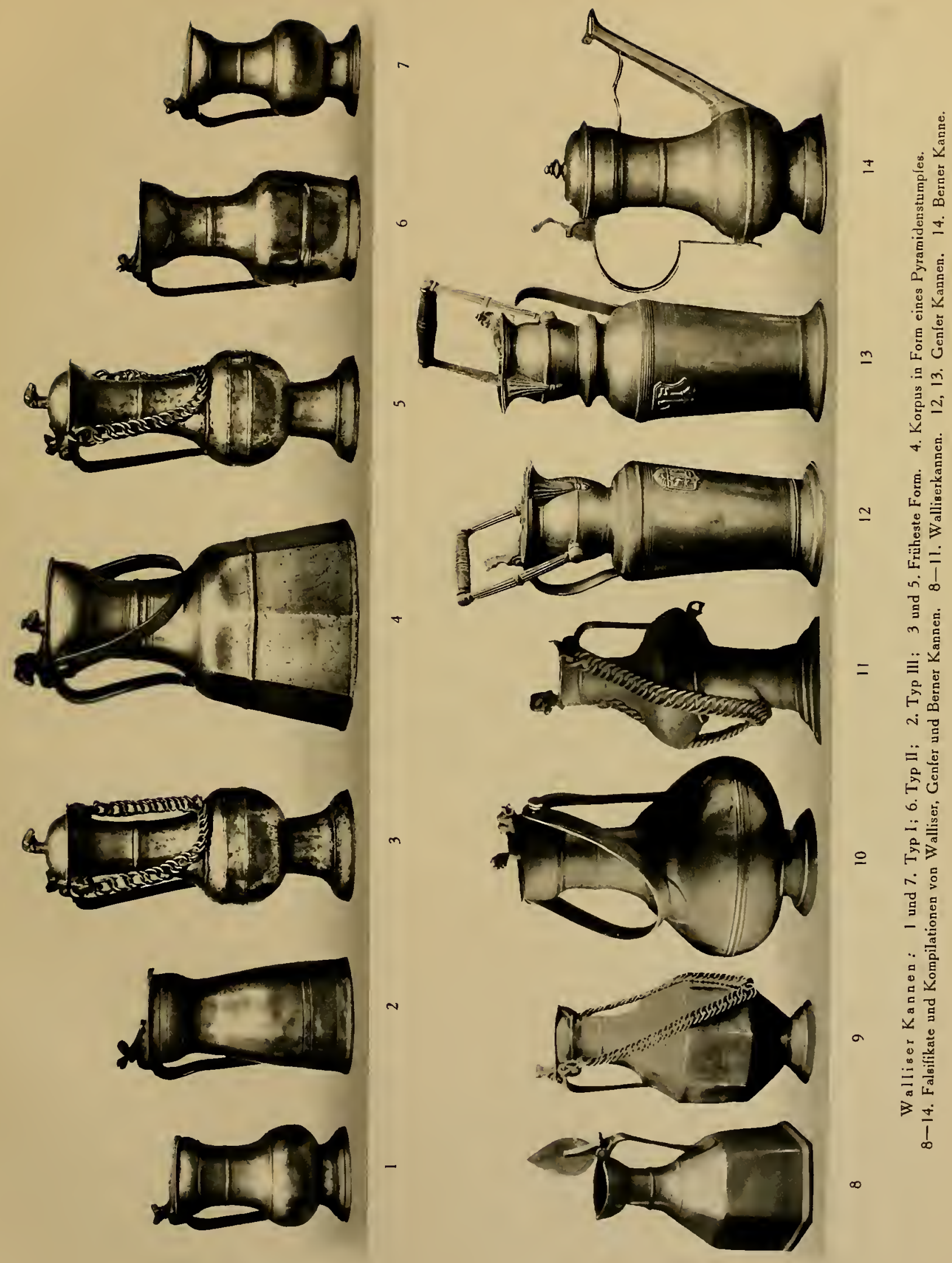




\section{Die Gegenstände}

\section{Die Kannen}

Die Kannen sind, wie überall, die wichtigsten Erzeugnisse der Zinngiesser. Um bei der Aufstellung der Erzeugnisse der verschiedenen Meister endlose Wiederholungen zu vermeiden, teile ich die Kannenformen in drei Typen ein. Jeder der drei Typen weist, je nach dem Meister, verschiedene kleine Varianten auf. Die drei Abbildungen der Tafel XVII, 5-8, bieten mehr als eine lange Beschreibung. Der Typ III kommt wohl nur im Wallis allein vor.

Ausser diesen Hauptformen gibt es wenige seltene Stücke mit anders geformtem Korpus; Fuss- und Halsteil bleiben sich gleich. Bei den Kannen mit prismatischem (sechs- bis achtseitig) oder pyramidenförmigem Korpus, ist der Halsteil gleich; der runde Fuss fehlt, weil der Korpus direkt aufliegt. Alle diese Kannen sind ausserordentlich selten und werden oft nachgemacht. Solche Imitationen findet man sogar in Museen in ganzen Serien. Bei vielen derartigen Stücken ist oft der Hals und der Fuss, sogar der Deckel mit den Meisterzeichen, echt alt aus der Zeit; der findige Zinngiesser hat nur den Korpus der seltenen Form dazwischen gesetzt.

Bei allen Kannen kann der Deckel mit grosser Leichtigkeit abgenommen und ausgewechselt werden. Dieses erfolgt nicht nur beim Zinngiesser, sondern viel häufiger beim Händler, welcher einer gut erhaltenen Kanne auch einen schönen Deckel gab. Darum ist es unmöglich, bei den Walliser, Waadtländer und Genfer Kannen die Provenienz nur allein aus dem Meisterzeichen zu bestimmen. Eine sehr genaue Kenntnis der kleinen Differenzen der Kannenformen, der Abarten der dekorativen Attribute, gewisser Eigenheiten einzelner Zinngiesser, der Hausund Eigentumszeichen ist unerlässlich. Um diesen schwierigen Punkt werden besonders die nur "rein wissenschaftlich» arbeitenden Autoren und Stubengelehrten nicht herumkommen. Dieses beweisen besonders die Abbildungen in ihren Büchern.

Die sogenannten Tragketten bei vielen westschweizerischen Kannen bilden nur eine Dekoration. Zum Tragen sind die Ketten völlig ungeeignet und meist viel zu schwach. Sie würden in kurzer Zeit durchgeschliffen sein und dienten niemals zum Tragen. Kannen mit echten, alten Ketten sind eine grosse Seltenheit; ich habe kaum zehn Stück gesehen, welche auch durch Berufszinngiesser von technischen Standpunkt als einwandfrei alt anerkannt wurden. Die Ketten waren eine richtige Mode geworden und die Liebhaber verlangten oft nur Kannen mit Ketten. Infolgedessen brachten die Zinngiesser solche Ketten auch an viele alte Kannen von Typ I und II an und zwar nicht nur im Wallis, sondern auch anderwärts.

Auf dem Deckel findet man, ausser dem Meisterzeichen, viele andere Marken, welche teils eingeschlagen, teils primitiv gravirt sind. Hervorragende Geschlechter, wie die Stockalper, v. Riedmatten, Roten, u.s.w., hatten hübsche Eigentumsstempel mit dem Familienwappen; in andern Fällen sind die Wappen eingravirt. Beim Volke auf dem Lande treten an die Stelle der Wappen die Hauszeichen, die ebenfalls entweder eingeritzt oder eingeschlagen wurden. Interessenten finden in den Walliser Monographien von Prof. F. G. Stebler, Zürich ', ganze Serien abgebildet, entsprechend verschiedener Talschaften. Hiebei handelt es sich um ganz primitive Zeichen, Striche, Kreuze, Kreise u. dgl., welche von einer Familie Jahrhunderte hindurch benutzt wurden. In den Gemeindehäusern wurden dieselben zur stetigen Kontrolle auf den sogenannten Tesseln aufbewahrt.

Die Schützengabenzeichen bilden die schönste Art der Marken, welche nirgends solche Dimensionen haben, wie im Wallis. Da bei den Schützenfesten die Kannen und Platten meist in Genf oder Vevey hergestellt wurden, findet man diese Abstempelung nur auf solchen Stücken. Eigentliche Prachtexemplare sind die grossen Marken von Sitten, Siders und Leuk, welche in Band I, Tafel XLII, abgebildet sind. Im XIX. Jahrhundert besassen auch einige leistungsfähige Walliser Zinngiesser eigene Schützengabenstempel, z. B. die Alvazzi (in Sitten).

1 Monographien von Praf. F. G. Stebler, Zürich : Ob den Heidenreben, 1901. Das Goms und die Gomser, 1903. Am Löıschberg, 1907. Sonnige Halden am Lötschberg, 1913. Vispentaler Sonnenberge, Jabrb. S. A. C. 1921. 
Die Aichzeichen, welche sich bis ins XVI. Jahrhundert zurückverfolgen lassen, finden sich nur auf Kannen in Wirtschaften oder Weinhandlungen. Im Privatgebrauch war die Aichung nicht obligatorisch; bei derselben wurde im Innern des Kannenhalses an der entsprechenden Stelle eine kleine Zinnkugel angelötet. Auf dem Deckel und oft auch aussen am Halse wurde der Aichstempel eingeschlagen. Diese bestanden früher im Wappen des einzelnen Zehnten, Goms, Leuk, Sitten, Conthey, etc.; später im allgemeinen Wappen des Wallis mit den 7 und später 13 Sternen (siehe Tafel XLI, Bd. I, Nr. 815-823). In vielen Fällen ist die Jahrzahl auf dem Stempel; im XIX. Jahrhundert wird die Jahrzahl der Aichung auf den Steg des Deckels eingeschlagen.

Die Initialen des Eigentümers sind oft eingeschlagen; in andern Fällen sind dieselben mehr oder weniger primitiv eingravirt oder nur eingekratzt. Seltener findet man voll ausgeschriebene Namen mit Jahrzahlen.

\section{Die Teller und Platten}

Das Wallis war eine richtige Fundgrube für die prachtvollen Breitrandplatten, welche meistens vor dem Jahre 1700 entstanden waren. Auf dem breiten Rand hatten die Schützenzeichen und die übrigen Marken reichlichen Platz. Häufig findet man kunstvoll eingravirte Wappen von Familien, Bischöfen, Städten und Ortschaften, zum Teil auch mit der Jahrzahl '. Die schmalrandigen, gewöhnlichen Teller bieten keine Besonderheiten.

Die Blumenteller in Reliefguss, die einzigen Reliefteller der Süd- und Westschweiz, finden sich bei ihrem Hersteller, dem Meister Joannes 2 Surd, beschrieben. Die Abbildung eines gleichen Exemplares findet sich auch in Nos Anciens, 1904, S. 94, Abhandlung von E. Naef.

\section{Die Zinngiesser im $W_{\text {allis }}$}

Surd, Joannes, führte das Meisterzeichen Nr. 788 und arbeitete wahrscheinlich zeitweise in Sitten, auch im Oberwallis. Ueber seine Wirkungszeit geben die sog. Walliser Blumen teller einigen Aufschluss, weil archivalische Angaben fehlen. Die Blumenteller tragen auf der Rückseite die Marke Nr. 788, auf der Vorderseite das Qualitätszeichen F mit Krone und bei zwei Exemplaren ein Familienwappen mit der Jahrzahl 1651 . (Tafel XXXVIII, 4.)

Gegenstände: Walliser Blumenteller ${ }^{3}$, auf dem schmalen Rande derbe Blatt- und Blumenranken in starkem Relief. In der Mitte des Bodens ein hervorstehender Umbo mit einem geschlossenen Renaissance-Ornament, ebenfalls in Reliefguss. Das Relief und der Guss ist bedeutend derber als derjenige der Nürnberger Teller der gleichen Zeit. An der Unterseite die Meistermarke Nr. 788. (Teller bei Herrn Theodor Fischer, Antiquar, Luzern),

Kanne, Typ II. Höhe $25,5 \mathrm{~cm}$; Durchmesser des Fusses 11,5 cm. Am Deckelgriff zwei Granatäpfel. Auf dem Deckel die Meistermarke Nr. 788, daneben die gravirten Initialen I. C. Nahe dem obern Rande der Kanne, an der vordern Seite, ein schönes, eingeschlagenes Stadtzeichen von Sitten (Bd. I, Nr. 815). Am Aequator des Korpus und in der Mitte des Halses je ein lräftig prominirender Wulst. Im Boden eine eingesetzte Rosette mit französischer Lilie. (Tafel XLVIII, 6.)

$Z_{w e i}$ Messkännchen, Typ I. Höhe $11,2 \mathrm{~cm}$; Durchmesser des Fusses 4,7 cm. Am Deckelgriff zwei Eicheln. Auf dem Deckel das Meisterzeichen Nr. 788, davor in Gravirung A und V (Aqua, Vinum). In der Mitte des Halses circulärer Wulst. Korpus ganz glatt.

1 E. Naf. L'étain, Genéve 1920, Tafel IX-XI.

2 Der Vorname ist sn geschrieben, wie er auf der Meistermarke steht.

${ }^{3}$ Ein gleiches Exemplar ist abgebildet in "Nos Anciens 1904*. S. 94 " 
Sior, Joan, führte das Meisterzeichen Nr. 783. Der Stil seiner Kannen entspricht dem Anfang des XVII. Jahrhunderts.

Gegenstände: Zwei schlanke Kannen, Typ I. Höhe $35 \mathrm{~cm}$; Durchmesser des Fusses $12 \mathrm{~cm}$. Am Deckelgriff zwei Eicheln. Deckel am Rand flach, in der Mitte kuppelförmig mit aufgesetztem Widderkopf. Auf der Kuppel das Meisterzeichen Nr. 783 und die Qualitätsmarke F mit Krone. Zu beiden Seiten der obern Kannenrandes je eine starke Oese zur Befestigung der Tragkette. Echte, alte, gerillte Zinnketten. Korpus kugelförmig mit flachem Band am Aequator. In der Mitte des Halses glatter Wulst. Der Fuss der Kanne ist schlank und steil in die Höhe steigend. (Ein gleiches Exemplar findet sich bei Naef, Tafel XXI, Fig. 2.) (Tafel XLVIII, 3, 5.)

Stor, Antonius, führte das Meisterzeichen Nr. 781 mit der Jahrzahl 1703.

Gegenstand: Kanne, Typ I; $11 \mathrm{~cm}$ hoch; Durchmesser des Fusses 4,7 cm. Am Deckelgriff zwei Granatäpfel. Auf dem Deckel Meisterzeichen Nr. 781 . Korpus kugelförmig und glatt. Am Hals ein glatter circulärer Wulst.

Stor, Johan, führte die Meistermarke $\mathrm{Nr} .78 \mathbf{2}$.

Gegenstand: Kanne, Typ I, 27,5 cm hoch; Im Antiquitätenhandel in Luzern.

Storno, Antonii. Sein Meisterzeichen findet sich in Die deutschen Zinngiesser und ibre Marken, von E. Hintze, Band VII, S. 387, Nr. 2404 . Auf dem Stempel die Jahrzahl 1712. Er heisst aber Antonii und nicht Leonti.

Gegenstand: Kanne, Typ I. Höhe 29,6 cm. Am Deckelgriff zwei Eicheln. Vorn am Steg ein Widderkopf.

Storno, Joseph, führte das Meisterzeichen $\mathrm{Nr} .780$ (auf dem Deckel).

Gegenstand: Kanne, Typ I, $28 \mathrm{~cm}$ hoch. Im Antiquitätenhandel in Luzern.

I. S. Meister I. S. führte die Meistermarke Nr. 784 .

Gegenstand: Kanne, Typ I. Höhe 24,2 cm; Durchmesser des Fusses $10 \mathrm{~cm}$. Am Deckelgriff zwei Eicheln. Auf dem Deckel die Meistermarke Nr. 784. Daneben der Eigentumsstempel I. M., Jahrzahl ${ }_{1754}$ und Wappen der Familie Roten. Innen am Boden eine grosse französische Lilie als Bodenrosette. Korpus kugelförmig, glatt. Am Hals kräftiger, circulärer Wulst.

A. S. Meister A. S. führte das Meisterzeichen Nr. 785 (auf dem Deckel).

Gegenstand: Kanne, Typ I. Höhe $24 \mathrm{~cm}$. Im Antiquitätenhandel in Zürich.

P. S. Meister P. S. führte die Meisterzeichen Nr. 789 und 791 .

Gegenstände: Kanne, Typ I, $33 \mathrm{~cm}$ hoch; Durchmesser des Fusses 14,5 cm. Am

Deckelgriff zwei Granatäpfel. In der Mitte des Deckels vor dem Steg ein Hundekopf mit a usgestreckter Zunge. Daneben die Meistermarke Nr. 791 und die Zahl XXXV eingeschlagen. Aussen, unterhalb des obern Kannenrandes, ein Walliser Aichzeichen (Nr. 820). Korpus glatt. In der Mitte des Halses kräftiger Wulst.

Kanne, Typ I, $24 \mathrm{~cm}$ hoch; Durchmesser des Fusses $10 \mathrm{~cm}$. Am Deckelgriff zwei Eicheln. Meisterzeichen Nr. 791 auf dem Deckel, daneben ein Hauszeichen. Innen am Boden eine französische Lilie als Bodenrosette.

Simaval, Pier Tonii, führte die Meistermarke Nr. 793. Dieses Zeichen wurde nachgemacht und viele neugegossene Kannen damit gestempelt, sowohl Kannentyp I und II.

Gegenstände: Kanne, Typ III. Höhe $20 \mathrm{~cm}$; Durchmesser des Fusses 10,3 cm. Am Deckelgriff zwei Eicheln. Auf dem Deckel das Meisterzeichen Nr. 793. Am Korpus zwei circuläre Rillen, ebenso unterhalb des obern Kannenrandes.

Kanne, Typ I, im Museum Valeria in Sitten.

P.A. S. I. Vielleicht die Initialen von Pier Antoni Simaval, des vorigen Meisters. Er führte das Meisterzeichen Nr. $79^{2}$.

Gegenstände: Kanne, 36,7 cm hoch; Durchmesser des Fusses 24,7 cm. Der Korpus besteht aus einer abgestumpften, achtseitigen Pyramide; zwischen dem dritten und vierten Viertel des Korpus ein stark prominirender Wulst; ebenso in der Mitte des Halses, dazu noch circuläre Rillen. Am Deckeldrücker zwei Widderköpfe. Vor dem Steg in der 
Mitte des Deckels ein kleiner Widderkopf mit einem Knopf zum Heben des Deckels. Auf demselben die Meistermarke Nr. 792 und die Initialen RD.I.H.B. Mehrere circuläre Wülste geben dem Deckel ein eigenartiges Aussehen. $\mathrm{Zu}$ beiden Seiten des Halses je ein starker Knopf zur Befestigung des halbkreisförmigen Zinnhenkels, der frei beweglich ist und als Traghenkel dient. (Tafel XLVIII, 4.)

K'anne, Typ I, $34 \mathrm{~cm}$ hoch; Durchmesser des Fusses 15,5 cm. Am Deckelgriff zwei Widderköpfe, vorn am Steg ein kleinerer Widderkopf, um denselben herum kräftige, circuläre Wülste. Daneben die Meistermarke Nr. 792 und das Qualitätszeichen F mit Krone, ferner die Initialen RD.PM. Korpus sphäroidal, von oben nach unten zusammengedrückt. In der Mitte des Halses ein kräftiger, circulärer Wulst.

G. B. Meister G. B. führte die Meisterzeichen Nr. 786, 787 und 8 og.

Gegenstand: Kanne, Typ I. Höhe 17,5 cm; Durchmesser des Fusses 7,5 cm. Am Deckelgriff zwei Eicheln. Auf dem Deckel die Meistermarke Nr. 787 und drei eingeschlagene gleiche Familienwappen. Der Korpus ist glatt; in der Mitte des Halses ein breiter, circulärer Wulst.

Kanne, $32 \mathrm{~cm}$ hoch, in gleicher Ausführung.

Kanne: Korpus pyramidenförmig. Höhe 29,7 cm. Am Deckelgriff zwei Eicheln. Auf dem Deckel die Meistermarke Nr. 786. Im Museum Allerheiligen in Schaffhausen.

I. B. Meister I. B führte das Meisterzeichen Nr. 832.

Gegenstand: Kanne, Typ I. Höhe 13,2 cm. Durchmesser des Fusses 7,2 cm. Am Deckelgriff zwei Eicheln. Meistermarke Nr. 832 auf dem Deckel. Korpus glatt; in der Mitte des Halses zwei circuläre Rillen.

I. G. Meister I. G., vielleicht ein Giesser Namens Gacci, jedenfalls ein fahrender Meister, führte die Meisterzeichen Nr. 795 und 843 .

Gegenstand: Kanne, Typ I. Höhe 14,3 cm; Durchmesser des Fusses 6,7 cm. Am Deckelgriff zwei Eicheln. Auf dem Deckel das Meisterzeichen Nr. 843 und im Tremolirstich die Initialen I A A MF. An der Aussenseite des Halses ist das Wappen des Zehnten Leuk (Nr. 818) eingeschlagen, vielleicht anlässlich der Aichung.

P.A.G. Meister PAG. führte das Meisterzeichen Nr. 833. Ca. 1700 tätig.

Gegenstand: Kanne, Typ I. Höhe 33,5 cm; Durchmesser des Fusses $14 \mathrm{~cm}$. Am Deckelgriff zwei Granatäpfel. Vorn am Steg ein Widderkopf. Auf dem Deckel die Marke Nr. 833. Korpus glatt mit circulären Rillen. In der Mitte des Halses circulärer Wulst und Rillen.

A. P. Meister A P. führte ein Meisterzeichen wie Nr. 802, aber mit den Initialen A P. Tätig ca. 1700 .

Gegenstand: Kanne, Typ I. Höhe 32,8 cm; Durchmesser des Fusses 13,7 cm. Am Deckeldrücker zwei Granatäpfel. In der Mitte des Deckels vor dem Steg ein $\mathrm{Hundekopf}$ mit herausgetreckter Zunge wie bei der Kanne des Meisters P S. Auf dem Steg ein Hauszeichen. Daneben die Meistermarke A P und der Qualitätsstempel F mit Krone. Korpus kugelförmig und glatt. In der Mitte des Halses ein profilirter circulärer Wulst; zuoberst am Hals vier tiefe circuläre Rillen.

I. B. G. Meister I. B G führte die Meistermarke Nr. 810 und war in der zweiten Hälfte des XVIII. Jahrhunderts tätig. Weitere Meistermarken : Nr. 83o und 831.

Gegenstände: Kannen, Typ I, mittlere und kleinere im Antiquitätenhandel in Bern und Lausanne.

Gacci. Meister Gacci führte das Meisterzeichen Nr. 795 und war als fahrender Zinngiesser in der zweiten Hälfte des XVIII. Jahrhunderts tätig.

Gegenstände: Kännchen, Typ I, im Antiquitätenhandel in Luzern (Hirsbrunner).

I. P. Z. führte das Meisterzeichen Nr. 794 mit der sehr undeutlichen Jahrzahl 1731 . Auch Z im Stempel ist undeutlich. Auffallend ist das Zeichen des Löwen mit dem Hammer, das auch das Wappen von Martigny bildet. 
Gegenstand: Kanne, Typ I. Höhe $36 \mathrm{~cm}$; Durchmesser des Fusses 15,8 cm. Am Deckelgriff zwei Widderköpfe und einer vor dem Steg. Auf dem Deckel die Marke Nr. 794 und daneben ein tief eingeschlagener Schild mit Traube und Rebenblatt, das Zeichen der Winzer. Der mächtige Korpus ist glatt und weist vier feine Rillen auf; in der Mitte des Halses ein flacher Wulst.

Tonietti, Jan Tomas, auch Gio Tomas, führte das Meisterzeichen Nr. 807 und 808 . In der Mitte des Meisterzeichens ein Löwe mit einem Hammer, das Wappen von Martigny.

Gegenstand: Kanne, Typ I. Höhe 31,5 cm; Durchmesser des Fusses 13,7 cm. Am Deckeldrücker zwei Eicheln. Auf dem Deckel das Meisterzeichen Nr. 8o7 und ein eingeschlagener Eigentumsstempel mit den Initialen G. I. Am Korpus und in der Mitte des Halses je ein breiter, schön profilirter Wulst.

Variolly, Vincent, in Martigny, führte das Meisterzeichen Nr. 812. Er war im Hauptberuf Spengler. Er starb in Martigny-Bourg, ca. 64 Jahre alt, am 31. Mai 188o (Etat-civil de Martigny).

Gegenstand: Kanne, Typ II. Höhe 17,7 cm; Durchmesser des Fusses 8,8 cm. Am Deckelgriff zwei Granatäpfel. Auf dem Deckel die Marke Nr. 812. Korpus glatt, mit schön proportionirtem Fussteil. In der Mitte des Halses ein circulärer Wulst.

Rey, in Monthey, führte das Meisterzeichen Nr. 811, mit gekreuzten Gewehren.

Gegenstände: Teller und Kannen, Typ I und II, im Antiquitätenhandel in Lausanne und Genf, auch in Vevey.

Kanne, Typ II. Höhe $20,7 \mathrm{~cm}$; Durchmesser des Fusses $11 \mathrm{~cm}$. Als Deckelgriff zwei Granatäpfel. In der Mitte des Halses ein starker Wulst. Fuss mit guter Ausladung.

I. A. J. Alvazzi (?), führte das Meisterzeichen Nr. 8oo. Auf einer grossen Kanne mit der Jahrzahl 1696. Typ. I.

I. A. J. Alvazzi (?), führte die Meisterzeichen Nr. 801 und 802.

Gegenstände: Kanne, Typ III. Höhe $25 \mathrm{~cm}$; Durchmesser des Fusses $12,5 \mathrm{~cm}$. Am Deckeldrücker zwei Granatäpfel. Am Korpus und unterhalb des obern Kannenrandes je zwei circuläre Rillen. Auf dem Deckel das Meisterzeichen $\mathrm{Nr} .801$, die Initialen I A und zwei Hauszeichen. (Tafel XVII, 8; XLVIII, 2.)

Kanne, Typ I. Höhe $28,8 \mathrm{~cm}$; Durchmesser des Fusses 12,7 cm. Am Deckelgriff zwei Eicheln. Vorn am Steg ein Widderkopf. Auf dem Deckel das Meisterzeichen Nr. 801 und die gravirten Initialen P Z. Korpus glatt mit zwei circulären Rillen; in der Mitte des Halses ein Wulst.

Kanne, Typ I. Höhe $37,2 \mathrm{~cm}$; Durchmesser des Fusses 15,8 cm. Am Deckeldrücker zwei Widderköpfe und einer vorne am Steg. Auf dem Deckel das Meisterzeichen Nr. 8o2, daneben eingeritzt das Wappen des Zehnten Goms, die Jahrzahl 1788 und die Initialen B V M. Korpus glatt, mit zwei circulären Rillen; in der Mitte des Halses ein Wulst.

Kanne, Typ I. Höhe 37,5 cm; Durchmesser des Fusses $16 \mathrm{~cm}$. Am Deckelgriff zwei Widderköpfe. Vorn am Steg in der Mitte des Deckels ein sitzender Löwe. Daneben das Meisterzeichen Nr. 859, in Verbindung mit dem Schützengabenzeichen der Mousquetire. Am Korpus circulärer profilirter Wulst und Rillen. Am Hals glatter Wulst mit Rillen. (Tafel XVII, 1o.)

Kanne, Typ I. Höhe 18,2 cm; Durchmesser des Fusses 7,7 cm. Am Deckelgriff zwei Eicheln. Auf dem Deckel das Meisterzeichen Nr. 802 und die eingeritzten Initialen P A. Korpus glatt, am Hals ein circulärer Wulst. Die Aussenseite des Henkels ist mit etwas grob reliefirten Blumen- und Blattranken überzogen.

Castel, Joseph, führte die Meisterzeichen Nr. 803 und 804 .

Gegenstände: Kannen, Typ I und II, in allen Grössen; im Antiquitätenhandel in Lausanne und Sitten.

Diverse Platten und Teller mit schmalem Rand im Antiquitätenhandel in Sitten.

Alvazzi und Castel, führen die Meisterzeichen $\mathrm{Nr}$. 805 und 806.

Gegenstände: Kanne, Typ I. Höhe $32 \mathrm{~cm}$; Durchmesser des Fusses 15,7 cm. Am 
Deckelgriff zwei Widderköpfe. Auf dem Deckel die Meistermarke Nr. $8 \circ 5$ und zwei Mal das Qualitätszeichen F mit Krone. Daneben in Gravirung ANDRE ZUBER. Korpus glatt mit zwei circulären Rillen. In der Mitte des Halses flacher Wulst und Rillen.

Kanne, Typ 1I. Höhe 25,3 cm ; Durchmesser des Fusses 13,8 cm. Am Deckelgriff zwei Eicheln. Auf dem Deckel das Meisterzeichen Nr. 805 und der Aichstempel Nr. 820 mit 13 Sternen. Korpus glatt, in der Mitte des Halses kleiner Wulst. Zu beiden Seiten des obern Kannenrandes zwei starke Knöpfe mit daran befestigter alter Zinnkette.

Kanne, Typ I. Höhe $18 \mathrm{~cm}$; Durchmesser des Fusses 7,7 cm. Am Deckelgriff zwei Eicheln. Auf dem Deckel das Meisterzeichen Nr. 806, davor das Aichzeichen Nr. 820 und XXXV, ferner die Initialen S B T G. Korpus glatt; in der Mitte des Halses ein circulärer Wulst und Rillen. Am Henkel in grobem unscharfem Relief Blatt- und Blumenranken.

Maciago, Paulo G., Zinngiesser in Brig, der Onkel des folgenden Giuseppe Maciaco. Paulo war schon vor dem Jahre 1842 in Brig. Er stammt von Bognanco-Dentro, Provinz Novara, Italien. Im Jahre 1842 trat sein Enkel Petrus Giuseppe in sein Geschäft ein und arbeitete mit ihm. Paulo führte die Meistermarke Nr. 798.

Gegenstände: Kanne, Typ II. Höhe 28,7 cm; Durchmesser des Fusses 13,5 cm. Am Deckeldrücker zwei Eicheln. Auf dem Deckel das Meisterzeichen Nr. 798 und die Jahrzahl der Aichung 1846.

Kanne, Typ II. Höhe $23,8 \mathrm{~cm}$; Durchmesser des Fusses $12 \mathrm{~cm}$. Am Deckelgriff zwei Eicheln.

Maciaco, Giuseppe, arbeitete gemeinsam mit seinem Onkel Paulo. Er führte das Meisterzeichen Nr. 799 und starb im Jahre $1850 . \mathrm{X} .1$.

Gegenstände: Kanne, Typ I. Höhe $20,8 \mathrm{~cm}$; Durchmesser des Fusses $10 \mathrm{~cm}$. Am Deckelgriff zwei Eicheln. Auf dem Deckel die Meistermarke Nr. 799 und die Jahrzahl einer Aichung von 1881 . (Tafel XLVIII, 7.)

Kanne, Typ I. Höhe ${ }_{17}, 8 \mathrm{~cm}$; Durchmesser des Fusses $7,8 \mathrm{~cm}$. Marke wie oben Nr. 799. Aichungs-Jahrzahl von 1861 .

Kanne, Typ I. Höhe 17,3 cm; Durchmesser des Fusses 7,6 cm. Auf dem Deckel der Stempel Nr. 799, die Jahrzahl der Aichung von 1865 und das Eigentumszeichen C. I.

Maciaco, Petrus Giuseppe, führte die Meistermarke Nr. 797. Er war der Sohn des Vorigen, in Bognanco-Dentro, Provinz Novara geboren am 3o. Januar 1820 . Im Jahre 1842 kommt er nach Brig zu seinem Grossonkel Paulo; 1850 ist er neben seiner Mutter Vormund seiner Brüder. Er starb am 18 . September 1892 . Bei ihm arbeitete ca. sieben Jahre lang Lorenzo della Bianca. Als Maciaco sein Geschäft auflöste, verkaufte er einen Teil seiner Formen für 200 Franken an den Zinngiesser Possa in Leuk.

Gegenstände: Kanne, Typ I. Höhe 20,9 cm; Durchmesser des Fusses 10,2 cm. Auf dem Deckelgriff zwei Eicheln; auf dem Deckel das Meisterzeichen Nr. 797 und die Initialen des Eigentümers RD. FL. (Tafel XLVIII, 1.)

Kanne, Typ I. 13,1 cm hoch; Durchmesser des Fusses 7,2 cm. Eicheln am Deckeldrücker. Initialen M. R D und Marke Nr. 797.

Kanne, Typ I. 13,1 cm hoch; Durchmesser des Fusses 7,1 cm. Auf dem Deckel die Marke Nr. 797. Keine Initialen.

Meister L. M. führte als Meisterzeichen Nr. 796.

Gegenstände: Kanne, Typ I. Höhe 19,3 cm; Durchmesser des Fusses 7,8 cm. Am Deckelgriff zwei flache Granatäpfel. Auf dem Deckel dic Marke Nr. 796. Stempel der Aichung Nr. 820, auch am Halse.

Kanne, Typ I ; $28,5 \mathrm{~cm}$ hoch. Am Deckeldrücker zwei Eicheln (vgl. Hintze, Bd. VII, S. 389 , Nr. 2412 ).

Della Bianca, Lorenzo, Zinngiesser in Visp, führte die Meisterzeichen Nr. 813 und 814 . Er wurde geboren am 31. Juli 1867 und lebt noch in Visp. Seine Mutter war Domenica 
Maria Maciaco, die Schwester des Petrus Giuseppe, bei welchem Lorenzo della Bianca sieben Jahre arbeitete. Sein Geschäft in Visp besteht seit dem Jahre 1892 .

Gegenstände : Alle Sorten und Grössen von Kannen, Typ I und II ; auch ungewöhnliche Formen, wie polyedrische, pyramidale und andere Formen. Teller und Platten. Er lieferte auch die kleinen Kännchen für das Centralfest des schweiz. Alpenklubs in Zermatt im Jahre 1922 .

Della Bianca, Louis, der Sohn des Vorigen, ist am 17. März 1902 geboren und führt gegenwärtig das Geschäft seines Vaters in Visp weiter.

Possa, Laurent, Zinngiesser in Leuk; geboren 1850, gestorben im Juni 1917. Peter Josef Maciaco kam im Jahre 1890-91 nach Leuk und verbrachte den Winter in der Familie Possa und lehrte den Spengler Laurent Possa die Zinngiesserei, besonders den Guss von Kannen und Platten. Possa kaufte ihm die Modelle ab um ca. 20o Franken. Die Drehbänke wurden alle noch von Hand getrieben. Laurent Possa lieferte hauptsächlich an die Schützengesellschaften, besonders im Unterwallis.

Possa, Léon, Sohn des Vorigen, führte ab 1917 das Zinngiessereigeschäft weiter. Erst 1931 wurde ein Motor eingebaut zum Betrieb der Drehbänke. Er arbeitet in Leuk und in Leukerbad.
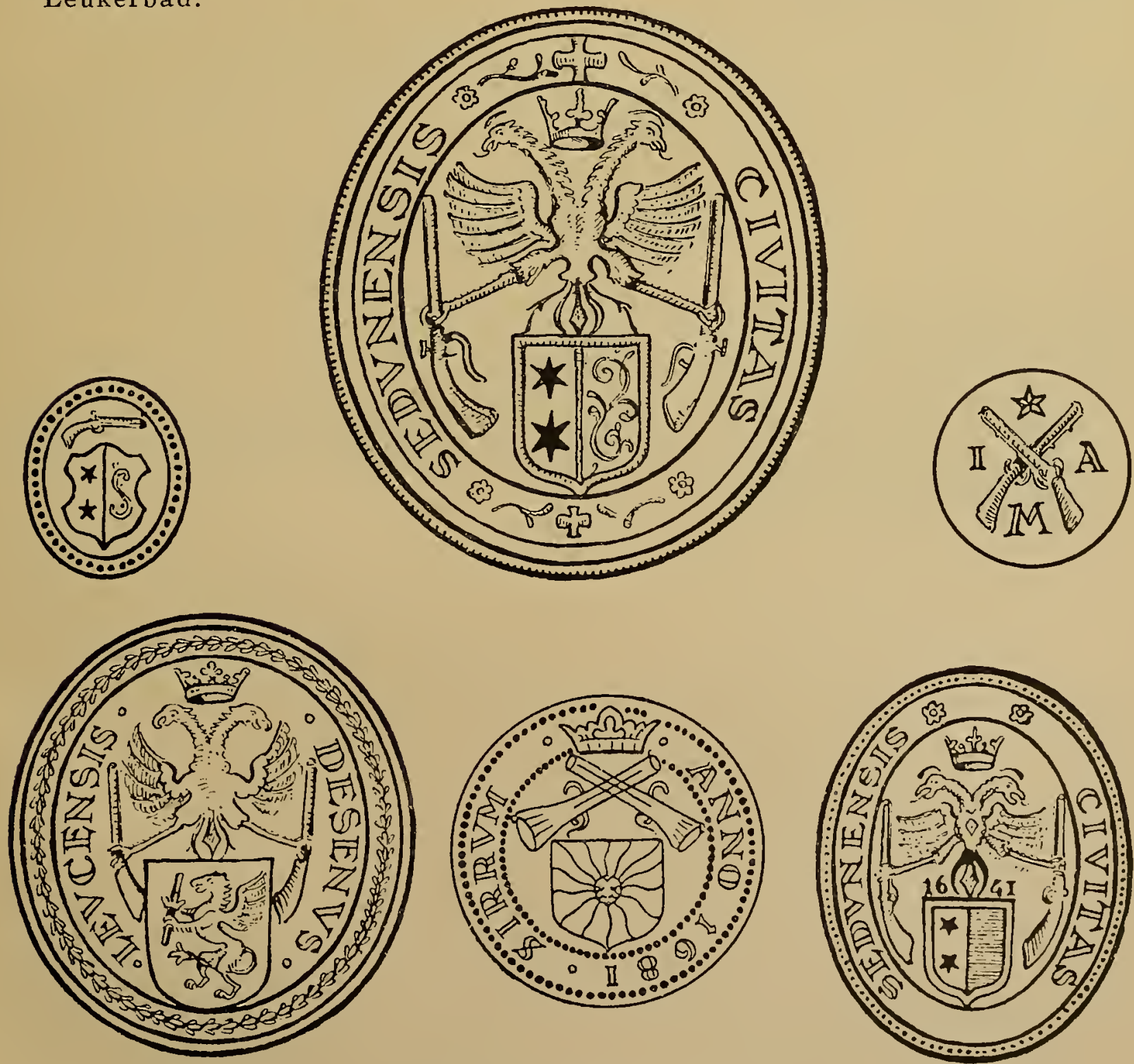

Walliser Schützengaben-Stempel 


\section{TESSIN}

In Italien blühte seit dem XIV. Jahrhundert die Majolika-Industrie, welche fast alle Ess- und Trinkgeschirre lieferte. Darum konnte das Zinngiesserhandwerk weder im Tessin noch im angrenzenden Italien eine ansehnliche Bedeutung erlangen. In den Manuali Hoepli, De Mauri, L'Amatore di oggetti d'arte di curiosità, wird das Thema über Zinn ausserordentlich spärlich behandelt. Italienische und tessinische Meister werden nicht erwähnt; auch keine Meisterzeichen, welche hier in Betracht kommen. Von den sechs im Tessin gefundenen Meisterzeichen konnte keines einer bestimmten Stadt zugeteilt werden, weil kein Beschauzeichen irgend einer Stadt vorhanden ist. Auch fehlt jegliches archivalisches Material. Die tessinischen Museen sind arm an Zinngegenständen und es fehlt an jeglichem Material zu Studienzwecken.

Das zur Verfügung stehende Material, fast ausnahmslos Platten und Teller einfachster Art, stammt aus der Zeit um 1800; von denselben kommen die sechs Meisterzeichen, Nr. 722 727 (Bd. I). Im Tessin findet man aber oft Zinngeschirr von deutschschweizerischen Zinngiessern, entsprechend den damals regierenden Landvögten, welche den Handel mit ihrer jeweiligen Heimat begünstigten.

Auch ist es sehr wahrscheinlich, dass fahrende Zinngiesser das Land durchzogen. So kann man die Erzeugnisse von Gotardo Gamba vom Tessin bis nach Schwyz verfolgen. An letzterem Orte war er vielleicht am längsten tätig (siehe unter Schwyz). Die Respini, Zanoni und Rossi waren vielleicht ansässige Meister.

\section{Die $Z_{\text {inngiesser }}$}

And(rea) e Fra(telli), Respini, führten das Meisterzeichen Nr. 723 .

Giosep. ed Andrea, Respini, führten das Meisterzeichen Nr. 724 .

Fratelli, Respini, führten das Meisterzeichen Nr. 722.

Zanoni, Antoine, führte das Meisterzeichen Nr. $7_{22}$.

Gamba, Gotardo, führte das Meisterzeichen Nr. 726 . Von ihm stammen sechsseitig prismatische

Kannen, einfache Messkännchen, Kastengiessfässer mit vertikal gewellter Vorderwand und Teller (siehe unter Schwyz).

Rossi, Gio. Ant., führte das Meisterzeichen Nr. 727 . 

GEDRUCKT VON DER

ROTO-SADAG A.G.

GENF

IM DEZEMBER $\quad 1934$ 







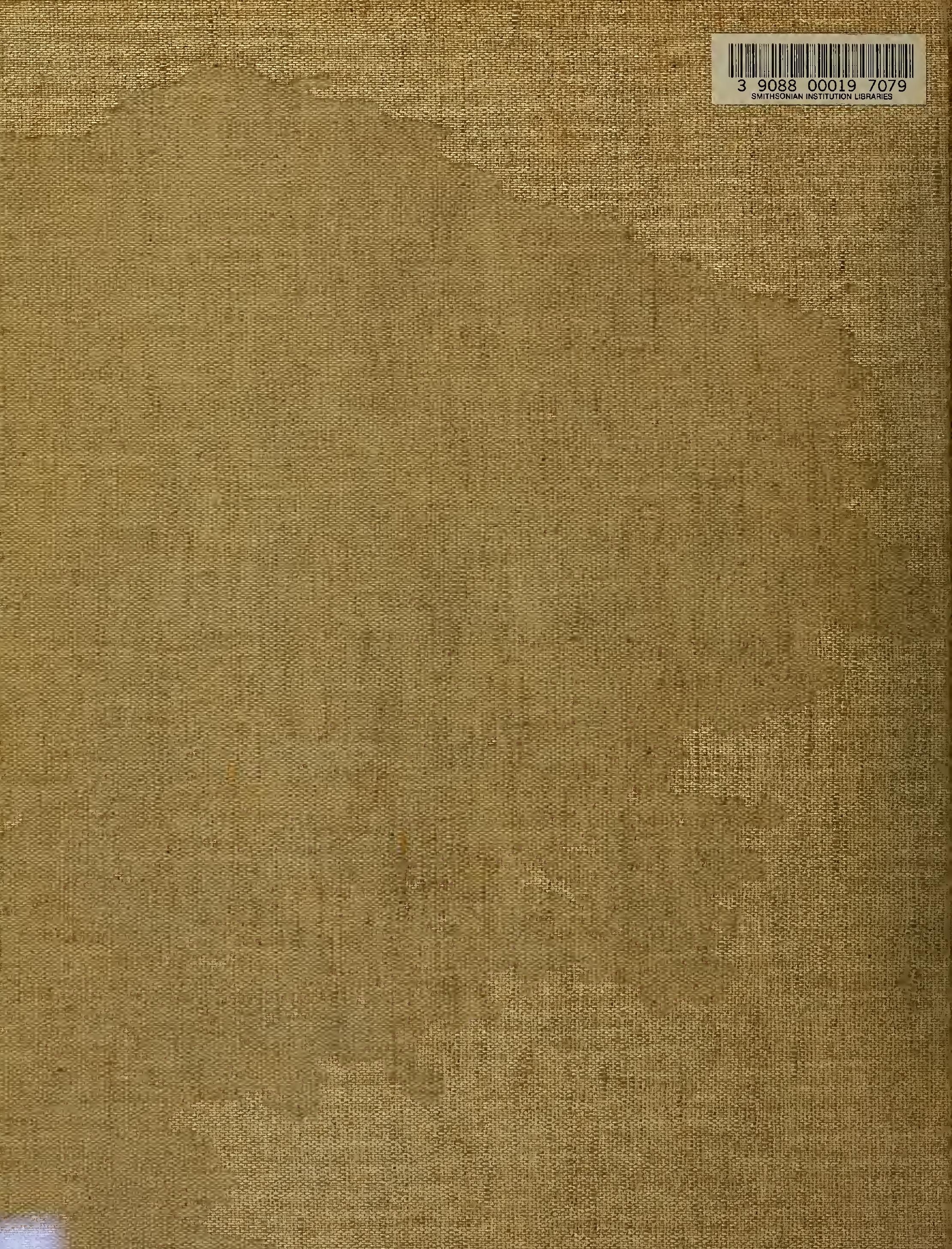

